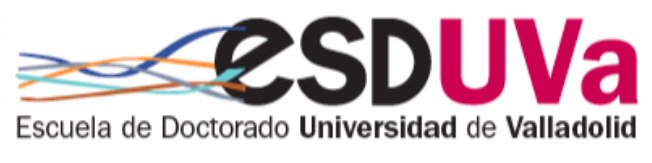

Universidad deValladolid

\author{
PROGRAMA DE DOCTORADO EN \\ INGENIERÍA INDUSTRIAL \\ INGENIERÍA ENERGÉTICA
}

TESIS DOCTORAL:

\title{
HERRAMIENTAS DE GESTIÓN ENERGÉTICA \\ PARA EL DESARROLLO SOSTENIBLE EN \\ EDIFICIOS APLICADO A UN CAMPUS \\ UNIVERSITARIO EN COLOMBIA
}

Presentada por Rosaura del Pilar Castrillón
Mendoza, para optar al grado de
Doctor/a por la Universidad de Valladolid

Dirigida por:

D. Francisco Javier Rey Martínez

D. Paúl Andrés Manrique 


\section{Dedicatoria}

\section{A mis tres amores}

Antonio Puente Castrillòn mi hijo, por su hermosa carcajada que irrumpe cualquier momento de tensión para robar la atención y hacerte caer en cuenta lo maravilloso que resulta vivir en familia.

Esteban Puente Castrillòn mi hijo, por su maravillosa curiosidad que te invita siempre a estar en constante alerta para seguir investigando.

Orlando Puente mí esposo, por su entrañable compromiso de padre y compañero de vida, siempre atento y respetuoso a remar hacia objetivos comunes de familia. 


\section{Agradecimientos}

A mi familia por su comprensión y acompañamiento durante todo este proceso, por respetar mis decisiones y a mis hijos por quitarles parte de su tiempo e incluirlos en esta aventura sin poder siquiera opinar pero con el cariño y compresión para acompañarme.

A D. Francisco Javier Rey por su dedicación y tiempo de asesoría durante todo el proceso, por ánimo y paciencia y por enseñarme a valorar cada conocimiento y convertirlo en algo útil para los objetivos propuestos, por compartir de manera generosa su conocimiento y ponerlo al servicio de esta investigación y por su amistad.

Al resto del departamento de Ingeniería Energética D. Eloy Velasco Gómez, D. Julio Francisco San José Alonso y Dña. Ana Tejero González, por su hospitalidad, ánimo y constantes palabras de apoyo.

D. Javier Ma Rey Hernández por su apoyo incondicional y su constante reconocimiento al trabajo realizado en esta investigación, por compartir su experiencia.

A la profesora María de Jesús Hernández, por ser el complemento perfecto entre hospitalidad, gastronomía y cultura y sobre todo por su desinteresado acompañamiento y amistad para quienes estamos de paso en este país.

A D. Paul Andrés Manrique por su asesoría y aporte en el transcurso de esta investigación.

A mis estudiantes del semillero de investigación en Gestión y Eficiencia energética los hoy Ingenieros Álvaro José Colonia, Paul Andrés Wallens por su colaboración. De manera muy especial a la Ingeniera Andrea María Quintero por su valioso e incondicional acompañamiento a lo largo de estos años, por su interlocución respetuosa, oportuna para cuestionar y hacerte reflexionar y por darme siempre el mejor de los ánimos, por su generosidad y amistad.

A la vicerrectoría Académica, al doctor Álvaro del Campo Parra, Al Centro de Desarrollo Académico, a la doctora Sonia Cadena, A la facultad de Ingeniería Dr. Freddy Naranjo Pérez por su apoyo incondicional y permanente confianza. A mis compañeros y grupo GIEN. 


\section{Resumen}

Los contenidos de la memoria de la presente tesis doctoral, estructurados a través de diferentes capítulos son:

Revisión del estado actual de la eficiencia energética a nivel mundial haciendo especial énfasis en la situación de Latinoamérica, específicamente en Colombia. Si bien, se encuentran algunas respuestas favorables en torno al adelanto de estrategias para apostarle al cumplimiento de los ODS, específicamente lo relacionado con el sector de edificaciones donde se destaca una participación activa en torno al desarrollo de políticas enmarcadas en la planificación energética del país, los ministerios y/ u organizaciones relacionadas con la construcción ; estos elementos de alguna manera permiten reflexionar y/o identificar algunos vacíos y la necesidad de trabajar estratégicamente hacia directrices que permitan contar con lineamientos claros respecto a temas de edificaciones sostenibles con disposiciones que permitan contar con códigos de construcción sostenibles, certificaciones propias y reglamentación clara hacia la operación eficiente de los edificios durante su ciclo de vida. Lo anterior, favorece la reciente hoja de ruta que ha establecido la IEA para los países de Latinoamérica.

Realización de un análisis de las relevancias de un sistema de gestión energética SGEn y de las herramientas y técnicas utilizadas para el desarrollo de los procesos de planificación energética y algunos de los componentes más significativos. Se destacan aspectos relacionados con la forma de aplicar estos conceptos a las edificaciones y enfatizando en el cumplimiento especifico de las normas de apoyo a los sistemas de gestión en pro del mejoramiento de la eficiencia energética en edificaciones.

Presentación de las bases teóricas y se propone una metodología para la aplicación y desarrollo de los 4 modelos para la estimación de líneas bases e indicadores. En este sentido, se desarrolla el uso de los modelos basados en series de tiempos para edificaciones que solo utilizan la variable consumo, modelos de regresión univariable y multivariable, cuando existan recursos de medición de otros parámetros adicionales al consumo energético y se analiza el uso de la simulación dinámica a través de Design Builder, como un recurso importante para establecer condiciones iniciales en la formulación de líneas bases e indicadores para diseños nuevos y cuando existan recursos de información arquitectónica y de monitorización en los existentes. De tal forma se presentan diferentes alternativas al usuario de una edificación con respecto a qué modelo usar con referencia a la selección de los límites y el periodo de reporte de la información, la verificación de la fuente y calidad de los datos, así como la revisión de las variables relevantes de mayor afectación al consumo energético, el análisis muestral y el patrón de comportamiento de los datos. Todo lo anterior, validado con un análisis estadístico realizado en software $\mathrm{R}$ estudio. 
Análisis y conclusiones detallado de los efectos en la estimación de ahorros energéticos de los modelos propuestos para evaluar la línea base e indicadores, mostrando que la selección de uno u otro implica la sobreestimación o subestimación en el pronóstico de consumo de energía que afecta los valores de ahorros estimados en un análisis de eficiencia energética y estudio medioambiental.

Los análisis anteriores se soportan sobre medidas experimentales del campus universitario y de un edificio de aulas 4, donde se analizaron los datos de monitorización de los años 2017 a 2019, utilizando herramientas de gestión energética. Se seleccionó un edificio de aulas para realizar la simulación dinámica en Design Builder, la misma conto con datos de monitorización de sensores ubicados dentro de este espacio para medir consumos de equipo de uso final y condiciones climáticas, como referencia para calibrar el modelo de simulación que no solo permitió encontrar algunas MAES acorde a las condiciones de ubicación geográfica climáticas del campus, además nos permitió utilizar la simulación dinámica como herramienta adicional para establecer líneas bases. Finalmente, se estableció un análisis energético del caso práctico mediante indicadores energéticos, ambientales, económicos, de gestión energética y caracterización de un edificio casi nulo nZEB como análisis para las condiciones de Colombia. 


\section{Abstract}

The Doctoral Thesis is structured according to the following steps:

World Energy Efficiency Review, focusing on the situation in Latin America, mainly in Colombia. Although there are some favorable responses regarding the advancement of strategies to achieve the SDGs, specifically related to the building sector, where an active participation in the development of policies framed in the energy development of the country, the ministries and organizations related to the building sector is highlighted.

These elements somehow allow reflecting and identifying some gaps, or the need to work strategically towards guidelines that allow having clear guidelines regarding sustainable building issues with regulations that allow having sustainable building standards, certifications and clear regulations towards the efficient operation of buildings during their life cycle. This is in line with the recent roadmap established by the IEA for Latin American countries.

An analysis of the relevance of an Energy Management system (EMS), the tools and techniques used for the development of energy planning processes, as well as some of the most significant components.

Aspects related to how to apply these concepts to buildings are highlighted, focusing on the specific compliance with the standards that support management systems for the improvement of energy efficiency in buildings.

Theoretical bases are discussed, providing a methodology for the application and development of the 4 models for the estimation of baselines and indicators. In this sense, the use of models based on time series is developed for buildings that only use the consumption variable, univariate and multivariate regression models, when there are resources for measuring other parameters, besides energy consumption.

The use of dynamic simulation through Design Builder is analyzed as an important resource to establish initial conditions in the formulation of baselines and indicators for new designs and when there are architectural information and energy monitoring resources in the existing ones. In this way, different alternatives have been shown to the building user, regarding which model to use with reference to the selection of the limits and the reporting period of the information, the verification of the source and quality of the data, as well as the review of the relevant variables with the greatest impact on energy consumption, the sample analysis and the performance pattern of the data.

All of the above, validated with a statistical analysis performed in R Studio software.

Detailed analysis and results of the effects on the estimation of energy savings of the proposed models to evaluate the baseline and indicators. It is shown that the choice of one or the other, leads to an overestimation or underestimation in the energy consumption forecast that affects the estimated savings values in an energy efficiency analysis and environmental study. The above analyses are supported on experimental measurements of the university campus, and of a classroom building 4, where monitoring data from the years 2017 to 2019 were 
analyzed using energy management tools. A classroom building was selected to perform the dynamic simulation in Design builder.

The simulation used monitoring data from sensors located within this space to measure enduse equipment consumption and climatic conditions, as a reference to calibrate the simulation model that not only allowed us to find some Energy Saving Measures (ESM) according to the weather data at the campus location, but also allowed us to use the dynamic simulation as an additional tool to set baselines.

Finally, an energy analysis of the case study has been established by means of energy, environmental, economic, energy management indicators, and characterization regarding a near-zero building nZEB, as an analysis for the Colombian scenario. 


\section{ÍNDICE}

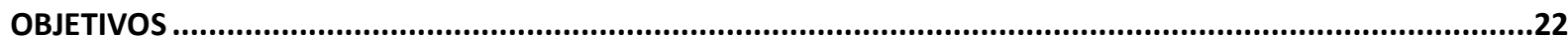

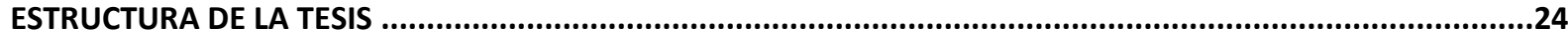

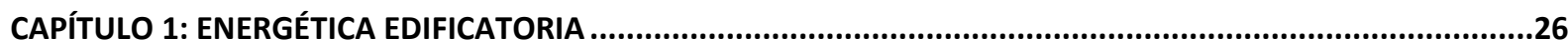

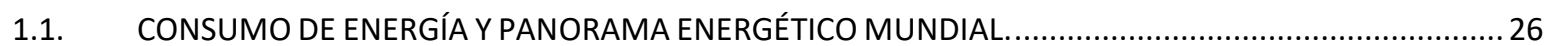

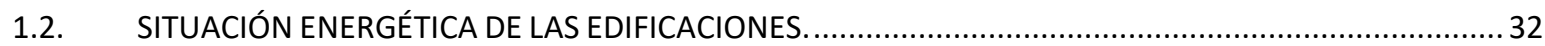

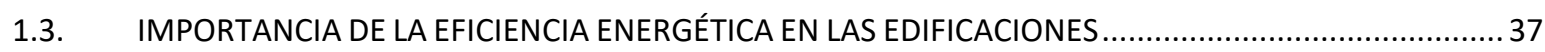

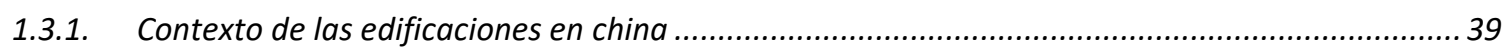

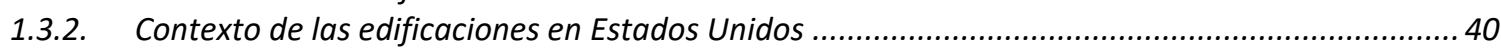

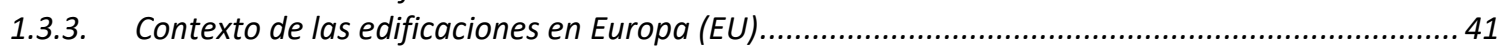

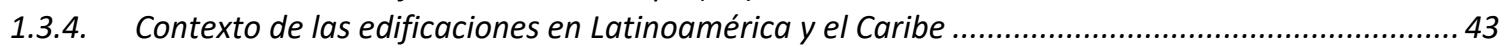

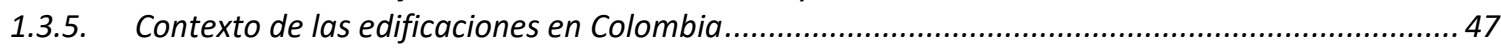

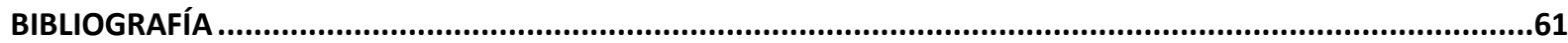

CAPÍTULO 2: SISTEMA DE GESTIÓN ENERGÉTICA. HERRAMIENTAS DE LA PLANIFICACIÓN ENERGÉTICA ..........64

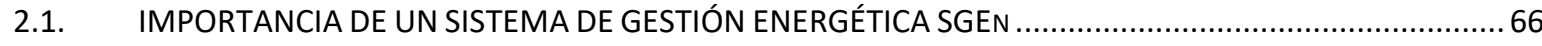

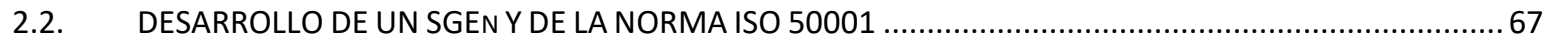

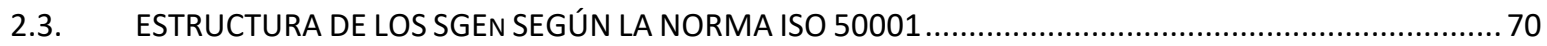

2.3.1. Normas relacionadas con la familia de normas de la ISO 50001................................................ 77

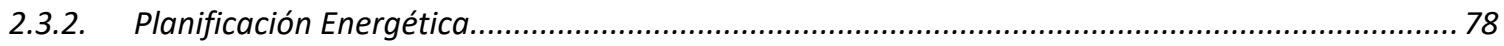

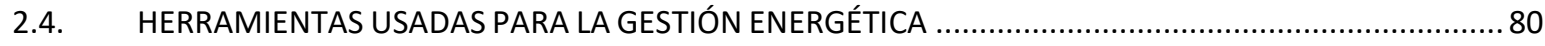

2.4.1. Herramientas usadas para el análisis de los usos y consumos de energía ................................... 81

2.4.2. Herramientas usadas para identificar las áreas de uso significativo de la energía (USE) ..............85

2.4.3. Herramientas usadas para la identificación y priorización de oportunidades para el mejoramiento

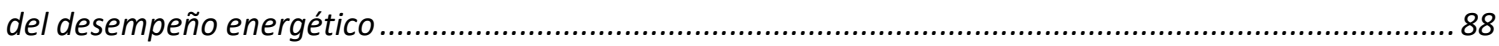

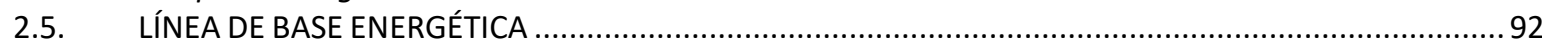

2.5.1. Etapas para el establecimiento de una línea de base energética ............................................... 94

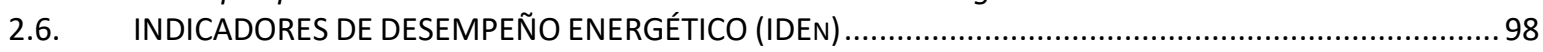

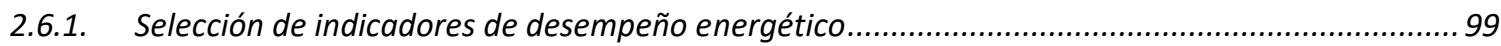

2.6.2. Indicadores de Desempeño Energético en Edificaciones .......................................................... 103

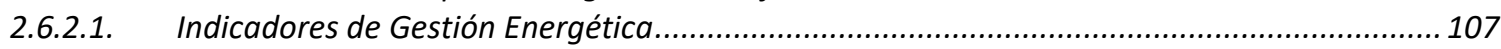

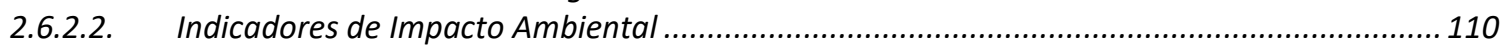

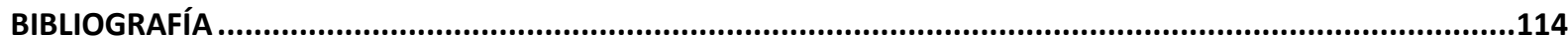

CAPÍTULO 3: MODELOS PARA LA ESTIMACIÓN DE LÍNEAS BASES..............................................................117

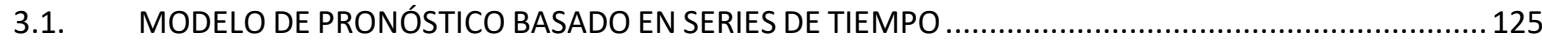

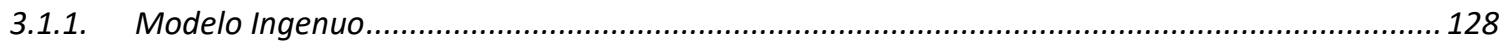

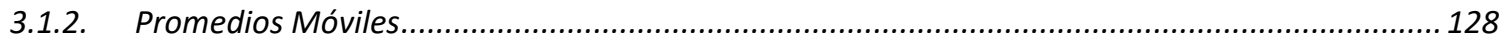

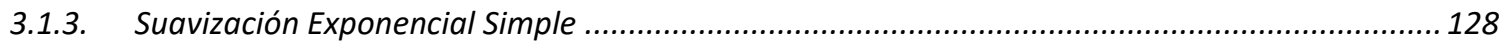

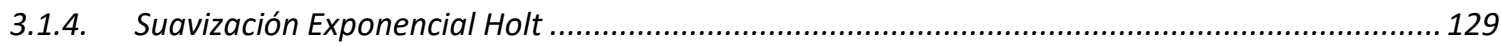

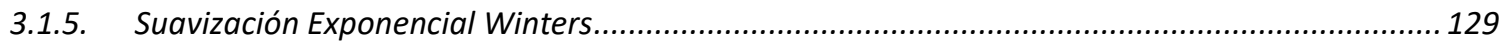

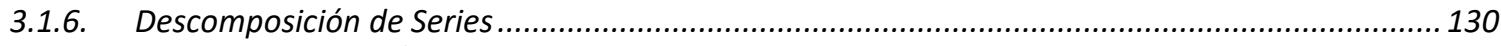

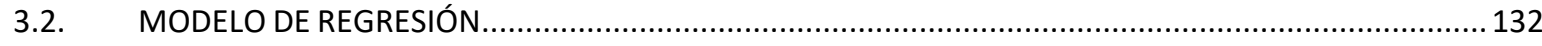

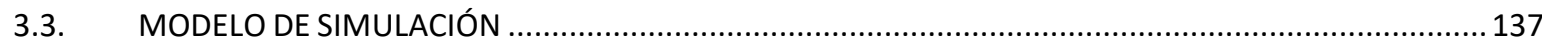


Índices

BIBLIOGRAFÍA

CAPÍTULO 4: CASO ESTUDIO ENERGÉTICO DEL CAMPUS UNIVERSIDAD AUTÓNOMA DE OCCIDENTE, UAO ..142

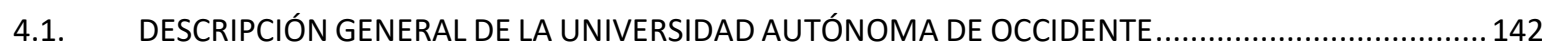

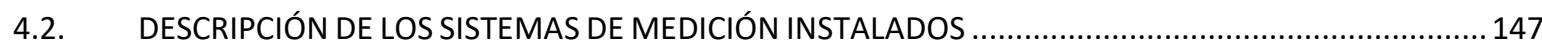

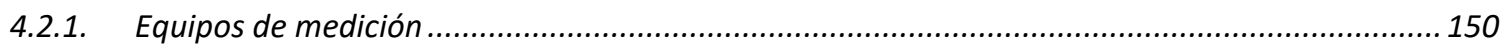

4.3. ANÁLISIS DE LOS USOS Y CONSUMOS DE LA ENERGÍA EN EL CAMPUS............................................. 161

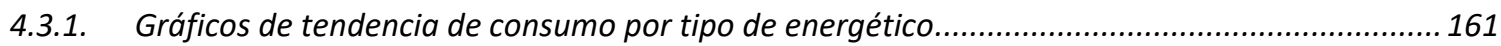

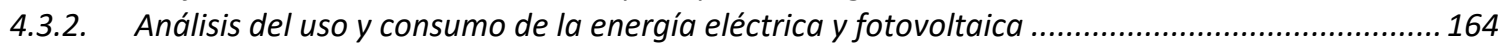

4.3.3. Análisis del Consumo de energía eléctrica global de la UAO en los años $2014-2019$............... 168

4.3.4. Análisis de consumo de energía eléctrica del campus UAO en una semana ...............................169

4.3.5. Análisis del uso y consumo de la energía eléctrica por subestaciones ......................................171

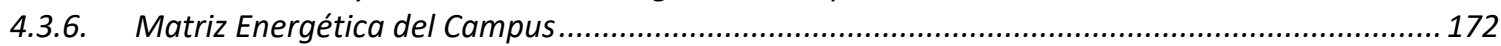

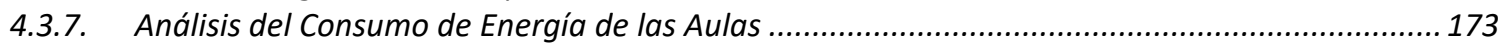

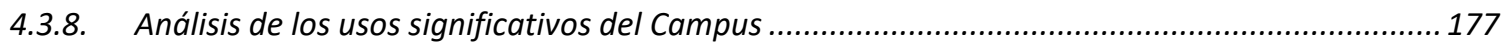

CAPÍTULO 5: ANÁLISIS Y ESTUDIO ENERGÉTICO DEL EDIFICIO DE AULAS 4 DE LA UNIVERSIDAD AUTÓNOMA DE

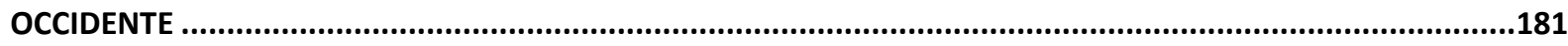

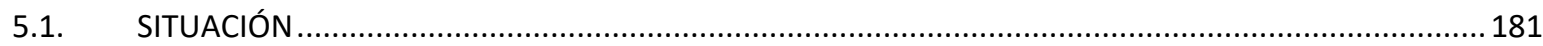

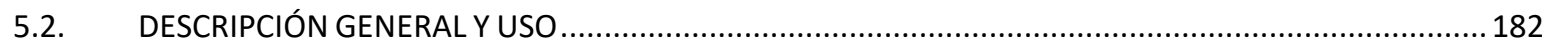

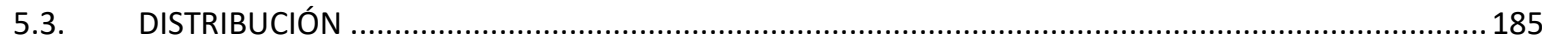

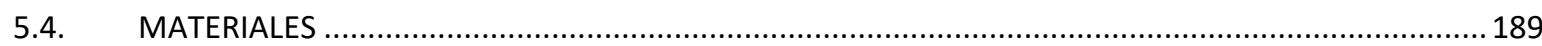

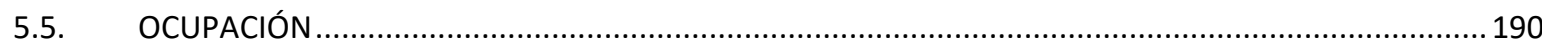

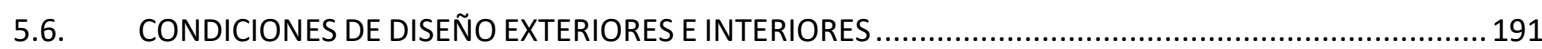

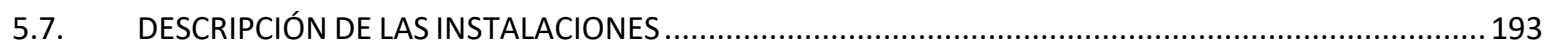

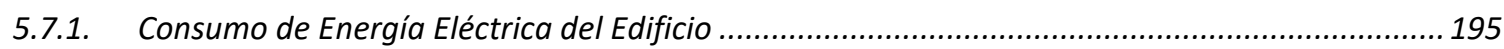

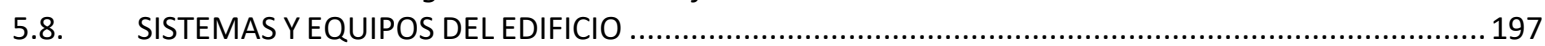

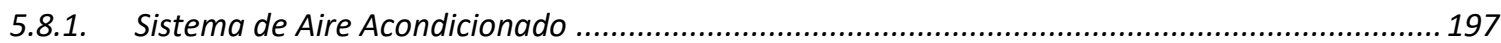

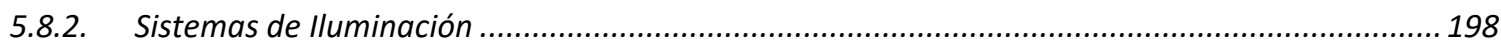

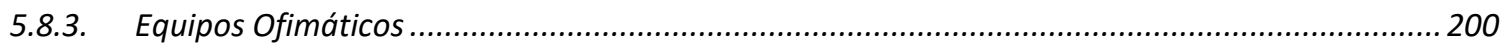

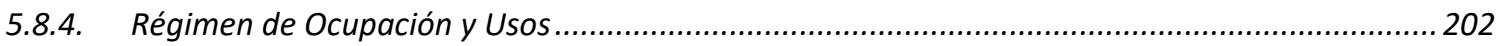

5.9. COSTE ECONÓMICO DEL CONSUMO ENERGÉTICO E IMPACTO MEDIOAMBIENTAL.........................202

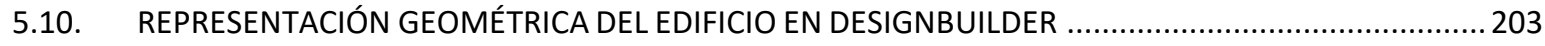

5.11. COMPARACIÓN DE LOS CONSUMOS ENERGÉTICOS MEDIDOS Y SIMULADOS ....................................209

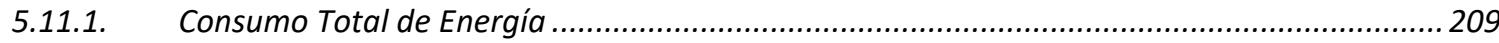

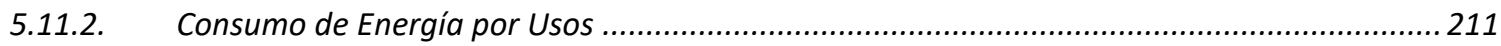

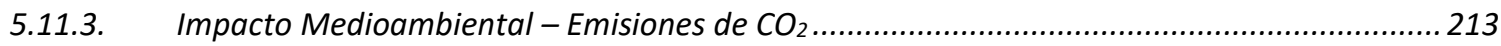

CAPÍTULO 6: PROPUESTAS DE MAE'S PARA EL EDIFICIO DE AULAS 4 MEDIANTE SIMULACIÓN ENERGÉTICA 214

6.1. MAE I-SISTEMA DE AIRE ACONDICIONADO MÁS EFICIENTE. ...................................................214

6.1.1. Análisis comparativo de consumos energéticos del edificio base vs el edificio con la MAE I ...... 221

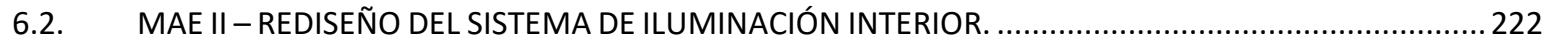

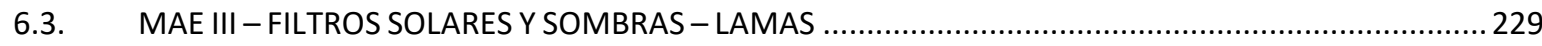

6.3.1. Análisis comparativo de consumos energéticos del edificio base vs el edificio con la MAE III .... 233

6.4. MAE IV - FILTROS SOLARES Y SOMBRAS - VIDRIO ELECTROCRÓMICO ….......................................2 234

6.4.1. Análisis comparativo de consumos energéticos del edificio base vs el edificio con la MAE IV .... 237

6.5. MAE V - FILTROS SOLARES Y SOMBRAS - VOLADIZOS ................................................................ 238

6.5.1. Análisis comparativo de consumos energéticos del edificio base vs el edificio con la MAE V..... 242

6.6. MAE VI - FILTROS SOLARES Y SOMBRAS - PERSIANAS REFLECTIVAS ............................................... 243

6.6.1. Análisis comparativo de consumos energéticos del edificio base vs el edificio con la MAE VI .... 246 
Índices

6.7. MAE VII - FILTROS SOLARES Y SOMBRAS - PELICULAS PROTECTORAS ...........................................247

6.7.1. Análisis comparativo de consumos energéticos del edificio base vs el edificio con la MAE VII ...250

6.8. MAE VIII - IMPLEMENTACIÓN DE TODAS LAS MAE'S PROPUESTAS...............................................251

6.8.1. Análisis comparativo de consumos energéticos del edificio base vs el edificio con la MAE VIII .. 254

PROPUESTA DE ALMACENAMIENTO PARA EL SISTEMA DE ILUMINACIÓN ...............................................256

CAPÍTULO 7: DESARROLLO DE LA METODOLOGÍA PARA ESTIMAR LÍNEAS BASES E INDICADORES ..................258

7.1. METODOLOGÍA PARA LA SELECCIÓN DE MODELOS DE LINEA BASE E INDICADORES .......................258

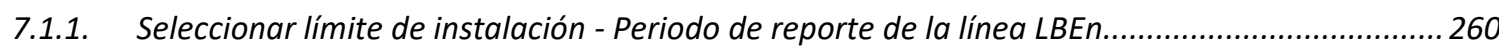

7.1.2. Verificar la fuente y calidad de los datos para cuantificar el consumo de energía y las variables

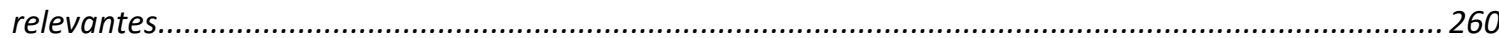

7.1.3. Revisar las variables relevantes que afectan el consumo y los factores estáticos durante el periodo

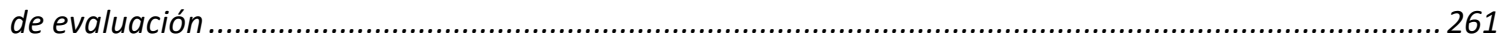

7.1.4. Análisis de la información muestral y patrón de comportamiento de los datos a analizar.........262

7.1.5. Definir un modelo para su utilización ............................................................................263

7.2. APLICACIÓN DE LA METODOLOGIA PROPUESTA AL EDIFICIO DE AULAS DE LA UNIVERSIDAD

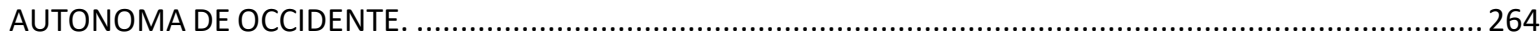

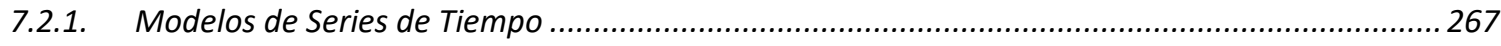

7.2.2. Modelos de Regresión Lineal y Multivariable ...................................................................2.279

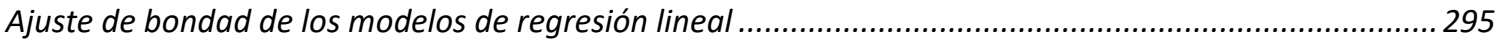

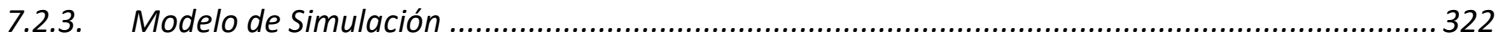

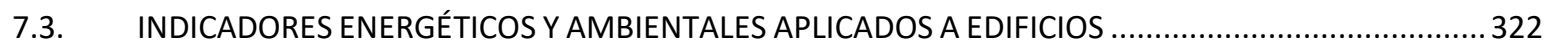

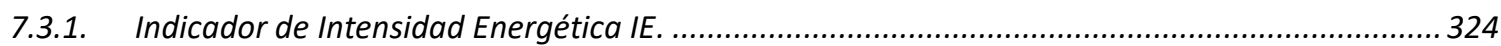

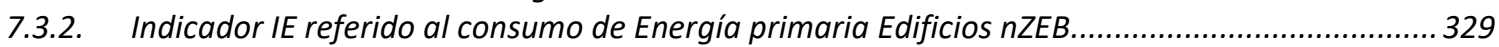

7.3.3. Indicador del Impacto Ambiental - Emisiones de CO2 ...........................................................334

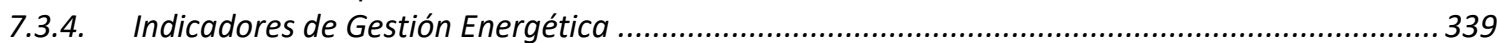

7.4. EFECTOS DE LOS MODELOS DE ESTIMACIÓN DE LÍNEA BASE E INDICADORES SOBRE LA ESTIMACIÓN DE

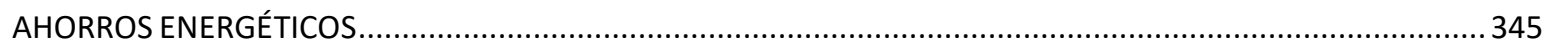

7.4.1. Análisis del modelo 2019 considerando datos diarios, semanales y mensuales .........................349

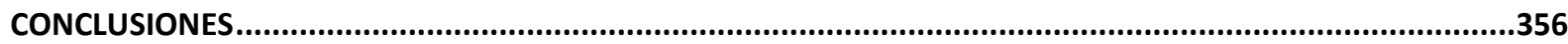

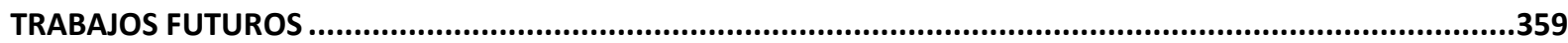




\section{ÍNDICE DE FIGURAS}

Figura 1. Población urbana y rural del mundo, 1950-2050............................................................ 26 Figura 2. Cambio en la demanda de energía primaria. Fuente: World Energy Outlook 2017 [4]....... 27 Figura 3. Emisiones de CO2 en diferentes regiones 2014-2040 Fuente: World Energy Outlook 2017 [4]

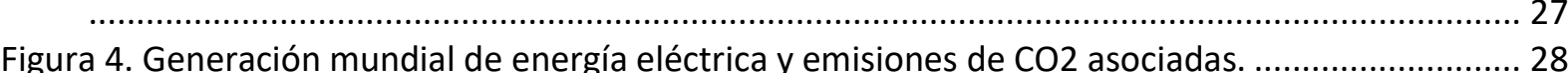

Figura 5. Consumo de Energía por regiones. Fuente: BP - Outlook for Energy 2017 [5] ................... 28

Figura 6. Fuentes de Energía Primaria - Matriz Energética Mundial................................................ 29

Figura 7. Consumo de energía primaria a 2014 Fuente: Energy Efficiency Policies 2016. World Energy

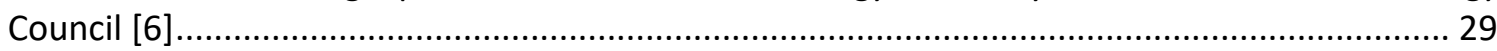

Figura 8. Medidas para pasar de un 6DS al 2DS. Fuente: Energy Technology Perspectives 2016 IEA [7].

Figura 9. Reducción acumulada de emisiones de CO2 por sector y tecnología horizonte 2050. Fuente:

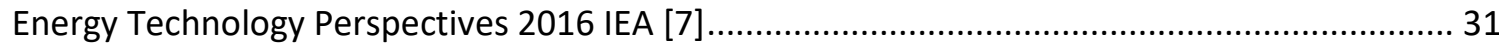

Figura 10. Impacto de la Eficiencia en el consumo final de energía a nivel global en el 2DS .............. 31

Figura 11. Reducciones globales de Co2 entre 6DS y 2DS por sector. Fuente: Energy Technology

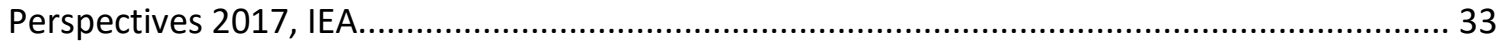

Figura 12. Uso final de energía por $\mathrm{m} 2$ a nivel mundial. Fuente: UN Environment and International

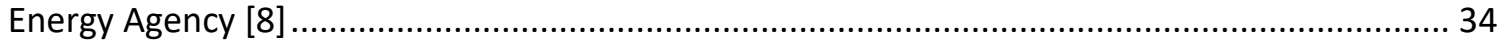

Figura 13. Consumo global de Energía en edificios. Fuente: UN Environment and International Energy

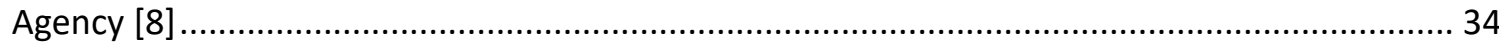

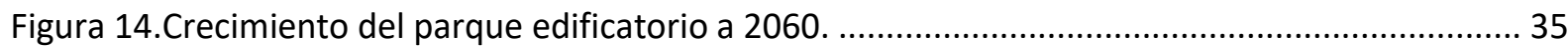

Figura 15. Códigos de energía por País Fuente: Building Energy Efficiency Policies [9] ..................... 35

Figura 16. Proporción del consumo de energía final 2016. Fuente: UN Environment and International

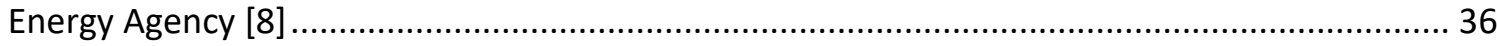

Figura 17. Proporción de emisiones de CO2 2016. Fuente: UN Environment and International Energy

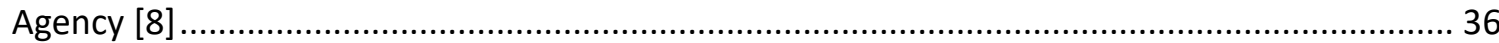

Figura 18. Consumo de energía del sector de edificios, intensidad energética y superficie (2010-16)

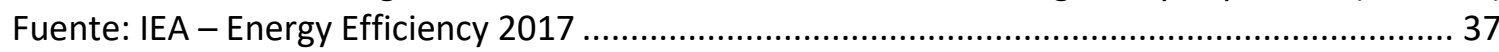

Figura 19. Proporción del progreso de la política de eficiencia de la calefacción y la refrigeración espaciales desde el año 2000 a partir de la construcción de sobres frente a los equipos HVAC Fuente: IEA - Energy Efficiency 2017

Figura 20. Proyecciones de consumo final de energía de edificios para las principales regiones y países, 2012-50. 39

Figura 21. Consumo de energía por fuente para el año 2017 Fuente: IEA, 2018 …......................... 40

Figura 22. Consumo de energía por sector para el 2017 Fuente: IEA, 2018 ...................................... 40

Figura 23. Energía final demandada en 2017 países de la Unión Europea Fuente: Comisión Europea, 2017 [19]

Figura 24. Participación del Consumo Final por Energético y Sectores: América Latina y El Caribe - 2017

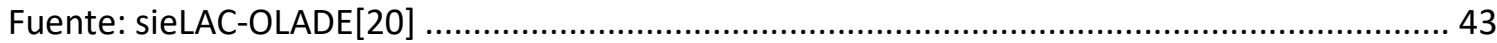

Figura 25. Porcentaje de consumo final y emisiones de GEI en las edificaciones en Latinoamérica ... 44 Figura 26. Antecedentes de la política nacional de edificaciones sostenibles Fuente: Dirección de Desarrollo Urbano DNP 
Índices

Figura 27. Objetivos de Desarrollo Sostenible relacionadas con las edificaciones sostenibles Fuente: Dirección de Desarrollo Urbano DNP, basado en la ODS 54

Figura 28. Índice del PIB total y construcción 2017 Fuente: Cálculos DNP con base en cuentas trimestrales DANE 56

Figura 29. Emisiones directas de GEI por sector 2016 Fuente: Inventario nacional de GEI - Colombia [37] 56

Figura 30. Consumo Nacional de Energía Fuente: Ministerio de Minas y energía, y UPME - PROURE 2017. 57

Figura 31. Consumo de energía eléctrica, gas natural y GLP en el Sector Terciario Fuente: UPME - PAI

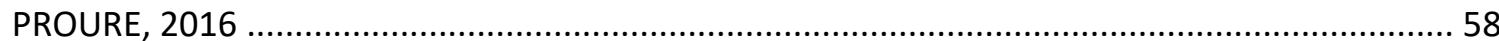

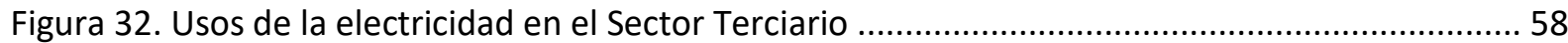

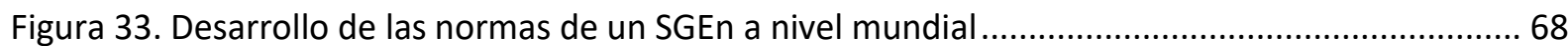

Figura 34. Ciclo de Mejora Continua PHVA norma ISO 50001:2018 ............................................... 71

Figura 35. Cambios principales norma ISO 50001:2018 con respecto a la ISO 50001:2011............... 72

Figura 36. Términos y definiciones de la nueva versión de la ISO $50001: 2018$................................ 73

Figura 37. Familia de normas de ISO5000 que aportan a la implementación de los SGEn ................. 77

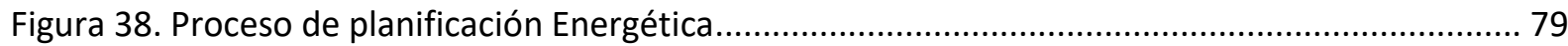

Figura 39. Herramientas usadas para la revisión energética ......................................................... 80

Figura 40. Proceso de auditoria energética adaptado según requisitos ISO50002 ........................... 90

Figura 41. Concepto de periodo base y periodo de reporte para IDE ............................................ 93

Figura 42. Pasos para el establecimiento de una línea de base energética........................................94

Figura 43. Lo que se quiere conseguir con una LBE ..................................................................... 98

Figura 44. Aspectos para tener en cuenta en el establecimiento de indicadores de desempeño

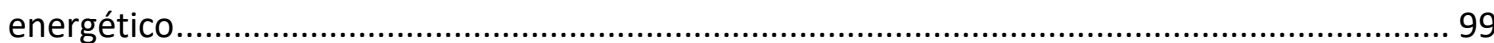

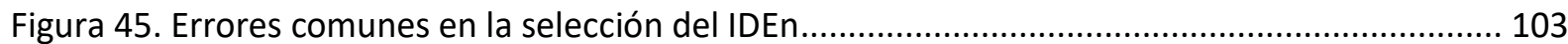

Figura 46. Gráfico ilustrativo del indicador de Eficiencia Energética............................................. 108

Figura 47. Gráfica seguimiento Indicador de Eficiencia IEE ........................................................ 108

Figura 48. Diagrama para ejemplificar el proceso para desarrollar, usar y actualizar IDE y LBE según la norma ISO 50006. Tomado y adaptado de la norma ISO 50006 versión 2016 ......................... 124

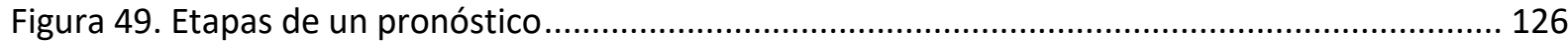

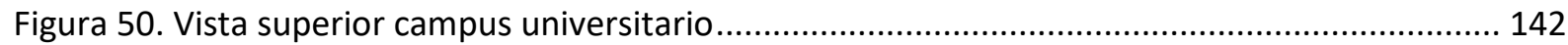

Figura 51. Vista frontal y entrada peatonal principal del campus universitario ............................... 143

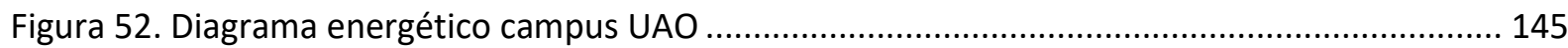

Figura 53. Sistema de medición de energía eléctrica instalado en la UAO ..................................... 147

Figura 54. Sistema de medición de energía eléctrica instalado en la UAO..................................... 148

Figura 55. Vista superior del campus universitario y sistemas marcación de los SSFV del campus ... 149

Figura 56. Consumo de energía total y por áreas de la UAO.................................................... 151

Figura 57. Energía activa consumida y subestaciones del campus................................................. 151

Figura 58. Parámetros eléctricos monitorizados de Aulas 4 .......................................................... 152

Figura 59. Diagrama unifilar general de medición UAO.................................................................... 152

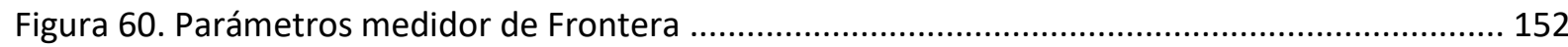

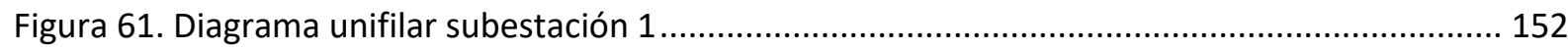

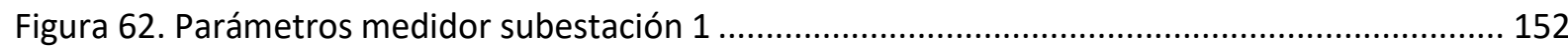

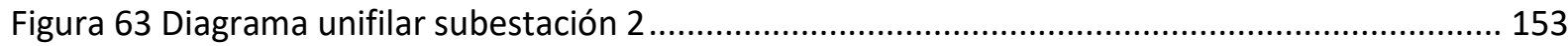

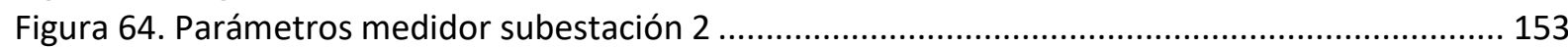

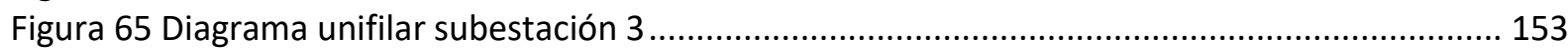




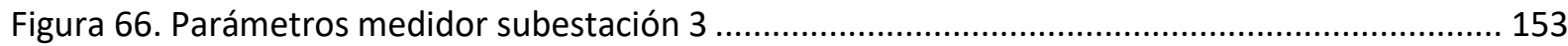

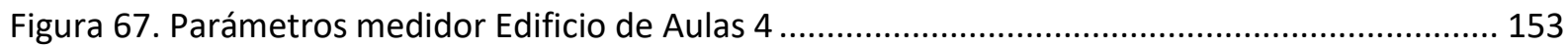

Figura 68. Estación meteorológica Davis Vantage pro 2 ............................................................. 155

Figura 69. Diagrama de condensación Planta de agua fría Edificio Central. Metasys ....................... 155

Figura 70. Diagrama planta de agua fría - Enfriadora de agua Edificio central. Metasys ................. 156

Figura 71. Diagrama planta de agua fría con información desplegada- Enfriadora de agua Edificio

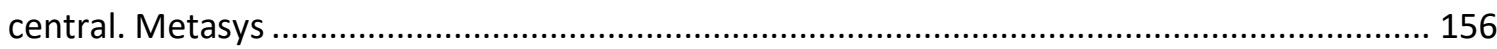

Figura 72. Curvas de comportamiento y parámetros monitorizados en planta de agua fría ............. 156

Figura 73. Tendencia de consumo por tipo de energético año 2016 .............................................. 163

Figura 74. Tendencia de consumo por tipo de energético año 2017 .............................................. 163

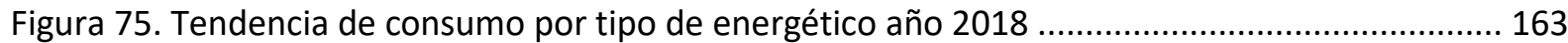

Figura 76. Tendencia de consumo por tipo de energético año 2019 ............................................ 164

Figura 77. Tendencia de generación sistema fotovoltaico por area año 2017 ................................. 165

Figura 78. Tendencia de generación sistema fotovoltaico por area año 2018 ............................... 166

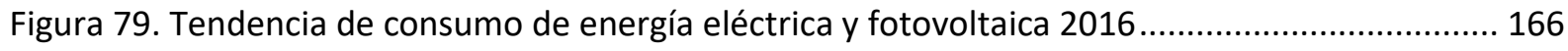

Figura 80. Tendencia de consumo de energía eléctrica y fotovoltaica 2017 ................................... 167

Figura 81. Distribución de la Generación de Energía SSFV 2017 .................................................. 167

Figura 82. Tendencia de consumo de energía eléctrica y fotovoltaica 2018.................................... 167

Figura 83. Distribución de la Generación de Energía SFV 2018 ................................................... 168

Figura 84. Tendencia de consumo de energía eléctrica mensual desde el año 2014-2019 .............. 169

Figura 85. Análisis consumo de energía eléctrica global UAO en una semana de marzo 2017.......... 170

Figura 86. Análisis consumo de energía eléctrica global UAO en una semana de junio 2017............ 170

Figura 87. Análisis consumo de energía eléctrica global UAO en una semana de marzo 2018.......... 170

Figura 88. Análisis consumo de energía eléctrica global UAO en una semana de junio 2018........... 171

Figura 89. Participación de subestaciones en el consumo de energía eléctrica .................................. 171

Figura 90. Matrices de consumo de energía años 2016 - 2018................................................... 172

Figura 91. Perfil de consumo de energía en un día de la subestación 3 ........................................ 173

Figura 92. Perfil de consumo semanal subestación 3 ................................................................ 173

Figura 93. matriz de consumo de energía electrica de aulas 2016 - 2019 .................................... 174

Figura 94. tendencia de consumo de energía electrica aulas por jornada-Años 2016 y 2017 .......... 176

Figura 95. Pareto uso significativo de energía eléctrica UAO .................................................... 177

Figura 96. Pareto general de consumo de energía eléctrica UAO ................................................. 178

Figura 97. Pareto de consumo de energía eléctrica por usos significativos en edificio central UAO. 178

Figura 98. Pareto de consumo de energía eléctrica por usos significativos en bienestar universitario

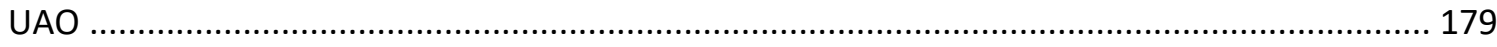

Figura 99. Pareto consumo de energía eléctrica por usos significativos aulas 1 ............................ 179

Figura 100. Pareto consumo de energía eléctrica por usos significativos aulas 2 ........................... 179

Figura 101. Pareto consumo de energía eléctrica por usos significativos aulas 3 ........................... 180

Figura 102. Pareto consumo de energía eléctrica por usos significativos aulas 4 ............................ 180

Figura 103. Ubicación Campus Universitario Universidad Autónoma de Occidente......................... 181

Figura 104. Localización del edificio de aulas 4.................................................................... 182

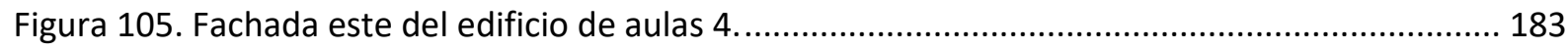

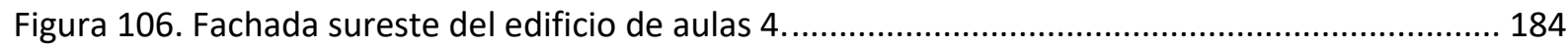

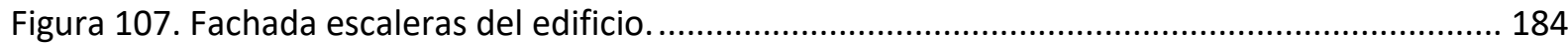

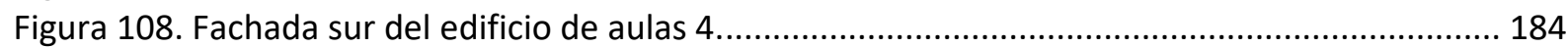

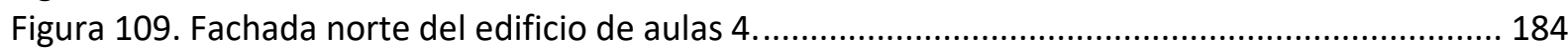




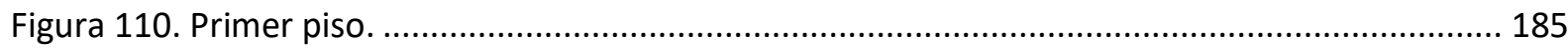

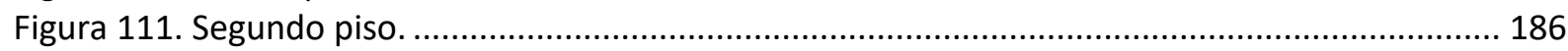

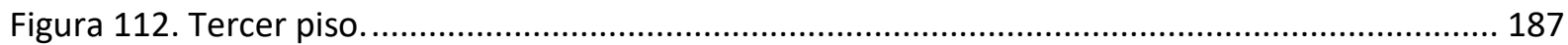

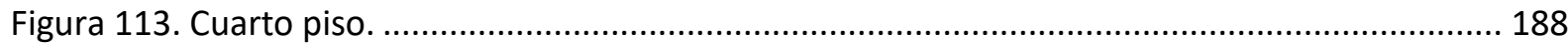

Figura 114. Condiciones de diseño exteriores anuales................................................................. 191

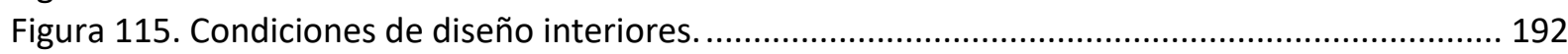

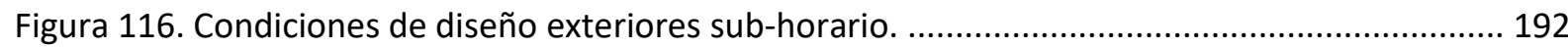

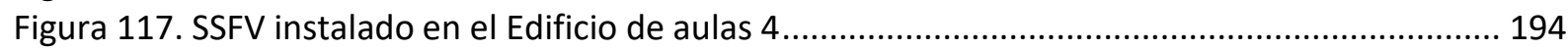

Figura 118. Diagrama Unifilar de subestación 2 con ubicación del medidor del aula 4 .................... 195

Figura 119. Consumo de Energía Eléctrico anual ...................................................................... 196

Figura 120. Histórico de consumo de energía eléctrica mensual 2016 - 2019 ................................ 196

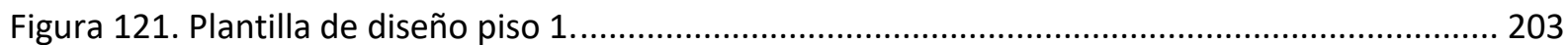

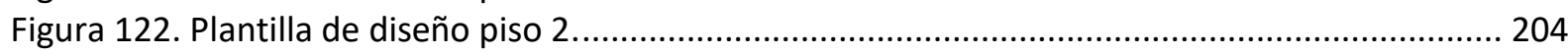

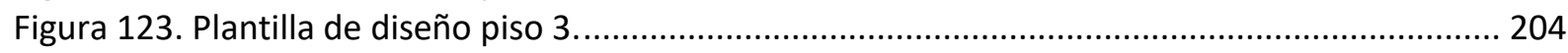

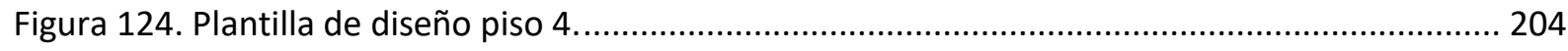

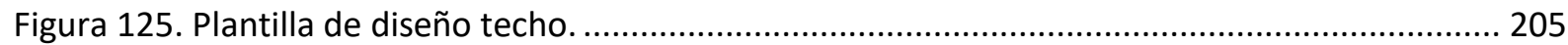

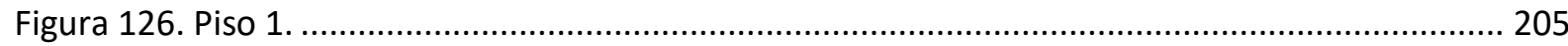

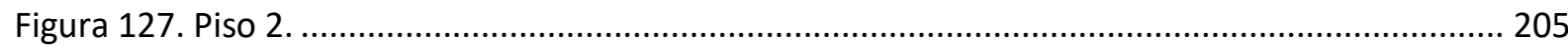

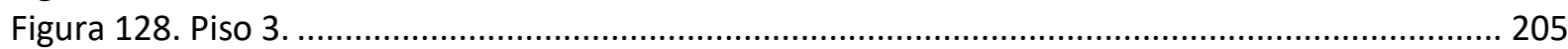

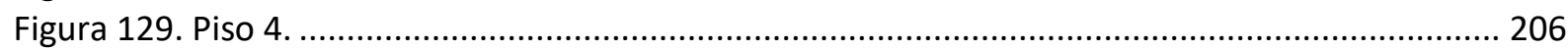

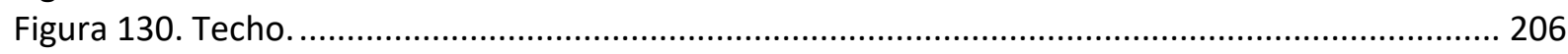

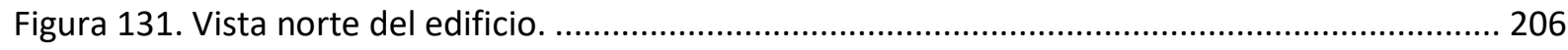

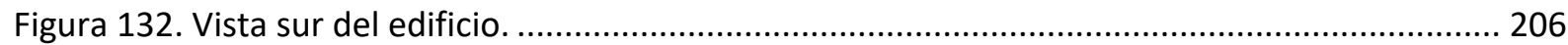

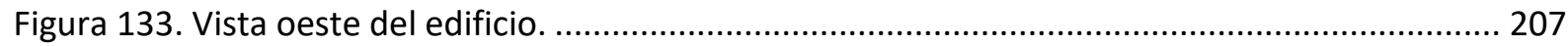

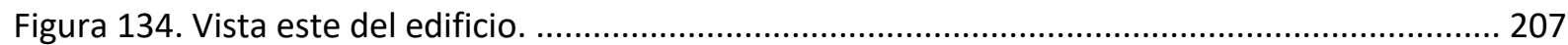

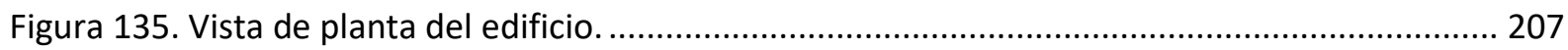

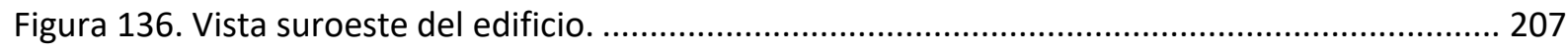

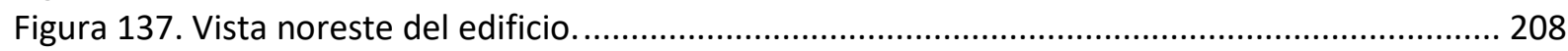

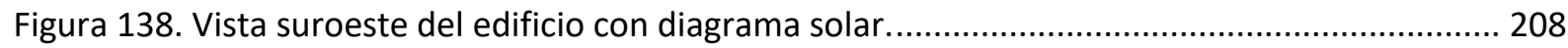

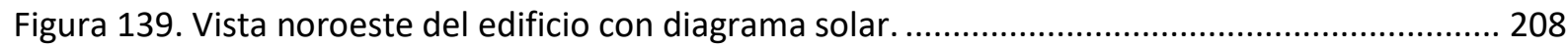

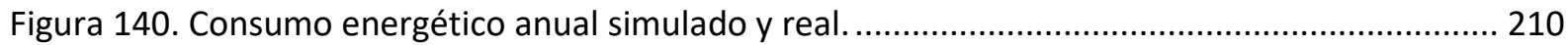

Figura 141. Distribución de consumo energético mensual desglosado por uso final........................ 212

Figura 142. Distribución porcentual de consumo energético por uso final....................................... 212

Figura 143. Diagrama de barras distribución del consumo energético anual. .................................. 213

Figura 144. Emisiones de $\mathrm{CO}_{2}$ mensual para el edificio ........................................................... 213

Figura 145. Distribución de consumo energético anual. ................................................................ 218

Figura 146. Distribución de consumo energético anual desglosado por uso final para MAE I.......... 219

Figura 147. Distribución porcentual de consumo energético por uso final para MAE I .................... 219

Figura 148. Diagrama de barras distribución del consumo energético anual. .................................... 220

Figura 149. Emisiones de $\mathrm{CO}_{2}$ mensual para el edificio con la MAE I ............................................ 221

Figura 150. Consumo energético mensual Edificio Base y Edificio con MAE I................................. 221

Figura 151. Consumo energético anual Edificio Base y Edificio con MAE I...................................... 222

Figura 152. Emisiones de $\mathrm{CO}_{2}$ mensual para el edificio con la MAE II ......................................... 228

Figura 153. Vista norte del edificio con implementación de lamas ................................................. 229

Figura 154. Vista sur del edificio con implementación de lamas......................................................... 229

Figura 155. Vista este del edificio con implementación de lamas ..................................................... 229 
Índices

Figura 156. Vista oeste del Edificio con implementación de lamas ............................................. 229

Figura 157. Distribución de consumo energético anual edificio con MAE III................................... 230

Figura 158. Distribución de consumo energético anual desglosado por uso final para MAE III......... 231

Figura 159. Distribución porcentual de consumo energético por uso final para MAE III .................. 231

Figura 160. Diagrama de barras distribución del consumo energético anual con MAE III................. 232

Figura 161. Emisiones de $\mathrm{CO}_{2}$ mensual para el edificio con la MAE III ............................................. 232

Figura 161. Consumo energético mensual Edificio Base y Edificio con MAE III................................ 233

Figura 162. Consumo energético anual Edificio Base y Edificio con MAE III.................................... 233

Figura 164. Distribución de consumo energético anual desglosado por uso final para MAE IV ........ 235

Figura 165. Distribución porcentual de consumo energético por uso final para MAE I .................... 235

Figura 166. Diagrama de barras distribución del consumo energético anual. .................................. 236

Figura 167. Emisiones de $\mathrm{CO}_{2}$ mensual para el edificio con la MAE IV ......................................... 236

Figura 168. Consumo energético mensual Edificio Base y Edificio con MAE IV ................................. 237

Figura 169. Consumo energético anual Edificio Base y Edificio con MAE IV .................................. 237

Figura 170. Vista norte del edificio con implementación de voladizos ........................................... 238

Figura 171. Vista sur del edificio con implementación de voladizos .............................................. 238

Figura 172. Vista oeste del edificio con implementación de voladizos ........................................... 238

Figura 173. Vista este del edificio con implementación de voladizos.............................................. 238

Figura 174. Distribución de consumo energético anual con MAE V implementada.......................... 239

Figura 175. Distribución de consumo energético anual desglosado por uso final para MAE V ......... 240

Figura 176. Distribución porcentual de consumo energético por uso final para MAE V ................... 240

Figura 177. Diagrama de barras distribución del consumo energético anual implementando MAE V.

Figura 178. Emisiones de $\mathrm{CO}_{2}$ mensual para el edificio con la MAE V ......................................... 241

Figura 179. Consumo energético mensual Edificio Base y Edificio con la MAE V.............................. 242

Figura 180. Consumo energético anual Edificio Base y Edificio con la MAE V................................... 242

Figura 181. Distribución de consumo energético anual con MAE VI............................................. 243

Figura 182. Distribución de consumo energético anual desglosado por uso final para MAE VI ........ 244

Figura 183. Distribución porcentual de consumo energético por uso final para MAE VI.................. 244

Figura 184. Diagrama de barras distribución del consumo energético anual. ................................. 245

Figura 185. Emisiones de $\mathrm{CO}_{2}$ mensual para el edificio con la MAE VI ........................................ 245

Figura 186. Consumo energético mensual Edificio Base y Edificio con MAE VI................................ 246

Figura 187. Consumo energético anual Edificio Base y Edificio con MAE VI ................................... 246

Figura 188. Distribución de consumo energético anual con MAE VII........................................... 247

Figura 189. Distribución de consumo energético anual desglosado por uso final para MAE VII ....... 248

Figura 190. Distribución porcentual de consumo energético por uso final para MAE VII ................. 248

Figura 191. Diagrama de barras distribución del consumo energético anual. ................................. 249

Figura 192. Emisiones de $\mathrm{CO}_{2}$ mensual para el edificio con la MAE VII ........................................... 249

Figura 193. Consumo energético mensual Edificio Base y Edificio con MAE VII................................. 250

Figura 194. Consumo energético anual Edificio Base y Edificio con MAE VII .................................... 250

Figura 195. Distribución de consumo energético anual. ............................................................ 251

Figura 196. Distribución de consumo energético anual desglosado por uso final para MAE VIII ...... 252

Figura 197. Distribución porcentual de consumo energético por uso final para MAE VIII ................ 253

Figura 198. Diagrama de barras distribución del consumo energético anual. .................................. 253

Figura 198. Emisiones de $\mathrm{CO}_{2}$ mensual para el edificio con la MAE VIII ............................................. 254

Figura 200. Consumo energético mensual Edificio Base y Edificio con las 6 MAE's e iluminación. ... 254 
Índices

Figura 201. Consumo energético anual Edificio Base y Edificio con 6 MAE's e iluminación .............. 255

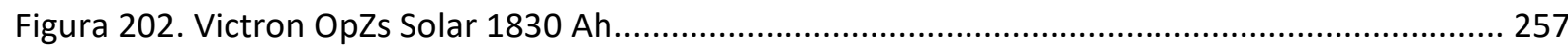

Figura 203. Metodología para la selección de modelos de líneas bases e indicadores ..................... 259

Figura 204. Comportamiento histórico del consumo mensual de energía eléctrica del edificio aulas 4

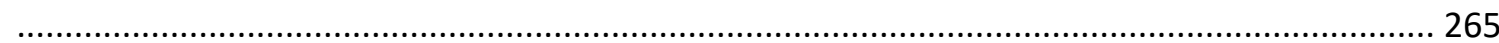

Figura 205. Grafica comportamiento estacional del edificio de aulas 4 ........................................ 266

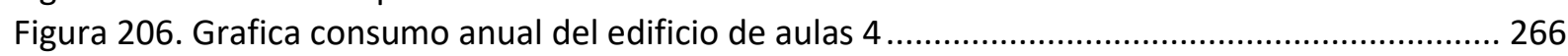

Figura 207. Promedio del consumo mensual histórico de energía Eléctrica (2016 - 2018).............. 267

Figura 208. Promedio ponderado del consumo mensual histórico de energía Eléctrica (2016 - 2018)

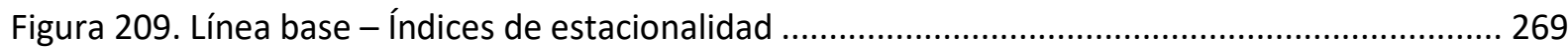

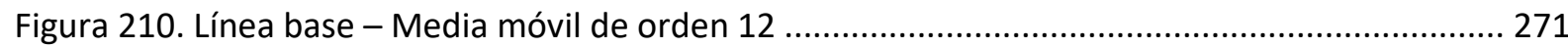

Figura 211. Consumo semanal de energía eléctrica para el año 2016 ............................................ 271

Figura 212. Consumo semanal de energía eléctrica para el año 2016 .......................................... 271

Figura 213. Consumo semanal de energía eléctrica para el año 2016 ......................................... 272

Figura 214. Consumo semanal de energía para el periodo de vacaciones (Años 2016 - 2018)........ 272

Figura 215. Consumo semanal de energía para el periodo de invierno (Años 2016 - 2018) ............. 273

Figura 216. Consumo semanal de energía para el periodo de verano (Años 2016 - 2018) ............... 273

Figura 217. Consumo semanal de energía para el primer semestre (Años 2016 - 2018) ................. 273

Figura 218. Consumo semanal de energía para el segundo semestre (Años 2016 - 2018) ............... 273

Figura 219. Consumo promedio según programación académica................................................. 274

Figura 220. Línea base - consumo promedio según programación académica ................................. 274

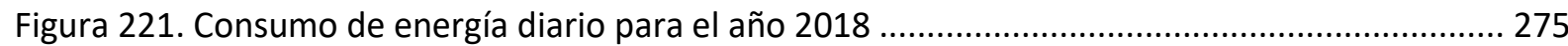

Figura 222. Consumo de energía diario promedio por distintos periodos del $2018, \ldots \ldots \ldots \ldots \ldots \ldots \ldots . . . . . . . . . .276$

Figura 223. Pronóstico diario del consumo de energía eléctrica considerando el consumo promedio

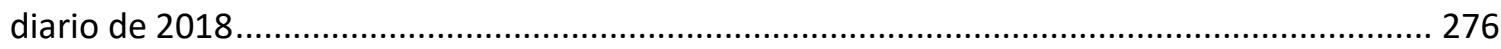

Figura 224. Pronóstico semanal del consumo de energía eléctrica considerando el consumo promedio

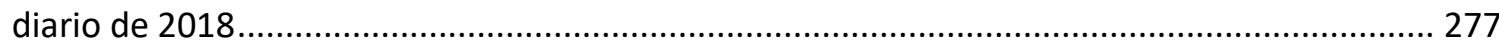

Figura 225. Línea base - consumo promedio según programación académica ................................ 277

Figura 226. Resultados obtenidos con los diferentes métodos de pronóstico utilizados para obtener

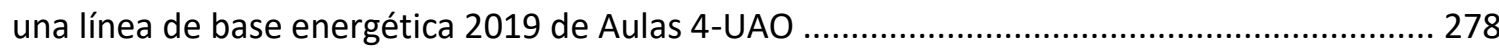

Figura 227. Correlación entre variables - Software R Studio ........................................................ 280

Figura 228. Correlación entre el Consumo de energía final Total y las variables independientes -

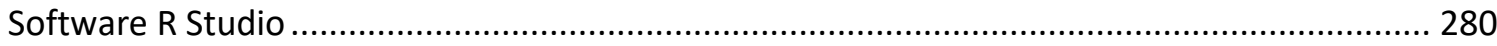

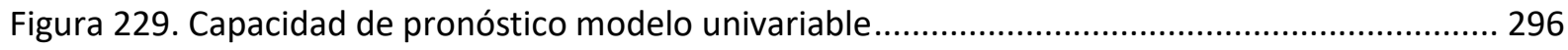

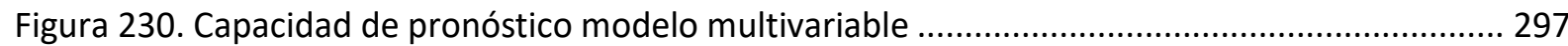

Figura 231. Distribución del tipo de semana para el año 2018 ..................................................... 299

Figura 232. Indicadores de Eficiencia Energética del consumo de energía eléctrica total del Campus

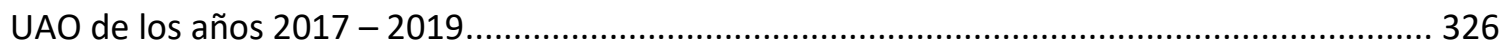

Figura 233. Indicadores de Eficiencia Energética de Generación FV del Campus UAO de los años 2017

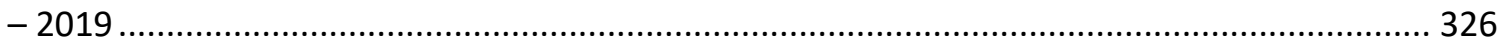

Figura 234. Indicadores de Eficiencia Energética del consumo de energía eléctrica total del Edificio de

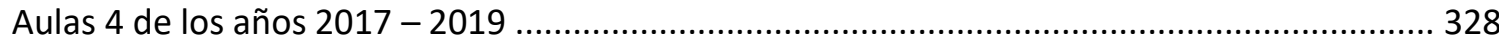

Figura 235. Indicadores de Eficiencia Energética de la generación de Energía Solar FV en el Edificio de

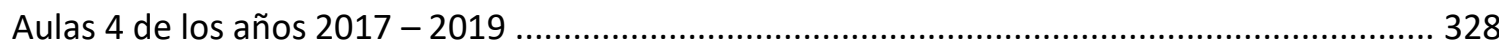

Figura 236. Etapas de Energía primaria a Energía Útil .................................................................. 329 
Índices

Figura 237. Emisiones anuales de CO2 de los años 2017 - 2019 campus UAO ............................... 335

Figura 238. Emisiones mensuales de CO2 de los años 2017 - 2019 campus UAO ............................ 336

Figura 239.Indicador Ambiental mensual de los años 2017 - 2019 campus UAO ............................ 336

Figura 240. Emisiones anuales de CO2 de los años 2017 - 2019 campus UAO ................................. 337

Figura 241. Emisiones mensuales de CO2 de los años 2017 - 2019 campus UAO ............................. 338

Figura 242. Indicador Ambiental mensual de los años 2017 - 2019 campus UAO............................ 338

Figura 243. Indicador de Eficiencia Energética anual - Edificio de Aulas 4 .................................... 340

Figura 244. Indicador de Eficiencia Energética IEE del edificio de aulas 4 años $2017-2019$............ 341

Figura 245. Indicador de Eficiencia Energética IEE del edificio de aulas 4 años 2017 y $2019 . \ldots \ldots \ldots . . . . .341$

Figura 246. Indicador de Sumas Acumulativas CUSUM del edificio de aulas 4 años $2017-2019 \ldots . .343$

Figura 247. Indicador de Sumas Acumulativas CUSUM del edificio de aulas 4 años 2017 y 2019 ..... 344

Figura 248. Indicador de Eficiencia Energética mensual de los diferentes modelos ........................ 347

Figura 249. Indicador CUSUM de los diferentes modelos ......................................................... 348

Figura 250. Indicador de Eficiencia Energética de los modelos de LBE diaria, semanal, mensual y

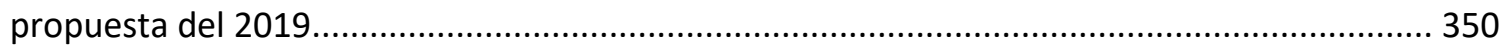

Figura 251. Indicador CUSUM de los modelos de LBE diaria, semanal, mensual y propuesta del 2019 


\section{ÍNDICE DE TABLAS}

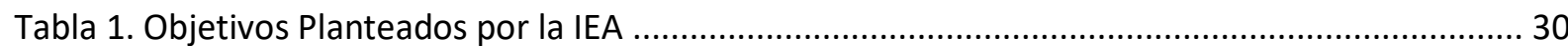

Tabla 2. Evolución de la aplicación de la norma ISO50001 desde su publicación en 2011 ..................69

Tabla 3. Herramientas usadas para el análisis de uso y consumo de energía ..................................... 81

Tabla 4. Herramientas usadas para la identificación de USE's ....................................................... 86

Tabla 5. Herramientas para la identificación y priorización de oportunidades para el mejoramiento del

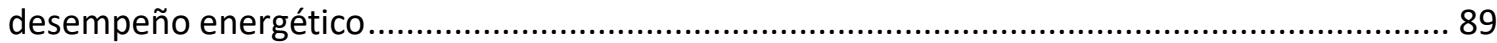

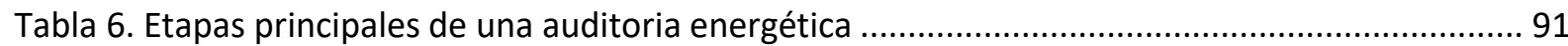

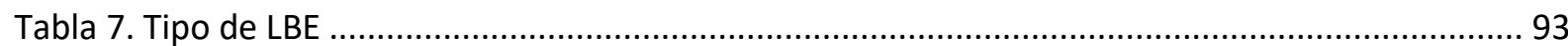

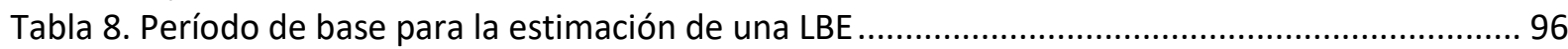

Tabla 9. Selección de un método para la estimación de la LBE de acuerdo con el tipo de instalación 97

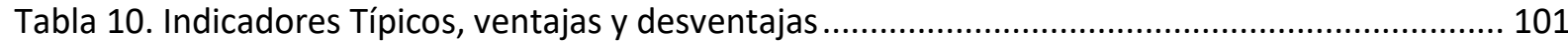

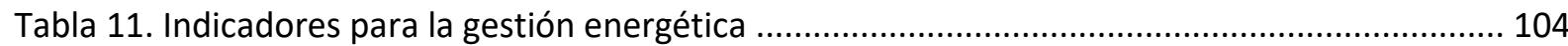

Tabla 12.Clasificación de KPI o Indicadores energéticos para edificios ............................................ 105

Tabla 13. Tipos de indicadores y líneas base propuesto por la norma ISO50006........................... 119

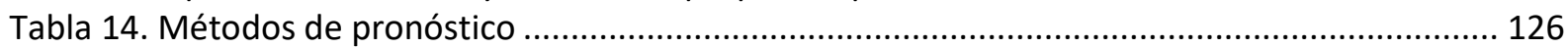

Tabla 15. Componentes de una serie de tiempo ...................................................................... 126

Tabla 16. Métodos de series de tiempo y características de los datos.......................................... 127

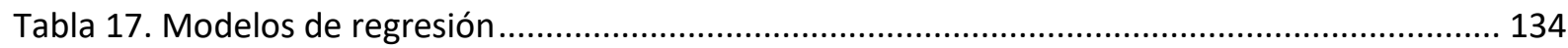

Tabla 18. Supuestos Estadisticos para el modelo de regresión ..................................................... 135

Tabla 19. Equipos de uso final y distribución por áreas del campus de la UAO .............................. 146

Tabla 20. Descripción de los SSFV instalados en el campus de la UAO ............................................ 149

Tabla 21. Medidores de Energía Eléctrica instalados en el campus ............................................. 150

Tabla 22. Características técnica estación meteorológica ............................................................... 154

Tabla 23. Equipos de medida usados en la auditoria energética del campus .................................. 157

Tabla 24. cronograma de mediciones de consumo de energía eléctrica según lineamientos de la ISO50002

Tabla 25. Datos de consumo de energía eléctrica y código de medidores implementados en la UAO

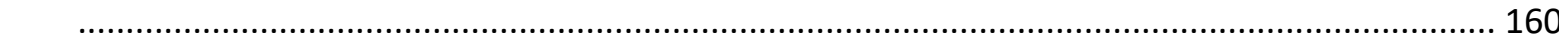

Tabla 26 datos de consumo por tipo de energéticos 2016-2019 ................................................ 162

Tabla 27. Datos de consumo energía eléctrica y fotovoltaica ........................................................ 165

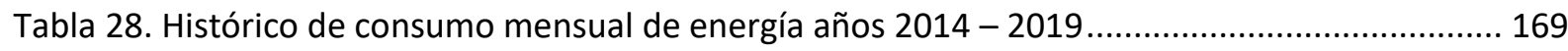

Tabla 29. Datos de consumo por tipo de energía años 2016 - 2018 ............................................. 172

Tabla 30. Relacion de incremento o decremento en el consumo de energía electrica para las aulas en

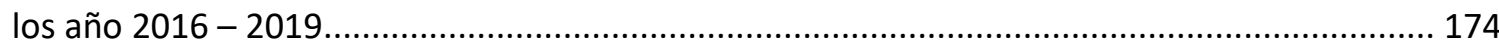

Tabla 31. Consumo de energía electrica promedio por mes edificios de aulas 2016 - 2019............ 175

Tabla 32. consumo de energía electrica promedio en cada aulas por jornada -2016 y 2017 ............ 176

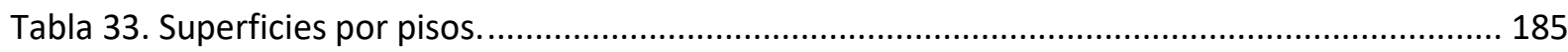

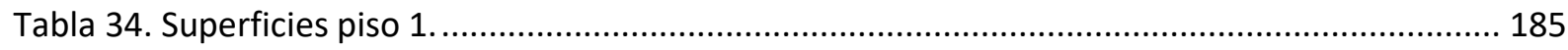

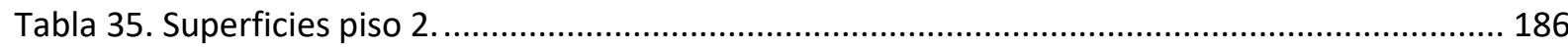

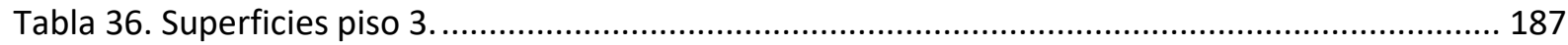

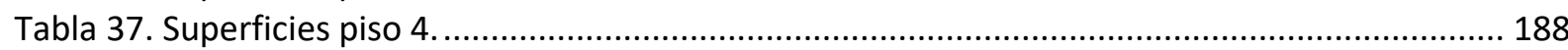

Tabla 38. Materiales de construcción de los espacios del Edificio ................................................... 189 


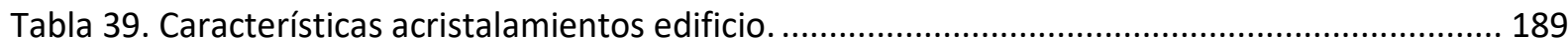

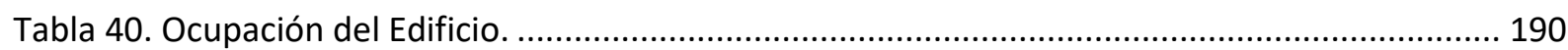

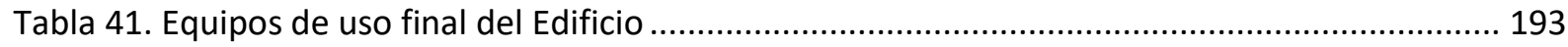

Tabla 42. Histórico de consumos de Energía Eléctrica.................................................................... 195

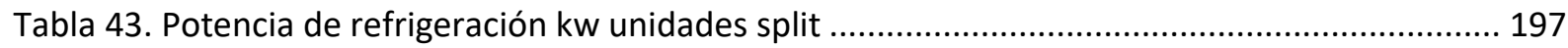

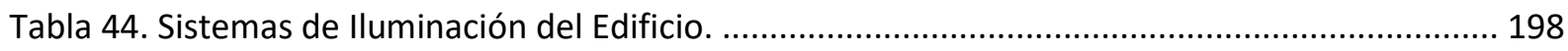

Tabla 45. Equipos de uso ofimático del Edificio......................................................................... 200

Tabla 46. Costes Económicos e Impacto medioambiental Edificio de Aulas 4 ................................. 202

Tabla 47. Valores de consumo eléctrico reales y simulados ........................................................... 209

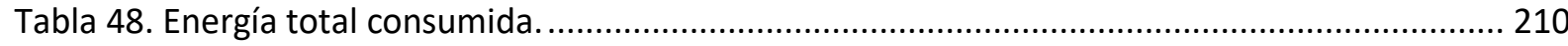

Tabla 49. Distribución de consumos energéticos por uso. ............................................................ 211

Tabla 50. Distribución de consumos energéticos desglosados mes a mes por uso........................... 211

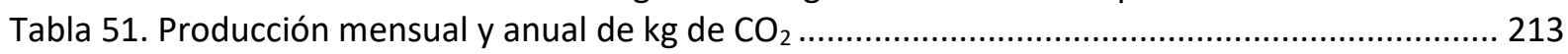

Tabla 52. Características técnicas extractores ............................................................................ 214

Tabla 53. Características técnicas de los equipos de acondicionamiento de recintos ....................... 215

Tabla 54. Resumen datos recintos climatizados actualizados del edificio....................................... 216

Tabla 55. Distribución de consumos energéticos por uso. ........................................................... 218

Tabla 56. Distribución de consumos energéticos desglosados mes a mes por uso............................ 218

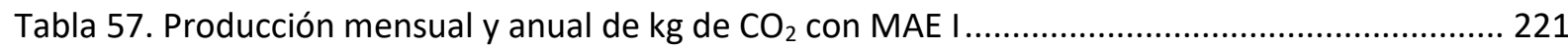

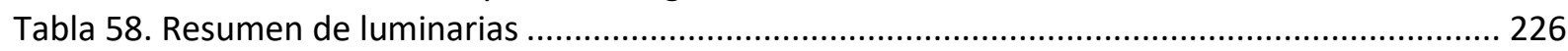

Tabla 59. Niveles de iluminancia con la propuesta de diseño de iluminación................................... 227

Tabla 60. Consumo Kwh diseño de iluminación nuevo vs actual.................................................... 227

Tabla 61. Producción mensual y anual de kg de $\mathrm{CO}_{2}$ con MAE II ................................................. 228

Tabla 62. Distribución de consumos energéticos por uso. ........................................................... 230

Tabla 63. Distribución de consumos energéticos desglosados mes a mes por uso............................ 230

Tabla 64. Producción mensual y anual de $\mathrm{kg}$ de $\mathrm{CO}_{2}$ con MAE III ................................................ 232

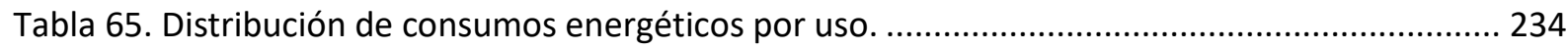

Tabla 66. Distribución de consumos energéticos desglosados mes a mes por uso............................ 234

Tabla 67. Producción mensual y anual de kg de $\mathrm{CO}_{2}$ con MAE IV ................................................ 236

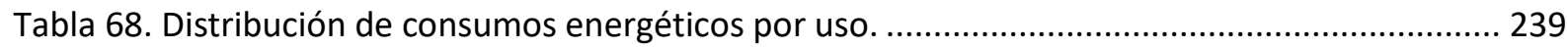

Tabla 69. Distribución de consumos energéticos desglosados mes a mes por uso........................... 239

Tabla 70. Producción mensual y anual de kg de $\mathrm{CO}_{2}$ con MAE V...................................................... 241

Tabla 71. Distribución de consumos energéticos por uso. ................................................................ 243

Tabla 72. Distribución de consumos energéticos desglosados mes a mes por uso............................ 243

Tabla 73. Producción mensual y anual de kg de $\mathrm{CO}_{2}$ con MAE VI................................................. 245

Tabla 74. Distribución de consumos energéticos por uso. ........................................................... 247

Tabla 75. Distribución de consumos energéticos desglosados mes a mes por uso........................... 247

Tabla 76. Producción mensual y anual de $\mathrm{kg}$ de $\mathrm{CO}_{2}$ con MAE VII................................................ 249

Tabla 77. Distribución de consumos energéticos por uso. ............................................................... 251

Tabla 78. Distribución de consumos energéticos desglosados mes a mes por uso............................ 252

Tabla 79. Producción mensual y anual de kg de $\mathrm{CO}_{2}$ con MAE VIII................................................ 254

Tabla 80. Resumen ahorros de las MAE's aplicadas al edificio....................................................... 255

Tabla 81. Potencia Total atendida y Nivel de tensión para sistemas de acumulación de energía ..... 256

Tabla 82. Línea base - Promedio del consumo mensual histórico .................................................. 267

Tabla 83. Línea base - Promedio ponderado del consumo mensual histórico ..................................... 268

Tabla 84. Línea base - Índices de estacionalidad.......................................................................... 269 


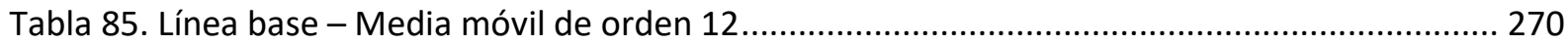

Tabla 86. Línea base - consumo promedio según programación académica ................................... 274

Tabla 87. Línea base - consumo promedio según programación académica .................................. 277

Tabla 88. Modelos de pronósticos implementados para determinar el consumo de energía de Aulas 4

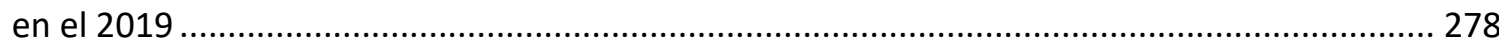

Tabla 89. Error Absoluto Porcentual MAPE de los modelos de series de tiempo ............................ 279

Tabla 90. Información mensual de variables monitoreadas en el edificio para el 2017 ................... 279

Tabla 91. Supuestos y pruebas de verificación para los modelos de regresión.................................. 281

Tabla 92. Consolidado cumplimiento de supuestos estadísticos de los modelos de Regresión ......... 294

Tabla 93. Ajuste de bondad de los modelos de regresión lineal ...................................................... 295

Tabla 94. Capacidad de pronóstico del modelo de Regresión lineal univariable .............................. 296

Tabla 95. Capacidad de pronóstico modelo univariable ................................................................ 296

Tabla 96. Capacidad de pronóstico del modelo de Regresión lineal multivariable ........................... 297

Tabla 97. Capacidad de pronóstico modelo multivariable............................................................ 297

Tabla 98. Información mensual de variables monitoreadas en el edificio para el 2018 ................... 298

Tabla 99. Distribución del tipo de semana para el año 2018 ....................................................... 299

Tabla 100. Datos semanales - Periodo Semestre del año 2018................................................... 300

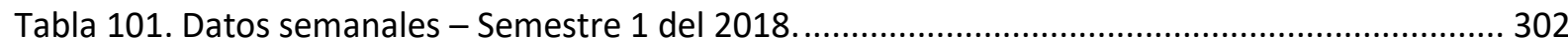

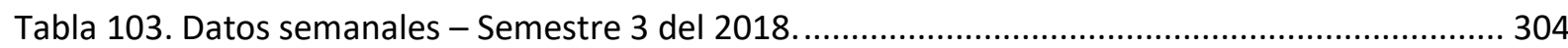

Tabla 103. Ajuste de bondad del modelo de regresión lineal........................................................ 309

Tabla 104. Capacidad de pronóstico del modelo de Regresión lineal multivariable semanal............ 310

Tabla 105. Información mensual de variables monitoreadas en el edificio para el 2019 ................. 311

Tabla 106. Información semanal de las variables monitoreadas en el edificio para el año 2019 ...... 312

Tabla 107. Información diaria de las variables monitoreadas para marzo ....................................... 315

Tabla 108. Modelos de regresión lineal multivariable para el 2019 ................................................ 318

Tabla 109. Pronóstico de consumo de energía eléctrica para el mes de marzo de 2019 utilizando las

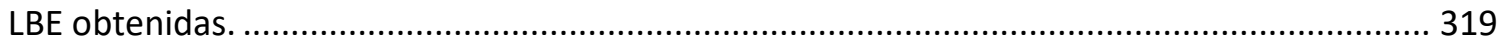

Tabla 110. Pronóstico de consumo eléctrico mes a mes empleando LBE diarias, semanales y mensual

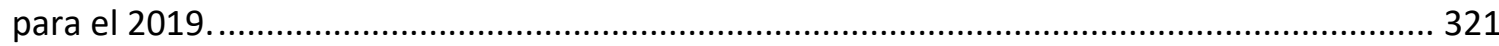

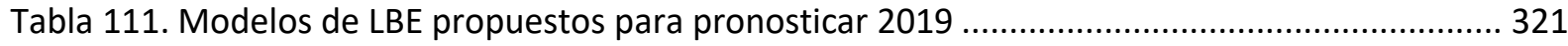

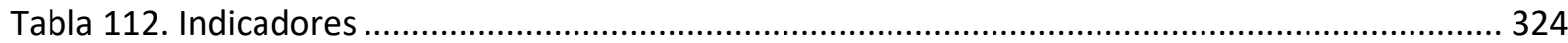

Tabla 113. Indicadores de Eficiencia Energética por vectores energéticos en el Campus UAO de los años

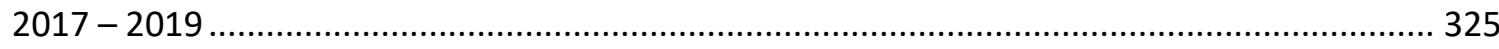

Tabla 114. Indicadores de Eficiencia Energética por servicios de uso final en el Campus UAO de los años

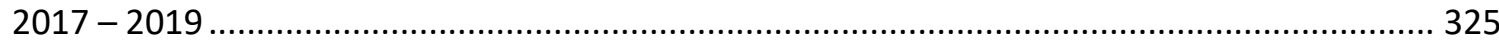

Tabla 115. Indicadores de Eficiencia Energética de Generación FV y consumo de energía eléctrica total

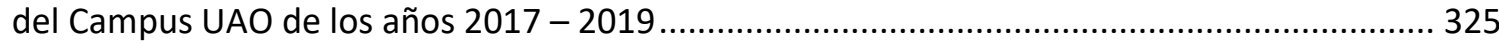

Tabla 116. Indicadores de Eficiencia Energética por energéticos en el Edificio de Aulas 4 de los años

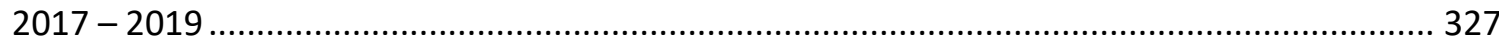

Tabla 117. Indicadores de Eficiencia Energética por servicios de uso final en el Edificio de Aulas 4 de los

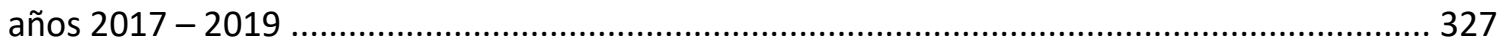

Tabla 118. Indicadores de Eficiencia Energética de Generación FV y consumo de energía eléctrica total

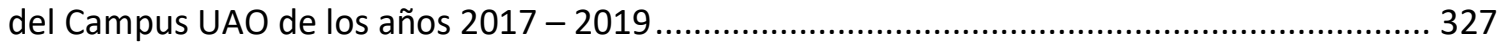

Tabla 119. Escenario de IE con implementación de MAE's en el edificio de aulas 4 ......................... 328

Tabla 120. Factores de paso de energía final a Energía primaria - Colombia ................................... 331

Tabla 121. IE de energía primaria no renovable Kw h, renovable y total en el CAMPUS UAO........... 331 
Índices

Tabla 122. IE de energía primaria no renovable, renovable y total en Kwh en el Edificio de Aulas 4331

Tabla 123. Factores de paso de energía final a Energía primaria - España

332

Tabla 124. IE de energía primaria no renovable, renovable y total en kWh en el CAMPUS UAO ...... 332

Tabla 125. IE de energía primaria no renovable, renovable y total en kWh en el Edificio de Aulas 4332

Tabla 126. Tabla comparativa Edificio de aulas 4 vs Edificio con MAE's propuestas ......................... 333

Tabla 127. Consumo de energía final total y emisiones de CO2 por meses en el CAMPUS UAO....... 335

Tabla 128. Consumo de energía final total y emisiones de CO2 por meses en el Edificio de Aulas 4337

Tabla 129. Consumo eléctrico real y estimado para los años $2017-2019$ del edificio de aulas 4 .... 339

Tabla 130. Indicador de Eficiencia Energética IEE del edificio de aulas 4 años 2017 - 2019............. 340

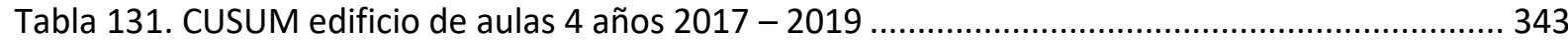

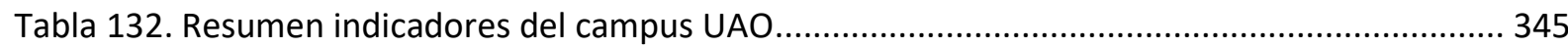

Tabla 133. Resumen de indicadores del Edificio de Aulas 4 ........................................................... 345

Tabla 134. Consumo eléctrico real y estimados en kWh en los diferentes modelos para el año de 2019

346

Tabla 135. Indicador de Eficiencia Energética de los diferentes modelos ......................................... 346

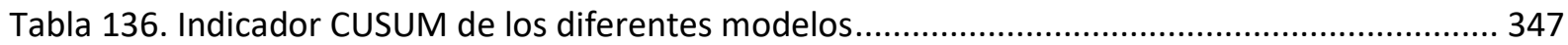

Tabla 137. Consumo eléctrico real y estimados en $\mathrm{kWh}$ bajo las LBE diaria, semanal, mensual y

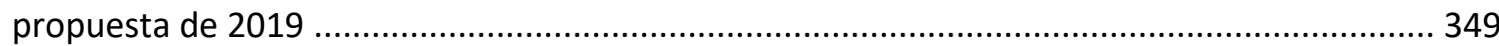

Tabla 138. Indicador de Eficiencia Enegética de los modelos de LBE diaria, semanal mensual y

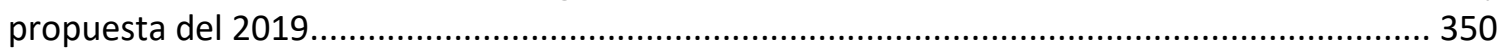

Tabla 139. Indicador CUSUM de los modelos de LBE diaria, semanal mensual y propuesta del 2019 


\section{OBJETIVOS}

Una de las problemáticas actuales a nivel mundial del cambio climático, es el elevado consumo energético que se produce en nuestras sociedades, existen 3 sectores importantes en consumo energético como el industrial, transporte y edificios.

En Colombia, se ha desarrollado políticas energéticas de ahorro energético encaminadas fundamentalmente a nivel industrial y transporte, sin embargo, el sector edificios sea relegado y ahora estudios recientes han demostrado la importancia en el consumo energético de este sector.

El objetivo principal de esta tesis va dirigido al estudio de herramientas de Gestión Energética para cumplir los ODS que propone la ONU y a los recientes compromisos que ha suscrito Colombia en términos de transición energética, donde los pilares fundamentales están enfocados a incrementar la matriz energética en la parte de energías renovables y fortalecer la eficiencia energética en toda la cadena productiva.

A lo largo de la estructura de esta tesis se componen diversos objetivos específicos como son:

1. Presentar un panorama actual del estado de las edificaciones a nivel mundial con especial énfasis en Latinoamérica y Colombia.

2. Analizar las herramientas de planificación energética en un sistema de gestión, destacando la construcción de las líneas de base energética e indicadores de desempeño energético.

3. Proponer modelos para estimar las líneas base e indicadores en edificaciones desarrollando cuatro modelos, en el primero y segundo se aporta modelo basado en series de tiempo, en el tercero modelos de regresión univariable y multivariable y en el cuarto se proponer la simulación dinámica utilizando el motor de cálculo energy plus y software desing builder. Lo anterior validados sobre bases matemáticas y estadísticas.

4. Realizar una revisión de la energética edificatoria del campus y edificio de aulario 4 seleccionado como caso de estudio.

5. Analizar la monitorización experimental del campus y del aulario 4. 
6. Realizar la simulación dinámica del edificio de aulario seleccionado, utilizando software Design Builder con su motor de cálculo energy plus, verificar, calibrar el modelo con datos experimentales arrojador de la revisión energética.

7. Obtener medidas de ahorro MAES, en las cuales se va a analizar frente al edificio base, el impacto ambiental en kg CO2 y finalmente el ahorro económico.

8. Proponer una metodología para implementar la selección y aplicación de modelos para la estimación de líneas bases e indicadores energéticos en edificios planteando alternativas según los recursos de monitorización y operación de la edificación.

9. Establecer los efectos de los ahorros energéticos en la selección de los modelos propuestos de acuerdo a las condiciones de monitorización, precisión y pronóstico de la línea base energética.

10. Establecer un análisis energético del caso práctico mediante indicadores propuestos que serán energéticos, ambientales, económicos, de gestión energética y caracterización de un edificio casi nulo nZEB. 


\section{ESTRUCTURA DE LA TESIS}

La tesis está estructurada en siete capítulos:

En el primer capítulo se presenta un panorama global de la situación energética en el mundo en torno al incremento de la población, aumento de la demanda y participación de las energías renovables y eficiencia energética, como elementos para mitigar el aumento de las emisiones de $\mathrm{CO} 2$ y los compromisos que exige el acuerdo de París y los objetivos de desarrollo sostenible. De igual, forma se expone la situación del parque edificatorio en algunos países como China, Estados Unidos, Europa y Latinoamérica; enfatizando en la situación de Colombia y la dinámica en torno a la política energética que se viene desarrollando en Latinoamérica y en el caso específico de Colombia.

En el segundo capítulo se describe la importancia de un sistema de gestión energética SGEn y la relación que se tiene con aspectos normativos. De igual forma, se describen las herramientas y técnicas utilizadas para el desarrollo de los procesos de planificación energética y algunos de los componentes más significativos, como es el caso de la revisión energética y aspectos descriptivos en lo que se refiere a los conceptos de líneas de base e indicadores energéticos y su aporte en el mejoramiento de la eficiencia energética en edificaciones.

En el tercer capítulo se presenta los soportes teóricos para la aplicación de los modelos para la estimación de líneas bases e indicadores, como herramientas para responder a las condiciones exigidas por las normas de apoyo a la implementación de sistemas de gestión SGEn, específicamente la ISO 50006. Lo anterior, sustentado con análisis matemáticas y estadísticas a fin de poder contar con resultados válidos y aplicables a las condiciones de funcionamiento de las edificaciones. Enfatizando como resultado significativo la posibilidad de contar con alternativas de análisis según las condiciones de medición, disponibilidad de datos y condiciones reales de operación de los edificios. Respondiendo a los vacíos normativos en torno a validar e implementar sus modelos.

En el cuarto capítulo se presenta la revisión energética realizada al campus y al edificio de aulario 4, la misma se ejecutó siguiendo los estándares normativos recomendados por la ISO 50002, donde se muestra la monitorización y medidas de los años 2016 a 2019, específicamente del consumo de energía eléctrica, aprovechando el sistema de monitorización power monitor de Schneider. Así mismo, se cuenta con equipos portátiles como analizadores de red, sensores y data logger de IAQ e intensidad lumínica, además de una estación meteorológica. Elementos que permitieron hacer un análisis detallado de la situación energética de los edificios objeto de estudio. 
En los capítulos quinto y sexto, se realiza el análisis de la situación actual del edificio aulario (aulas 4) relativo al consumo energético, a través de los datos obtenidos mediante el programa de simulación dinámica Design Builder, previamente calibrado con los datos experimentales de monitorización continua con un sistema BMS. Lo anterior, permitió presentar una serie de medidas de mejoras energéticas MAES en el edificio con miras a realizar recomendaciones de orden pasivo y activo para mejorar la operación del edificio y conseguir mayores ahorros energéticos, menores costes económicos $y$, finalmente, una reducción del impacto medioambiental.

En el capítulo siete se presenta el desarrollo de una metodología para implementar la selección y aplicación de modelos para la estimación de líneas bases e indicadores energéticos en edificios; como respuesta a los vacíos normativos donde se propone el empleo de algunos modelos para estimar las líneas bases e indicadores, sin precisar las bases teóricas, métodos estadísticos y criterios para determinar si una línea base o un indicador son válidos para establecer una referencia de consumo y un ahorro energético. En este sentido, se presentan 4 modelos en los que se utiliza las series de tiempos, los modelos de regresión univariable y multivariable en los que se emplea el software R estudio y la simulación dinámica con Design Builder. Lo anterior, soportado sobre bases estadísticas y herramientas como el cusum para analizar los efectos en la estimación de ahorros energéticos.

La tesis doctoral finaliza con el cálculo de los indicadores propuestos de intensidad energética, impacto medioambiental, gestión energética y los EPnorenovable y ERR en lo concerniente al comportamiento del edificio nZEB para el caso de estudio. 


\section{CAPÍTULO 1: ENERGÉTICA EDIFICATORIA}

En este capítulo se presenta un panorama global de la situación energética en el mundo en torno al incremento de la población, aumento de la demanda y participación de las energías renovables y eficiencia energética, como elementos para mitigar el aumento de las emisiones de $\mathrm{CO} 2$ y los compromisos que exige el acuerdo de parís y los objetivos de desarrollo sostenible. De igual, forma se presenta la situación del parque edificatorio en algunos países como China, Estados Unidos, Europa y Latinoamérica; enfatizando en la situación de Colombia y la dinámica en torno a la política energética que se viene desarrollando en el país. Lo anterior respecto al ámbito de edificaciones sostenibles y lineamientos del Plan indicativo 2017 - 2022 que traza las metas energéticas en cada uno de los subsectores transporte, industria, servicios y residencial. Además de las perspectivas de entidades como la IEA en torno al desarrollo del sector edificaciones en Latinoamérica.

\subsection{CONSUMO DE ENERGÍA Y PANORAMA ENERGÉTICO MUNDIAL.}

El aumento de la población en áreas urbanas plantea retos frente al incremento de la demanda energética y el impacto global causado al medio ambiente. Al año 2014, el 54\% de la población mundial vive en áreas urbanas y se espera que la misma continúe creciendo, de modo que, para el año 2050 aproximadamente, se espera sea un tercio rural $34 \%$ y dos tercios urbanos 66\%, según el informe World Urbanization Prospects [1], [2], [3]. Actualmente entre las regiones más urbanizadas se encuentran Norte América con el 82\%, América Latina y el Caribe $80 \%$ y Europa $73 \%$. Por el contrario, África y Asia siguen siendo principalmente rurales, con $40 \%$ y $48 \%$ respectivamente.

En la figura 1, se presenta la tendencia de crecimiento de la población a nivel mundial donde desde el año 2007 la población urbana supera a la población rural y la tendencia se mantiene según las proyecciones al año 2050.

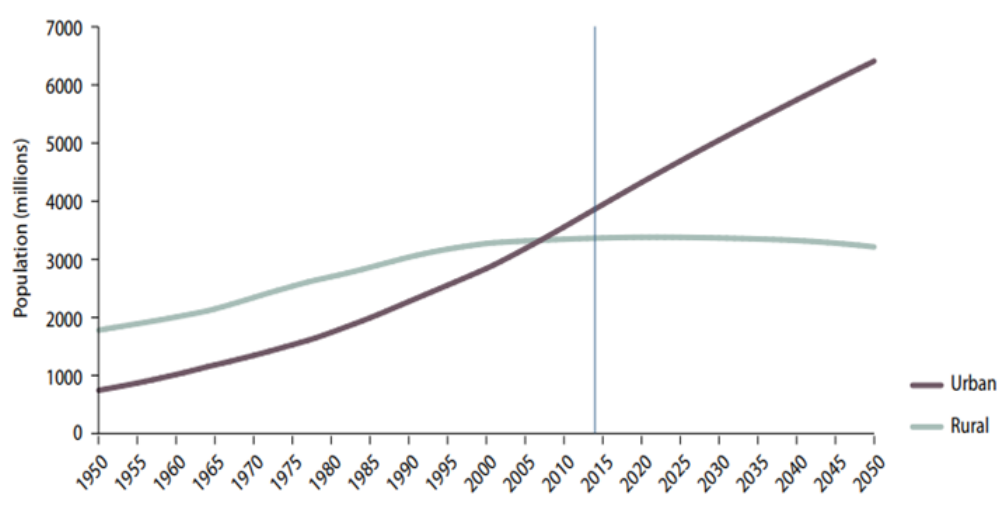

Figura 1. Población urbana y rural del mundo, 1950-2050 Fuente: World Urbanization Prospects [3]. 
El consumo de energía tiene una dependencia directa con el aumento de la población y su desarrollo económico. Las tendencias demográficas y económicas a nivel global (IEA, 2017) pronostican que para el 2040 la población mundial pase de 7.400 millones a 9.000 millones de habitantes, lo cual representa un impulso en la demanda mundial de energía de aproximadamente un $30 \%$. Se provee un cambio en la demanda de energía primaria en el mundo y los roles que juegan países como Estados Unidos e India, donde el primero se convertirá en un importante exportador de energía mientras que India, será el mayor consumidor como se indica en la figura 2.

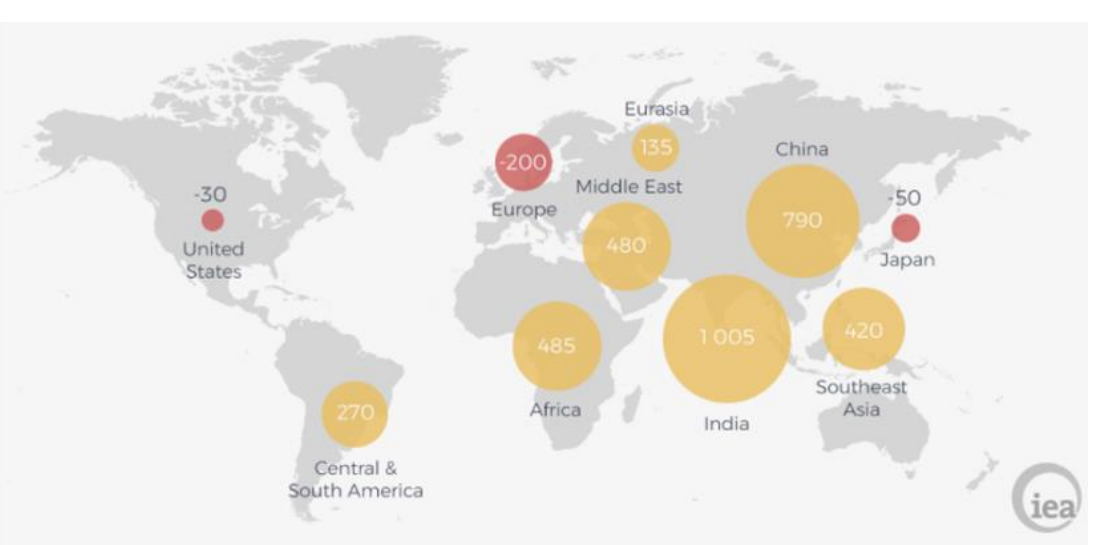

Figura 2. Cambio en la demanda de energía primaria.

Fuente: World Energy Outlook 2017 [4]

Según informes de la IEA, se proyecta que el incremento en la demanda de energía a nivel global entre 2013 y 2040 crezca un tercio [4]. La relación entre el crecimiento económico global, la demanda de energía y las emisiones de gases a la atmosfera está disminuyendo, gracias a acciones de mercados importantes como China que están realizando cambios estructurales en su economía, como incorporación de tecnologías más eficientes. Sin embargo, la demanda de servicios energéticos sigue creciendo y se provee que las emisiones de $\mathrm{CO} 2$ relacionadas con la energía sean un $16 \%$ superior en 2040 , como se presenta en la figura 3.

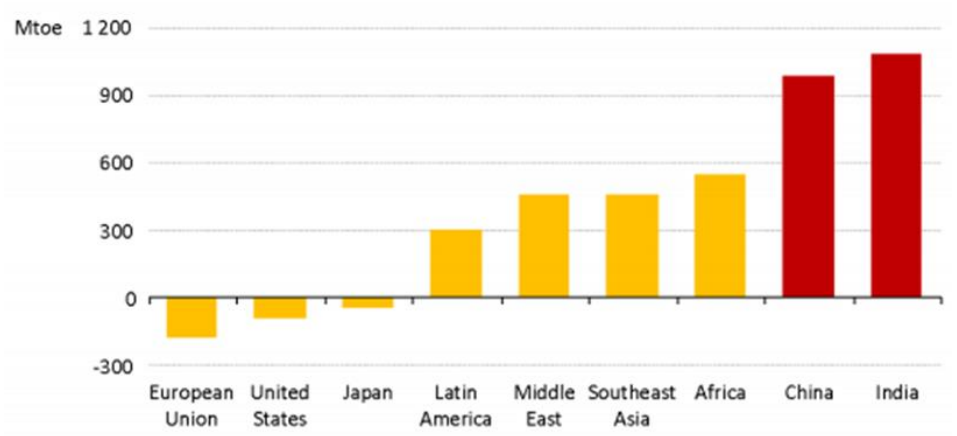

Figura 3. Emisiones de $\mathrm{CO} 2$ en diferentes regiones 2014-2040 Fuente: World Energy Outlook 2017 [4] 
Tras el inminente aumento de la demanda mundial de electricidad, se llevan a cabo múltiples acciones para reducir las consecuencias medioambientales asociadas a su generación. En este e escenario se estima que para el inicio del 2030 las energías renovables jugarán un papel importante por encima del carbón como principal fuente de generación eléctrica. Se proyecta que para el 2040 el 50\% de la generación en la Unión Europea, un $30 \%$ en China y Japón, y por encima del $25 \%$ en los Estados Unidos, contribuyan a la mitigación de las emisiones de $\mathrm{CO} 2$ como lo presenta la figura 4.

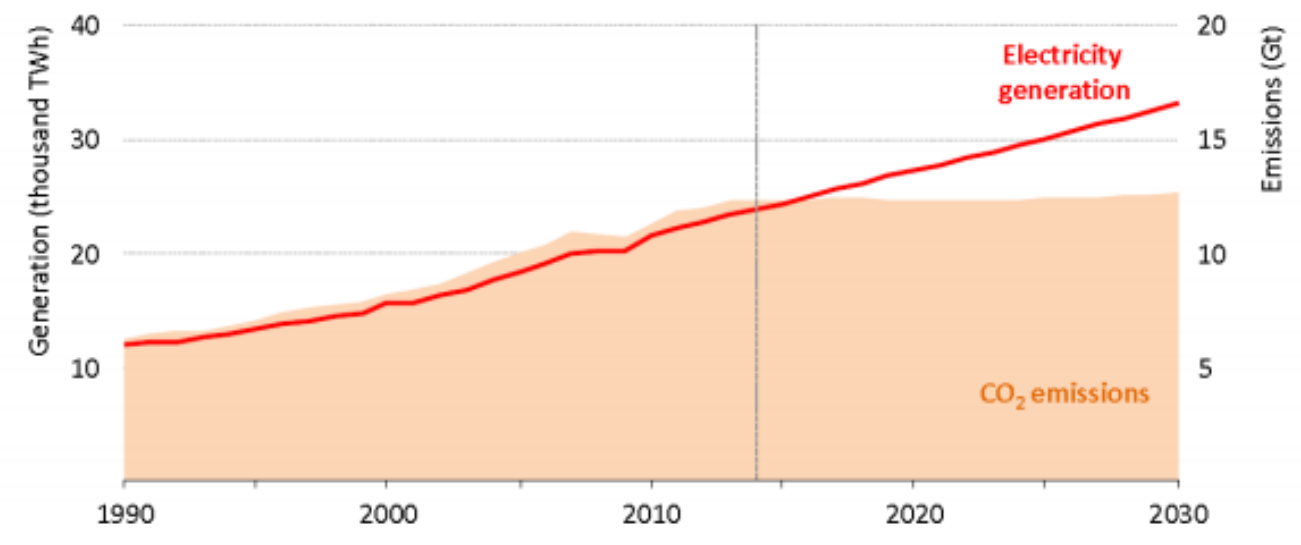

Figura 4. Generación mundial de energía eléctrica y emisiones de $\mathrm{CO} 2$ asociadas.

Fuente: Fuente: World Energy Outlook 2017 [4]

Proyecciones de la IEA en el año 2010 señalaban disminuciones de consumo y pronosticaban que el consumo en los mercados energéticos tendría una disminución, lo cual estuvo atravesado por la recesión económica de esos años. Una vez superada la recesión económica se restableció la tendencia de consumo energético a nivel mundial, desestimando los cálculos pronosticados para ese momento, tendencia que continua en incremento como lo muestra la siguiente Figura 5 [5].

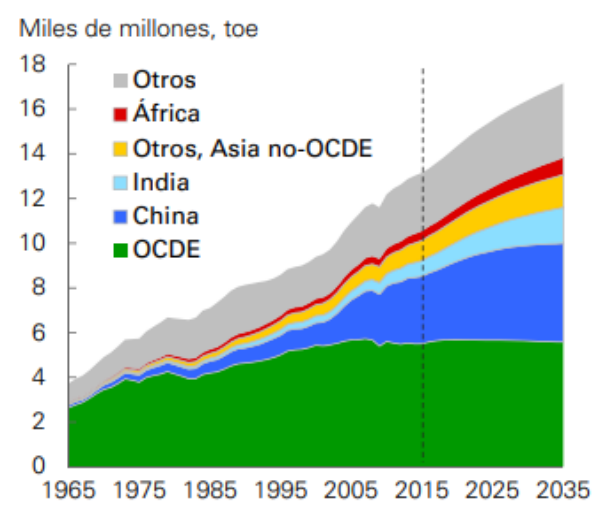

Figura 5. Consumo de Energía por regiones.

Fuente: BP - Outlook for Energy 2017 [5] 
El aumento en la demanda energética a nivel mundial ha ocasionado que la capacidad instalada de fuentes primarias de energía aumente y este cambiando en comparación con los últimos 25 años como lo presenta la figura 6. A nivel de generación de energía el gas natural proyecta incrementos en el consumo alrededor del $45 \%$, seguido del aumento de las energías renovables que cubren alrededor del $40 \%$ del aumento de la energía primaria. No obstante, las múltiples actuaciones de la eficiencia energética vienen contrarrestando el aumento en el uso final de energía. Para el IEA [4], sin eficiencia energética se proyectaría más del doble del consumo.

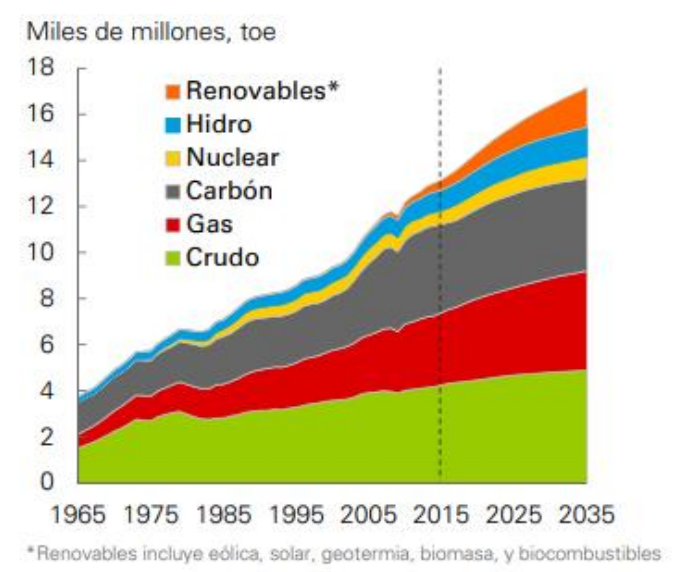

Figura 6. Fuentes de Energía Primaria - Matriz Energética Mundial.

Fuente: BP - Outlook for Energy 2017 [5]

En esta dirección la eficiencia energética trae consigo beneficios asociados con la mejora en la seguridad del suministro, reducción de las emisiones de $\mathrm{CO} 2$, creación de empleo, mejora de la productividad, acceso a la energía; razón por la cual se considera un recurso energético denominado como el primer combustible según el World Energy Council [6]. Por otro lado, la base de datos de indicadores del World Energy Council muestra que la participación de la eficiencia energética en el consumo total de energía primaria en 2014 fue del 38\%, por delante del petróleo en $19 \%$ y carbón / lignito en 18\%, como se evidencia en la figura 7.

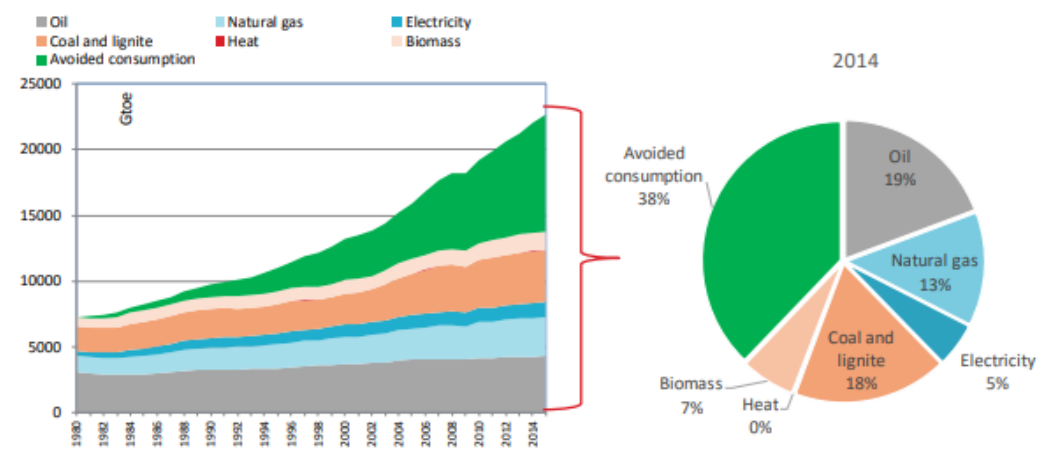

Figura 7. Consumo de energía primaria a 2014

Fuente: Energy Efficiency Policies 2016. World Energy Council [6] 
Por tal razón, la eficiencia energética se ha convertido en una prioridad en las políticas energéticas a nivel mundial, debido a su competitividad, rentabilidad de implementación, su amplia disponibilidad y los beneficios que trae consigo. A nivel gubernamental, la eficiencia energética ha sido incluida como uno de los 17 Objetivos de Desarrollo Sostenible de las Naciones Unidas, donde se planteó como objetivo “duplicar la tasa mundial de mejora de la eficiencia energética para 2030".

La Agencia Internacional de Energía plantea 3 escenarios claves para el cumplimiento de los Objetivos de Desarrollo Sostenible como lo enseña la tabla 1.

Tabla 1. Objetivos Planteados por la IEA

\begin{tabular}{|c|l|}
\hline Objetivo & \multicolumn{1}{|c|}{ Escenario } \\
\hline 6DS & $\begin{array}{l}\text { Es un escenario muy poco ambicioso que asume pocas medidas } \\
\text { de cambio climático }\end{array}$ \\
\hline 4DS & $\begin{array}{l}\text { incluye objetivos y políticas aprobadas, con cierta ambición } \\
\text { climática. }\end{array}$ \\
\hline 2DS & $\begin{array}{l}\text { Este escenario asume la puesta en marcha de las medidas para } \\
\text { limitar el incremento de la temperatura global por debajo de } \\
2^{\circ} \mathrm{C}\end{array}$ \\
\hline
\end{tabular}

Teniendo en cuenta estos escenarios, el reto básico es adoptar las medidas necesarias para pasar de un escenario como el 6DS a uno de 2DS que permita cumplir el objetivo del Acuerdo de París. La figura 8., enseña las acciones necesarias a realizar, donde se evidencia que el principal bloque de actuaciones será destinado a la mejora la eficiencia energética (el 36\% de la reducción de emisiones necesaria), el segundo será la promoción de energías renovables ( $29 \%$ de la reducción necesaria). Por último, se consideran otro tipo de medidas, como la energía nuclear (tecnología libre de emisiones de CO2) o la Captura y Almacenamiento de CO2 (CCS, en sus siglas en inglés).

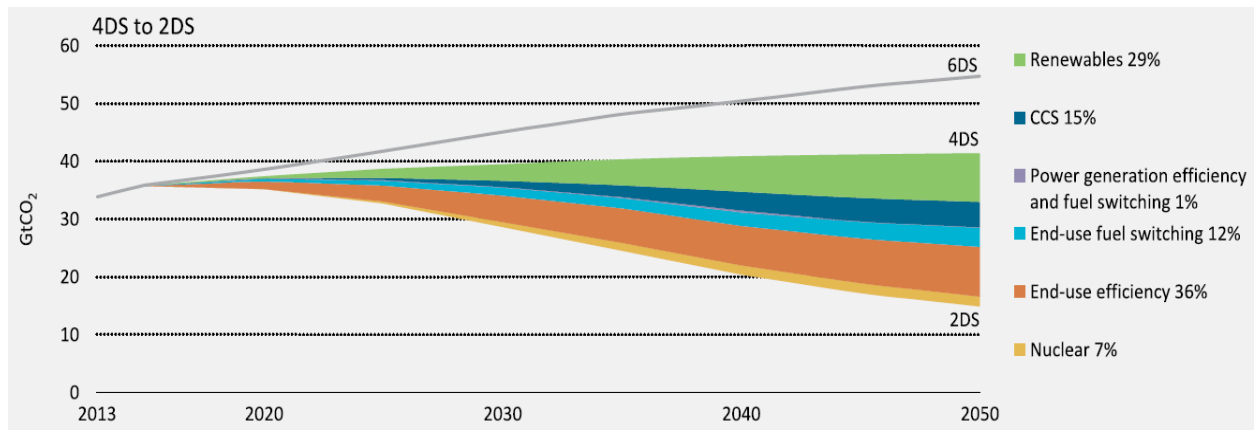

Figura 8. Medidas para pasar de un 6DS al 2DS.

Fuente: Energy Technology Perspectives 2016 IEA [7]. 
Para la puesta en marcha de todas estas soluciones climáticas, es clave el desempeño del sector eléctrico. Estudios realizados por la Agencia Internacional de Energía [4], destacan el papel básico que el sector debe desempeñar para mitigar las Emisiones de CO2 y cumplir el escenario de 2DS, la figura 9., muestra las acciones a realizar, entre ellas se destacan:

Mejorar la eficiencia de los usos de la electricidad en la industria y los edificios, tiene efecto en la reducción de $\mathrm{CO} 2$ provocadas por el ahorro de electricidad de estos sectores, lo que representan el $12 \%$ de la reducción acumulativa de emisiones para alcanzar el 2DS.

El sector eléctrico debe hacer el mayor esfuerzo para reducir las emisiones de CO2, Ilegando a la descarbonización del sector para el año 2050. Se prevé que, para evitar el incremento de $2^{\circ} \mathrm{C}$, el sector deberá haber un despliegue masivo de tecnologías de generación bajas en carbono que conduzcan a la baja en las emisiones de $\mathrm{CO} 2$ por debajo de 40 gr CO2/kWh en 2050.

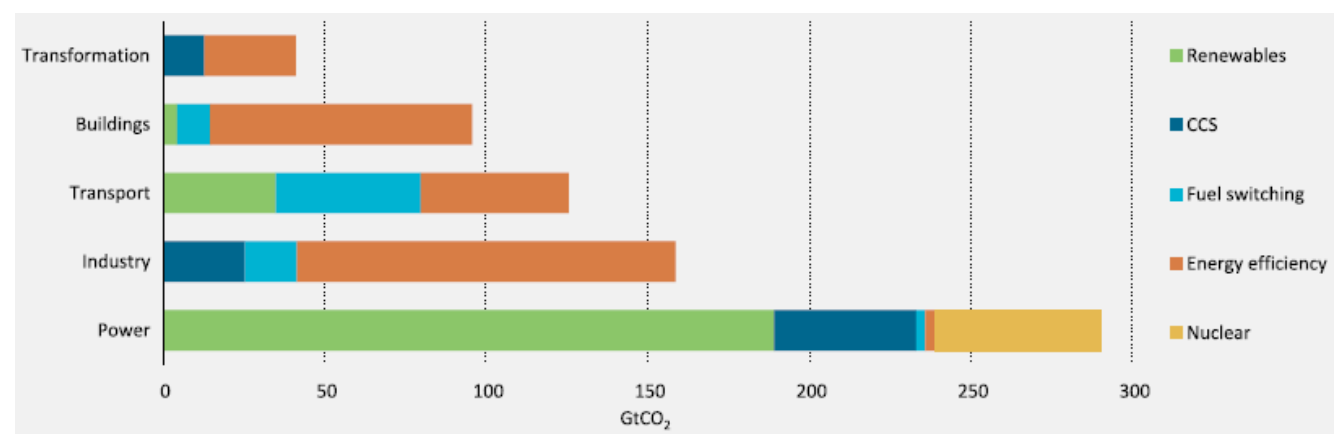

Figura 9. Reducción acumulada de emisiones de CO2 por sector y tecnología horizonte 2050.

Fuente: Energy Technology Perspectives 2016 IEA [7]

En este mismo sentido, la mejora de la eficiencia energética en los edificios, la industria y el transporte es clave para los objetivos 2DS, el consumo de energía final de los tres sectores combinados articulados a políticas establecidas bajo el objetivo 2DS, contribuirían a la reducción en un 30\% para 2050. Aproximadamente 126 EJ en comparación con el 6DS, como lo enseña la figura 10.

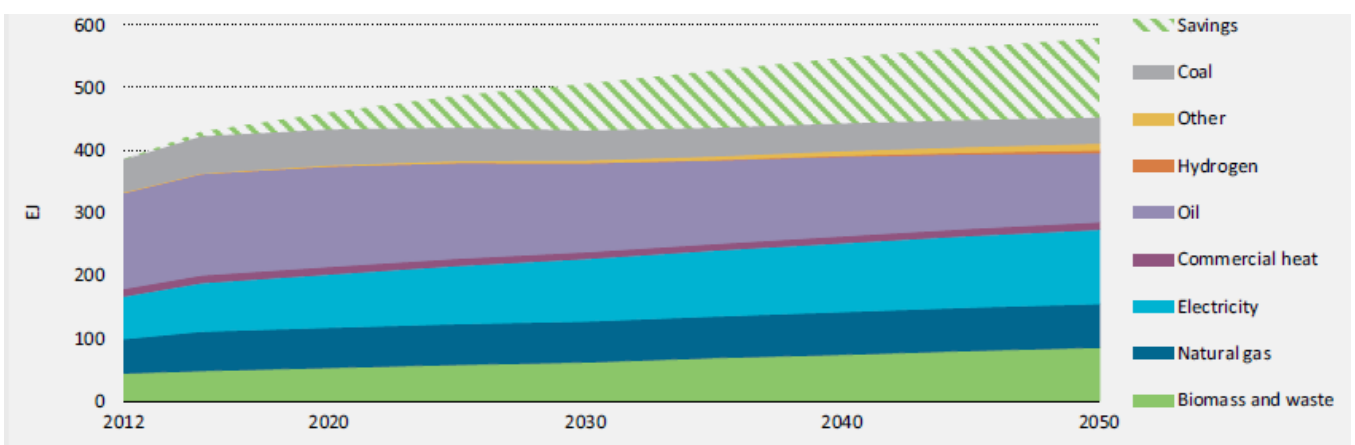

Figura 10. Impacto de la Eficiencia en el consumo final de energía a nivel global en el 2DS

Fuente: Energy Technology Perspectives 2016 IEA [7] 
Teniendo en cuenta el crecimiento del mercado de equipos eléctricos a nivel mundial, la eficiencia de los equipos constituye una de las estrategias principales de la eficiencia energética que permite cumplir las metas propuesta. Actualmente los gobiernos establecen estándares mínimos de rendimiento energético (MEPS) y etiquetado de equipos (neveras, lavadoras, aires acondicionados, lámparas, motores, etc.), automóviles e incluso viviendas, con el fin de promover en los fabricantes una renovación eficiente de sus equipos e instalaciones, a su vez, en los consumidores crear consciencia en el uso de soluciones eficientes y de bajo costo.

En términos económicos, la Agencia Internacional de energía señala que la inversión al sistema energético a nivel global en el año 2015 fue de aproximadamente US \$1,800 billones, lo cual representó más del $2 \%$ del producto interno bruto (PIB) mundial en ese año [4]. La gran mayoría de estas inversiones (US $\$ 1,600$ billones) se hicieron para agregar o reemplazar equipos del lado de la oferta del sistema energético, mientras que, en eficiencia energética se invirtieron unos US $\$ 220$ billones, principalmente en los sectores de uso final (edificios, transporte e industria).

Para cumplir con los objetivos propuestos, se prevén en términos económicos varios escenarios, trabajar mundialmente bajo el escenario 4DS, que implica una inversión en eficiencia energética y energía baja en carbono (LCEI-Gap) a corto plazo (2030) de aproximadamente US $\$ 130$ mil millones anuales. Si el objetivo es, en cambio, trabajar bajo el escenario 2DS y mantener las temperaturas globales por debajo de los $2^{\circ} \mathrm{C}$ a largo plazo, la inversión a corto plazo rápidamente escalará a US \$300 mil millones o US \$460 mil millones.

A continuación, se presenta un panorama del sector energético de las edificaciones en relación con la situación ambiental y el compromiso con la reducción del consumo energético y la necesidad de contribuir desde la investigación en generar acciones que aporten al seguimiento de indicadores de eficiencia.

\subsection{SITUACIÓN ENERGÉTICA DE LAS EDIFICACIONES.}

Como parte de los compromisos de limitar el incremento de la temperatura global en 2 grados Celsius $\left({ }^{\circ} \mathrm{C}\right)$ para el año 2050 , el sector de las edificaciones deberá reducir sus emisiones totales de dióxido de carbono (CO2) en $60 \%$. Esto incluye, tanto los subsectores residenciales y de servicios, que consumen aproximadamente el $30 \%$ de la energía global, siendo responsable de aproximadamente el $28 \%$ de las emisiones totales de $\mathrm{CO} 2$ provenientes de los consumidores finales de energía, según estadísticas del año 2016. En la Figura 11 se observa que aplicando tecnologías sostenibles (eficiencia energética, energías renovables, smart grid, entre otras) las edificaciones pueden contribuir en un $12 \%$ a la reducción de las emisiones totales, lo cual es necesario para mitigar el incremento de la temperatura. A su vez, para llegar a la transición al 2DS, requiere que se tomen medidas 
en todos los sectores dentro del sistema de la energía. Esfuerzos en el lado de la oferta, generación de energía, y otras transformaciones, o el lado del uso final que involucra edificios, industria, y transporte. Aspectos que aportan aproximadamente la mitad de las reducciones necesarias.

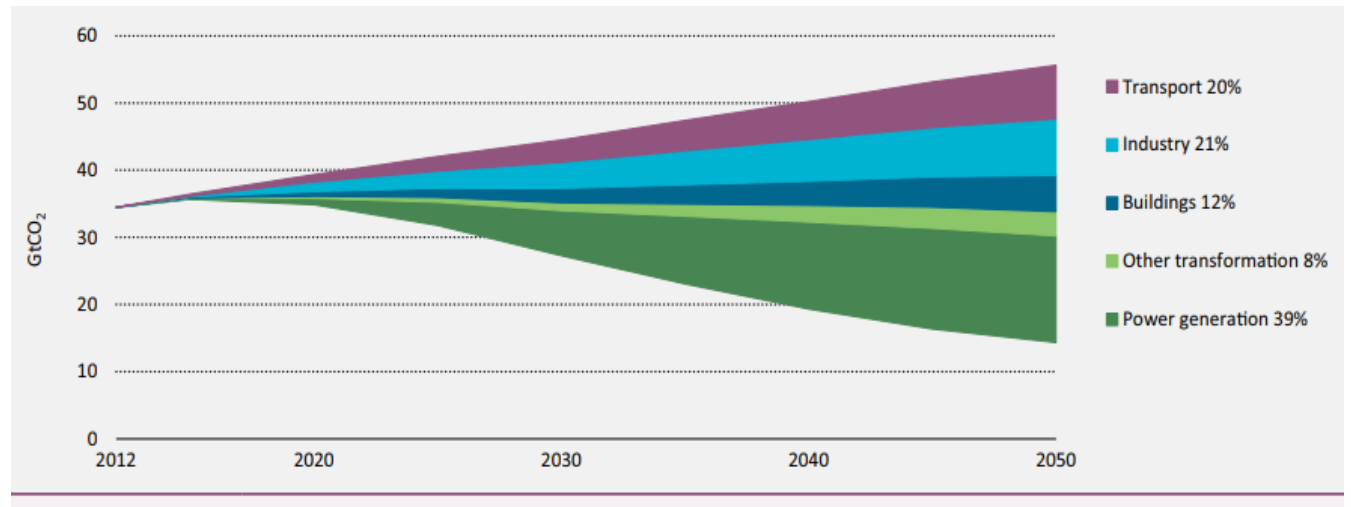

Figura 11. Reducciones globales de Co2 entre 6DS y 2DS por sector. Fuente: Energy Technology Perspectives 2017, IEA

A medida que se incremente la población a nivel mundial, en ese mismo sentido lo hará el parque edificatorio, lo que implica más consumo de energía, principalmente eléctrica, destinada a abastecer hogares, oficinas, escuelas, centros comerciales, iglesias, centros de salud, escuelas, universidades, entre otros.

Los edificios y construcciones en conjunto representan el 36\% del uso final de la energía a nivel mundial y el 39\% de las emisiones de CO2, relacionadas con la energía [8]. Múltiples esfuerzos se llevan a cabo para tener construcciones sostenibles (nuevas y existentes), pero no se mantienen al ritmo de un parque edificatorio en constante crecimiento y un alza en la demanda energética de los mismos. La demanda de energía eléctrica por $\mathrm{m} 2$ del sector de edificios a nivel mundial (figura 12), necesita mejorar en un $30 \%$ en comparación con el 2015, para cumplir con las ambiciones climáticas establecidas en el Acuerdo de París.

Los edificios y construcciones en conjunto representan el $36 \%$ del uso final de la energía a nivel mundial y el 39\% de las emisiones de $\mathrm{CO} 2$, relacionadas con la energía [8]. A pesar de las acciones para contar con construcciones sostenibles (nuevas y existentes), no son suficientes frente al constante crecimiento de un parque edificatorio que implica aumentos en la demanda energética. De tal forma la demanda de energía eléctrica por $\mathrm{m} 2$ del sector de edificios a nivel mundial, requiere mejorar en un 30\% en comparación con el 2015, para cumplir con los objetivos climáticas establecidas en el Acuerdo de París (figura 12). 


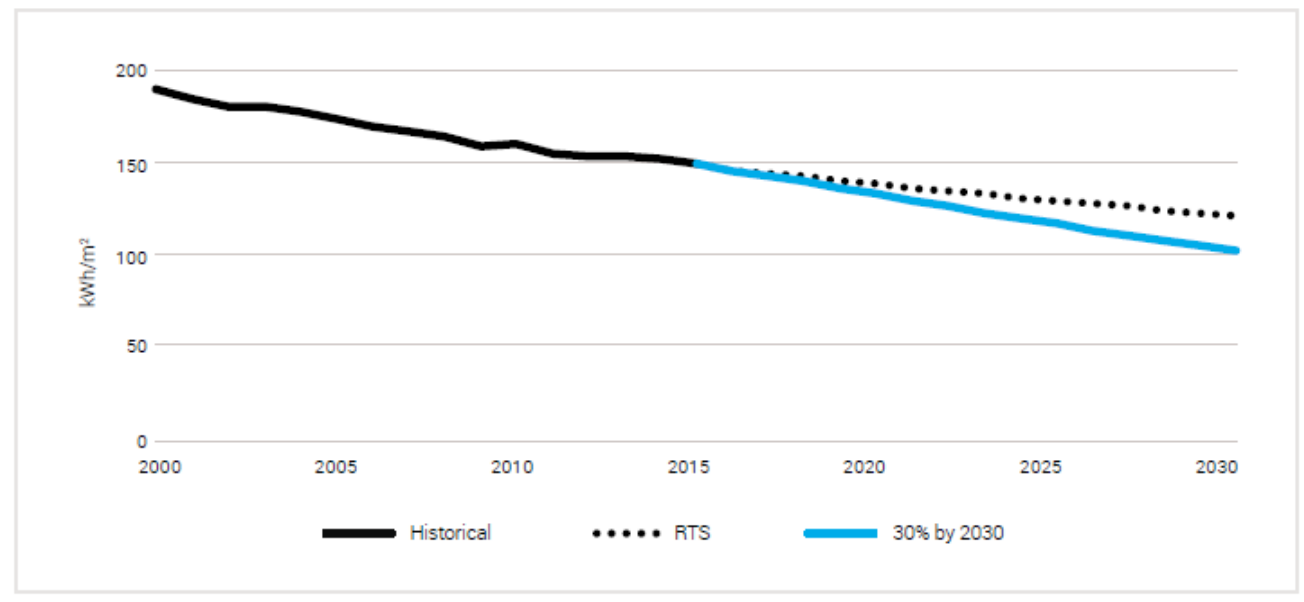

Notes: EJ = exajoules; $\mathrm{kWh} / \mathrm{m} 2$ = kilowatt-hours per square metre: $\mathrm{RTS}=$ Reference Technology Scenario.

Figura 12. Uso final de energía por $\mathrm{m} 2$ a nivel mundial.

Fuente: UN Environment and International Energy Agency [8]

El área del parque edificatorio mundial alcanzó en el año 2016 aproximadamente 235 mil millones de $\mathrm{m} 2$. El uso final de energía por parte del parque edificatorio pasó de 119 EJ en 2010 a 125 EJ en 2016, el aumento en los 5 EJ, como resultado de la escasa aplicación de acciones de eficiencia energética al nivel de las edificaciones. Se señala que, en la mayoría de países, los edificios, su potencial de ahorro y emisiones de $\mathrm{CO} 2$, permanecen sin explotar debido a la falta de políticas efectivas y el poco interés para invertir en construcción sostenible (figura 13).

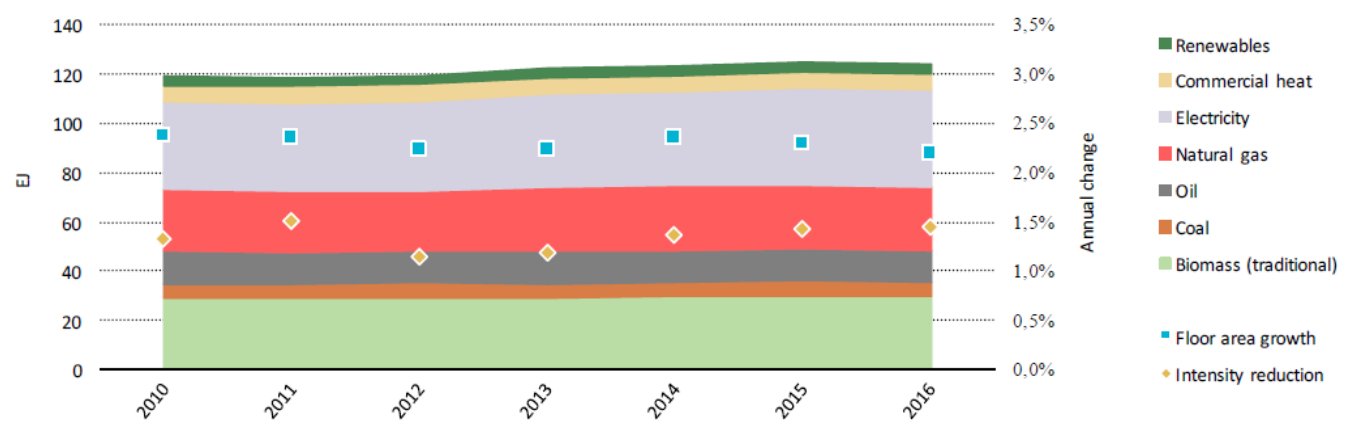

Figura 13. Consumo global de Energía en edificios.

Fuente: UN Environment and International Energy Agency [8]

En los próximos 20 años se estima que el crecimiento del parque edificatorio estará concentrado en China, Asia y África, los dos últimos países no poseen códigos de construcción que incluyan el uso eficiente de energía eléctrica. En este sentido, se hace necesaria la actuación de organismos que regulen, exijan e implementen en cada país códigos de construcción que contemplen el uso eficiente de la energía, tanto en edificios nuevos, como en edificios ya existentes y su repotenciación (figura 14). 


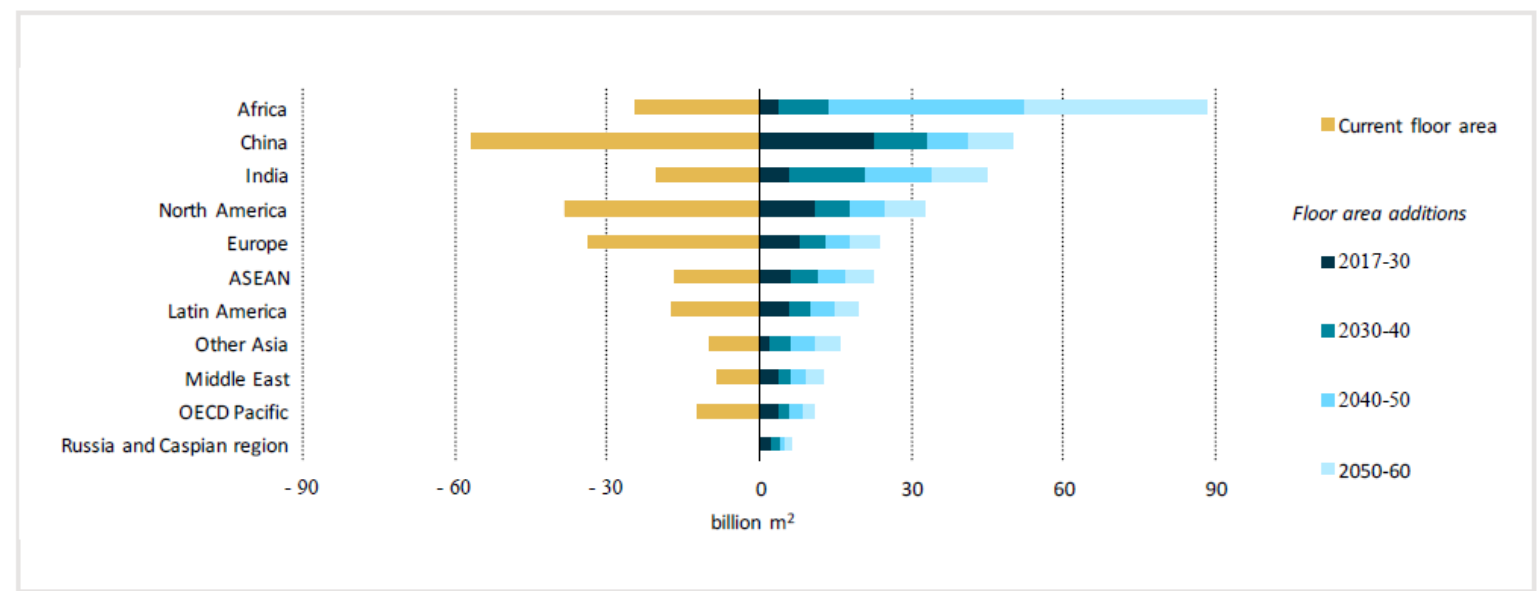

Notes: OECD Pacific includes Australia, New Zealand, Japan and Korea; ASEAN = Association of Southeast Asian Nations.

Figura 14.Crecimiento del parque edificatorio a 2060.

Fuente: UN Environment and International Energy Agency [8]

A 2016 existían más de 60 países en todo el mundo con códigos y normas de energía para edificaciones, las cuales establecen requisitos mínimos para la eficiencia energética y el autoabastecimiento (instalación y uso de energías renovables) de las edificaciones nuevas. Los códigos y norma pueden ser de cumplimiento obligatorio o voluntario según cada país [9] (figura 15).

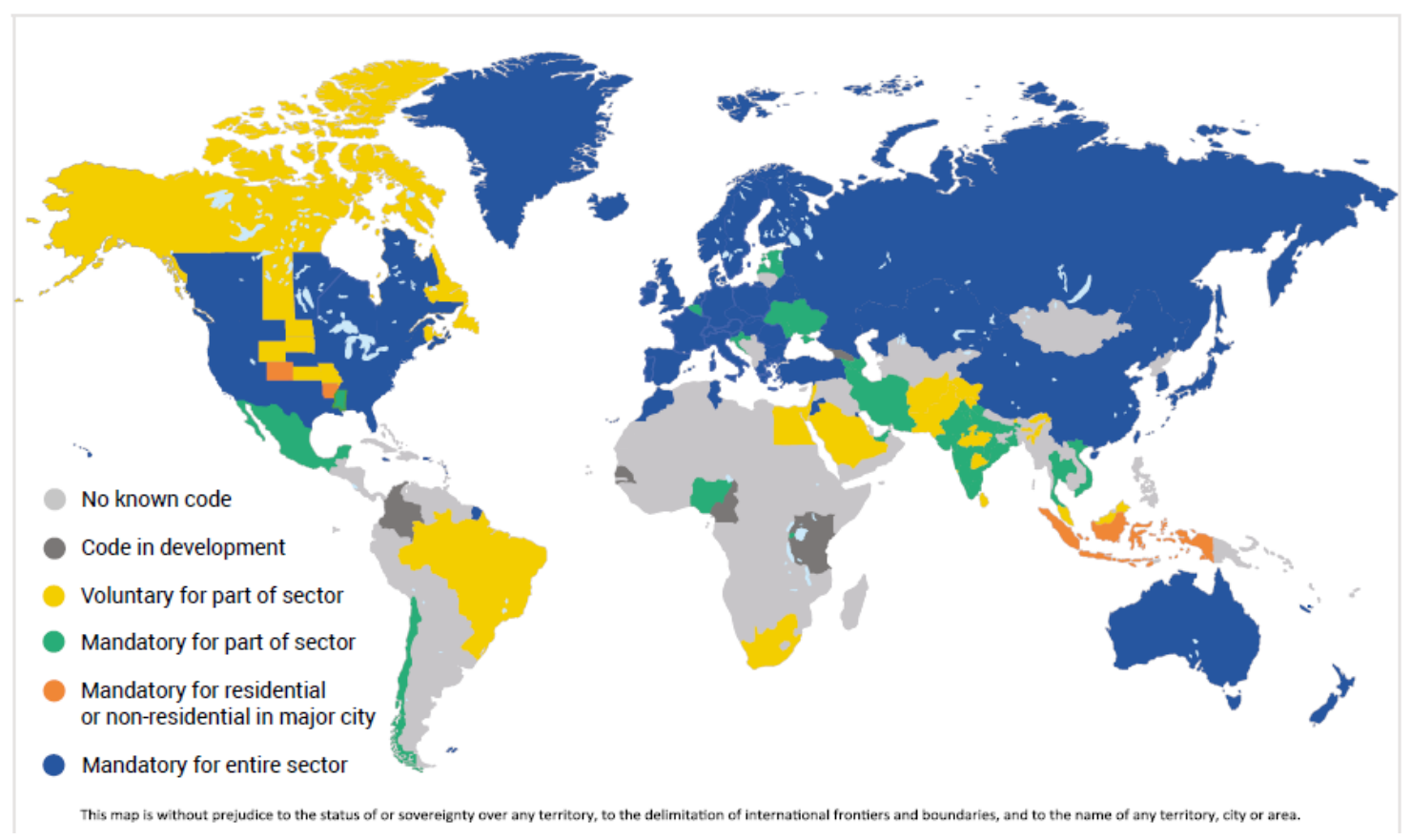

Figura 15. Códigos de energía por País

Fuente: Building Energy Efficiency Policies [9] 
En consecuencia, existe la necesidad de implementar y hacer obligatorias las normas y regulaciones relacionadas a la energía en las edificaciones. Se espera que en países en desarrollo sean construidos más de 100 mil millones de m2 al año 2060, a pesar de no contar con códigos de energía.

En cuanto a la matriz de consumo de energía suele dividirse en 4 sectores: Transporte, Industria, Edificaciones o sector servicios y residencial, y otros. Para el año 2016, el sector de edificios a nivel global consumió cerca de 125 EJ, un 30\% del uso total de energía final (figura 16).

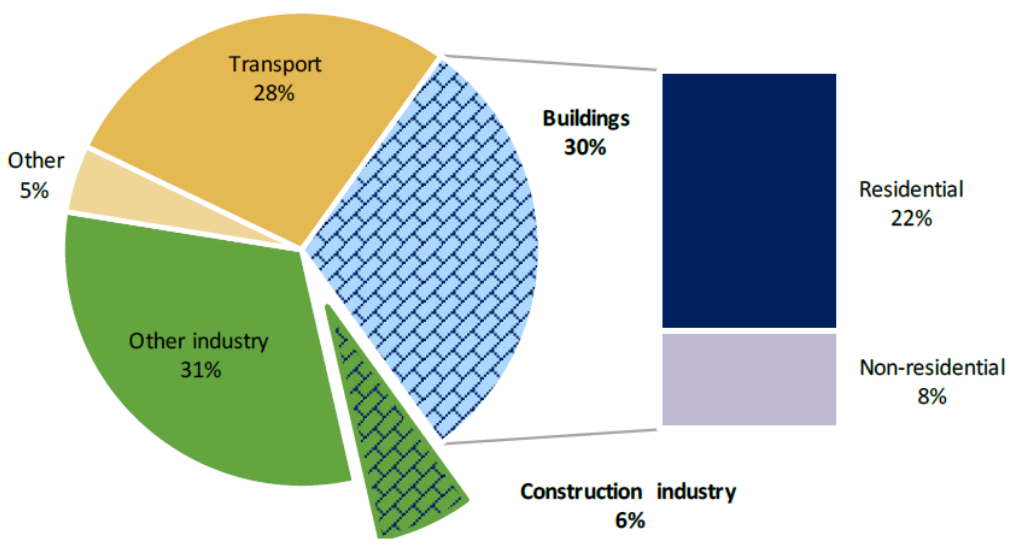

Figura 16. Proporción del consumo de energía final 2016.

Fuente: UN Environment and International Energy Agency [8]

En este sentido, el consumo de energía final está relacionado con las emisiones de CO2. El sector de edificios a nivel mundial presentó el $28 \%$ de las emisiones de $\mathrm{CO} 2$ relacionadas con energía. Teniendo en cuenta las emisiones directas (combustibles fósiles) e indirectas (fabricación de materiales para la construcción como acero, cemento) (figura 17).

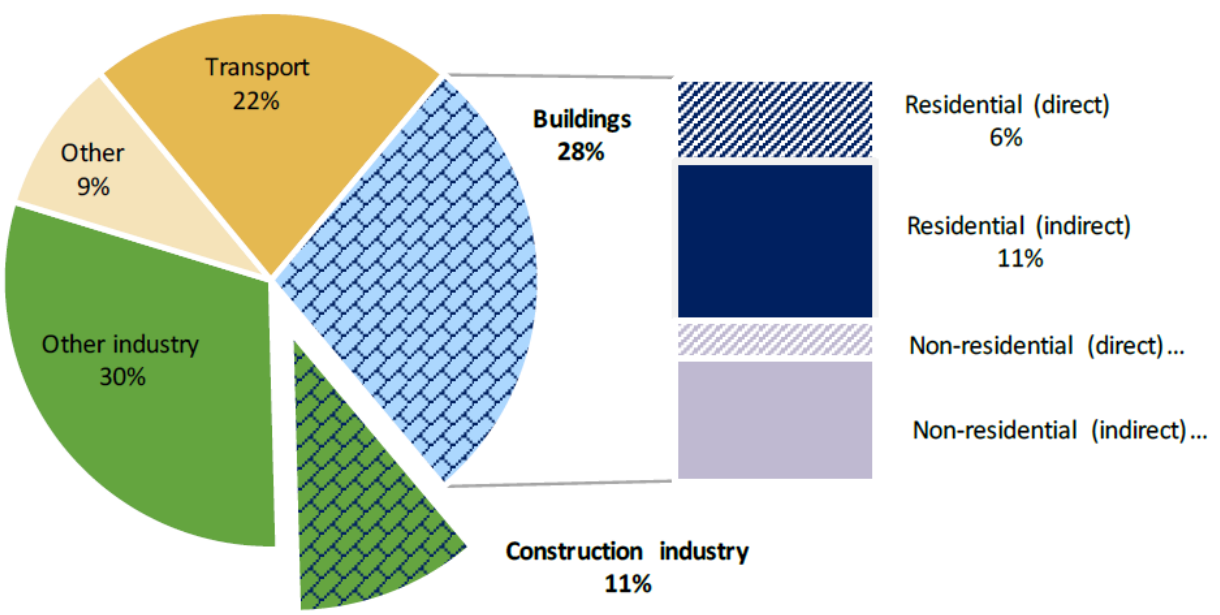

Figura 17. Proporción de emisiones de CO2 2016.

Fuente: UN Environment and International Energy Agency [8] 


\subsection{IMPORTANCIA DE LA EFICIENCIA ENERGÉTICA EN LAS EDIFICACIONES}

Según el informe Energy Efficiency 2017 de la IEA [4], en el sector de edificaciones se han logrado avances en eficiencia energética con iniciativas tanto políticas como tecnológicas. En el caso de las emisiones de GEl relacionadas con la construcción, se alcanzó un máximo de 9.5 giga toneladas (GtCO2-eq) en el año 2013 que disminuyeron a $9.0 \mathrm{Gt}$ en año 2016.

Sin embargo, el consumo final de energía de los edificios creció constantemente de 119 EJ en 2010 a 124 EJ en 2016, como resultado de la tendencia del incremento en el área dedicada a la construcción de edificaciones, condición que, de alguna manera, supera la reducción de la intensidad energética (Figura 18).

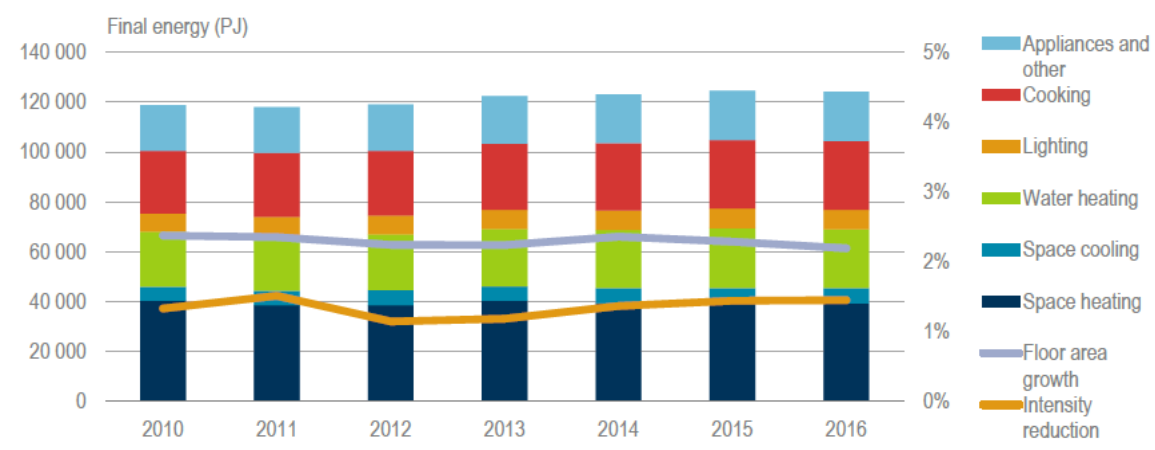

Figura 18. Consumo de energía del sector de edificios, intensidad energética y superficie (2010-16) Fuente: IEA - Energy Efficiency 2017

Los avances en materia de política de eficiencia energética para edificios van en ascenso en muchos países del mundo, en algunos casos, impulsados por el sector de la construcción y en otros por los adelantos tecnológicos en equipos de calefacción, ventilación y aire acondicionado (HVAC). En algunos países, como Dinamarca y Alemania, la política de construcción ha sido el factor clave para el progreso en términos de eficiencia energética, mientras que, en otros países, como Japón y Corea, el impulso se encuentra asociado a los equipos de HVAC (Figura 19).

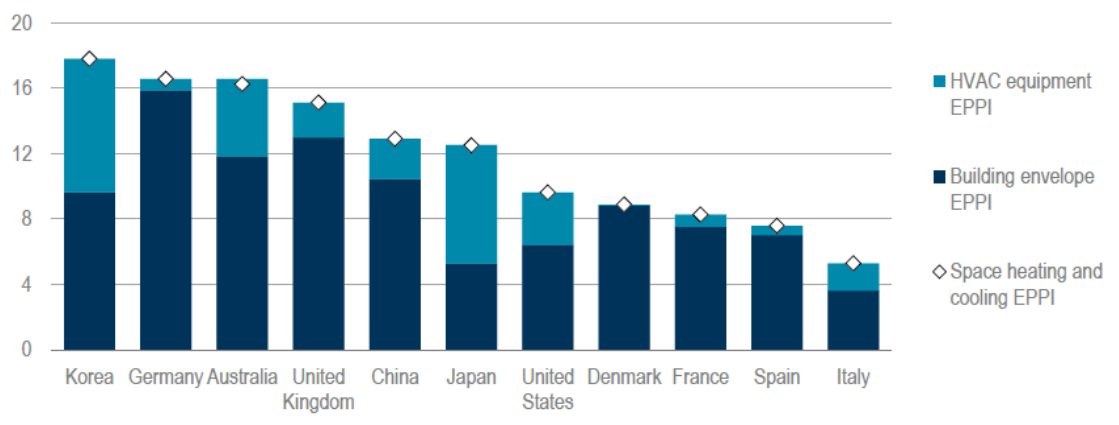

Figura 19. Proporción del progreso de la política de eficiencia de la calefacción y la refrigeración espaciales desde el año 2000 a partir de la construcción de sobres frente a los equipos HVAC Fuente: IEA - Energy Efficiency 2017 
Una combinación de políticas en términos de construcción como de mejoramiento de la eficiencia en equipo de uso final, resulta fundamental para la transición a edificios sostenibles. Es decir, edificio altamente eficiente que integren el uso de equipos y fuentes de energía de mayor eficiencia, como la recuperación de calor residual a baja temperatura, bombas de calor y energía renovable. En este sentido, políticas que integren códigos de construcción que favorezcan la transición hacia edificaciones sostenibles, generan confianza en los mercados a nivel mundial para invertir en la construcción de edificios nuevos que sean eficientes en el consumo de energía. Un avance relacionado a lo anterior se presentó en México donde se dieron dos pasos importantes en el último año, incluida la publicación del primer código nacional de eficiencia energética de edificios en colaboración con el International Code Council, y el lanzamiento de una hoja de ruta del código de energía del edificio que proporciona objetivos nacionales en incrementos de tres años hasta 2050.

El 19 de junio de 2017, India lanzó actualización del Código de Construcción de Conservación de Energía, un código modelo nacional que puede ser adoptado y aplicado por los gobiernos estatales y locales para mejorar la eficiencia de los edificios no residenciales [10]. De otro lado en lo concerniente a electrodomésticos, la implementación de estándares que favorezcan el reemplazo de equipos con mayor eficiencia resulta una alternativa de muchos países para cumplir con compromisos de ahorro energético. Algunos informes del IEA señalan ahorros entre el $16 \%$ al $26 \%$ en los últimos 10 años para electrodomésticos, siendo significativo la participación de la iluminación en ahorros del 75\% por cambio de iluminación halógena a iluminación LED. Algunas proyecciones estiman que el mercado de iluminación eficiente continuará creciendo y que el $90 \%$ de toda la iluminación interior será eficiente (CFL y LED) para 2022, debido a una combinación de política y costo decreciente de iluminación eficiente.

Otro elemento importante para aumentar la eficiencia son los equipos generadores de agua caliente (ACS), debido a las variaciones en el consumo de agua caliente del consumidor, las condiciones ambientales y el impacto de la infraestructura energética. Los estudios señalan que se puede ahorrar más energía por cambio tecnológico, es decir cambiando los tipos de equipos aumentando la eficiencia energética; En este caso las bombas de calor permiten un ahorro de energía del $60 \%$ al $85 \%$ en comparación con las calderas instantáneas y de almacenamiento típicos.

Otro elemento que aporta una mejora de la eficiencia energética en las edificaciones lo constituye la medición, control y análisis uso de la energía del edificio, como elemento para tomar decisiones sobre políticas y construcción de estrategias. Este enfoque compromete la digitalización, capacidad de capturar y análisis de datos.

A continuación, se presenta el contexto normativo y el impacto de las edificaciones en algunas regiones de alta importancia en la demanda energética a nivel mundial. 


\subsubsection{Contexto de las edificaciones en china}

El informe China Building Energy Use 2016 [11], del Centro de Investigación de Energía en Edificaciones de la Universidad de Tsinghua, China., relaciona las decisiones estratégicas que ha tomado el gobierno chino según su desarrollo económico, social, político e histórico en vía de contribuir una sociedad eficiente en el uso de los recursos. Como estrategia principal, se encuentra el ahorro de energía en los diferentes sectores de consumo y como foco principal las edificaciones. Para ello, se hacen necesarias acciones que conlleven al desarrollo de medidas de eficiencia energética en las edificaciones [12].

China se caracteriza por ser un país con una economía de rápido crecimiento, con una tasa de crecimiento promedio de PIB de 6.5\%, según el 13 Plan quinquenal (2016-2020) [13]. En ese sentido, el comportamiento del sector de edificios también es de crecimiento, los hogares urbanos aumentaron de 155 millones en 2001 a 264 millones en 2014, mientras que, los hogares rurales se redujeron de 193 millones a 160 millones [14].

Según lo anterior, China se considera en el sector de la construcción como un importante actor y consumidor de energía. Es la economía que mayor energía consume a nivel mundial y el segundo consumidor de energía en edificios después de Estados Unidos con un consumo cercano al $16 \%$ del consumo total de energía final en edificios a nivel mundial en el 2012. El consumo de energía final entre los años 2000 - 2012 en los edificios creció en un $37 \%$, si la tendencia se mantiene, se estima que para el periodo $2012-2050$ el aumento sea de un $70 \%$ adicional (figura 20 ) [15].
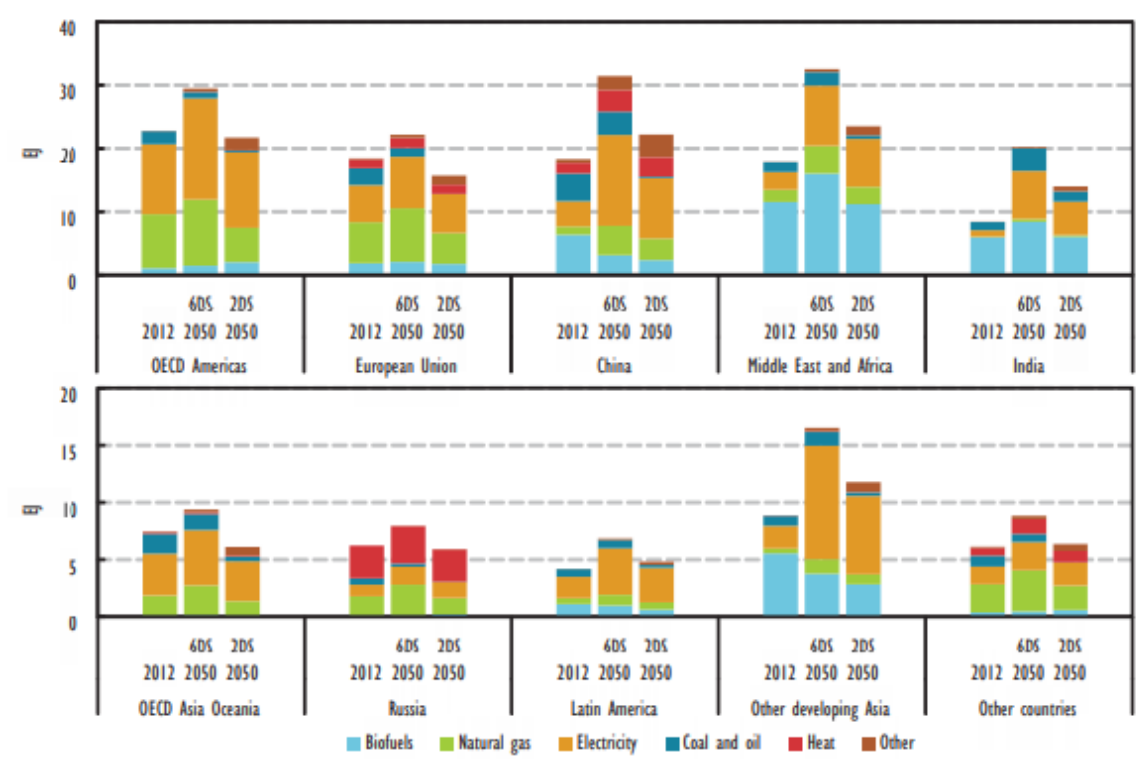

Figura 20. Proyecciones de consumo final de energía de edificios para las principales regiones y países, 2012-50

Fuente: IEA, 2015 [15]. 
Con el fin de cumplir los objetivos propuestos en el 2014 el consejo de estado del gobierno chino [16], dio a conocer el Plan de acción estratégico de desarrollo energético 2014 - 2020. En el cual se establecieron como metas principales: la reducción de consumo anual de energía primaria a 4.800 millones de TCE (141 EJ), limitar el uso total de carbón en aproximadamente 4.200 millones de TCE (aproximadamente 123 EJ) para 2020 y dio pie al desarrollo del Plan Nacional de Nueva Urbanización para 2014 a 2020 [17], que tiene como objetivo la promoción del desarrollo verde y bajo en carbono; la conservación del agua, la tierra, la energía y otros recursos y el uso eficiente; la restauración y tratamiento ambiental; la promoción del desarrollo de ciudades verdes e inteligentes, y fomentar estilos de vida sostenibles y métodos de construcción, operación y gestión de ciudades bajas en carbono.

\subsubsection{Contexto de las edificaciones en Estados Unidos}

Estados Unidos es un país altamente desarrollado e industrializado, para el año 2015 fue el país con el mayor consumo de energía en el sector servicios (edificios) y la segunda economía consumidora de energía después de China [12].

Según el informe energético del 2017 presentado por la Agencia Internacional de Energía [4], muestra que en Estados Unidos el consumo de energía fue de 97.7 cuatrillones de BTU, la fuente principal de energía proviene de elementos fósiles (petróleo 37\%, gas natural 29\%) y, solo el $11 \%$ (11 cuatrillones de BTU) son generados con energías renovables como lo enseña la figura 21. La energía consumida por el país como lo enseña la figura 22, fue en el sector industrial con un $32 \%$, sector transporte con el $29 \%$, y el mayor en edificios con un $20 \%$ en el sector residencial y $18 \%$ en el sector comercial.

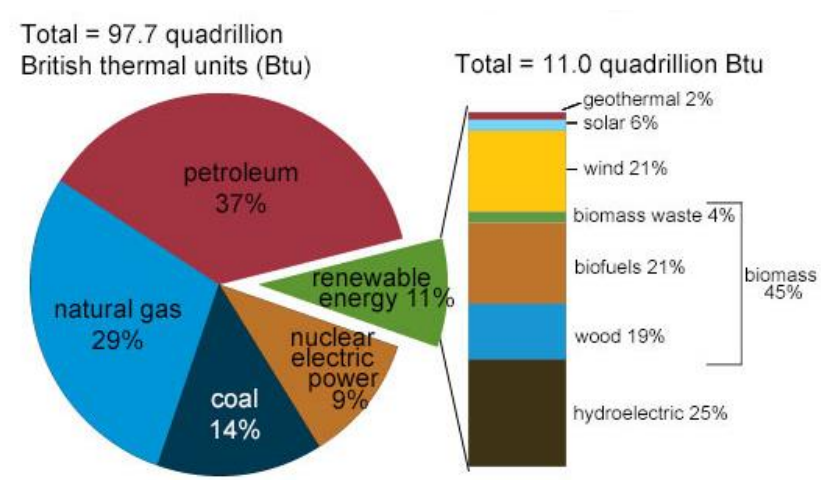

Figura 21. Consumo de energía por fuente para el año 2017 Fuente: IEA, 2018

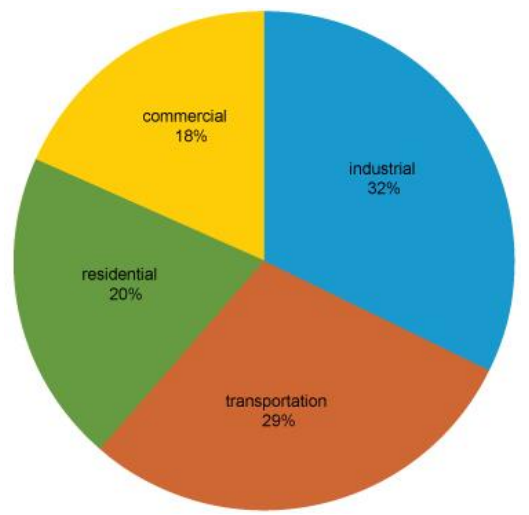

Figura 22. Consumo de energía por sector para el 2017 Fuente: IEA, 2018 
Según los datos anteriores, aproximadamente el 38\% del consumo de energía es debido a los sectores residencial y comercial que relacionan directamente el sector construcción y de edificaciones. Si bien, no se estima que el sector edificaciones crezca sustancialmente en los próximos años, debido a la composición de la matriz energética (principalmente fuentes fósiles, mayores emisiones de CO2 y Gases de Efecto Invernadero) se deben llevar a cabo acciones para minimizar el consumo energético en el país, principalmente en este sector.

En vía de reducir las emisiones de $\mathrm{CO} 2$ y contribuir al desarrollo renovable y sostenible del país, Estados Unidos ha desarrollado una política energética que aborda problemas de producción de energía, distribución y consumo, códigos de edificación y estándares de consumo de combustible [18].

Los códigos de construcción desarrollados se basan en la energía, su aprovechamiento y uso final. Así pues, los códigos de energía de los edificios garantizan que se utilice la energía de manera eficiente durante la vida útil del edificio, para ello se tiene el respaldo y acompañamiento de la Building Technologies Office (BTO) con el fin de aplicar los códigos en proyectos nuevos o remodelación de los existentes [18].

Además de los códigos de construcción desarrollados e implementados, estados unidos cuenta con una serie de normas de eficiencia energéticas y de certificaciones voluntarias (por ejemplo, Energy Star y LEED) con el fin de disminuir el consumo energético del país y asegurar su abastecimiento energético.

\subsubsection{Contexto de las edificaciones en Europa (EU)}

En la Unión europea (UE) los edificios son responsables de aproximadamente el $40 \%$ del consumo de energía y el 36\% de las emisiones de CO2. Cerca del 35\% de los edificios tienen más de 50 años y el $75 \%$ del parque inmobiliario es eficiente en energía, mientras que solo el $0,4-1,2 \%$ del parque inmobiliario se renueva cada año. Una mayor renovación de los edificios existentes conduciría a importantes ahorros de energía, reduciendo potencialmente el consumo total de energía de la UE en un 5-6\% y reduciendo las emisiones de $\mathrm{CO} 2$ en aproximadamente un 5\% [19].

Mejorar la eficiencia energética de los edificios también puede generar beneficios económicos, sociales y ambientales. Los edificios de mejor rendimiento proporcionan mayores niveles de confort y bienestar para sus ocupantes, y mejoran la salud al reducir las enfermedades causadas por una mala calidad del aire interior (IAQ).

Los países europeos consumen menos energía que hace 10 años, principalmente gracias al aumento de la eficiencia energética. Europa también depende menos de los combustibles fósiles gracias al ahorro de energía y la utilización, más rápida de lo previsto, de energías renovables. En la década de 2005-2015, la proporción de energías renovables en el consumo de energía de la UE prácticamente se duplicó, pasando del $9 \%$ a cerca del $17 \%$. 
Algunos sectores y países están marcando la pauta por lo que se refiere a la energía limpia. Sin embargo, a pesar de que su cuota de mercado se está reduciendo, los combustibles fósiles siguen siendo la fuente de energía dominante en Europa. La figura 23., muestra la energía demandada por los países de la UE para el año 2017, donde se encuentra como mayor consumidor Alemania, seguido de Francia, Inglaterra y España.

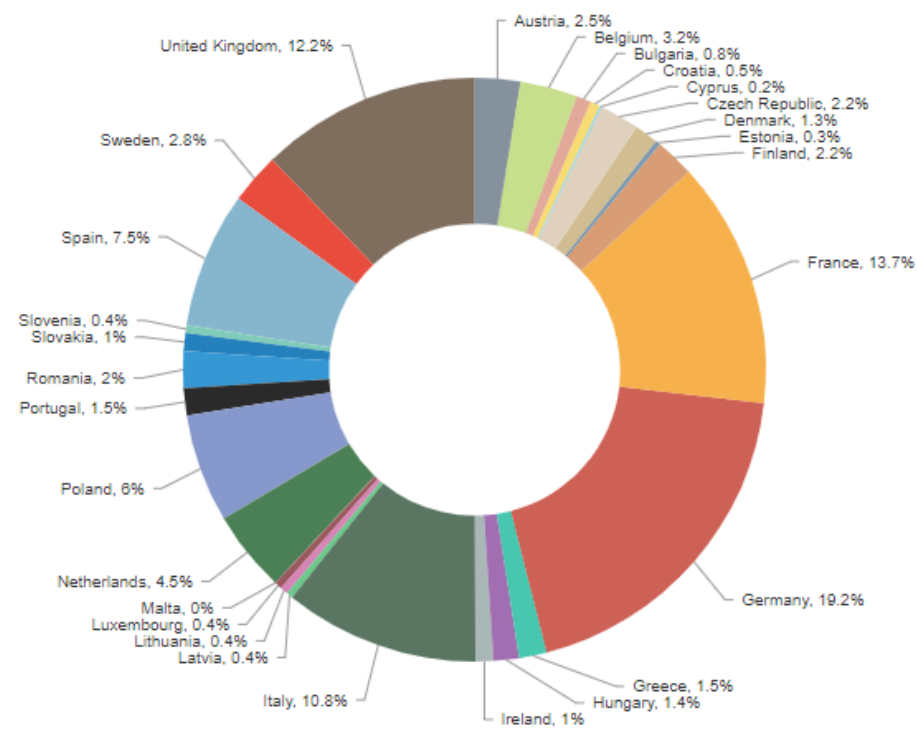

Figura 23. Energía final demandada en 2017 países de la Unión Europea Fuente: Comisión Europea, 2017 [19]

Dada la importancia del consumo de energía en los 28 países que conforman la UE, se ha puesto en marcha un conjunto de directivas de obligatorio cumplimiento para todos los países, entre los más significativos están la EPBD (Eficiencia energética de Edificios 2018) para crear en Europa una Unión de la Energía y así garantizar que los ciudadanos y las empresas de la UE tengan un suministro energético seguro, asequible y respetuoso con el clima. Otras de las estrategias importantes es la estrategia Europa 2020, una estrategia para un crecimiento inteligente, sostenible e integrador que propone, como uno de los cinco objetivos principales para la Unión Europea, conocido como 20-20-20:

- Reducción de las emisiones de gases de efecto invernadero en un 20\% respecto de 1990 con el compromiso bajo acuerdo internacional de elevar el objetivo hasta el $30 \%$.

- Alcanzar el $20 \%$ de fuentes renovables en el consumo energético de la UE en 2020 y un $10 \%$ en el sector del transporte.

- Aumentar la eficiencia energética con el fin de ahorrar un $20 \%$ del consumo energético de la UE respecto de las proyecciones para el año 2020. 


\subsubsection{Contexto de las edificaciones en Latinoamérica y el Caribe}

Las edificaciones en Latinoamérica y el caribe en el 2017 [20], fueron responsables de aproximadamente el $21.8 \%$ del consumo energético (comercial, servicios y público $5.2 \%$, construcción y otros $0.9 \%$ y residencial $15.7 \%$ ) según datos de la Organización Latinoamericana de Energía OLADE. Además, el principal energético fue la Gasolina/Alcohol con un $19.4 \%$ de participación seguido por el Diesel Oil con un $19.0 \%$ y la electricidad con un $16.0 \%$., como se presenta en la figura 24.

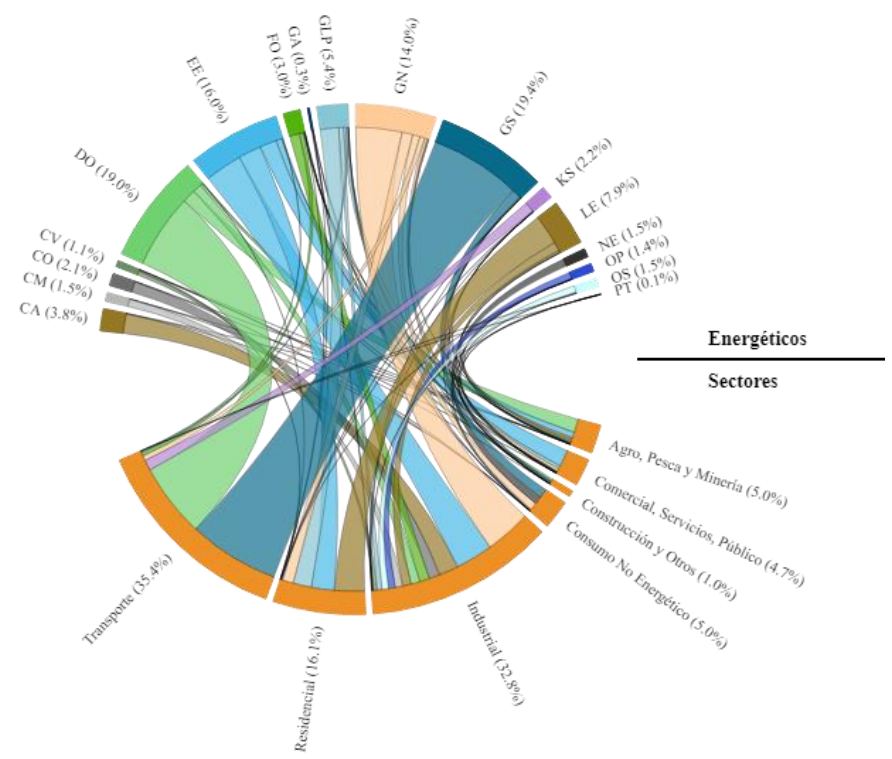

\begin{tabular}{|c|c|}
\hline CA & Caña de Azúcar y Derivados \\
\hline CM & Carbón Mineral \\
\hline CO & Coque \\
\hline CV & Carbón Vegetal \\
\hline DO & Diésel Oil \\
\hline EE & Electricidad \\
\hline FO & Fuel Oil \\
\hline GA & Gases \\
\hline GLP & Gas Licuado \\
\hline GN & Gas Natural \\
\hline GS & Gasolina/Alcohol \\
\hline KS & Kerosene/Jet fuel \\
\hline LE & Leña \\
\hline NE & No Energético \\
\hline OP & Otras Prim \\
\hline PT & Petróleo \\
\hline
\end{tabular}

Figura 24. Participación del Consumo Final por Energético y Sectores: América Latina y El Caribe 2017

Fuente: sieLAC-OLADE[20]

Las ciudades y edificaciones representan un gran reto (presente y futuro) para Latinoamérica y el caribe, puesto que es la región más urbanizada del planeta, con casi el $80 \%$ de su población viviendo en las ciudades. Y, aunque las ciudades ocupan sólo el $3 \%$ de las tierras del planeta, son responsables de hasta el $80 \%$ del consumo de energía y del $75 \%$ de las emisiones de carbono [21].

Para el año 2018, los edificios en Latinoamérica [22] representaron el $24 \%$ del consumo total de energía final, y el $21 \%$ del total de emisiones de $\mathrm{CO} 2$ relacionadas con el proceso excluyendo las emisiones de la fabricación de materiales de construcción y productos como acero, cemento y vidrio, como se presenta en la Figura 25. 

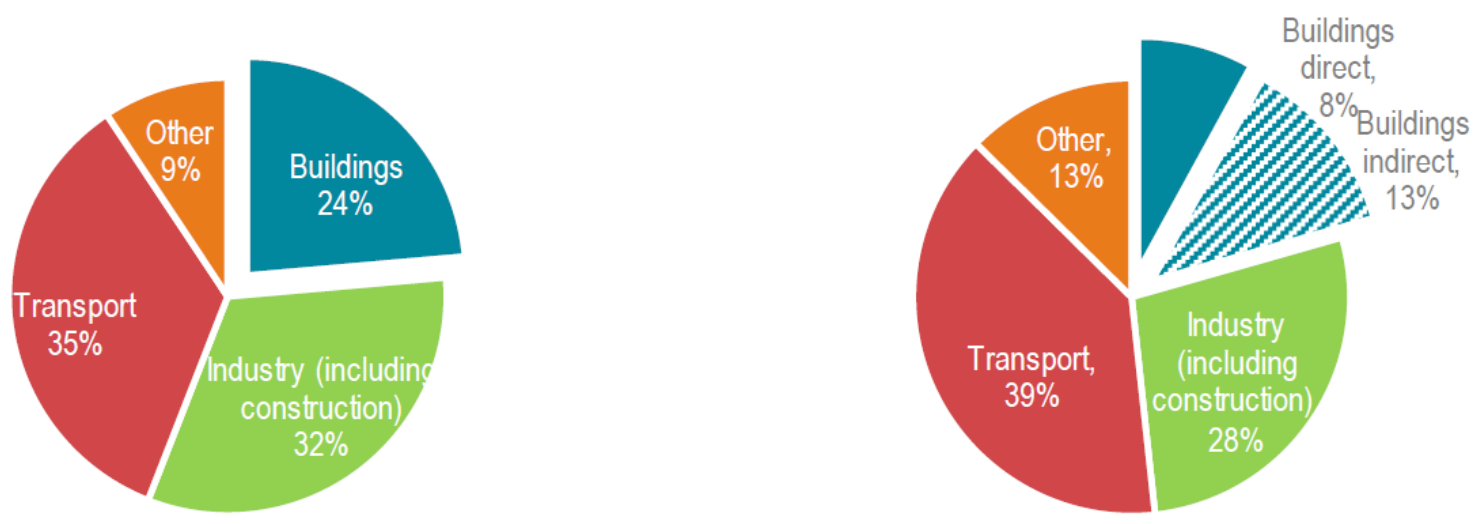

Figura 25. Porcentaje de consumo final y emisiones de GEI en las edificaciones en Latinoamérica Fuente: Latin America Roadmap for Buildings and Construction 2020-2050 [22]

Las emisiones de GEI generadas por los edificios crecieron más del $15 \%$ desde 2010 . El contenido de carbono de la red eléctrica en América Latina es comparativamente bajo debido a la alta proporción de energía hidroeléctrica y al uso de biomasa tradicional en edificios en aproximadamente el $23 \%$ del consumo final total.

Para abordar las tendencias emergentes y hacer avanzar el sector de los edificios hacia una alta eficiencia y cero emisiones de carbono, se necesitan políticas efectivas que permitan abordar las barreras actuales del mercado y permitir la adopción de tecnologías de mejores prácticas. Sin embargo, el progreso en los códigos de energía de los edificios en la región está cambiando muy lentamente y no está alineado con la cantidad de edificios existentes o los nuevos edificios necesarios para satisfacer el crecimiento de la población.

Con políticas apropiadas en cuanto a su diseño e implementación, una gama de tecnologías rentables puede resultar en ahorros de energía y reducciones de emisiones hasta 2050. Enfocarse en el uso de sistemas de calefacción, refrigeración e iluminación de alta eficiencia, técnicas de construcción adaptadas localmente y la adopción de bajo costo, eficiente la construcción de envolventes puede generar importantes ahorros de energía y reducciones de emisiones.

Los edificios juegan un papel dominante en la transición de la energía limpia, en este sentido la Agencia Internacional de Energía y la Alianza Global para los edificios y la construcción han construido una Hoja de ruta para América Latina [22] centrada en delinear los objetivos y los plazos necesarios para lograr un stock de construcción de cero emisiones, altamente eficiente y resistente desde ahora hasta 2050.

En la hoja de ruta se han establecido 8 actividades como áreas estratégicas y prioritarias para lograr el objetivo delimitado. Las actividades, el estado actual y las acciones necesarias hacia la meta a largo plazo y la meta a largo plazo son: 
1. Planeación urbana: Utilizar políticas de planificación urbana para permitir una menor demanda de energía, aumentar la capacidad de energía renovable y mejorar la capacidad de recuperación de la infraestructura.
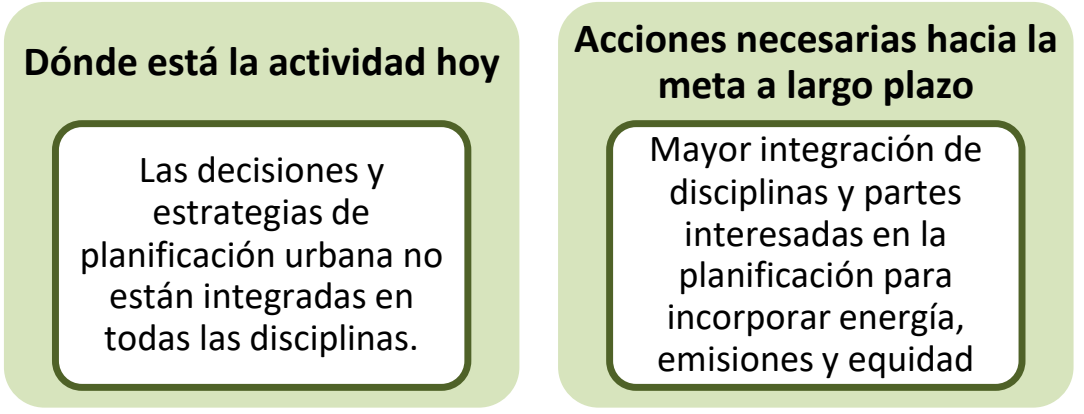

Meta a largo plazo

Planificación integrada con planificación espacial eficiente para ciudades equitativas bajas en carbono.

2. Nuevos edificios: Aumentar la captación de emisiones netas de la operación de los edificios.

\section{Dónde está la actividad hoy}

Muchos países no cuentan con código obligatorio para requisitos mínimos de rendimiento energético de edificios nuevos

\section{Acciones necesarias hacia la meta a largo plazo}

NZEB operativo para 2030 para nuevos edificios.

Mayor adopción y aplicación de códigos y políticas de construcción
Meta a largo plazo

Todos los edificios nuevos operan con cero carbono neto

3. Edificios existentes: Aumentar la tasa de renovación de energía de los edificios y aumentar el nivel de eficiencia energética en los edificios existentes.

\section{Dónde está la actividad hoy}

Pocos edificios renovados con fines de rendimiento energético, falta de información de referencia.

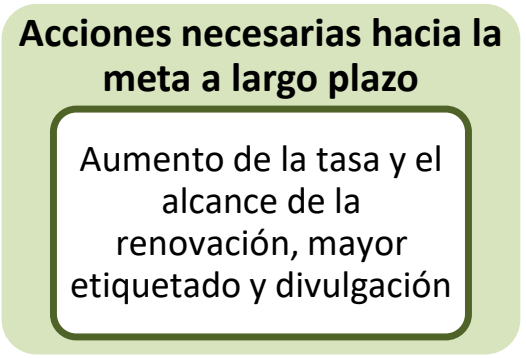

Meta a largo plazo

Todos los edificios operan con cero carbono neto 
4. Operaciones de edificios: Reducir la energía operativa y las emisiones a través de herramientas mejoradas de gestión de energía y creación de capacidad operativa.

\section{Dónde está la actividad hoy}

Uso mínimo del rendimiento energético y gestión ambiental
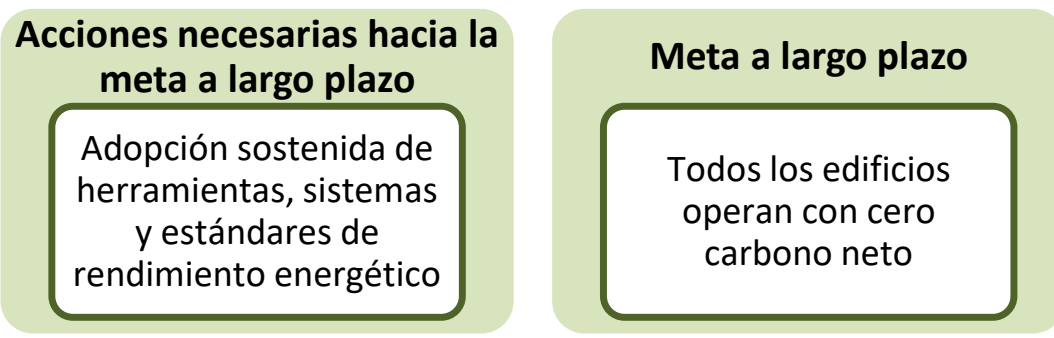

5. Electrodomésticos y sistemas: Reducir la demanda de energía de los sistemas, electrodomésticos, iluminación y cocina.

\section{Dónde está la actividad hoy}

Baja penetración de iluminación, electrodomésticos y equipos eficientes

\section{Acciones necesarias hacia la meta a largo plazo}

Mejora en los sistemas de construcción a través de mejoras de rendimiento, estándares y una mayor conectividad
Meta a largo plazo

Uso generalizado y conocimiento de sistemas altamente eficientes

6. Materiales: Reducir el impacto ambiental de los materiales y equipos en los edificios y la cadena de valor de la construcción tomando un enfoque de ciclo de vida.

\section{Dónde está la actividad hoy}

Alto contenido de energía, emisiones y potencial de calentamiento global de materiales, poca concientización e información del impacto

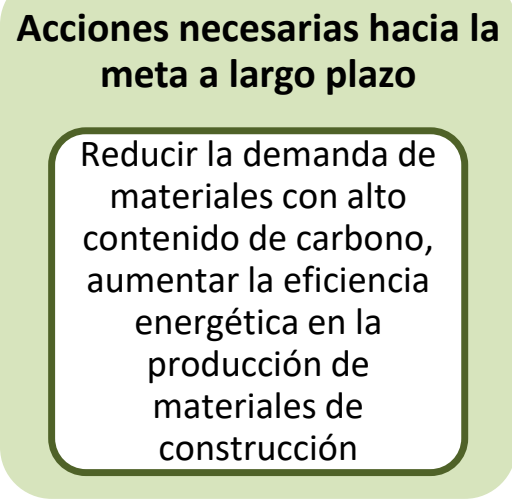

Meta a largo plazo

Uso generalizado de materiales bajos en carbono y divulgación del carbono incorporado 
7. Resiliencia: Reducir los riesgos de construcción relacionados con el cambio climático adaptando el diseño del edificio y mejorando la resiliencia.
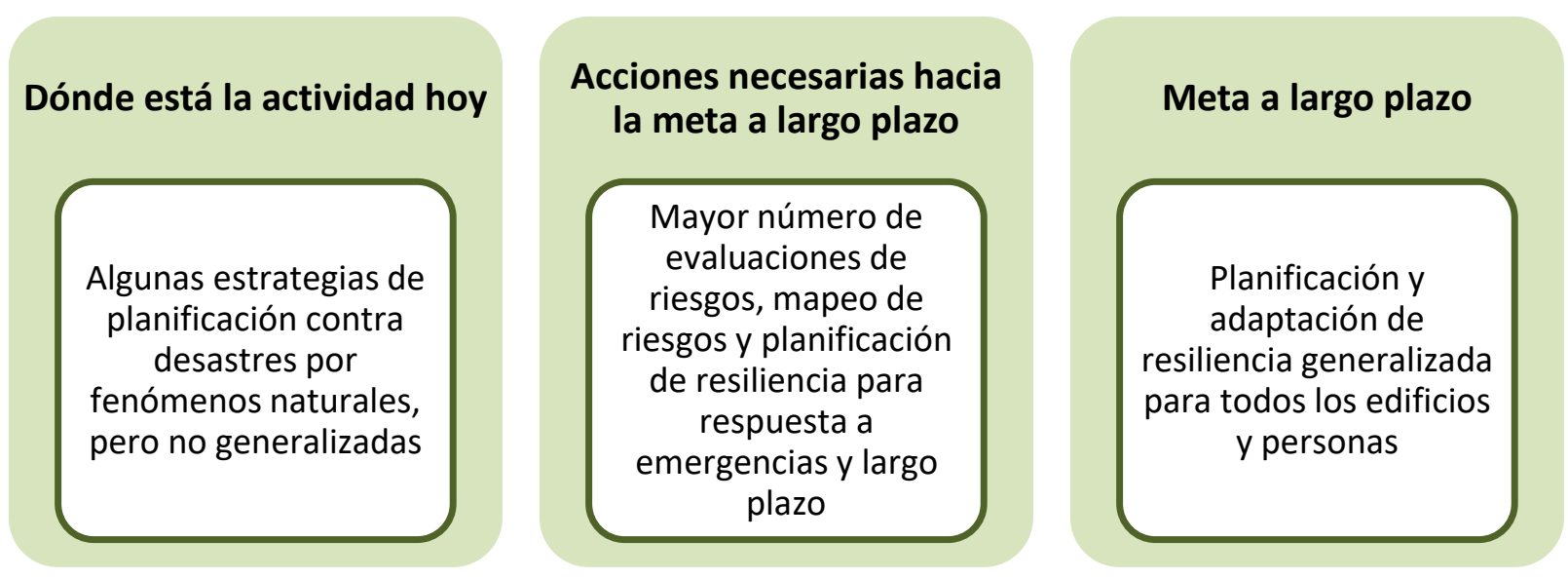

8. Energía limpia: Aumentar la energía segura, asequible y sostenible y reducir la huella de carbono de la demanda de energía en los edificios.

\section{Dónde está la actividad hoy}

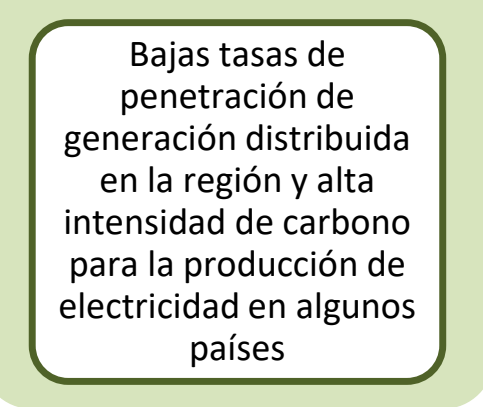

\section{Acciones necesarias hacia la} meta a largo plazo

Mayor participación de energía hidroeléctrica, eólica y solar fotovoltaica para reducir la intensidad de carbono de la red.

Aumento de la generación distribuida

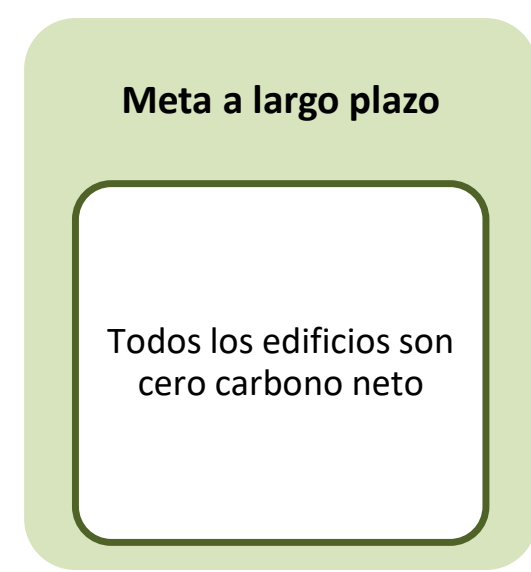

\subsubsection{Contexto de las edificaciones en Colombia}

\section{ANTECEDENTES}

Las edificaciones y su construcción, son considerados uno de los motores de crecimiento de la economía colombiana, para el 2017 la participación del sector en el producto interno bruto (PIB) de la economía colombiana fue de 4,9\%, cifra que aumentó considerablemente si es comparada con la obtenida el en 2001 , donde la participación del sector en el PIB fue de $1,8 \%[23]$.

En Colombia, el sector edificaciones según datos de la UPME (PAI PROURE, 2016) representa el $22 \%$ del consumo de energía final $(16,71 \%$ sector residencial, 5,32\% sector comercial y público y $0,03 \%$ en la construcción). Las emisiones de gases de efecto invernadero (GEI) 
relacionados con las edificaciones residenciales representan un $10,5 \%$ de las emisiones totales. El crecimiento del sector, indica pues, que se presente un aumento en la emisión de GEI y residuos ligados a la construcción. Además, de la extracción y sobreconsumo de recursos y materia prima necesarios para la construcción.

Se estima que, para los próximos 35 años, lleguen a las ciudades colombianas aproximadamente 18 millones de nuevos habitantes, para los cuales el sector deberá tomar papel principal y generar la construcción de nuevas edificaciones, que generan impactos ambientales de suma importancia. Por tal razón es necesario la adopción de pautas que permitan minimizar los efectos negativos del sector en el país. Si bien, se han realizado y formulado lineamientos para apuntar a la sostenibilidad del sector, como lo son la Resolución 0549 de 2015 del Ministerio de Vivienda, Ciudad y Territorio, en donde se adopta la guía para el ahorro de agua y energía en edificaciones. La Norma Técnica Colombiana (NTC 6112 de 2016, Sello Ambiental Colombiano) del Ministerio de Ambiente y Desarrollo Sostenible, por la cual se establecen criterios ambientales para el diseño y construcción de edificaciones con uso diferente a vivienda. No se cuenta con unos criterios de sostenibilidad integral a lo largo de las etapas del ciclo de vida de las edificaciones que le permita al país y al sector de la construcción enfrentar los retos que representa su crecimiento, además de considerar no solo las edificaciones futuras, sino, las edificaciones existentes.

En el Plan Nacional de Desarrollo (PND) 2014-2018 se establecieron tres objetivos para avanzar hacia el crecimiento verde en el país: (i) avanzar hacia un crecimiento sostenible y bajo en carbono; (ii) proteger y asegurar el uso sostenible del capital natural y mejorar la calidad y gobernanza ambiental; y (iii) lograr un crecimiento resiliente y reducir la vulnerabilidad frente a los riesgos de desastres y al cambio climático. Bajo estas iniciativas y en el mismo plan resulta la Misión de crecimiento verde, enfoque que busca un desarrollo sostenible que garantice el bienestar económico y social de la población en el largo plazo, asegurando que la base de los recursos provea los bienes y servicios ecosistémicos que el país necesita y el ambiente natural sea capaz de recuperarse ante los impactos de las actividades productivas, estrategia de Crecimiento Verde (PND 2014-2018). En este sentido y siguiendo las iniciativas anteriores, en el año 2018 se presenta el documento Política Nacional De Edificaciones Sostenibles CONPES 3919 que busca articular las medidas anteriores en busca de un uso eficiente de los recursos del agua, la energía, el suelo, la madera y otros materiales hacia una economía circular para el sector de las edificaciones [24].

Las iniciativas que ha llevado a cabo el país relacionadas con sostenibilidad no son solo las presentadas anteriormente. En los últimos años (figura 26) se han llevado a cabo múltiples políticas, resoluciones, acuerdos y certificaciones en línea con el desarrollo sostenible principalmente en el sector de las edificaciones, tomando como referencia en algunas legislaciones locales e internacionales que tienen clara la necesidad de incorporar en las políticas nacionales parámetros de sostenibilidad en el sector. 
A nivel nacional, las políticas de edificaciones sostenibles se han dividido en cinco grupos temáticos: i) políticas y programas de mitigación al cambio climático; (ii) lineamientos de sostenibilidad en el sector en las edificaciones a nivel nacional y en entidades territoriales; (iii) programas y experiencias de eficiencia energética y uso eficiente del agua; (iv) uso eficiente de materiales y residuos; (v) desarrollo urbano y suelo [24].

- Ley 23: Código de recursos naturales y de protección del medio ambiente

-Decreto 2811: Por el cual se dicta el Código Nacional de Recursos Naturales Renovables y de Proteccion del Medio Ambiente

-Decreto 1449: Proteccion aprovechamiento y conservacion de Aguas y suelos

-Ley 9: Por la cual se dictan medidas sanitarias

- Ley 142: Por la cual se establece el régimen de los servicios públicos domiciliarios y otras disposiciones

-Acuerdo 20: Por el cual se adopta el Código de construcción del Distrito Capital de Bogotá

-Decreto 1791: Por el cual se establece el régimen de aprovechamiento forestal (MinAmbiente)

-Ley 388: La ley orgánica de ordenamiento territorial

-Decreto 3102: Por el cual se reglamenta el articulo 15 de la ley 373 de 1997 en relación con la instalación de equipos, sistemas e implementos de bajo consumo de agua

-Ley 373: Por la cual se establece el programa para el uso eficiente y ahorro del agua

- Ley 685: Por la cual se expide el Código de Minas y se dictan otras disposiciones

•Resolución 3957: (Secretaria Distrital de Bogotá)

-Resolución 493 (MinAmbiente)

-Documento CONPES 3700: Estrategia institucional para la articulación de politicas y acciones en materia de cambio climático en Colombia

-Estrategias Colombianas de Desarrollo Bajo en Camrbono (ECDBC) (MinAmbiente)

- Política Nacional de Cambio Climatico (PNCC) (MinAmbiente)

-Plan de acción sectorial de mitigacion para el sector vivienda y desarrollo territorial (MinVivienda)

- Código Colombiano de Fontanería NTC1500

- Ley 1715: Por la cual se regula la Integración de las Energias Renovables no convencionales al Sistéma Energético Naciona

-Decreto 1285 (MinVivienda)

- Resolución 0549 (MinVivienda)

- Ley 1753: Por la cual se expide el Plan Nacional de Desarrollo 2014-2018

-Acuerdo Municipal de Construcción Sostenible del Valle de Aburrá

-Documento CONPES 3870: Programa Nacional para la formulación y actualización de planes de ordenamiento territorial: POT Modernos

•Resolución 3348 (DNP)

-Plande Acción Indicativo PROURE 2017-2022 (UPME)

- Ley 1844: Por la cual se aprueba el Acuerdo de París

-Resolución 0472 (MinAmbiente)

-Resolución 1988 (MinAmbiente)

-Resolución 585 (UPME)

Figura 26. Antecedentes de la política nacional de edificaciones sostenibles Fuente: Dirección de Desarrollo Urbano DNP 
Entre los antecedentes principales se encuentra:

\section{i. Políticas y programas de mitigación al cambio climático}

Estrategia Institucional para la Articulación de Políticas y Acciones en Materia de Cambio Climático en Colombia CONPES 3700 (2011) [25], aunque no incluía dentro de su alcance acciones con respecto al sector edificaciones, contiene recomendaciones y objetivos estratégicos financieros e institucionales para incluir variables climáticas para la planificación y diseño de proyectos en desarrollo, en vía de implementar medidas de adaptación y mitigación contra cambio climático.

La Estrategia Colombiana de Desarrollo en Bajo Carbono (ECDBC) (2011), es un programa del gobierno colombiano que busca equilibrar la relación del crecimiento económico nacional y las emisiones de gases de efecto invernadero, por medio de la planificación, diseño e implementación de medidas sectoriales a corto, mediano y largo plazo que mitiguen las emisiones de gases de efecto invernadero y sea mayor la eficiencia energética.

La Política Nacional de Cambio Climático (PNCC) (2014), busca avanzar en el desarrollo resiliente al clima y bajo en carbono, con el fin de mitigar el cambio climático y sus riesgos. Incorporando dicha política a las decisiones que sean tomadas en los sectores públicos y privados. Además, considera la eficiencia energética en edificaciones y la necesidad de presentar incentivos para promover su inclusión, la construcción sostenible, la conservación de los paisajes verdes y diversidad ecológica. En este mismo sentido aparece la Ley 1844 de 2017, que aprueba y adopta el Acuerdo de Paris, por medio de compromisos nacionales que reduzcan las emisiones de gases de efecto invernadero (GEI), para lograr que la temperatura no aumente más de dos grados centígrados.

\section{ii. Lineamientos de sostenibilidad en el sector de las edificaciones a nivel nacional y entidades territoriales}

Decreto 1285 (2015), Establece lineamientos generales de construcción sostenible para edificaciones, encaminados al mejoramiento de la calidad de vida de los habitantes y al ejercicio de actuaciones con responsabilidad ambiental y social.

Resolución 0549 (2015) [26], [27], Establece los porcentajes obligatorios de ahorro de agua y energía para el sector de las edificaciones en el país, lineamientos generales de sostenibilidad para edificaciones, conceptos asociados a la construcción sostenible, implementación de mesas interinstitucionales y reglamentación de la política. Además, de contener dos anexos: (i) la Guía de Construcción Sostenible para el Ahorro de Agua y Energía en Edificaciones y (ii) el Mapa de clasificación del clima en Colombia para la identificación de los requisitos de la resolución según la característica del nivel térmico. Esta normativa es 
de cumplimiento obligatorio para edificaciones de centros educativos, oficinas, comerciales y viviendas, y aplica para licencias urbanísticas en la modalidad de obra nueva. Establece pautas como la implementación de medidas activas (inclusión de aparatos y tecnologías ahorradoras) y medidas pasivas (acondicionamiento arquitectónico).

En la actualidad se han implementado políticas de construcción sostenible en once municipios del país, entre ellos Bogotá y su Política Pública de Ecourbanismo y Construcción Sostenible de Bogotá, El valle de Aburrá y sus diez municipios con la Política De Construcción Sostenible Del Valle De Aburrá y Cali que se encuentra en etapa de construcción de su Política.

El Programa de Eficiencia Energética en Edificaciones, promovido e implementado por la alcaldía de Bogotá en alianza con el Instituto de Recursos Mundial (WRI) y el Consejo Colombiano de Construcción Sostenible (CCCS), promueve la eficiencia energética como oportunidad para una ciudad baja en carbono desde el sector de las edificaciones y su entorno urbano.

\section{iii. Programas y experiencias de eficiencia energética y uso eficiente del agua}

\section{Eficiencia Energética}

Colombia ha desarrollado un marco político en torno a la eficiencia energética desde el año 2001 con la ley 697 (2001) que fomenta el uso racional y eficiente de la energía, se promueve la utilización de energías alternativas y se dictan otras disposiciones. Posteriormente, con el Decreto 3683 (2003) por la cual se crea una Comisión Intersectorial para el Uso Racional y Eficiente de la Energía y Fuentes no Convencionales CIURE.

En el 2010, el Ministerio de Minas y Energía, adoptó el Plan de Acción Indicativo (PAI) 20102015 para desarrollar el Programa de Uso Racional y Eficiente de la Energía (PROURE), con metas y acciones de eficiencia energética por sector de consumo prioritario.

EI PROURE establece e incorpora iniciativas de eficiencia energética que aplican al sector de edificaciones como: el Reglamento Técnico de Instalaciones Eléctricas (RETIE), Reglamento Técnico de Etiquetado (RETIQ), y Reglamento Técnico de lluminación y Alumbrado Público (RETILAP). Además, de proponer incentivos en vía de promover la eficiencia energética en vivienda, el diseño e implementación de planes de gestión eficiente de energía en entidades públicas y en el desarrollo de capacidades técnicas para los actores involucrados dentro del mercado de edificaciones sostenibles dentro de su plan de acción.

Ley 1715 (2014) por medio de la cual se regula la integración de las energías renovables no convencionales al sistema energético nacional, propone incentivos tributarios para la integración de energías renovables al sistema energético nacional como plan estratégico para la producción y consumo de energía. 
Resolución 585 (2017) establece el procedimiento para conceptuar sobre los proyectos de eficiencia energética y gestión eficiente de la energía que se presenten para acceder al beneficio tributario.

Resolución 1988 (2017) establece que las solicitudes en materia de eficiencia energética se presentarán ante la Autoridad Nacional de Licencias Ambientales (ANLA), para optar por la exclusión del impuesto sobre las ventas.

\section{Uso Eficiente del agua}

La normativa colombiana ha sido desarrollada a partir de la Ley 373 (1997) por la cual se establece el programa para el uso eficiente y ahorro del agua a través de la promoción de buenas prácticas por parte de los usuarios, la exigencia a los constructores y urbanizadores de incluir aparatos de bajo consumo de agua en los proyectos, y la obligación de los proveedores de servicios públicos de apoyar los procesos de implementación y uso de las tecnologías ahorradoras en el territorio.

Código Colombiano de Fontanería NTC 1500 (2014) guía para la inclusión de medidas asociadas al uso racional del agua, implementación de tecnologías ahorradoras.

Uso eficiente de los materiales de construcción y residuos

El Instituto Colombiano de Normas Técnicas y Certificación (Icontec), ha establecido una serie de normas técnicas en vía de generar criterios ambientales para materiales de construcción, entre ellas se encuentran la Norma Técnica Colombiana (NTC) 6112 del 2016 del Sello Ambiental Colombiano (SAC) para edificaciones diferentes a vivienda, las NTC 6100, 2500 y 3489 relacionadas a materiales maderables, y la serie de guías de asistencia técnica para VIS del Ministerio de Ambiente, Vivienda y Desarrollo Territorial del 2011.

En 2012, el Ministerio de Ambiente y Desarrollo Sostenible desarrolla la guía de criterios ambientales para el diseño de la construcción de vivienda urbana en la que presenta lineamientos para el uso del agua, la energía, el suelo y los materiales para vivienda urbana. Resolución 0472 (2017) define los lineamientos para la gestión integral de residuos sólidos generados en las actividades de RCD.

Documento CONPES 3874 Política nacional para la gestión integral de residuos sólidos (2016), busca implementar medidas de prevención en la generación de recursos y reducir la disposición final a través de la promoción de la reutilización, aprovechamiento y tratamiento de los residuos.

A pesar de los esfuerzos realizados por el gobierno nacional, las normas técnicas y resoluciones no han sido lo suficientemente aplicadas dado que tienen un enfoque más orientador y voluntario en el sector de las edificaciones. 


\section{Desarrollo urbano y suelo}

Las edificaciones impactan su entorno inmediato según su ubicación y zona en la que se construyan por esta razón se han generado distintas iniciativas sobre los procesos de ocupación de estas construcciones.

Ley 388 (1997) establece un mandato para que todos los municipios del país formulen sus respectivos planes de ordenamiento territorial (POT), en esta se regula la utilización, transformación y ocupación del espacio en relación con las estrategias socioeconómicas, de medio ambiente y tradiciones históricas y culturales.

Política de Gestión Ambiental Urbana (PGAU, 2008) plantea entre sus objetivos principales, contribuir al mejoramiento de la calidad del hábitat urbano, asegurando la sostenibilidad ambiental de las actividades de servicios públicos, la movilidad, la protección y uso sostenible del paisaje y del espacio público, así como el de la infraestructura y la vivienda.

Documento CONPES 3718 Política Nacional de Espacio Público (2012) [28], busca la articulación a las políticas de adaptación al cambio climático, medio ambiente, gestión del riesgo, movilidad urbana, urbanismo y construcción sostenible, y manejo de drenajes urbanos.

Las políticas desarrolladas en aras del desarrollo sostenible, han sido enmarcadas en los escenarios internacionales como lo son: el Acuerdo de París (COP21 - 2015), los Objetivos de Desarrollo Sostenible (ODS - 2016) y la Nueva Agenda Urbana (NAU - 2016).

El Acuerdo de París, establece el compromiso de reducir los GEI en un $20 \%$ para 2030 y propone acciones de mitigación para evitar que la temperatura mundial supere los $2^{\circ} \mathrm{C}$. Los ODS presentan acciones orientadas a solucionar las causas fundamentales de la pobreza y adoptan medidas para mejorar las condiciones sociales y ambientales de todos los países. El cumplimiento de estos objetivos está estrechamente relacionado con el aporte al acatamiento de las metas de la COP21 y se enmarca en los planteamientos de la Nueva Agenda Urbana (NAU).

La implementación de una política de edificaciones sostenibles, apunta a 9 de los 17 objetivos de desarrollo sostenible, presentados en la Figura 27. 


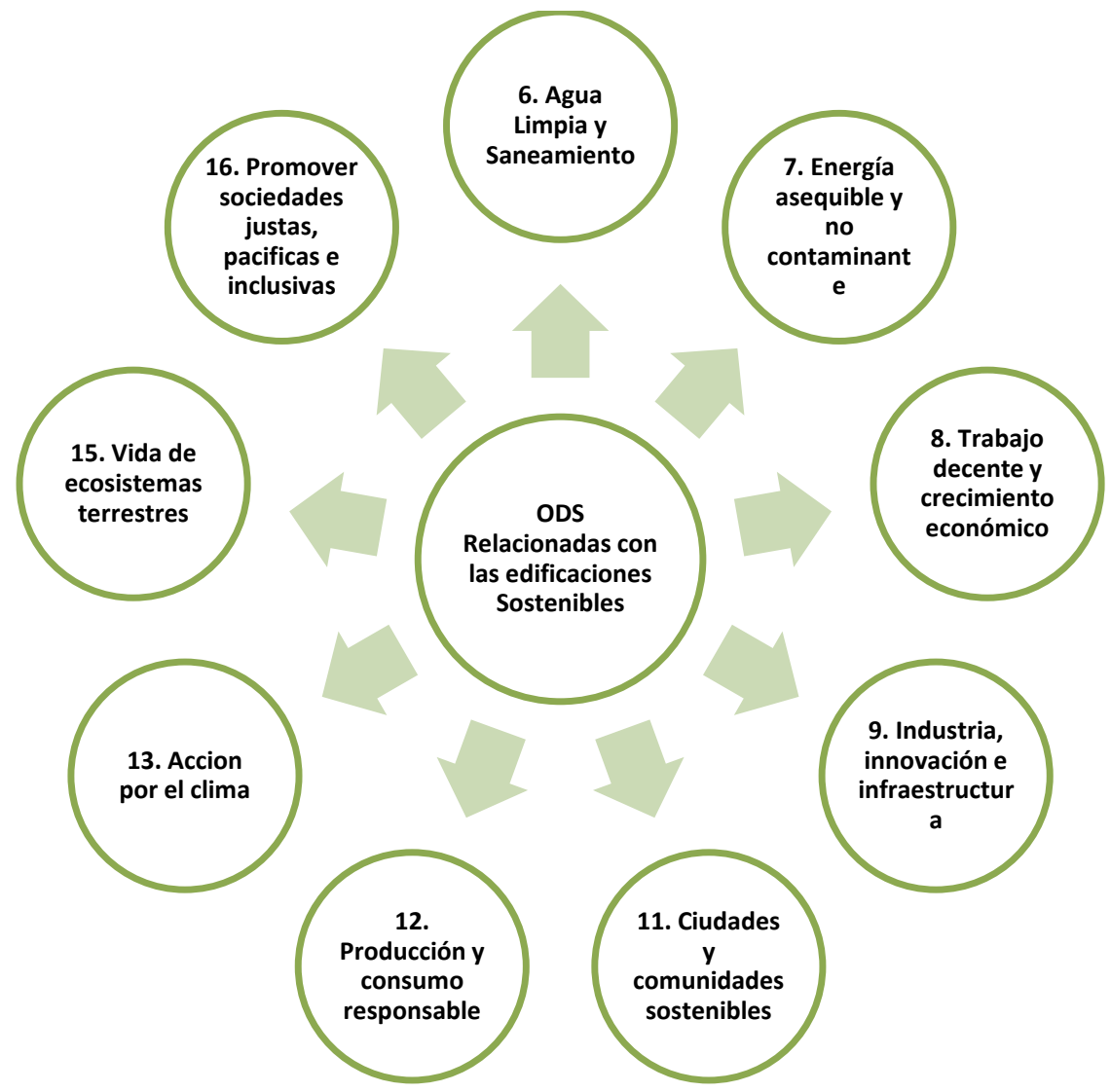

Figura 27. Objetivos de Desarrollo Sostenible relacionadas con las edificaciones sostenibles Fuente: Dirección de Desarrollo Urbano DNP, basado en la ODS

Actualmente, Colombia no ha implementado un sistema de incentivos económicos y/o tributarios para fortalecer la sostenibilidad en edificaciones nuevas y existentes. Sin embargo, diversos proyectos de construcción (viviendas, edificios educativos, edificios de instituciones gubernamentales) han adoptado de forma voluntaria los objetivos de construcción sostenibles y buscado su certificación bajo los estándares internacionales.

Dentro de los sellos de certificación sostenibles usados en Colombia se encuentran:

- Referencial casa colombia: Herramienta de certificación voluntaria [29], propuesta por el Centro Colombiano de Construcción Sostenible en 2016. Su objetivo es impulsar la incorporación de criterios de sostenibilidad, transformando la construcción de viviendas y edificaciones en el país alineado con las políticas nacionales de crecimiento verde. Siguiendo un concepto de sostenibilidad integral en donde se reúne el uso eficiente de los recursos, teniendo en cuenta la salud y el bienestar de los ocupantes. 
- LEADERSHIP IN ENERGY AND ENVIRONMENTAL DESIGN - LEED: El sistema de certificación LEED [30], [31] fue creado para proporcionar un estándar nacional de edificaciones y de certificación voluntaria en los EE. UU por el US Green Building Council (USGBC) en el año 2000, actualmente ha ampliado su influencia a más de 160 países, considerándose uno de los estándares de calificación y certificación de construcción ecológica más usados en todo el mundo. Ha certificado más de 90000 proyectos a nivel mundial.

- BUILDING RESEARCH ESTABLISHMENT ENVIRONMENTAL ASSESSMENT METHODOLOGY - BREEAM: Creado en 1990 por el Building Research Establishment (BRE) [32] del Reino Unido, fue el primer sello de certificación desarrollado después del Protocolo de Kyoto. Este sello es una herramienta que mide la sostenibilidad de distintos tipos de edificaciones, nuevas y existentes y se enfoca en los impactos de las edificaciones en su entorno.

Dentro de los proyectos certificados en Colombia, se encuentran: 520 apartamentos de viviendas social del proyecto Piamonte en Madrid, Cundinamarca [33]; edificio del Centro Administrativo Nacional en Bogotá [34]; Institución Educativa Gabriel García Márquez Sede Panorama, en Yumbo, Valle del Cauca [35]; Universidad Nacional de Colombia en Tumaco, Tumaco Pacífico Campus.

\section{LAS EDIFICACIONES Y SU CONCEPCION NACIONAL}

La Ley 400 (1997) establece que una edificación es una construcción cuyo uso primordial es la ocupación por seres humanos, y su producción y consumo están determinados por las etapas dentro del ciclo de vida. Y que, su desarrollo sostenible proviene del equilibrio de sostenibilidad económica (asequibilidad, empleo, innovación), sostenibilidad ambiental (uso racional de agua, energía y materiales., generación de pocos residuos) y sostenibilidad social (accesibilidad, inclusión, ambientes saludables y sanos). Es entonces, que una edificación sostenible es aquella que hace uso de energía, agua y materiales de un modo eficiente, adecuada a su ubicación, y provee confort, salud y bienestar a sus usuarios.

En el crecimiento económico del país tiene gran influencia el sector edificaciones, influyendo en el PIB total del país (figura 28), con un crecimiento anual del 4,1\% (20112017). Así mismo, el sector de la construcción es una importante fuente de empleo, ocupando un total de 1,4 millones de trabajadores, lo que representa el 6,3\% del total de la fuerza laboral del país [36]. 


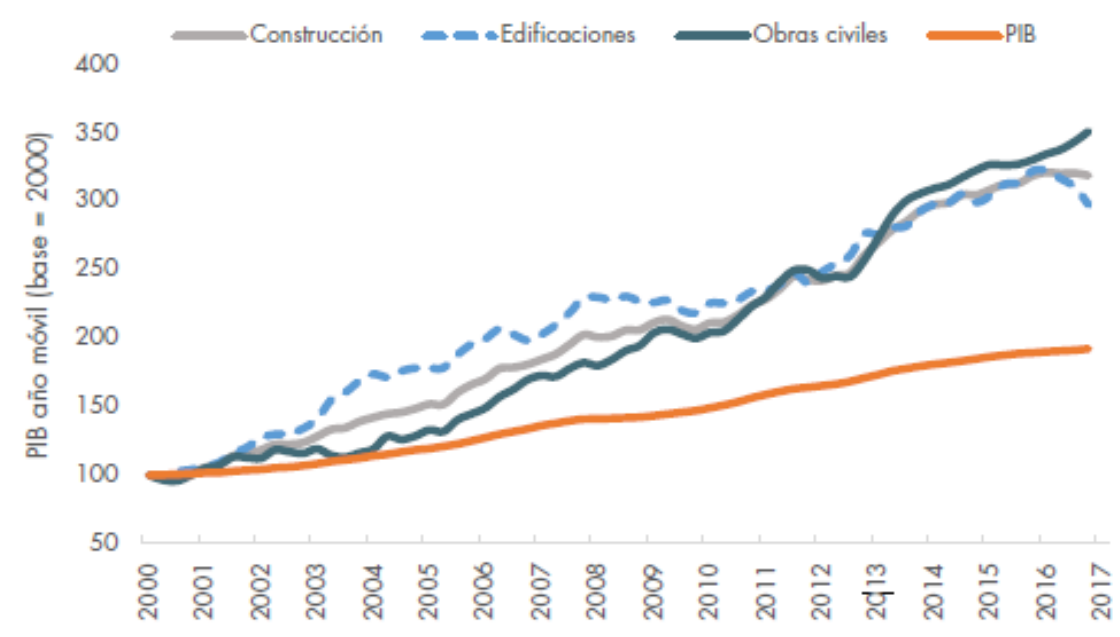

Figura 28. Índice del PIB total y construcción 2017

Fuente: Cálculos DNP con base en cuentas trimestrales DANE

Si bien, el crecimiento del sector edificaciones representa un crecimiento en la economía nacional, también representa un incremento en el consumo de recursos (energía, agua, madera, pétreos entre otros) y a su vez aumento en las emisiones de GEI, residuos sólidos y aguas residuales. A nivel mundial entre 1970 y 2014 se incrementaron en un $70 \%$ las emisiones de GEI y las edificaciones contribuyen con más del 30\% de las mismas [1].

Las emisiones directas de GEI para el año 2016 presentadas por el Ideam [37] (figura 29), deja ver que el sector de construcción presenta el $15 \%$ de las emisiones y un $4 \%$ de las mismas son producto de las actividades residenciales y comerciales.

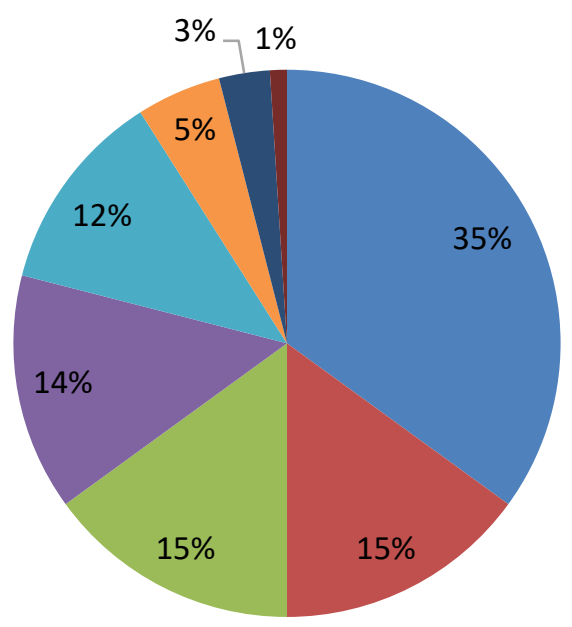

Forestal
Manufactura y construcción
$\square$ Transporte
$\square$ Ind de Energía
$\square$ Agropecuario
$\square$ Saneamiento
Residencial
$\square$ Comercial

Figura 29. Emisiones directas de GEI por sector 2016 Fuente: Inventario nacional de GEI - Colombia [37] 
Por medio del Balance Energético Colombiano (BECO) para el año 2016, se estima que la energía no aprovechada representa un $6.3 \%$ del consumo nacional anual, representado en aproximadamente USD 4.700 millones. El sector edificaciones constituye un $22.04 \%$ del consumo. La figura 30 presenta la participación porcentual del consumo nacional de energía por sector [38].

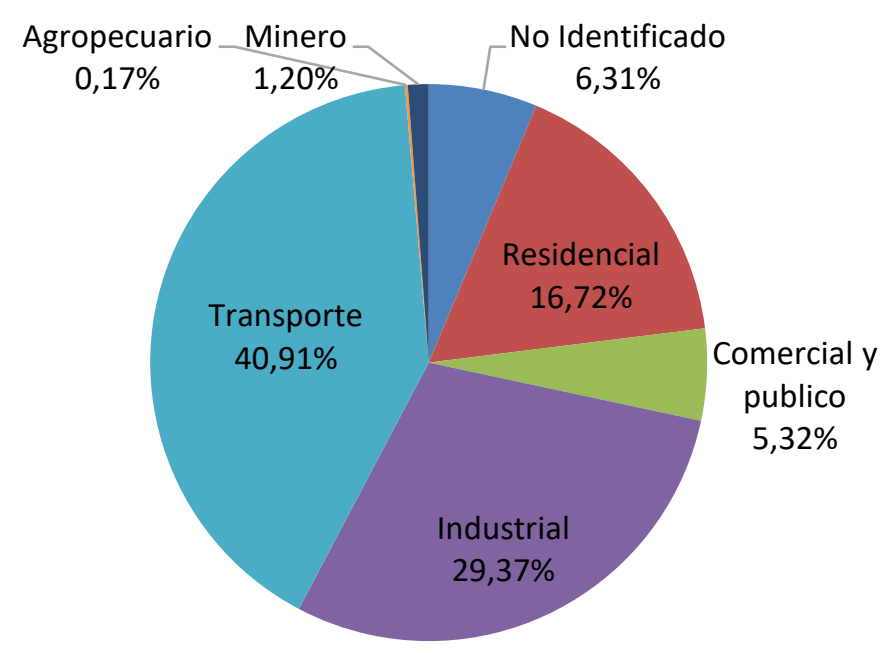

Figura 30. Consumo Nacional de Energía

Fuente: Ministerio de Minas y energía, y UPME - PROURE 2017

El sector residencial de las principales áreas urbanas representa un consumo del $8.2 \%$ del consumo anual de agua según datos presentados por el Ideam y el ministerio de ambiente y desarrollo sostenible [39].

A nivel mundial, más de diez mil tipos de materiales son usados en las diversas etapas de construcción de edificaciones, en su mayoría son de origen minero [2] lo cual representa una presión importante en la extracción de recursos naturales a escala global.

En Colombia, la demanda de materiales de construcción la componen: 19\% obras civiles, $14 \%$ sector edificaciones, $61 \%$ cadena de distribución y $6 \%$ por la industria [40].

Según los datos presentados anteriormente, las edificaciones representan altos consumos de los diferentes recursos naturales. Por esta razón, el establecer políticas en vía de hacerlos cada vez más sostenible tiene la capacidad para generar ambientes más saludables y confortables, aumentar la calidad habitacional y los niveles de satisfacción y productividad en el trabajo en sus ocupantes. Las determinantes que definen las características de calidad de un inmueble están definidas además en las medidas activas (sistemas operativos) y pasivas (diseño arquitectónico), entre las que se incluye la localización, las determinantes 
del sitio, así como criterios de asequibilidad, accesibilidad, seguridad jurídica de tenencia y adecuaciones culturales de ocupación, entre otros.

En términos de consumo, las edificaciones están catalogadas en el sector servicios o terciario que corresponde a edificaciones de uso comercial, educativo, hoteles, restaurantes, entre otros. Los consumos de este sector según la UPME [38] se muestran en la figura 31, donde el mayor energético consumido es energía eléctrica con un $66.24 \%$, seguido de Gas Natural con un $28.92 \%$ y el GLP con $4.84 \%$. Los principales usos de la electricidad son: iluminación (31\%), aire acondicionado $(22,8 \%)$ y refrigeración $(13,9 \%)$ (Figura 32).

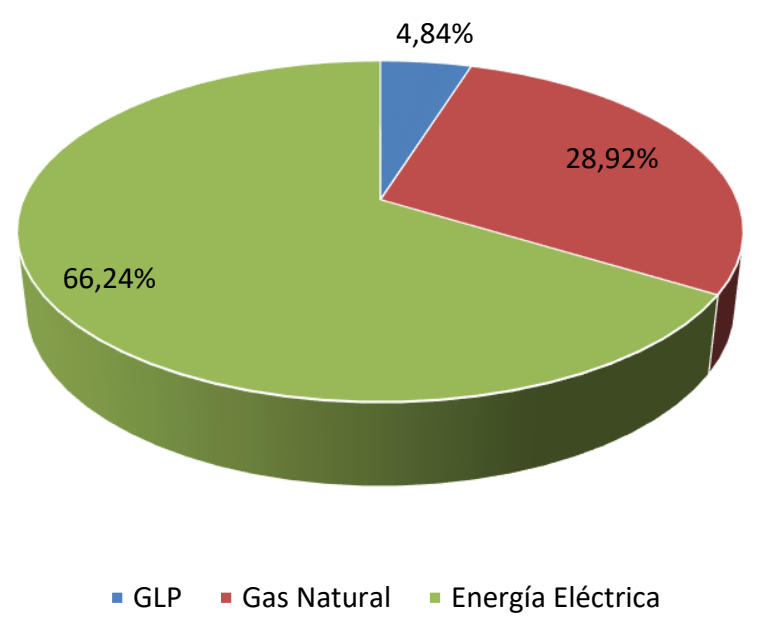

Figura 31. Consumo de energía eléctrica, gas natural y GLP en el Sector Terciario

Fuente: UPME - PAI PROURE, 2016

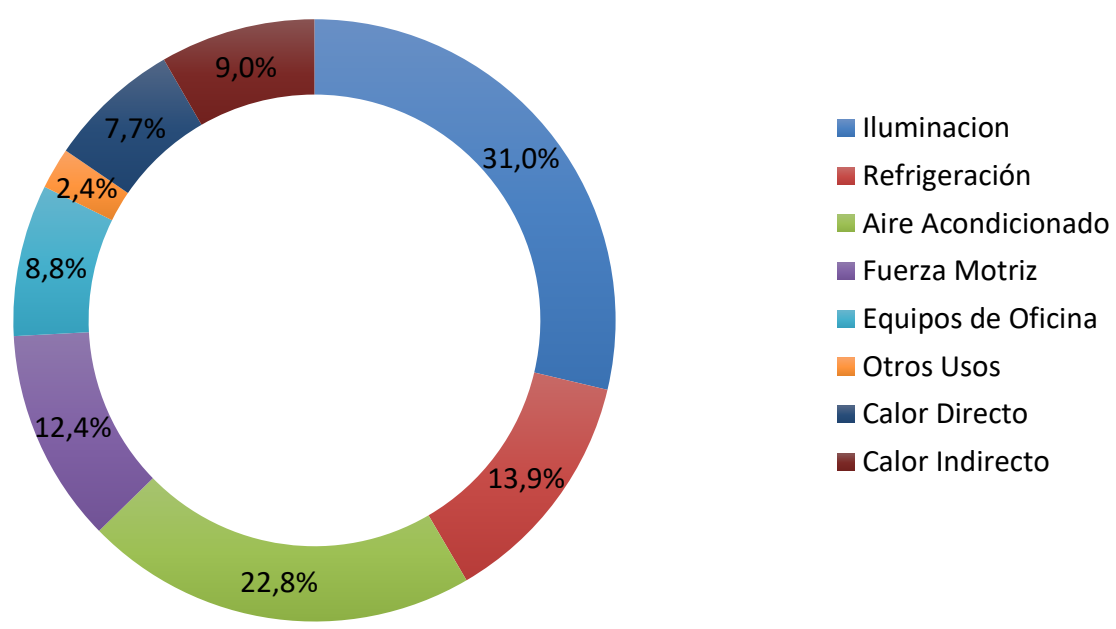

Figura 32. Usos de la electricidad en el Sector Terciario Fuente: UPME - PAI PROURE, 2016 
Como estrategia para la implementación de la política nacional de ahorro de agua y energía en nuevas edificaciones (Resolución 0549 de 2015), el Depto. Administrativo de Gestión del Medio Ambiente (DAGMA) de la alcaldía de Santiago de Cali buscó cooperación internacional con el programa Acelerador de Eficiencia Energética en Edificaciones (Building Efficiency Accelerator, BEA) de la iniciativa Sustainable Energy for All (SE4ALL) de la Organización de las Naciones Unidas. El programa BEA es una alianza público-privada de ciudades, empresas y organizaciones que comparten el objetivo de mejorar la eficiencia energética en edificaciones con el fin de reducir la huella urbana de la construcción al 2030., [41], [42]. Dicha cooperación dio como resultado la construcción del Manual de construcción Sostenible para el área urbana de Santiago de Cali que fue aprobado y adoptado bajo la Resolución 1529 del 24 de diciembre de 2019 [43], [44].

El Manual de Construcción Sostenible producto final de cooperación internacional y el aporte de diversos estamentos de la sociedad como organismos municipales, la academia, una selección de gremios asociados y de las entidades dedicadas a la construcción., presenta un instrumento dinámico y de carácter continuo que se erige como respuesta por parte del Municipio de Santiago de Cali en cabeza del DAGMA de cara a la ciudadanía para tratar, debatir, concertar y dar soluciones a los temas derivados de la gestión del medio ambiente en el sector de la construcción. En él se recogen y establecen los primeros aportes y directrices de las temáticas:

- Ahorro de energía y uso de energías alternativas.

- Ahorro de agua, reutilización de aguas, tratamiento de aguas residuales y aprovechamiento de aguas lluvias y/o aguas condensadas.

- Uso de materiales reciclables en la construcción.

- Adaptación climática.

- Protección de la biota y emplazamiento de coberturas vegetales en la construcción.

El panorama expuesto anteriormente plantea la importancia que, para un país como Colombia, significa avanzar en temas de investigación, que aporten a la disminución de consumo de energético, emisiones y que conduzcan acciones para mejorar la eficiencia energética no solo desde las políticas energéticas del sector de las edificaciones, sino también desde la normativa. De igual modo compromete el monitoreo permanente de indicadores de desempeño energético, que nos permitan una información en la gestión del consumo energético en las edificaciones sostenibles.

El objetivo de este trabajo de investigación consiste en estudiar Herramientas de gestión energética para el desarrollo sostenible en edificaciones aplicado a un campo en Colombia. a través de una metodología que permite evaluar e integrar indicadores de desempeño energético según la disponibilidad de medición y la incorporación de elementos de simulación, que puedan incorporarse a un sistemas de gestión energética brindando elementos metodológicos que permitar estimar líneas bases e indicadores energéticos 
acorde a las condiciones operativas de las edificaciones y con un nivel de precisión que posibilite tener certeza de los ahorros estimados y metas energéticas proyectadas mediante la validación estadística. Siendo un aporte para quienes administran o hacen seguimiento energético en una edificación. De igual forma constituye una contribución a organismos normativos como la ISO o UNE en lo concerniente a implementación de líneas bases e indicadores energéticos elementos importante para implementar un sistema de gestión en una edificación. 


\section{BIBLIOGRAFÍA}

[1] PNUMA, "Building and Climate Change", Paris, 2009.

[2] PNUMA, "Greening the Building supply chain. Sustainable Building \& Climate Initiative", Paris, 2014.

[3] United Nations, "World Urbanization Prospects: The 2014 Revision", 2014.

[4] International Energy Agency, "World Energy Outlook 2017", 2018.

[5] BP Energy, "BP Energy Outlook | Economia energetica”, 2018.

[6] Exxon Mobil Corporation, "2017 Outlook for Energy", 2016. [En línea]. Disponible en: http://cdn.exxonmobil.com/ /media/global/files/outlook-for-energy/2017/2017outlook-for-energy.pdf.

[7] I. International Energy Agency, "Energy Technology Perspectives 2012. Pathways to a Clean Energy System", Paris, 2012.

[8] International Energy Agency, "Global Status Report 2017 United Nation Environment and International Energy Agency: Towards a zero-emission, efficient, and resilient buildings and construction sector", 2017.

[9] International Energy Agency, "Building Energy Efficiency Policies", 2018. [En línea]. Disponible en: https://www.iea.org/beep/. [Consultado: 16-jul-2018].

[10] International Energy Agency, "Building Energy Efficiency Policies". [En línea]. Disponible en: https://www.iea.org/beep/.

[11] Building Energy Research Center y Tsinghua University, "China Building Energy Use 2016", Tsinghua, 2016.

[12] IEA; BERC, "Transforming Construction and Influencing Consumption to 2050", Beijing, 2015.

[13] Li, "Report on the Work of the Government 2016", Beijing, 2016.

[14] NBS, "China Statistical Yearbook on Construction 2015", Beijing, 2015.

[15] IEA, "Indicadores de Eficiencia Energética: Bases Esenciales para el Establecimiento de Políticas", Agencia Int. Energía, p. 182, 2015.

[16] State Council, “Energy Development Strategy Action Plan”, Beijing, 2014.

[17] State Council, "National Plan on New Urbanisation for 2014 to 2020", Beijing, 2014.

[18] E. OFFICE OF ENERGY EFFICIENCY \& RENEWABLE ENERGY, "Estrategic goals 2016 2020 in US", Washington, 2015.

[19] Comisión Europea, "Unión Europea en Datos", 2017.

[20] Organización Latinoamericana de Energía, "Participación del Consumo Final por Energético y Sectores: América Central", 2018. [En línea]. Disponible en: http://sier.olade.org/consultas/tablero-participacion-consumo-energerticosectores.aspx?or=603\&ss=2\&v=3. [Consultado: $16-j u l-2018]$.

[21] J. Marczak, P. Engelke, D. Bolh, y A. Saldarriaga-Jiménez, “América Latina y el Caribe 2030 : Escenarios futuros", 2016.

[22] IEA, "Latin America Roadmap for Buildings and Construction 2020-2050", 2019.

[23] DANE y Ministerio de Minas y Energía, "PIB anual en precios constantes (tercer trimestre 2017). El cálculo corresponde a la Tasa de Crecimiento Anual Compuesta 
(TCAC) entre el acumulado doce meses con corte al tercer trimestre de los años 2001 y 2017.", 2018. [En línea]. Disponible en: http://www1.upme.gov.co/DemandaEnergetica/MarcoNormatividad.

[24] Consejo Nacional de Política Económica y Social - CONPES, Política Nacional De Edificaciones Sostenibles CONPES 3919. Bogotá, 2018.

[25] República de Colombia, Conpes 3700 - ESTRATEGIA INSTITUCIONAL PARA LA ARTICULACIÓN DE POLÍTICAS Y ACCIONES EN MATERIA DE CAMBIO CLIMÁTICO EN COLOMBIA. 2011, p. 75.

[26] Ministerio de Vivienda Ciudad y Territorio, Resolución 0549 de 2015. Colombia, 2015, p. 9.

[27] Ministerio de Vivienda Ciudad y Territorio, Anexo 1. Guía de construcción sostenible para el ahorro de agua y energía en edificaciones. Bogotá, Colombia, 2015, p. 89.

[28] República de Colombia, Conpes 3718 - Política Nacional de Espacio Público. 2012, p. 41.

[29] Consejo Colombiano de Construcción Sostenible - CCCS, "Referencial CASA Colombia". [En línea]. Disponible en: https://www.cccs.org.co/wp/referencial-casacolombia/.

[30] U.S. Green Building Council, "Projects LEED". [En línea]. Disponible en: https://www.usgbc.org/projects/.

[31] Consejo Colombiano de Construcción Sostenible (CCCS), “Programa LEED ${ }^{\circledR}$ en Colombia". [En línea]. Disponible en: https://www.cccs.org.co/wp/capacitacion/talleres-de-preparacion-leed/.

[32] BREEAM, "BREEAM: el método de evaluación de sostenibilidad líder en el mundo para proyectos de planificación maestra, infraestructura y edificios - BREEAM". [En línea]. Disponible en: https://www.breeam.com/.

[33] "Noticias I PRODESA". [En línea]. Disponible en: http://www.prodesa.com/noticias/piamonte-prodesa-obtuvo-certificado-hqe/.

[Consultado: 16-jul-2019].

[34] Agencia Nacional Inmobiliaria Virgilio Barco Vargas y Presidencia de la República, "Informe de Sostenibilidad del primer Edificio del Centro Administrativo Nacional", 2017.

[35] Consejo Colombiano de Construcción Sostenible - CCCS, "Primer Colegio con Estandares LEED en Yumbo", 2016. [En línea]. Disponible en: https://www.cccs.org.co/wp/2016/06/07/en-yumbo-se-construye-el-primercolegio-publico-con-estandares-leed/.

[36] DANE, "Gran Encuesta Integrada de Hogares (serie trimestre móvil 01-17 con corte a diciembre). Incluye obras civiles.", 2017.

[37] Ideam y UPME, "Inventario Nacional y Departamental de Gases Efecto Invernadero Colombia”, 2016. [En línea]. Disponible en: http://documentacion.ideam.gov.co/openbiblio/bvirtual/023634/INGEI.pdf.

[38] Ministerio de Minas y Energía y Unidad de Planeación Minero Energética, "Plan de Acción Indicativo de Eficiencia Energética PAI-PROURE 2017 - 2022", Bogotá, 
Colombia, 2016.

[39] Ideam, “Estudio Nacional del Agua 2014", Bogotá, 2014.

[40] UPME, "Evaluación de la situación actual y futura del mercado de los materiales de construcción y arcillas en las ciudades de Bogotá, Medellín, Bucaramanga, Barranquilla, Santa Marta y eje cafetero", Bogotá, 2014.

[41] Alcaldia Santiago de Cali, "Cali recibirá cooperación internacional para el Manual de Construcción Sostenible", 30 Mayo 2019, 2019. [En línea]. Disponible en: https://www.cali.gov.co/gobierno/publicaciones/147691/cali-recibira-cooperacioninternacional-para-el-manual-de-construccion-sostenible/. [Consultado: 21-may2020].

[42] Consejo Colombiano de Construcción Sostenible - CCCS, "Lanzamiento de las estrategias nacional y sub-nacional de eficiencia energética en edificaciones para ciudades BEA en Colombia - Consejo Colombiano de Construcción Sostenible CCCS", Mayo 27 de 2019, 2019. [En línea]. Disponible en: https://www.cccs.org.co/wp/2019/05/27/lanzamiento-de-las-estrategias-nacionaly-sub-nacional-de-eficiencia-energetica-en-edificaciones-para-ciudades-bea-encolombia/. [Consultado: 21-may-2020].

[43] DAGMA y Alcaldia Santiago de Cali, "Manual de Construcción Sostenible para el área urbana de Santiago de Cali", Cali, 2019.

[44] Alcaldia Santiago de Cali, Resolución 1529 del 24 de diciembre de 2019. Colombia, 2019, p. 7.

[45] J. H. Wilson y B. Keating, Pronósticos para los negocios con ForecastX basado en inglés, 5a ed. Ciudad de México: McGraw-Hill Interamericana, 2007.

[46] Ministerio de Fomento, Documento de bases para la actualización del Documento Básico DB-HE. España, 2016, p. 13.

[47] UPME, "BALANCE ENERGETICO COLOMBIANO - BECO”. [En línea]. Disponible en: https://www1.upme.gov.co/InformacionCifras/Paginas/BalanceEnergetico.aspx.

[Consultado: 07-may-2020]. 


\section{CAPÍTULO 2: SISTEMA DE GESTIÓN ENERGÉTICA. HERRAMIENTAS DE LA PLANIFICACIÓN ENERGÉTICA}

En este capítulo se describe la importancia de un sistema de gestión energética SGEn y la relación que se tiene con aspectos normativos. De igual forma se describen las herramientas y técnicas utilizadas para el desarrollo de los procesos de planificación energética y algunos de los componentes más significativos, como es el caso de la revisión energética y aspectos descriptivos en lo que se refiere a los conceptos de líneas de base e indicadores energéticos y su aporte en el mejoramiento de la eficiencia energética en edificaciones.

Algunos antecedentes de aplicación de la norma en distintos sectores señalan que las Investigaciones actuales se centran en estudios relacionados al desempeño y la gestión energética, basados en la norma ISO 50001. Se estima que la norma ISO 50001, aplicada a los distintos sectores económicos, podría influir en un ahorro de hasta un $60 \%$ en el consumo de energía del mundo [1]. La reducción de este consumo de energía es fundamental para que los países logren sus compromisos nacionales e internacionales de reducción de gases de efecto invernadero [2].

La gestión energética se ha convertido en pieza clave para el desarrollo del sector industrial como un enfoque estructurado para reducir el costo de producción y reducir la huella de carbono. Con el desarrollo del estándar ISO 50001, la gestión de la energía ha atraído la atención del nivel superior de gestión en términos de mejora continua, como lo establece Kanneganti et al. [3]. En cuanto a la implementación de los lineamientos de la norma, Gopalakrishnan et al. [4] desarrolló una herramienta de software que facilita el desarrollo de un sistema de gestión de energía compatible con ISO 50001 . El software está diseñado para ser una guía de referencia para consultores de gestión de energía para ayudar a las plantas de fabricación a comprender y cumplir con los requisitos de la norma ISO 50001.

McKane et al. [2] presenta una metodología para establecer los impactos de la implementación de la norma ISO 50001, para ello ,se estudió un caso proyectado a 2030 bajo un escenario del $50 \%$ del consumo mundial de energía para el sector industrial y de servicios con gestión de la norma ISO 50001, generaría ahorros de energía primarios acumulados de aproximadamente 105 EJ, ahorros de costos económicos de casi US \$700 mil millones, y la reducción de 6500 millones de toneladas métricas (Mt) de emisiones de CO 2 evitadas. Casos de desarrollos y estudios aplicados presentan información valiosa de la implementación de la norma en distintas partes del mundo, Benedetti et al. [5] presenta una metodología para gestionar el rendimiento energético mediante el desarrollo, análisis y mantenimiento de indicadores de rendimiento energético en plantas de fabricación ,teniendo en cuenta los requisitos de ISO 50001: 2011 e ISO 50006: 2014, la metodología propuesta permite una identificación inmediata de las desviaciones de rendimiento energético de la planta de fabricación a través del monitoreo de los Indicadores de 
rendimiento energético a lo largo del tiempo y la identificación de posibles causas y responsabilidades de dichas desviaciones. Pelser et al. [6] desarrolló e implementó un informe de rendimiento energético automatizado que abarca la verificación de la planificación de la norma ISO 50001 en una planta sudafricana, donde el costo de energía eléctrica se redujo en un $25 \%$. Las consultas cualitativas confirmaron que el sistema promueve la implementación de las prácticas de gestión ISO 50001, permite monitorear el rendimiento energético de los equipos y mejorar continuamente las operaciones. Bonacina et al. [7] ilustró el estado de implementación de las certificaciones ISO 50001 en Italia, el panorama general muestra que Italia, uno de los países líderes en políticas de eficiencia energética, sufre una demora significativa en la implementación de los EnMS en la industria.

La definición de indicadores de rendimiento energético, el establecimiento de líneas de base energética y un plan de monitoreo constituyen los requisitos más críticos para el cumplimiento de las empresas. Aproximadamente el 35\% de las empresas certificadas en ISO 50001 han recibido beneficios en términos de ahorro de energía por encima del 5\%, lo que aumenta la competitividad de la empresa. Jovanović et al. [8] estudió la implementación de la norma ISO 50001 en 52 empresas de los sectores industriales prioritarios en serbia y establecido el nivel de cumplimiento de las empresas para cada etapa de la norma. En general el cumplimiento es del 59,05\%, los resultados del estudio ofrecieron datos científicos para mejorar la política nacional y la educación sobre la gestión de la energía en Serbia.

Además de la implementación de la norma y sus casos exitosos en cuanto a los sistemas de gestión y ahorros energéticos, es importante conocer los estudios realizados sobre los factores. Da Silva y Mil-Homens [9] realizan una evaluación sobre la efectividad al implementar la norma ISO 50001 desde el punto de vista del desarrollo sostenible, las brechas encontradas y las mejoras capaces de satisfacer dichas brechas. Posteriormente los resultados encontrados fueron propuestos a 146 expertos en SGEn quienes por medio de encuestas opinaron y validaron el estudio llevado a cabo con una concordancia positiva del 64,4\%. Cooremans y Schonenberger [10], presentan el proyecto de investigación "La gestión como motor clave del rendimiento energético" donde se buscaba comprender cómo las empresas de consumo de energía a gran escala en Suiza toman decisiones de inversión en eficiencia energética. Se encontró que cuando la eficiencia energética se percibe como estratégica, las empresas tienden a tener un alto nivel de gestión energética. Cuanto mejor sea el sistema de gestión de energía, mayores serán las posibilidades de una decisión positiva sobre la inversión en eficiencia energética. La investigación desarrollada por Sousa et al. [11] caracterizó el proceso de difusión de la norma ISO 50001 en todo el mundo y estableció los principales factores que determinan la adopción de EnMS en las diferentes regiones del planeta, teniendo en cuenta el número de certificaciones e indicadores ambientales, energéticos, sociales, económicos, y cambio climático. Se observó que Europa tiene el mayor número de certificaciones ISO 50001 y Asia es la región de más 
rápido crecimiento. Alemania y el Reino Unido son los países con mayor difusión de ISO 50001.

\subsection{IMPORTANCIA DE UN SISTEMA DE GESTIÓN ENERGÉTICA SGEn}

La mayor importancia de un SGEn consiste en lograr el uso eficiente y eficaz de la energía, consiguiendo reducir los costes de producción en la industria y de servicios en las edificaciones, aumentando las ganancias y alcanza una mejora la posición competitiva de las empresas.

La Gestión Energética ha ido obteniendo cada vez más importancia a nivel mundial, pues además de aumentar las utilidades de la empresa, permite reducir las emisiones de $\mathrm{CO} 2$, contribuyendo a evitar el cambio climático; así, actualmente se constituye en una parte imprescindible de la gestión empresarial. La importancia estratégica de la gestión energética es reconocida por la Norma ISO 50001 Energy Management Systems, que declara que su implementación es un tema estratégico y debe ser tratado por los niveles más altos de la organización. Esto significa que un SGEn es un subsistema que debe de integrarse a los otros Sistemas de Gestión Empresarial (Sistema de Gestión de Calidad, Sistema de Gestión ambiental, Sistema de Higiene y Seguridad Industrial, etc.). Así, cuando el SGE es una parte del Sistema Integrado de Gestión de la empresa, la organización concibe a la eficiencia energética como el logro de los requisitos establecidos por el cliente con el menor gasto energético posible y la mínima contaminación ambiental.

Son muchos los beneficios que la implementación de un SGE aporta a la empresa, entre ellos están:

$\checkmark$ Organizar las áreas de la empresa con el objetivo de medir, controlar y reducir el gasto energético.

$\checkmark$ Conocer los procesos y puntos claves de ahorro y gasto.

$\checkmark$ Establecer la Línea de Base Energética de cada proceso, para planificar y fijar metas reales en la reducción del consumo energético.

$\checkmark$ Identificar las variables que afectan la eficiencia del proceso, y generar procedimientos de actuación sobre las mismas.

$\checkmark$ Establecer y monitorear los indicadores de desempeño energético de los procesos.

$\checkmark$ Identificar las mejores prácticas operacionales y convertirlas en hábitos.

$\checkmark$ Asegurar la conformidad del SGE con la política de la empresa.

$\checkmark$ Reducir la contaminación ambiental (al disminuir las emisiones de CO2), lo que además mejora la imagen de la compañía. 
$\checkmark$ Cultivar buenas comunicaciones sobre el tema de la energía, desarrollando interés y dedicación en todos los empleados hacia el programa de gestión de la energía.

$\checkmark$ Posibilidad de obtener la certificación de la ISO 50001, la ISO 14001 y el reconocimiento asociado.

$\checkmark$ Identificar y aplicar medidas de cambios tecnológicos de baja, media y alta inversión.

$\checkmark$ Tener procedimientos de planeación y coordinación operacional de la producción para minimizar el consumo energético.

$\checkmark$ Tener herramientas para hacer benchmarking del índice de consumo y costo de la energía.

$\checkmark$ Reducir el impacto de reducciones totales o parciales, o cualquier interrupción en el suministro de energía.

$\checkmark$ Aprovechar las oportunidades de exoneración tributaria por participación en programas de Investigación, Desarrollo e Innovación, I+D+i, sobre eficiencia energética.

\subsection{DESARROLLO DE UN SGEn Y DE LA NORMA ISO 50001}

La tendencia que se impuso a nivel mundial con el objetivo de avanzar hacia la eficiencia energética en el sector industrial y de servicios en edificios, fue la implementación de los SGEn. Así, desde el año 1982, muchos países habían adoptado normas nacionales de gestión energética. Entre los países pioneros en esta tendencia, tenemos a Japón, Corea, Australia, Canadá, China, USA (con la MSE 2000), Dinamarca, Suecia, Holanda, etc. En Colombia, en el 2007 se propuso el Sistema de Gestión Integral de la Energía -SGIE- y una norma de gestión energética, y en el 2009 se formó el Comité Técnico 228 Gestión Energética de Icontec. El resultado más destacado, en este proceso global, se logró cuando representantes de procesos de normalización y expertos en políticas energéticas de los cinco continentes, acordaron la formulación de una norma internacional, la ISO 50001 (Energy Management Systems), publicada oficialmente en el 2011. Reconociendo la necesidad de adaptarla a los contextos tecnológicos, socioculturales y económicos de cada país, esta Norma se constituye en el marco definitivo para la aplicación de los SGEn. Actualmente Desde el pasado 20 de agosto de 2018 se publicó la nueva versión de la ISO 50001, sistema de gestión energética. Esta versión que suple a la anterior de 2011, presenta cambios orientados a ayudar a desarrollar e implementar prácticas con el fin de conseguir una mejora en el desempeño energético y un aumento de la eficiencia energética, puesto que presenta un mayor énfasis en la responsabilidad del liderazgo, aclara conceptos clave relacionados con el rendimiento energético, y favorece la compatibilidad con ISO 14001, ISO 9001, y otros estándares del sistema de gestión ISO [12].

En la Figura 33 se presenta el desarrollo de las normas de sistemas de gestión a nivel mundial. 


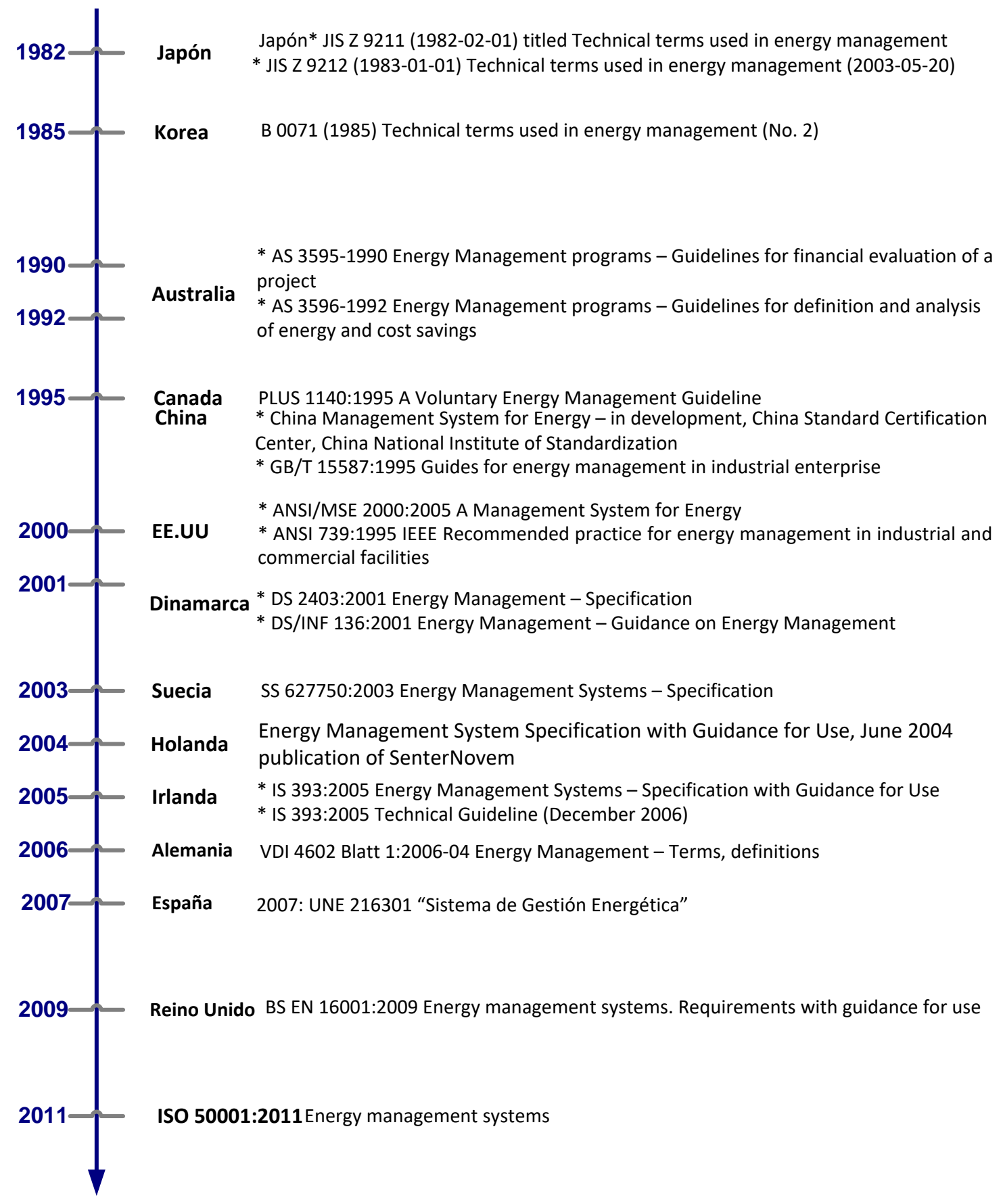

Figura 33. Desarrollo de las normas de un SGEn a nivel mundial

Fuente: ISO 50001: avanzando hacia la implementación de la norma internacional

A continuación, se presenta en la Tabla 2 el impacto que ha tenido la implementación de la norma ISO 50001 desde su publicación en 2011, así como también el crecimiento en relación con otros sistemas de gestión. De igual forma se presenta un gráfico donde evidencia la participación de $84,60 \%$ de Europa en estas certificaciones, seguido de Asia 
Oriental y el Pacifico, Centro y sur de Asia, Medio Oriente, Centro y sur América, Norte América y África.

Se identifican los 10 primeros países a nivel mundial que más han crecido en certificaciones (SGEn).

Tabla 2. Evolución de la aplicación de la norma ISO50001 desde su publicación en 2011

\begin{tabular}{|l|c|c|c|c|}
\multicolumn{1}{|c|}{ Estandar ISO } & $\mathbf{2 . 0 1 6}$ & $\mathbf{2 0 1 7}$ & $\mathbf{2 0 1 8}$ & $\mathbf{2 0 1 9}$ \\
\hline ISO 9001:2015 & 1.105 .937 & 1.058 .504 & 878.664 & 883.521 \\
\hline ISO 14001:2015 & 346.147 & 362.610 & 307.059 & 312.580 \\
\hline ISO 50001:2011\&2018 & 20.216 & 21.501 & 18.059 & 18.227 \\
\hline ISO 27001:2013 & 33.290 & 39.501 & 31.910 & 36.362 \\
\hline ISO 22000: 2005\&2018 & 32.139 & 32.722 & 32.120 & 33.502 \\
\hline ISO 13485:2003\&2016 & 29.585 & 31.520 & 19.472 & 23.045 \\
\hline ISO 22301:2012 & 3.853 & 4.281 & 1.506 & 1.693 \\
\hline ISO 20000-1:2011 & 4.537 & 5.005 & 5.308 & 6.047 \\
\hline ISO 28000:2007 & 356 & 494 & 617 & 1.874 \\
\hline ISO39001:2012 & 478 & 620 & 547 & 864 \\
\hline ISO 37001: 2016 & 0 & 0 & 389 & 872 \\
\hline ISO 45001:2018 & 0 & 0 & 11.952 & 38.654 \\
\hline \multicolumn{1}{|c|}{ Total } & $\mathbf{1 . 5 7 6 . 5 3 8}$ & $\mathbf{1 . 5 5 6 . 7 5 8}$ & $\mathbf{1 . 3 0 7 . 6 0 3}$ & $\mathbf{1 . 3 5 7 . 2 4 1}$ \\
\hline
\end{tabular}

Fuente: The ISO Survey of Management System Standard Certifications - Explanatory Note- 2016 to 2019

\begin{tabular}{|c|c|c|}
\hline \multicolumn{3}{|c|}{ Certificados ISO 50001} \\
\hline Año & Sitios & Certificaciones \\
\hline $\mathbf{2 0 1 1}$ & 634 & 459 \\
\hline $\mathbf{2 0 1 2}$ & 2.120 & 2236 \\
\hline $\mathbf{2 0 1 3}$ & 3.471 & 4826 \\
\hline $\mathbf{2 0 1 4}$ & 6.914 & 6765 \\
\hline $\mathbf{2 0 1 5}$ & 20.562 & 11985 \\
\hline $\mathbf{2 0 1 6}$ & 23.377 & 20.216 \\
\hline $\mathbf{2 0 1 7}$ & 22.870 & 21.501 \\
\hline $\mathbf{2 0 1 8}$ & 46.769 & 18.059 \\
\hline $\mathbf{2 0 1 9}$ & 42.215 & 18.227 \\
\hline
\end{tabular}

Número de certificaciones ISO 50001: 2011 \& 2018 25000

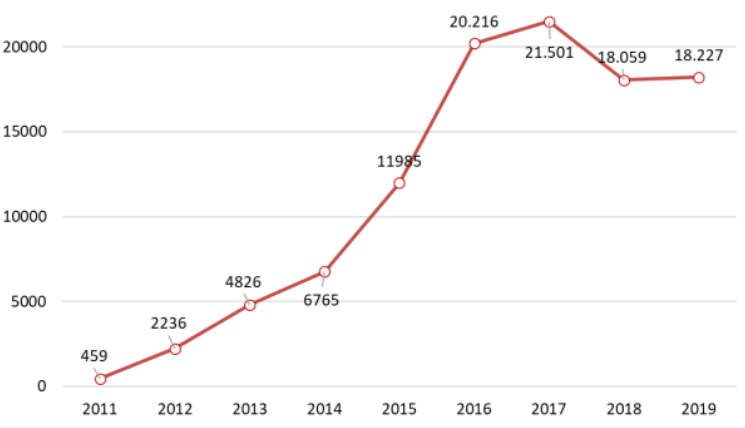

10 primeros paises con mayor numero de certificaciones ISO 50001 en el

10 primeros paises de América con mayor número de certificaciones ISO 50001.
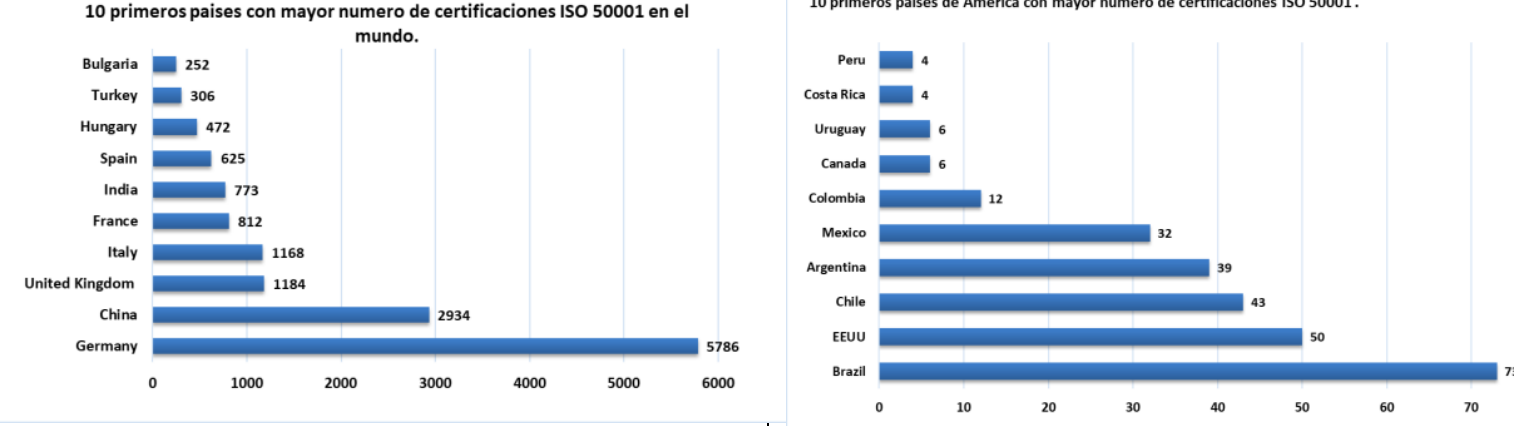


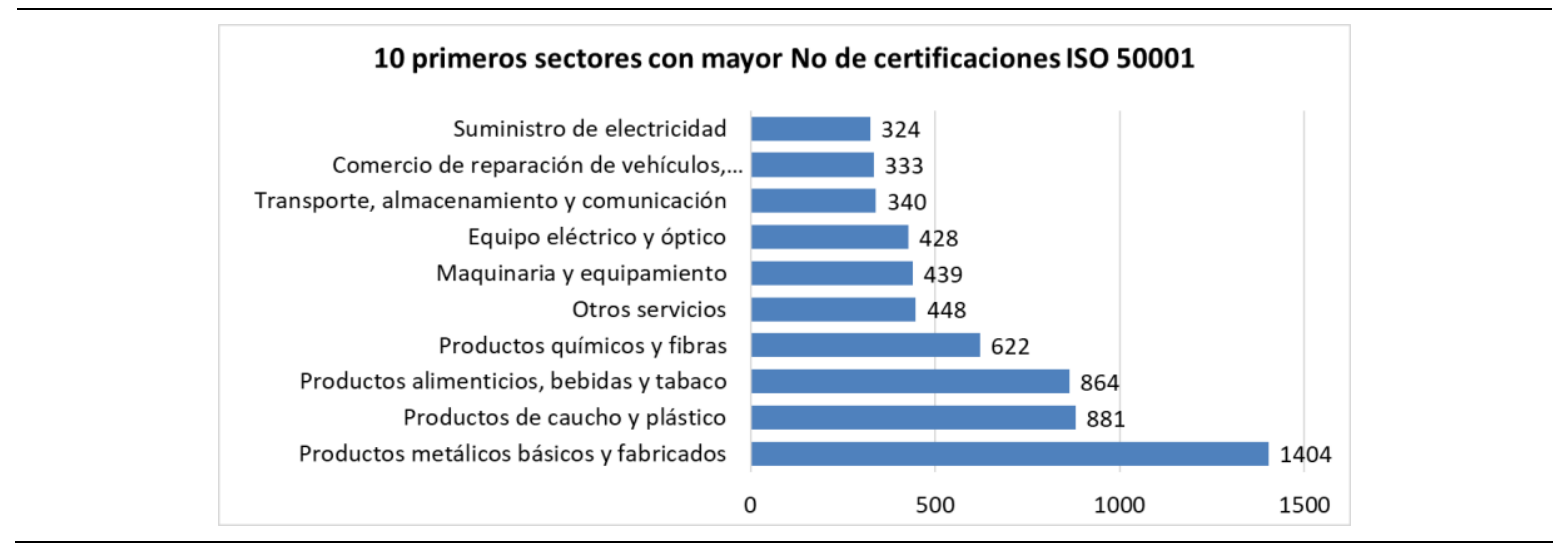

Fuente: The ISO Survey of Management System Standard Certifications - Explanatory Note- 2016 to 2019

\subsection{ESTRUCTURA DE LOS SGEn SEGÚN LA NORMA ISO 50001}

La norma internacional ISO 50001 [13] define los requisitos generales para la estructura operativa y organizativa de un SGEn, lo cual parte de la identificación de la situación actual del consumo energético de los equipos, sistemas o procesos de una organización, en relación con la producción o los servicios realizados. Ello se obtiene mediante la implementación de una línea de base energética e indicadores de desempeño energético en los usos significativos de la energía, así como el análisis de las variables de control que deben ser monitoreadas para lograr la mejora en la eficiencia energética.

Esta norma ha sido desarrollada sobre la base de los elementos comunes que se encuentran en todas las normas de gestión ISO, tales como la gestión de la calidad (ISO 9001), o la gestión ambiental (ISO 14001); por tanto, es posible implementarla en cualquier tipo de organización, independientemente de su tamaño, su función o la ubicación geográfica.

La ISO 50001 requiere de la definición de políticas y planes de acción; la introducción de requisitos de eficiencia energética, en cuanto al diseño, la compra y la instalación de equipos; el conocimiento y monitoreo del marco legal y regulatorio energético vigente aplicable a la organización, además del control operacional de la eficiencia energética y la incorporación de todos estos elementos en el modelo de gestión empresarial.

La estructura misma de la norma se complementa e integra a todos los procesos y sistemas de gestión de la organización, para obtener una mejora continua en el uso de la energía, un consumo eficiente y una reducción en los costos financiero-asociados. Lo anterior, con el fin de lograr las metas de incremento de productividad y reducción del impacto ambiental de la organización. 
La Norma ISO 50001:2108 se basa en el ciclo de mejoramiento continuo, Planear-HacerVerificar-Actuar (PHVA), e incorpora la gestión energética a las prácticas habituales tal como lo enseña la Figura 34.

El enfoque del modelo de la norma se puede describir de la siguiente manera:

Planificar : Entender el contexto de la organización, establecer una política energética y un equipo de gestión de energía, considerar las acciones para hacer frente a los riesgos y oportunidades, realizar una revisión energética, identificar los usos significativos de la energía (USE) y establecer los indicadores de desempeño energético (IDEn), las líneas de base energéticas (LBEn), los objetivos, las metas energéticas y los planes de acción necesarios para lograr los resultados que mejorarán el desempeño energético de acuerdo con la política energética de la organización.

Hacer: implementar planes de acción, controles operacionales y de mantenimiento y comunicaciones, garantizar la competencia y considerar el desempeño energético en el diseño y las adquisiciones.

Verificar: realizar las acciones de seguimiento, medición, análisis, evaluación, auditoría y revisión(es) por la dirección del desempeño energético y del SGEn.

Actuar: tomar medidas para solucionar las no conformidades y mejorar en forma continua el desempeño energético y el SGEn.

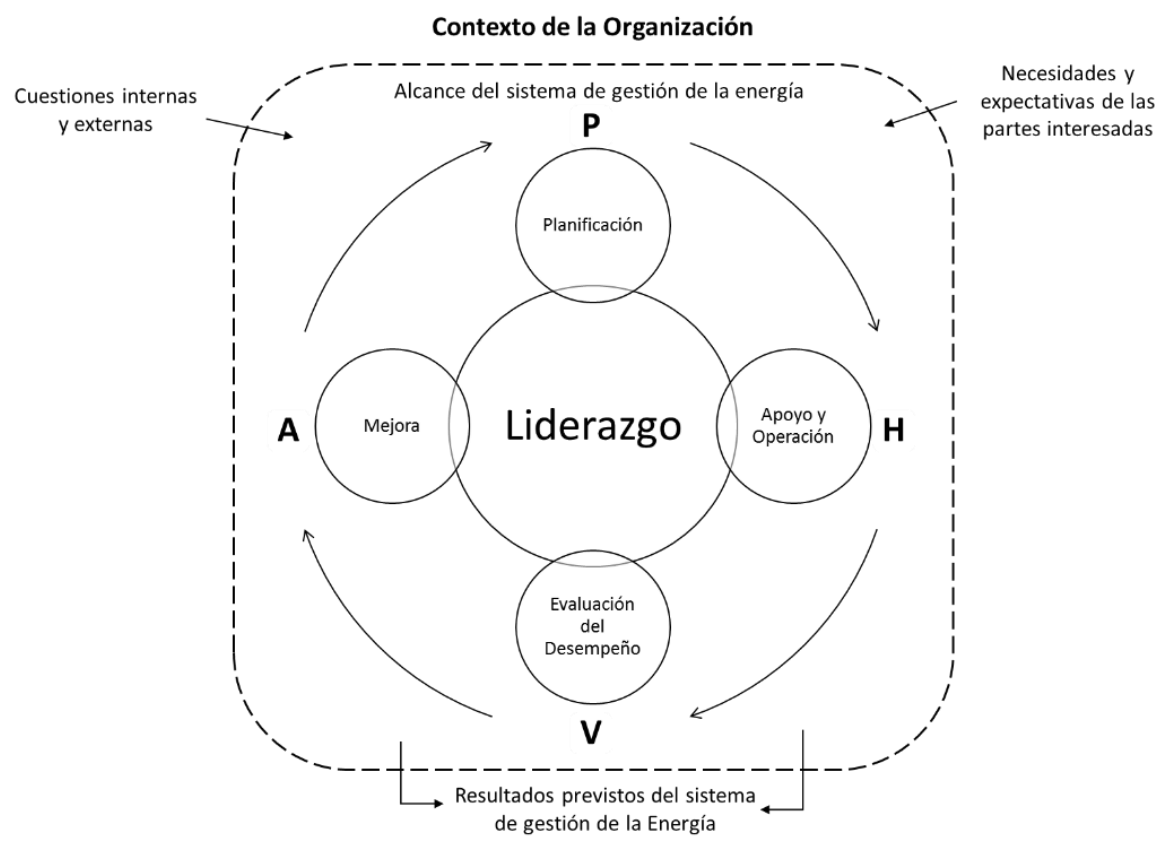

Figura 34. Ciclo de Mejora Continua PHVA norma ISO 50001:2018

Fuente: ISO 50001:2018 
La Figura 35 presenta algunas de las consideraciones y cambios más importantes que tuvo la norma ISO 50001 versión 2018 con respecto a la primera edición del año 2011.

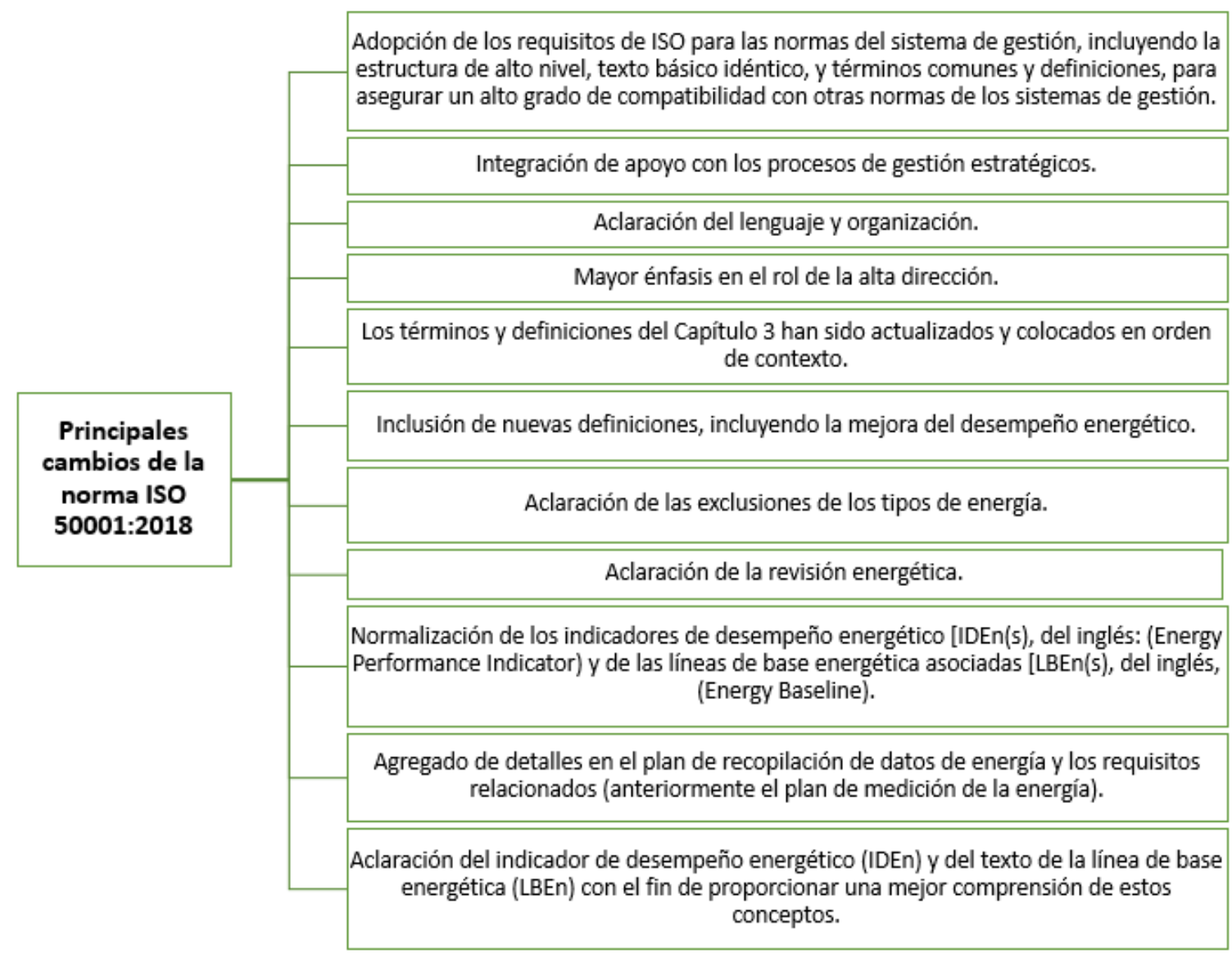

Figura 35. Cambios principales norma ISO 50001:2018 con respecto a la ISO 50001:2011

Fuente: ISO 50001:2018

En cuanto a los términos y definiciones

La versión nueva de la ISO 500012019 incluyó 5 subcapítulos donde se agrupan los términos y definiciones según se muestran en la Figura 36. 


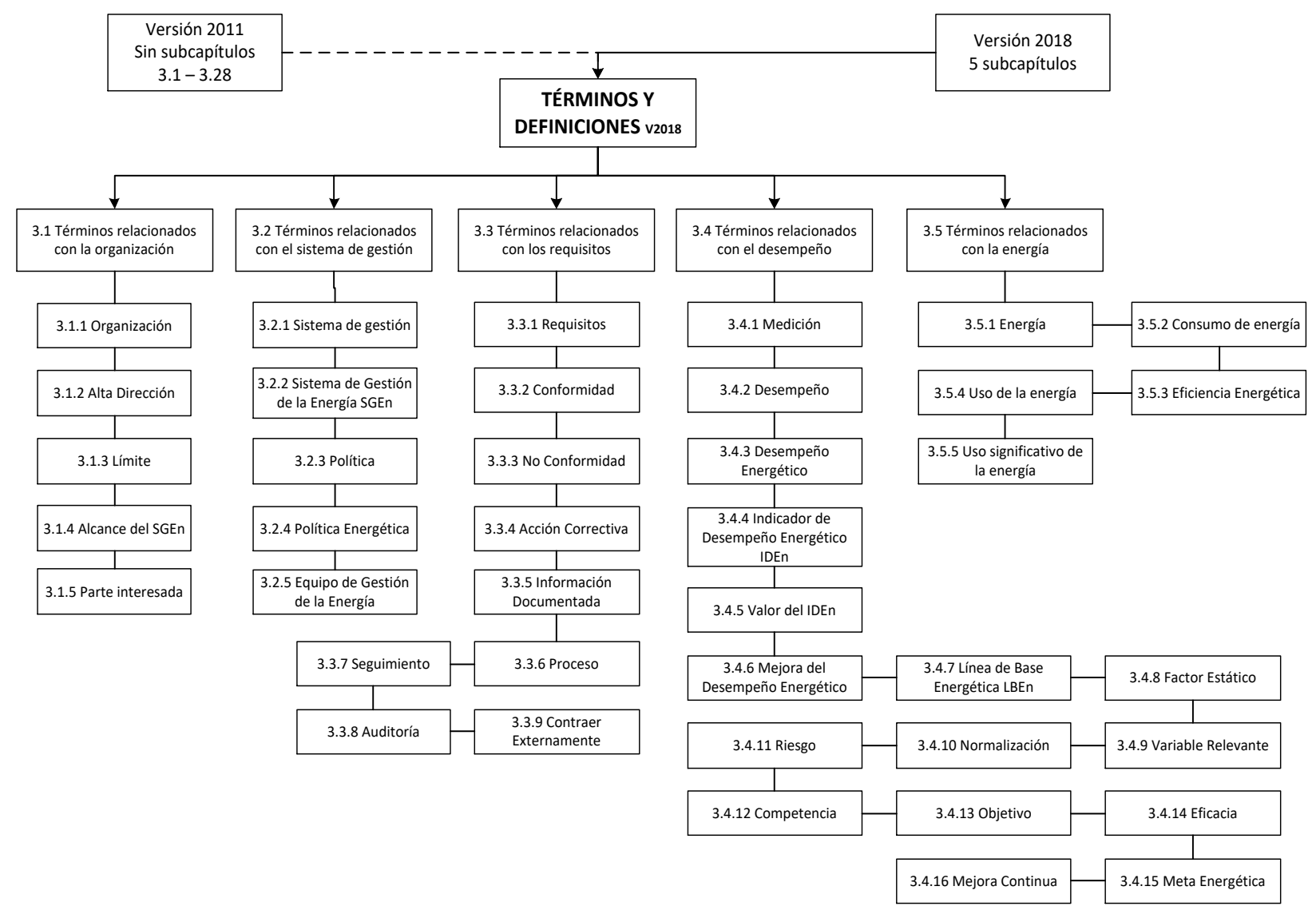

Figura 36. Términos y definiciones de la nueva versión de la ISO 50001 :2018

\section{La estructura genérica considerada por la ISO contempla los siguientes aspectos:}

- Objeto y campo de aplicación.

- Referencias normativas.

- Términos y definiciones.

- Entender el contexto de la organización, su SG y sus procesos.

- Liderazgo, política y responsabilidades.

- Procesos para la planificación y consideración de riesgos y oportunidades.

- Procesos para el apoyo, incluyendo recursos, a las personas y la información.

- Procesos operativos relativos a los clientes y a los productos y servicios.

- Procesos para la evaluación del desempeño.

- Procesos para la mejora. 


\section{Aspectos de Riesgos y Liderazgo}

Uno de los aspectos más importantes para la implementación de un sistema de Gestión de la energía, es el compromiso y liderazgo que debe garantizar la alta dirección para la implementación, mantenimiento y mejora continua. Cuando se decide implementar un SGEn, la alta dirección adquiere un conjunto de compromisos que se relacionan con requisitos independientes de la norma ISO 50001. Estos aspectos deben ser de dominio de la alta dirección, quien debe aprobar y realizar revisiones de cada uno de ellos. Para dar cumplimiento a estos compromisos la alta dirección debe designar las responsabilidades necesarias dentro de las cuales resulta importante la asignación de un gestor energético para liderar el proceso de implementación, así como un equipo de gestión de la energía. El compromiso de la alta dirección se sintetiza en una política energética y se refleja en la designación de roles, responsabilidades y autoridades en la organización. La alta dirección debe tener en cuenta que con el compromiso de implementar el SGE también adquiere el compromiso de asignación de recursos materiales y humanos. En este sentido, un sistema de gestión debe integrar armoniosamente procesos, personas, recursos y métodos de manera coherente, para lograr los propósitos fundamentales y los objetivos estratégicos del éxito sostenible.

No obstante, las normas ISO que establecen requisitos y recomendaciones para los componentes de un sistema de gestión están justificadas, puesto que permiten la transferencia de tecnología, mediante la cual se pueden promover, difundir y exigir buenas prácticas en las organizaciones, tanto a nivel estratégico como operativo de los procesos y proyectos. De esta manera, la tecnología ayuda a reducir la vulnerabilidad y mejorar el rendimiento de la organización.

Las buenas prácticas se centran principalmente en la creación y protección de valor, basadas en la gestión de planificación y control en los niveles estratégicos y operativos de la organización. Las buenas prácticas que respaldan las normas ISO sobre sistemas de gestión se basan en riesgos; en este contexto, la gestión de riesgos significa la anticipación y el control de lo que puede y debe ocurrir en los procesos y la práctica empresarial.

La gestión de riesgos debe esforzarse por cumplir con los objetivos, propósitos y compromisos estratégicos asociados con los proyectos, procesos, productos y servicios.

La gestión de riesgos implica la toma de decisiones estratégicas sobre la dirección de negocios e instituciones, decisiones en la planificación y desarrollo de proyectos, decisiones en la gestión de procesos, productos y servicios, y decisiones en la interacción de las personas con su entorno y partes interesadas

El ciclo del proceso de gestión de riesgos es similar al de las oportunidades y debe implementarse de forma regular y sistemática. Dependiendo de su tema o naturaleza, cada riesgo se gestiona en diferentes niveles. Especialmente, cada riesgo requiere tiempo para 
recopilar y analizar la información, para tomar decisiones y para planificar, ejecutar, retroalimentar y completar con éxito las acciones requeridas para la gestión efectiva del riesgo u oportunidad. [14]

Otros elementos incluidos en esta nueva versión se relacionan con los términos variables relevantes y factores estáticos como elementos que contribuyen a identificar aspectos que pueden afectar el desempeño energético de una organización.

\section{Variables relevantes y factores estáticos}

La identificación de variables relevantes es una tarea necesaria en la revisión energética para posteriormente el desarrollo de indicadores de desempeño energético, líneas de base energética y para el seguimiento al desempeño energético del SGEn. Por su parte los factores estáticos representan un concepto esencial y oportuno para entender cuándo deben realizarse actualizaciones de las líneas de base energética y abordar otras decisiones del SGEn [13].

\section{Variables relevantes}

Las variables relevantes son aquellas que impactan significativamente en el desempeño energético y cambian de forma rutinaria. Las mismas se refieren a parámetros operacionales, actividades de mantenimiento, eventos o actividades de planeación de la producción, que cambian en la operación cotidiana de la organización y cuya su variación produce cambios significativos en el consumo de energía.

Las fuentes de identificación de estas variables pueden ser: los instructivos de operación; los instructivos de mantenimiento; los procedimientos operacionales y de mantenimiento; los manuales de operación de equipos; los programas de mantenimiento de los equipos; los programas de producción; la experiencia de los operadores, mantenedores y planeadores de la producción.

Pueden ser variables relevantes para un USE: la producción; ocupación; condiciones operacionales (tipos de agrupamiento de equipos, presión, temperatura, velocidad, viscosidad, rpm, relación aire/combustible, tiempos de cambio de producto, tiempos de arranque, paradas, reprocesos, regímenes de operación, cantidad de purgas al día, planeación de la producción, etc.); condiciones climáticas (grados día de temperatura, humedad relativa, presión ambiente, polución, densidad); condiciones de mantenimiento (frecuencia de limpieza, lubricación, frecuencia de inspecciones, ajustes, tiempos de cambio de partes y piezas, confiabilidad, disponibilidad) [15].

Pueden existir muchas variables que al cambiar produzcan cambios en el consumo de energía, para se trata de reducir el análisis a solo aquellas que produzcan cambios relevantes en el consumo de energía. 
El conocimiento de estas variables y de su influencia cuantitativa sobre el desempeño energético permite identificar las oportunidades de mejora en el USE. Generalmente estas oportunidades de mejora van dirigidas a reducir la variabilidad no deseada de estas variables o a controlar la misma para reducir el consumo de energía.

Para la validación cuantitativa de la influencia de cada variable sobre el consumo de energía es indispensable disponer de la información suficiente y representativa de la misma y del consumo de energía asociado, en un periodo significativo de tiempo.

No todas las variables relevantes pueden ser controladas para mejorar el desempeño energético, mediante un sistema de control operacional, tal como establece la ISO 50001. Existen variables climáticas o de otro tipo, no controlables, que pueden impactar de forma relevante el consumo de energía.

Por ejemplo, los grados días de temperatura impactan relevantemente el consumo de energía en los sistemas de climatización o de producción de frio industrial. También la cantidad de producto realizado en cualquier línea de producción es una variable relevante que influye en el consumo de energía de la línea, sin embargo, no es una variable que puede ser controlada para reducir el consumo ya que no podemos producir menos para ahorrar energía.

Aquellas variables relevantes que no pueden ser controladas por ninguna de las actividades operacionales, de la gestión del mantenimiento o de la gestión de la producción, para mejorar el desempeño energético del USE, deben ser utilizadas para normalizar la evaluación del desempeño energético del USE en cuestión, evitando así la influencia de la variación de la misma en la evaluación del desempeño energético. Esta normalización se realiza al establecer la línea base del USE para la evaluación de su desempeño energético. En conclusión, la determinación de las variables relevantes de los USE sirve para establecer el control operacional del desempeño energético, para identificar posibles oportunidades de mejora del desempeño y además para lograr la normalización de la evaluación del desempeño.

\section{Factores estáticos}

Son aquellos que impactan significativamente en el desempeño energético y no cambian de forma rutinaria. Generalmente son factores fijos inherentes a la tecnología existente y que determinan la eficiencia energética de la tecnología en uso [13], [28].

Cuando hay cambios importantes en los factores estáticos, es porque existen cambios en la tecnología y la organización deberá revisar las líneas de base energética que fueron elaboradas antes de esos cambios.

Ejemplo de factores estáticos: tipo de equipo instalado (motor eléctrico de baja, media o alta eficiencia), capacidad instalada (equipo sobredimensionado que trabaja subcargado), área de un edificio, tipo de luminarias (de alta eficiencia o de baja eficiencia); tipo de sistema 
de control que impacta relevantemente el consumo de energía (un control manual de flujo que puede ser modificado a un control por variador de frecuencia del motor eléctrico) etc. La identificación y registro de los factores estáticos es importante porque estos deben ir a la ficha de la línea base elaborada. En caso de que cambien los factores estáticos, que son factores relevantes que impactan el desempeño energético de un USE, se debe cambiar también la línea base elaborada, ya que la que existe antes del cambio no representa el comportamiento energético de ese USE.

Otro elemento importante de la identificación de los factores estáticos es que estos son fuentes de oportunidades de mejoras tecnológicas de los USE para la mejora del desempeño energético.

\subsubsection{Normas relacionadas con la familia de normas de la ISO 50001}

En el diagrama de la Figura 37, se agrupan las normas de la familia ISO 50000 trabajadas en el comité 301, Gestión de la Energía y Ahorros Energéticos de la entidad internacional ISO.

\section{FAMILIA ISO 50000}

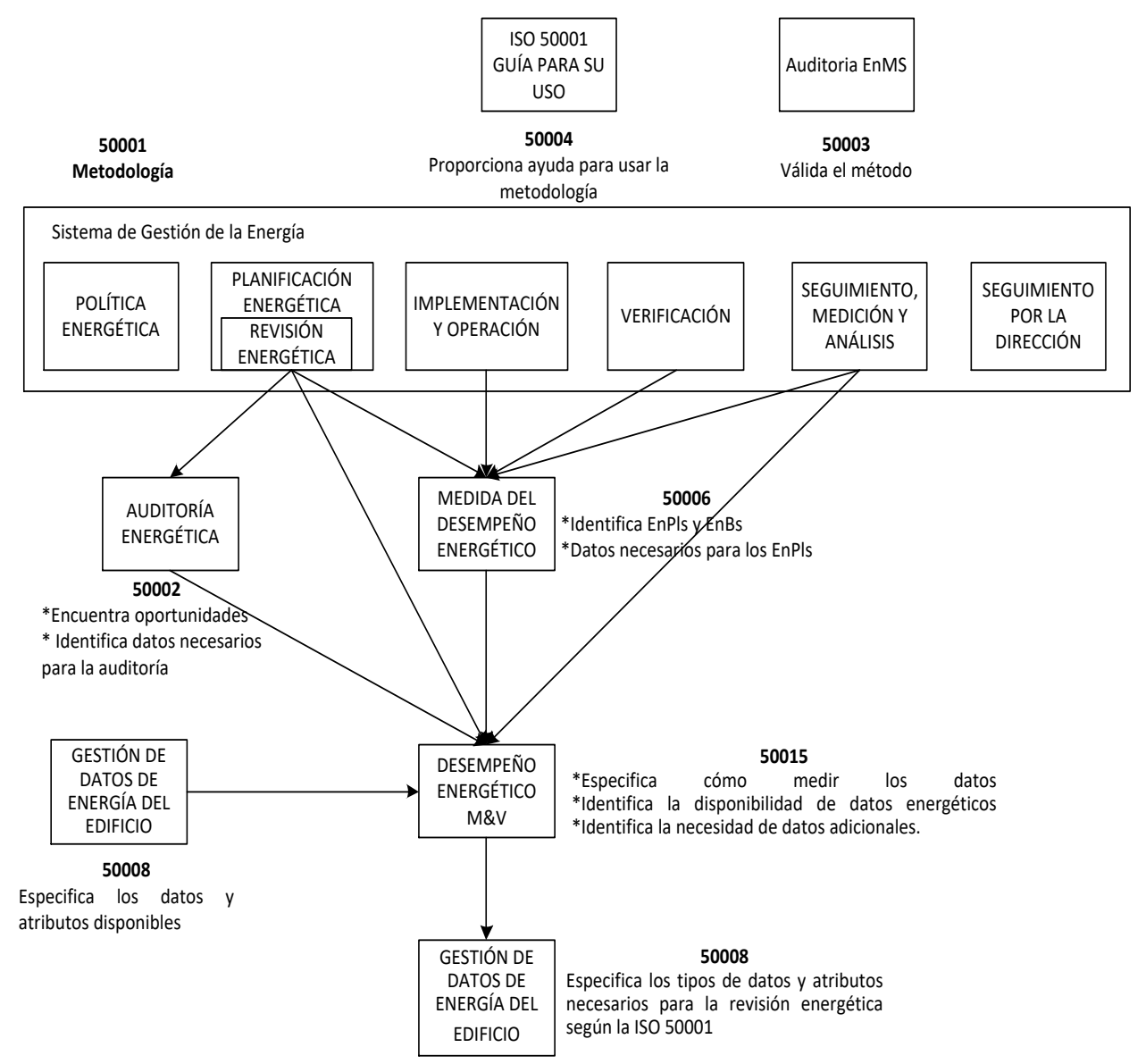

Figura 37. Familia de normas de ISO5000 que aportan a la implementación de los SGEn 


\subsubsection{Planificación Energética}

Dentro de la estructura de la norma ISO 50001, la planificación y sus elementos son considerados el núcleo de un SGEn, puesto que proporcionan la base para el desarrollo de una estrategia de mejora del desempeño energético, con objetivos específicos y actividades para la organización. En la versión ISO 50001:2018 se han incorporados aspectos importantes en cuanto a las consideraciones sobre los riesgos y las oportunidades como parte de la toma de decisiones estratégicas de alto nivel en la organización. Al identificar los riesgos y las oportunidades cuando se planifica el SGEn, la organización es capaz de anticipar los escenarios potenciales y las consecuencias, de manera de que los efectos no deseados se pueden abordar antes de que ocurran. En este sentido para la definición de acciones concretas dentro de esta etapa, es necesario realizar la identificación y evaluación de los aspectos energéticos, a través de objetivos, metas energéticas que pueden incluir tanto las mejoras generales al SGEn, como las metas de mejora del desempeño energético, específicas y medibles.

Otro aspecto importante es la revisión energética, entendida como el proceso de identificación de los tipos de energía y de evaluación del uso y consumo energético, con el propósito de que la organización determine las áreas de uso significativo de energía y que identifique las oportunidades de mejora del desempeño energético. De igual forma están incluidos dentro de la etapa de planificación, establecer indicadores del desempeño energético con resultados medibles para comparar el desempeño energético antes (valor de referencia del IDEn) y después (valor resultante o real del IDEn) de la implementación de planes de acción y de otras acciones. En la misma dirección está el establecimiento de la línea de base energética, en el período de tiempo apropiado significa que la organización da cuenta de los ciclos operativos, los requisitos reglamentarios o las variables que afectan el consumo de energía y la eficiencia energética, de manera de que el período de datos demuestre adecuadamente la gama completa del desempeño. Finalmente se incorpora al proceso de la planificación para recopilación de datos energéticos, los cuales tienen importancia crítica para el seguimiento y la mejora del desempeño energético. La planificación de qué datos recopilar, cómo hacerlo y con qué frecuencia a menudo ayuda a asegurar la disponibilidad de los datos necesarios para mantener la revisión energética y los procesos de seguimiento, medición, análisis y evaluación. Los datos pueden variar desde una simple cuenta numérica progresiva, hasta sistemas completos de seguimiento y medición, conectados a una aplicación de software capaz de consolidar los datos y entregar un análisis automático. En este sentido la organización debe planificar la manera de obtener la información necesaria para el seguimiento a sus metas energéticas y al desempeño energético. La planificación deberá incluir tanto planes de medición de las variables relevantes y consumos energéticos, como la recopilación de información adicional requerida para el desempeño energético ( $p$. ej. cambios en los usos significativos de la energía, criterios operacionales asociados a los USE). 
Para la ISO 50001 la medición se define como el proceso realizado para obtener un valor. En este sentido, la medición de variables claves del SGE representa actividades que pueden incluir desde la lectura (manual o automática) de medidores de energía hasta la revisión de registros de producción.

Para poder realizar el seguimiento, medición y análisis se requiere establecer un plan de medición apropiado al tamaño, complejidad y equipos de medición de la organización. Un plan de medición debe incluir: dónde se mide, en qué unidades físicas se mide, con qué frecuencia se mide, quién mide, dónde se registra la información quién tiene acceso a la misma, quién la procesa, quién registra los resultados del proceso, quién la analiza, a quién se comunica los resultados del análisis y otros aspectos que la organización considere.

La organización debe definir y revisar periódicamente sus necesidades de medición (áreas y equipos que requieren ser medidos).

La organización debe asegurar que el equipo usado en el seguimiento y medición de las características clave proporcione información exacta y repetible. Esto significa que estos equipos deben incorporarse al plan de calibración y verificación de instrumentos de medición de la empresa y que deben mantenerse los registros de las calibraciones y de las actividades establecidas por la empresa para verificar la exactitud y repetibilidad en estos equipos.

A continuación, se presenta la

Figura 38 que resumen los aspectos más importantes a considerar para realizar una adecuada planificación energética tanto en una industria como en una edificación.

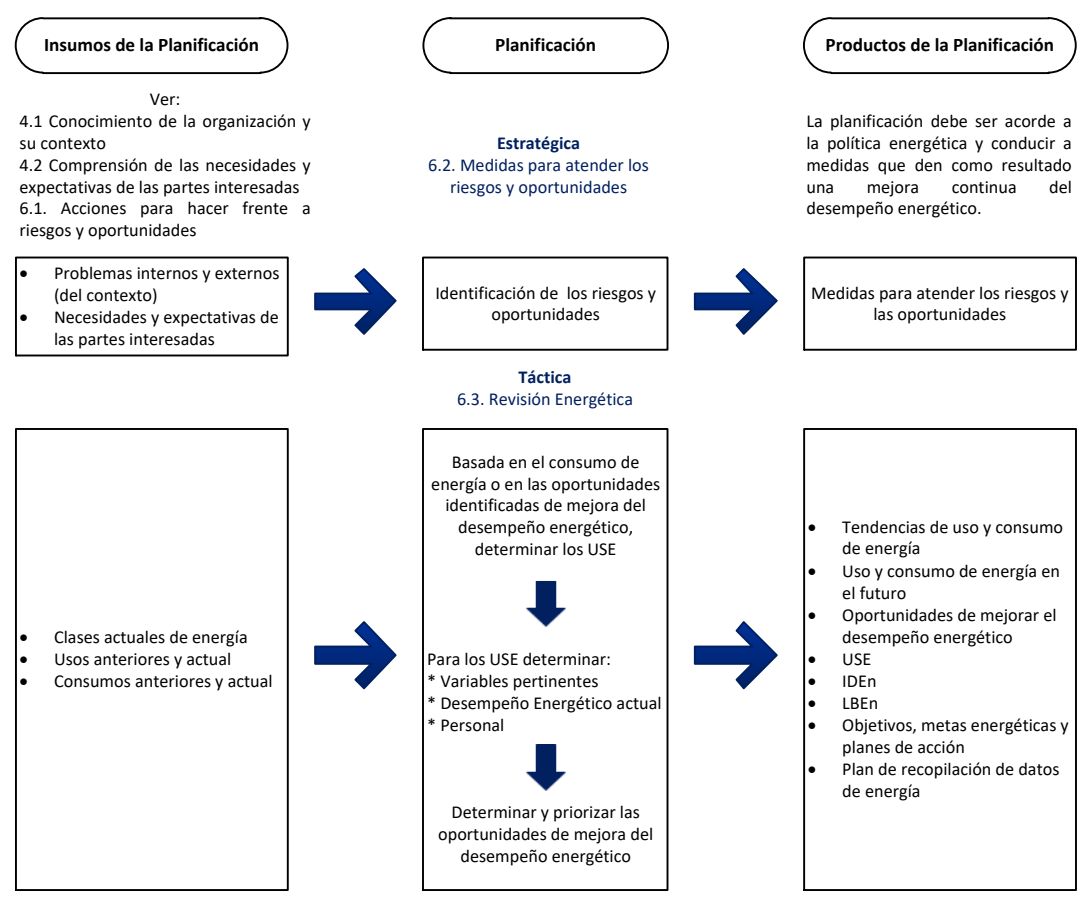

Figura 38. Proceso de planificación Energética

Fuente: ISO50001 2018 


\subsection{HERRAMIENTAS USADAS PARA LA GESTIÓN ENERGÉTICA}

Las herramientas presentadas a continuación corresponden a elementos que posibilitan el análisis y elaboración de procedimientos para facilitar la ejecución de una revisión energética que provee una visión sobre cómo mejorar su desempeño en una organización, es decir, optimizar los usos, los consumos y la eficiencia energética. Como resultado de dicho proceso es posible establecer un plan de acción que permita la implementación de un Sistema de Gestión Energética (SGEn) acorde con los requisitos de la norma y, como consecuencia, se reduzcan costos, emisiones de gases de efecto invernadero y otros impactos ambientales.

La revisión energética se desarrolla en tres etapas principales:

a. Análisis de los usos de energía.

b. Identificación de usos significativos de energía.

c. Identificación de oportunidades de mejoramiento.

Para este análisis, se sugiere el uso de una serie de herramientas que facilitan el cumplimiento de los objetivos de cada una de las etapas por desarrollar, según se describen en la Figura 39.

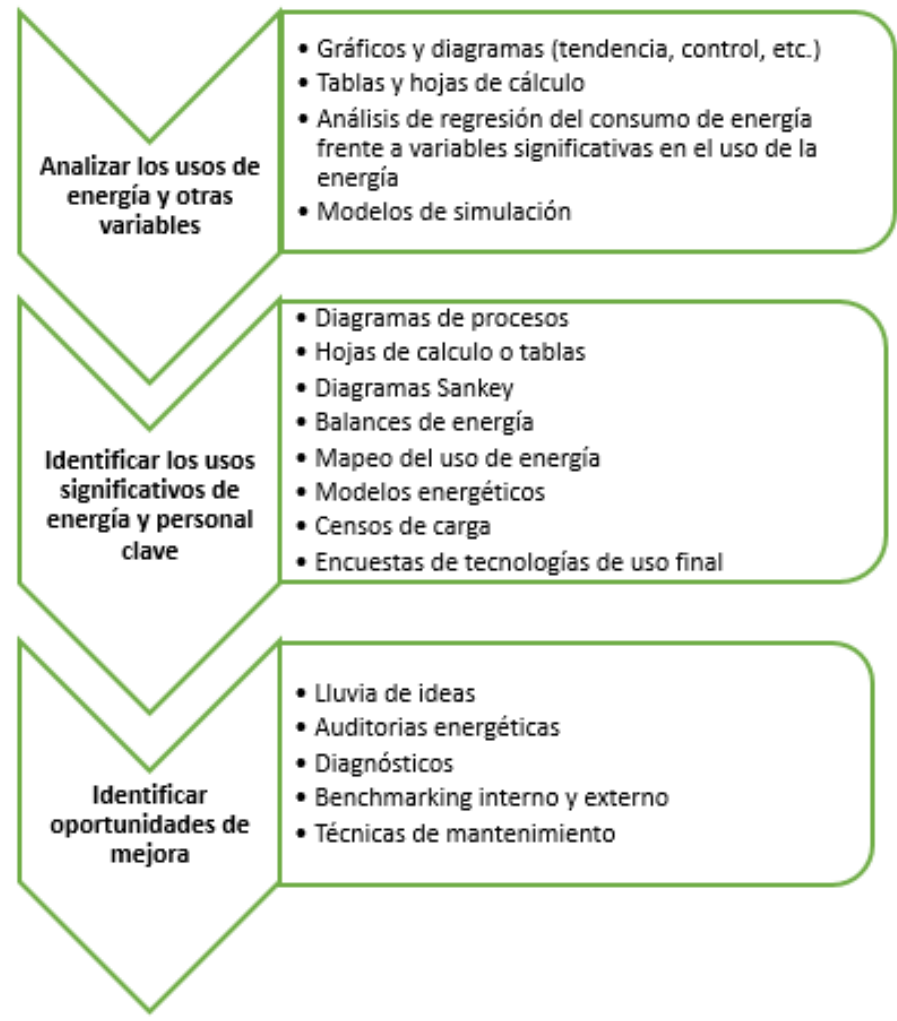

Figura 39. Herramientas usadas para la revisión energética

Fuente: Metodología Para la Planificación Energética a Partir de la Norma ISO 50001 [15] 


\subsubsection{Herramientas usadas para el análisis de los usos y consumos de energía}

Esta etapa de la revisión energética tiene como objeto establecer tendencias generales en el uso y consumo de energía. Dicho análisis se realiza a partir de mediciones y otro tipo de datos, como facturas o estimativos; no obstante, la información suministrada debe ser clara y precisa para obtener resultados confiables. La frecuencia de los datos debe ser suficiente para evaluar la variabilidad del desempeño energético y detectar anomalías entre el consumo de energía y el producto realizado o los servicios prestados. Algunas posibles técnicas que se plantean para presentar la información de análisis y los usos y consumos de energía son: los gráficos de barras, lineales, áreas, gráficos de control, tablas y matrices. Lo anterior es presentado y explicado en la Tabla 3.

Tabla 3. Herramientas usadas para el análisis de uso y consumo de energía

\section{Análisis de los usos y consumos de energía}

\section{Gráficos de Tendencia}

Muestran el comportamiento de los consumos energéticos en el tiempo (incrementos, decrementos o tendencias sin variación) [15]. Dejan visualizar cambios que sufren los procesos en un período de tiempo, o comparar el desempeño energético obtenido después de implementar una acción correctiva.

A continuación, se presentan algunos gráficos para analizar la información.

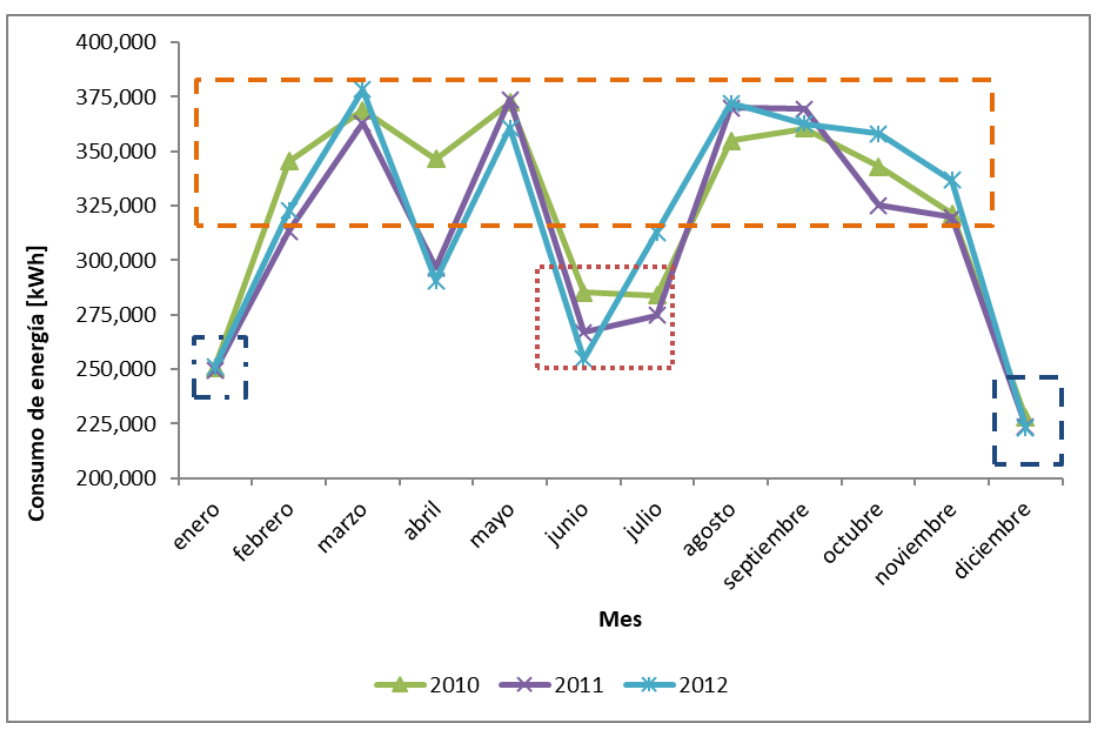

De estos gráficos se puede analizar los siguientes comportamientos:

Carga base de la demanda; es el menor valor del gráfico del consumo de energía.

Carga máxima de la demanda; el mayor valor del gráfico del consumo de energía.

Demanda promedio de energía.

Períodos de mayores y menores consumos de energía. 
Posibles causas de las variaciones del consumo de energía (disminución o aumento de la producción, la ocupación en una edificación, cambio estacional, cambio de equipos o procesos, etc.)

Es conveniente también realizar un gráfico en el que se muestre de manera conjunta la evolución de los consumos energéticos y la cantidad de producción y / ocupación en el tiempo. De esta manera, se identificará si las variables tienen tendencias similares y posibles comportamientos atípicos que puedan ser objeto de analizar [15].

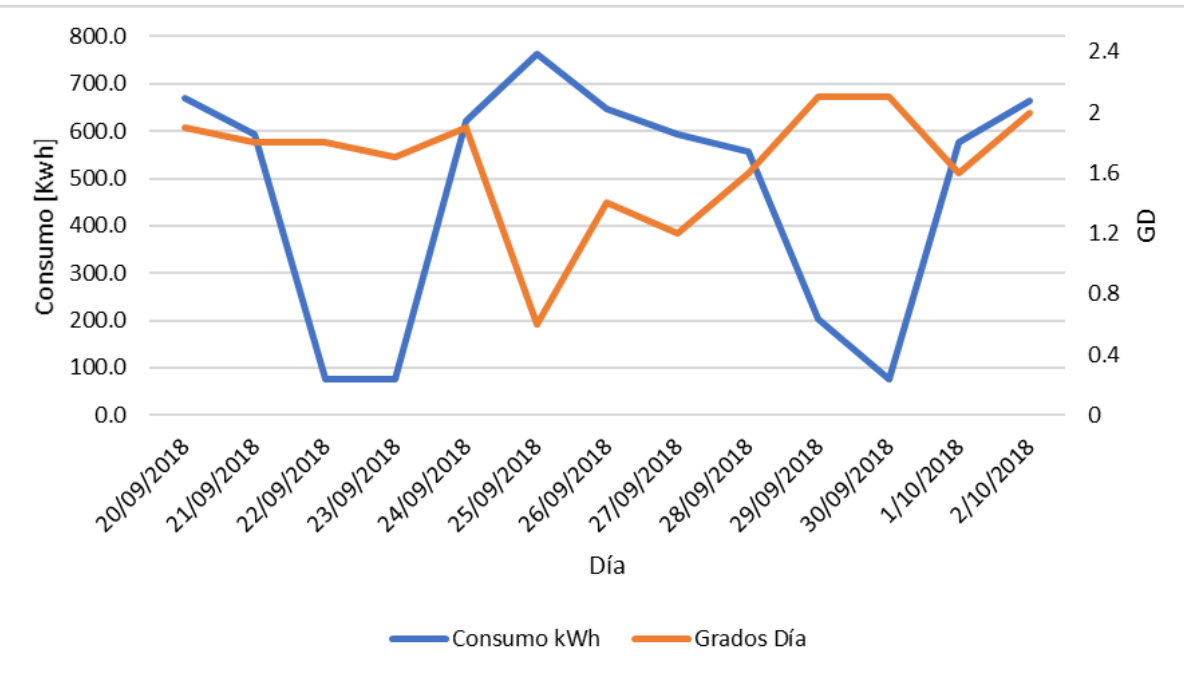

Gráfico de tendencia Consumo de Energía Eléctrica vs Grados Día

\section{Gráficos de Control}

Son herramientas estadísticas utilizadas para entender la variabilidad de los procesos, determinar capacidades de proceso, y hacer un seguimiento de los efectos de las variables sobre la diferencia entre las metas y el desempeño real. Indican los límites de control superior (LCS) e inferior (LCl) y, con frecuencia, incluyen una línea central (promedio), para ayudar a detectar la tendencia de los valores representados [17].

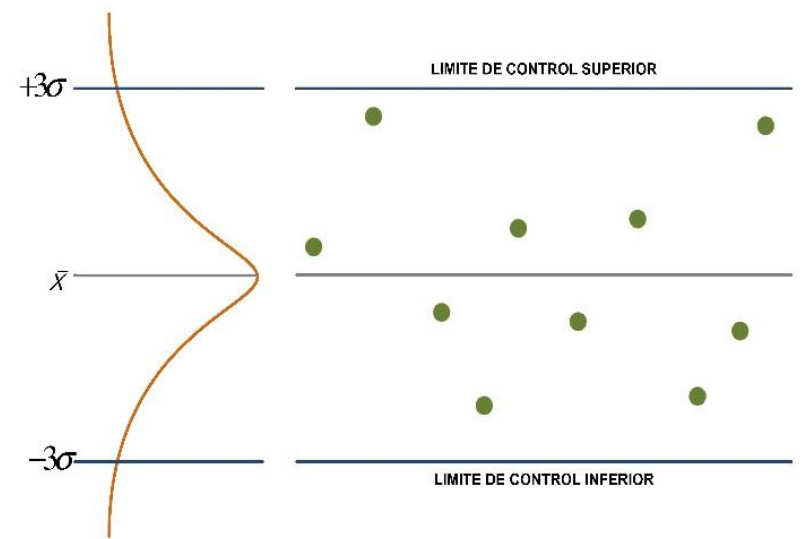

Fuente: Anderson D., Sweeney D. “Estadística para administración y economía [17] 
En ese sentido, el objetivo del uso de este gráfico es determinar si los consumos y costos energéticos tienen un comportamiento estable o anómalo, de tal forma que se pueda conocer si las variables evaluadas están bajo control, identificando cuáles son sus límites. Igualmente, reconocer los comportamientos que requieren explicación; identificar las causas no aleatorias que influyen en el comportamiento de los consumos, y conocer la influencia de las acciones correctivas sobre los mismos y los costos energéticos asociados [18].

En la elaboración de un gráfico de control de medias para la evaluación de los consumos energéticos, se requiere:

Realizar una tabla de datos de consumos de energía para un período de tiempo determinado.

Calcular la media de los datos a partir de la ecuación, la cual determina el valor medio para evaluar el consumo de energía observado:

$$
\mathrm{X}=\frac{\sum_{i=1}^{n} X_{i}}{n}
$$

Calcular los límites de control:

Los límites de control se calculan a partir de la desviación estándar de los datos y la media de los mismos.

$\sigma=\sqrt{\frac{\sum_{i-1}^{n}\left(x_{i}-x\right)^{2}}{n-1}}$

$$
\mathrm{LCS}=\mathrm{x}+3 \sigma \quad \mathrm{LCl}=\mathrm{x}-3 \sigma
$$

Dibujar las líneas rectas paralelas al eje $x$ de $\bar{x}, L C S, L C l$ y los puntos de las muestras $x_{i}$.

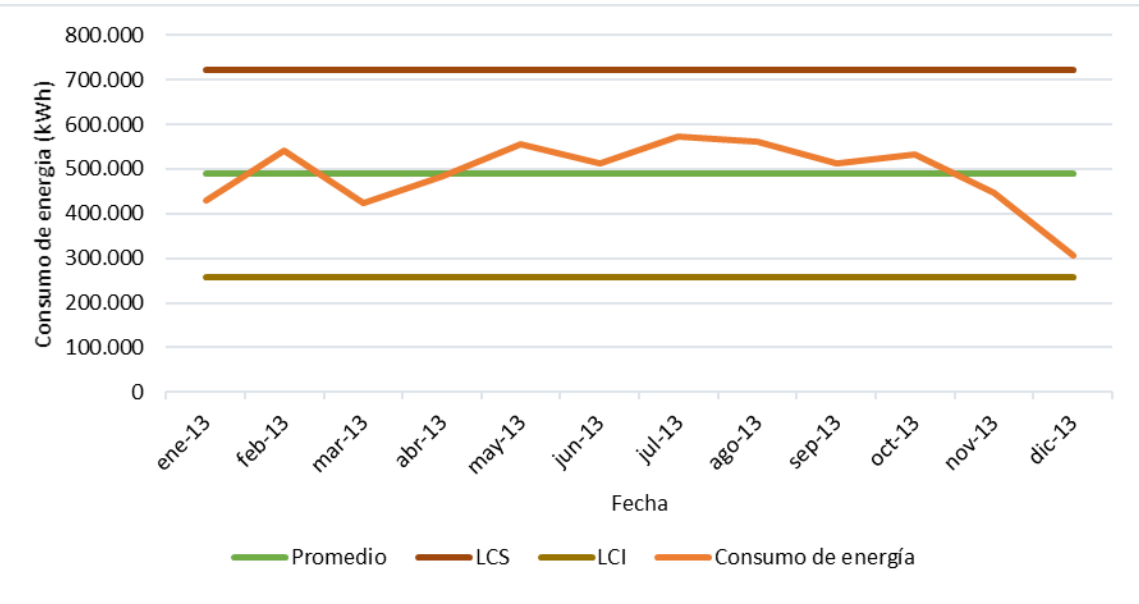

Gráfico de control de consumo de energía 


\section{Matriz Energética}

Es un instrumento [15] que facilita la identificación y el análisis de las diferentes fuentes de energía disponibles en una organización, indicando la importancia de cada una de ellas y el modo en el cual se utilizan.

En la matriz energética se debe especificar la fuente del energético, ya sean energías primarias (la hidroenergía, el petróleo crudo, el gas natural, el carbón mineral, la biomasa, energía solar y eólica); o secundarias, como la energía eléctrica de las centrales de generación o el diésel de las refinerías de combustibles. De igual forma, se deben incluir los distintos usos o consumos de todas y cada una de las fuentes de energía en los equipos de uso final (equipos de iluminación, aparatos eléctricos, sistemas de climatización, producción de agua caliente sanitaria, entre otros).

\begin{tabular}{|c|c|c|c|c|c|c|}
\hline $\begin{array}{l}\text { Fuente del } \\
\text { energético }\end{array}$ & \multicolumn{2}{|c|}{ Tipo de energético } & $\begin{array}{c}\text { Consumo } \\
\text { anual }\end{array}$ & PCS & $\begin{array}{c}\text { Consumo } \\
\text { anual } \\
\text { equivalente }\end{array}$ & $\begin{array}{c}\% \\
\text { Representación } \\
\text { en la matriz }\end{array}$ \\
\hline \multirow{8}{*}{ Energía Primaria } & \multirow{4}{*}{ No Renovable } & Carbón & & & & \\
\hline & & Petróleo & & & & \\
\hline & & $\begin{array}{l}\text { Gas } \\
\text { Natural }\end{array}$ & & & & \\
\hline & & Otro: & & & & \\
\hline & \multirow{4}{*}{ Renovable } & Solar & & & & \\
\hline & & Eólica & & & & \\
\hline & & Biomasa & & & & \\
\hline & & $\begin{array}{l}\text { Otros } \\
\text { renovables }\end{array}$ & & & & \\
\hline \multicolumn{7}{|c|}{ Total consumo energía primaria } \\
\hline \multirow{6}{*}{ Energía Secundaria } & & $\begin{array}{l}\text { Energía } \\
\text { Eléctrica }\end{array}$ & & & & \\
\hline & & Vapor & & & & \\
\hline & & Diésel & & & & \\
\hline & & Gasolina & & & & \\
\hline & & Biogás & & & & \\
\hline & & Otro: & & & & \\
\hline \multicolumn{3}{|c|}{ Total consumo energía secundaria } & & & & \\
\hline
\end{tabular}

Fuente del energético: Se distinguen dos fuentes: primaria, si el energético proviene de un recurso natural; $y$, secundario, si el energético es resultado de la transformación de otro energético ya procesado.

Tipo de energético: Se refiere a la clasificación de la fuente de los energéticos; por ejemplo, las energías primarias se clasifican en renovables, si es que son fuentes energéticas de uso sustentable en el tiempo; $y$, en no renovables, si hace referencia a fuentes energéticas de uso limitado. 
Es conveniente que además de construir la matriz energética, se realice una matriz de costos energéticos en la que se compare el peso que tiene el costo de cada tipo de energía sobre el costo total de todos los tipos de energía. Esto permitirá tener dos dimensiones de la matriz: su desempeño energético y su impacto económico.

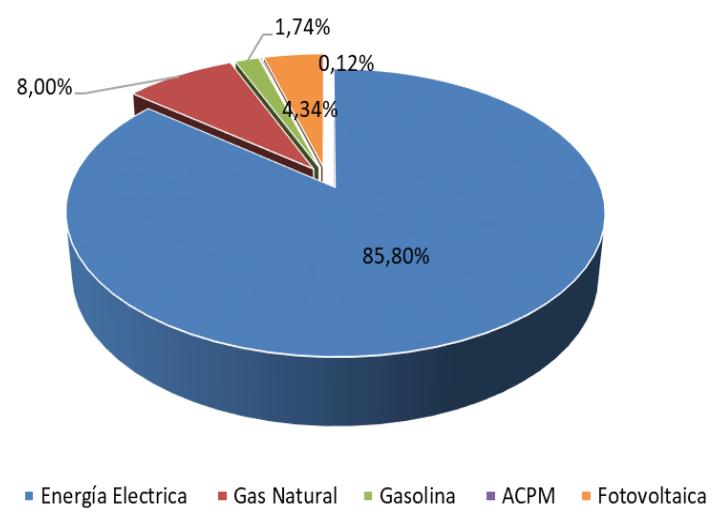

Gráfico Matriz de energéticos de una edificación.

\subsubsection{Herramientas usadas para identificar las áreas de uso significativo de la energía (USE)}

Uso de la energía (Electricidad, combustible, vapor, calor, aire comprimido y otros medios similares; es decir diferentes tipos de energía que se pueden comprar, almacenar, tratar utilizar en equipos o en un proceso o recuperar, incluyendo la renovable. Que representa consumo de energía, cantidad utilizada sustancial y /o que ofrece un potencial considerable para la mejora del desempeño energético [13].

Los usos significativos de la energía (USE) son aquellos donde la organización centrará los esfuerzos para la mejora del desempeño energético. Algunos elementos del SGEn en las etapas de operación y apoyo se centran en los USE por lo que una buena identificación reviste de alta importancia para el sistema.

El criterio principal para seleccionar los USE es identificar aquellos usos de la energía que agrupen los mayores consumos de la organización. No obstante, la organización podría identificar que los usos con mayores consumos no tienen potenciales de ahorro representativos o, por el contrario, que algún uso de la energía con consumos menores tiene altos potenciales de ahorro. En este caso, la organización podría determinar un USE basado en los potenciales de ahorro asociados [16].

Una vez identificados los usos significativos de la energía, es necesario levantar datos e información relevante que permita su gestión a través de los diferentes elementos del SGEn.

Algunas de las herramientas utilizadas para identificar áreas de uso significativo son presentadas en la Tabla 4. 
Tabla 4. Herramientas usadas para la identificación de USE's

Herramientas utilizadas para la identificación de las áreas de uso significativo de la energía (USE)

\section{Diagrama Energético-Productivo}

El diagrama energético-productivo es un esquema de procesos en donde se identifican las operaciones básicas en forma de bloques, las corrientes de flujos másicos principales, la información crítica para definir el proceso, así como los tipos y cantidades aproximadas de energía que entran y salen en cada etapa u operación básica del proceso [19].

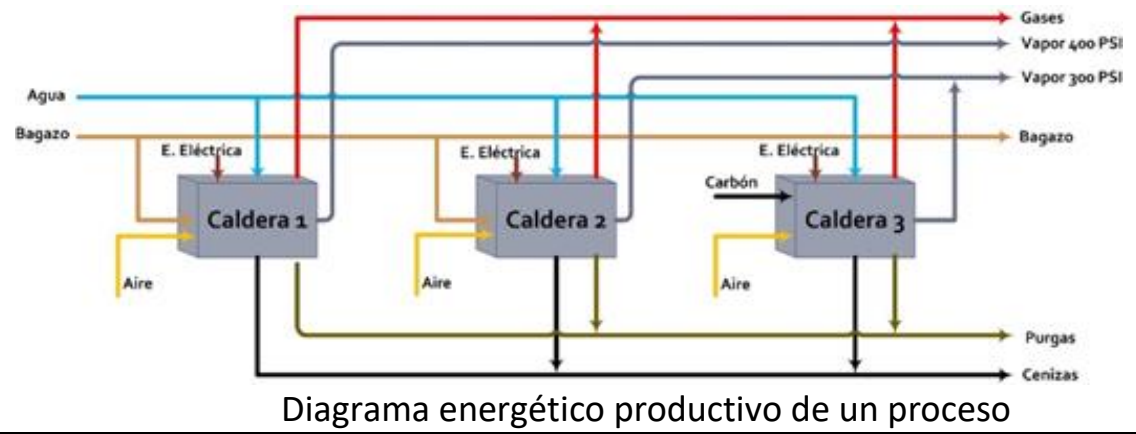

\section{Diagrama Sankey}

Es una ilustración gráfica que permite visualizar los flujos energéticos de materiales o de dinero, a través de un proceso o sistema con más facilidad que una tabla de datos numéricos. Por lo general, los flujos se ilustran como flechas y su ancho es proporcional a la magnitud que representan. Para el caso de un análisis energético, cuanta más gruesa es la línea o flecha, mayor será la transferencia de energía involucrada.

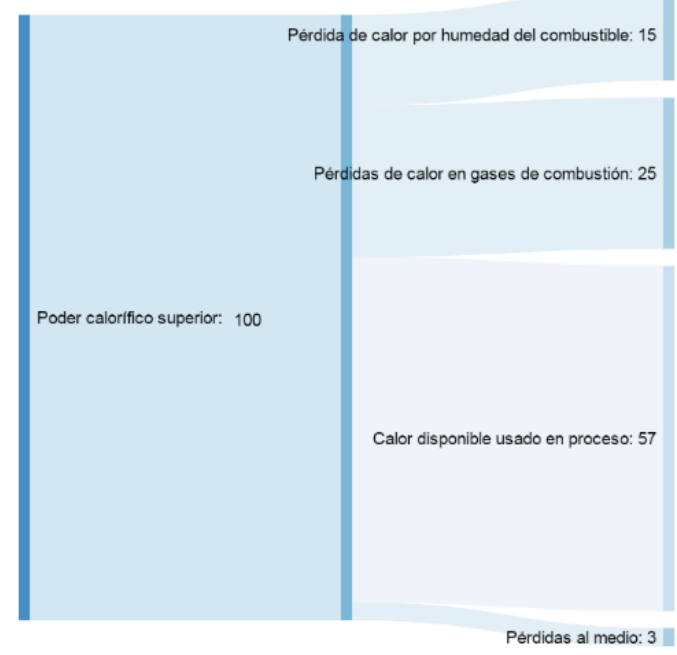




\section{Censo de Carga}

Esta herramienta consiste en un inventario de equipos o de instalaciones energéticas, localizados en los diferentes departamentos o áreas de una organización. La información obtenida permite visualizar la situación real de su consumo de energía.

Los resultados de un censo de carga sirven para la identificación de áreas o equipos críticos en el consumo energético, así como para el establecimiento de acciones para la reducción de consumos, el balanceo de cargas, la detección de fugas, entre otros [20].

\begin{tabular}{|c|c|c|c|c|c|c|}
\hline \multirow{3}{*}{\multicolumn{5}{|c|}{ Formato de censo de carga }} & \multicolumn{2}{|c|}{ Formato no. } \\
\hline & & & & & \multirow{2}{*}{\multicolumn{2}{|c|}{$\begin{array}{l}\text { Fecha: } \\
\text { Responsable: }\end{array}$}} \\
\hline & & & & & & \\
\hline Área & $\begin{array}{l}\text { Equipo/ } \\
\text { instalación }\end{array}$ & Cantidad & $\begin{array}{l}\text { Potencia } \\
\text { de placa } \\
{[\mathrm{kW}]}\end{array}$ & $\begin{array}{l}\text { Potencia } \\
\text { de } \\
\text { operación } \\
{[\mathrm{kW}]}\end{array}$ & $\begin{array}{l}\text { Tiempo } \\
\text { de uso } \\
\text { mes [h] }\end{array}$ & $\begin{array}{l}\text { Energía } \\
\text { consumida } \\
\text { [kWh/mes] }\end{array}$ \\
\hline & & & & & & \\
\hline & & & & & & \\
\hline & & & & & & \\
\hline & & & & & & \\
\hline & & & & & & \\
\hline
\end{tabular}

\section{Diagrama de Pareto}

El propósito de esta etapa es establecer prioridades para la gestión energética y el mejoramiento del desempeño energético. El diagrama de Pareto como herramienta de gestión energética, permite identificar y concentrar esfuerzos en los puntos claves de un problema o fenómeno, como pueden ser: los mayores sistemas, áreas, equipos consumidores de energía de la empresa, las mayores pérdidas energéticas. De igual forma facilita predecir la efectividad de una mejora al conocer la influencia de la disminución de un efecto, cuando reduce la barra de la causa principal que lo produce [15], [21].

El uso del diagrama de pareto es un instrumento clave para la gestión energética, y la información resultado de éste, sirve como criterio de selección para el direccionamiento de acciones en la mejora de la eficiencia energética de una organización.

Resume y muestra la importancia relativa de las diferencias entre grupos de datos; y muestra dónde se deben enfocar esfuerzos para la resolución de problemas.

Es vital tener en cuenta que, tanto la distribución de los efectos como sus posibles causas, no son un proceso lineal, sino que el $20 \%$ de las causas totales hace que sean originados el $80 \%$ de los efectos. 


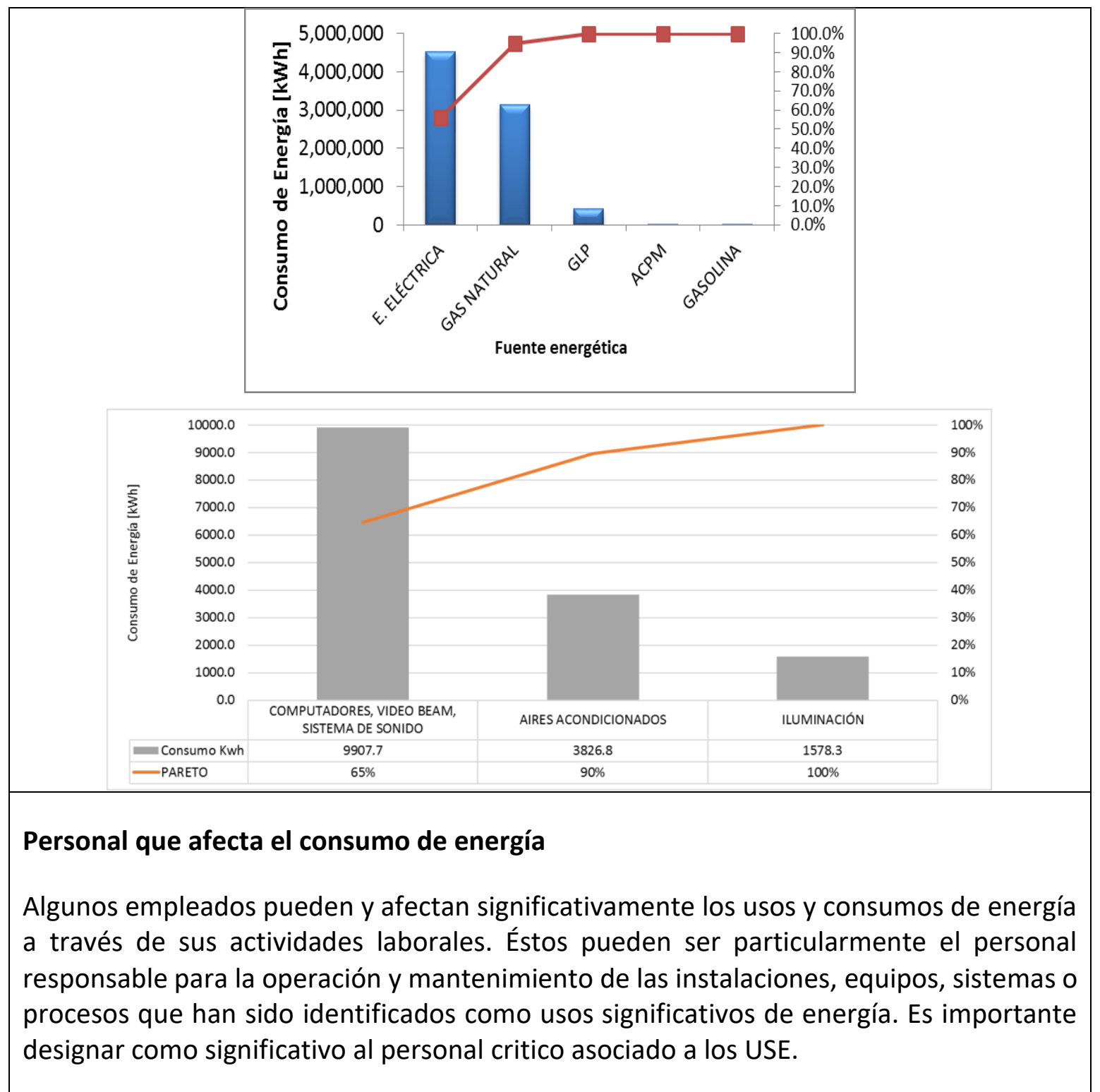

\subsubsection{Herramientas usadas para la identificación y priorización de oportunidades para el mejoramiento del desempeño energético}

La identificación de oportunidades de mejoramiento es el primer paso para el establecimiento de proyectos y planes para el incremento del desempeño energético de la organización.

Existen diversos métodos que facilitan la identificación de aspectos mejorables, algunos cualitativos, entre los cuales se destacan los grupales focales, la lluvia de ideas, las entrevistas semiestructuradas y la opinión del personal experto; así como otros métodos cuantitativos, como lo son las encuestas, los diagnósticos o auditorías energéticas. 
Las oportunidades comienzan con las ideas de mejora. Estas pueden ser generadas a partir del análisis de uso y consumo de energía, la determinación de los usos significativos de energía y el análisis de su desempeño energético o de una variedad de otras fuentes.

Dichas ideas se convierten en oportunidades, a través del examen y el perfeccionamiento utilizando el análisis de datos, para determinar el potencial de mejora del desempeño energético. La Tabla 5 presenta algunas de estas herramientas.

Tabla 5. Herramientas para la identificación y priorización de oportunidades para el mejoramiento del desempeño energético

\section{Herramientas utilizadas para la identificación y priorización de oportunidades para el mejoramiento del desempeño energético}

\section{Brainstorming o Lluvia de Ideas}

Es una de las técnicas más utilizadas para la obtención de información [24]. Se trata de una herramienta grupal, cuya clave está en la elección de las personas que conforman el grupo, el cual debe estar formado por profesionales conocedores del tema en un número no superior a 10 [25]. Para la gestión energética, dicho grupo puede estar conformado por el líder o gestor energético, quien será el moderador o responsable del conjunto, exponiendo la situación; mientras que el resto del personal debe incluir el comité energético, jefes de áreas y personal de uso significativo de energía identificado.

Al llevar a cabo una sesión de lluvia de ideas, el objetivo final es la identificación de oportunidades de mejoramiento del desempeño energético.

\section{Benchmarking Energético}

El benchmarking tiene como objetivo la generación de información para la empresa que le permita tener ideas sobre cómo planificar y adoptar prácticas basadas en la experiencia y el éxito ya alcanzados por otras organizaciones. El benchmarking energético es la parte del benchmarking dedicada a la eficiencia energética en los procesos que tienen lugar en la industria o una edificación. Puede ser una herramienta analítica muy útil, puesto que, proporciona información valiosa sobre la distribución del consumo de energía a través de la capacidad de producción de un sector, en el caso de los edificios es usado para describir el proceso de comparar el consumo de energía de un edificio con una base de datos de edificios similares, con el objetivo de evaluar el desempeño, la eficiencia operacional y los potenciales de mejora, así como para priorizar la selección de edificios para diagnósticos energéticos y retrofits [26].

Aunque todos los sistemas de benchmarking energético buscan alcanzar la mayor eficiencia energética posible, existen muchos tipos de benchmarking en función de la finalidad concreta que se tenga, de los datos de los que se dispongan y de otros factores. 
En este caso resulta importante que la comparación se realice basado en indicadores energéticos e identificando las variables que pueden alterar los resultados al compararse entre empresas. En este caso resulta importante que la comparación se realice basado en indicadores energéticos e identificando las variables que pueden alterar los resultados al compararse entre empresas. En ese sentido, resulta difícil adquirir los datos de energía pertinente y suficiente para caracterizar los distintos procesos. Por otro, la medición del rendimiento energético y la verificación es a veces una tarea difícil. Además, la información detallada de la energía es una materia sensible debido a las preocupaciones sobre aspectos como competitividad, datos de propiedad o confidencialidad [27].

\section{Auditoria Energética}

Conocida también como diagnóstico, este proceso consiste en una inspección y análisis sistemático del uso y el consumo de energía, con el propósito de identificar los flujos de energía y las oportunidades potenciales para mejorar el desempeño energético en una organización. La auditoría energética es una de las herramientas disponibles en apoyo de una revisión energética. Como proceso se describe en la norma ISO 50002 y proporciona el conocimiento sobre el consumo de energía que conduce a mejoras en el desempeño energético [22].

La Figura 40 presenta un diagrama de flujo del proceso de auditoria energética adaptado a los requisitos de la norma ISO 50002.

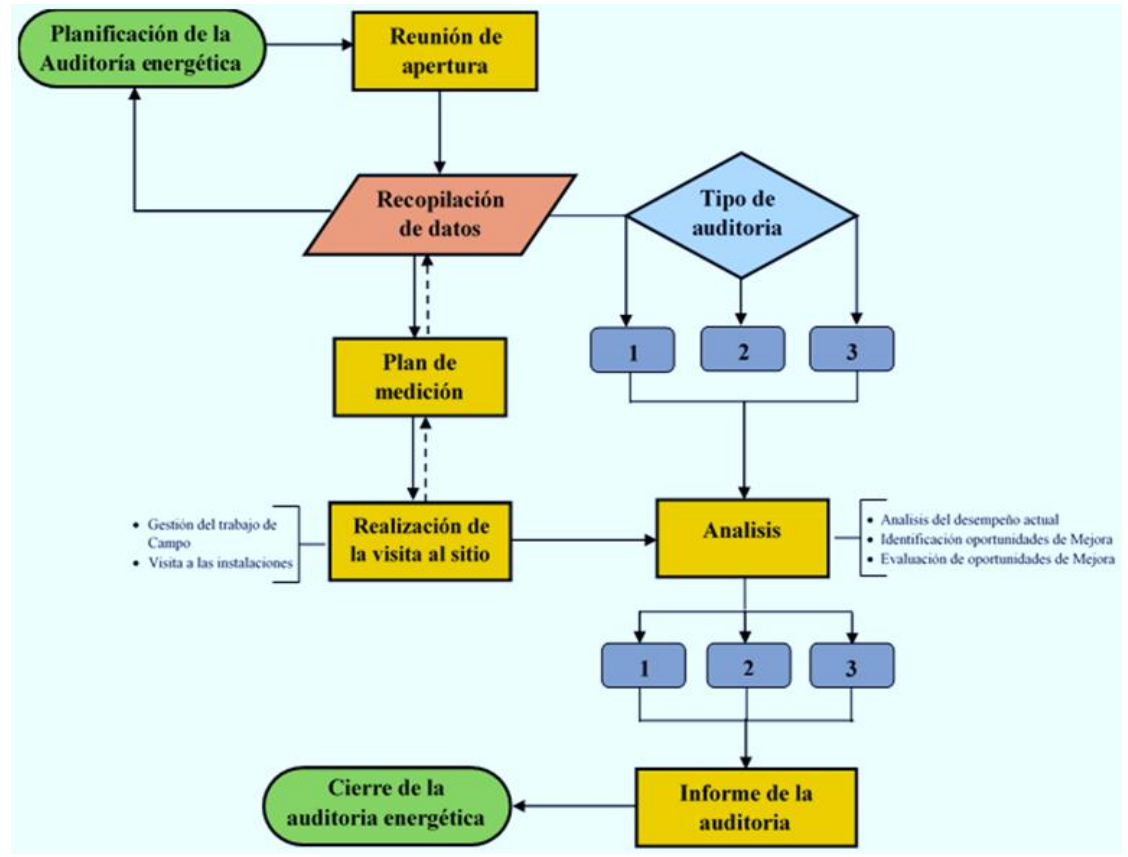

Figura 40. Proceso de auditoria energética adaptado según requisitos ISO50002 
Una auditoría energética puede arrojar información sobre una o más partes de la revisión energética. El alcance de una auditoría energética puede comprender una revisión detallada del desempeño energético de una organización, los USE, los sistemas, los procesos que usan energía o los equipos. Por lo general, se basa en una medición y observación adecuadas del desempeño energético actual según el alcance definido de la auditoría energética. Los elementos de salida de la auditoría energética, por lo común, incluyen información sobre el consumo actual de energía y el desempeño energético y pueden venir acompañados por una serie de recomendaciones específicas clasificadas por mejora del desempeño energético o retorno financiero sobre la inversión, con base en el análisis de los datos específicos y las condiciones operativas del emplazamiento [20],[22],[23].

Una auditoria energética puede desarrollarse en siete etapas principales, las cuales involucran una serie de actividades como las que se describen en la Tabla 6.

Tabla 6. Etapas principales de una auditoria energética

\begin{tabular}{|c|l|}
\hline \multirow{2}{*}{$\begin{array}{c}\text { Contacto } \\
\text { preliminar }\end{array}$} & $\begin{array}{l}\text { Definir alcances, límites y objetivos de la auditoria energética. } \\
\text { Identificar intenciones, necesidades y expectativas de la auditoría energética. } \\
\text { Definir cronogramas, compromisos y recursos. } \\
\text { Solicitar información necesaria requerida antes de iniciar la auditoría y verificar la } \\
\text { disponibilidad, validez y el formato de datos de energía y datos de producción, entre otros. } \\
\text { Informar a la organización de los equipos o instalaciones necesarias, para llevar a cabo la } \\
\text { auditoría energética. }\end{array}$ \\
\hline \multirow{5}{*}{$\begin{array}{c}\text { Reunión de } \\
\text { apertura }\end{array}$} & $\begin{array}{l}\text { Informar a todas las partes interesadas e involucradas acerca de los objetivos de auditoría } \\
\text { energética, así como el alcance, los límites, los objetivos y el nivel de detalle. } \\
\text { Definir responsables de la auditoría dentro de la organización. } \\
\text { Hacer acuerdos entre las partes. }\end{array}$ \\
\hline Recolección \\
de datos & $\begin{array}{l}\text { Recopilar información sobre: } \\
\text { Datos disponibles sobre procesos, sistemas y/o equipos consumidores, inventarios, } \\
\text { características detalladas de los equipos auditados (incluyendo variables relevantes } \\
\text { conocidas). } \\
\text { Datos históricos de consumos de energía, variables relevantes (producción, temperatura, } \\
\text { ocupación, entre otras). } \\
\text { Planes futuros que afecten el uso de la energía. } \\
\text { Documentos de diseño, operación y mantenimiento. } \\
\text { Auditorias o estudios previos relacionados con el uso de energía y el desempeño energético. } \\
\text { Tarifas energéticas y otros datos económicos relevantes. } \\
\text { Estado del sistema de gestión de la energía. }\end{array}$ \\
\hline
\end{tabular}




\begin{tabular}{|c|c|}
\hline $\begin{array}{c}\text { Trabajo en } \\
\text { campo }\end{array}$ & $\begin{array}{l}\text { Evaluar el uso de la energía, de acuerdo con los alcances, límites y el nivel de la auditoría } \\
\text { acordados entre las partes. } \\
\text { Comprender la operación. } \\
\text { Generar ideas. } \\
\text { Realizar mediciones y observaciones de una manera confiable, en condiciones normales de } \\
\text { operación y bajo condiciones climáticas adecuadas. También resulta beneficioso realizar este } \\
\text { procedimiento durante las horas no laborales, períodos de parada, o cuando no se esperan } \\
\text { cargas debido a condiciones climáticas. } \\
\text { Identificar personal responsable de planta que facilite la instalación de medidores o equipos } \\
\text { de monitoreo de energía. }\end{array}$ \\
\hline Análisis & $\begin{array}{l}\text { Determinar el rendimiento energético actual, según los límites establecidos. } \\
\text { Evaluar el impacto de las oportunidades identificadas sobre el desempeño energético. } \\
\text { Clasificar y priorizar las oportunidades de mejora identificadas. }\end{array}$ \\
\hline Reporte & $\begin{array}{l}\text { Asegurar que los requisitos de la auditoría energética acordados con la organización. } \\
\text { Resumir las mediciones pertinentes realizadas durante la auditoría energética. } \\
\text { Indicar si los resultados del análisis están basados en cálculos, simulaciones o valores } \\
\text { asumidos/proyecciones. } \\
\text { Resumir el análisis detallando las suposiciones. }\end{array}$ \\
\hline $\begin{array}{l}\text { Reunión de } \\
\text { cierre }\end{array}$ & $\begin{array}{l}\text { Presentar el informe final sobre la auditoría energética, mostrando los resultados de una } \\
\text { manera que facilite la toma de decisiones por parte de la organización. }\end{array}$ \\
\hline
\end{tabular}

\subsection{LÍNEA DE BASE ENERGÉTICA}

Una Línea de Base Energética (LBE) es una referencia cuantitativa que proporciona la base de comparación del desempeño energético. Esta permite evaluar el consumo, el uso y la eficiencia energética de un equipo, área, departamento, instalación o planta dentro de los límites seleccionados para la instalación del SGE.

De manera que, una LBE es una herramienta esencial para evaluar el progreso de la implementación de un sistema de gestión de la energía, pues permite la comparación del desempeño energético entre el período de tiempo para el cual fue construida y el evaluado por el indicador de desempeño, en donde se han implementado medidas de mejora, jornadas de sensibilización y/o buenas prácticas de operación y mantenimiento, para alcanzar los objetivos y metas establecidas en relación con la política energética.

La selección de una línea de base energética está ligada a retos que puede afrontar la organización, abordando aspectos tales como el tamaño de las instalaciones, el perfil de producción, la cultura organizacional, entre otros. Algunos desafíos frecuentes son el requerimiento de mezclas de productos, o la justificación de múltiples fuentes de energía; otras variables complejas corresponden a retrasos en el tiempo entre los datos de producción y los medidores de energía, la identificación de múltiples variables que pueden afectar el consumo energético en una edificación [13], [23]. 
Por otra parte, el establecimiento de una LBE debe contar con la participación de diversas personas en su planeación, quienes deben ser capaces de hablar más allá de la simple perspectiva del uso de la energía, e involucrar factores tales como ciclos recurrentes del proceso, eventos que ocurrieron una sola vez en el pasado, y otros que se espera ocurran en los siguientes meses del año. De modo que, al tener en cuenta dichos aspectos, se defina una LBE apropiada para la organización, y se seleccione un método adecuado para su cuantificación como lo presenta la Figura 41.

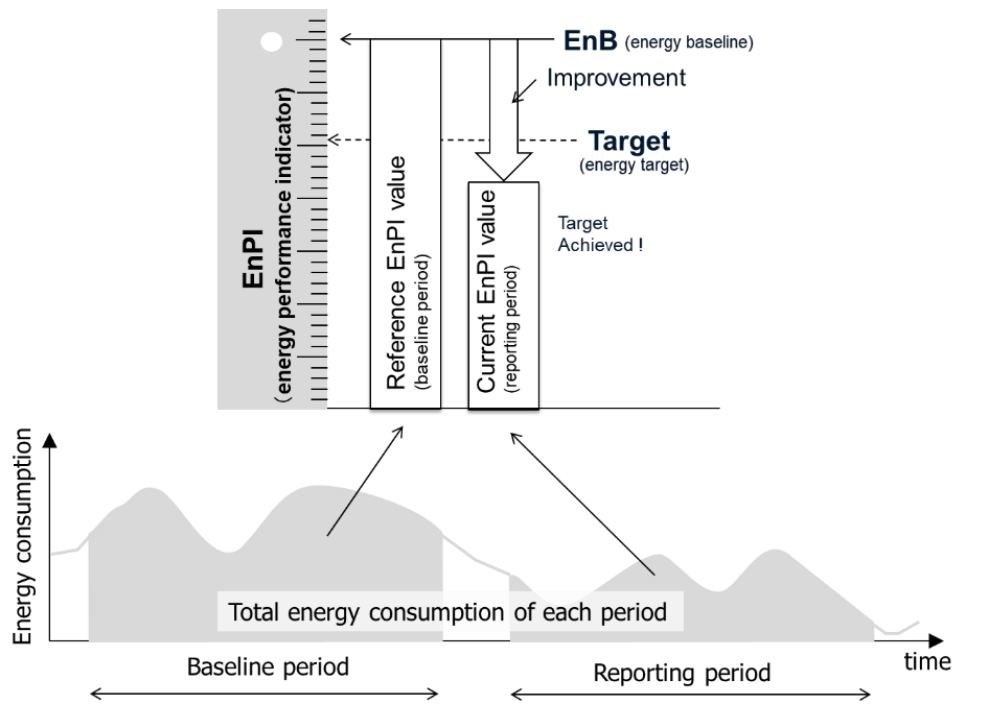

Figura 41. Concepto de periodo base y periodo de reporte para IDE

Fuente: ISO 50006:2014 [29]

Considerando ahora que una línea puede ser establecida como un valor medido hasta un modelo basado en simulaciones, se muestra a continuación la propuesta que realiza la norma ISO 50006 - Línea de base energética e indicadores de desempeño energético [29], como ayuda para la selección de una LBE exponiendo utilidad y desventajas del tipo o método escogido.

La Tabla 7 presenta el tipo de líneas de base energéticas (LBE) que las organizaciones pueden utilizar según la norma ISO 50006.

Tabla 7. Tipo de LBE

\begin{tabular}{|c|}
\hline Tipo de LBE \\
\hline Consumo Absoluto \\
\hline Consumo de Energía Específico \\
\hline Modelo Estadístico \\
\hline $\begin{array}{c}\text { Modelo de Ingeniería o simulación basada en } \\
\text { principios científicos }\end{array}$ \\
\hline
\end{tabular}

Fuente: ISO 50006:2014 [29] 
El tipo de LBE o el método para establecerla, varía dependiendo de la complejidad de la organización, así como de otros factores mencionados. Por ejemplo, con instalaciones pequeñas con un uso sencillo de la energía y variables significativas sencillas de entender, la LBE puede establecerse rápidamente gracias a un método simple.

Sin embargo, en una organización grande, con varias fuentes energéticas, con usos complejos de energía aplicados a varios productos en tiempos variables a lo largo del año; seleccionar y establecer un tipo de línea de base energética adecuada, puede tomar tiempo y requerir esfuerzos basados en el análisis, a través del establecimiento de modelos estadísticos o matemáticos.

\subsubsection{Etapas para el establecimiento de una línea de base energética}

A continuación, se presenta en cinco pasos las etapas necesarias para establecer una línea base energética LBE. Esta involucra las etapas mostradas en la Figura 42, partiendo de la definición de límites físicos y/u organizaciones en donde se desea establecer la línea; seguidamente, la identificación de fuentes energéticas primarias o secundarias; la detección de variables significativas de mayor impacto en el consumo de energía dentro de los límites establecidos; y, la recolección de información necesaria en el período de base seleccionado; todo ello, para finalmente cuantificar la LBE a partir del método elegido [15].

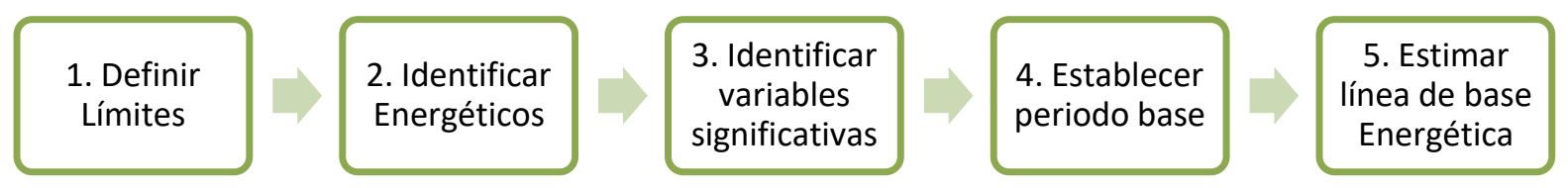

Figura 42. Pasos para el establecimiento de una línea de base energética

\subsubsection{Definir los límites de la línea de base energética}

Los límites pueden ser físicos o de lugar y/u organizacionales, tal como los define la organización. Esta primera etapa consiste en identificar todas las instalaciones y operaciones que se hallen incluidas dentro del SGEn.

Límites Físicos: Concierne a un proceso, un grupo de procesos, unas instalaciones, una organización completa o múltiples lugares bajo el control de una organización. Ejemplo: una caldera, un edificio.

Límites organizacionales: Se refiere a los puestos, divisiones, departamentos o unidades de negocio de una organización, a los cuales se establecen metas de desempeño energético. Ejemplo: una multinacional que cuenta con una línea de ensamble como unidad de negocio en diferentes países. Esta puede seleccionar un límite que incluya todos los lugares que 
cuentan con esa línea de ensamble, con el objetivo de evaluar el desempeño y los costos energéticos para un producto dado, ensamblado en múltiples instalaciones.

Los límites físicos y organizacionales pueden sufrir cambios, debido a eventos tales como expansiones de los procesos o cierres parciales de departamentos o áreas productivas, lo cual justifica un restablecimiento de estos, en el que se recopilen los datos y se administra la energía.

\subsubsection{Descripción de las fuentes de energía}

Una vez se definen los límites, el siguiente paso corresponde a identificar los energéticos utilizados dentro de estos.

Por otro lado, se trata de identificar las fuentes de energía y, en el caso de la planeación de un Sistema de Gestión Energético, se debe abordar el cómo los usos y consumos de energía serán medidos y registrados.

De tal forma, las fuentes de energía son divididas en dos categorías principales: primarias y secundarias. Las primeras se refieren a aquellas provenientes de un recurso natural, como lo son el carbón, el petróleo, la biomasa, la energía solar, entre otras.

Una fuente secundaria, como típicamente la energía eléctrica, viene de una empresa de servicios. No obstante, también puede provenir de fuentes de generación locales, como el sol o el viento, o de la recuperación del calor en efluentes energéticos.

La energía térmica puede provenir de numerosas fuentes de combustible, incluyendo gas natural, derivados del petróleo, carbón o biomasa. Sus fuentes pueden también ser suministradas desde un proveedor externo en la forma de vapor o agua fría.

La mayoría de las instalaciones estándar cuenta con medidores de energía eléctrica y de gas, para la medición del consumo en la frontera del suministro que les llegan de las compañías de servicios. Los registros de las facturas de los servicios identifican la cantidad de energía consumida durante el período de registro, el cual puede ser convertido en el consumo de energía promedio por día; por ejemplo, kWh/día promedio y BTU/día promedio. Estos valores diarios pueden ser recogidos para el período de la LBE y aplicados para su análisis.

\subsubsection{Definir el período base}

El período seleccionado para construir una Línea de Base Energética, debe ser lo suficientemente largo para que los datos incluyan los diferentes estados operacionales de los equipos, instalaciones y/o áreas dentro de los límites energéticos establecidos.

Así que, el período de medición seleccionado y el intervalo de registro de datos, deben proporcionar una muestra representativa para ser estadísticamente válida en la 
construcción de una LBE que proporcione una precisión aceptable, para la estimación de ahorros energéticos y el seguimiento del desempeño energético.

De manera que, la organización debe determinar un período adecuado de datos, considerando la naturaleza de sus operaciones. Una LBE de un año se presenta como la mejor opción. Sin embargo, cuando los registros históricos de datos de las variables relevantes identificadas, no están disponible, se pueden realizar estimaciones basadas en intervalos de datos más cortos, haciendo proyecciones a partir de este análisis.

En la Tabla 8, se analizan tres posibles períodos de tiempo para la recolección de información, durante el establecimiento de una LBE, evaluando las ventajas y requerimientos operacionales y de monitoreo cuando se selecciona.

Tabla 8. Período de base para la estimación de una LBE

\begin{tabular}{|c|c|c|}
\hline $\begin{array}{l}\text { Período } \\
\text { de la } \\
\text { LBE }\end{array}$ & Ventajas & Requerimientos \\
\hline Un año & $\begin{array}{l}\text { Estimación de una LBE alineada con los objetivos de negocio } \\
\text { de la gestión energética, que incluye el rango completo de } \\
\text { estacionalidades y el impacto de variables relevantes como } \\
\text { clima y otras propias del funcionamiento de la organización } \\
\text { (ciclos operativos, demanda del mercado). }\end{array}$ & $\begin{array}{l}\text { Registros históricos } \\
\text { confiables y disponibles. }\end{array}$ \\
\hline $\begin{array}{l}\text { Menor a } \\
\text { un año }\end{array}$ & $\begin{array}{l}\text { Se puede establecer una LBE a partir de la evaluación de un } \\
\text { trimestre o semestre, considerando que corresponde a un } \\
\text { rango de tiempo razonable, donde se capturan patrones } \\
\text { operativos representativos de la organización. }\end{array}$ & $\begin{array}{l}\text { Tasas de producción } \\
\text { estables a lo largo del } \\
\text { año. } \\
\text { Suficiente cantidad de } \\
\text { registros históricos } \\
\text { confiables y disponibles. }\end{array}$ \\
\hline $\begin{array}{l}\text { Más de } \\
\text { un año }\end{array}$ & $\begin{array}{l}\text { La estacionalidad y tendencias de la organización se pueden } \\
\text { combinar, para hacer que una LBE multianual resulte óptima. } \\
\text { Se adapta a procesos en los cuales existen ciclos de } \\
\text { producción anual corto, donde una empresa opera por } \\
\text { algunos meses cada año y permanece relativamente inactivo } \\
\text { el resto del año. Por ejemplo, una compañía de vinos. }\end{array}$ & $\begin{array}{l}\text { Suficiente cantidad de } \\
\text { registros históricos } \\
\text { confiables y disponibles } \\
\text { de los ciclos de } \\
\text { producción. }\end{array}$ \\
\hline
\end{tabular}

\subsubsection{Definir variables significativas}

Las variables significativas se refieren a aquellas que más influyen en el consumo de energía de un equipo, instalación o área. En la aplicación de edificios, el clima consigue considerarse una variable significativa, pues el consumo de una instalación puede depender de las condiciones climáticas externas; y, aunque esta variable no es controlable, debe ser considerada en el análisis, para evitar interpretaciones erróneas en la evaluación del desempeño energético. 
Para la determinación de las variables significativas de uso de energía, las organizaciones deben tener en cuenta la función u objeto para el cual fue diseñada una instalación o equipo; también una inspección visual, la discusión con el personal de operación, o incluso aproximaciones a través de balances de materia y energía. Las variables significativas de uso de energía pueden variar, desde una sola variable que se correlaciona lineal con el consumo de energía, hasta modelos complejos que combinan, clima y otros factores.

Posteriormente, un análisis estadístico puede demostrar que algunas variables identificadas, en realidad, tienen influencia en el consumo de energía. Estas correlaciones, a menudo, pueden ser de la forma de estadísticas-T o valores-P que demuestran el nivel de confianza de una correlación entre variables. En la práctica, el nivel de confianza del análisis debería de estar en el intervalo de 90-95\%.

\subsubsection{Estimar línea de base energética}

Con respecto a la estimación o cuantificación de la LBE, se debe seleccionar un método adecuado, teniendo en cuenta la complejidad de las instalaciones donde se requiere establecer. Para algunas organizaciones, puede ser válido un valor promedio, como para otras un modelo de simulación o regresiones.

En la Tabla 9, se presenta una matriz en donde se analizan tres tipos de instalaciones: simple, moderada, y compleja; también algunos requerimientos, y se recomienda un método para estimar la LBE [15].

Tabla 9. Selección de un método para la estimación de la LBE de acuerdo con el tipo de instalación

\begin{tabular}{|c|c|c|c|c|c|c|}
\hline $\begin{array}{l}\text { Tipo de } \\
\text { instalación }\end{array}$ & Límites & $\begin{array}{l}\text { Fuentes de } \\
\text { energía }\end{array}$ & $\begin{array}{l}\text { Período de } \\
\text { Línea Base }\end{array}$ & $\begin{array}{l}\text { Variables } \\
\text { significativas }\end{array}$ & $\begin{array}{l}\text { Ajustes } \\
\text { requeridos }\end{array}$ & $\begin{array}{l}\text { Método para la } \\
\text { estimación de la } \\
\text { LBE }\end{array}$ \\
\hline Simple & $\begin{array}{l}\text { Instalación } \\
\text { única, límites } \\
\text { claros }\end{array}$ & $\begin{array}{l}\text { Reporte de } \\
\text { energía claro } \\
\text { y consistente }\end{array}$ & $\begin{array}{l}\text { Operación } \\
\text { estable en cada } \\
\text { período }\end{array}$ & $\begin{array}{l}\text { Producto único } \\
\text { que impulsa el } \\
\text { uso de energía }\end{array}$ & $\begin{array}{l}\text { Ningún factor que } \\
\text { requiera ajustes }\end{array}$ & $\begin{array}{l}\text { Proporción: } \\
\text { energía especifica } \\
\text { / Modelo de } \\
\text { regresión lineal } \\
\text { univariable. }\end{array}$ \\
\hline Moderada & $\begin{array}{l}\text { Múltiples } \\
\text { instalaciones, } \\
\text { límites } \\
\text { moderadamente } \\
\text { claros }\end{array}$ & $\begin{array}{l}\text { Más de una } \\
\text { fuente de } \\
\text { energía } \\
\text { (electricidad y } \\
\text { gas) }\end{array}$ & $\begin{array}{l}\text { La producción } \\
\text { varia durante el } \\
\text { año, con base en } \\
\text { estaciones }\end{array}$ & \begin{tabular}{lr}
\multicolumn{2}{l}{ Producto único; } \\
parada por \\
clima \\
estaciones
\end{tabular} & $\begin{array}{l}\text { Factor único que } \\
\text { puede resultar en } \\
\text { revisión de la línea } \\
\text { de base }\end{array}$ & $\begin{array}{l}\text { Modelo de } \\
\text { regresión lineal } \\
\text { multivariable. } \\
\text { Modelo de } \\
\text { regresión no lineal }\end{array}$ \\
\hline Compleja & $\begin{array}{l}\text { Múltiples } \\
\text { instalaciones y/u } \\
\text { operaciones }\end{array}$ & $\begin{array}{l}\text { Múltiples } \\
\text { fuentes de } \\
\text { energía, } \\
\text { cogeneración, } \\
\text { energía usada } \\
\text { como materia } \\
\text { prima }\end{array}$ & $\begin{array}{l}\text { La producción } \\
\text { cambia } \\
\text { constantemente, } \\
\text { salida de } \\
\text { producto e } \\
\text { intensidad } \\
\text { energía }\end{array}$ & $\begin{array}{l}\text { Variables } \\
\text { significativas } \\
\text { complejas, } \\
\text { intensidades de } \\
\text { energía varían, } \\
\text { influencia del } \\
\text { clima }\end{array}$ & $\begin{array}{l}\text { Factores } \\
\text { importantes que } \\
\text { requieren ajustes, } \\
\text { cambios en diseño } \\
\text { del proceso, nuevos } \\
\text { productos }\end{array}$ & $\begin{array}{l}\text { Modelo de } \\
\text { regresión no lineal } \\
\text { Simulaciones }\end{array}$ \\
\hline
\end{tabular}


En particular, cada organización y sus instalaciones son diferentes, en especial, las industrias, presentando características de variados niveles de complejidad, de acuerdo con la Tabla 9. Por ejemplo, una instalación puede tener límites "simples", variables significativas complejas y un período de base y ajustes requeridos "moderados"; en consecuencia, a menudo una aproximación híbrida es la más adecuada para su tipificación y para la selección del método para la cuantificación de la Línea de Base Energética. La Figura 43 enseña lo que se busca conseguir con una línea de base de energía.

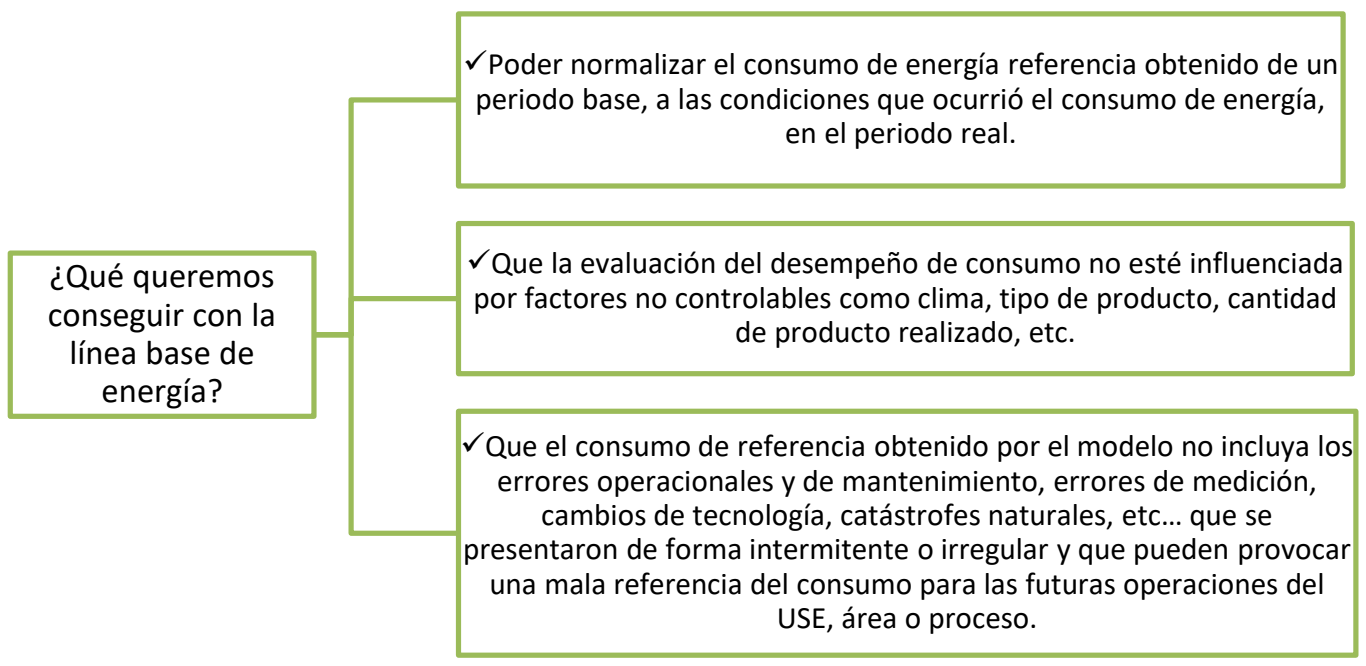

Figura 43. Lo que se quiere conseguir con una LBE

\subsection{INDICADORES DE DESEMPEÑO ENERGÉTICO (IDEn)}

Las organizaciones deben identificar Indicadores de Desempeño Energético (IDEn) adecuados para la medición y seguimiento, de acuerdo con los requerimientos de la norma ISO 50001:2018.

La medición del desempeño energético a través de los IDEn, se basa en una relación cuantitativa entre el consumo de energía y una o varias variables significativas. Sin embargo, Ios IDEn pueden definirse como un simple parámetro, una relación o un modelo complejo. Algunos ejemplos de indicadores de desempeño energético pueden incluir el consumo de energía por tiempo, consumo de energía por metro cuadrado y modelos multivariables.

La organización puede elegir los IDEn que indiquen el desempeño energético de sus operaciones, y que puedan ser actualizados cuando las actividades o la LBE cambien y afecten significativamente el indicador [13].

Por consiguiente, en la selección de los IDE es importante identificar el propósito que este tenga, a qué persona de la organización involucra y la cantidad y calidad de los datos e información requerida. Ello, de manera que sea responsabilidad del representante de la 
gerencia para la gestión energética y del equipo de expertos en energía, internos y terceros, trabajar en conjunto para el establecimiento de dichos indicadores.

Los IDEn son utilizados para ayudar a normalizar los costos energéticos, identificar oportunidades de mejoramiento, y detectar buenas prácticas operativas para el progreso del desempeño energético. En ese sentido, una organización puede tener múltiples indicadores de desempeño energéticos. Dependiendo de su operación, estos pueden ser establecidos en varios niveles, incluyendo el organizacional, el físico y los relacionados con sistemas. Por ejemplo, se pueden definir a un nivel de toda la organización, a nivel de la planta, o corresponder a un sistema, subsistema o a un equipo específico.

Los conceptos y la metodología empleada para constituirlos y para su seguimiento, deben ser documentados, al igual que las suposiciones, cálculos específicos y previsiones.

\subsubsection{Selección de indicadores de desempeño energético}

El indicador de desempeño energético adecuado se considera aquel que proporciona orientación y retroalimentación sobre el avance propuesto en un plan de acción, de manera que se pueda cumplir con los objetivos y metas establecidas para el mejoramiento del desempeño energético.

Para esto, es necesario tener claridad sobre el propósito del indicador, el cual está relacionado con la intención de evaluar usos, consumos y eficiencia energética dentro de unos límites establecidos; de igual manera, el interés de los usuarios internos de hacer seguimiento a los indicadores, de acuerdo a sus niveles, roles y funciones dentro de la organización; así mismo, los usuarios externos de los indicadores, motivados por la verificación de requisitos legales y evaluación del desempeño energético. $Y$, finalmente, el reto de contar con la cantidad y calidad de información necesaria para establecer los IDEn requeridos, acorde con el propósito y los usuarios definidos como lo presenta la Figura 44.
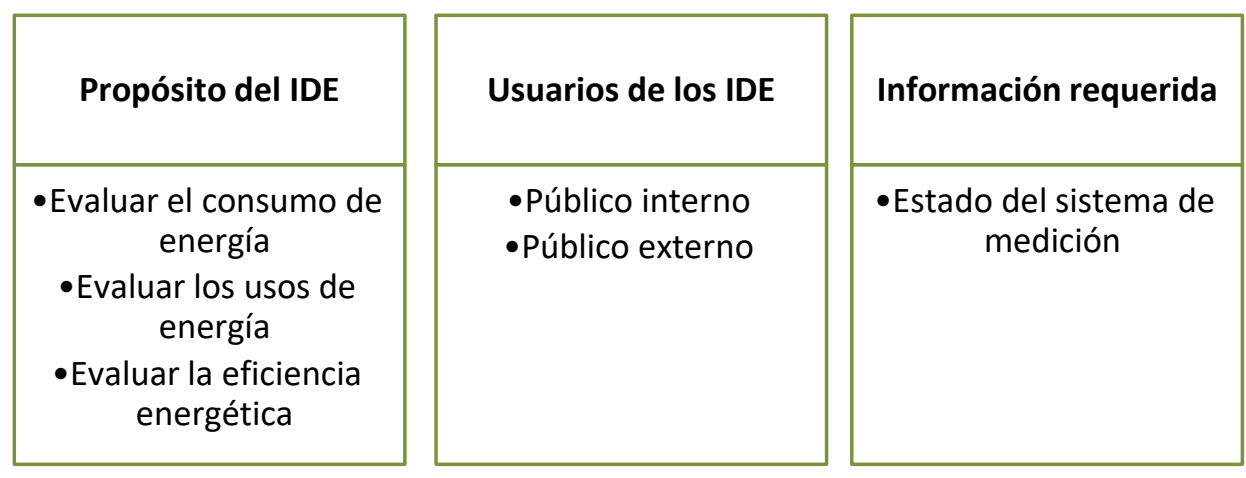

Figura 44. Aspectos para tener en cuenta en el establecimiento de indicadores de desempeño energético 
El propósito de los IDE es definido en la Norma ISO 50001 como la medición y seguimiento del desempeño energético, es decir, la evaluación del consumo de energía, el uso de la misma y la eficiencia energética, con referencia a la LBE establecida.

Así pues, cuantificar elementos específicos del desempeño energético, como lo es el uso, consumo o la eficiencia energética, implica requerimientos asociados a los datos energéticos y su medición; además, debe tener en cuenta métodos de medida, sin desconocer los retos asumidos por la organización cuando afronta la evaluación del desempeño energético.

Por ejemplo, cuantificar el consumo de energía puede basarse en mediciones puntuales o en línea. Ello resulta simple y funciona bien para el establecimiento de IDE en algunas instalaciones, en donde sus entradas no cambian estacionalmente, o con los niveles de producción y cuyos procesos no son muy dependientes de la temperatura. Por otro lado, la organización puede afrontar el reto de no contar con medición energética acorde con los requerimientos del SGEn.

Con respecto al uso de energía, este relaciona la cantidad de energía consumida para usos específicos. Típicamente los IDEn, para evaluar este aspecto del desempeño energético, se basan en una relación única, como, por ejemplo, el consumo de energía por unidad de producción ( $\mathrm{kWh} /$ unidad producción), para una instalación industrial; o consumo por área $\left(\mathrm{kWh} / \mathrm{m}^{2}\right)$, para una edificación. Para su elaboración, debe contarse con datos de cantidad de energía consumida y de la variable relacionada, cantidades de producción, área de edificios, entre otras. El reto que puede afrontar la organización al implementar indicadores para evaluar el uso de energía, al igual que el consumo, se debe a que la medición de energía existente no sea suficiente, o a la falta de datos de la variable de salida.

En cuanto a la eficiencia energética, definir un IDEn para su evaluación es muy similar a la cuantificación del uso, e implica especificar la cantidad de salidas producidas en relación a la energía consumida. Algunos ejemplos de IDE para la eficiencia energética son energía requerida/energía utilizada (donde la energía requerida puede ser derivada de un modelo teórico o de otra relación); y salida/entrada, puede ser aquella usada por toneladas de producción o los grados día de enfriamiento por unidad de energía usada.

Finalmente, los resultados medibles del desempeño energético, tales como el consumo, el uso y la eficiencia energética, pueden ser cuantificados y evaluados a través de IDE diseñados para estos propósitos.

Los IDEn determinados por la organización deben describir, adecuadamente, el desempeño energético en los distintos niveles, y para diferentes propósitos y usos. Los objetivos de los indicadores pueden ser específicos y relevantes para cierto personal encargado de gestionar la energía, a niveles particulares de la operación. 
Los IDEn pueden estar dirigidos a dos tipos de público: uno interno, motivado por la necesidad de gestionar el mejoramiento del desempeño energético; $y$, otro externo que se interesa en obtener la información derivada de requerimientos legales y otros. Este último público incluye actores regulatorios, asociaciones profesionales y sectoriales, y auditores en ISO 50001. En este sentido cada organización debe determinar por sí misma cómo desea cuantificar el desempeño energético, siguiendo algunos requisitos:

El indicador debe reflejar y demostrar la mejora del desempeño energético Los valores de los indicadores del desempeño energético establecidos deben ser comparados con sus respectiva(s) líneas base(s).

En caso de que existan variables relevantes que influyan en el valor del indicador y no puedan ser controlables (clima, producción, horas etc.) estas variables deben estar incluidas en la línea base para permitir que la comparación del indicador con su línea base sea en igualdad de condiciones de esas variables.

El método para determinar y actualizar los indicadores de desempeño establecidos debe mantenerse en el sistema como información documentada. A continuación, la Tabla 10 presenta los indicadores mayormente usados en la industria y edificios y sus ventajas y desventajas.

Tabla 10. Indicadores Típicos, ventajas y desventajas

\begin{tabular}{|c|c|c|c|c|c|}
\hline $\begin{array}{l}\text { Tipo de } \\
\text { indicador }\end{array}$ & Descripción & Uso & Ventajas & Desventajas & Observaciones \\
\hline $\begin{array}{c}\text { Consumo } \\
\text { especifico de } \\
\text { energía en la } \\
\text { industria }\end{array}$ & $\begin{array}{c}\text { Energia/resultado. } \\
\text { Ej. KWh /Kg } \\
\text { KWh /unidad } \\
\text { MMBTU/Ton }\end{array}$ & $\begin{array}{l}\text { Evaluación del } \\
\text { desempeño } \\
\text { energético } \\
\text { mediante el } \\
\text { consumo } \\
\text { unitario de } \\
\text { energía }\end{array}$ & $\begin{array}{l}\text { Muy usado en } \\
\text { la industria. } \\
\text { Permite } \\
\text { asociación al } \\
\text { costo unitario } \\
\text { de energía. }\end{array}$ & $\begin{array}{l}\text { Es influenciado por } \\
\text { los cambios en la } \\
\text { producción o la } \\
\text { variable unitaria } \\
\text { (denominador) de } \\
\text { los períodos a } \\
\text { comparar. }\end{array}$ & $\begin{array}{c}\text { Requiere ser } \\
\text { utilizado para } \\
\text { iguales valores de } \\
\text { la producción de } \\
\text { los períodos a } \\
\text { comparar. Y } \\
\text { mediante línea } \\
\text { base del indicador. }\end{array}$ \\
\hline $\begin{array}{l}\text { Consumo } \\
\text { específico de } \\
\text { energía en } \\
\text { sector } \\
\text { comercial }\end{array}$ & $\begin{array}{c}\text { Energia/parámetro } \\
\text { Ej. KWh /m2 de } \\
\text { superficie } \\
\text { KWh / visitante }\end{array}$ & $\begin{array}{l}\text { Evaluación del } \\
\text { desempeño } \\
\text { energético } \\
\text { mediante el } \\
\text { consumo de } \\
\text { energía } \\
\text { referido a: m2 } \\
\text { de superficie; } \\
\text { visitantes; } \\
\text { empleados }\end{array}$ & $\begin{array}{l}\text { En caso que el } \\
\text { consumo de } \\
\text { energía se } \\
\text { refiera a } \\
\text { parámetros } \\
\text { que no } \\
\text { cambian (m2 } \\
\text { de superficie) } \\
\text { es preciso. En } \\
\text { caso contrario } \\
\text { no. }\end{array}$ & $\begin{array}{l}\text { En caso que el } \\
\text { consumo de } \\
\text { energía este } \\
\text { referido a } \\
\text { parámetros que } \\
\text { cambian (cantidad } \\
\text { de empleados; } \\
\text { visitantes), es } \\
\text { influenciado por } \\
\text { los cambios de } \\
\text { estos parámetros } \\
\text { de los periodos a } \\
\text { comparar. }\end{array}$ & $\begin{array}{l}\text { Requiere ser } \\
\text { utilizado para } \\
\text { iguales valores de } \\
\text { los parámetros } \\
\text { que pueden } \\
\text { cambiar de los } \\
\text { períodos a } \\
\text { comparar. } \\
\text { Requiere ser } \\
\text { utilizado mediante } \\
\text { línea base del } \\
\text { indicador. }\end{array}$ \\
\hline
\end{tabular}




\begin{tabular}{|c|c|c|c|c|c|}
\hline $\begin{array}{c}\text { Presupuesto de } \\
\text { energía }\end{array}$ & $\begin{array}{l}\text { Energia*Tarifa } \\
\text { Ej. \$/mes; } \\
\text { \$/año de } \\
\text { energéticos. }\end{array}$ & $\begin{array}{c}\text { Evaluación del } \\
\text { desempeño } \\
\text { energético } \\
\text { mensual } \\
\text { mediante } \\
\text { cumplimiento } \\
\text { del } \\
\text { presupuesto } \\
\text { de energía. }\end{array}$ & $\begin{array}{l}\text { Indicador } \\
\text { usado en } \\
\text { otras áreas. } \\
\text { Cultura de uso } \\
\text { a nivel } \\
\text { gerencial. }\end{array}$ & $\begin{array}{l}\text { Es influenciado por } \\
\text { los cambios en la } \\
\text { producción o la } \\
\text { variable unitaria } \\
\text { (denominador) de } \\
\text { los períodos a } \\
\text { comparar. }\end{array}$ & $\begin{array}{l}\text { Requiere ser } \\
\text { utilizado para } \\
\text { iguales valores de } \\
\text { la producción de } \\
\text { los períodos a } \\
\text { comparar. } \\
\text { Requiere ser } \\
\text { utilizado mediante } \\
\text { línea base del } \\
\text { indicador. }\end{array}$ \\
\hline $\begin{array}{l}\text { Consumo de } \\
\text { energía/unidad } \\
\text { de tiempo }\end{array}$ & $\begin{array}{l}\mathrm{KWH} / \text { mes } \\
\mathrm{KWh} / \text { año }\end{array}$ & $\begin{array}{l}\text { Evaluación del } \\
\text { desempeño } \\
\text { por consumo } \\
\text { de energía en } \\
\text { iguales } \\
\text { periodos de } \\
\text { tiempo. }\end{array}$ & $\begin{array}{l}\text { Permite } \\
\text { rápida } \\
\text { asociación al } \\
\text { costo de la } \\
\text { energía. }\end{array}$ & $\begin{array}{c}\text { Es preciso para } \\
\text { evaluar el } \\
\text { desempeño, solo } \\
\text { cuando las } \\
\text { variables no } \\
\text { controlables por la } \\
\text { gestión se } \\
\text { mantienen } \\
\text { constantes } \\
\text { (temperatura } \\
\text { ambiente, } \\
\text { producción, } \\
\text { visitantes etc..) } \\
\end{array}$ & $\begin{array}{l}\text { Requiere ser } \\
\text { utilizado mediante } \\
\text { línea base del } \\
\text { indicador. }\end{array}$ \\
\hline $\begin{array}{l}\text { Modelos de } \\
\text { línea base }\end{array}$ & $\begin{array}{l}\quad \mathrm{E}=\mathrm{m} * \mathrm{P}+\mathrm{Eo} \\
\quad \mathrm{E}=\mathrm{m} 1 * \mathrm{~V} 1+ \\
\mathrm{m} 2 * \mathrm{~V} 2+\ldots \mathrm{mn} * \mathrm{Vn}+ \\
\quad \text { Eo } \\
\text { Donde: } \\
\text { E- consumo de } \\
\text { energía o índice de } \\
\text { consumo de } \\
\text { Energía, } \mathrm{m} 1, \\
\text { m2.mn- constantes } \\
\text { del modelo } \\
\mathrm{P}-\text { producción } \\
\mathrm{V} 1, \mathrm{~V} 2, \mathrm{Vn}- \\
\text { variables } \\
\text { significativas no } \\
\text { controlables } \\
\text { Eo- constante }\end{array}$ & $\begin{array}{c}\text { Evaluación del } \\
\text { desempeño } \\
\text { energético } \\
\text { mediante } \\
\text { comparación } \\
\text { del indicador } \\
\text { real con un } \\
\text { indicador } \\
\text { base, } \\
\text { obtenido } \\
\text { mediante un } \\
\text { modelo } \\
\text { univariable o } \\
\text { multivariable, } \\
\text { estadístico, en } \\
\text { un periodo } \\
\text { base }\end{array}$ & $\begin{array}{c}\text { Mayor } \\
\text { precisión en la } \\
\text { evaluación del } \\
\text { desempeño al } \\
\text { considerar } \\
\text { más variables. }\end{array}$ & $\begin{array}{l}\text { Mayor complejidad } \\
\text { por la elaboración } \\
\text { de la línea base y la } \\
\text { identificación de } \\
\text { las variables que } \\
\text { deben integrar el } \\
\text { modelo. }\end{array}$ & $\begin{array}{l}\text { Requiere de una } \\
\text { selección } \\
\text { adecuada de la } \\
\text { información del } \\
\text { período base para } \\
\text { elaborar el } \\
\text { modelo; de una } \\
\text { selección } \\
\text { adecuada de las } \\
\text { variables que } \\
\text { intervienen en el } \\
\text { modelo y de la } \\
\text { verificación del } \\
\text { grado de } \\
\text { significación del } \\
\text { modelo. }\end{array}$ \\
\hline
\end{tabular}

A continuación, se presentan en la Figura 45 algunos errores comunes al seleccionar los IDEn. 


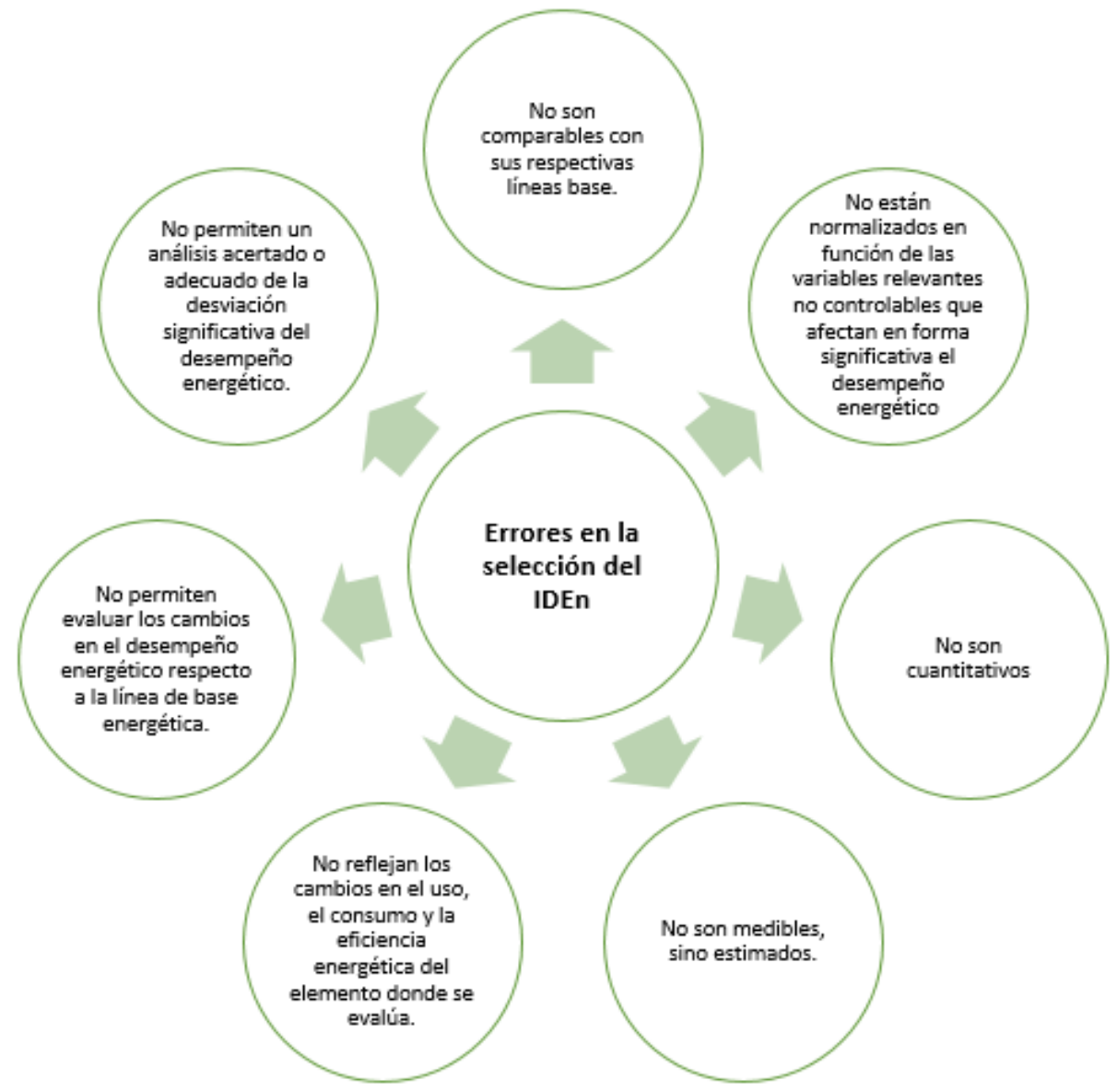

Figura 45. Errores comunes en la selección del IDEn

\subsubsection{Indicadores de Desempeño Energético en Edificaciones}

Los Indicadores de Desempeño Energético son clavea para medir el nivel del rendimiento energético de un proceso.

Para el caso de los indicadores de eficiencia energética [30] estos pueden ser agregados (por ejemplo, el consumo total de la edificación) o desagregados (por ejemplo, el consumo de calefacción por área o por piso). Los indicadores por lo general se componen de un consumo de energía como numerador y una información de actividad como denominador.

Dentro de la literatura se encuentran artículos donde los autores han desarrollado y/o propuesto una serie de indicadores para de gestión energética. Como es el caso de Marinakis y Doukas [31] quienes en el artículo "An Advanced loT-based System for Intelligent Energy Management in Buildings" proponen los indicadores de gestión energética enseñados en la Tabla 11. 
CAPÍTULO 2: SISTEMA DE GESTIÓN ENERGÉTICA. HERRAMIENTAS DE LA PLANIFICACIÓN ENERGÉTICA

Tabla 11. Indicadores para la gestión energética

\begin{tabular}{|c|c|c|}
\hline Índice & Nombre de KPI & Unidad \\
\hline I-11 & Energía eléctrica por superficie & $\mathrm{KWh} / \mathrm{m} 2$ \\
\hline I-12 & Energía eléctrica por superficie y por tipo de uso & $\begin{array}{c}\mathrm{kWh} / \mathrm{m} 2 \text { por tipo de uso } \\
\text { (iluminación, refrigeración y } \\
\text { otro uso) }\end{array}$ \\
\hline $\mathrm{I}-13$ & $\begin{array}{l}\text { Consumo de combustible para calefacción por } \\
\text { superficie }\end{array}$ & It/m2 para gas natural \\
\hline $\mathrm{I}-14$ & Energía eléctrica por superficie y usuario & $\begin{array}{c}\mathrm{KWh} / \mathrm{m} 2 / \text { persona o } \\
\mathrm{KWh} / \mathrm{m} 2 / \text { hora usuario }\end{array}$ \\
\hline I-15 & $\begin{array}{l}\text { Consumo de combustible para calefacción por } \\
\text { superficie }\end{array}$ & It/m2/persona \\
\hline $\mathrm{I}-21$ & Potencia eléctrica & $\mathrm{kW}$ \\
\hline $\mathbf{I}-22$ & Factor de potencia & $\cos \phi$ \\
\hline I-31 & $\begin{array}{c}\text { Emisiones de CO2 por consumo de energía eléctrica } \\
\text { por superficie }\end{array}$ & $\mathrm{Kg} \mathrm{CO} 2 / \mathrm{m} 2$ \\
\hline I-32 & $\begin{array}{l}\text { Emisiones de CO2 por consumo de combustible para } \\
\text { calefacción por superficie }\end{array}$ & $\mathrm{Kg} \mathrm{CO} 2 / \mathrm{m} 2$ \\
\hline $\mathrm{I}-33$ & Energía producida por fuentes renovables en sitio & kWh \\
\hline $\mathrm{I}-41$ & Facturación de Energía por superficie & $\$ / \mathrm{m} 2$ \\
\hline $1-42$ & $\begin{array}{l}\text { Facturación de combustible para calefacción por } \\
\text { superficie }\end{array}$ & $\$ / m 2$ \\
\hline $1-43$ & Correlación grados día y usuarios & NA \\
\hline
\end{tabular}

Fuente: An Advanced loT-based System for Intelligent Energy Management in Buildings [30].

Según la tabla, el primer grupo de indicadores se enfocan en reportar el consumo de energía del edificio, ya sea de electricidad y otros energéticos. I-11, I-12, I-13 correlacionan el uso de la energía con los metros cuadrados del edificio, ya sea reportando el indicador total o por tipo de uso (iluminación, refrigeración y otro uso). I-14, I-15 son más detallados y proporcionan información del consumo energética por ocupación.

El segundo grupo de indicadores I-21, I-22 tiene un enfoque más técnico con el fin de proporcionar información sobre la operación y la identificación de fallas.

El tercer grupo I-31, I-32; I-33 mide el impacto ambiental asociado al uso de la energía.

El cuarto grupo I-42, I-43 es una medida que relaciona el costo del energético utilizado por unidad de superficie y las oportunidades a través de la correlación con los grados día y los usuarios.

Por su parte Pinzón et al. [31] presenta la importancia de establecer indicadores energéticos en los edificios como base de comparación y monitorización para controlar y reducir las pérdidas energéticas de las distintas actividades y evaluar los potenciales de reducción de dichas pérdidas, los indicadores deben contar con las siguientes características:

- Ser relevante

- Ser entendible 
- Basado e información confiable

- Transparente y verificable

- Basado en información específica con relación al proceso/sistema y el tiempo

- Poder medir cambios en una condición o situación a través del tiempo

- Que permita observar de cerca los resultados de iniciativas o acciones

- Ser instrumentos valiosos para determinar cómo se pueden alcanzar mejores resultados en proyectos de desarrollo

El artículo propone 4 tipos de indicadores presentados en la Tabla 12.

Tabla 12.Clasificación de KPI o Indicadores energéticos para edificios

\begin{tabular}{|c|c|c|c|c|c|}
\hline \multicolumn{6}{|c|}{ Nivel 1 de indicadores energéticos. Por dependencias/ zonas/pisos } \\
\hline Indicador & \multicolumn{2}{|c|}{$\begin{array}{l}\text { Dependencia, } \\
\text { zona o piso }\end{array}$} & \multicolumn{2}{|c|}{ Unidad } & Fuente de información \\
\hline \multirow{3}{*}{$\begin{array}{l}\text { Índice de consumo } \\
\text { energético por piso }\end{array}$} & \multicolumn{2}{|c|}{ Piso 1} & \multirow{3}{*}{\multicolumn{2}{|c|}{$\mathrm{kWh} / \mathrm{mes}-\mathrm{m} 2$}} & $\begin{array}{l}\text { Los consumos a partir de } \\
\text { los medidores a instalar y }\end{array}$ \\
\hline & \multicolumn{2}{|c|}{ Piso 2} & & & construidas (en $\mathrm{m}^{2}$ ) de los \\
\hline & \multicolumn{2}{|c|}{ Piso $n$} & & & planos arquitectónicos \\
\hline \multirow{3}{*}{$\begin{array}{l}\text { Índice de potencia } \\
\text { instalada por piso }\end{array}$} & \multicolumn{2}{|c|}{ Piso 1} & \multirow{3}{*}{\multicolumn{2}{|c|}{$\mathrm{W} / \mathrm{m}^{2}$}} & Potencia instalada del \\
\hline & \multicolumn{2}{|c|}{ Piso 2} & & & $\begin{array}{c}\text { de equipos actualizado y el } \\
\text { área de los planos }\end{array}$ \\
\hline & \multicolumn{2}{|c|}{ Piso $n$} & & & arquitectonicos. \\
\hline \multicolumn{6}{|c|}{ Nivel 2 de indicadores energéticos. Por equipos/sistemas principales } \\
\hline $\begin{array}{c}\text { Indicador } \\
\text { Sistema/equipo }\end{array}$ & \multicolumn{2}{|c|}{$\begin{array}{c}\text { Indicador } \\
\text { Sistema/equipo }\end{array}$} & \multicolumn{2}{|c|}{ Unidad } & Fuente de información \\
\hline \multirow{3}{*}{$\begin{array}{l}\text { Índice de consumo } \\
\text { energético por } \\
\text { aplicación }\end{array}$} & \multicolumn{2}{|c|}{$\begin{array}{l}\text { Equipos de } \\
\text { cómputo }\end{array}$} & \multirow{3}{*}{\multicolumn{2}{|c|}{$\mathrm{kWh} / \mathrm{mes}-\mathrm{m}$}} & $\begin{array}{l}\text { Los consumos a partir de } \\
\text { los medidores a instalar }\end{array}$ \\
\hline & \multicolumn{2}{|c|}{ Iluminación } & & & y las dimensiones físicas \\
\hline & \multicolumn{2}{|c|}{ HVAC } & & & $\begin{array}{l}\text { construidas }\left(e n \mathrm{~m}^{2} \text { ) de los }\right. \\
\text { planos arquitectónicos }\end{array}$ \\
\hline \multirow{3}{*}{$\begin{array}{l}\text { Índice de potencia } \\
\text { instalada por } \\
\text { aplicación }\end{array}$} & \multicolumn{2}{|c|}{$\begin{array}{l}\text { Equipos de } \\
\text { cómputo }\end{array}$} & \multirow{3}{*}{\multicolumn{2}{|c|}{$\mathrm{W} / \mathrm{m}^{2}$}} & $\begin{array}{l}\text { Potencia instalada del } \\
\text { aforo de carga o inventario }\end{array}$ \\
\hline & \multicolumn{2}{|c|}{ Iluminación } & & & de equipos actualizado \\
\hline & \multicolumn{2}{|c|}{ HVAC } & & & $\begin{array}{l}\text { y el área de los planos } \\
\text { Arquitectónicos. }\end{array}$ \\
\hline \multicolumn{6}{|c|}{ Nivel 3 de indicadores energéticos. Por edificio } \\
\hline \multicolumn{2}{|c|}{ Indicador Sistema/equipo } & \multicolumn{2}{|c|}{ Unidad } & \multicolumn{2}{|c|}{ Fuente de información } \\
\hline \multicolumn{2}{|c|}{$\begin{array}{l}\text { Índice de consumo energético } \\
\text { por área total }\end{array}$} & \multicolumn{2}{|c|}{$\mathrm{kWh} / \mathrm{mes}-\mathrm{m}^{2}$} & \multicolumn{2}{|c|}{$\begin{array}{l}\text { A partir de las facturas de energía y de } \\
\text { los planos arquitectónicos. }\end{array}$} \\
\hline
\end{tabular}


CAPÍTULO 2: SISTEMA DE GESTIÓN ENERGÉTICA. HERRAMIENTAS DE LA PLANIFICACIÓN ENERGÉTICA

\begin{tabular}{|c|c|c|}
\hline $\begin{array}{c}\text { Índice de potencia instalada } \\
\text { por área total. }\end{array}$ & $\mathrm{W} / \mathrm{m}^{2}$ & $\begin{array}{c}\text { Potencia total instalada del inventario } \\
\text { de equipos o de un censo de carga y } \\
\text { área de los planos arquitectónicos. }\end{array}$ \\
\hline $\begin{array}{c}\text { Índice de consumo energético } \\
\text { por persona. }\end{array}$ & $\mathrm{kWh} / \mathrm{mes}$-persona & $\begin{array}{c}\text { Número total de empleados y calcular el } \\
\text { promedio de estudiantes en el edificio. }\end{array}$ \\
\hline $\begin{array}{c}\text { Índice de potencia instalada } \\
\text { por persona. }\end{array}$ & $\mathrm{W} /$ persona & $\begin{array}{c}\text { Potencia total instalada del inventario } \\
\text { de equipos o censo de carga y con el } \\
\text { número total de empleados sumado } \\
\text { al promedio de estudiantes en el } \\
\text { edificio. }\end{array}$ \\
\hline \multicolumn{2}{|c|}{ Nivel 4 de indicadores energéticos. Emisiones } \\
\hline $\begin{array}{c}\text { Indicador de emisiones de CO2 } \\
\text { por área de edificio }\end{array}$ & Unidad & Fuente de información \\
\hline $\begin{array}{c}\text { Índice de emisiones de CO2 } \\
\text { por persona }\end{array}$ & $\mathrm{kg} \mathrm{CO2/mes-persona}$ & $\begin{array}{c}\text { Convertir los consumos } \\
\text { energéticos en emisiones } \\
\text { CO2 con el índice actual }\end{array}$ \\
\hline
\end{tabular}

Fuente: Implementación de indicadores energéticos en centros educativos CASO DE ESTUDIO:

Edificio Alejandro Suárez Copete- Universidad Distrital Francisco José de Caldas [32].

Dentro de los indicadores principales más utilizados en análisis de desempeño energético en edificaciones en los países de la Unión Europea se encuentran:

- Las emisiones anuales de $\mathrm{CO} 2$ ( $\mathrm{kg} \mathrm{CO} 2 / \mathrm{m}^{2}$ de superficie útil).

- Consumo anual de energía primaria ( $\left.\mathrm{kWh} / \mathrm{m}^{2} \mathrm{año}\right)$.

Dependiendo del país contarán con uno u otro como indicador principal. Además, existen una serie de indicadores complementarios de eficiencia energética que son:

- Energía primaria no renovable anual ( $\mathrm{KWh} / \mathrm{m}^{2} \mathrm{año}$.

- Energía primaria anual procedente de fuentes renovables ( $\mathrm{KWh} / \mathrm{m}^{2} \mathrm{año}$ ).

- Porcentaje de energía primaria anual procedente de fuentes de energías renovables respecto a la energía primaria total anual.

- Energía primaria total anual desagregada por usos de calefacción, refrigeración, producción de agua corriente sanitaria e iluminación ( $\mathrm{KWh} / \mathrm{m}^{2}$ año).

- Demanda energética anual de calefacción ( $\mathrm{KWh} / \mathrm{m}^{2}$ año).

- Demanda energética anual de refrigeración ( $\mathrm{KWh} / \mathrm{m}^{2}$ año).

- Las emisiones anuales de CO2 desagregadas por servicios. 


\subsubsection{Indicadores de Gestión Energética}

\section{Indicador de Eficiencia IEE:}

Es un indicador de gestión energética que refleja el comportamiento de los resultados del desempeño energético respecto a la línea de base energética tomando como cumplimiento el valor 1.

Representa en qué porcentaje el consumo de energía de un área, proceso o equipo, ha alcanzado el valor del consumo de la línea de base energética, para iguales cantidades de la variable relevante con la que se construyó la línea base.

Permite conocer en qué porcentaje se aumentó o disminuyó el desempeño energético por causa de un cambio en la eficiencia energética de la tecnología o el proceso, un cambio en las prácticas de uso de la energía o un cambio en el consumo, influenciado por el estado técnico o del mantenimiento de la tecnología.

El indicador se forma por la siguiente expresión:

$$
I E E=\frac{E_{\text {medida }}}{E_{\text {Base }}}
$$

Donde:

$E_{B a s e}=$ Energía que teóricamente se debió consumir según la línea base ( $\left.m^{*} \mathrm{P}+\mathrm{E} 0\right)$

$E_{\text {medida }}=$ valor real del consumo de energía medido.

Si IEE > 1 hay una disminución del desempeño ya que el consumo de energía fue superior al de la línea de base establecida como referencia.

Si IEE $1<1$ hay una mejora del desempeño, puesto que el consumo de energía fue inferior al de la línea de base establecida como referencia, como se ilustra en la Figura 46. 


$$
I E E=\frac{E_{\text {medida }}}{E_{\text {Base }}}
$$

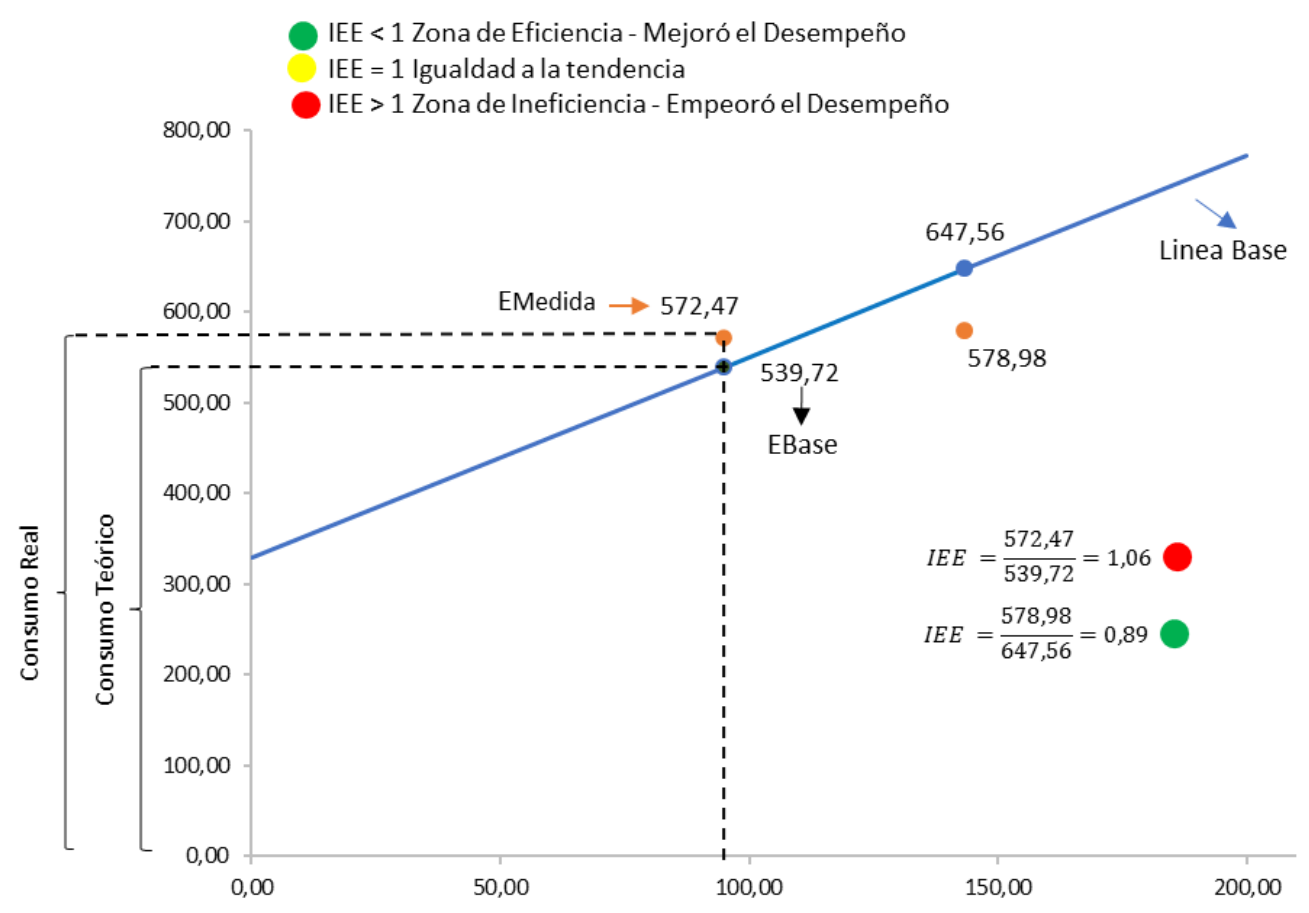

Figura 46. Gráfico ilustrativo del indicador de Eficiencia Energética.

El valor del indicador, en el intervalo de tiempo que sea calculado (horario, diario, mensual, etc.) puede ser graficado. El valor 1 en el gráfico será el valor de cumplimiento del desempeño energético (igual al de la línea base), por encima de 1 será la zona de no conformidad del desempeño y por debajo de 1 la zona de conformidad del desempeño, según se presenta en la Figura 47.

Indicador de Eficiencia Energética

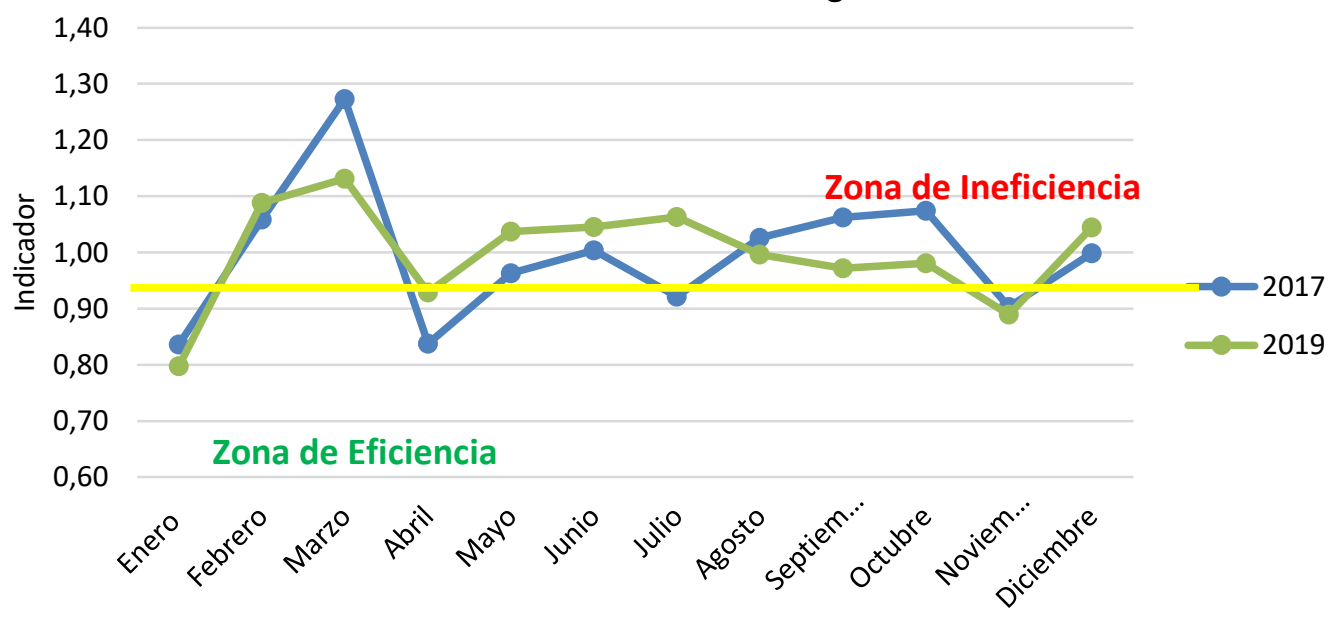

Figura 47. Gráfica seguimiento Indicador de Eficiencia IEE 
Este indicador [33] ha sido incorporado recientemente por el protocolo EVO (Energy Performance Indicator (SEnPI)) para hacer seguimiento al desempeño energético en su programa Superior Energy Performance 50001 ${ }^{\text {TM }}$ (SEP 50001TM).

\section{Indicador de tendencia del desempeño energético (CUSUM)}

El indicador de tendencia del desempeño energético consiste en conocer cuál es la tendencia acumulada de las desviaciones del consumo de energía real respecto al de la línea de base energética.

La tendencia de las desviaciones puede tener tres alternativas de comportamiento:

- Oscilaciones entre valores negativos y positivos alrededor del valor cero: indica que no existe una variable relevante que mueva la tendencia de forma permanente hacia arriba o hacia abajo del valor 0 . Por tanto, sería indicativo que el proceso está bajo control y no está impactado por una mejora o desmejora del desempeño.

- Tendencia ascendente sobre el valor cero: indica que las desviaciones del consumo de energía real respecto al consumo de la línea de base energética se mantienen, es decir, que el consumo real es mayor al consumo base.

- Tendencia descendente sobre el valor cero: el consumo real es menor que el consumo base.

Si hay un cambio de tendencia de ascendente a descendente o viceversa, indica el efecto de una o más variables relevantes sobre el consumo de energía. Un cambio de pendiente del gráfico ascendente o descendente indica también la influencia de una nueva variable en el mismo sentido de la tendencia. Es decir, me indica la presencia de un factor permanente que afecta esa desviación.

Para construir el indicador de tendencia de desempeño energético se utiliza la técnica estadística CUSUM (cumulative-sum) que significa suma acumulada. Los gráficos CUSUM se basan en la representación de la acumulación de las desviaciones de cada observación respecto a un valor de referencia.

Con la técnica CUSUM se obtendrá la suma acumulativa de las desviaciones del valor del consumo de energía real respecto al consumo de la línea de base energética. Para ello, es necesario calcular la diferencia entre el consumo energético real y el consumo de la línea de base energética:

$$
\text { Suma acumulativa }=\left(E_{r}-E_{L B}\right)_{i}+\left(E_{r}-E_{L B}\right)_{i-1}
$$

Donde:

$\left(E_{r}-E_{L B}\right)_{i}$ : Diferencia entre el valor del consumo de energía real respecto al consumo de la línea de base energética para el periodo $i$. 
$\left(E_{r}-E_{L B}\right)_{i-1}$ : Diferencia entre el valor del consumo de energía real respecto al consumo de la línea de base energética para el periodo inmediatamente anterior.

El primer valor de desviación del consumo de energía en la suma acumulativa coincide con $E_{r}-E_{L B}$. El segundo valor de la revisión de la desviación, en la suma acumulativa, es la suma de la primera desviación más la segunda y así sucesivamente.

Las ventajas del indicador de tendencia CUSUM son:

- Indica la tendencia del desempeño en un periodo dado.

- Permite saber el momento de cambio de tendencia y asociarlo con el cambio de las variables de control operacional o eventos.

- El valor final cuantitativo es el ahorro o desahorro obtenido del desempeño en el periodo analizado.

- Permite cuantificar en el tiempo cuánto cuesta en energía no actuar sobre la tendencia a desmejorar el desempeño energético.

\subsubsection{Indicadores de Impacto Ambiental}

Indicador de emisiones de $\mathrm{CO}_{2}$

El ahorro energético de cualquier fuente trae asociado una mejora ambiental producto de las llamadas emisiones indirectas, las cuales dependen de la fuente de generación o del combustible utilizado. El Factor de Emisiones, representa la cantidad de $\mathrm{CO} 2$ que se libera de la producción de cada unidad de electricidad, o en el caso de combustibles, la cantidad de $\mathrm{CO} 2$ que se libera por unidad consumida de este energético. El indicador de emisiones de CO2 consistirá en la comparación de la cantidad de CO2 emitidas con la cantidad de emisiones calculadas con la línea base.

Es el producto del ahorro y/o sobreconsumos por el factor de emisión de CO2e. Sus unidades son $\mathrm{Kg}$ de $\mathrm{CO} 2 \mathrm{e}$ y dependerá de las fuentes de generación de la energía que es suministrada al proceso y/o USEn.

Este indicador nos brinda información de las emisiones de dióxido de carbono equivalente (CO2e) dejadas de emitir o emitidas respecto a la línea de base energética establecida.

$$
I_{M}=C_{\text {final }} * \text { FactorElectricidad }{ }_{C O 2}
$$

\subsubsection{Indicadores para edificios cero energía nZEB}

Los indicadores de uso final más usados corresponden a Indicadores de edificios de consumo de energía casi nulo nZEB.

El nuevo CTE-HE 2018 [31] establecerá una serie de limitaciones a los siguientes indicadores: 


\section{Indicador de Consumo de Energía Primaría Total}

El objetivo del indicador de consumo de energía primaria total [34], [35] es asegurar un equilibrio entre el uso eficiente de energía procedente de fuentes renovables y el uso de estrategias de reducción de la demanda. El indicador aparece como "equivalente" a un indicador de limitación de la demanda, ya que para alcanzar un valor límite, debe reducirse al máximo la demanda o mejorar la eficiencia de las instalaciones.

El indicador de energía primaria resume toda la energía entregada y exportada (electricidad, calefacción y refrigeración urbanas, combustibles) en un solo indicador, y se calcula a partir de la energía entregada y exportada con el factor de energía primaria nacional como:

$$
E_{p, n r e m}=\sum_{i}\left(E_{\text {del, } i} f_{\text {del,nren }, i}\right)-\sum_{i}\left(E_{\text {exp }, i} f_{\text {del,exp }, i}\right)
$$

Donde:

$E_{p, n r e m}:$ Energía primaria no renovable $(\mathrm{kWh} / \mathrm{a})$

$E_{d e l, i}$ : Energía suministrada in situ o cerca $(\mathrm{kWh} / \mathrm{a})$ del vector energético i

$f_{\text {del,nren, } i}$ : Factor de energía primaria no renovable del vector energético suministrado i

$E_{\text {exp }, i}$ : Energía exportada in situ o cercana ( $\left.\mathrm{kWh} / \mathrm{a}\right)$ o el vector energético i

$f_{\text {del,exp }, i}$ : Factor de energía primaria no renovable de la energía suministrada compensado por la energía exportada para el vector energético i, que es por defecto igual al factor de la energía suministrada, si no está definido a escala nacional de otra manera.

$$
E P_{p}=\frac{E_{p, n r e m}}{A_{\text {net }}}
$$

$E P_{p}:$ Indicador de energía primaria $(\mathrm{kWh} / \mathrm{m} 2 \cdot \mathrm{a})$

$E_{p, n r e m}:$ Energía primaria no renovable $(\mathrm{kWh} / \mathrm{a})$

$A_{n e t}$ : Área útil (m2) calculado según la definición nacional

\section{Indicador de Consumo de energía primaria no renovable}

El objetivo del indicador de consumo de energía primaria no renovable (Cep;nren) [34], [35] es limitar el uso de recursos no renovables para reducir las emisiones asociadas de gases de efecto invernadero, favorecer la independencia energética y evitar el agotamiento de recursos no renovables

Limitando el consumo de energía primaria no renovable, se pretende promover el uso de la energía procedente de fuentes renovables. Se trata de un indicador que se utiliza actualmente, comprensible por los agentes del sector y fácil de calcular, ya que contamos con factores de conversión entre energías finales y energía primaria no renovable. 
Este indicador forma parte de los recogidos por la norma ISO 52000-1. En esta norma se establece una posibilidad de diferenciar dos indicadores en función de si la energía renovable se ha producido en el propio edificio o no. La generación de energía renovable in situ puede producirse mediante energía solar térmica o fotovoltaica y energía mini-eólica. También tienen consideración de energía renovable la biomasa y la geotermia, hidrotermia y aerotermia.

$$
E_{\text {p,nrem }}=C E T_{R E D_{\text {Medido }}} * f_{\text {nrem Colombia }}
$$

Donde:

$E_{p, n r e m}$ : Energía primaria no renovable $(\mathrm{kWh} / \mathrm{a})$

$C E T_{R E D_{\text {Medido }}}$ : Medida del Consumo Eléctrico Total de la red

$f_{\text {nrem }}$ Colombia $:$ Factor de Electricidad no Renovable para Colombia obtenido de la matriz energética

\section{Indicador de Consumo de energía primaria renovable}

Para calcular la cuota de uso de energías renovables, la proporción de energías renovables RER, todas las fuentes de energía renovables tienen que ser contabilizadas. Entre ellas se incluyen la energía solar térmica, la electricidad solar, la energía eólica e hidroeléctrica, la energía renovable captada a partir de fuentes de calor ambiente mediante bombas de calor y la refrigeración gratuita, los combustibles renovables y la energía renovable fuera del emplazamiento. Las fuentes de calor ambiente de las bombas de calor y la free-cooling deben incluirse en el límite del sistema de uso de energía renovable, porque en el cálculo de la RER, las bombas de calor y la free-cooling no sólo se tienen en cuenta en el cálculo de la energía suministrada basado en el COP, sino también en la energía extraída de las fuentes de calor ambiente.

La proporción de energía renovable se calcula en relación con todo el uso de energía en el edificio, en términos de energía primaria total. Se tiene en cuenta que la energía exportada compensa la energía entregada. Por defecto, se considera que la energía exportada compensa la mezcla de la red o, en el caso de la energía térmica, la mezcla de la red de calefacción o refrigeración urbana. Para la energía renovable in situ y cercana, el factor de energía primaria total es 1,0, y el factor de energía primaria no renovable es 0.

La ecuación RER basada en la energía primaria total es la siguiente:

$$
R E R_{p}=\frac{\sum_{i} E_{\text {ren }, i}+\sum_{i}\left(\left(f_{\text {del }, \text { tot }, i}-f_{\text {del }, \text { nrem }, i}\right) E_{\text {del }, i}\right)}{\sum_{i} E_{\text {ren }, i}+\sum_{i}\left(E_{\text {del }, i} f_{\text {del }, \text { tot }, i}\right)-\sum_{i}\left(E_{\text {exp }, i} f_{\text {exp }, \text { tot }, i}\right)}
$$

Donde:

$R E R_{p}$ : Proporción de energía renovable basada en la energía primaria total

$E_{r e n, i}$ : Energía renovable producida in situ o en las proximidades para el vector energético i, $(\mathrm{kWh} / \mathrm{a})$

$f_{d e l, t o t, i}$ : Factor de energía primaria total del vector energético suministrado i

$f_{\text {del,nren,i }}$ : Factor de energía primaria no renovable para el vector energético suministrado i 
$E_{d e l, i}$ : Energía suministrada en el lugar o en las cercanías ( $\left.\mathrm{kWh} / \mathrm{a}\right)$ para el vector energético i

$f_{\text {exp,tot }, i}$ : Factor de energía primaria total de la energía suministrada compensado por la energía exportada para el vector energético $i$

$E_{\text {exp }, i}$ : Energía exportada in situ o en las cercanías (kWh/a) para el vector energético i

Donde:

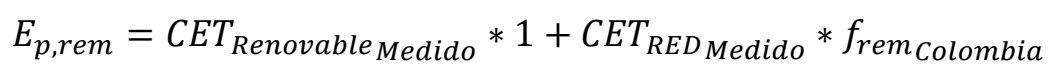

$E_{p, r e m}:$ Energía primaria renovable (kWh/a)

$C E T_{\text {Renovable }}$ Medido: Medida del Consumo Eléctrico Total generado de Energía removable $C E T_{R E D_{\text {Medido }}}$ : Medida del Consumo Eléctrico Total de la red

$f_{\text {rem }}$ Colombia : Factor de Electricidad Renovable para Colombia obtenido de la matriz energética 


\section{BIBLIOGRAFÍA}

[1]IEA, "Indicadores de Eficiencia Energética: Bases Esenciales para el Establecimiento de Políticas", Agencia Int. Energía, p. 182, 2015.

[2]A. McKane et al., "Predicting the quantifiable impacts of ISO 50001 on climate change mitigation", Energy Policy, vol. 107, núm. May, pp. 278-288, 2017.

[3]H. Kanneganti et al., "Specification of energy assessment methodologies to satisfy ISO 50001 energy management standard", Sustain. Energy Technol. Assessments, vol. 23, núm. September, pp. 121-135, 2017.

[4]B. Gopalakrishnan, K. Ramamoorthy, E. Crowe, S. Chaudhari, y H. Latif, "A structured approach for facilitating the implementation of ISO 50001 standard in the manufacturing sector", Sustain. Energy Technol. Assessments, vol. 7, pp. 154-165, 2014.

[5]M. Benedetti, V. Cesarotti, y V. Introna, "From energy targets setting to energy-aware operations control and back: An advanced methodology for energy efficient manufacturing", J. Clean. Prod., vol. 167, pp. 1518-1533, 2018.

[6]W. A. Pelser, J. C. Vosloo, y M. J. Mathews, "Results and prospects of applying an ISO 50001 based reporting system on a cement plant", J. Clean. Prod., vol. 198, pp. 642-653, 2018.

[7]F. Bonacina, A. Corsini, L. De Propris, A. Marchegiani, y F. Mori, "Industrial Energy Management Systems in Italy: state of the art and perspective", vol. 82, pp. 562-569, 2015. [8]B. Jovanović, J. Filipović, y V. Bakić, "Energy management system implementation in Serbian manufacturing - Plan-Do-Check-Act cycle approach”, J. Clean. Prod., vol. 162, núm. 2017, pp. 1144-1156, 2017.

[9]V. António da Silva Gonçalves y F. J. Mil-Homens dos Santos, "Energy management system ISO 50001:2011 and energy management for sustainable development", Energy Policy, vol. 133, núm. June, p. 110868, 2019.

[10]C. Cooremans y A. Schönenberger, "Energy management: A key driver of energyefficiency investment?”, J. Clean. Prod., vol. 230, pp. 264-275, 2019.

[11]J. M. Sousa Lira, E. G. Salgado, y L. A. Beijo, "Which factors does the diffusion of ISO 50001 in different regions of the world is influenced?", J. Clean. Prod., vol. 226, pp. 759767, 2019.

[12] SGS Tecnos S.A., "Actualización ISO 50001: avanzando hacia la implementación de la norma internacional | SGS España", 2018. [En línea]. Disponible en: https://www.sgs.es/eses/news/2018/11/actualizacion-iso-50001. [Consultado: 27-ago-2019].

[13] ISO, ISO 50001:2018 Energy management systems - Requirements with guidance for use. SUIZA, 2018.

[14] P. P. Poveda-Orjuela, J. C. García-Díaz, A. Pulido-Rojano, y G. Cañón-Zabala, “ISO 50001: 2018 and its application in a comprehensive management system with an energyperformance focus", Energies, vol. 12, núm. 24, 2019.

[15] R. Castrillón y A. Gonzalez, Metodología Para la Planificación Energética a Partir de la Norma ISO 50001. Cali, 2018. 
[16] Red Colombiana de Conocimiento en Eficiencia Energética - RECIEE, Implementación de un sistema de Gestión de la Energía - Guía con base en la norma ISO 50001:2018, 2da ed. Colombia, 2019.

[17] D. R. Anderson, D. J. Sweeney, y T. A. Williams, Estadística para administración y economía, 10a ed. México DF, 2008.

[18] R. Castrillón, E. C. Quispe, A. Gonzalez, M. Urhan, y D. Fandiño, Metodología para la implementación del Sistema de Gestión Integral de la Energía. Fundamentos y casos prácticos. 2015.

[19] J. C. Campos, E. D. Lora, C. A. Rofriguez, R. M. Contreras, E. C. Quispe, y R. Castrillón, Herramientas para la implementación de un Sistema de Gestión Integral de la Energía en la industria Petrolera Upstream y Downstream. Barranquilla, 2011.

[20]A. Aranda, F. Barrio, I. Zabalza, y S. Díaz, Técnicas para la elaboración de auditorías energéticas en el sector industrial. Zaragoza, 2010.

[21] H. Kume, Herramientas estadísticas básicas para el mejoramiento de la calidad. Bogotá: Norma, 2002.

[22] ISO, ISO 50002:2014 Energy audits - Requirements with guidance for use. SUIZA, 2014.

[23] Z. K. Morvay y D. D. Gvozdenac, Applied Industrial Energy and Environmental Management. 2009.

[24] IONOS, "Brainstorming o lluvia de ideas: definición, técnicas y ejemplos - IONOS", 2018.

[En línea]. Disponible en:

https://www.ionos.es/startupguide/productividad/brainstorming-o-lluvia-de-ideas/.

[Consultado: 27-ago-2019].

[25] I. Legaz y A. Luna, “Experiencia de innovación educativa con 'Brainstorming' en la Universidad de Murcia", Murcia, 2014.

[26] D. Saygin, E. Worrell, M. K. Patel, y D. J. Gielen, "Benchmarking the energy use of energy-intensive industries in industrialized and in developing countries", Energy, vol. 36, núm. 11, pp. 6661-6673, 2011.

[27] A. A. Fernández, Revisión de metodologías y aplicaciones de Benchmarking Energético en la Industria, 1a ed. Sevilla, 2014.

[28] L. Martínez, "Variables relevantes y factores estáticos | ISO 50001 - Gestión de la energía". [En línea]. Disponible en: http://50001iso.com/?p=66. [Consultado: 27-ago-2019]. [29] ISO 50006, "Energy management systems - Measuring energy performance using energy baselines (EnB) and energy performance indicators (EnPI) - General principles and guidance", 2016.

[30] M. Moreno, "Metodología para la Aplicación de Sistemas BMSy BEMS para la Operación Eficiente de Edificios", Universidad Autónoma de Occidente, 2019.

[31] V. Marinakis y H. Doukas, "An Advanced loT-based System for Intelligent Energy Management in Buildings", Sensors, vol. 18, núm. 2, p. 610, feb. 2018.

[32] J. D. Pinzón, A. Corredor, F. Santamaría, J. A. Hernández, y C. L. Trujillo, "Implementación de indicadores energéticos en centros educativos CASO DE ESTUDIO: Edificio Alejandro Suárez Copete- Universidad Distrital Francisco José de Caldas", Rev. EAN, pp. 186-201, 2012. 
[33] U.S. DEPARTMENT OF ENERGY, "Superior Energy Performance 50001 ${ }^{\mathrm{TM}}$ Program Measurement \&amp; Verification Protocol: 2019". U.S. DEPARTMENT OF ENERGY, California, p. 38, 2019.

[34] Ministerio de Fomento, Documento de bases para la actualización del Documento Básico DB-HE. España, 2016, p. 13.

[35] Comité técnico CTN 100 y Asociación Española de Normalización, "Eficiencia energética de los edificios Evaluación global de la eficiencia energética de los edificios Parte 1: Marco general y procedimientos (ISO 52000-1:2017)", Madrid, 2019. 


\section{CAPÍTULO 3: MODELOS PARA LA ESTIMACIÓN DE LÍNEAS BASES}

En este capítulo se presentan los fundamentos teóricos para la aplicación de los modelos de estimación de líneas bases e indicadores, como respuesta a la necesidad de establecer una referencia que permita medir ahorros y pronosticar consumos futuros cuando se requiera hacer gestión energética en una edificación. A lo largo de la investigación se identificó que existen numerosos vacíos en torno a las condiciones para la recolección de los datos, procesarlos y dar la validación estadística. Esto permite tener la certeza que el valor establecido como referencia o línea de base energética es válido para el periodo de análisis.

Desde esta perspectiva, en el desarrollo de este capítulo, partiremos de los cuatro modelos propuestos por la norma ISO50006, para establecer una Línea base energética e indicadores, desarrollando las bases teóricas para la implementación de cada modelo y la aplicación del mismo, según los recursos disponibles tanto de medición como objetivos de ahorro. Cabe mencionar que la norma propone los modelos, pero no desarrolla las bases teóricas, métodos estadísticos y criterios para determinar si una línea base o un indicador son válidos para establecer una referencia de consumo y posteriormente un ahorro energético.

A continuación, hacemos una breve descripción de los métodos recomendados por la norma ISO50006 y seguidamente se mostrará el tratamiento estadístico realizado en función de contar con una línea base energética validada que permita monitorizar, implementar indicadores y evaluar medidas de ahorro energético.

\section{Medición del valor absoluto de Energia}

Para los procesos en los que la organización no tiene datos que indiquen que las variables relevantes afectan el rendimiento energético, el consumo absoluto puede servir como el valor de indicador y su respectiva línea base energética, puesto que, permiten estimar a partir de información pasada, el consumo de energía futuro, considerando que el sistema en estudio no sufrirá modificaciones. De tal forma que la medición de reducciones o incrementos en el uso o consumo absoluto de la energía; resulta de utilidad para el cumplimiento de requisitos legales que se basen en ahorros absolutos; seguimiento y control de inventarios y costos energéticos; también es usado para la comprensión de las tendencias en el consumo de la energía y para cuantificar el gasto energético a través de procesos de medición directa, usando un instrumento de medición de energía o indirecta usando un factor de conversión [1]. 
Este modelo permite cuantificar el consumo energético que se ha realizado en la operación de un servicio HVAC o iluminación en un edificio durante un periodo de tiempo. El modelo medición del valor absoluto de energía, considera una única variable, como es el consumo de energía del sistema en estudio, cuantificada en periodos de análisis.

\section{Cociente de los valores medido o relación simple}

El modelo cociente de valores medidos, $\mathrm{kWh} / \mathrm{m} 2 \mathrm{a}$, también conocido como consumo de energía específico de intensidad energética en edificios IE, se usa comúnmente porque es simple, pero supone que no hay un consumo de energía de base (fijo). De tal forma, que resulta útil para el seguimiento de la eficiencia energética de sistemas que tienen una única variable relevante; seguimiento de sistemas con una carga base muy pequeña o inexistente; estandarización de comparaciones entre múltiples instalaciones organizacionales (benchmarking), en organizaciones que operan múltiples instalaciones de uso similar, este indicador es utilidad para comparar el desempeño energético de una instalación respecto a las otras, o para compararse contra estándares de otros edificios similares para el cumplimento de requisitos legales basados en eficiencia energética; también pueden expresar la eficiencia energética de una pieza de equipo o de un sistema.

\section{Modelo estadístico}

Los modelos estadísticos se desarrollan utilizando datos del período de referencia para cuantificar el impacto de una o más variables relevantes en el consumo de energía. Los modelos estadísticos aplicados a edificios cuantifican la influencia de variables independientes, como los grados día GD climáticos de temperatura exterior, en la variable dependiente, consumo de energía. El resultado es una relación matemática mediante la cual se puede predecir el consumo de energía utilizando los valores de las variables relevantes, con una pronostico razonable.

La validez del modelo debe confirmarse mediante pruebas estadísticas. Por ejemplo, el $R^{2}$ ajustado indica con qué precisión el modelo predice el consumo de energía real. Los resultados también dependen de la calidad y cantidad de datos.

Antes de realizar la regresión, el usuario debe determinar si el modelo debe ser lineal o no lineal.

\section{Modelo de ingeniería o simulación}

Los modelos basados en ingeniería pueden representar una gran cantidad de variables relevantes. La preparación de modelos de ingeniería o simulación, requiere un conocimiento detallado del comportamiento del consumo de energía de la energía utilizando el sistema que se está modelando. El modelado basado en ingeniería se puede usar cuando no hay datos anteriores disponibles. 
Los modelos de ingeniería también son útiles cuando existen variables importantes que no son independientes entre sí, como la temperatura y el caudal, en modelos de edificaciones completas que tienen en cuenta horas de operación, sistemas de climatización (HVAC) distribuidos vs centralizados y variación en las necesidades de los ocupantes.

Los indicadores obtenidos con modelos de ingeniería son de gran utilidad para medir el desempeño energético debido a cambios operacionales cuando las variables a considerar son numerosas; también en procesos y/o sistemas transitorios que involucran ciclos dinámicos de retroalimentación $o$ en sistemas que con variables relevantes interdependientes (como temperatura y el caudal); resultan adecuados para estimar el desempeño energético en una etapa de diseño.

Considerando ahora que una línea puede ser establecida como un consumo absoluto medido hasta un modelo de ingeniería o simulación, se presenta una tabla donde se resume la selección de una LBE exponiendo utilidad y desventajas del tipo o método escogido.

La Tabla 13, presenta los tipos de indicadores y líneas base propuesto por la norma ISO 50006 versión 2016.

Tabla 13. Tipos de indicadores y líneas base propuesto por la norma ISO50006

\begin{tabular}{|c|c|c|c|}
\hline Tipo de LBE & Útil para & Ejemplos & Observación \\
\hline $\begin{array}{c}\text { Medición de } \\
\text { valor de } \\
\text { energía }\end{array}$ & $\begin{array}{l}\text { - Medición de la } \\
\text { reducción en el uso } \\
\text { absoluto o consumo de } \\
\text { energía. } \\
\text { - Cumplir los requisitos } \\
\text { reglamentarios basados } \\
\text { en ahorros absolutos. } \\
\text { - Monitoreo y control de } \\
\text { las reservas y costos de } \\
\text { energía. } \\
\text { - Comprensión de las } \\
\text { tendencias en el } \\
\text { consumo de energía. } \\
\text { - Supervisión del } \\
\text { rendimiento energético. } \\
\text { - Determinar la mejora del } \\
\text { rendimiento energético } \\
\text { en los casos en que no } \\
\text { hay variables relevantes } \\
\text { que afecten el consumo } \\
\text { y la carga base sea } \\
\text { insignificante }\end{array}$ & $\begin{array}{l}\text { - Consumo de energía } \\
\text { (kWh, GJ) } \\
\text { - Consumo de energía } \\
\text { (kWh) para } \\
\text { iluminación. } \\
\text { - } \text { Consumo de } \\
\text { combustible (GJ) de las } \\
\text { calderas. } \\
\text { - Consumo de } \\
\text { electricidad (kWh) } \\
\text { durante horas pico. } \\
\text { - } \text { Ahorros energéticos } \\
\text { totales (GJ) de } \\
\text { programas } \\
\text { relacionados con } \\
\text { eficiencia energética }\end{array}$ & 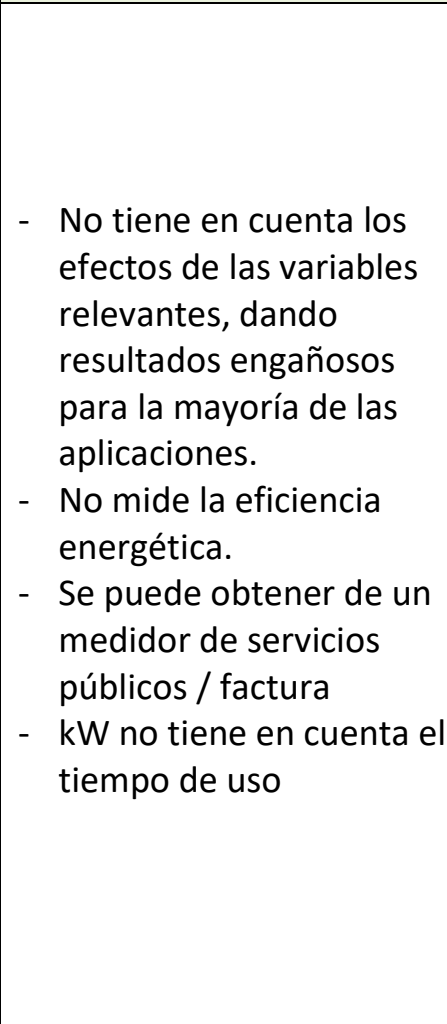 \\
\hline
\end{tabular}




\begin{tabular}{|c|c|c|c|}
\hline $\begin{array}{l}\text { Cociente de } \\
\text { valores } \\
\text { medidos }\end{array}$ & $\begin{array}{l}\text { - Expresar la eficiencia } \\
\text { energética de un equipo } \\
\text { o sistema, } \\
\text { particularmente en } \\
\text { condiciones estándar o } \\
\text { equivalentes. } \\
\text { - Monitorear la eficiencia } \\
\text { energética de los } \\
\text { sistemas que tienen solo } \\
\text { una variable relevante } \\
\text { - Comparaciones entre } \\
\text { múltiples instalaciones u } \\
\text { organizaciones } \\
\text { (benchmarking) } \\
\text { - Cumplir los requisitos } \\
\text { reglamentarios basados } \\
\text { en la eficiencia } \\
\text { energética. } \\
\text { - Comprender las } \\
\text { tendencias de eficiencia } \\
\text { energética. } \\
\text { - Usado comúnmente en } \\
\text { varios sectores } \\
\text { económicos y como } \\
\text { parte de los requisitos } \\
\text { legales de presentación } \\
\text { de informes. }\end{array}$ & 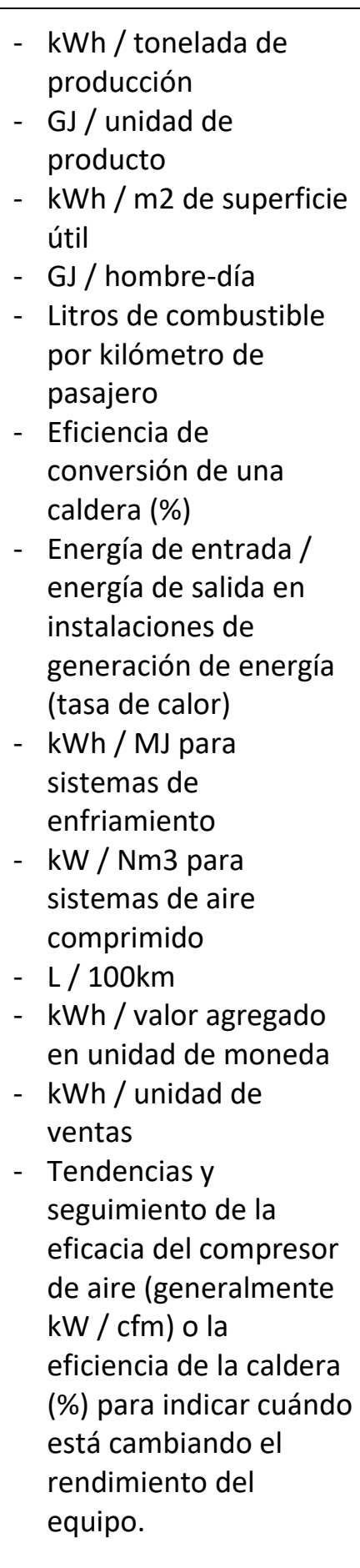 & $\begin{array}{l}\text { - Típicamente, fácil de } \\
\text { calcular e implica un } \\
\text { grado de normalización } \\
\text { - Puede ser engañoso, } \\
\text { especialmente el } \\
\text { consumo específico de } \\
\text { energía (SEC) (por } \\
\text { ejemplo, kJ / ton y kJ / } \\
\text { ocupante), y debe usarse } \\
\text { con precaución y } \\
\text { después de una } \\
\text { cuidadosa consideración. } \\
\text { - Muy pocos sistemas no } \\
\text { tienen carga base o solo } \\
\text { una variable relevante } \\
\text { - Como métricas de } \\
\text { mejora del rendimiento } \\
\text { energético, deben } \\
\text { evitarse los cálculos del } \\
\text { valor de EnPI de tipo } \\
\text { SEC, a menos que se } \\
\text { requiera lo contrario } \\
\text { para informes } \\
\text { organizativos o } \\
\text { reglamentarios. Cuando } \\
\text { se requieren SEC, sería } \\
\text { una buena práctica } \\
\text { incluir los supuestos } \\
\text { subyacentes al informar } \\
\text { estos valores. } \\
\text { - Debe usarse con } \\
\text { precaución para } \\
\text { determinar e informar la } \\
\text { mejora del rendimiento } \\
\text { del equipo } \\
\text { - Las líneas base de tipo } \\
\text { SEC pueden no cumplir } \\
\text { con los requisitos de } \\
\text { normalización en ISO } \\
\text { 50001: 2018 }\end{array}$ \\
\hline $\begin{array}{c}\text { Modelo } \\
\text { Estadístico }\end{array}$ & $\begin{array}{l}\text { Sistema con una o más } \\
\text { variables relevantes y un } \\
\text { consumo significativo de } \\
\text { energía de carga base }\end{array}$ & $\begin{array}{l}\text { - Desempeño energético } \\
\text { de una instalación de } \\
\text { producción con dos o } \\
\text { más tipos de } \\
\text { productos. }\end{array}$ & $\begin{array}{l}\text { - El desarrollo de modelos } \\
\text { estadísticos debe incluir } \\
\text { la consideración de la } \\
\text { relación de ingeniería } \\
\text { entre las variables }\end{array}$ \\
\hline
\end{tabular}




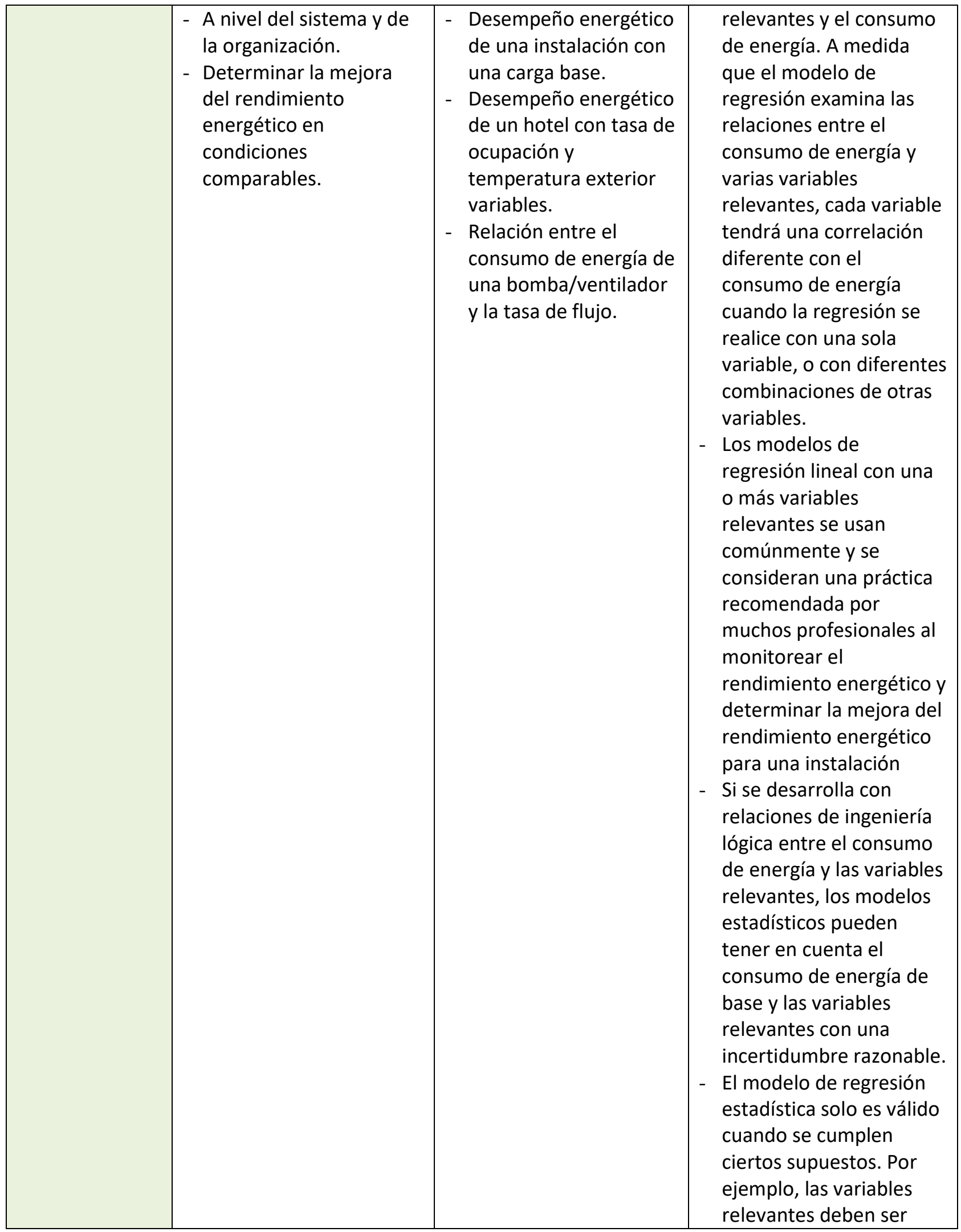




\begin{tabular}{|c|c|c|c|}
\hline & & & $\begin{array}{l}\text { independientes y los } \\
\text { datos deben estar } \\
\text { normalmente } \\
\text { distribuidos. Si los } \\
\text { supuestos estadísticos } \\
\text { básicos no se cumplen, } \\
\text { se requieren técnicas } \\
\text { estadísticas avanzadas, } \\
\text { pero el esfuerzo de llevar } \\
\text { a cabo este análisis } \\
\text { avanzado puede no ser } \\
\text { justificable }\end{array}$ \\
\hline $\begin{array}{c}\text { Modelo de } \\
\text { Ingeniería o } \\
\text { simulación }\end{array}$ & $\begin{array}{l}\text { - Evaluar el rendimiento } \\
\text { energético donde el uso } \\
\text { de energía y las variables } \\
\text { relevantes son } \\
\text { numerosas. Muchas } \\
\text { industrias tienen } \\
\text { modelos de ingeniería } \\
\text { sofisticados, rigurosos y } \\
\text { ampliamente aceptados } \\
\text { para procesos } \\
\text { específicos. } \\
\text { - Para complementar las } \\
\text { mediciones de flujo de } \\
\text { energía y, en algunos } \\
\text { casos, para inferir o } \\
\text { calcular efectivamente } \\
\text { los flujos de energía a } \\
\text { partir de variables } \\
\text { relevantes. } \\
\text { - En una fase de diseño } \\
\text { para optimizar } \\
\text { conceptualmente el } \\
\text { rendimiento energético } \\
\text { o estimar la mejora del } \\
\text { rendimiento energético } \\
\text { para una EPIA específica } \\
\text { antes de realizar } \\
\text { inversiones }\end{array}$ & $\begin{array}{l}\text { - El modelado de } \\
\text { edificios, incluida la } \\
\text { simulación calibrada, } \\
\text { es otro ejemplo de } \\
\text { cálculo de un valor de } \\
\text { EnPI a partir de } \\
\text { modelos de ingeniería. } \\
\text { - Modelo de una } \\
\text { refinería de petróleo. } \\
\text { - Los modelos de } \\
\text { ingeniería pueden } \\
\text { usarse incluso si las } \\
\text { variables relevantes no } \\
\text { son independientes } \\
\text { entre sí (p. Ej. } \\
\text { Temperatura y presión) } \\
\text { - Modelo de un horno } \\
\text { de arco eléctrico: } \\
\text { además de los flujos } \\
\text { eléctricos y de gas } \\
\text { medidos, se agrega } \\
\text { polvo de carbono al } \\
\text { lote para ajustar la } \\
\text { química del acero. Este } \\
\text { carbono también } \\
\text { agrega energía de } \\
\text { combustión al lote, y } \\
\text { aunque normalmente } \\
\text { se rastrea el número } \\
\text { de bolsas, el modelo de } \\
\text { proceso a menudo se } \\
\text { usa para calcular la } \\
\text { contribución de } \\
\text { energía. Modelos de }\end{array}$ & $\begin{array}{l}\text { - La recopilación de datos } \\
\text { y el requisito de } \\
\text { cuantificación de EnPI } \\
\text { deben revisarse para los } \\
\text { EnPI seleccionados. } \\
\text { - Algunas veces } \\
\text { denominadas } \\
\text { simulaciones, los } \\
\text { modelos de ingeniería } \\
\text { pueden capturar el } \\
\text { rendimiento energético } \\
\text { de sistemas e } \\
\text { instalaciones simples o } \\
\text { complejos. } \\
\text { - Los modelos de } \\
\text { ingeniería pueden } \\
\text { encapsular una gran } \\
\text { cantidad de variables } \\
\text { relevantes y } \\
\text { proporcionar } \\
\text { información sobre el } \\
\text { proceso y / o la } \\
\text { operación transitoria del } \\
\text { sistema cuando se } \\
\text { calibra adecuadamente } \\
\text { al rendimiento medido. } \\
\text { Si están bien calibrados, } \\
\text { los modelos de } \\
\text { ingeniería pueden } \\
\text { proporcionar una base } \\
\text { normalizada para } \\
\text { determinar la mejora del } \\
\text { rendimiento energético. }\end{array}$ \\
\hline
\end{tabular}




\begin{tabular}{|l|l|l|l|}
\hline \multirow{5}{|l|}{} & edificaciones & - El modelado basado en \\
& completas que tienen & ingeniería también se \\
en cuenta horas de & puede utilizar para \\
operación, sistemas de & calcular directamente las \\
& climatización (HVAC) & pérdidas o ganancias de \\
& distribuidos vs & energía, por ejemplo. \\
& centralizados y & Recuperación adicional \\
& variación en las & de calor residual. \\
& necesidades de los & \\
& ocupantes & \\
\hline
\end{tabular}

Fuente: Traducción de la norma ISO 50006 versión 2016

En este sentido, la selección de una línea de base energética está ligada a retos que puede afrontar la organización, abordando aspectos tales como el tamaño de las instalaciones, el perfil de producción, la cultura organizacional, niveles de ocupación en una edificación, condiciones climáticas entre otros. En este sentido, el establecimiento de una LBE debe contar con la participación de diversas personas en su planificación, quienes deben ser capaces de hablar más allá de la simple perspectiva del uso de la energía, e involucrar factores tales como ciclos recurrentes del proceso, eventos que ocurrieron una sola vez en el pasado, y otros que se espera ocurran en los siguientes meses del año. De modo que, al tener en cuenta dichos aspectos, se defina una LBE apropiada para la organización, y se seleccione un método adecuado para su cuantificación.

La Figura 48 presenta un esquema para ejemplificar el proceso para desarrollar, usar y actualizar indicadores y líneas base según la recomendación de la ISO 50006. 


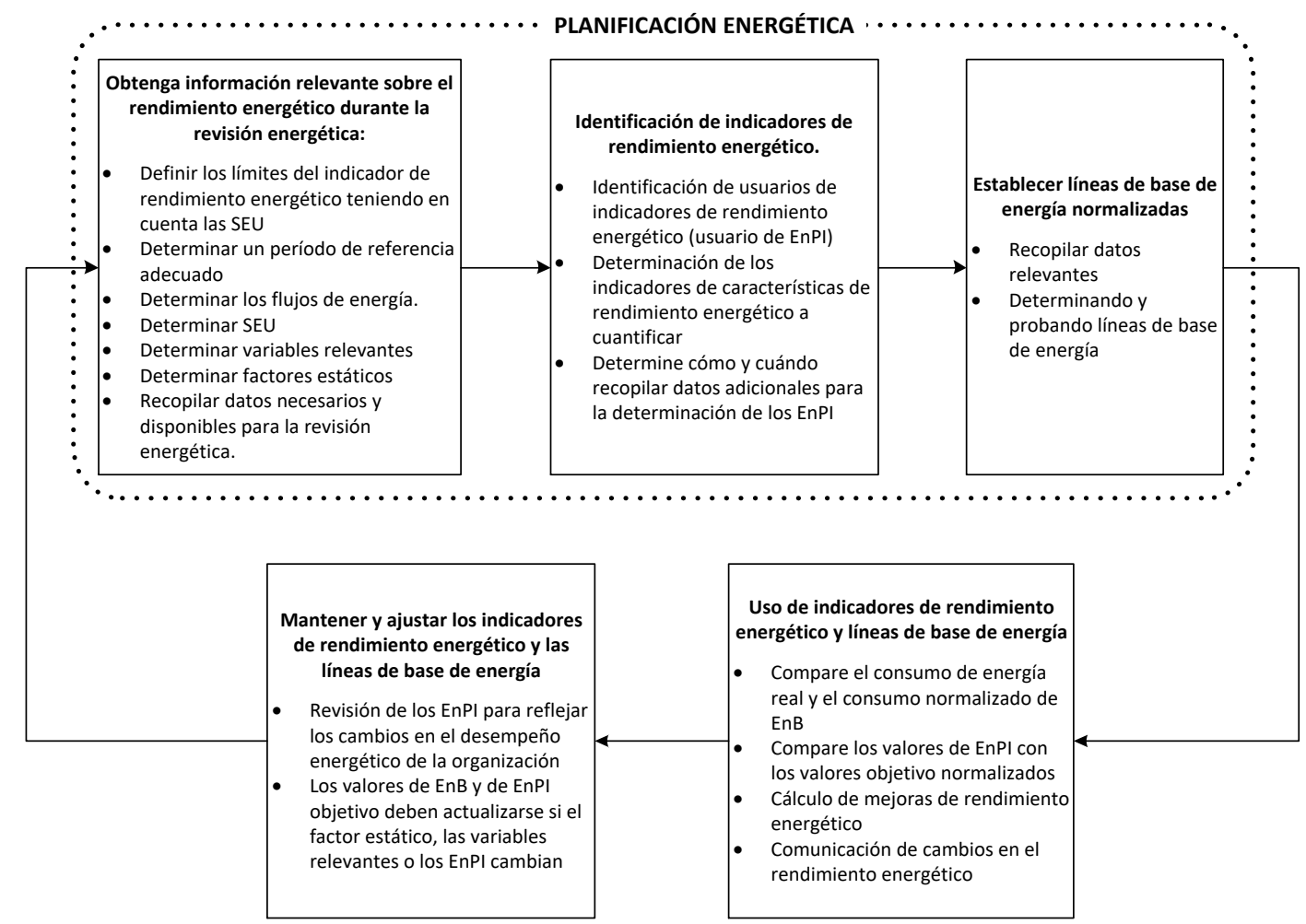

Figura 48. Diagrama para ejemplificar el proceso para desarrollar, usar y actualizar IDE y LBE según la norma ISO 50006. Tomado y adaptado de la norma ISO 50006 versión 2016

Para implementar una línea de base energética basado en el modelo de consumo absoluto y consumo energético específico se propone utilizar el análisis estadístico basado en series de tiempos. Las mismas han sido utilizadas como herramienta de pronóstico, para examinar patrones, tendencias y ciclos del pasado para predecir patrones, tendencias y ciclos en el futuro [2]. Contreras et al. [3] presenta un caso de estudio, donde implementa series de tiempo en una empresa dedicada al almacenamiento de productos perecederos, con el fin de estimar el volumen de almacenamiento y así, poder prever los requerimientos de instalaciones adicionales, personal y materiales necesarios para la movilidad de los productos. En el artículo "Estudio del pronóstico de la demanda de energía eléctrica, utilizando modelos de series de tiempo" [4], los autores describen el pronóstico de demanda de energía eléctrica usando series de tiempo bajo la metodología ARIMA (Autorregresive-Integrated-Moving Average), el paquete estadístico SPSS, teniendo datos históricos de un año. Sergio Botero y Jovan A. Cano [5], por su parte implementaron y analizaron las series de tiempo para predecir los precios de la energía eléctrica en la bolsa de Colombia, donde se obtiene que entre mayor sean los datos del histórico, mejor es el modelo pronóstico. Valencia et al. [6] en el artículo "Modelo de promedios móviles para de pronóstico horario de potencia y energía eléctrica", realizan el modelo de pronóstico horario de energía y potencia eléctrica usando series de tiempo, bajo la metodología de promedios móviles. Deb et al. [7] revisó 9 metodologías de series de tiempo para pronosticar el consumo de energía en edificios existentes, donde obtuvo que el modelo que 
más se ajustó a su caso de estudio fue el "hibrido" que combina dos o más técnicas de pronóstico.

A continuación, se describen algunos de los conceptos teóricos más importante para la aplicación de esta técnica y las validaciones necesaria para poder utilizar estos modelos de pronosticos aplicados a la selección adecuada de una línea base energética.

Para tal caso es necesario tener en cuenta algunos aspectos relacionados con los modelos a analizar:

- El modelo medición del valor absoluto de energía no tiene en cuenta los efectos de las variables relevantes.

- El modelo cociente de los valores medido o relación determina un valor resultado del cociente entre el consumo de energía y la variable relevante del sistema en estudio, para un periodo de tiempo, no considera el tipo de relaciones matemáticas que puedan existir entre las variables involucradas en dicho cociente. En este caso su interés es determinar cómo es de óptimo el sistema en estudio en el uso y/o en el consumo de energía en el tiempo.

\subsection{MODELO DE PRONÓSTICO BASADO EN SERIES DE TIEMPO}

Pronosticar [8], [9] es una estimación cuantitativa o cualitativa de uno o varios factores (variables) que conforman un evento futuro, con base en información actual o del pasado. Su objetivo es reducir la incertidumbre del futuro, mediante la anticipación de eventos cuya probabilidad de ocurrencia sea relativamente alta, respecto a otros eventos posibles.

Los métodos de pronóstico [10] se clasifican como cualitativos y cuantitativos. Los métodos cuantitativos de pronóstico se suelen usar cuando:

1) Se cuenta con información del pasado acerca de la variable que se desea pronosticar, 2) esa información se puede cuantificar, 3) es razonable pensar que el patrón seguido en el pasado continuará en el futuro. En tales casos es posible obtener un buen pronóstico mediante un método de series de tiempo o un método causal.

En los métodos cualitativos, para obtener un pronóstico, suele necesitarse el criterio de un experto, la ventaja es que pueden aplicarse cuando la información sobre la variable que se está pronosticando no puede cuantificarse o es escasa.

La Tabla 14, presenta una visión general de los métodos de pronóstico y las técnicas usadas en cada método. 
Tabla 14. Métodos de pronóstico

\begin{tabular}{|c|c|c|}
\hline \multirow{8}{*}{$\begin{array}{l}\text { Métodos de } \\
\text { pronóstico }\end{array}$} & \multirow{5}{*}{$\begin{array}{c}\text { Cuantitativo } \\
\text { Numérico - Basado en Datos y } \\
\text { estadística }\end{array}$} & Investigación de mercados \\
\hline & & Analogías históricas \\
\hline & & Método Delphi \\
\hline & & Consenso general \\
\hline & & Análisis de escenarios \\
\hline & \multirow{3}{*}{$\begin{array}{l}\text { Cualitativo } \\
\text { Subjetivo - Opiniones y } \\
\text { Experiencia de Expertos }\end{array}$} & Extrapolativas \\
\hline & & Análisis de series de tiempo \\
\hline & & Modelos Causales \\
\hline
\end{tabular}

Para llevar a cabo un buen pronóstico se deben cumplir una serie de etapas y así garantizar los datos iniciales y su resultado final, como se presenta en la Figura 49.

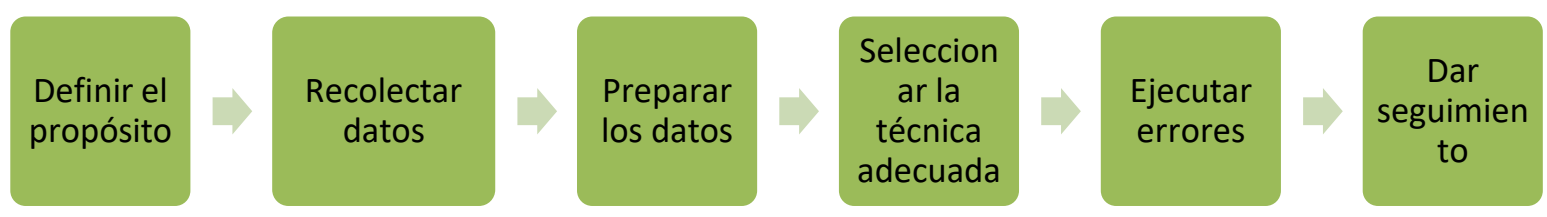

Figura 49. Etapas de un pronóstico

Una serie de tiempo es un conjunto de observaciones de una variable medida en puntos sucesivos en el tiempo o en periodos de tiempo sucesivos [10]. El objetivo de una serie de tiempo es descubrir en los datos históricos un patrón para después extrapolar ese patrón al futuro; el pronóstico se basa únicamente en los valores de la variable en el pasado o en errores de pronóstico en el pasado.

El patrón o el comportamiento que siguen los datos de una serie de tiempo se debe a diversos componentes. Por lo general los componentes son: de tendencia, cíclico, estacional e irregular que son presentados en la Tabla 15.

Tabla 15. Componentes de una serie de tiempo

\begin{tabular}{|c|c|c|c|c|c|}
\hline Componente & Descripción & Ejemplo & \multicolumn{3}{|c|}{ Gráfica } \\
\hline Tendencia & $\begin{array}{l}\text { Es el componente de } \\
\text { largo plazo que } \\
\text { representa el } \\
\text { crecimiento o } \\
\text { disminución en la serie }\end{array}$ & $\begin{array}{l}\text { Crecimiento de la } \\
\text { población, cambio en } \\
\text { la productividad. }\end{array}$ & $\because$ & $\stackrel{\cdots}{\cdots}$ & $\therefore \because$ \\
\hline & $\begin{array}{c}\text { sobre un periodo } \\
\text { amplio. }\end{array}$ & & $\begin{array}{c}\text { Tiempo } \\
\text { A. No lineal }\end{array}$ & $\begin{array}{c}\text { Tiempo } \\
\text { B. Tendencial lineal dereeceiente }\end{array}$ & $\begin{array}{c}\text { Tiem } \\
\text { c. Sin ten }\end{array}$ \\
\hline
\end{tabular}




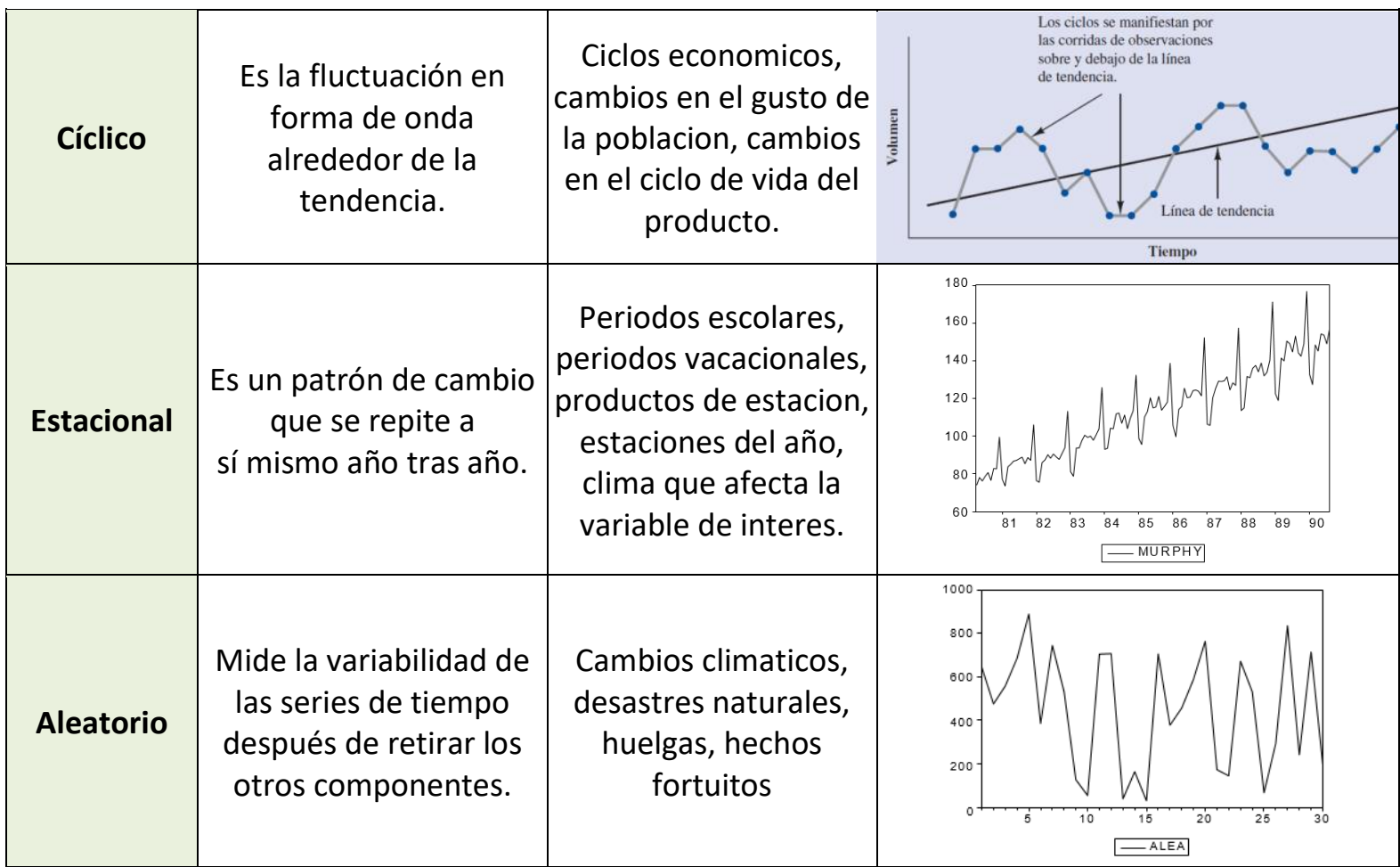

Fuente: Estadística para administración y economía, 2008.

Dentro de las series de tiempo, se encuentran una serie de métodos para realizar el pronóstico, según sean los datos históricos que se tengan. La Tabla 16 presenta las características de datos para cada uno de los métodos de pronóstico.

Tabla 16. Métodos de series de tiempo y características de los datos

\begin{tabular}{|c|c|c|c|}
\hline Método & Patrón de datos & Observaciones & $\begin{array}{l}\text { Horizonte de } \\
\text { pronóstico }\end{array}$ \\
\hline Ingenuos & Estacionario & Pocos & Muy corto \\
\hline Promedios móviles & Estacionario & Muchos & Muy corto \\
\hline Suav Exp. Simple & Estacionario & Pocos & Muy corto \\
\hline Suav Exp. Holt & Tendencia & Pocos & Corto a Medio \\
\hline Suav Exp. Winters & Tendencia y Estacionalidad & $\begin{array}{c}\text { Mínimo } 4 \text { o } 5 \\
\text { por Estación }\end{array}$ & Corto a Medio \\
\hline Descomposición de series & Tendencia, Estacionalidad y ciclos & Muchos & $\begin{array}{c}\text { Corto, Medio y } \\
\text { Largo }\end{array}$ \\
\hline
\end{tabular}




\subsubsection{Modelo Ingenuo}

El método ingenuo [11] es el método más sencillo de pronóstico. Supone que el pronóstico para un periodo futuro es el valor observado en el periodo Winter anterior. La ecuación para obtener el pronóstico es:

$$
F_{t+i}=X_{t}
$$

donde:

$t=$ periodo actual

$i=$ número de periodos adelantados pronosticados

$F_{t+i}=$ pronóstico del periodo $\mathrm{t}+\mathrm{i}$

$X_{t}=$ último valor real en el periodo $\mathrm{t}$

\subsubsection{Promedios Móviles}

En el método de los promedios móviles [10], para pronosticar el periodo siguiente, se emplea el promedio de los valores de los $n$ datos más recientes de la serie de tiempo. El cálculo de un promedio móvil se hace de la forma:

$$
\text { Promedio móvil }=\frac{\sum(\text { de los } n \text { datos más recientes })}{n}
$$

El término móvil se usa porque cada vez que en la serie de tiempo hay una nueva observación, ésta sustituye a la observación más antigua que se emplee en la ecuación y se calcula un nuevo promedio. De esta manera, el promedio se modifica, o se mueve, cada vez que se tiene una nueva observación.

\subsubsection{Suavización Exponencial Simple}

La suavización exponencial simple [10], utiliza un promedio ponderado de los valores pasados de la serie de tiempo; es un caso especial del método de promedios ponderados móviles; en este caso sólo hay que elegir un peso, el peso para la observación más reciente. Los pesos para los demás datos se calculan automáticamente y son más pequeños a medida que los datos son más antiguos. El modelo viene dado de la forma:

$$
F_{t+1}=\alpha Y_{t}+(1-\alpha) F_{t}
$$

donde:

$F_{t+1}=$ pronóstico para el periodo $t+1$ de la serie de tiempo

$\mathrm{Y}_{\mathrm{t}}=$ valor real en el periodo $\mathrm{t}$ de la serie de tiempo

$\mathrm{F}_{\mathrm{t}}=$ pronóstico para el periodo $\mathrm{t}$ de la serie de tiempo 
$\alpha=$ constante de suavización $(0 \leq \alpha \leq 1)$

A pesar de que con el suavizamiento exponencial se obtiene un pronóstico que es el promedio ponderado de todas las observaciones pasadas, no es necesario conservar todos los datos pasados para calcular el pronóstico para el periodo siguiente. En efecto, una vez elegida la constante de suavizamiento $\alpha$, sólo se necesitan dos informaciones para calcular el pronóstico. En la ecuación se observa que dada una $\alpha$, para calcular el pronóstico en el periodo $t+1$ sólo se necesita conocer el valor real y el valor pronosticado de la serie de tiempo para el periodo $t$, es decir, $Y_{t}$ y $F_{t}$.

\subsubsection{Suavización Exponencial Holt}

La suavización exponencial de Holt [9] es apropiada cuando los datos presentan tendencia, pues es una ampliación del modelo de suavización exponencial simple, adiciona un factor de crecimiento (tendencia). Este modelo cuenta con tres ecuaciones, la primera se encarga de la suavización simplemente la segunda de la tendencia y la tercera agrega las primeras dos. La suavización exponencial de Holt está dada por:

$$
\begin{gathered}
F_{t+1}=\alpha Y_{t}+(1-\alpha)\left(F_{t}+T_{t}\right) \\
T_{t+1}=\gamma\left(F_{t+1}-F_{t}\right)+(1-\gamma) T_{t} \\
\hat{Y}_{t+m}=F_{t+1}+m * T_{t+1}
\end{gathered}
$$

donde:

$Y_{t}=$ valor observado en el periodo $t$

$\alpha=$ constante de suavización $(0 \leq \alpha \leq 1)$

$\mathrm{F}_{\mathrm{i}}=$ estimaciónde la suavización para el periodo $\mathrm{i}$

$\gamma=$ constante de suavización para la Tendencia $(0 \leq \gamma \leq 1)$

$\mathrm{T}_{\mathrm{i}}=$ estimación de la Tendenciapara el periodo $\mathrm{i}$

$\mathrm{m}=$ número de periodos a pronosticar

$\mathrm{Y}_{\mathrm{t}+\mathrm{m}}=$ valor pronosticado para el periodo $\mathrm{t}+\mathrm{m}$

\subsubsection{Suavización Exponencial Winters}

La suavización exponencial de Winters [9] es apropiada cuando la serie de datos presentan tendencia y Estacionalidad, es una ampliación del modelo de suavización de Holt que adiciona una ecuación para estimar Estacionalidad. Cuando hay estacionalidad el modelo de suavización simple y de Holt se quedan cortos.

El modelo está compuesto por cuatro ecuaciones: la primera se encarga de la suavización simple, la segunda estima la estacionalidad, la tercera estima la tendencia y la cuarta agrega las estimaciones de las tres primeras ecuaciones. Las ecuaciones que representan el modelo son: 


$$
\begin{gathered}
F_{t}=\alpha \frac{Y_{t}}{S_{t-p}}+(1-\alpha)\left(F_{t-1}+T_{t-1}\right) \\
S_{t}=\beta \frac{Y_{t}}{F_{t}}+(1-\beta) S_{t-p} \\
T_{t}=\gamma\left(F_{t}-F_{t-1}\right)+(1-\gamma) T_{t-1} \\
\hat{Y}_{t+m}=\left(F_{t}+m * T_{t}\right) S_{t+m-p}
\end{gathered}
$$

donde:

$\mathrm{Y}_{\mathrm{t}}=$ valor observado en el periodo $\mathrm{t}$

$\alpha=$ constante de suavización $(0 \leq \alpha \leq 1)$

$\mathrm{F}_{\mathrm{i}}=$ estimaciónde la suavización para el periodo $\mathrm{i}$

$\gamma=$ constante de suavización para la Tendencia $(0 \leq \gamma \leq 1)$

$\mathrm{T}_{\mathrm{i}}=$ estimación de la Tendenciapara el periodo $\mathrm{i}$

$\mathrm{m}=$ número de periodos a pronósticar

$\beta=$ constante de suavización para la estacionalidad $(0 \leq \beta \leq 1)$

$\mathrm{S}_{\mathrm{i}}=$ estimación de la estacionalidad para el periodo $\mathrm{i}$

$p=$ número de periodos en el ciclo estacional

$\mathrm{Y}_{\mathrm{t}+\mathrm{m}}=$ valor pronosticado para el periodo $\mathrm{t}+\mathrm{m}$

\subsubsection{Descomposición de Series}

Existen tres modelos de series de tiempos conocidos como descomposición de series [12], que generalmente se aceptan como buenas aproximaciones a las verdaderas relaciones, entre los componentes de los datos observados. Estos son:

$$
\begin{gathered}
\text { Aditivo } \Rightarrow X(t)=T(t)+E(t)+A(t) \\
\text { Multiplicativo } \Rightarrow X(t)=T(t) * E(t) * A(t) \\
\text { Mixto } \Rightarrow X(t)=T(t) * E(t)+A(t)
\end{gathered}
$$

donde:

$\mathrm{X}(\mathrm{t})$ : serie observada en instante $\mathrm{t}$

$T(t)$ : componente de tendencia

$E(t)$ : componente estacional

$A(t)$ : componente aleatoria

Una suposición usual es que $\mathrm{A}(\mathrm{t})$ sea una componente aleatoria o ruido blanco con media cero y varianza constante. 
Un modelo aditivo, es adecuado, cuando $\mathrm{E}(\mathrm{t})$ no depende de otras componentes, como $\mathrm{T}(\mathrm{t})$, sí por el contrario la estacionalidad varía con la tendencia, el modelo más adecuado es un modelo multiplicativo.

\subsubsection{Medidas de Error}

Es importante establecer medidas de error [8],[9],[11], como herramienta para evaluar la calidad y validez del modelo de pronóstico realizado, normalmente se realizan pronosticos con varios métodos al tiempo, las medidas de error permiten evaluar la precisión de dichos métodos y seleccionar el óptimo.

El error correspondiente a cualquier pronóstico es la diferencia entre el valor observado en la serie de tiempo y el pronóstico. El error de pronóstico puede ser positivo o negativo dependiendo si el pronóstico es demasiado alto o demasiado bajo.

Los errores de pronóstico [13], normalmente calculados son:

\section{Error de pronóstico}

\section{Error de pronóstico $=$ Demanda real - valor pronosticado}

Su cálculo permite tomar decisiones frente a qué método de pronóstico es el mejor y logran detectar cuando algo en nuestra previsión de la demanda no está marchando bien, con lo que conseguimos cambiar el rumbo de nuestras decisiones a fin tomar las mejores elecciones.

\section{Suma acumulada de errores de pronóstico (CFE) o error medio}

$$
C F E=\sum \text { Error de pronóstico }
$$

Es la medida más básica de todas y es la que da origen a las demás. Es la suma acumulada de los errores de pronóstico. Permite evaluar el sesgo del pronóstico. Por ejemplo, si a través de los periodos el valor real de la demanda siempre resulta superior al valor de pronóstico, la CFE será más grande, indicando la existencia de un error sistemático en el cálculo de la demanda.

\section{Desviación media absoluta (MAD)}

$$
M A D=\frac{\sum \mid \text { real }- \text { pronóstico } \mid}{n}
$$

Mide la dispersión del error de pronóstico o, dicho de otra forma, la medición del tamaño del error en unidades. Es el valor absoluto de la diferencia entre la demanda real y el pronóstico, dividido sobre el número de periodos. 


\section{Error cuadrático medio (MSE)}

$$
M S E=\frac{\sum(\text { error de pronóstico })^{2}}{n}
$$

Al igual que la MAD, el MSE es una medida de dispersión del error de pronóstico, sin embargo, esta medida maximiza el error al elevar al cuadrado, castigando aquellos periodos donde la diferencia fue más alta a comparación de otros. En consecuencia, se recomienda el uso del MSE para periodos con desviaciones pequeñas o en casos que se prefiere una técnica que produzca errores moderados a otra que generalmente tenga errores pequeños, pero ocasionalmente arroje algunos muy grandes.

\section{Error porcentual medio absoluto (MAPE)}

$$
M A P E=\frac{\frac{\sum_{i=1}^{n} \mid \text { Real }_{i}-\text { Pronóstico }_{i} \mid}{\text { Real }_{i}}}{n}
$$

El MAPE entrega la desviación en términos porcentuales y no en unidades como las anteriores medidas. Es el promedio del error absoluto o diferencia entre la demanda real y el pronóstico, expresado como un porcentaje de los valores reales. Se conoce también como Porcentaje de error medio absoluto (PEMA) o EPAM.

EI PEMA indica qué tan grande son los errores comparados con los valores reales de la serie. Se utiliza para comparar la precisión de la misma u otra técnica sobre dos series completamente diferentes.

\subsection{MODELO DE REGRESIÓN}

Los modelos de regresión han sido usados en diversas ocasiones para estimar la tendencia que siguen los datos y predecir su comportamiento en un futuro. En temas de energía, es común que sean usados para estimar o predecir el consumo en un proceso, instalación o edificio. Para estimar líneas de base energética y predecir el consumo de energía en edificaciones, son usados mayormente los modelos de regresión lineal, según autores como Syarifah Permai y Heruna Tanty [14], Jonathan Roth y Ram Rajagopal [15], Nelson Fumo y Rafe Biswas [16], Beñat Arregi y Roberto Garay [17] y Aranda et al. [18], entre otros. Sin embargo, autores como Bilous et al. [19] utilizan modelos de regresión no lineal.

Numerosos estudios se han llevado a cabo para estimar líneas de base energética, aplicando modelos de regresión univariable y multivariable, a los cuales se les ha probado el cumplimiento de una serie de supuestos estadísticos para que el modelo de regresión planteado sea válido. Dentro de la literatura se encuentran: 
Strachan [20], empleó la metodología para predecir niveles de consumo energético en el Reino Unido, como herramienta para el establecimiento de políticas energéticas.

Sakamoto et al. [21] utilizó el modelo de línea base para predecir la demanda energética de Japón para el año 2030, teniendo en cuenta variables climáticas y aspectos socioeconómicos del país, el resultado apuntó hacia un aumento en el sector edificios y un descenso en el consumo industrial.

Alves et al. [22], Ko et al. [23] y Elbeltagi et al. [24], proponen que la construcción de una línea base de energía es un punto de partida para comprender la demanda de energía de las ciudades donde no se tienen puntos de referencia de consumo de energía de edificios, y se hace difícil la toma de decisiones sobre las intervenciones en el stock de edificios, pues no se conocen ni el rendimiento energético existente ni el alcanzable.

El artículo "Development and application of a statistical methodology to evaluate the predictive accuracy of building energy baseline models" [25] desarrolló y aplicó una metodología estadística para evaluar la precisión de los modelos de línea base de energía en 29 edificaciones, centrándose en su aplicación a M\&V (medición y verificación) del ahorro energético del edificio.

Liang et al. [26] en su estudio, establece que existen numerosos modelos para predecir la línea de base de energía en un edificio, pero en la mayoría no se tiene en cuenta la ocupación como variable, la cual ha sido considerada como esencial en estudios anteriores.

El artículo "Building energy performance forecasting: A multiple linear regression approach" [27] desarrolló un modelo de regresión lineal alternativo y confiable para determinar las necesidades de energía del edificio, partiendo de un modelo dinámico detallado y calibrado, en el que implementó 195 escenarios de rendimiento energético para determinar la demanda de energía térmica del edificio en función de solo unos pocos parámetros conocidos.

Uno de los aspectos más relevantes de la Estadística [28]-[30] es el análisis de la relación o dependencia entre variables, pues resulta interesante conocer el efecto que una o varias variables pueden causar sobre otra, e incluso predecir en mayor o menor grado valores en una variable a partir de otra.

Los métodos de regresión estudian la construcción de modelos para explicar o representar la dependencia entre una variable dependiente $(Y)$ y la(s) variable(s) explicativa(s) o dependiente(s), X. Normalmente son de tipo univariable o multivariable.

El modelo univariable está dado de la forma: 


$$
Y=\beta_{0}+\beta_{1} X_{1}
$$

El modelo multivariable es descrito por:

$$
Y=\beta_{0}+\beta_{1} X_{1}+\beta_{2} X_{2}+\cdots+\beta_{n} X_{n}
$$

Existen diversos modelos de regresión, según las características de los datos que se tengan (número de variables medidas, temporalidad, etc.), la Tabla 17 presenta tres de modelos de regresión.

\begin{tabular}{|c|c|}
\hline Modelo & Característica \\
\hline $\begin{array}{c}\text { Regresión } \\
\text { Lineal simple }\end{array}$ & $\begin{array}{l}\text { Examina la relación lineal entre dos variables: dependiente }(\mathrm{Y}) \text { y explicativa } \\
(\mathrm{X}) \text {. Cuando las dos variables están relacionadas, es posible predecir un valor } \\
\text { de respuesta }(\mathrm{Y}) \text { a partir de un valor predictor }(\mathrm{X}) \text {. } \\
\text { Los métodos de estimación que suelen utilizarse son: mínimos cuadrados } \\
\text { ordinarios (MCO) y máxima verosimilitud (MV). } \\
\text { Los pronosticos obtenidos son de largo plazo basados en el rango de } \\
\text { información analizada, no es confiable el pronóstico para eventos por fuera } \\
\text { de los valores máximos y mínimos. } \\
\text { El modelo es de tipo: } Y=\beta_{0}+\beta_{1} X_{1}\end{array}$ \\
\hline $\begin{array}{c}\text { Regresión } \\
\text { Lineal multiple }\end{array}$ & $\begin{array}{l}\text { Examina las relaciones lineales entre una variable dependiente }(\mathrm{Y}) \text { y dos o más } \\
\text { explicativas. Si el número de variables explicativas es grande, se deben utilizar } \\
\text { técnicas de selección de modelo paso a paso para excluir las variables } \\
\text { explicativas que no estén asociadas a la variable de respuesta }(\mathrm{Y}) \text {. } \\
\text { Permite obtener pronósticos de largo plazo basados en el rango de } \\
\text { información analizada, no es confiable el pronóstico para eventos por fuera } \\
\text { de los valores máximos y mínimos de las variables explicativas. } \\
\text { El modelo es de tipo: } Y=\beta_{0}+\beta_{1} X_{1}+\beta_{2} X_{2}+\cdots+\beta_{n} X_{n}\end{array}$ \\
\hline $\begin{array}{l}\text { Regresión } \\
\text { polinomial }\end{array}$ & $\begin{array}{l}\text { Examina la relación lineal entre dos variables: dependiente }(\mathrm{Y}) \text { y explicativa } \\
(\mathrm{X}) \text {. Cuando la variable de respuesta }(\mathrm{Y}) \text { depende del comportamiento } \\
\text { polinomial de la variable explicativa }(\mathrm{X}) \text {. } \\
\text { Los pronósticos son a largo plazo basados en el rango de información } \\
\text { analizada, el pronóstico no es confiable para eventos por fuera de los } \\
\text { valores máximos y mínimos de la variable explicativa. } \\
\text { El modelo es de tipo: } Y=\beta_{0}+\beta_{1} X_{1}+\beta_{2} X^{2}+\cdots+\beta_{n} X^{n}\end{array}$ \\
\hline
\end{tabular}

Tabla 17. Modelos de regresión 
Usualmente, los modelos de regresión son evaluados con el porcentaje de variación de la variable dependiente, explicada por las variables independientes $\boldsymbol{R}^{2}$, el cual varía entre $0 \%$ y $100 \%$, y entre mayor sea el valor de $\mathrm{R} 2$, mejor es el ajuste del modelo a los datos.

Sin embargo, tener un modelo de regresión con un alto valor de $\mathrm{R}^{2}$, no garantiza que el modelo tenga la mejor capacidad de pronóstico, y se hace necesario el cumplimiento de una serie de supuestos estadísticos que garanticen la validez del modelo.

La Tabla 18, presenta los supuestos estadísticos [28]-[31] que deben cumplir los modelos de regresión.

Tabla 18. Supuestos Estadísticos para el modelo de regresión

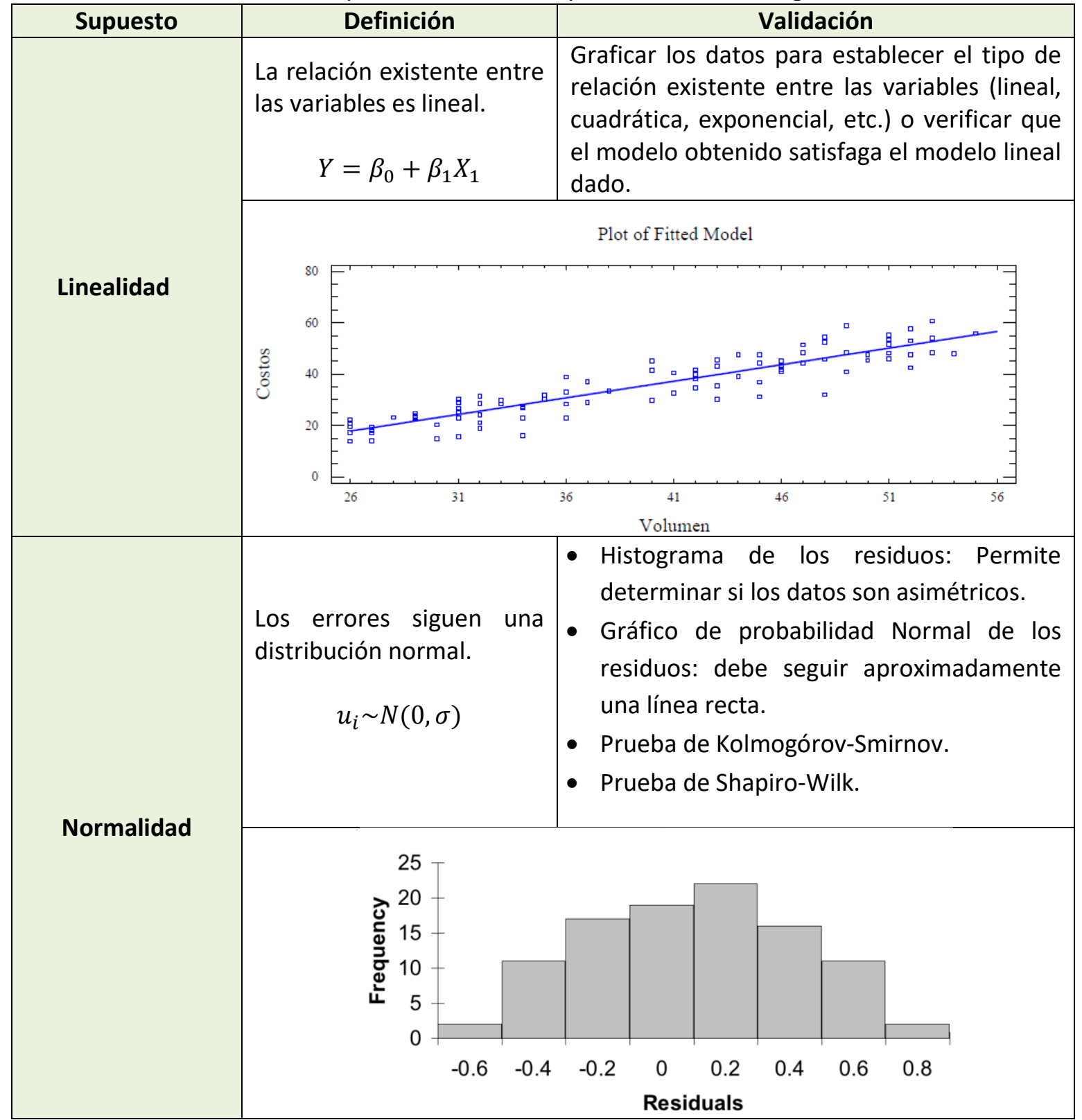




\begin{tabular}{|c|c|c|c|}
\hline \multirow[b]{2}{*}{ Homocedasticidad } & $\begin{array}{l}\text { La varianza de los errores } \\
\text { es constante. } \\
\qquad \operatorname{Var}\left(U_{i}\right)=\sigma^{2}\end{array}$ & \multicolumn{2}{|c|}{$\begin{array}{l}\text { - Gráfico de residuos vs valores ajustados: } \\
\text { Verificar gráfico sin pautas de asociación. } \\
\text { - Estadístico de Levene. } \\
\text { - Prueba de Breush Pagan. } \\
\text { - Prueba de Barleth }\end{array}$} \\
\hline & 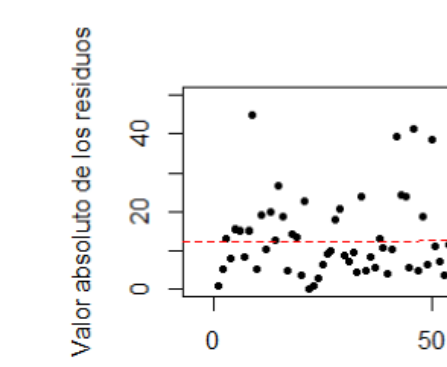 & 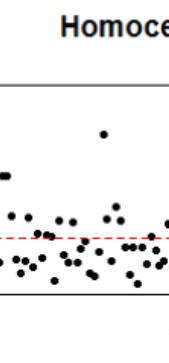 & 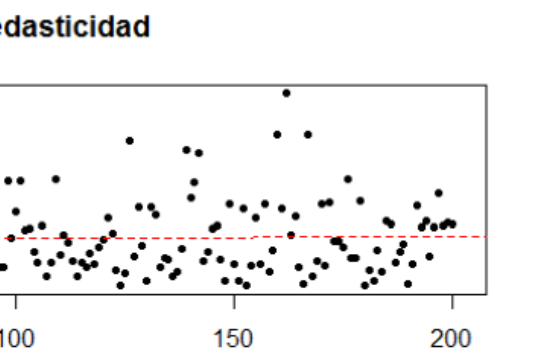 \\
\hline \multirow{2}{*}{ Independencia } & $\begin{array}{l}\text { Los datos deben ser } \\
\text { independientes. } \\
\text { Una observación no debe } \\
\text { dar información sobre las } \\
\text { demás. } \\
\qquad E\left[u_{i} u_{j}\right]=0\end{array}$ & \multicolumn{2}{|c|}{$\begin{array}{l}\text { - Gráfico de residuos vs orden: Permite } \\
\text { comprobar la independencia de los } \\
\text { residuos, estos deben tener un } \\
\text { comportamiento aleatorio, sin exhibir } \\
\text { patrones o tendencias. } \\
\text { - Estadístico de Durbin Watson }\end{array}$} \\
\hline & 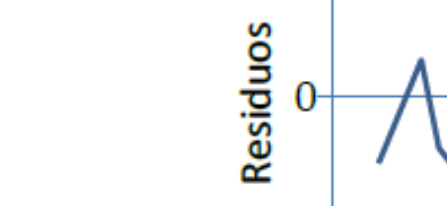 & 11 & $\sqrt{V}$ \\
\hline $\begin{array}{l}\text { Multicolinealidad } \\
\text { (Sólo para el } \\
\text { modelo } \\
\text { multivariable) }\end{array}$ & \multicolumn{2}{|c|}{$\begin{array}{l}\text { Existe multicolinealidad cuando una o } \\
\text { más variables, son una combinación } \\
\text { lineal de otra, es decir, que el } \\
\text { coeficiente de correlación entre estas } \\
\text { dos variables de } 1 . \\
\text { Al enfrentar problemas de } \\
\text { multicolinealidad severa, una de las } \\
\text { soluciones más simples consiste en } \\
\text { omitir del modelo una de las variables } \\
\text { colineales. }\end{array}$} & $\begin{array}{l}\text { Factor de inflación de la varianza } \\
\text { (FIV), cuantifica la intensidad de la } \\
\text { multicolinealidad: } \\
\text { FIV=1: No hay multicolinealidad. } \\
\text { FIV>1: existe multicolinealidad } \\
\text { entre las variables } \\
\text { independientes. }\end{array}$ \\
\hline
\end{tabular}




\subsection{MODELO DE SIMULACIÓN}

Para el autor Robert E. Shannon [32], [33] "La simulación es el proceso de diseñar un modelo de un sistema real y llevar a término experiencias con él, con la finalidad de comprender el comportamiento del sistema o evaluar nuevas estrategias - dentro de los límites impuestos por un cierto criterio o un conjunto de ellos- para el funcionamiento del sistema".

El objetivo de una simulación energética [34] es modelar un edificio y su entorno, y determinar de forma anticipada su comportamiento energético, tiene en características constructivas del edificio (geometría y los materiales que lo componen) como, las condiciones climatológicas del exterior, además de su uso (niveles de ocupación y horarios de funcionamiento, cargas interiores debidas al uso previsto, etc.).

La simulación energética de edificios [32], consiste en analizar en función del tiempo las necesidades energéticas de un edificio al proporcionar unas condiciones básicas de confort, según su diseño y su entorno condicionado por variables como la radiación solar directa o difusa, la ocupación, orientación del edificio o caracterización térmica de sus componentes arquitectónicos. La simulación energética dinámica, permite experimentar posibles modificaciones, con la intención de mejorar las condiciones de diseño y optimizarlo. Buscando un equilibrio entre consumo de energía, economía, confort y medio ambiente. En países de la UE, la simulación energética es necesaria en:

- Proyectos constructivos: Cualquier proyecto constructivo de un edificio debe incluir una Certificación Energética, basada en una simulación previa a su ejecución, realizada con alguno de los programas oficialmente reconocidos.

- Rehabilitación: La rehabilitación de un edificio en aras de mejorar su eficiencia energética es un caso característico en el que es interesante una simulación, para prever el comportamiento energético obtenido con las medidas de mejoras que se desean incorporar.

- Obtención de sello de certificación ambiental: Muchos de los sellos y programas de certificación ambiental de edificios, requieren datos obtenidos en una simulación previa, como energía/consumo final o emisiones de CO2.

- Auditoría Energética: En una auditoría energética se analiza el comportamiento energético real de un edificio, y el coste asociado. El objetivo suele ser la reducción del consumo, tanto a nivel energético como a nivel económico. Algunas propuestas de mejora se suelen basar en predicciones de comportamiento del edificio con la variación de las condiciones aportadas por dichas mejoras, que sólo son posibles si contamos con una buena simulación energética que nos permita decidir la conveniencia o no de llevar a cabo la medida. 
La simulación energética en edificios se ha convertido en pieza clave para la mejora del consumo y eficiencia energética [35], pues permite, mediante herramientas de cálculo evaluar el comportamiento energético de los edificios y sus instalaciones, y, a partir de datos reales recogidos mediante medición directa, validar el estado actual del edificio, y posteriormente generar propuestas de mejora y reducción del consumo energético.

Para esto se han desarrollado una serie de programas de simulación que permiten el desarrollo de estas propuestas, entre ellos se encuentran: TERESE (Tecnologías para la Rehabilitación y sistemas para la eficiencia energética de edificios), Energy plus, Design Builder, Simergy, Ecotect, Transys, Equest, Fluent y para el caso puntual de España, Lider y Calener, todos ellos con mejoras en la interfaz gráfica y niveles de aproximación en los cálculos más precisos.

Para el desarrollo de este trabajo, se decidió utilizar la herramienta de simulación Design Builder con el motor de cálculo EnergyPlus, de elevado reconocimiento internacional, siendo este un software de simulación de alta precisión, que permite la construcción del edificio en tres dimensiones, y el desarrollo de los cálculos energéticos pertinentes que entregan información relacionada al cálculo de cargas térmicas, cálculo de demandas de calefacción y refrigeración, cálculo de consumos y emisiones de $\mathrm{CO} 2$, cálculo de condiciones ambientales interiores, entre otras; todo esto mediante la implementación de una amplia biblioteca de componentes y materiales de construcción, por los cuales se pueden simular los distintos tipos de estructuras existentes.

El motor de simulación Energy Plus [32] es un motor de simulación gratuito. Sin embargo, su complejidad radica en la entrada de datos (lenguaje propio que debe utilizarse un entorno tipo "bloc de notas"). Energy Plus está pensado para que se desarrollen en torno al mismo, aplicaciones gráficas y manejables que aprovechen su potencia de cálculo, como es el caso del programa Design Builder.

Design Builder lleva integrado Energy Plus de forma que, al simular, automáticamente se lanza el cálculo en Energy Plus y Design Builder recoge los resultados que éste le proporciona para mostrarlos gráfica y numéricamente.

Energy Plus es un motor completo y complejo, del que Design Builder incorpora sus principales funcionalidades y existe la posibilidad de exportar el modelo desde Design Builder a formato Energy Plus y trabajar con él externamente para incorporar aquel elemento que pueda haber quedado fuera del alcance de Design Builder.

Los datos que Design Builder entrega a través de la simulación con Energy Plus son:

- Cálculo de cargas: Design Builder implementa de forma específica el cálculo de cargas máximas de calefacción y refrigeración conforme al estándar ASHRAE. 
- Cálculo de la demanda de calefacción y refrigeración: Permite calcular la demanda de forma ágil durante las primeras etapas del diseño orientado a la mejora del diseño bioclimático del edificio, sin entrar a modelar en detalle las instalaciones de climatización.

- Cálculo de los consumos de calefacción, refrigeración y ACS y de las emisiones de CO2: Introduciendo las instalaciones, que pueden modelarse en diferentes niveles de detalle y complejidad, se obtienen los consumos energéticos y el gasto en combustible (electricidad, gas, biomasa, etc.) así como las emisiones de $\mathrm{CO} 2$ asociadas.

- Cálculo de las condiciones ambientales interiores: Con los recintos climatizados o no, se obtienen las condiciones interiores del edificio, temperatura y humedad, en cualquier instante del año.

- Cálculo de las condiciones de confort: A través de diversos índices de confort, como el PMV, PPD, la temperatura operativa o el porcentaje de horas a determinadas temperaturas, se puede obtener información sobre las condiciones de confort en los recintos del edificio.

- Balance Térmico: Design Builder presenta las ganancias solares, por ocupación, iluminación, etc. así como las pérdidas en ventilación, transmisión de cerramientos, etc. Dando así información importante sobre los elementos más críticos en el balance térmico del edificio. 


\section{BIBLIOGRAFÍA}

[1]ISO 50006, "Energy management systems - Measuring energy performance using energy baselines (EnB) and energy performance indicators (EnPI) - General principles and guidance", 2016.

[2]R. A. Wienclaw, "Time Series", Salem Press Encyclopedia. Great Neck Publishing, 2019. [3]A. C. Juárez, C. A. Zuñiga, J. L. M. Flores, y D. S. Partida, "Análisis de series de tiempo en el pronóstico de la demanda de almacenamiento de productos perecederos", Estud. Gerenciales, vol. 32, núm. 141, pp. 387-396, 2016.

[4]J. Murillo, A. Trejos, y P. Carvajal, "Estudio del pronóstico de la demanda de energía eléctrica, utilizando modelos de series de tiempo", Sci. Tech., vol. IX, núm. 23, pp. 37-42, 2003.

[5]S. Botero Botero y J. A. Cano Cano, "ANÁLISIS DE SERIES DE TIEMPO PARA LA PREDICCIÓN DE LOS PRECIOS DE LA ENERGÍA EN LA BOLSA DE COLOMBIA", Cuadernos de Economía, vol. 27. scieloco, pp. 173-208, 2008.

[6]A. L. Valencia, C. A. Lozano, y C. A. Moreno, "Modelo de promedios móviles para el pronóstico horario de potencia y energía eléctrica”, El Hombre y La Máquina, vol. 29, pp. 96-105, 2007.

[7]C. Deb, F. Zhang, J. Yang, S. E. Lee, y K. W. Shah, "A review on time series forecasting techniques for building energy consumption", Renew. Sustain. Energy Rev., vol. 74, núm. July 2016, pp. 902-924, 2017.

[8]M. Mendoza Ramírez, "Pronósticos y Estadística para la Administración".

[9]F. Villarreal, "'Introducción a los Modelos de Pronósticos'”, Buenos Aires, 2016.

[10]D. R. Anderson, D. J. Sweeney, y T. A. Williams, Estadística para administración y economía, 10a ed. México DF, 2008.

[11]Universidad de las Américas Puebla, "Metodología”, Puebla, 2015.

[12]M. Arellano, "Introducción al análisis clásico de Series de Tiempo", 2010. [En línea].

Disponible en: http://ciberconta.unizar.es/LECCION/seriest/100.HTM. [Consultado: 10nov-2019].

[13]D. F. Betancourt, “Medición del error en pronósticoz de demanda”, 2016. [En línea]. Disponible en: https://ingenioempresa.com/medicion-error-pronostico/. [Consultado: 10nov-2019].

[14]S. D. Permai y H. Tanty, “Linear regression model using bayesian approach for energy performance of residential building”, en Procedia Computer Science, 2018, vol. 135, pp. 671-677.

[15]J. Roth y R. Rajagopal, "Benchmarking building energy efficiency using quantile regression", Energy, vol. 152, pp. 866-876, jun. 2018.

[16]N. Fumo y M. A. Rafe Biswas, "Regression analysis for prediction of residential energy consumption", Renewable and Sustainable Energy Reviews, vol. 47. Elsevier Ltd, pp. 332343, 2015.

[17]B. Arregi y R. Garay, "Regression analysis of the energy consumption of tertiary buildings", en Energy Procedia, 2017, vol. 122, pp. 9-14. 
[18]A. Aranda, G. Ferreira, M. D. Mainar-Toledo, S. Scarpellini, y E. Llera Sastresa, "Multiple regression models to predict the annual energy consumption in the Spanish banking sector", Energy Build., vol. 49, pp. 380-387, jun. 2012.

[19]I. Bilous, V. Deshko, y I. Sukhodub, "Parametric analysis of external and internal factors influence on building energy performance using non-linear multivariate regression models", J. Build. Eng., vol. 20, pp. 327-336, nov. 2018.

[20]N. Strachan, "Business-as-Unusual: Existing policies in energy model baselines", Energy Econ., vol. 33, núm. 2, pp. 153-160, mar. 2011.

[21]T. Sakamoto, K. Takase, R. Matsuhashi, y S. Managi, "Baseline of the projection under a structural change in energy demand”, Energy Policy, vol. 98, pp. 274-289, nov. 2016.

[22]T. Alves, L. Machado, R. G. de Souza, y P. de Wilde, "A methodology for estimating office building energy use baselines by means of land use legislation and reference buildings", Energy Build., vol. 143, pp. 100-113, 2017.

[23]J. H. Ko, D. S. Kong, y J. H. Huh, "Baseline building energy modeling of cluster inverse model by using daily energy consumption in office buildings", Energy Build., vol. 140, pp. 317-323, 2017.

[24]E. Elbeltagi, H. Wefki, S. Abdrabou, M. Dawood, y A. Ramzy, "Visualized strategy for predicting buildings energy consumption during early design stage using parametric analysis", J. Build. Eng., vol. 13, núm. July, pp. 127-136, 2017.

[25]J. Granderson y P. N. Price, "Development and application of a statistical methodology to evaluate the predictive accuracy of building energy baseline models", Energy, vol. 66, pp. 981-990, 2014.

[26]X. Liang, T. Hong, y G. Q. Shen, "Improving the accuracy of energy baseline models for commercial buildings with occupancy data", Appl. Energy, vol. 179, pp. 247-260, 2016.

[27]G. Ciulla y A. D'Amico, "Building energy performance forecasting: A multiple linear regression approach", Appl. Energy, vol. 253, núm. April, p. 113500, 2019.

[28]D. Montoro, "Regresión lineal simple", 2016.

[29]A. Arribas, "Estadística II Tema 4. Regresión lineal simple", 2010.

[30]U. Morelisa, "Modelo de regresión lineal simple", 2013.

[31]P. Fonseca, "Regresión Lineal", Barcelona, 2018.

[32]D. Quesada, "ESTUDIO DE LA EFICIENCIA ENERGÉTICA EN EDIFICIOS MUNCIPALES COMPARANDO HERRAMIENTAS DE SIMULACIÓN CON MEDIDAS EXPERIMENTALES", Universidad de Valladolid, 2016.

[33]R. Shannon y J. D. Johannes, "Systems Simulation: The Art and Science", IEEE Trans. Syst. Man. Cybern., vol. SMC-6, núm. 10, pp. 723-724, jul. 2008.

[34]A. Gavilán, "ANÁLISIS COMPARATIVO DE LA EFICIENCIA ENERGÉTICA EN EDIFICIOS EXISTENTES CON DIFERENTES HERRAMIENTAS DE SIMULACIÓN ENERGÉTICA", Universidad de Valladolid, 2017.

[35]A. J. Colonia y F. J. Riascos, "Análisis del Desempeño Energético del edificio de aulas 4 de la Universidad Autónoma De Occidente mediante simulación computacional", Univ. Autónoma de Occidente, 2018. 


\section{CAPÍTULO 4: CASO ESTUDIO ENERGÉTICO DEL CAMPUS UNIVERSIDAD AUTÓNOMA DE OCCIDENTE, UAO}

El siguiente capítulo expone la revisión energética adelantada al campus y al edificio de aulario 4, mostrando la monitorización y medidas de los años 2016 a 2019. Se incorporan procedimientos en la auditoria energética, según recomendaciones normativas. Lo anterior da una idea de los consumos reales de las diferentes áreas y equipos instalados, tanto en el campus como en el edificio de estudio. Para el análisis se contó con el sistema de monitorización instalado power monitor de Schneider, con equipos portátiles como sensores y data logger de IAQ e intensidad lumínica, analizadores de red y una estación meteorológica. En conjunto, los procedimientos adelantados posibilitaron un análisis detallado de la situación energética de los edificios objeto de estudio.

\subsection{DESCRIPCIÓN GENERAL DE LA UNIVERSIDAD AUTÓNOMA DE OCCIDENTE}

La Universidad Autónoma de Occidente (UAO) es una institución de educación superior universitaria en Colombia con funciones de docencia, investigación y proyección social e internacional. La Figura 50, muestra la vista superior del campus universitario.

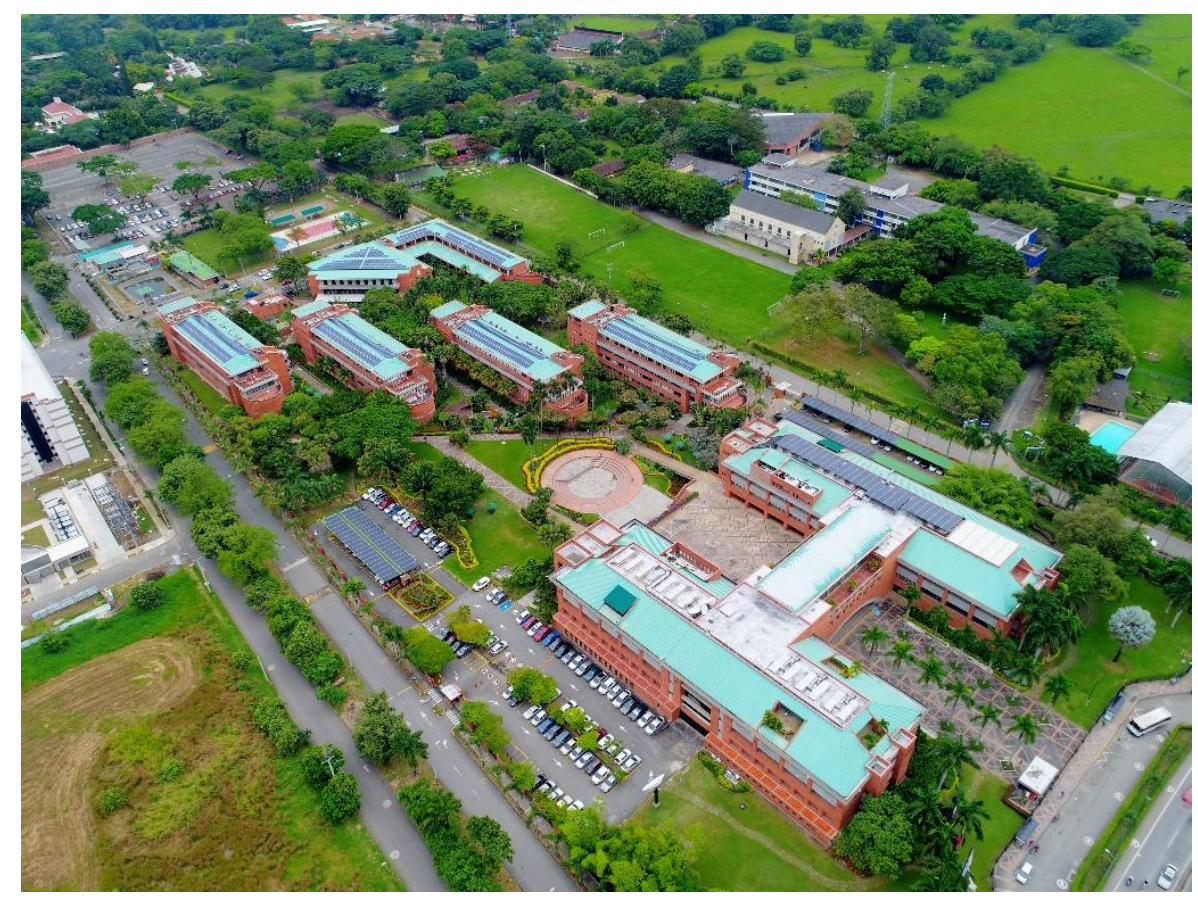

Figura 50. Vista superior campus universitario 
En la actualidad, la Autónoma de Occidente tiene dos sedes en la ciudad de Cali; la principal ubicada en la vía Cali- Jamundí y otra pequeña en San Fernando. La Universidad para garantizar la calidad y el compromiso con la sociedad, ha implementado y recibido las respectivas certificaciones de los sistemas de gestión: calidad-ISO 9001 y ambiental ISO 14001, los cuales han recibido las respectivas certificaciones ISO 9001 e ISO 14001. Recientemente en el año 2015 se aprobó con el fin de abordar y contribuir a la sostenibilidad, el proyecto "modelo de Campus Sostenible" que articula las acciones y programas generados desde la academia, la investigación, la operación interna y la proyección social de la Universidad Autónoma de Occidente, en función del compromiso y responsabilidad ambiental y social. En el marco del proyecto se ha venido trabajando en temas relacionados con: tratamiento de agua potable y residual, composición del campus en cuanto al paisaje y la flora que lo adorna, mejor disposición de residuos, eficiencia energética, y la conservación del agua. La Figura 51., muestra la vista frontal y entrada peatonal principal del campus universitario.

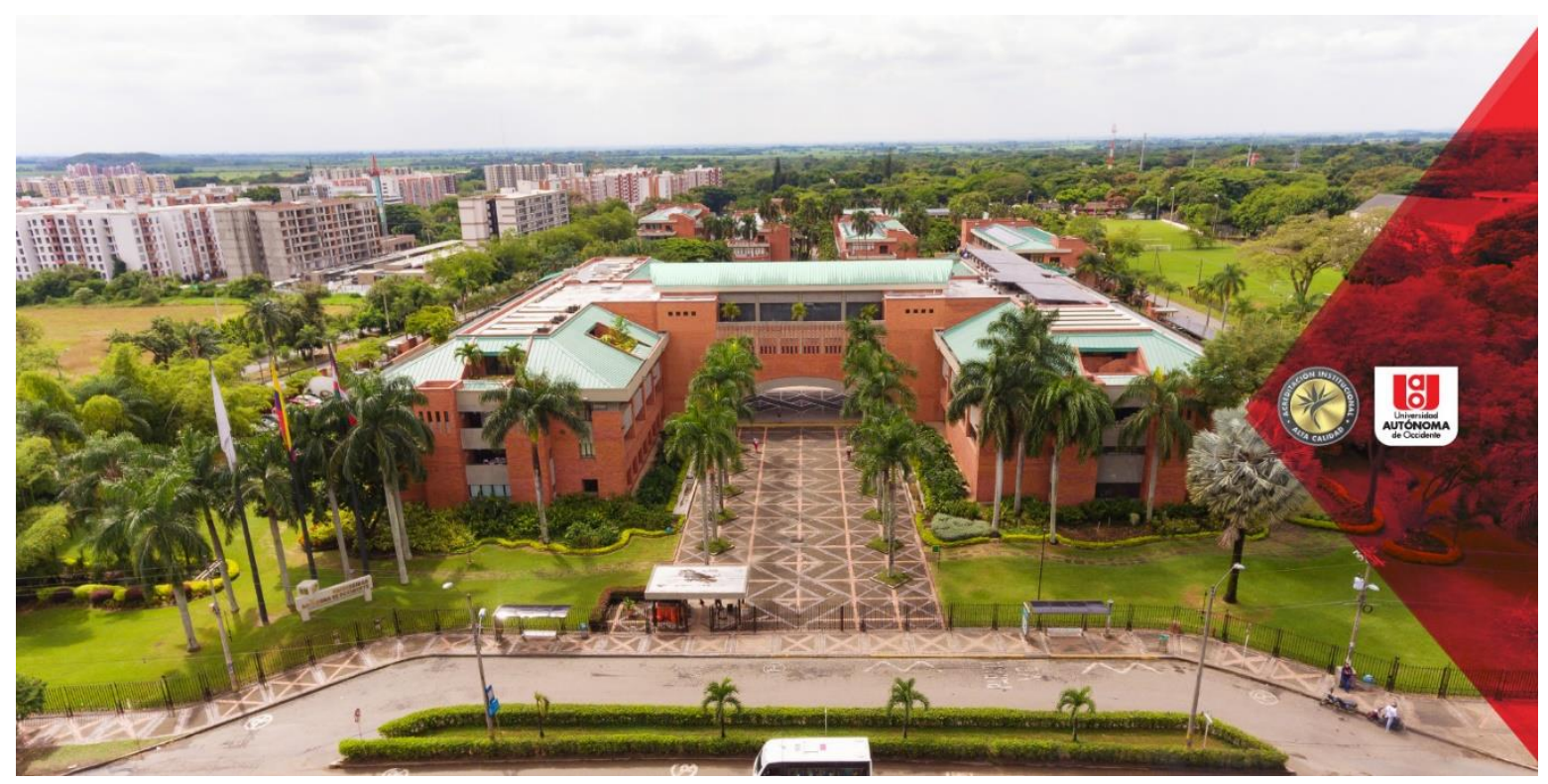

Figura 51. Vista frontal y entrada peatonal principal del campus universitario

Como resultado del trabajo realizado en el ámbito de la eficiencia energética y el proyecto de campus sostenible; la Universidad Autónoma de Occidente ha obtenido el Premio Andesco-MinMinas-Findeter a la Eficiencia Energética 2015; adicionalmente se ubicó tercera en la clasificación de instituciones latinoamericanas y la primera en Colombia de la UI Greenmetric World University Sustainability Ranking que publicó la Universidad de Indonesia en el 2017; y en ese mismo año el programa Campus Sostenible fue reconocido una vez más a nivel internacional, ya que fue elegido ganador, por unanimidad del jurado, del III Premio de buenas prácticas en gestión para universidades colombianas, otorgado por la Fundación Internacional OCU, con sede en Madrid, España; lo anterior permite evidenciar la puesta en marcha de las acciones académicas, de investigación y de proyección; que promueven el compromiso y la responsabilidad ambiental, social y energética de la universidad. 
El campus de la UAO consta de cuatro bloques fundamentales de edificios que son:

\section{-Área 1: Edificio Central}

En este se desarrollan los principales procesos administrativos de la Universidad; se encuentra dividido en dos secciones denominados ala norte y ala sur, que constan de cuatro pisos cada uno. En ala sur se encuentran ubicados dos auditorios, la biblioteca y las facultades de ciencias básicas y humanidades. En ala norte se ubica la vicerrectoría administrativa y financiera, varias dependencias asociadas a la misma, la vicerrectoría académica con las facultades de ingeniería, comunicación social y ciencias económicas y administrativas, y rectoría.

Adicionalmente, se ubican en esta área los dos sótanos donde se encuentran los laboratorios y el estudio de televisión.

\section{-Área 2: Aulas}

Se compone de cuatro edificios numerados de 1 a 4, con cuatro pisos cada uno y con similares características estructurales, sin embargo, con diferencias apreciables en cuanto a la potencia eléctrica instalada: En el edificio de aulas 1 se encuentra, además de los salones de clase y auditorios (denominados por la institución como torreones), el instituto de idiomas, el almacén de compras, el taller de mantenimiento y el laboratorio de prototipado. En el cuarto piso de aulas 2 y aulas 4 se han dispuesto los salones de postgrado, operacionalmente diferentes a los demás salones de clase, pues cada salón tiene su unidad de tratamiento de aire acondicionado (UTA). En las diferentes aulas se encuentran también algunas oficinas asociadas a departamentos o procesos administrativos, por ejemplo, en aulas 3 se encuentra el departamento de mantenimiento, en aulas 2 el de seguridad y control y en aulas 4 la dirección de educación virtual, entre otros.

\section{-Área 3: Bienestar Universitario y Cafetería}

Se asocian a esta área dos edificios de tres pisos donde principalmente se encuentran ubicadas las oficinas de bienestar universitario y se prestan los servicios de cafetería a través de cinco locales con consumos independientes entre sí.

\section{-Área 4: Plantas de Tratamiento de Agua}

Esta área comprende los equipos principalmente; bombas y motores utilizados para el tratamiento de agua potable (PTAP) y de agua residual (PTAR).

La Figura 52., muestra el diagrama energético productivo del campus universitario de la UAO. 


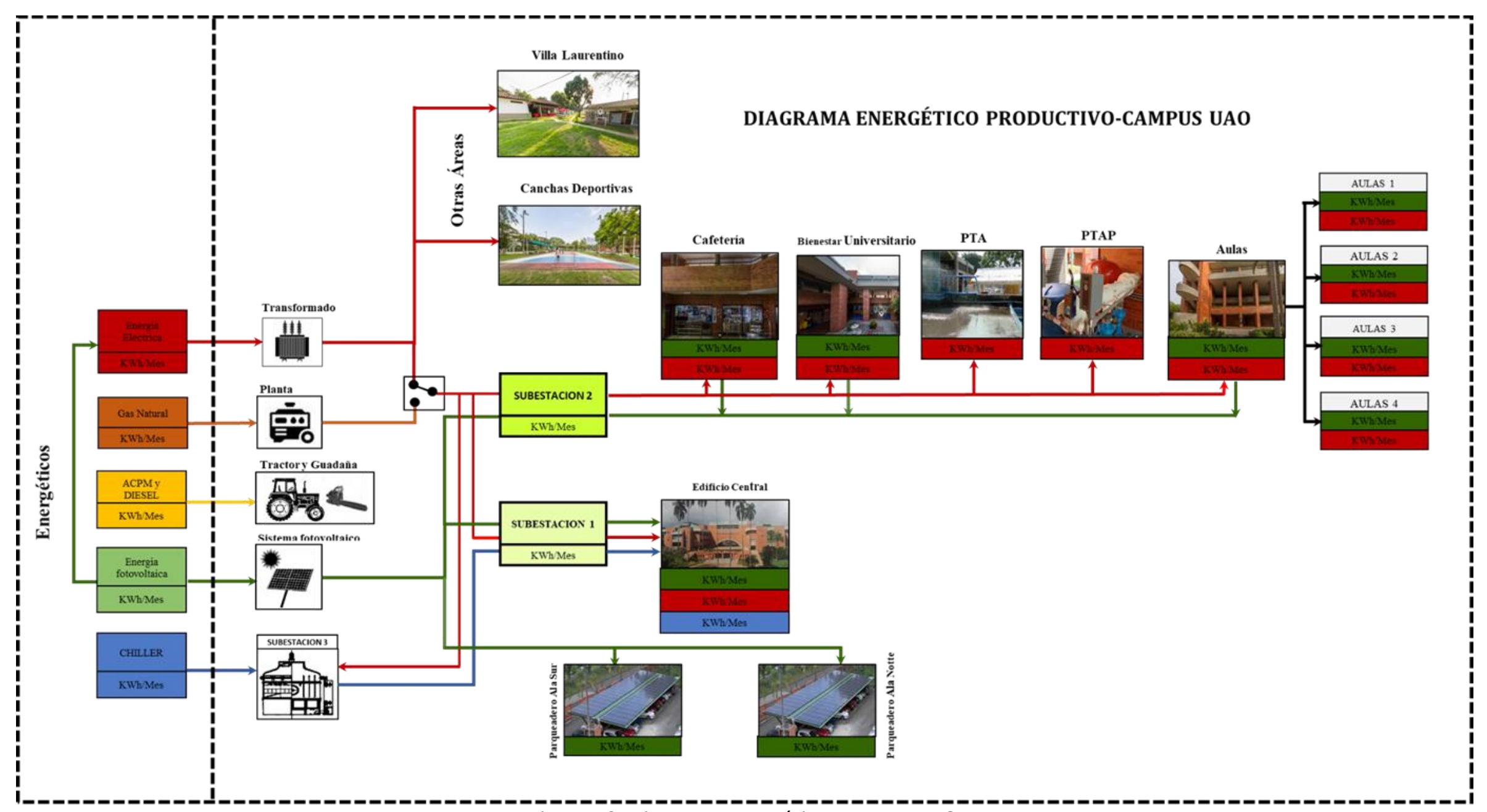

Figura 52. Diagrama energético campus UAO 
La Tabla 19, muestra la distribución por áreas del campus universitario UAO y los principales equipos de uso final que equipan las áreas.

Tabla 19. Equipos de uso final y distribución por áreas del campus de la UAO

\begin{tabular}{|c|c|c|c|c|c|}
\hline \multirow{2}{*}{ Área } & \multirow{2}{*}{ Energético } & \multicolumn{3}{|c|}{ Sistemas } & \multirow{2}{*}{ Funcionamiento } \\
\hline & & Iluminación & Climatización & Otros equipos & \\
\hline $\begin{array}{l}\text { Edificio } \\
\text { central }\end{array}$ & $\begin{array}{l}\text {-Electricidad } \\
\text { red } \\
\text {-Generación } \\
\text { fotovoltaica }\end{array}$ & $\begin{array}{c}\text { Panel LED } \\
\text { Sylvania 45w } \\
\text { Tubos LED } \\
18 \mathrm{w}\end{array}$ & $\begin{array}{l}2 \text { enfriadoras } \\
\text { de agua de } \\
879.21 \mathrm{~kW} \\
\text { Marca York }\end{array}$ & $\begin{array}{l}\text { Computadores } \\
\text { Dell } \\
\text { Impresoras Epson } \\
\text { Fotocopiadoras } \\
\text { Ricoh }\end{array}$ & $\begin{array}{c}\text { lunes a viernes } \\
\text { 8:00 am a 9:30 pm } \\
\text { sábado 8:00 am a } \\
5: 00 \mathrm{pm}\end{array}$ \\
\hline Aulas & $\begin{array}{c}\text {-Electricidad } \\
\text { red } \\
\text {-Generación } \\
\text { fotovoltaica }\end{array}$ & $\begin{array}{c}\text { Panel LED } \\
\text { Sylvania 45w } \\
\text { Tubos LED } \\
18 \mathrm{w}\end{array}$ & $\begin{array}{c}\text { Minisplit de } \\
10.55 \text { y } 17.58 \\
\text { kW }\end{array}$ & $\begin{array}{c}\text { Computadores } \\
\text { Dell } \\
\text { Video Beam } \\
\text { Epson } \\
\text { Parlantes } \\
\text { Behringer } \\
\end{array}$ & $\begin{array}{c}\text { lunes a viernes } \\
\text { 6:30 am a 9:30 pm } \\
\text { sábado 7:30 am a } \\
5: 00 \mathrm{pm}\end{array}$ \\
\hline $\begin{array}{l}\text { Edificio de } \\
\text { bienestar } \\
\text { universitario }\end{array}$ & $\begin{array}{c}\text {-Electricidad } \\
\text { red } \\
\text {-Generación } \\
\text { fotovoltaica }\end{array}$ & $\begin{array}{c}\text { Panel LED } \\
\text { Sylvania 45w } \\
\text { Tubos LED } \\
18 \mathrm{w}\end{array}$ & - & $\begin{array}{c}\text { Computadores } \\
\text { Dell } \\
\text { Impresoras Epson } \\
\text { Fotocopiadoras } \\
\text { Ricoh } \\
\end{array}$ & $\begin{array}{c}\text { lunes a viernes } \\
\text { 8:00 am a 9:30 pm } \\
\text { sábado 8:00 am a } \\
12: 00 \mathrm{pm}\end{array}$ \\
\hline Cafetería & $\begin{array}{c}\text {-Electricidad } \\
\text { red } \\
\text {-Generación } \\
\text { fotovoltaica } \\
\text {-Gas Natural } \\
\end{array}$ & $\begin{array}{c}\text { Panel LED } \\
\text { Sylvania 45w } \\
\text { Tubos LED } \\
18 \mathrm{w}\end{array}$ & - & $\begin{array}{l}\text { Refrigeradores } \\
\text { Hornos } \\
\text { Microondas } \\
\text { Licuadoras } \\
\text { Vitrinas } \\
\end{array}$ & $\begin{array}{c}\text { lunes a viernes } \\
\text { 6:00 am a 9:30 pm } \\
\text { sábado 8:00 am a } \\
5: 00 \mathrm{pm}\end{array}$ \\
\hline $\begin{array}{c}\text { Planta de } \\
\text { tratamiento } \\
\text { de agua }\end{array}$ & $\begin{array}{l}\text { Electricidad } \\
\text { Generación } \\
\text { fotovoltaica }\end{array}$ & $\begin{array}{c}\text { Tubos LED } \\
18 \mathrm{w}\end{array}$ & - & $\begin{array}{l}\text { Motores } \\
\text { Bombas }\end{array}$ & $\begin{array}{c}\text { lunes a viernes } \\
\text { 8:00 am a 9:30 pm } \\
\text { sábado 8:00 am a } \\
\text { 5:00 pm }\end{array}$ \\
\hline
\end{tabular}

La red eléctrica de suministro al Campus UAO se divide en 3 subestaciones:

La 1, suministra la energía del edificio central y tiene una capacidad de 500 KVA.

La 2, alimenta eléctricamente a los dos chiller del edificio central para aire acondicionado centralizado y tiene una capacidad de 800 KVA.

La 3, proporciona la energía necesaria a los servicios de los cuatro edificios de aulas, a los dos de bienestar Universitario y cafetería y a la planta de tratamiento de aguas y es de 1000 KVA

El campus de la UAO está monitorizado mediante 11 medidores eléctricos tipo SCHNEIDER, con telemedida que permiten medir la potencia y energía eléctrica consumida en las diferentes áreas.

También existe 8 medidores asociados a los sistemas solares Fotovoltaicos. 


\subsection{DESCRIPCIÓN DE LOS SISTEMAS DE MEDICIÓN INSTALADOS}

Energía Eléctrica: La UAO actualmente tiene instalado el medidor principal de consumo dispuesto por la empresa prestadora del servicio de energía del pacifico-EPSA, con un nivel de tensión de $13200 \mathrm{~V}$, a través de una acometida con su respectivo dispositivo de medición; este se divide en 3 subestaciones, cada una con su transformador, adicional a ello la organización en el año 2015 adquirió 11 medidores de consumo de energía eléctrica marca SCHNEIDER con sistemas de tele medida que recopilan información referente a: potencia activa y reactiva; y energía con periodicidad de 15 minutos, diaria, mensual y anual; los datos se reportan y almacenan en el programa Power monitor-GCE. La Figura 53 y la Figura 54, enseñan los sistemas de medición instalados en el campus.

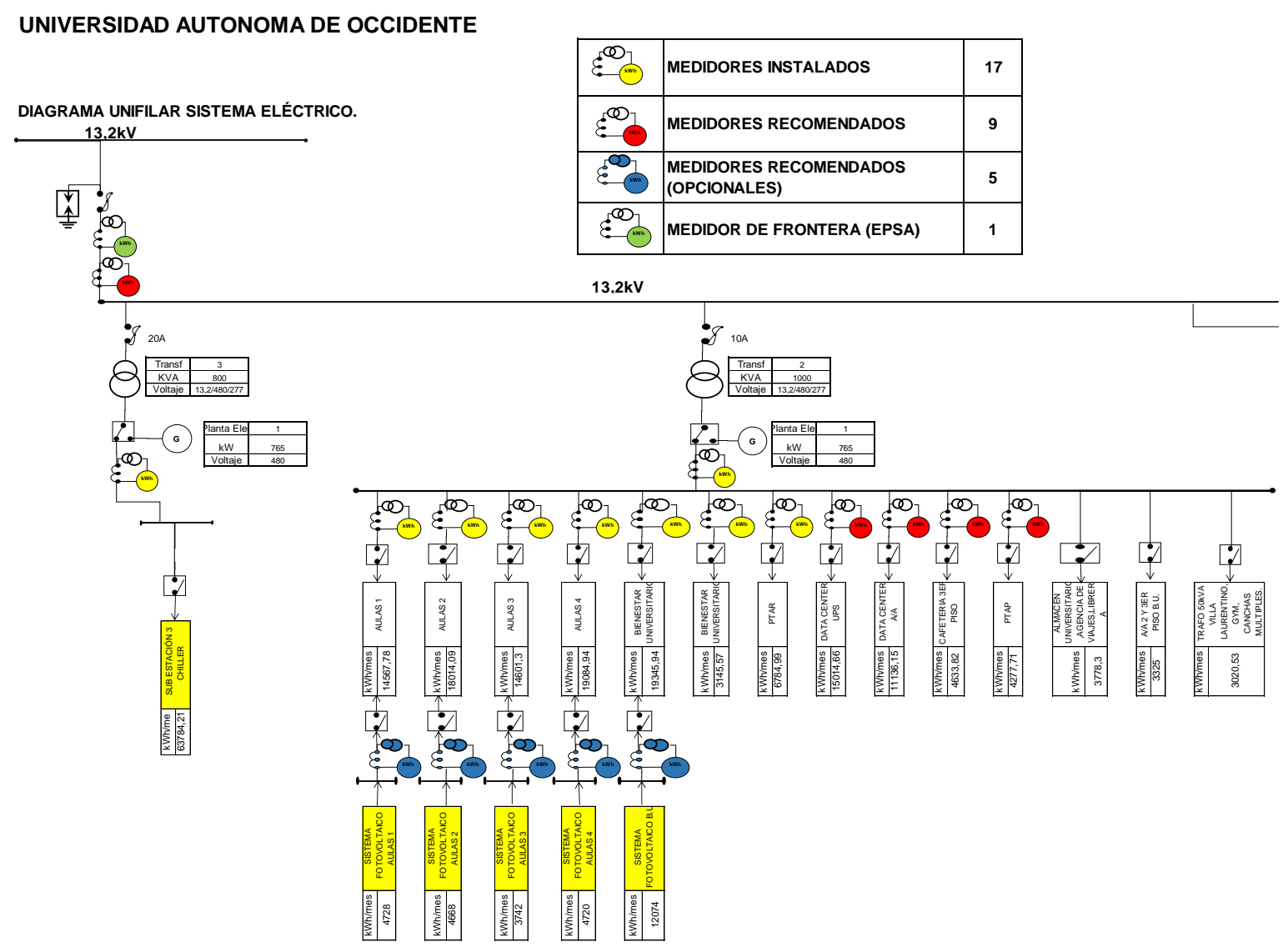

Figura 53. Sistema de medición de energía eléctrica instalado en la UAO

Las zonas donde se ubican los medidores son:

\section{Subestación Uno:}

- Circuito principal

-Ala Norte Piso Uno, Dos y Tres.

-Ala Sur Piso, Uno y Dos. 
Subestación Dos:

- Circuito Principal

-Aulas Uno, Dos, Tres y Cuatro

- Bienestar Piso Uno y Dos.

-PTAP

-PTAR

Subestación Tres:

- Circuito principal

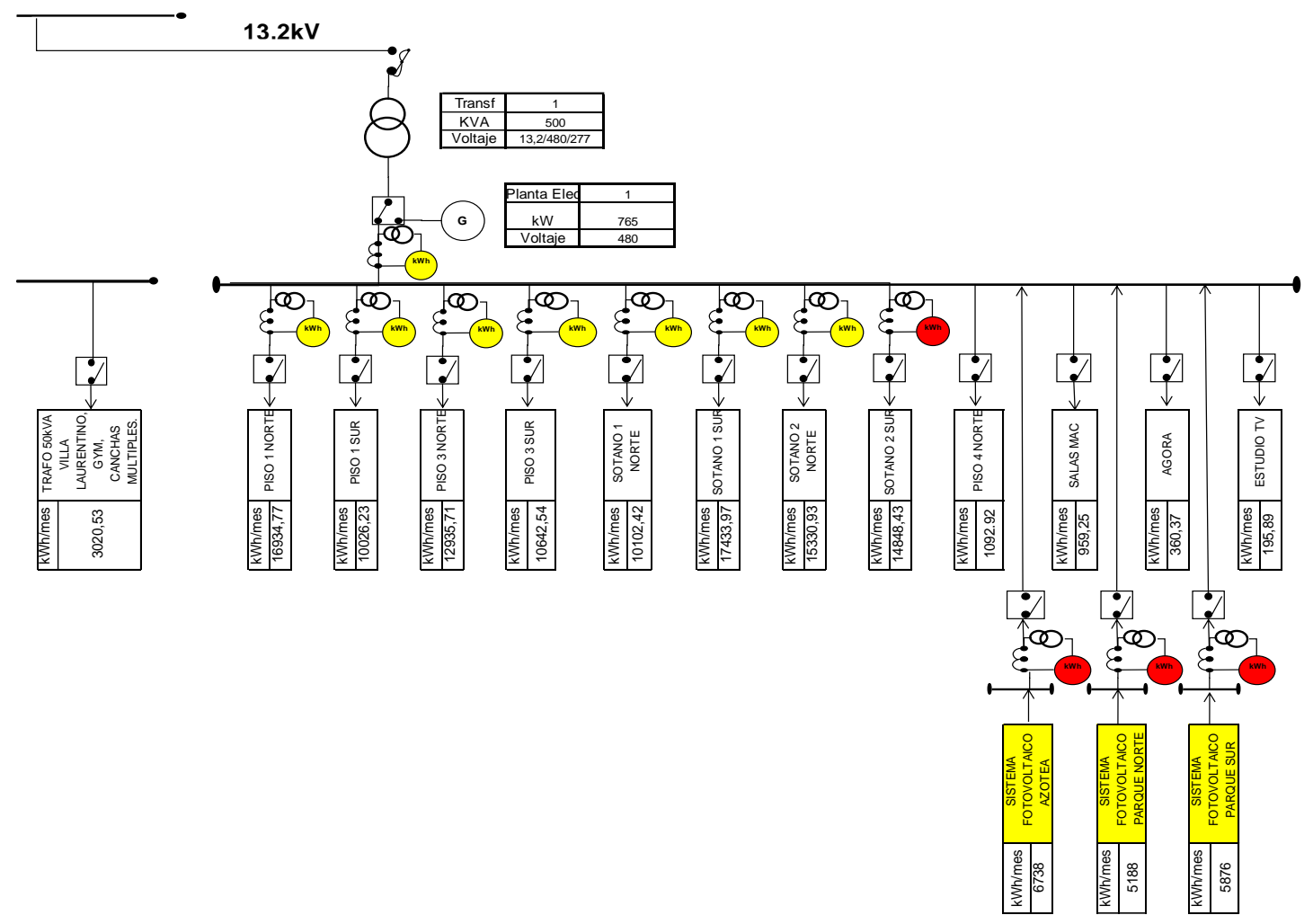

Figura 54. Sistema de medición de energía eléctrica instalado en la UAO

Gas natural: Se cuenta con un medidor de consumo energético de GN el cual es administrado por el proveedor del servicio Gases de Occidente, los registros de consumo en la organización se reportan mensualmente de la factura.

Energía Solar Fotovoltaica: El sistema solar fotovoltaico (SSFV) está conectado a la red de energía eléctrica y es utilizado por el proveedor del servicio de energía del pacifico-EPSA, quien reporta la generación mensualmente en la factura y a través de la página: https://solar.epsa.com.co/index.aspx 
La Figura 55 y la Tabla 20., presentan los sistemas de energía solar fotovoltaica (SSFV) instalados en el campus universitario y describe el número, tipo de paneles y potencia instalada por sistema.

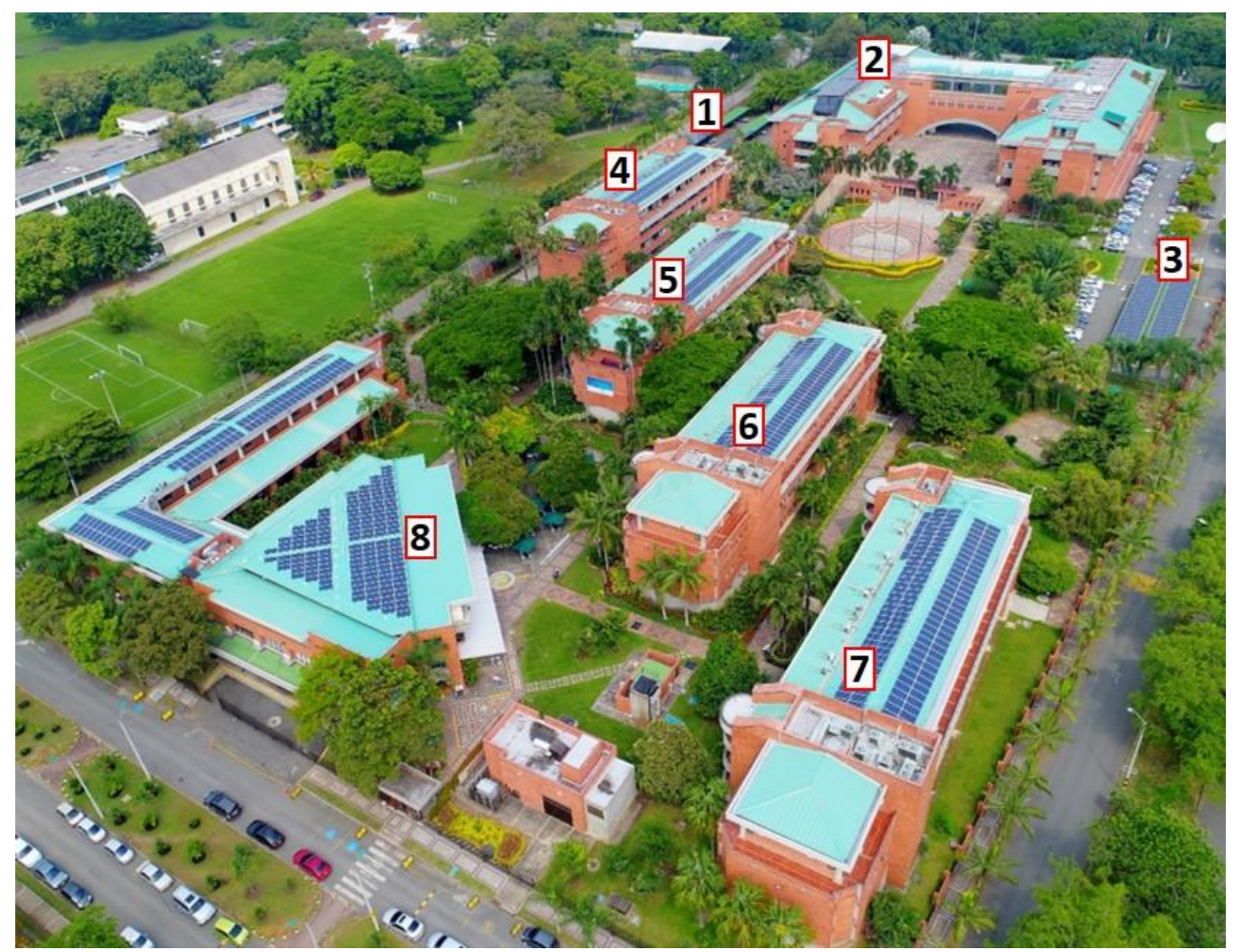

Figura 55. Vista superior del campus universitario y sistemas marcación de los SSFV del campus

Tabla 20. Descripción de los SSFV instalados en el campus de la UAO

\begin{tabular}{|c|c|c|c|c|}
\hline Sistema & Área & Equipo instalado & Cantidad & Potencia Instalada \\
\hline \multirow[t]{2}{*}{1} & \multirow{2}{*}{$\begin{array}{l}\text { Parqueadero } \\
\text { Ala sur }\end{array}$} & $\begin{array}{l}\text { Panel FV: PANASONIC VBHN240 } \\
\text { Tecnología HIT de } 240 \mathrm{Wp}\end{array}$ & 225 & \multirow[t]{2}{*}{$52.85 \mathrm{kWp}$} \\
\hline & & Inversor: SMA STP 24000TL-US de 24 kW & 2 & \\
\hline \multirow[t]{2}{*}{2} & \multirow{2}{*}{$\begin{array}{l}\text { Edificio } \\
\text { Central }\end{array}$} & $\begin{array}{l}\text { Panel FV: PANASONIC VBHN230 } \\
\text { Tecnología HIT de } 230 \mathrm{Wp}\end{array}$ & 230 & \multirow[t]{2}{*}{$52.9 \mathrm{kWp}$} \\
\hline & & Inversor SMA STP 24000TL-US de 24 kW & 2 & \\
\hline \multirow[t]{2}{*}{3} & \multirow{2}{*}{$\begin{array}{l}\text { Parqueadero } \\
\text { Ala norte }\end{array}$} & $\begin{array}{l}\text { Panel FV: PANASONIC VBHN240 } \\
\text { Tecnología HIT de } 240 \mathrm{Wp}\end{array}$ & 188 & \multirow[t]{2}{*}{$45.12 \mathrm{kWp}$} \\
\hline & & Inversor: SMA STP 20000TL-US de $20 \mathrm{~kW}$ & 2 & \\
\hline \multirow[t]{2}{*}{4} & \multirow[t]{2}{*}{ Aulas 1} & $\begin{array}{l}\text { Panel FV: JINKO SOLAR JKM265P Módulo } \\
\text { Policristalino de } 265 \mathrm{Wp}\end{array}$ & 144 & \multirow[t]{2}{*}{$38.2 \mathrm{kWp}$} \\
\hline & & Inversor: Fronius Symo 17.5-3 de 18 kW & 2 & \\
\hline \multirow[t]{2}{*}{5} & \multirow[t]{2}{*}{ Aulas 2} & $\begin{array}{l}\text { Panel FV: JINKO SOLAR JKM265P Módulo } \\
\text { Policristalino de } 265 \mathrm{Wp}\end{array}$ & 144 & \multirow[t]{2}{*}{$38.2 \mathrm{kWp}$} \\
\hline & & Inversor: Fronius Symo $17.5-3$ de 18 kW & 2 & \\
\hline \multirow[t]{2}{*}{6} & \multirow[t]{2}{*}{ Aulas 3} & $\begin{array}{l}\text { Panel FV: JINKO SOLAR JKM265P Módulo } \\
\text { Policristalino de } 265 \mathrm{Wp}\end{array}$ & 144 & \multirow[t]{2}{*}{$38.2 \mathrm{kWp}$} \\
\hline & & Inversor: Fronius Symo $17.5-3$ de 18 kW & 2 & \\
\hline
\end{tabular}




\begin{tabular}{|c|c|c|c|c|}
\hline \multirow[t]{2}{*}{7} & \multirow[t]{2}{*}{ Aulas 4} & $\begin{array}{l}\text { Panel FV: JINKO SOLAR JKM265P Módulo } \\
\text { Policristalino de } 265 \mathrm{Wp}\end{array}$ & 144 & \multirow[t]{2}{*}{$38.2 \mathrm{kWp}$} \\
\hline & & Inversor: Fronius Symo 17.5-3 de 18 kW & 2 & \\
\hline \multirow{2}{*}{8} & $\begin{array}{l}\text { Cafetería y } \\
\text { Bienestar }\end{array}$ & $\begin{array}{l}\text { Panel FV: JINKO SOLAR JKM265P Módulo } \\
\text { Policristalino de } 265 \mathrm{Wp}\end{array}$ & 368 & \multirow[t]{2}{*}{$97.56 \mathrm{kWp}$} \\
\hline & Universitario & Inversor: Fronius Symo 24.0-3 de 24 kW & 4 & \\
\hline
\end{tabular}

\subsubsection{Equipos de medición}

La UAO posee una serie de equipos de medida que permiten monitorizar sus consumos y la calidad de sus parámetros.

\section{Medición de Energía Eléctrica}

En el campus universitario de la UAO, se encuentran instalados 19 medidores de energía eléctrica certificados y calibrados marca Schneider presentados en la Tabla 21, la cual muestra las características técnicas de los equipos de medición instalados.

Tabla 21. Medidores de Energía Eléctrica instalados en el campus

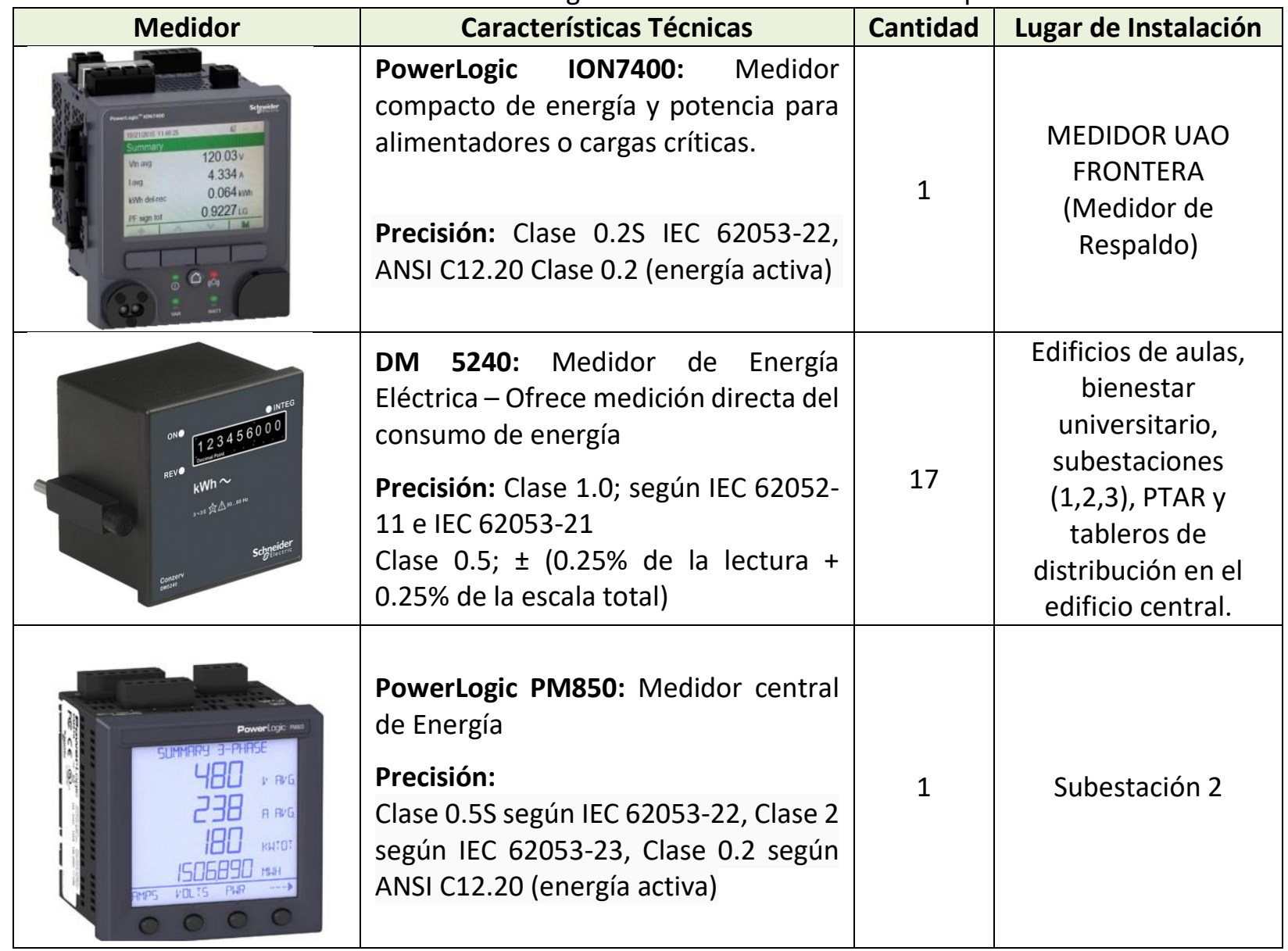

Fuente: Características técnicas tomadas de la página < https://www.se.com/co/es/?preferredCountry=yes $>$ 
La plataforma "Power Monitor Expert" de Schneider, integra la información de los medidores de energía eléctrica y permite la monitorización y análisis especializado para soluciones de gestión energética, gestionar la calidad eléctrica, disponibilidad y fiabilidad, optimizar el uso de la infraestructura y activos eléctricos, reducir costes energéticos y operacionales, entre otros. Las figuras $56-67$., muestra la información suministrada por la plataforma y el sistema de medición de energía eléctrica instalado en la UAO.

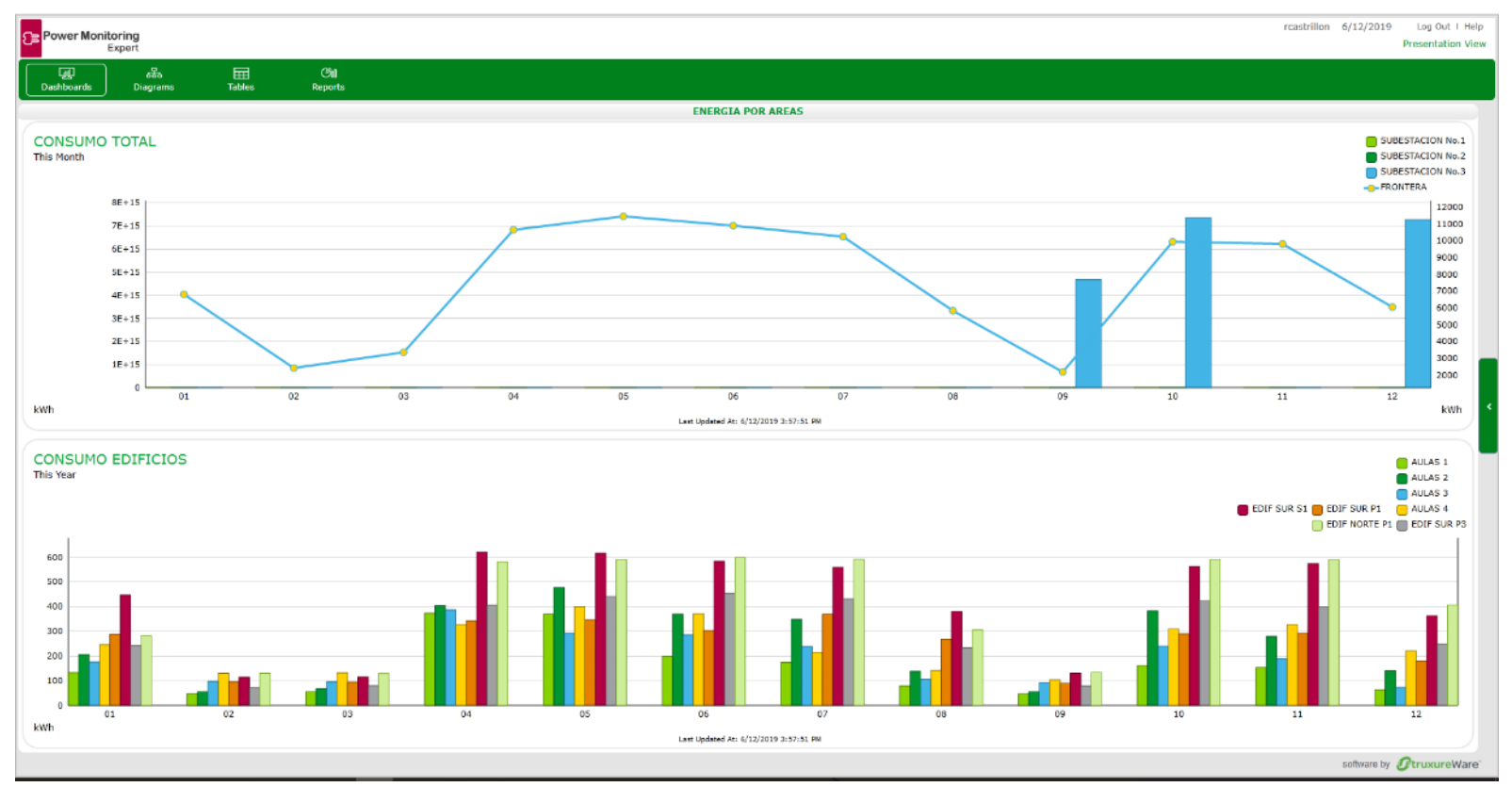

Figura 56. Consumo de energía total y por áreas de la UAO.

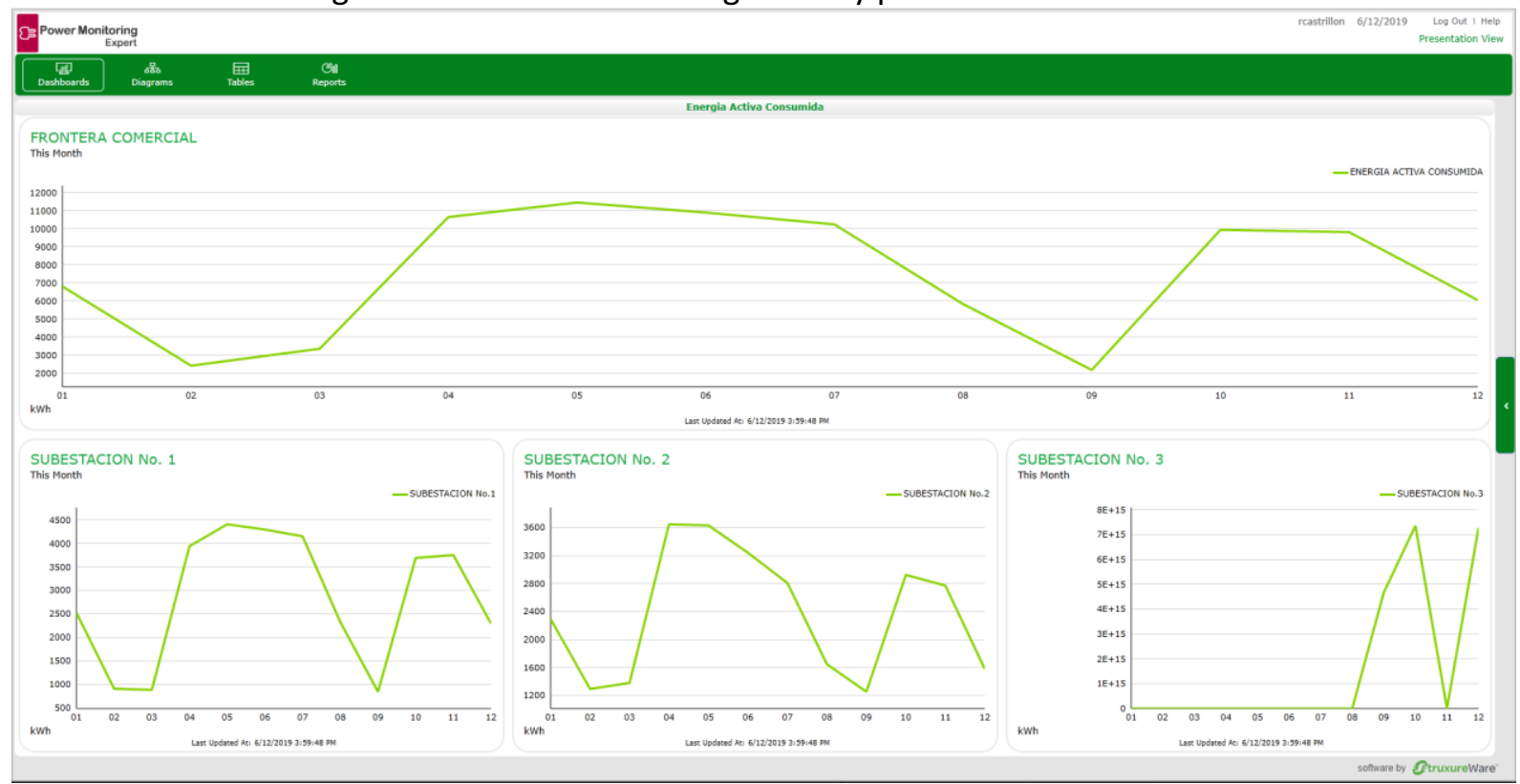

Figura 57. Energía activa consumida y subestaciones del campus. 


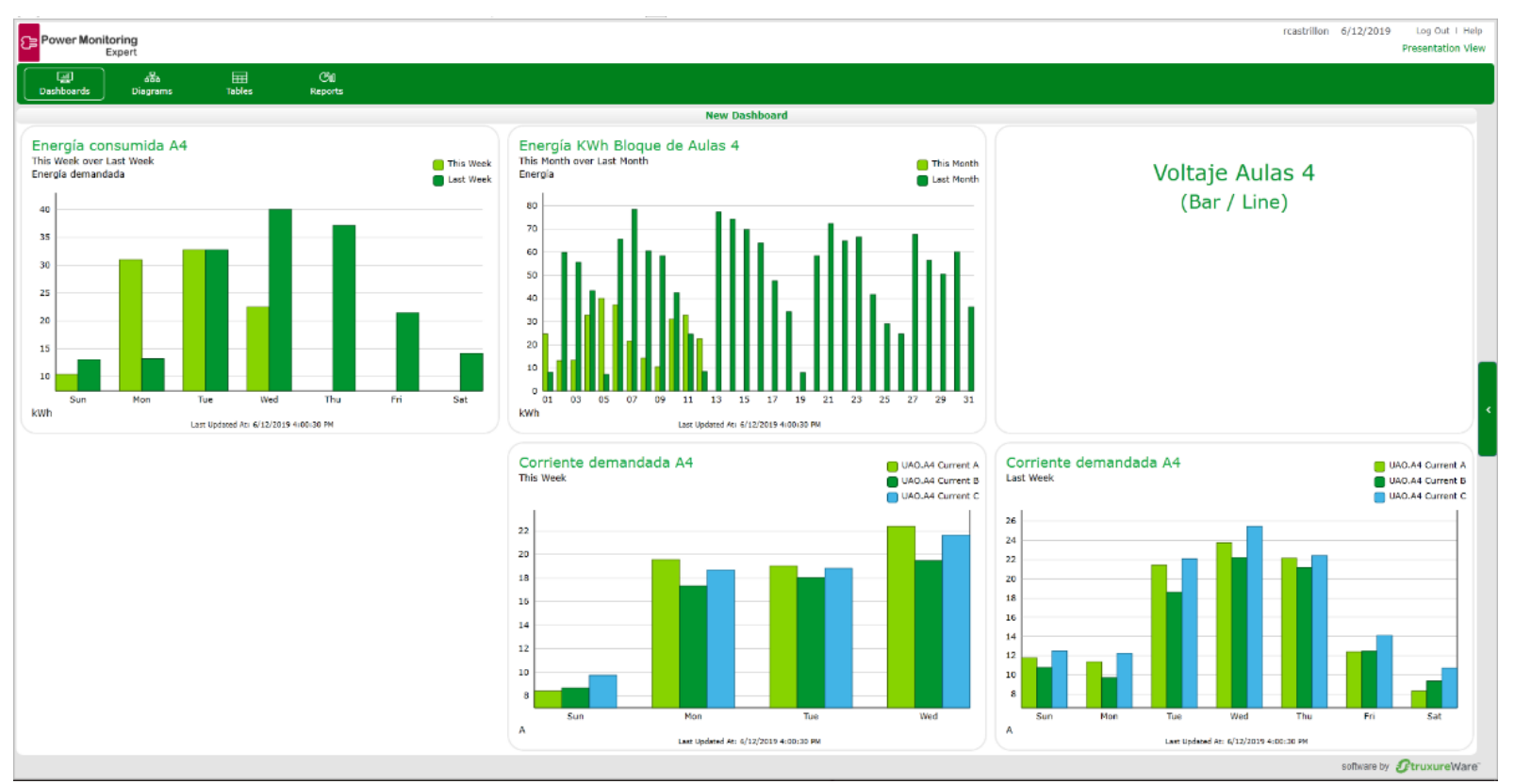

Figura 58. Parámetros eléctricos monitorizados de Aulas 4

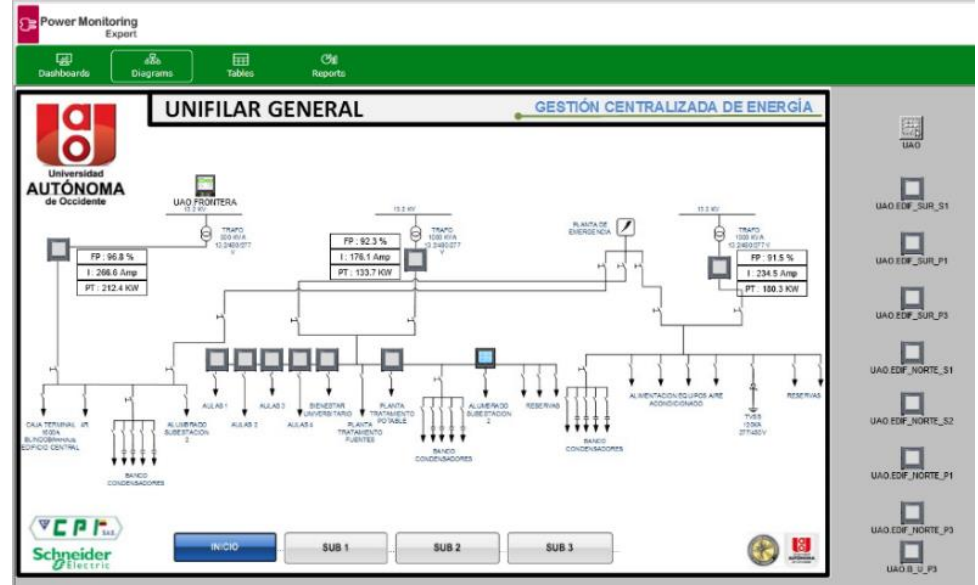

Figura 59. Diagrama unifilar general de medición UAO

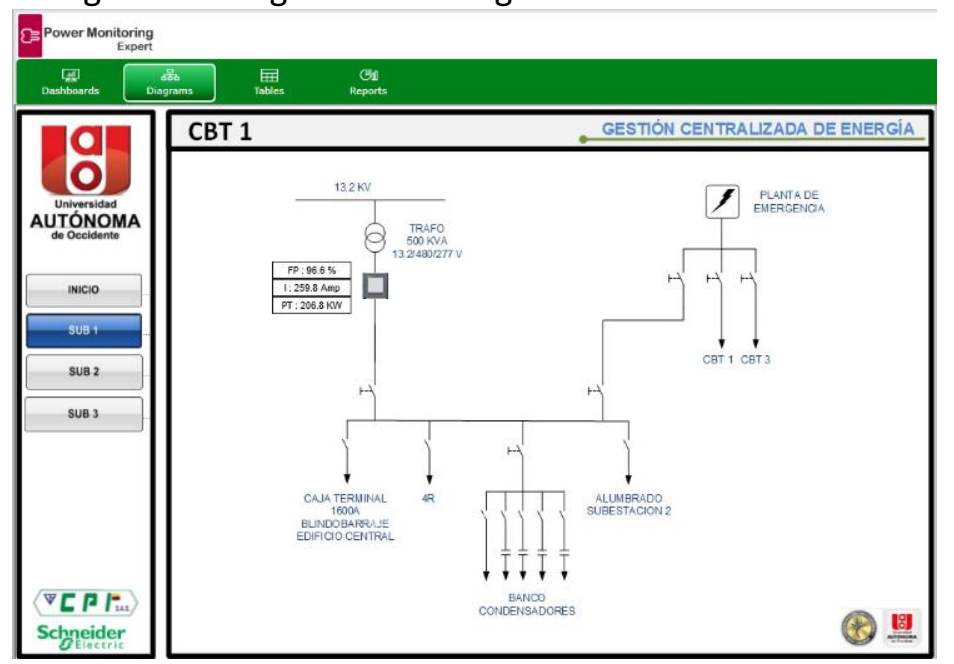

Figura 61. Diagrama unifilar subestación 1

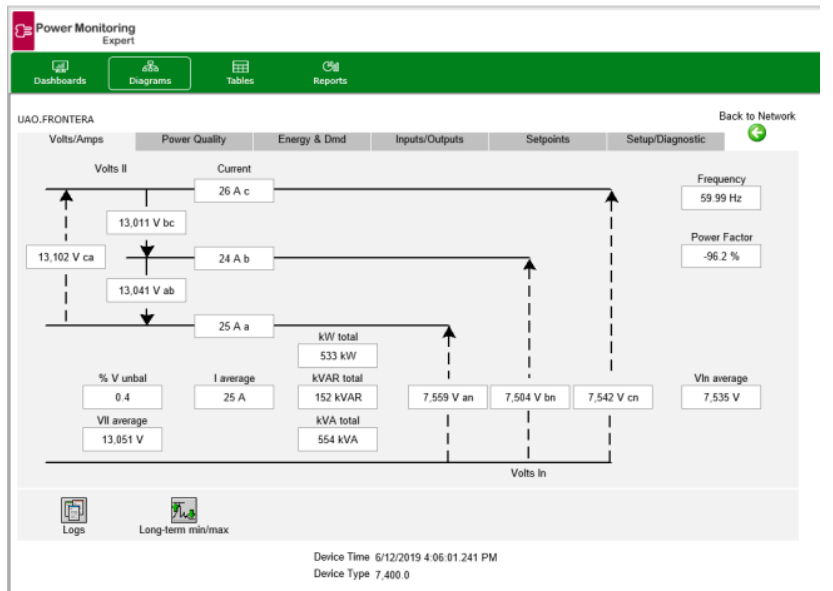

Figura 60. Parámetros medidor de Frontera

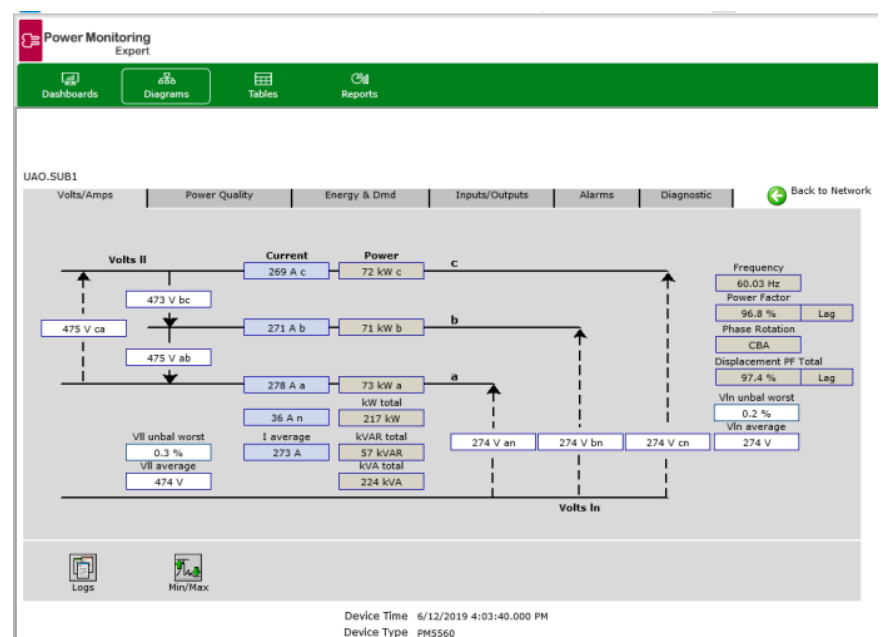

Figura 62. Parámetros medidor subestación 1 


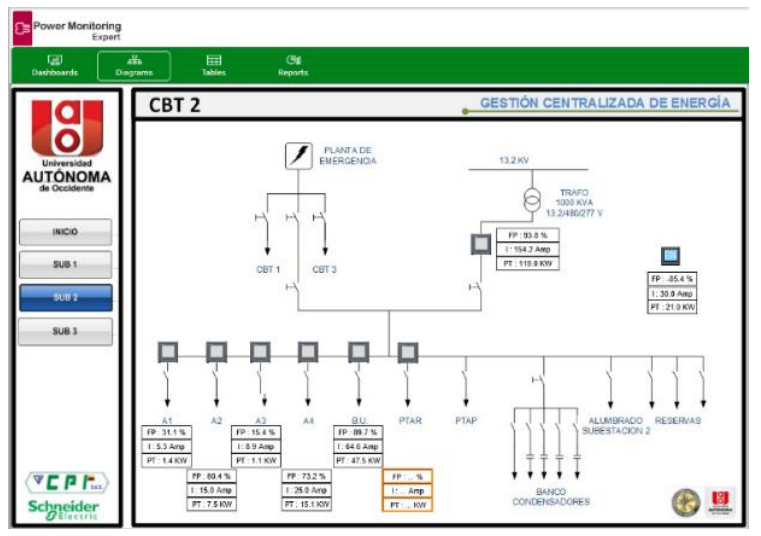

Figura 63 Diagrama unifilar subestación 2

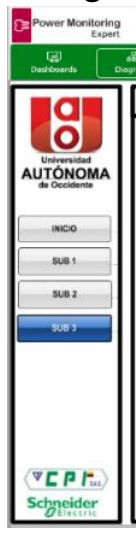

Figura 65 Diagrama unifilar subestación 3

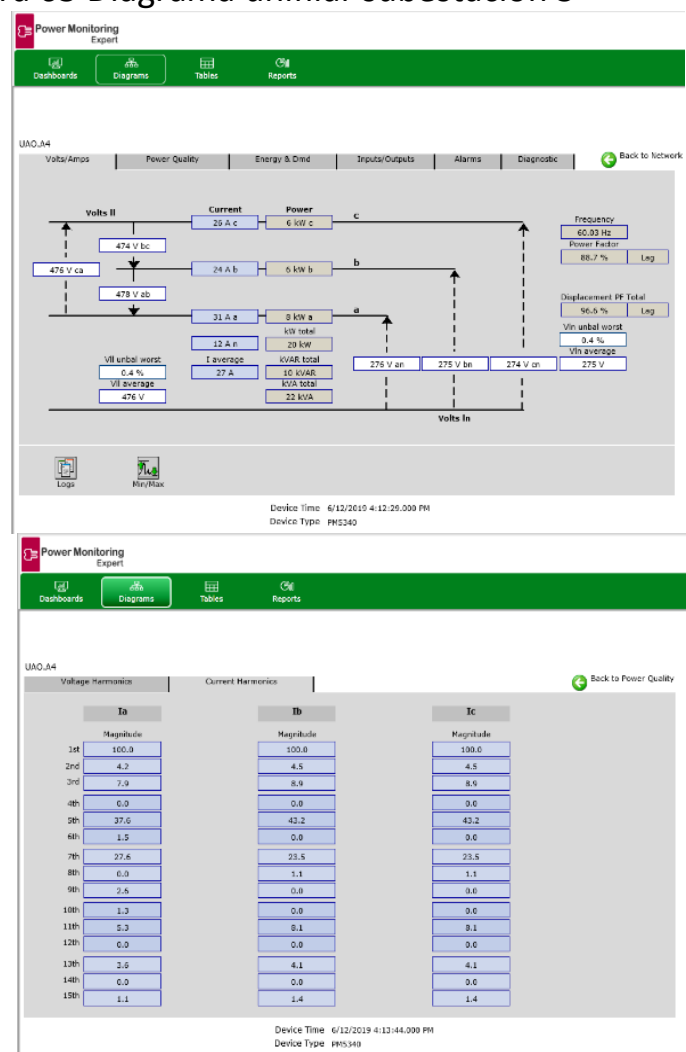

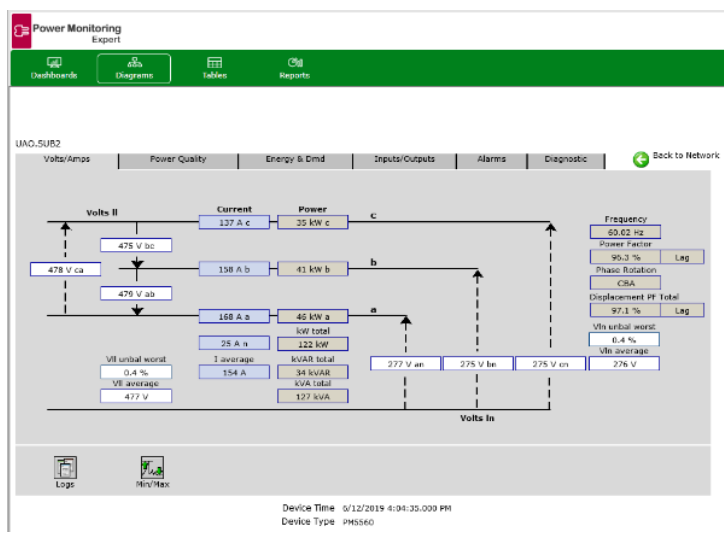

Figura 64. Parámetros medidor subestación 2 Fispower monotorny

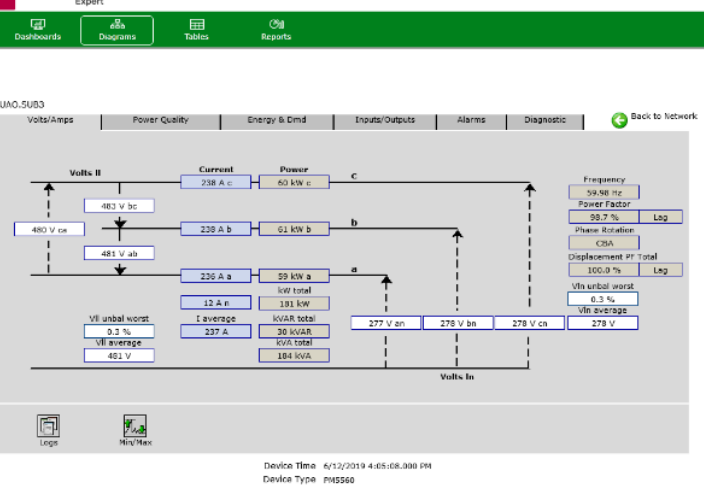

Figura 66. Parámetros medidor subestación 3

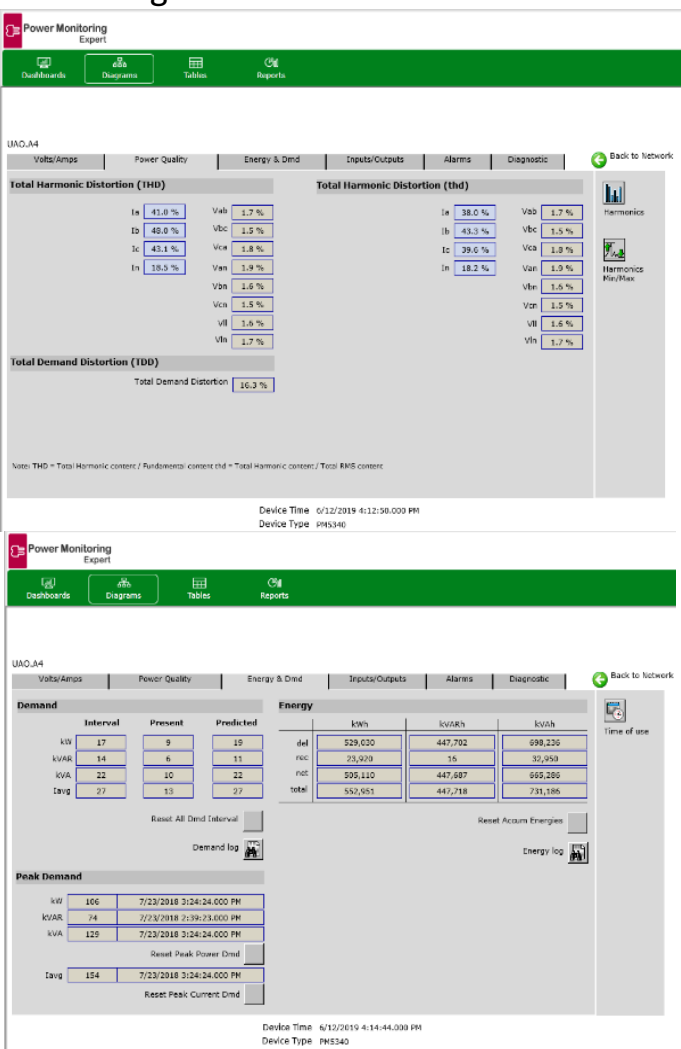

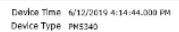




\section{Estación Meteorológica}

En el campus universitario se encuentra instalada una estación meteorológica portátil Davis Vantage Pro2 (Figura 68) que posee sensores integrados de lluvia, viento, temperatura y humedad con sensor UV y radiación solar. Entrega datos meteorológicos precisos actualizados cada 2,5 segundos. La Tabla 22. Muestra información detallada de la estación meteorológica.

Tabla 22. Características técnica estación meteorológica

\begin{tabular}{|c|c|c|c|}
\hline VARIABLE & RESOLUCIÓN & RANGO & PRECISIÓN NORMAL (+/-) \\
\hline Presión barométrica & $\begin{array}{c}0.01 » \mathrm{Hg} ; 0.1 \mathrm{~mm} ; \\
0.1 \mathrm{hPa} ; 0.1 \mathrm{mb}\end{array}$ & $\begin{array}{l}16 » \text { to } 32.5 » \mathrm{Hg} \\
410 \text { to } 820 \mathrm{~mm} \\
540 \text { to } 1100 \mathrm{hPa} \\
540 \text { to } 1100 \mathrm{mb}\end{array}$ & $\begin{array}{c}0.03 » \mathrm{Hg} \\
0.8 \mathrm{~mm} \mathrm{Hg} \\
1.0 \mathrm{hPa} \\
1.0 \mathrm{mb} \\
\end{array}$ \\
\hline Humedad & $1 \%$ & 1 to $100 \%$ & $\begin{array}{c}3 \% \mathrm{RH} ; \\
4 \% \text { por encima } 90 \%\end{array}$ \\
\hline Punto de Rocío & $1^{\circ} \mathrm{C}$ & $\begin{array}{l}-105^{\circ} \text { to }+130^{\circ} \mathrm{F} ; \\
-76^{\circ} \mathrm{C} \text { to }+54^{\circ} \mathrm{C}\end{array}$ & $3^{\circ} \mathrm{F} ; 1.5^{\circ} \mathrm{C}$ \\
\hline Radiación Solar & $1 \mathrm{~W} / \mathrm{m} 2$ & 0 to $1800 \mathrm{~W} / \mathrm{m} 2$ & $5 \%$ en escala completa \\
\hline Temperatura interior & $0.1^{\circ} \mathrm{F} ; 0.1^{\circ} \mathrm{C}$ & $\begin{array}{c}+32^{\circ} \text { to }+140^{\circ} \mathrm{F} ; \\
\quad 0 \text { to }+60^{\circ} \mathrm{C}\end{array}$ & $1{ }^{\circ} \mathrm{F} ; 0.5^{\circ} \mathrm{C}$ \\
\hline Temperatura exterior & $0.1^{\circ} \mathrm{F} ; 0.1^{\circ} \mathrm{C}$ & $\begin{array}{l}-40^{\circ} \text { to }+150^{\circ} \mathrm{F} ; \\
-40^{\circ} \text { to }+65^{\circ} \mathrm{C}\end{array}$ & $1{ }^{\circ} \mathrm{F} ; 0.5^{\circ} \mathrm{C}$ \\
\hline Índice de calor & $1^{\circ} \mathrm{F} ; 1^{\circ} \mathrm{C}$ & $\begin{array}{l}-40^{\circ} \text { to }+165^{\circ} \mathrm{F} ; \\
-40^{\circ} \text { to }+74^{\circ} \mathrm{C}\end{array}$ & $3^{\circ} \mathrm{F}\left(1.5^{\circ} \mathrm{C}\right)$ \\
\hline Dirección del viento & $1^{\circ}$ & 0 to $360^{\circ}$ & $3^{\circ}$ \\
\hline Rosa de los vientos & $22.5^{\circ}$ & 16 puntos de brújula & 0.3 puntos de brújula \\
\hline Velocidad del Viento & $\begin{array}{c}1 \mathrm{mph} ; 0.4 \mathrm{~m} / \\
\mathrm{s} ; 1 \mathrm{~km} / \mathrm{h}\end{array}$ & $\begin{array}{c}0 \text { to } 200 \mathrm{mph} ; \\
0 \text { to } 322 \mathrm{~km} / \mathrm{h} \text {, } \\
0 \text { to } 809 \mathrm{~m} / \mathrm{s}\end{array}$ & $\begin{array}{c}\text { mayormente de } \\
1 \mathrm{~m} / \mathrm{s} ; 3 \mathrm{~km} / \mathrm{h} \text { or } 5 \%\end{array}$ \\
\hline Sensación Térmica & $1^{\circ} \mathrm{F} ; 1^{\circ} \mathrm{C}$ & $\begin{array}{l}110^{\circ} \text { to }+135^{\circ} \mathrm{F} \\
-79^{\circ} \text { to }+57^{\circ} \mathrm{C}\end{array}$ & $2^{\circ} \mathrm{F} ; 1^{\circ} \mathrm{C}$ \\
\hline
\end{tabular}

Fuente: https://estaciondemeteorologia.com/davis-vantage-pro2-estacion-meteorologica-profesionalanalisis-y-opiniones/ 


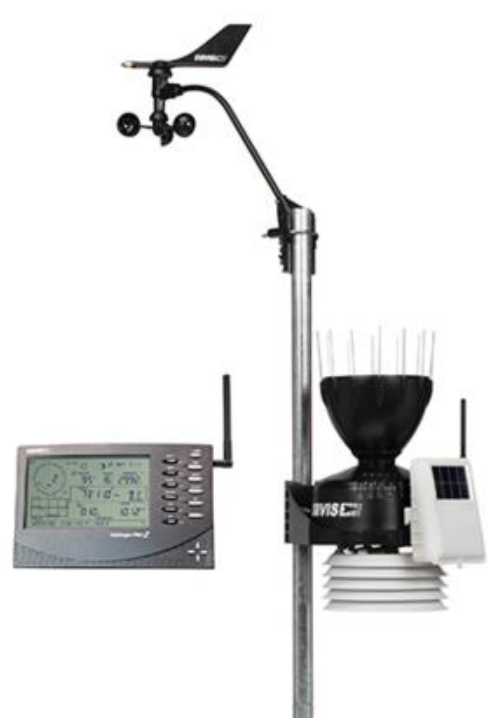

Figura 68. Estación meteorológica Davis Vantage pro 2

\section{Enfriadora de agua condensada por agua}

La enfriadora de agua del edificio central compuesta por 2 unidades marca YORK YVWA de $879.21 \mathrm{~kW}$ cada una con 2 compresores a tornillo y refrigerante R134A, cuenta con un sistema de control NCE de Johnson Controls que se encarga del encendido, apagado y el monitoreo del equipo, además de integrar la información a su plataforma BAS (Sistemas de Automatización de Edificios) llama Metasys.

La enfriadora de agua mediante la plataforma Metasys y su sistema de control posee setpoints o puntos de partida (seguimiento) en los horarios de funcionamiento (encendido y apagado), control y seguimiento de temperaturas, seguimiento del estado y funcionamiento de los compresores y condensadores, entre otros. Las figuras $69-72$, presentan pantallazos del aplicativo Metasys que monitorea La enfriadora de agua del edificio central.

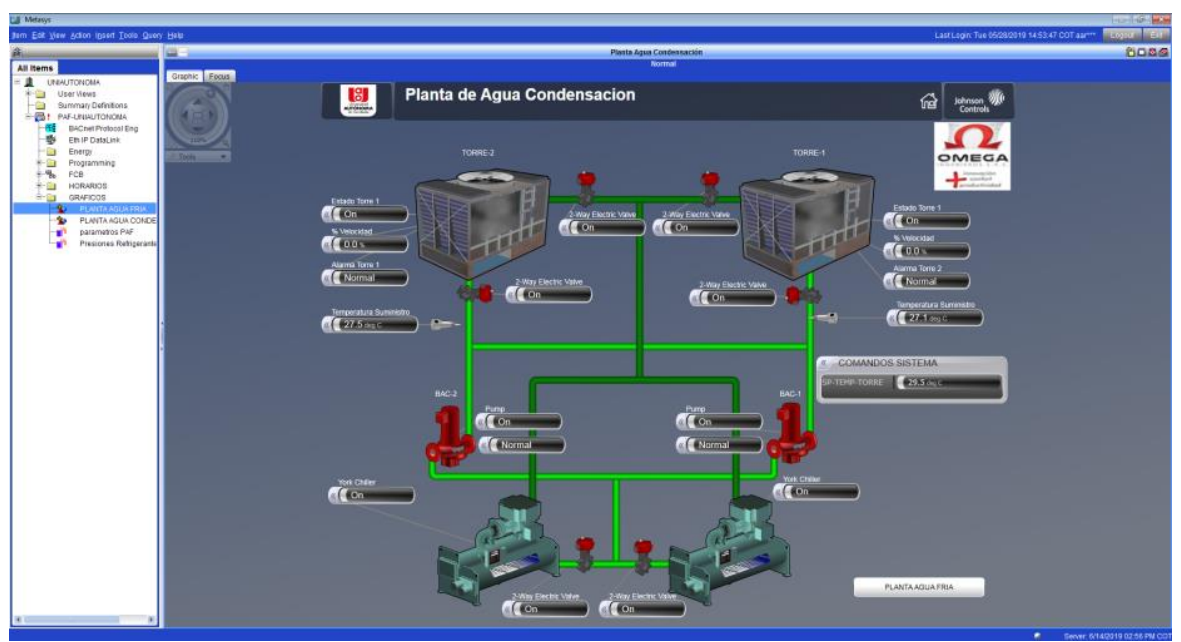

Figura 69. Diagrama de condensación Planta de agua fría Edificio Central. Metasys 


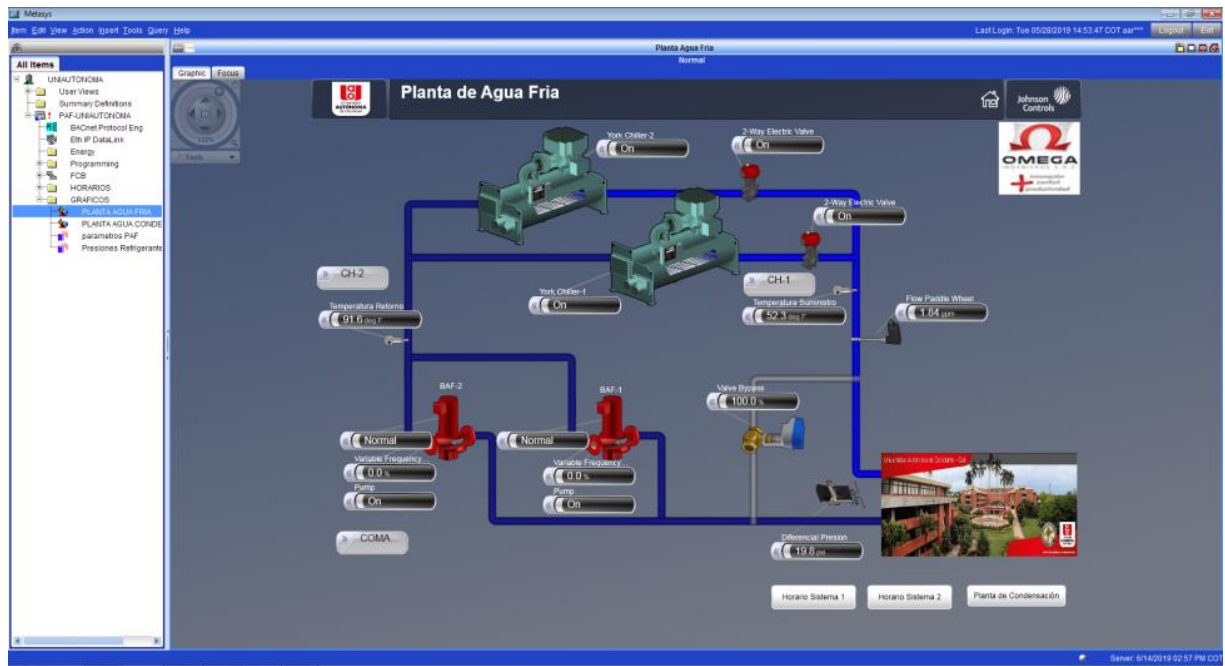

Figura 70. Diagrama planta de agua fría - Enfriadora de agua Edificio central. Metasys

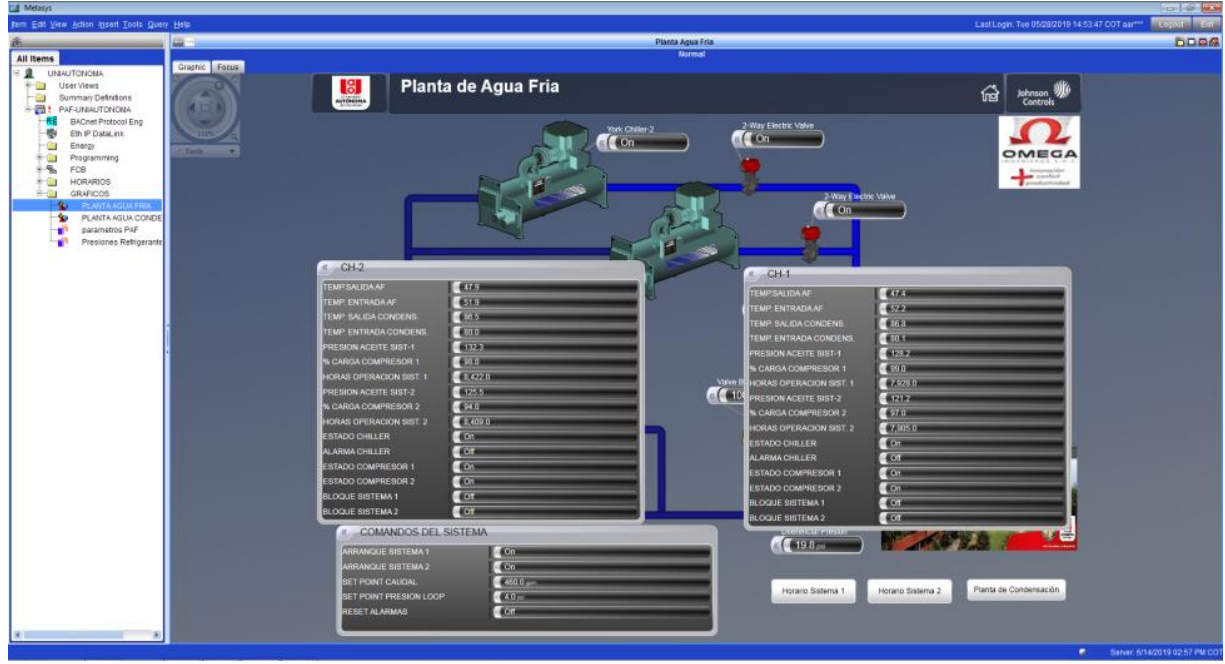

Figura 71. Diagrama planta de agua fría con información desplegada- Enfriadora de agua Edificio central. Metasys

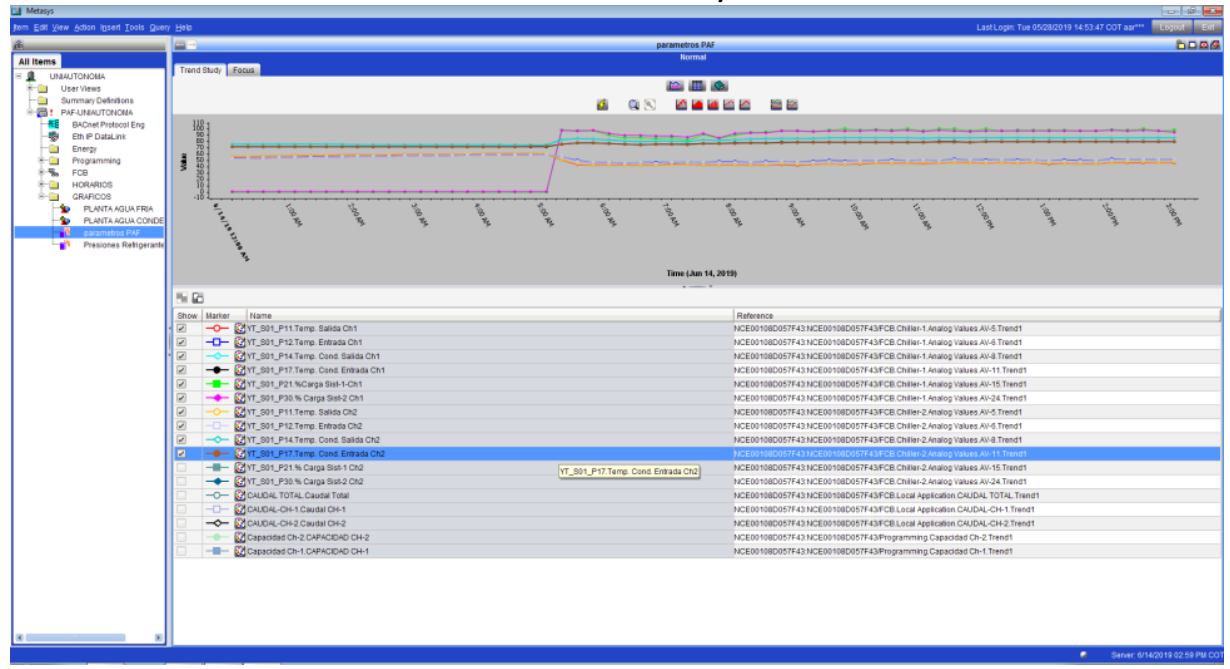

Figura 72. Curvas de comportamiento y parámetros monitorizados en planta de agua fría 


\section{Equipos de medición utilizados en la Auditoria}

A continuación, se presentan los equipos de medición usados en la auditoria energética realizada en el campus universitario de la UAO (Tabla 23).

Tabla 23. Equipos de medida usados en la auditoria energética del campus

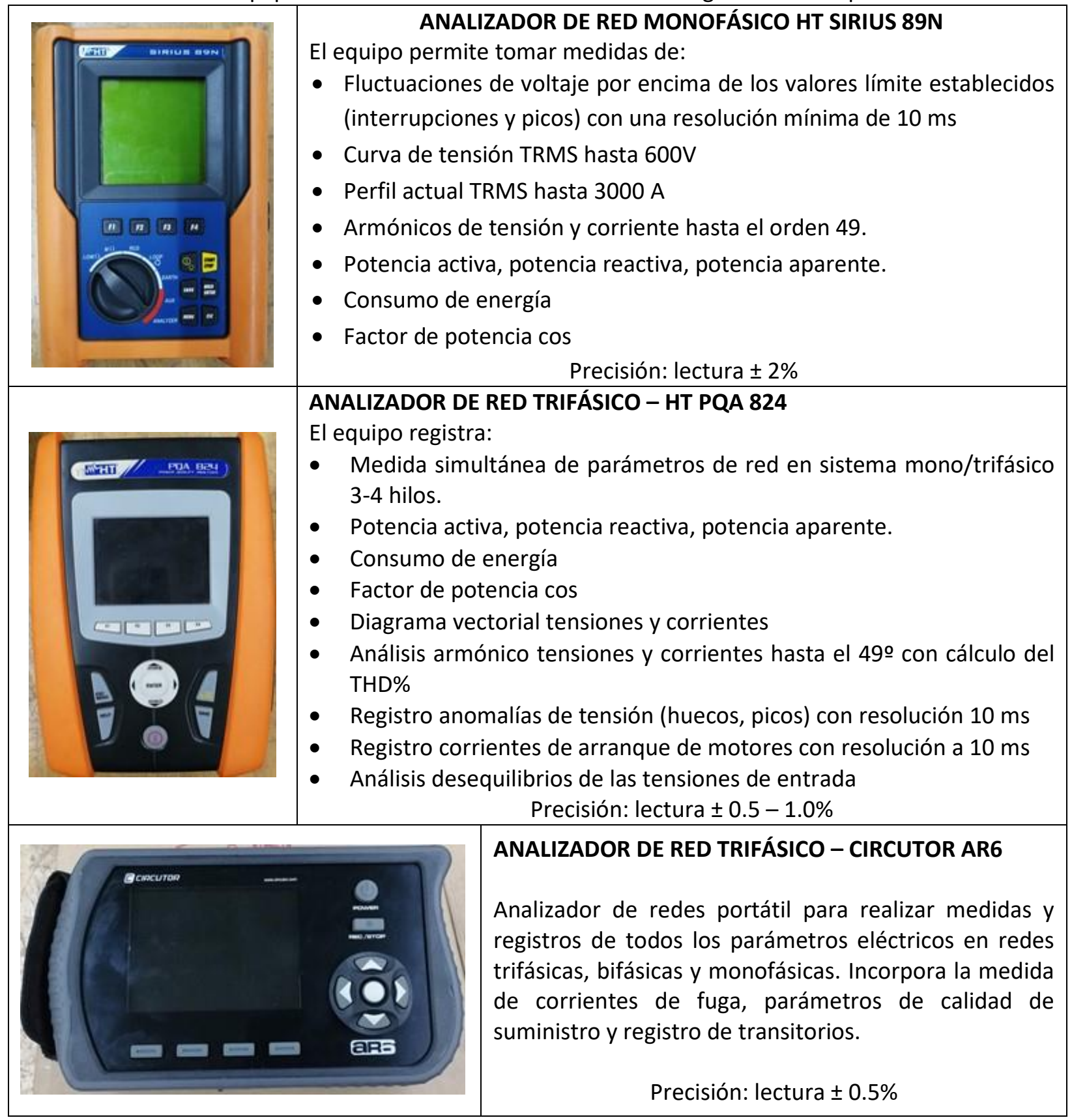




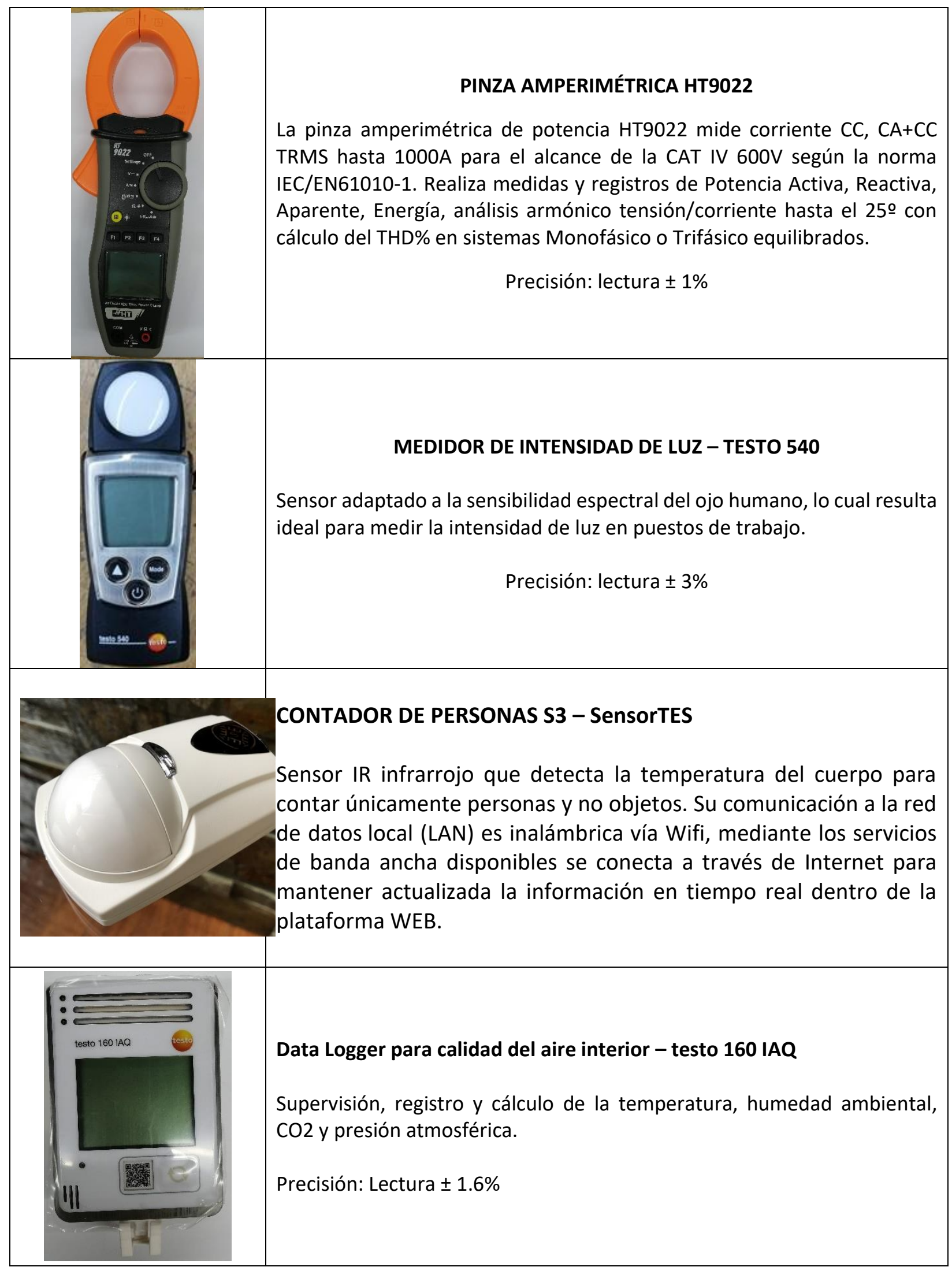


Además de los datos obtenidos por el sistema de medición en línea de Power monitor Expert, se llevaron a cabo mediciones en algunos de los circuitos. La Tabla 24., presenta el cronograma de medición que se llevó a cabo. Adicional, la Tabla 25, resume los consumos de energía eléctrica por áreas y se designa el número de código de los medidores implementados en el campus UAO.

Tabla 24. cronograma de mediciones de consumo de energía eléctrica según lineamientos de la ISO50002

\begin{tabular}{|c|c|c|c|c|}
\hline FECHA & ÁREA MEDIDA & TIEM & O DE MEDICIÓN & \\
\hline AÑO & SUB ESTACIÓN 2 & DESDE & HASTA & $\begin{array}{l}\text { TIEMPO } \\
\text { MEDIDO }\end{array}$ \\
\hline 2017 & A/A Bienestar Universitario & 28/10/2017 16:08:00 & 04/11/2017 16:33:00 & 7.02 \\
\hline 2017 & Cafetería tercer piso & 28/10/2017 03:55:00 & 04/11/2017 04:25:00 & 7.02 \\
\hline 2017 & $\begin{array}{l}\text { Tablero bienestar } \\
\text { universitario TD5 }\end{array}$ & 21/10/2017 03:07:00 & 28/10/2017 03:32:00 & 7.02 \\
\hline 2017 & Cafeterías segundo piso & 21/10/2017 15:21:00 & 28/10/2017 15:31:00 & 7.01 \\
\hline 2018 & Iluminación Cancha de futbol & 20/02/2018 05:33:00 PM & 21/02/2018 04:13:00 PM & 0.94 \\
\hline 2018 & A/A Bienestar Universitario & 20/02/2018 17:43:00 & 07/03/2018 16:59:00 & 14.97 \\
\hline 2018 & A/A Data center & $31 / 03 / 2018$ 16:32:00 & 17/04/2018 15:47:00 & 16.97 \\
\hline 2018 & Aulas 4 & $31 / 03 / 2018$ 17:14:00 & $17 / 04 / 2018$ 15:39:00 & 16.93 \\
\hline 2018 & Cafetera 3er piso & 10/02/2018 17:28:00 & 07/03/2018 16:46:00 & 24.97 \\
\hline 2018 & Cafetería 2do Piso & $10 / 02 / 201817: 58$ & $20 / 02 / 2018$ 15:58 & 9.92 \\
\hline 2018 & Canchas múltiples & 20/02/2018 17:22:00 & 07/03/2018 16:51:00 & 14.98 \\
\hline 2018 & PTAP & $10 / 02 / 2018$ 16:47:00 & 20/02/2018 16:56:00 & 10.01 \\
\hline 2018 & UPS Data Center & $31 / 03 / 2018$ 16:52:00 & $17 / 04 / 2018$ 15:42:00 & 16.95 \\
\hline 2018 & A1 AATORREONES & $18 / 05 / 2018$ 15:08:00 & $26 / 05 / 2018$ 15:08:00 & 8.00 \\
\hline 2018 & A2 AATORREONES & $12 / 05 / 2018$ 15:51:00 & 26/05/2018 15:01:00 & 13.97 \\
\hline 2018 & A3 AATORREONES & 05/05/2018 16:39:00 & 12/05/2018 15:49:00 & 6.97 \\
\hline 2018 & A4 AAPOSGRADOS & 05/05/2018 15:29:00 & 12/05/2018 14:49:00 & 6.97 \\
\hline AÑO & SUB ESTACIÓN 1 & DESDE & HASTA & $\begin{array}{l}\text { TIEMPO } \\
\text { MEDIDO }\end{array}$ \\
\hline 2018 & Ágora & 24/04/2018 17:13:00 & 28/04/2018 16:38:00 & 3.98 \\
\hline 2018 & Sala de tv & 24/04/2018 16:41:00 & 03/05/2018 15:21:00 & 8.94 \\
\hline 2018 & Salas Mac & 24/04/2018 16:20:00 & 28/04/2018 16:15:00 & 4.00 \\
\hline 2018 & TD 13 Trafo de 30kVA UPS & 16/11/2018 17:08:00 & 24/11/2018 15:13:00 & 7.92 \\
\hline 2018 & TD 13 75kVA & $16 / 11 / 2018$ 16:45:00 & $24 / 11 / 2018$ 15:15:00 & 7.94 \\
\hline 2018 & UMA QUINCHA & 26/05/2018 15:59:00 & 07/06/2018 19:11:00 & 12.13 \\
\hline 2018 & YQUINDE NORTE 16TON & 26/05/2018 17:07:00 & 16/06/2018 01:40:00 PM & 20.86 \\
\hline
\end{tabular}


Tabla 25. Datos de consumo de energía eléctrica y código de medidores implementados en la UAO

\begin{tabular}{|c|c|c|c|c|c|c|}
\hline $\begin{array}{c}\text { Subestación } \\
\text { de Energía } \\
\text { Eléctrica S/E }\end{array}$ & $\begin{array}{c}\text { Total } \\
\text { consumo } \\
\mathrm{S} / \mathrm{E} \\
\mathrm{kWh} / \mathrm{mes} \\
\end{array}$ & $\begin{array}{l}\text { Medidor de Energía } \\
\text { Eléctrica }\end{array}$ & $\begin{array}{c}\text { Ubicación } \\
\text { cuartos } \\
\text { Eléctricos UAO }\end{array}$ & $\begin{array}{l}\text { Consumo de } \\
\text { Energía } \\
\text { Eléctrica } \\
\text { (kwh/mes) }\end{array}$ & $\begin{array}{l}\text { Áreas } \\
\text { Medidas }\end{array}$ & \begin{tabular}{|c|} 
Consumo \\
de energía \\
por área \\
(kwh/mes) \\
\end{tabular} \\
\hline \multirow{12}{*}{1} & \multirow{12}{*}{$\begin{array}{l}n \\
6 \\
\infty \\
0 \\
\stackrel{-}{-1}\end{array}$} & MEDIDOR Schneider TD6 & Piso 1 norte & 16,935 & \multirow{2}{*}{$\begin{array}{c}\text { PISOS } 1 \mathrm{Y} \\
2\end{array}$} & \multirow{2}{*}{26,961} \\
\hline & & MEDIDOR Schneider TD7 & Piso 1 sur & 10,026 & & \\
\hline & & MEDIDOR Schneider TD8 & Piso 3 norte & 12,936 & \multirow{2}{*}{$\begin{array}{c}\text { PISOS } 3 \mathrm{Y} \\
4\end{array}$} & \multirow{2}{*}{23,578} \\
\hline & & MEDIDOR Schneider TD9 & Piso 3 sur & 10,643 & & \\
\hline & & $\begin{array}{l}\text { MEDIDOR Schneider } \\
\text { TD10 }\end{array}$ & Sótano 1 norte & 10,102 & \multirow{2}{*}{ SOTANO 1} & \multirow{2}{*}{27,536} \\
\hline & & $\begin{array}{l}\text { MEDIDOR Schneider } \\
\text { TD11 }\end{array}$ & Sótano 1 sur & 17,434 & & \\
\hline & & $\begin{array}{l}\text { MEDIDOR Schneider } \\
\text { TD12 }\end{array}$ & Sótano 2 norte & 15,331 & \multirow[t]{2}{*}{ SOTANO 2} & \multirow[t]{2}{*}{30,179} \\
\hline & & ANALIZADOR DE RED HT & Sótano 2 sur & 14,848 & & \\
\hline & & ANALIZADOR DE RED HT & Piso 4 norte & 1,093 & PISO 4 & 1,093 \\
\hline & & ANALIZADOR DE RED HT & Salas mac & 959 & SOTANO 1 & 959 \\
\hline & & ANALIZADOR DE RED HT & Ágora & 360 & SOTANO 1 & 360 \\
\hline & & ANALIZADOR DE RED HT & Estudio tv & 196 & SOTANO 2 & 196 \\
\hline \multirow{14}{*}{2} & \multirow{14}{*}{ 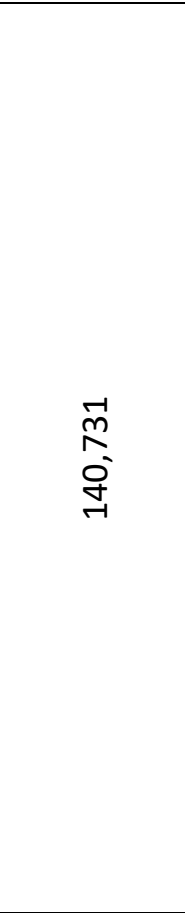 } & MEDIDOR Schneider TD1 & Aulas 1 & 14,568 & \multirow{4}{*}{ AULAS } & \multirow{4}{*}{66,268} \\
\hline & & MEDIDOR Schneider TD2 & Aulas 2 & 18,014 & & \\
\hline & & MEDIDOR Schneider TD3 & Aulas 3 & 14,601 & & \\
\hline & & MEDIDOR Schneider TD4 & Aulas 4 & 19,085 & & \\
\hline & & MEDIDOR Schneider TD5 & Bienestar Univ. & 19,346 & BIENESTAR & \multirow{2}{*}{22,492} \\
\hline & & MEDIDOR Schneider TD5 & Bienestar Univ. & 3,146 & UNIVERSIT & \\
\hline & & ANALIZADOR DE RED HT & PTAR & 6,785 & PTAR & 6,785 \\
\hline & & ANALIZADOR DE RED HT & Data center ups & 15,015 & DATA & \multirow{2}{*}{26,151} \\
\hline & & ANALIZADOR DE RED HT & Data center AA & 11,136 & CENTER & \\
\hline & & ANALIZADOR DE RED HT & Cafetería 3er $p$ & 4,634 & CAFETERIA & 4,634 \\
\hline & & ANALIZADOR DE RED HT & PTAP & 4,278 & PTAP & 4,278 \\
\hline & & ANALIZADOR DE RED HT & $\begin{array}{c}\text { Almacén, } \\
\text { Librería, etc. }\end{array}$ & 3,778 & CAFETERIA & 3,778 \\
\hline & & ANALIZADOR DE RED HT & AA 2 y 3 er piso & 3,325 & $\begin{array}{l}\text { BIENESTAR } \\
\text { UNIVERSIT }\end{array}$ & 3,325 \\
\hline & & ANALIZADOR DE RED HT & $\begin{array}{l}\text { trafo 50kva } \\
\text { villa laurentino, } \\
\text { gym, canchas } \\
\text { multiples. }\end{array}$ & 3,021 & \begin{tabular}{|c|} 
VILLA \\
LAURENTI \\
NO
\end{tabular} & 3,021 \\
\hline 3 & 63,784 & $\begin{array}{l}\text { MEDIDOR Schneider } \\
\text { SUBESTACIÓN } 3\end{array}$ & $\begin{array}{c}\text { Enfriadora de } \\
\text { agua }\end{array}$ & 63784.21 & CHILLER & 63,784 \\
\hline $\begin{array}{c}\text { TOTAL } \\
\text { CONSUMO } \\
\text { PROMEDIO } \\
\text { MES }\end{array}$ & 315,378 & & & & & \\
\hline
\end{tabular}




\subsection{ANÁLISIS DE LOS USOS Y CONSUMOS DE LA ENERGÍA EN EL CAMPUS}

En esta etapa se realizó la caracterización energética del campus, se llevó a cabo el análisis gráfico del comportamiento del uso y consumo de la energía, con el objeto de identificar los periodos y horas de mayor consumo de energía, además de reconocer variables que puedan afectar significativamente el uso y consumo de la energía. A partir de los resultados de este análisis fue posible identificar y priorizar oportunidades para mejorar el desempeño energético.

Las herramientas que se utilizaron para la evaluación correspondieron a gráficas de tendencias lineales, gráficos de control y los diagramas de Pareto. Para el presente análisis se evaluó el año 2016, 2017 y 2018.

Los energéticos que se utilizan en la UAO son: gas natural, energía eléctrica y energía solarfotovoltaica.

- El Gas Natural es usado en la planta de emergencia marca CATERPILAR cuya capacidad es de 1000 KVA, que opera como suministro de electricidad en caso de cortes.

- El sistema solar fotovoltaico que opera desde el 12 de febrero de 2015 hasta el año 2016 tenía 638 Módulos de $230 \mathrm{Wp}$ c/u, una capacidad instalada de 150 kWp y una producción mensual y anual de 15.000 y 180.000 kWh respectivamente, en el año 2017 se incrementó la capacidad, pues se instalaron paneles fotovoltaicos en las cubiertas de los edificios de Bienestar Universitario y los cuatro edificios de aulas, la potencia instalada fue de $38,2 \mathrm{kWp}$ por cada edificio de Aulas y de $97.56 \mathrm{kWp}$ para el edificio de Bienestar Universitario.

- La Energía Eléctrica es utilizada en los sistemas de iluminación, enfriadoras de agua, aires acondicionados mini Split, sistemas de cómputo u otros equipos tales como impresoras, Escáneres, Fotocopiadoras, Extractores, Secadores, Ventiladores, y Bebederos.

\subsubsection{Gráficos de tendencia de consumo por tipo de energético}

Se construyeron las gráficas de tendencia (Figuras 73 - 76) para el año 2016, 2017, 2018 y 2019 respectivamente; en las cuales fue posible evaluar de manera general el comportamiento de utilización de energía empleando los datos de consumo por mes: Energía eléctrica de la red, fotovoltaico y gas natural GN; para la conversión a kWh del Gas Natural se utilizó el factor 11.7 kWh/m3. (Para el año 2019 no se presenta información del consumo de Gas Natural, pues no fue posible conseguir la información son el Depto. encargado).

Se evidencia conforme al análisis realizado que la energía de mayor consumo en el campus UAO es la energía eléctrica de la red con porcentajes que oscilan entre 64.8 y 95.2 en los diferentes meses de los 4 años analizados; y con bajas participaciones en el consumo de energía están: gas natural y energía fotovoltaica. En el año 2017 se presentó una reducción 
del consumo del $18 \%$ en energía eléctrica de la red y $53 \%$ en gas natural; contrario al caso de la energía fotovoltaica, en el cual se incrementó en un 76\%, por la ampliación de la capacidad del sistema que se llevó a cabo.

Tanto en el año 2016 como en el 2017 los meses de mayor consumo de energía analizada se genera en el primer periodo académico que abarca los meses de febrero a mayo, se presenta una excepción en la energía fotovoltaica dado que en el año 2017 se produce aumentos en el tercer periodo académico (agosto a noviembre); debido a la ampliación de la capacidad. Los meses de menor consumo se presentaron en los periodos 2 y 4 que corresponden a las vacaciones; especialmente en la energía eléctrica, gas natural y fotovoltaica. El año 2018 por su parte, tiene los mayores consumos energéticos en los meses de abril, mayo, septiembre y noviembre. Sin embargo, se evidencia que los consumos energéticos totales se redujeron en un $2.55 \%$ con respecto al 2017 y de $22.8 \%$ con respecto al 2016. El 2019, presenta sus mayores consumos energéticos en los meses de mayo, agosto y octubre, y los menores consumos en los meses de enero y diciembre. Los datos de consumo de energía se registran en la Tabla 26.

Tabla 26 datos de consumo por tipo de energéticos 2016-2019

\begin{tabular}{|c|c|c|c|c|c|c|c|c|}
\hline Año & \multicolumn{4}{|c|}{2016} & \multicolumn{4}{|c|}{2017} \\
\hline Mes/Consumd & $\begin{array}{l}\text { Consumo } \\
\text { de Energía } \\
\text { KWh/mes }\end{array}$ & $\begin{array}{c}\text { Sistema } \\
\text { Solar } \\
\text { Fotovoltaic } \\
\text { a KWh/mes }\end{array}$ & $\begin{array}{c}\text { Gas } \\
\text { Natural } \\
\text { KWh/mes }\end{array}$ & $\begin{array}{c}\text { Consumo } \\
\text { Total } \\
\text { kWh/mes } \\
2016\end{array}$ & $\begin{array}{c}\text { Consumo } \\
\text { de Energía } \\
\text { KWh/mes }\end{array}$ & $\begin{array}{c}\text { Sistema } \\
\text { Solar } \\
\text { Fotovoltaic } \\
\text { a KWh/mes }\end{array}$ & $\begin{array}{c}\text { Gas } \\
\text { Natural } \\
\text { KWh/mes }\end{array}$ & $\begin{array}{c}\text { Consumo } \\
\text { Total } \\
\text { kWh/mes } \\
2017\end{array}$ \\
\hline Enero & 267.644 & 8.935 & 18.954 & 305.533 & 265.880 & 14.490 & 18.954 & 299.324 \\
\hline Febrero & 403.917 & 8.154 & 37.534 & 459.605 & 327.778 & 16.880 & 8.295 & 352.953 \\
\hline Marzo & 335.299 & 9.045 & 32.772 & 387.116 & 333.408 & 17.340 & 25.728 & 376.476 \\
\hline Abril & 385.732 & 17.127 & 166.713 & 569.572 & 8.846 & 17.580 & 539 & 302.065 \\
\hline Mayo & 368.364 & 18.219 & 27.846 & 414.429 & 313.901 & 28.210 & 58.980 & 401.091 \\
\hline Junio & 279.592 & 17.999 & 35.498 & 333.089 & 210.604 & 43.970 & 7.102 & 261.676 \\
\hline Julio & 299.786 & 18.681 & 3.803 & 322.270 & 239.874 & 49.670 & 2.422 & 291.966 \\
\hline Agosto & 418.899 & 17.517 & 7.827 & 444.243 & 297.252 & 48.990 & 39.920 & 386.162 \\
\hline Septiembre & 409.230 & 18.245 & 27.331 & 454.806 & 315.568 & 51.230 & 2.890 & 369.688 \\
\hline Octubre & 374.706 & 18.477 & 2.995 & 396.178 & 299.604 & 44.810 & 13.057 & 357.471 \\
\hline Noviembre & 341.199 & 16.346 & 983 & 358.528 & 269.742 & 45.388 & 15.362 & 330.493 \\
\hline Diciembre & 218.687 & 15.565 & 32.315 & 266.567 & 160.716 & 45.892 & 2.235 & 208.842 \\
\hline Total Año & 4.103 .055 & 214.310 & 394.571 & 4.711 .936 & 3.313 .173 & 424.450 & 200.585 & 3.938.208 \\
\hline Año & \multicolumn{4}{|c|}{2018} & \multicolumn{4}{|c|}{2019} \\
\hline Mes/Consumd & $\begin{array}{c}\text { Consumo } \\
\text { de Energía } \\
\text { KWh/mes }\end{array}$ & $\begin{array}{c}\text { Sistema } \\
\text { Solar } \\
\text { Fotovoltaic } \\
\text { a KWh/mes }\end{array}$ & $\begin{array}{c}\text { Gas } \\
\text { Natural } \\
\text { KWh/mes }\end{array}$ & $\begin{array}{c}\text { Consumo } \\
\text { Total } \\
\text { kWh/mes } \\
2018\end{array}$ & $\begin{array}{c}\text { Consumo } \\
\text { de Energía } \\
\mathrm{KWh} / \mathrm{mes}\end{array}$ & $\begin{array}{c}\text { Sistema } \\
\text { Solar } \\
\text { Fotovoltaic } \\
\text { a KWh/mes }\end{array}$ & $\begin{array}{c}\text { Gas } \\
\text { Natural } \\
\text { KWh/mes }\end{array}$ & $\begin{array}{c}\text { Consumo } \\
\text { Total } \\
\text { kWh/mes } \\
2019\end{array}$ \\
\hline Enero & 214.535 & 45.889 & 15.596 & 276.020 & 193.481 & 44.154 & - & 237.635 \\
\hline Febrero & 276.019 & 46.453 & 398 & 322.870 & 262.178 & 43.081 & - & 305.260 \\
\hline Marzo & 252.125 & 50.768 & 4.072 & 306.965 & 283.337 & 45.354 & - & 328.690 \\
\hline Abril & 271.791 & 43.382 & 37.148 & 352.321 & 247.512 & 42.641 & - & 290.152 \\
\hline Mayo & 281.236 & 42.996 & 22.757 & 346.989 & 307.745 & 41.529 & - & 349.274 \\
\hline Junio & 196.262 & 40.330 & 10.202 & 246.794 & 203.416 & 43.131 & - & 246.547 \\
\hline Julio & 238.238 & 43.397 & 34.223 & 315.858 & 253.210 & 48.891 & - & 302.101 \\
\hline Agosto & 284.049 & 48.193 & 11.291 & 343.533 & 300.874 & 50.617 & - & 351.491 \\
\hline Septiembre & 273.716 & 47.643 & 40.693 & 362.052 & 298.430 & 47.446 & - & 345.877 \\
\hline Octubre & 285.752 & 47.875 & 10.261 & 343.888 & 312.343 & 47.149 & - & 359.493 \\
\hline Noviembre & 247.129 & 40.099 & 94.349 & 381.577 & 277.115 & 40.582 & - & 317.697 \\
\hline Diciembre & 179.085 & 48.635 & 11.232 & 238.952 & 181.639 & 42.585 & - & 224.224 \\
\hline Total Año & 2.999 .937 & 545.660 & 292.219 & 3.837 .816 & 3.121 .281 & 537.160 & - & 3.658 .441 \\
\hline
\end{tabular}




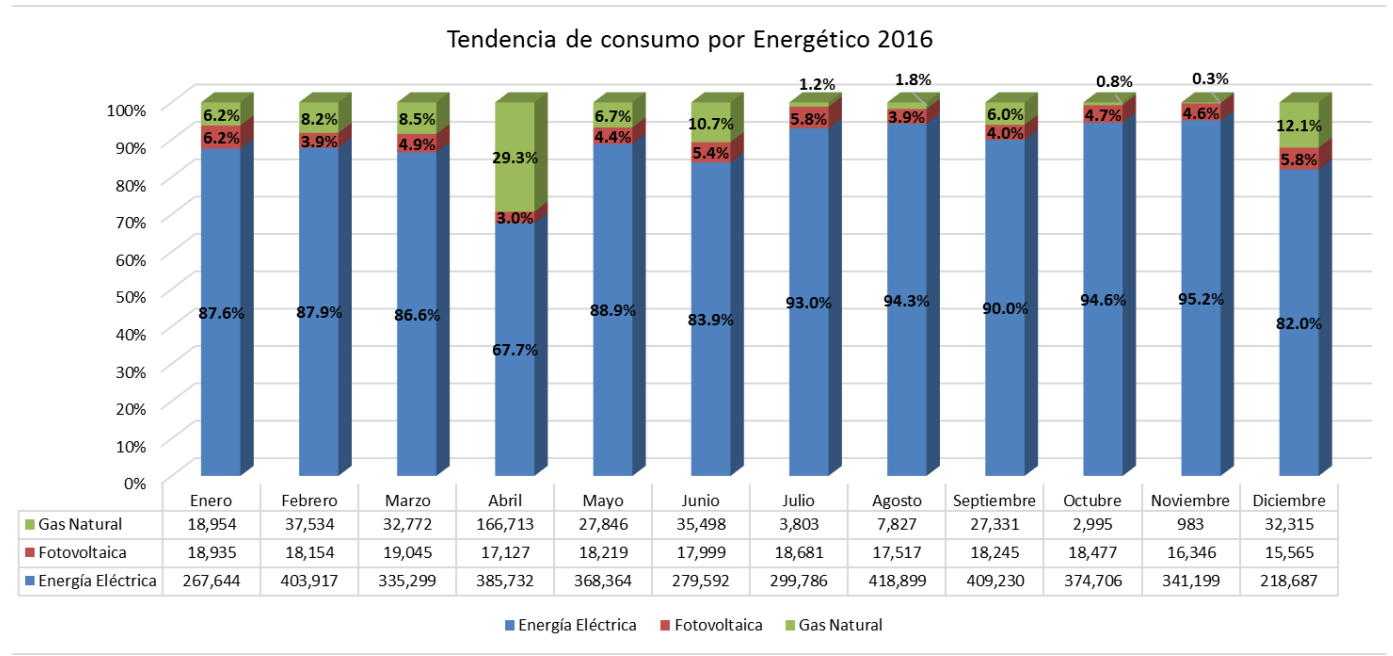

Figura 73. Tendencia de consumo por tipo de energético año 2016

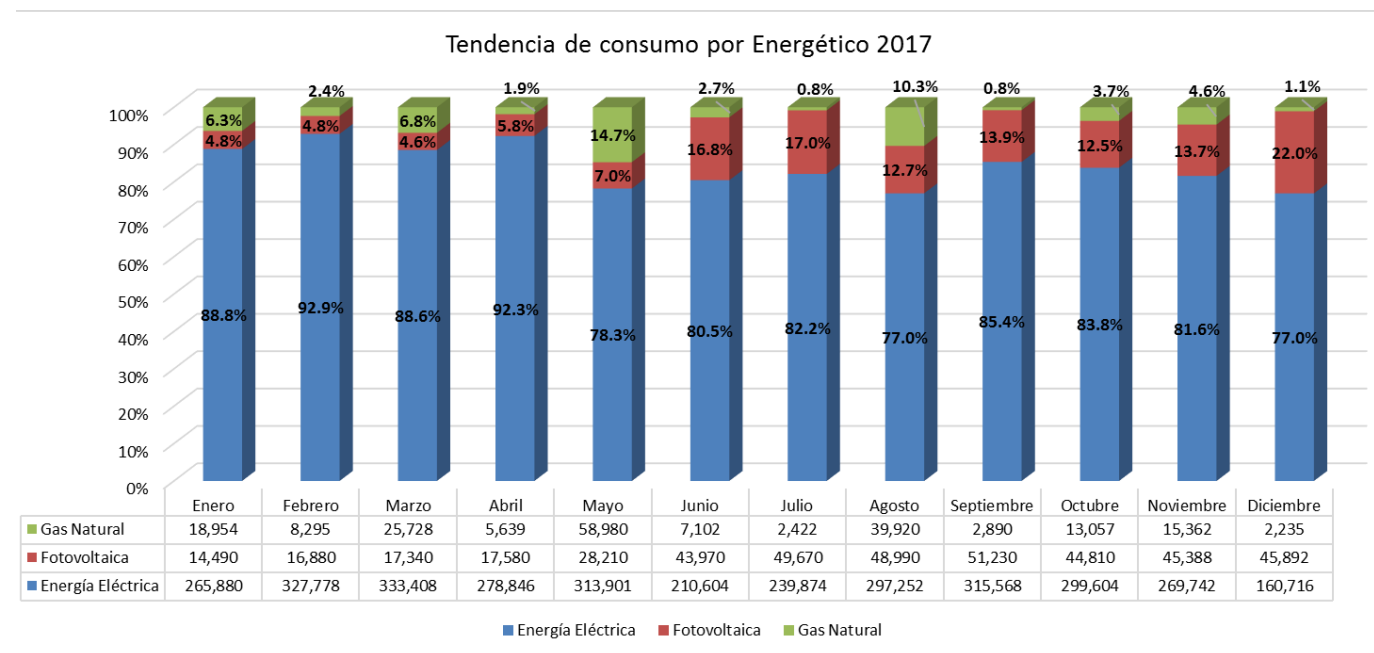

Figura 74. Tendencia de consumo por tipo de energético año 2017

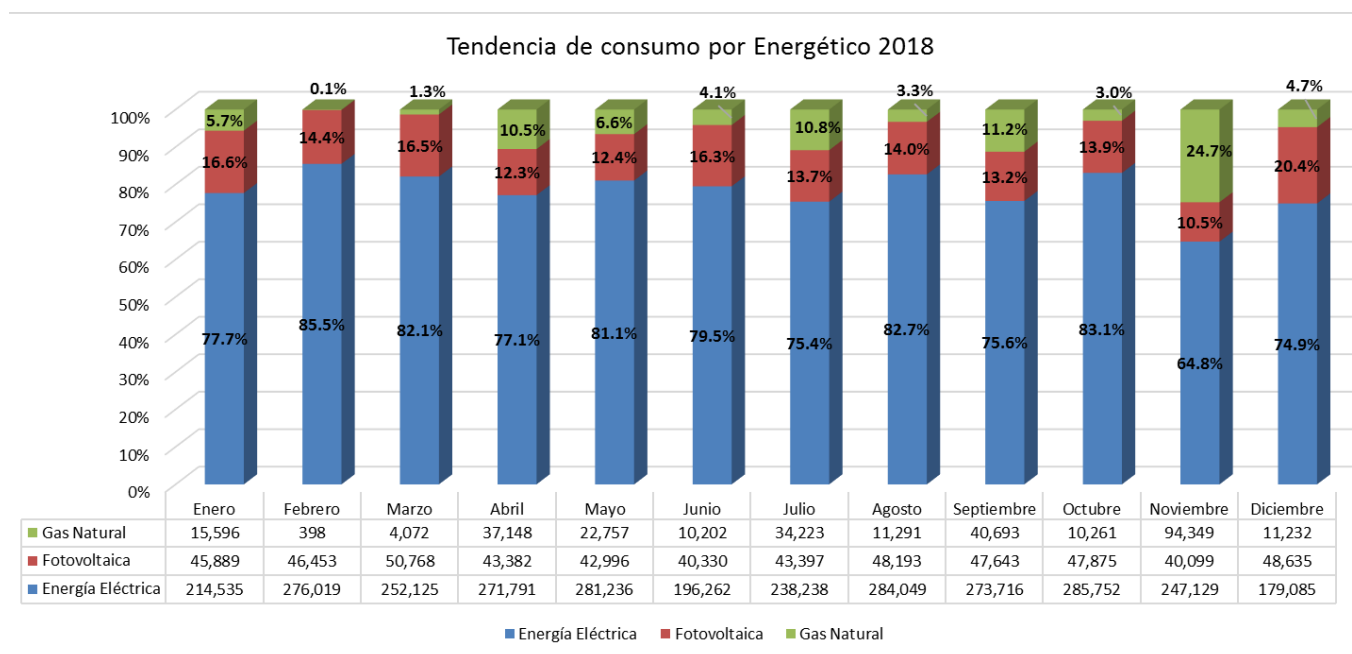

Figura 75. Tendencia de consumo por tipo de energético año 2018 


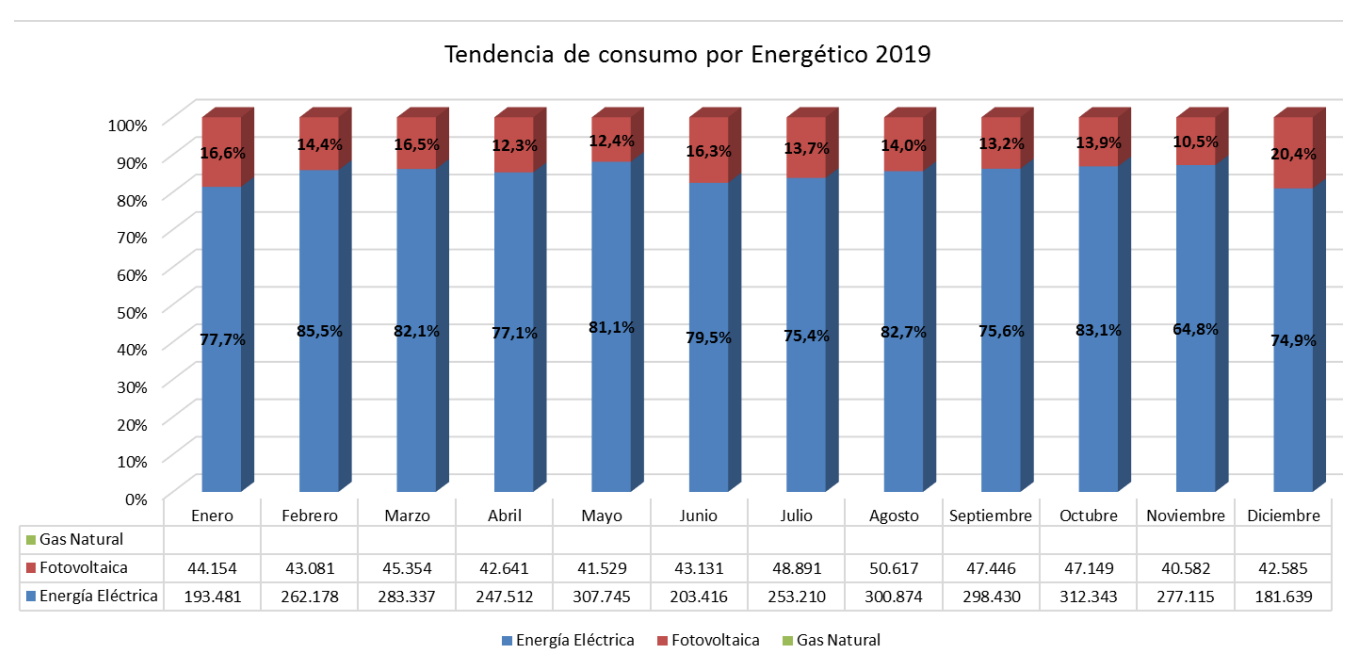

Figura 76. Tendencia de consumo por tipo de energético año 2019

\subsubsection{Análisis del uso y consumo de la energía eléctrica y fotovoltaica}

Se analizó el consumo total de la energía eléctrica y la generación de energía fotovoltaica de los años 2016, 2017, 2018, 2019 (figuras 77 y 78), se observa que en el año 2016 el sistema solar fotovoltaico aportó en los meses de enero y diciembre aproximadamente el 7\% del consumo de energía eléctrica y en promedio aportó el 5\% del consumo de energía eléctrica del campus, en el 2017 se presenta un aumento en la generación de energía solar fotovoltaica pues se aumentó la capacidad instalada en el campus, se pasó de suplir un $5 \%$ - 7\% mensual a suplir hasta el $22 \%$ del consumo de energía mensual del campus, en promedio el sistema solar fotovoltaico aportó el $11 \%$ del consumo anual de energía eléctrica del campus. En el año 2018 los meses de mayor aporte de energía solar fotovoltaica fueron marzo, agosto y diciembre con la generación de $50.768 \mathrm{kWh}, 48.193$ kWh y 48.635 kWh respectivamente; el sistema fotovoltaico aportó el $15 \%$ del consumo de energía eléctrica anual. En el año 2019 los meses de mayor aporte de energía solar fotovoltaica fueron julio, agosto, septiembre y octubre; el sistema fotovoltaico aportó el $15 \%$ del consumo de energía eléctrica anual. Los datos de consumo se presentan en la Tabla 27. 
Tabla 27. Datos de consumo energía eléctrica y fotovoltaica

\begin{tabular}{|c|c|c|c|c|c|c|c|c|}
\hline Año & \multicolumn{4}{|c|}{2016} & \multicolumn{4}{|c|}{2017} \\
\hline $\begin{array}{l}\text { Mes / } \\
\text { Consumo }\end{array}$ & $\begin{array}{c}\text { Consumo de } \\
\text { Energía } \\
\text { KWh/mes }\end{array}$ & $\begin{array}{c}\text { Sistema Solar- } \\
\text { Fotovoltaico } \\
\text { KWh/mes }\end{array}$ & $\begin{array}{c}\text { Consumo } \\
\text { total- } \\
\mathrm{KWh} / \mathrm{mes}\end{array}$ & $\begin{array}{c}\text { participación del } \\
\text { SSFV }\end{array}$ & $\begin{array}{c}\text { Consumo de } \\
\text { Energía } \\
\text { KWh/mes }\end{array}$ & $\begin{array}{c}\text { Sistema Solar- } \\
\text { Fotovoltaico } \\
\text { KWh/mes }\end{array}$ & $\begin{array}{c}\text { Consumo total- } \\
\mathrm{KWh} / \mathrm{mes}\end{array}$ & $\begin{array}{c}\text { participación del } \\
\text { SSFV }\end{array}$ \\
\hline Enero & 267.644 & 18.935 & 286.579 & $7 \%$ & 265.880 & 14.490 & 280.370 & $5 \%$ \\
\hline Febrero & 403.917 & 18.154 & 422.071 & $4 \%$ & 327.778 & 16.880 & 344.658 & $5 \%$ \\
\hline Marzo & 335.299 & 19.045 & 354.344 & $5 \%$ & 333.408 & 17.340 & 350.748 & $5 \%$ \\
\hline Abril & 385.732 & 17.127 & 402.859 & $4 \%$ & 278.846 & 17.580 & 296.426 & $6 \%$ \\
\hline Mayo & 368.364 & 18.219 & 386.583 & $5 \%$ & 313.901 & 28.210 & 342.111 & $8 \%$ \\
\hline Junio & 279.592 & 17.999 & 297.591 & $6 \%$ & 210.604 & 43.970 & 254.574 & $17 \%$ \\
\hline Julio & 299.786 & 18.681 & 318.467 & $6 \%$ & 239.874 & 49.670 & 289.544 & $17 \%$ \\
\hline Agosto & 418.899 & 17.517 & 436.416 & $4 \%$ & 297.252 & 48.990 & 346.242 & $14 \%$ \\
\hline Septiembre & 409.230 & 18.245 & 427.475 & $4 \%$ & 315.568 & 51.230 & 366.798 & $14 \%$ \\
\hline Octubre & 374.706 & 18.477 & 393.183 & $5 \%$ & 299.604 & 45.388 & 344.992 & $13 \%$ \\
\hline Noviembre & 341.199 & 16.346 & 357.545 & $5 \%$ & 269.742 & 45.892 & 315.634 & $15 \%$ \\
\hline Diciembre & 218.687 & 15.565 & 234.252 & $7 \%$ & 160.716 & 45.427 & 206.143 & $22 \%$ \\
\hline Total & 4.103 .055 & 214.310 & 4.317 .365 & $5 \%$ & 3.313 .173 & 425.067 & 3.738 .241 & $11 \%$ \\
\hline Año & \multicolumn{4}{|c|}{2018} & \multicolumn{4}{|c|}{2019} \\
\hline Mes/Consumo & $\begin{array}{c}\text { Consumo de } \\
\text { Energía } \\
\text { KWh/mes }\end{array}$ & $\begin{array}{c}\text { Sistema Solar- } \\
\text { Fotovoltaico } \\
\text { KWh/mes }\end{array}$ & $\begin{array}{c}\text { Consumo } \\
\text { total- } \\
\text { KWh/mes }\end{array}$ & $\begin{array}{c}\text { participación del } \\
\text { SSFV }\end{array}$ & $\begin{array}{c}\text { Consumo de } \\
\text { Energía } \\
\text { KWh/mes }\end{array}$ & $\begin{array}{c}\text { Sistema Solar- } \\
\text { Fotovoltaico } \\
\text { KWh/mes }\end{array}$ & $\begin{array}{c}\text { Consumo total- } \\
\mathrm{KWh} / \mathrm{mes}\end{array}$ & $\begin{array}{c}\text { participación del } \\
\text { SSFV }\end{array}$ \\
\hline Enero & 214.535 & 45.889 & 260.424 & $18 \%$ & 193.481 & 44.154 & 237.635 & $19 \%$ \\
\hline Febrero & 276.019 & 46.453 & 322.472 & $14 \%$ & 262.178 & 43.081 & 305.260 & $14 \%$ \\
\hline Marzo & 252.125 & 50.768 & 302.893 & $17 \%$ & 283.337 & 45.354 & 328.690 & $14 \%$ \\
\hline Abril & 271.791 & 43.382 & 315.173 & $14 \%$ & 247.512 & 42.641 & 290.152 & $15 \%$ \\
\hline Mayo & 281.236 & 42.996 & 324.232 & $13 \%$ & 307.745 & 41.529 & 349.274 & $12 \%$ \\
\hline Junio & 196.262 & 40.330 & 236.592 & $17 \%$ & 203.416 & 43.131 & 246.547 & $17 \%$ \\
\hline Julio & 238.238 & 43.397 & 281.635 & $15 \%$ & 253.210 & 48.891 & 302.101 & $16 \%$ \\
\hline Agosto & 284.049 & 48.193 & 332.242 & $15 \%$ & 300.874 & 50.617 & 351.491 & $14 \%$ \\
\hline Septiembre & 273.716 & 47.643 & 321.359 & $15 \%$ & 298.430 & 47.446 & 345.877 & $14 \%$ \\
\hline Octubre & 285.752 & 47.875 & 333.627 & $14 \%$ & 312.343 & 47.149 & 359.493 & $13 \%$ \\
\hline Noviembre & 247.129 & 40.099 & 287.228 & $14 \%$ & 277.115 & 40.582 & 317.697 & $13 \%$ \\
\hline Diciembre & 179.085 & 48.635 & 227.720 & $21 \%$ & 181.639 & 42.585 & 224.224 & $19 \%$ \\
\hline Total & 2.999 .937 & 545.660 & 3.545 .597 & $15 \%$ & 3.121 .281 & 537.160 & 3.658 .441 & $15 \%$ \\
\hline
\end{tabular}

Tendencia de generacion Sistemas Fotovoltaicos 2017

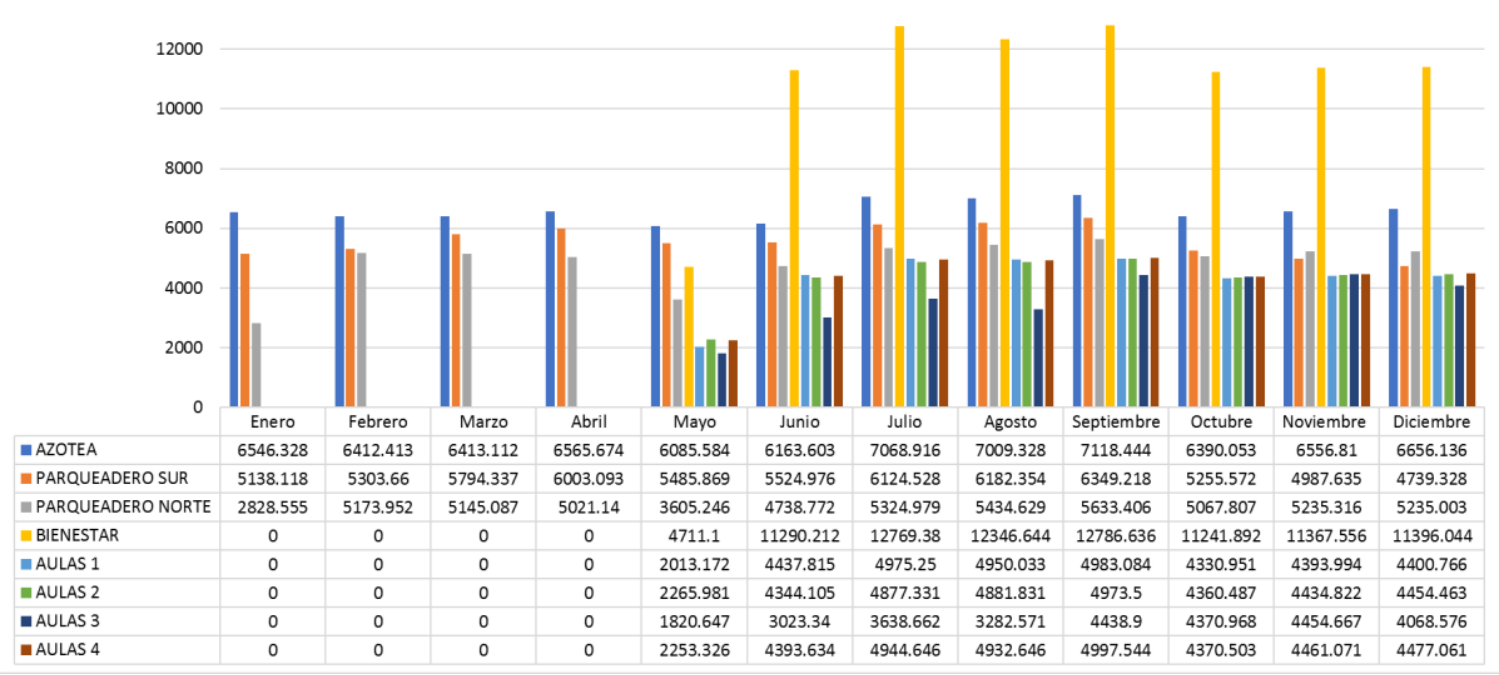

Figura 77. Tendencia de generación sistema fotovoltaico por area año 2017 


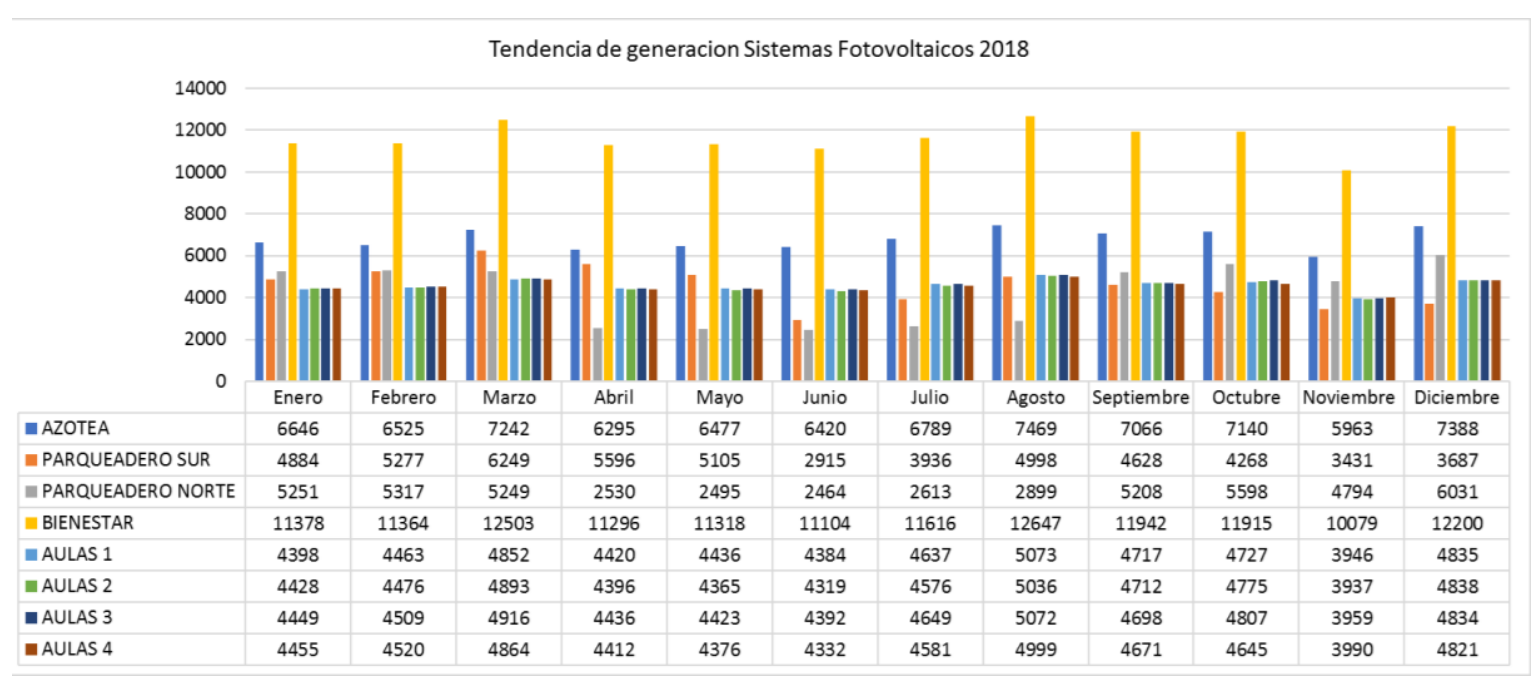

Figura 78. Tendencia de generación sistema fotovoltaico por area año 2018

A continuación, se presentan las tendencias de consumo de energía eléctrica de la red y la suministrada por los sistemas solares fotovoltaicos instalados.

Para el año 2016, el sistema solar fotovoltaico instalado en el campus universitario suplió el $5 \%$ del consumo de energía eléctrica como se muestra en la Figura 79.

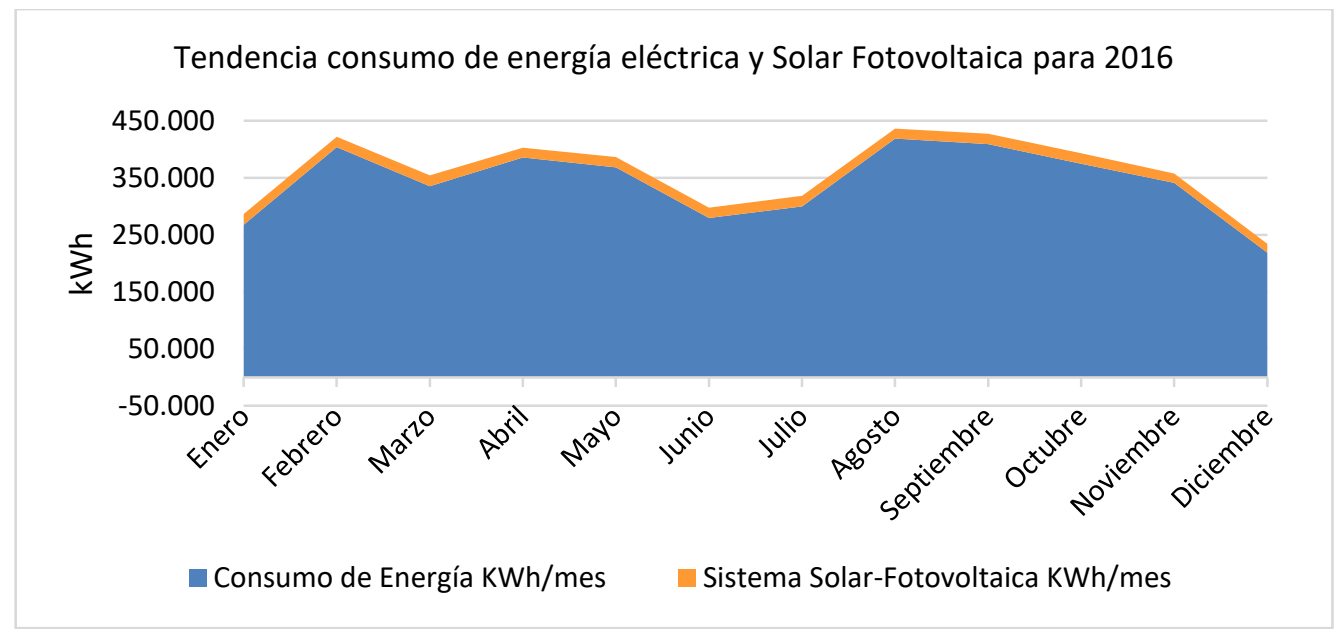

Figura 79. Tendencia de consumo de energía eléctrica y fotovoltaica 2016

Para el año 2017, el sistema solar fotovoltaico instalado en el campus universitario suplió el $11 \%$ del consumo de energía eléctrica, los sistemas con mayor participación fueron los instalados en el edificio de bienestar universitario, parqueadero norte y azotea del edificio central (Figuras 80 y 81 ). 
Tendencia consumo de energía eléctrica y Solar Fotovoltaica para 2017

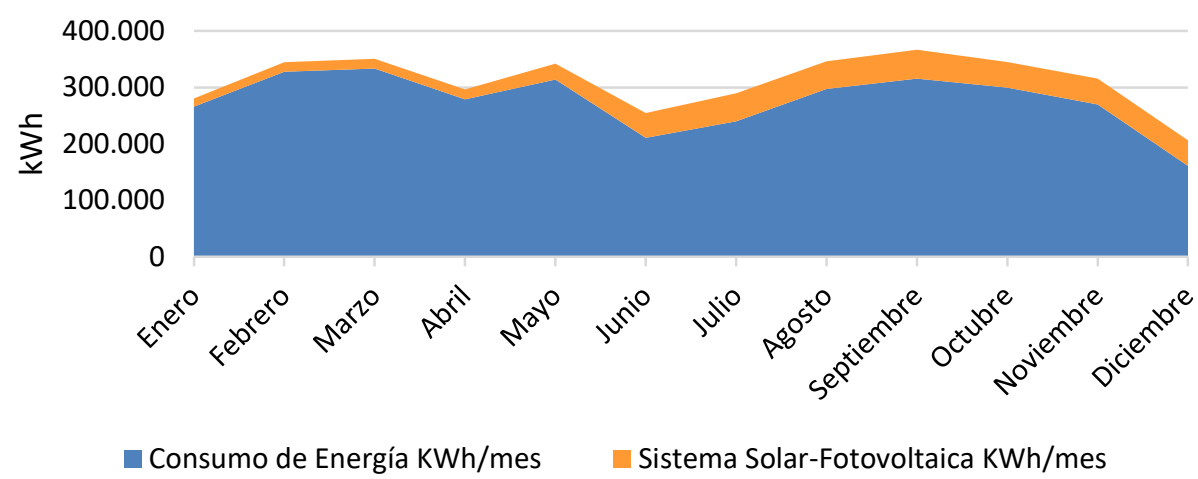

Figura 80. Tendencia de consumo de energía eléctrica y fotovoltaica 2017

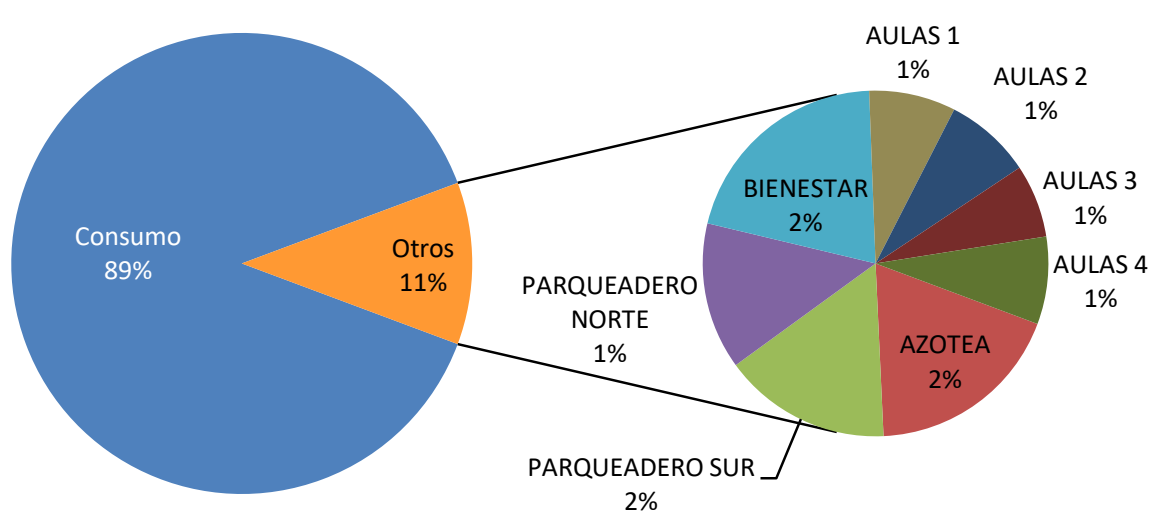

Figura 81. Distribución de la Generación de Energía SSFV 2017

Para el año 2018, el sistema solar fotovoltaico instalado en el campus universitario suplió el $15 \%$ del consumo de energía eléctrica, los sistemas con mayor participación fueron los instalados en el edificio de bienestar universitario, parqueadero sur, azotea del edificio central y los edificios de aulas 1 y 3 (Figuras 82 y 83 ).

Tendencia consumo de energía eléctrica y Solar Fotovoltaica para 2018

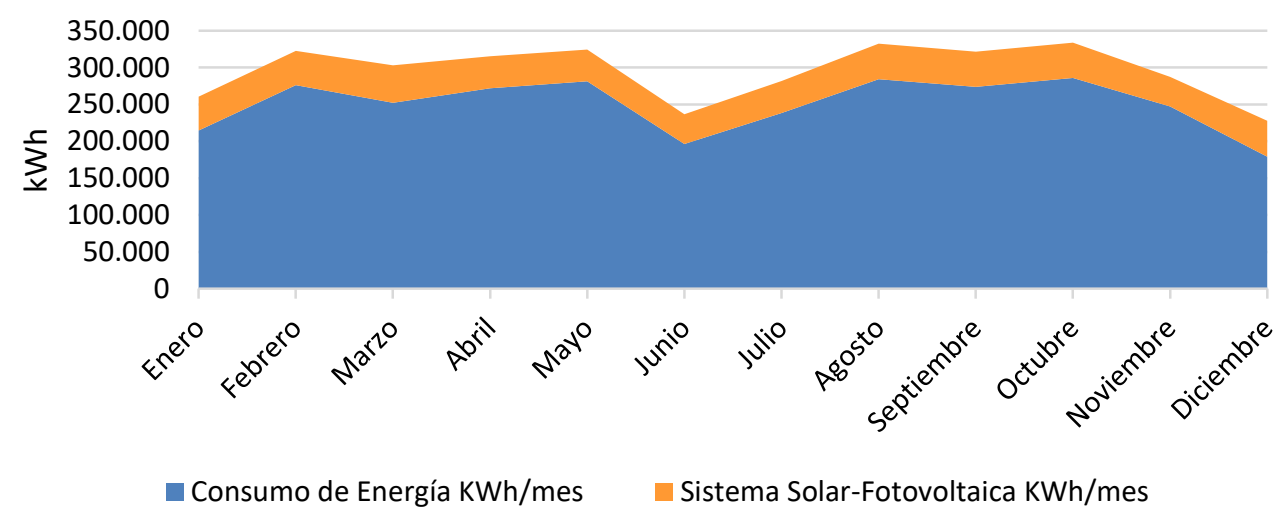

Figura 82. Tendencia de consumo de energía eléctrica y fotovoltaica 2018 


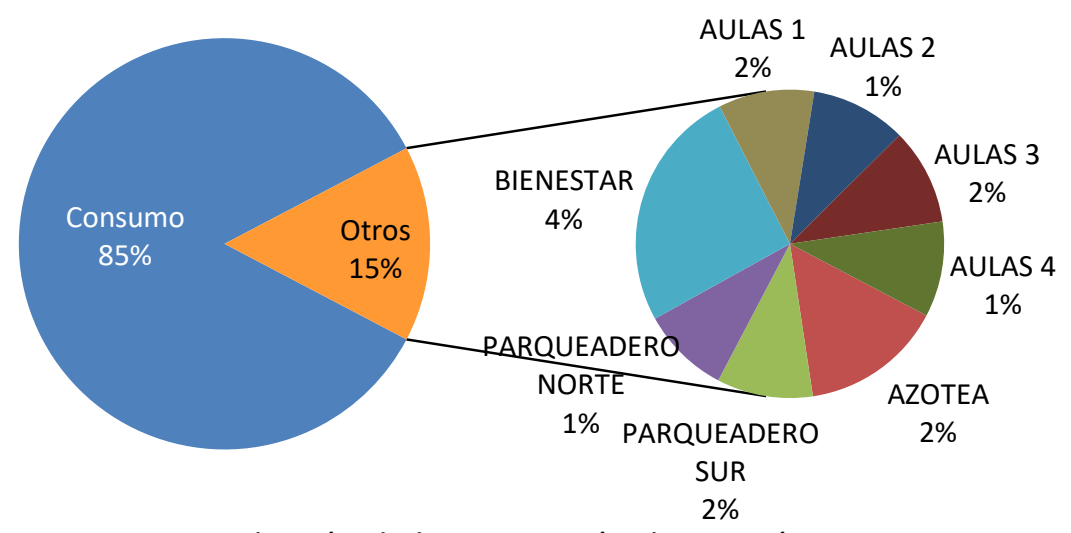

Figura 83. Distribución de la Generación de Energía SFV 2018

\subsubsection{Análisis del Consumo de energía eléctrica global de la UAO en los años 2014 - 2019}

Se comparó el histórico de consumo de energía eléctrica (2014 - 2019) donde se estableció que los menores consumos se presentaron en los años 2014, 2015, 2016, 2018 y 2019 en los meses de enero, junio y diciembre; mientras que en el año 2017 se da en junio y julio; meses correspondientes a los periodos 2 y 4 de receso. Los mayores consumos se obtuvieron en agosto, septiembre y octubre para los años 2014 hasta 2016, en el año 2017 fueron en febrero y marzo, y en el 2018 y 2019 los consumos más altos se presentaron en mayo, agosto y octubre.

Al analizar el consumo de energía eléctrica y estableciendo el año anterior como base, se encontró que en el año 2015 se presentó un aumento del 6,20\%, mientras que, en los años 2016, 2017 y 2018 se dieron reducciones del 2,98\%, 19,25\% y 9,45\% respectivamente. En el año 2017 se evidenció reducción en el consumo de energía eléctrica en todos los meses con respecto al año 2016 el mes con mayor ahorro fue agosto con una disminución del 29\%. El año 2018, también tuvo ahorros con respecto a 2017, principalmente en los meses de enero, febrero y marzo con reducciones del $19,3 \%, 15,8 \%$ y $24,4 \%$ respectivamente. En el año 2019 se evidencia que todos los meses tuvieron un incremento en el consumo de energía eléctrica con respecto al año anterior (2018), esto debido a las diversas modificaciones realizadas en sus instalaciones.

La Tabla 28 y la Figura 84, enseñan los históricos de consumo y la tendencia del consumo de energía eléctrica de los años 2014 - 2018. 
Tabla 28. Histórico de consumo mensual de energía años 2014 - 2019

\begin{tabular}{|c|c|c|c|c|c|c|}
\hline Meses / Año & $\begin{array}{c}\text { Consumo } \\
\mathbf{k W h / m e s} \\
\mathbf{2 0 1 4}\end{array}$ & $\begin{array}{c}\text { Consumo } \\
\mathbf{k W h} / \mathbf{m e s} \\
\mathbf{2 0 1 5}\end{array}$ & $\begin{array}{c}\text { Consumo } \\
\mathbf{k W h} / \mathbf{m e s} \\
\mathbf{2 0 1 6}\end{array}$ & $\begin{array}{c}\text { Consumo } \\
\mathbf{k W h} / \mathbf{m e s} \\
\mathbf{2 0 1 7}\end{array}$ & $\begin{array}{c}\text { Consumo } \\
\mathbf{k W h} / \mathbf{m e s} \\
\mathbf{2 0 1 8}\end{array}$ & $\begin{array}{c}\text { Consumo } \\
\mathbf{k W h} / \mathbf{m e s} \\
\mathbf{2 0 1 9}\end{array}$ \\
\hline Enero & 256.624 & 319.206 & 267.644 & 265.880 & 214.535 & 237.635 \\
\hline Febrero & 342.502 & 364.179 & 403.917 & 327.778 & 276.019 & 305.260 \\
\hline Marzo & 358.117 & 374.795 & 335.299 & 333.408 & 252.125 & 328.690 \\
\hline Abril & 336.394 & 370.267 & 385.732 & 278.846 & 271.791 & 290.152 \\
\hline Mayo & 373.582 & 377.389 & 368.364 & 313.901 & 281.236 & 349.274 \\
\hline Junio & 260.619 & 258.879 & 279.592 & 210.604 & 196.262 & 246.547 \\
\hline Julio & 368.982 & 352.281 & 299.786 & 239.874 & 238.238 & 302.101 \\
\hline Agosto & 366.459 & 398.638 & 418.899 & 297.252 & 284.049 & 351.491 \\
\hline Septiembre & 380.562 & 423.916 & 409.230 & 315.568 & 273.716 & 345.877 \\
\hline Octubre & 390.212 & 405.704 & 374.706 & 299.604 & 285.752 & 359.493 \\
\hline Noviembre & 320.647 & 340.648 & 341.199 & 269.742 & 247.129 & 317.697 \\
\hline Diciembre & 227.251 & 243.061 & 218.687 & 160.716 & 179.085 & 224.224 \\
\hline
\end{tabular}

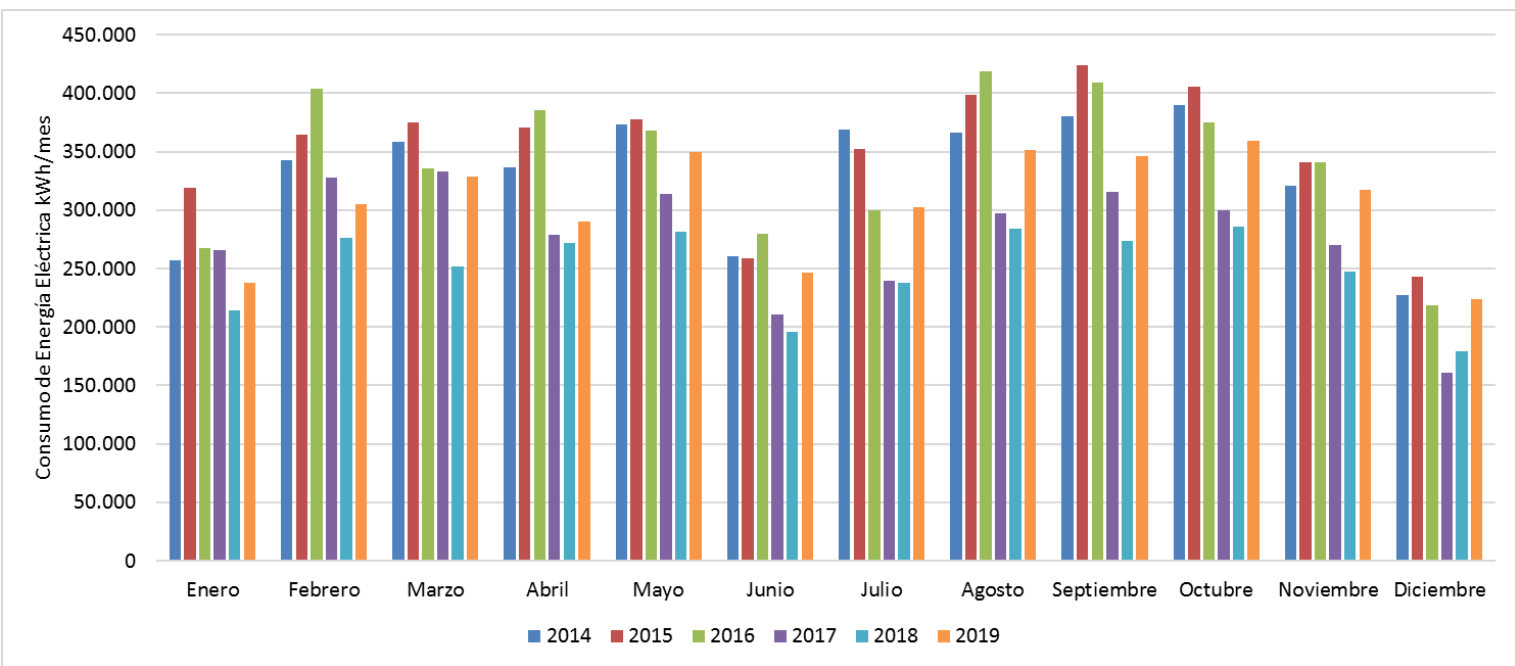

Figura 84. Tendencia de consumo de energía eléctrica mensual desde el año 2014-2019

\subsubsection{Análisis de consumo de energía eléctrica del campus UAO en una semana}

La Figura 85, muestra el consumo de energía eléctrica en una semana de marzo del año 2017, mes establecido como de mayor consumo energético, y la Figura 86 corresponde al consumo de energía eléctrica global de la UAO en una semana del mes de junio como menor consumo energético, en donde se evidencia que los días de semana (lunes a viernes) poseen una tendencia de consumo similar, con un consumo más reducido de 168,55 kWh y 150 Kwh marcado entre las $23 \mathrm{~h}$ y las $5 \mathrm{~h}$. Los sábados, el consumo disminuye significativamente y que el consumo de los domingos tiene un comportamiento constante equivalente al consumo más bajo.

Las figuras 87 y 88 , enseñan el consumo energético de las mismas semanas analizadas en el 2017 para el año 2018. En la semana del mes de marzo de 2018 se evidencia que el consumo más alto fue de $858.7 \mathrm{kWh}$, mientras que en el 2017 fue de $888.8 \mathrm{kWh}$, el comportamiento 
del consumo sigue una tendencia similar, donde el consumo empieza a crecer desde las 7 am, pero alcanza su nivel máximo alrededor de las $5 \mathrm{pm}$, para el 2017 los consumos picos se alcanzaban 1 hora antes (4pm). Para el mes de junio, catalogado de menor consumo, se evidencia que el consumo es mucho menor ( 669 kWh consumo más alto 2017 vs. 164.6 kWh consumo más alto de 2018), el consumo total del mes de junio disminuyó en un $6.8 \%$ con respecto al 2017.

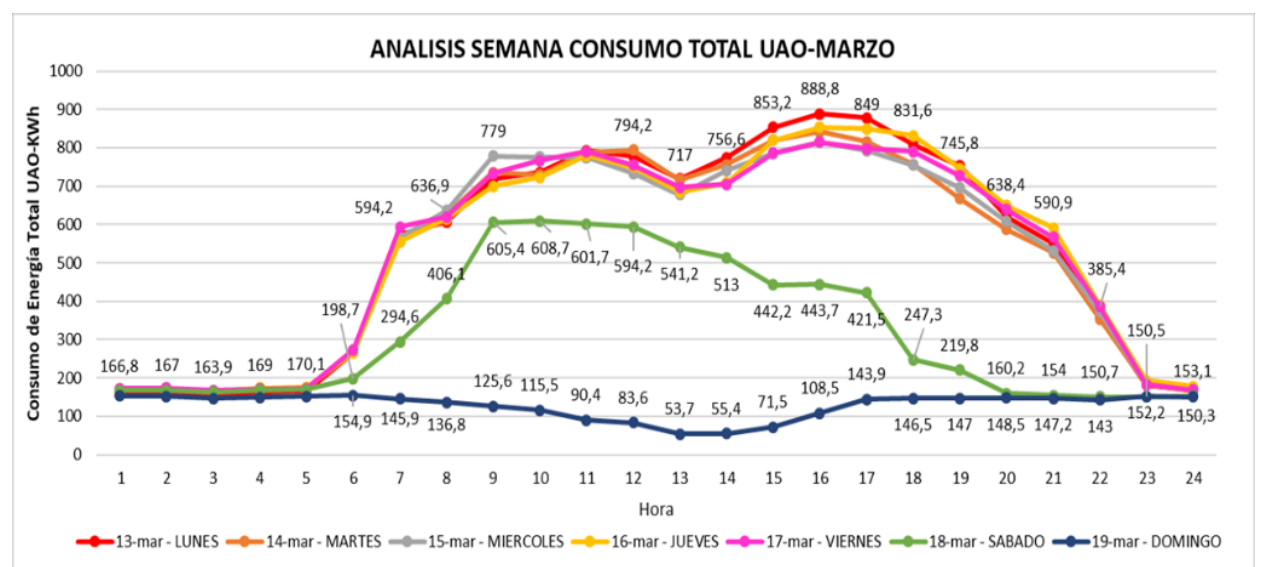

Figura 85. Análisis consumo de energía eléctrica global UAO en una semana de marzo 2017.

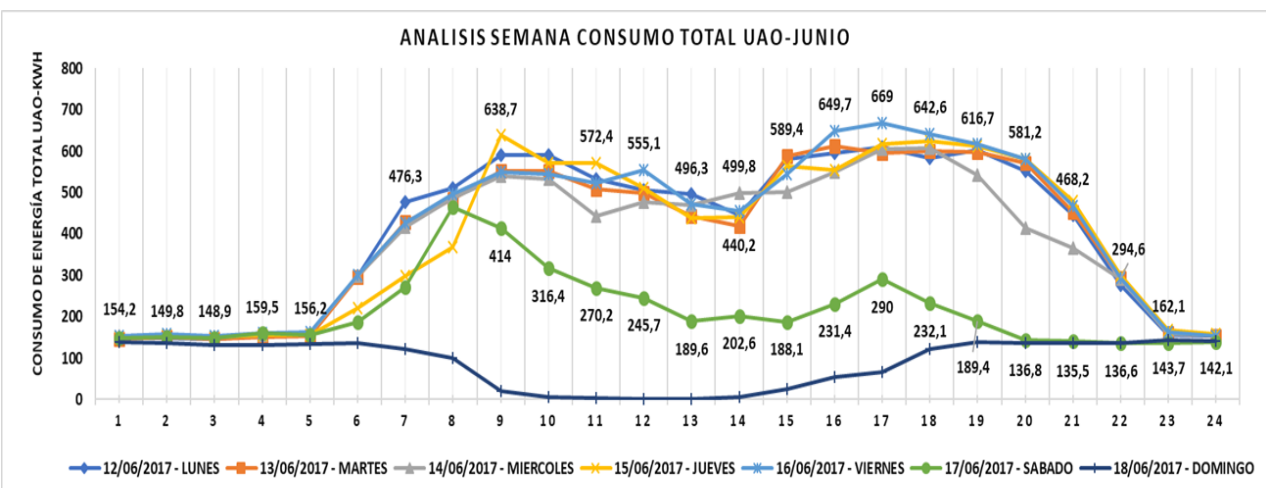

Figura 86. Análisis consumo de energía eléctrica global UAO en una semana de junio 2017

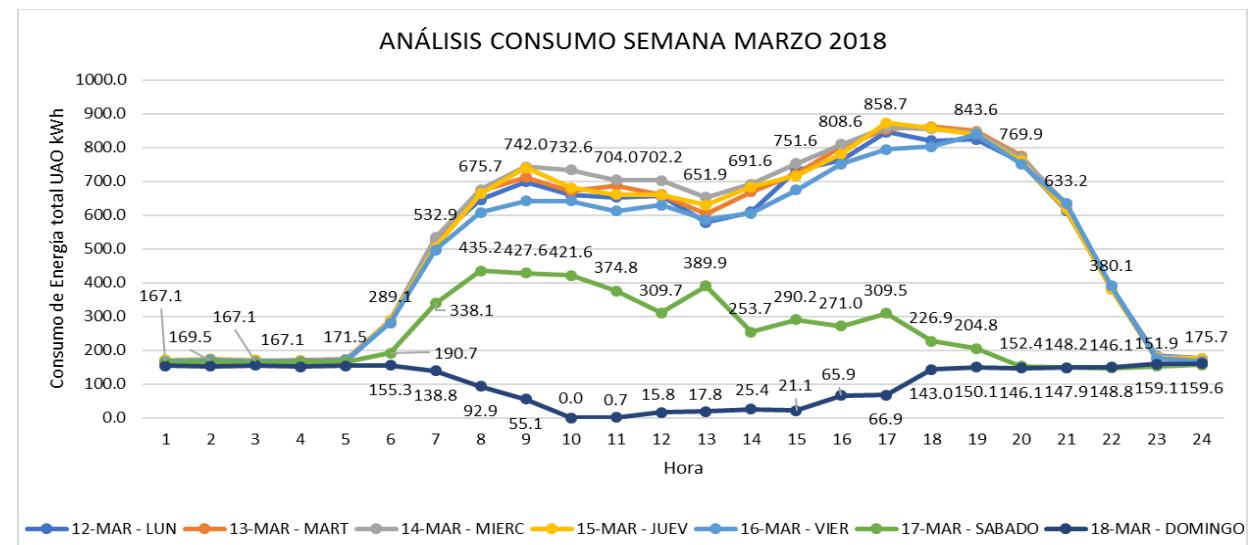

Figura 87. Análisis consumo de energía eléctrica global UAO en una semana de marzo 2018 


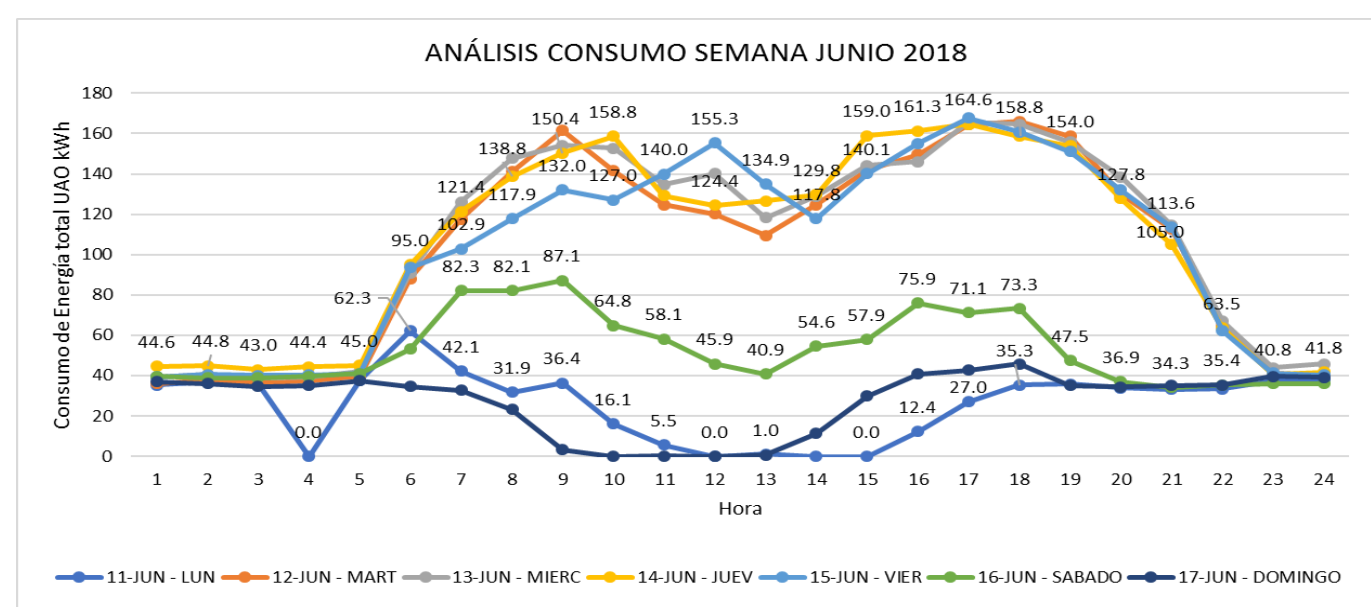

Figura 88. Análisis consumo de energía eléctrica global UAO en una semana de junio 2018

\subsubsection{Análisis del uso y consumo de la energía eléctrica por subestaciones}

En el análisis de consumo por subestaciones se examinaron los consumos de energía eléctrica de los años 2016, 2017 y 2018 de los medidores de consumo instalados en las 3 subestaciones del campus. Es importante precisar que cada subestación está conformada por:

- Subestación 1: Provee la energía del edificio central y tiene una capacidad de 500 KVA.

- Subestación 2: Proporciona la energía a los cuatro edificios de Aulas, bienestar universitario, cafetería y plantas PTAR y PTAP; y es de 1000 KVA.

- Subestación 3: Tiene una capacidad de 800 KVA y alimenta eléctricamente los Chiller del edificio central, estos últimos que fueron cambiados de 738.54 kW a 879.21 kW.

Conforme los datos arrojados por los medidores de consumo de energía eléctrica y la generación de energía fotovoltaica anuales de cada subestación es posible afirmar que la subestación 2 es la que tiene mayor participación en el consumo con el 39\%, 42\% y 38\% para los años 2016, 2017 y 2018 respectivamente, en segundo lugar, se encuentra la subestación 1 con una participación del 38\% para los años en mención, y en el último lugar con una contribución del 23-20-24\% está la subestación 3. En la Figura 89, se representa lo mencionado anteriormente.

Matriz de consumo Subestaciones - 2016

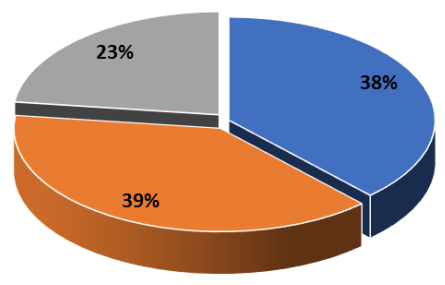

- S/E 1 -S/E 2 -S/E 3
Matriz de consumo Subestaciones - 2017

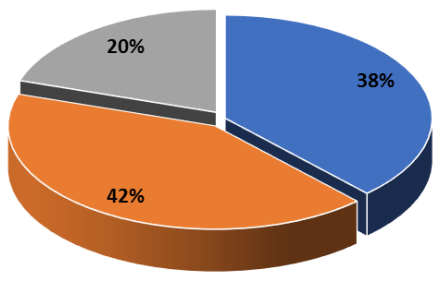

- S/E 1 -S/E 2 -S/E 3
Matriz de consumo Subestaciones - 2018

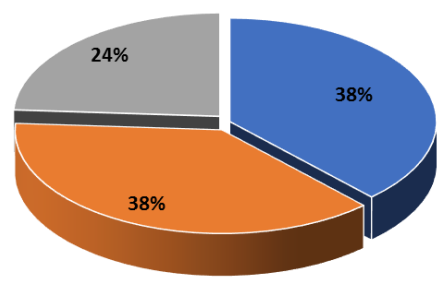

- S/E 1 - S/E 2 - S/E 3

Figura 89. Participación de subestaciones en el consumo de energía eléctrica 


\subsubsection{Matriz Energética del Campus}

Para la elaboración de la matriz energética del año 2016, 2017 y 2018 se utilizaron datos de consumos mensuales de los principales energéticos del campus.

En relación al peso energético que tiene cada portador energético dentro de la matriz de consumo total, la energía eléctrica es el tipo de energía de mayor consumo, con una participación del $87.1 \%, 84,1 \%$ y 78.2\% para el 2016, 2017 y 2018 respectivamente (Figura 90). En la Tabla 29 se detallan los porcentajes de participación y los consumos para cada uno de los años analizados. Se destaca la reducción del 32\% que se ha presentado en el consumo total gracias a los cambios tecnológicos efectuados en la iluminación y el sistema de refrigeración.
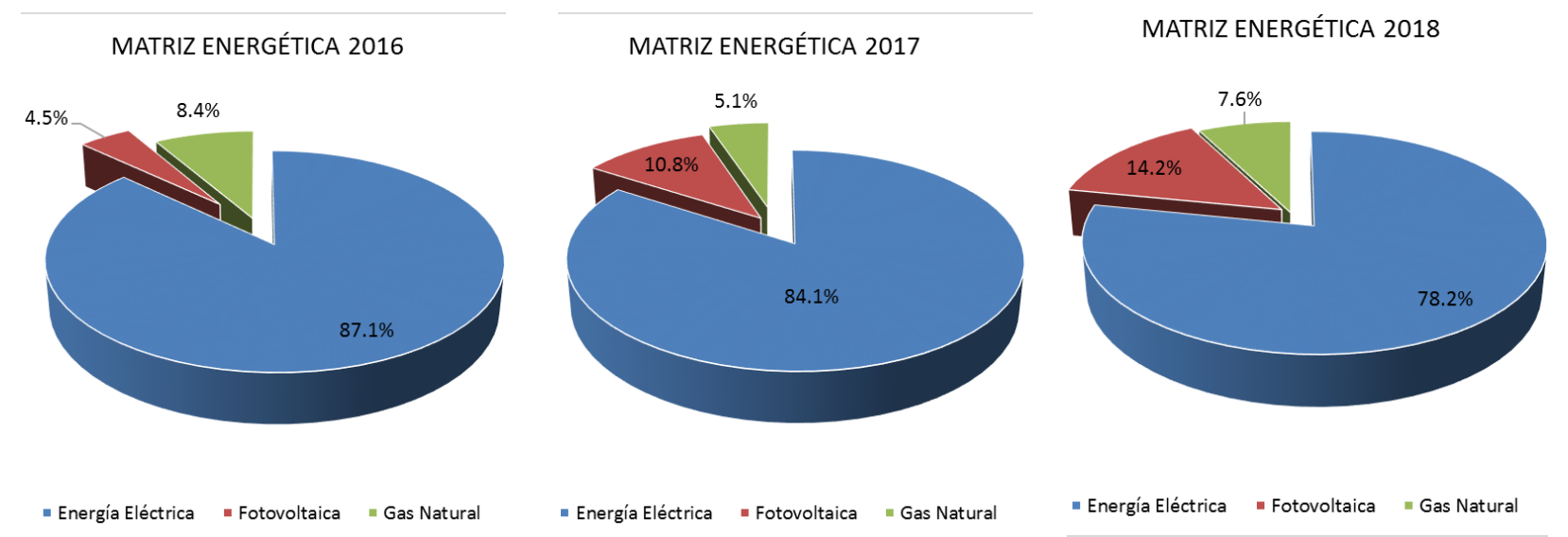

Figura 90. Matrices de consumo de energía años 2016 - 2018

Tabla 29. Datos de consumo por tipo de energía años 2016 - 2018.

\begin{tabular}{|c|c|c|c|c|c|c|}
\hline \multirow{2}{*}{ Año/Energético } & \multicolumn{2}{|c|}{2016} & \multicolumn{2}{c|}{2017} & \multicolumn{2}{c|}{2018} \\
\cline { 2 - 7 } & Consumo kWh & \% Participación & Consumo kWh & $\%$ Participación & Consumo kWh & \% Participación \\
\hline Energia Eléctrica & $4,103,055$ & $87.1 \%$ & $3,313,173$ & $84.1 \%$ & $2,999,937$ & $78.2 \%$ \\
\hline Fotovoltaica & 214,310 & $4.5 \%$ & 424,450 & $10.8 \%$ & 545,660 & $14.2 \%$ \\
\hline Gas Natural & 394,571 & $8.4 \%$ & 200,585 & $5.1 \%$ & 292,219 & $7.6 \%$ \\
\hline
\end{tabular}

La Figura 91 presenta el análisis del consumo de un día en la subestación 3 que alimenta a la enfriadora de agua y representa entre el $20-24 \%$ del total del consumo de la universidad. La Figura 92, presenta el análisis de una semana tipo en la subestación. 


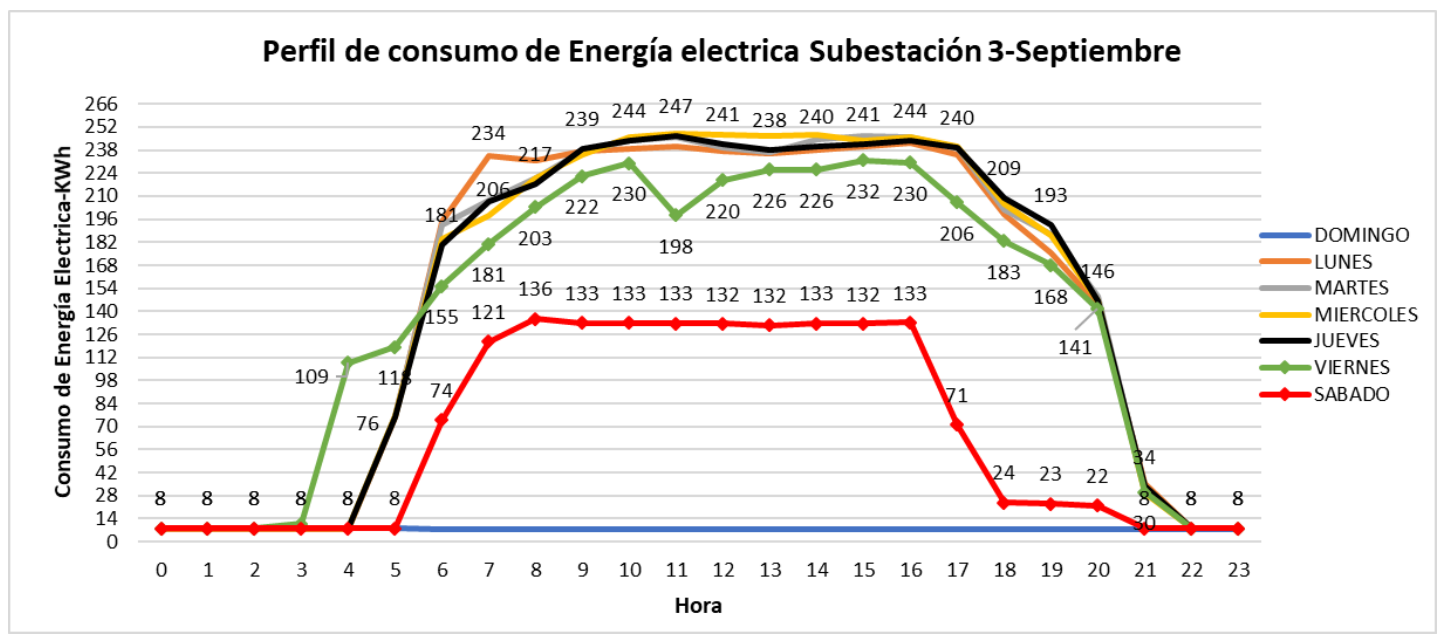

Figura 91. Perfil de consumo de energía en un día de la subestación 3

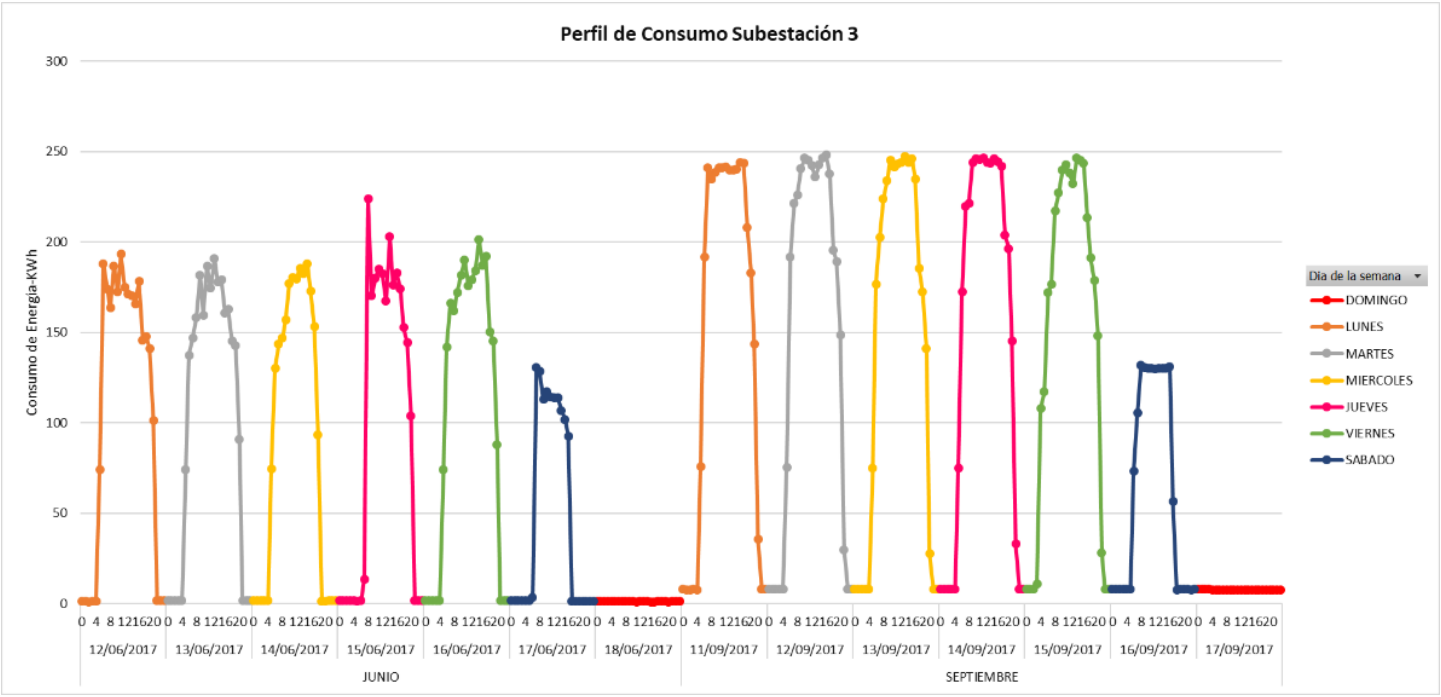

Figura 92. Perfil de consumo semanal subestación 3

\subsubsection{Análisis del Consumo de Energía de las Aulas}

Para el presente análisis de consumo de energía mensual en las cuatro aulas se incluyó la generación de energía fotovoltaica en el consumo de energía eléctrica este último que se registra en los cuatro medidores que instaló la Universidad.

\section{Matriz de consumo de energía Aulas}

La mayor participación en el consumo total para los años 2016 y 2017 se presentó en el edificio de aulas 2; con un porcentaje del 27\% y 28\% respectivamente. En el año 2018 y 2019, el edificio con mayor participación en el consumo total fue el edificio de aulas 4 con un porcentaje del 29\% (aumento de aproximadamente 2\% debido a las labores de remodelación que se llevaron a cabo en el edificio) para el 2018 y del 30\% para el 2019, la Figura 93 muestra las matrices de consumo de energía eléctrica para los edificios de aulas. 
La

Tabla 30, recopila el consumo de energía eléctrica en kWh para los edificios y su porcentaje de reducción o aumento para cada aula con respecto al periodo anterior, donde se obtuvo que para el año 2017 el edificio de aulas 1 presentó una disminución del 2.9\% consumo, mientras que los edificios de aulas 2 y 4 aumentaron su consumo en $5.2 \%$ y $5.3 \%$ respectivamente. Para el año 2018, el edificio de aulas 2 obtuvo una reducción del 10.7\% del consumo de energía con respecto al 2017 y el de aulas 4 presentó un aumento del $8.9 \%$ en el consumo de energía. El año 2019, presentó un incremento en el consumo de energía eléctrica en todos sus edificios, el de menor aumento fue el edificio de aulas 1 con un incremento del $2,5 \%$ y el de mayor aumento fue el edificio de aulas 4 con un incremento del $10,6 \%$.

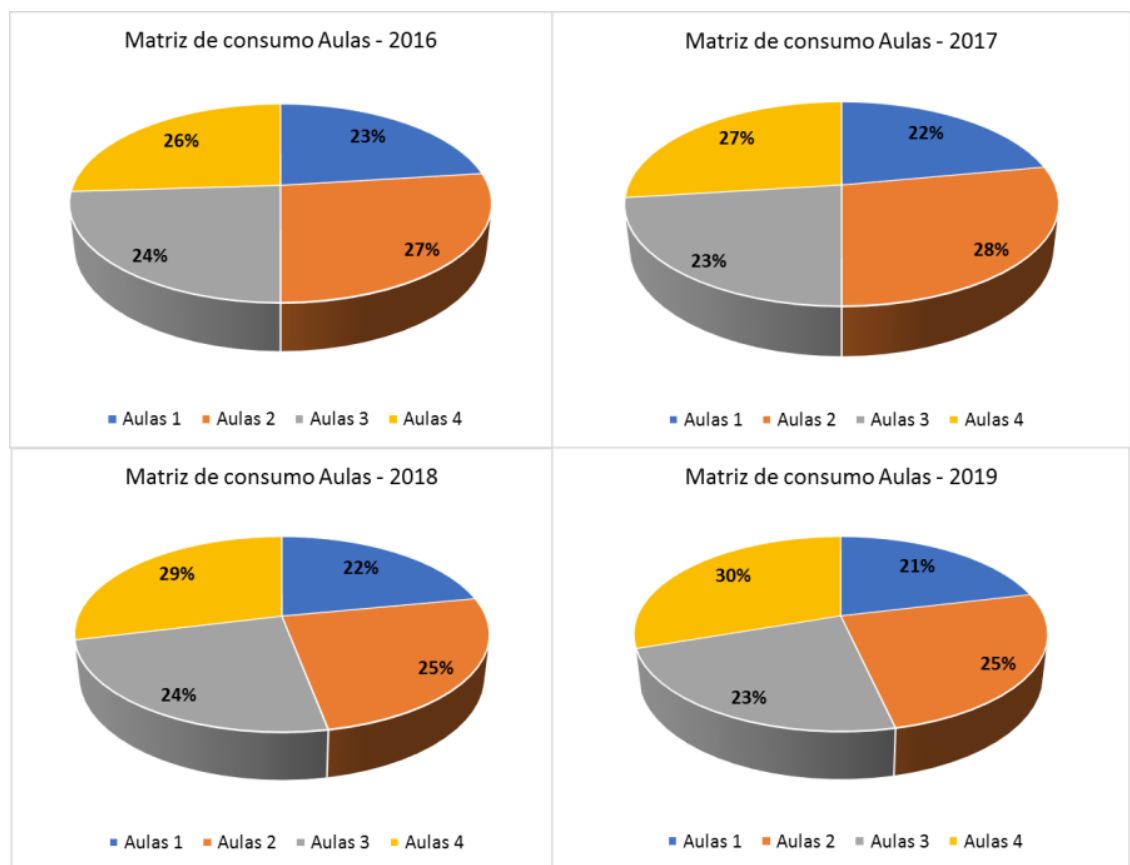

Figura 93. matriz de consumo de energía electrica de aulas 2016 - 2019

Tabla 30. Relacion de incremento o decremento en el consumo de energía electrica para las aulas en los año 2016 - 2019

\begin{tabular}{|c|c|c|c|c|c|c|c|}
\hline $\begin{array}{c}\text { Aulas / } \\
\text { Consumo }\end{array}$ & $\mathbf{2 0 1 6}$ & $\mathbf{2 0 1 7}$ & $\begin{array}{c}\text { \% reducción/ } \\
\text { aumento con } \\
\text { respecto a 2016 }\end{array}$ & $\mathbf{2 0 1 8}$ & $\begin{array}{c}\text { \%reducción/ } \\
\text { aumento con } \\
\text { respecto a 2017 }\end{array}$ & $\mathbf{2 0 1 9}$ & $\begin{array}{c}\text { \%reducción/ } \\
\text { aumento con } \\
\text { respecto a 2018 }\end{array}$ \\
\hline Aulas 1 & 149.188 & 144.826 & $-2,9 \%$ & 143.638 & $-0,8 \%$ & 147.157 & $2,5 \%$ \\
\hline Aulas 2 & 172.827 & 181.821 & $5,2 \%$ & 162.440 & $-10,7 \%$ & 179.001 & $10,2 \%$ \\
\hline Aulas 3 & 154.042 & 154.756 & $0,5 \%$ & 157.392 & $1,7 \%$ & 165.337 & $5,0 \%$ \\
\hline Aulas 4 & 164.358 & 173.063 & $5,3 \%$ & 188.383 & $8,9 \%$ & 208.376 & $10,6 \%$ \\
\hline
\end{tabular}




\section{Tendencia de consumo de energía en las cuatro aulas}

El comportamiento de consumo mensual que presentan las cuatro aulas es semejante pues en los meses de enero, junio, julio y diciembre se presentan diferencias que fluctúan del $41 \%$ a $74 \%$ entre los meses de mayor consumo como lo muestra la Tabla 31 . Además, se evidencia que en el año 2016 los meses de mayor consumo fueron febrero para aulas 2 y agosto para las aulas 1, 3 y 4; en el 2017 el mayor consumo también se presentó en los meses de febrero, agosto y septiembre; a excepción de aulas 4 en el que apareció en los meses de marzo y mayo. Para 2018 el consumo más alto se presentó en el mes de agosto para los 4 edificios de aula. Los mínimos consumos en los años 2016 y 2017 se presentan en los meses de enero y junio, mientras que en el 2018 los meses de menor consumo fueron junio y diciembre. En el 2019, el consumo más alto se dio en el mes de agosto para los 4 edificios de aulas, mientras que el mes de diciembre fue el de menor consumo para aulas 1,2 y 3 y en aulas 4 el menor consumo se presentó en el mes de enero.

Tabla 31. Consumo de energía electrica promedio por mes edificios de aulas 2016 - 2019

\begin{tabular}{|c|c|c|c|c|c|c|c|c|}
\hline \multirow{2}{*}{$\begin{array}{c}\text { Consumo / } \\
\text { Mes }\end{array}$} & \multicolumn{4}{|c|}{ Aulas $1[\mathrm{kWh} / \mathrm{mes}]$} & \multicolumn{4}{|c|}{ Aulas 2 [kWh/mes] } \\
\hline & 2016 & 2017 & 2018 & 2019 & 2016 & 2017 & 2018 & 2019 \\
\hline Enero & 8.433 & 8.665 & 10.124 & 8.915 & 9.761 & 9.769 & 10.603 & 11.626 \\
\hline Febrero & 16.478 & 15.748 & 14.957 & 14.120 & 20.416 & 20.165 & 16.503 & 18.084 \\
\hline Marzo & 13.583 & 16.002 & 14.161 & 14.503 & 16.040 & 19.561 & 15.434 & 18.014 \\
\hline Abril & 15.610 & 12.824 & 14.994 & 12.949 & 17.836 & 16.128 & 15.201 & 15.544 \\
\hline \begin{tabular}{|l|} 
Mayo \\
\end{tabular} & 14.778 & 15.621 & 14.221 & 14.198 & 16.841 & 18.355 & 14.216 & 17.386 \\
\hline Junio & 6.365 & 8.710 & 7.317 & 8.122 & 7.160 & 10.680 & 9.728 & 10.044 \\
\hline Julio & 8.536 & 11.316 & 10.238 & 10.114 & 9.755 & 14.137 & 11.151 & 11.614 \\
\hline Agosto & 17.469 & 16.227 & 15.093 & 16.035 & 20.325 & 21.677 & 16.726 & 20.551 \\
\hline Septiembre & 16.711 & 16.828 & 14.315 & 15.845 & 19.137 & 23.201 & 16.764 & 19.366 \\
\hline Octubre & 13.857 & 11.083 & 11.270 & 15.174 & 15.241 & 15.425 & 14.667 & 17.684 \\
\hline \begin{tabular}{|l} 
Noviembre \\
\end{tabular} & 12.256 & 8.718 & 8.843 & 11.209 & 14.022 & 10.030 & 11.733 & 12.427 \\
\hline Diciembre & 5.112 & 3.085 & 8.104 & 5.976 & 6.293 & 2.693 & 9.714 & 6.663 \\
\hline Total Aulas & 149.188 & 144.826 & 143.638 & 147.159 & 172.827 & 181.821 & 162.440 & 179.003 \\
\hline \multirow{2}{*}{$\begin{array}{c}\begin{array}{c}\text { Consumo / } \\
\text { Mes }\end{array} \\
\end{array}$} & \multicolumn{4}{|c|}{ Aulas 3 [kWh/mes] } & \multicolumn{4}{|c|}{ Aulas $4[\mathrm{kWh} / \mathrm{mes}]$} \\
\hline & 2016 & 2017 & 2018 & 2019 & 2016 & 2017 & 2018 & 2019 \\
\hline Enero & 8.511 & 10.330 & 11.877 & 11.396 & 7.517 & 8.621 & 11.945 & 8.157 \\
\hline Febrero & 15.933 & 15.439 & 16.503 & 14.961 & 19.123 & 19.672 & 18.621 & 18.339 \\
\hline Marzo & 13.467 & 15.871 & 15.372 & 15.406 & 15.921 & 20.782 & 17.860 & 19.271 \\
\hline Abril & 15.361 & 13.371 & 15.978 & 13.721 & 18.948 & 17.120 & 18.972 & 15.445 \\
\hline Mayo & 14.858 & 14.870 & 14.770 & 15.184 & 17.409 & 20.919 & 18.239 & 18.876 \\
\hline \begin{tabular}{|l|} 
Junio \\
\end{tabular} & 9.403 & 9.751 & 8.714 & 9.064 & 5.001 & 10.869 & 10.453 & 12.135 \\
\hline Julio & 9.700 & 13.606 & 11.983 & 11.808 & 8.365 & 11.163 & 13.731 & 20.271 \\
\hline Agosto & 17.337 & 17.725 & 16.402 & 18.167 & 19.859 & 18.805 & 19.144 & 24.242 \\
\hline Septiembre & 16.147 & 17.724 & 15.245 & 17.916 & 18.579 & 18.509 & 18.292 & 22.723 \\
\hline Octubre & 13.683 & 12.399 & 12.789 & 15.905 & 15.704 & 12.640 & 17.515 & 21.390 \\
\hline Noviembre & 11.989 & 9.275 & 9.932 & 13.865 & 12.879 & 10.409 & 14.198 & 17.109 \\
\hline Diciembre & 7.653 & 4.395 & 7.827 & 7.944 & 5.053 & 3.554 & 9.414 & 10.418 \\
\hline Total Aulas & 154.042 & 154.756 & 157.392 & 165.338 & 164.358 & 173.063 & 188.383 & 208.376 \\
\hline
\end{tabular}




\section{Perfil de Consumo aulas por Jornada}

Conforme al perfil de consumo por jornada que se muestra en la Figura 94 permite evidenciar que en todas las aulas incrementan los consumos en la jornada diurna con porcentajes que varían del $48 \%$ al $74 \%$ y que equivalen en promedio a $46.938 \mathrm{KWh} / \mathrm{mes}$ en el primer periodo; $10.609 \mathrm{KWh} /$ mes en el segundo periodo; $45.193 \mathrm{KWh} / \mathrm{mes}$ en el tercer periodo; y $9.437 \mathrm{KWh} / \mathrm{mes}$ en el cuarto periodo; mientras que los mínimos consumos se presentan en los periodos 1 y 3 en la jornada de madrugada; y en los periodos 2 y 4 de receso se alterna entre las jornadas de madrugada y nocturna. La Tabla 32, presenta el consumo de energía promedio en cada aula según la jornada de madrugada, diurna y nocturna para los años 2016 y 2017.

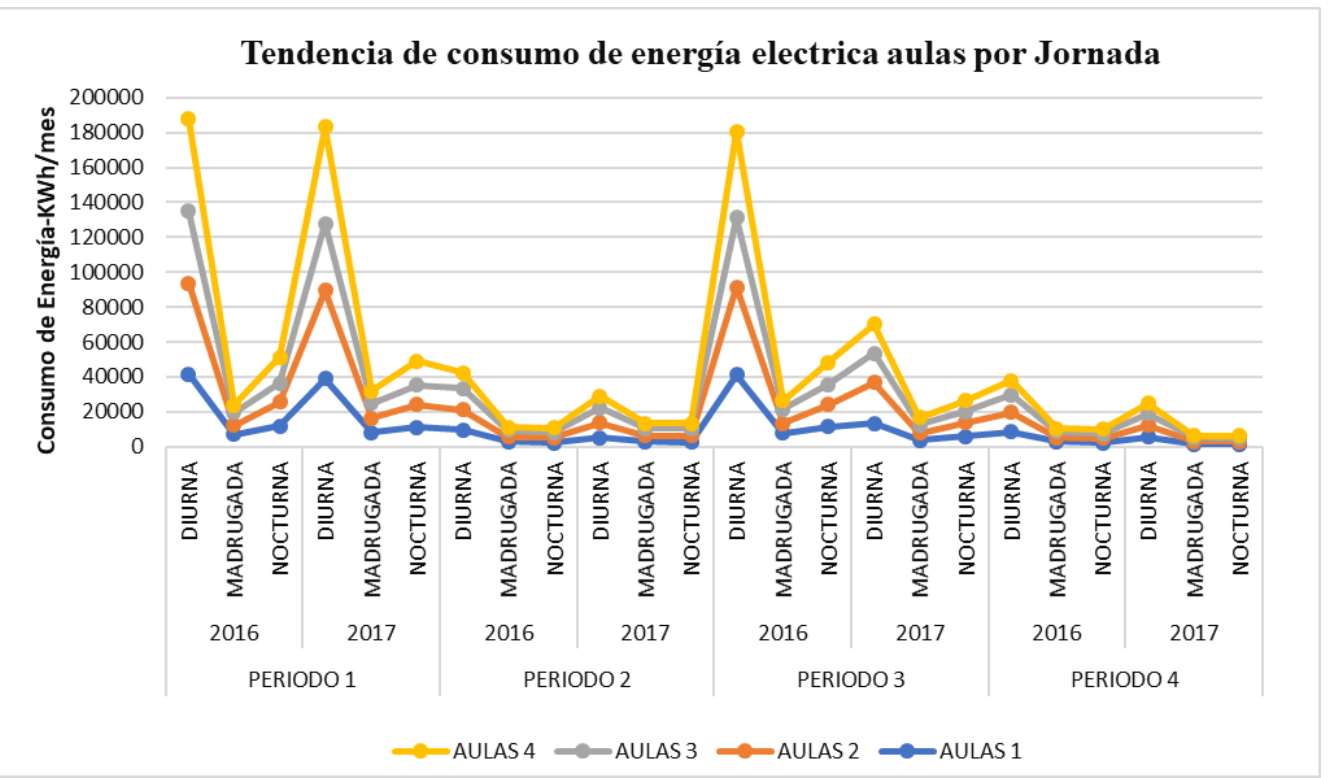

Figura 94. tendencia de consumo de energía electrica aulas por jornada-Años 2016 y 2017

Tabla 32. consumo de energía electrica promedio en cada aulas por jornada -2016 y 2017

\begin{tabular}{|c|c|c|c|c|c|c|c|c|}
\hline $\begin{array}{l}\text { Consumo } \\
\text { Jornada }\end{array}$ & $\begin{array}{c}\text { Aulas } 1 \\
\text { kWh/mes }\end{array}$ & $\begin{array}{c}\text { Aulas } 2 \\
\text { kWh/mes }\end{array}$ & $\begin{array}{c}\text { Aulas } 3 \\
\mathrm{kWh} / \mathrm{mes}\end{array}$ & $\begin{array}{c}\text { Aulas } 4 \\
\text { kWh/mes }\end{array}$ & $\begin{array}{c}\text { Aulas } 1 \\
\mathrm{kWh} / \mathrm{mes}\end{array}$ & $\begin{array}{c}\text { Aulas } 2 \\
\mathrm{kWh} / \mathrm{mes}\end{array}$ & $\begin{array}{c}\text { Aulas } 3 \\
\mathrm{kWh} / \mathrm{mes}\end{array}$ & $\begin{array}{c}\text { Aulas } 4 \\
\mathrm{kWh} / \mathrm{mes}\end{array}$ \\
\hline Periodo & \multicolumn{4}{|c|}{ Periodo 1} & \multicolumn{4}{|c|}{ Periodo 3} \\
\hline Año & \multicolumn{8}{|c|}{2016} \\
\hline Diurna & 41.626 & 51.888 & 41.603 & 52.636 & 41.182 & 50.254 & 39.700 & 49.638 \\
\hline Madrugada & 7.083 & 5.263 & 7.167 & 4.099 & 7.624 & 5.806 & 8.071 & 4.765 \\
\hline Nocturna & 11.741 & 13.982 & 10.849 & 14.666 & 11.487 & 12.664 & 11.385 & 12.619 \\
\hline Total 2016 & 60.449 & 71.133 & 59.619 & 71.401 & 60.293 & 68.725 & 59.156 & 67.022 \\
\hline Año & \multicolumn{8}{|c|}{2017} \\
\hline Diurna & 38.867 & 50.727 & 38.264 & 55.479 & 13.535 & 23.170 & 16.642 & 17.016 \\
\hline Madrugada & 8.305 & 7.923 & 8.640 & 6.982 & 3.580 & 4.036 & 4.944 & 4.009 \\
\hline Nocturna & 11.012 & 13.299 & 10.826 & 13.782 & 6.010 & 7.821 & 6.153 & 6.370 \\
\hline Total 2017 & 58.185 & 71.949 & 57.730 & 76.243 & 23.125 & 35.028 & 27.739 & 27.395 \\
\hline
\end{tabular}




\begin{tabular}{|l|c|c|c|c|c|c|c|c|}
\hline \multicolumn{1}{|c|}{ Periodo } & \multicolumn{9}{c|}{ Periodo 2 } & \multicolumn{7}{c|}{ Periodo 4 } \\
\hline \multicolumn{1}{|c|}{ Año } & \multicolumn{9}{|c|}{ 2016 } \\
\hline Diurna & 9.452 & 11.879 & 12.093 & 9.011 & 8.560 & 11.046 & 10.273 & 8.109 \\
\hline Madrugada & 3.118 & 2.335 & 3.773 & 1.874 & 2.789 & 2.397 & 3.252 & 1.895 \\
\hline Nocturna & 2.331 & 2.700 & 3.237 & 2.481 & 2.196 & 2.612 & 2.638 & 2.566 \\
\hline Total 2016 & 14.901 & 16.915 & 19.103 & 13.366 & 13.545 & 16.054 & 16.163 & 12.570 \\
\hline \multicolumn{10}{|c|}{ Año } & \multicolumn{7}{|c|}{2017} & & \\
\hline Diurna & 5.068 & 8.548 & 8.663 & 6.778 & 5.727 & 6.683 & 6.570 & 6.012 \\
\hline Madrugada & 2.814 & 3.290 & 4.214 & 2.933 & 1.554 & 1.435 & 2.042 & 1.153 \\
\hline Nocturna & 2.744 & 3.679 & 3.829 & 2.990 & 1.384 & 1.652 & 1.718 & 1.457 \\
\hline Total 2017 & 10.626 & 15.517 & 16.707 & 12.701 & 8.665 & 9.769 & 10.330 & 8.621 \\
\hline
\end{tabular}

\subsubsection{Análisis de los usos significativos del Campus}

Para el análisis de los usos significativos del campus y los edificios de aulas se utilizó la herramienta estadística diagrama de Pareto. La misma permitiò clasificar gráficamente la información de mayor a menor relevancia, con el fin de reconocer las áreas de mayor consumo y establecer prioridades en cuanto a los sitios de mayor oportunidad para el logro de ahorros energéticos.

Para la elaboración de los paretos de consumo de energía eléctrica por área y global se utilizaron datos arrojados por los 19 medidores que están instalados la Universidad.

\section{Pareto Usos significativos de energía eléctrica campus UAO}

Se evidenció que el aire acondicionado es el que mayor participación tiene en el consumo de energía eléctrica total con un porcentaje del $40 \%$ y un valor de $126.967 \mathrm{KWh} / \mathrm{mes}$; seguido con el $32 \%$ de los Computadores, impresoras y equipos de laboratorio UAO como lo muestran las figuras 95 y 96.

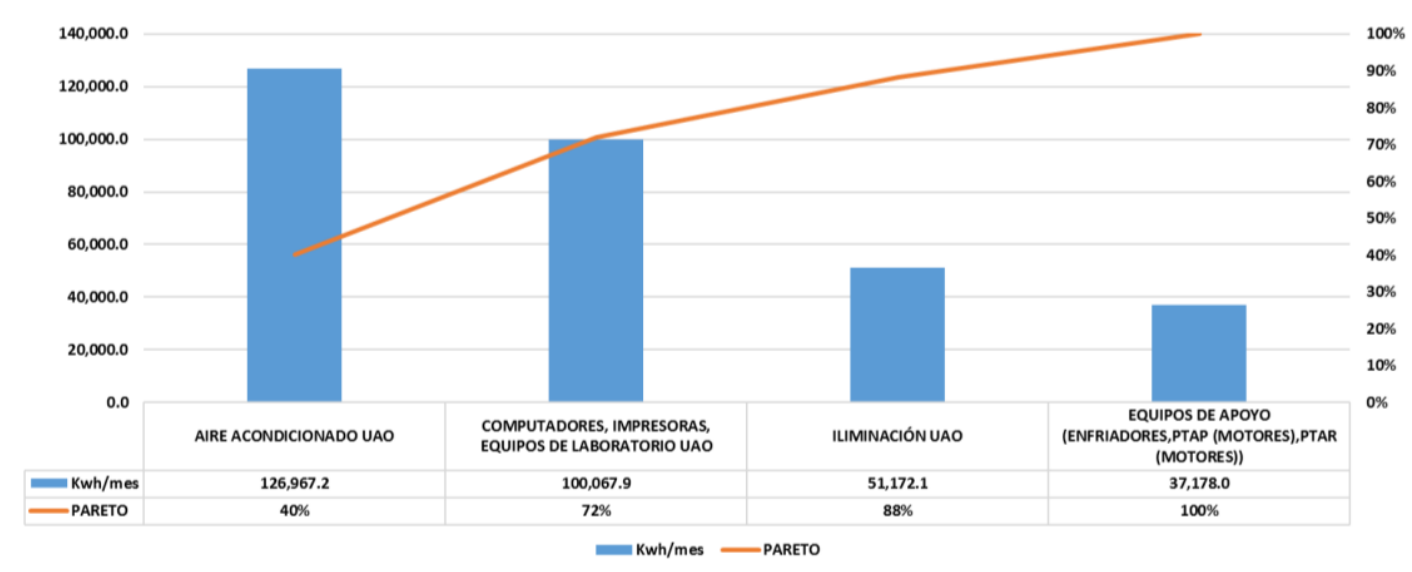

Figura 95. Pareto uso significativo de energía eléctrica UAO 


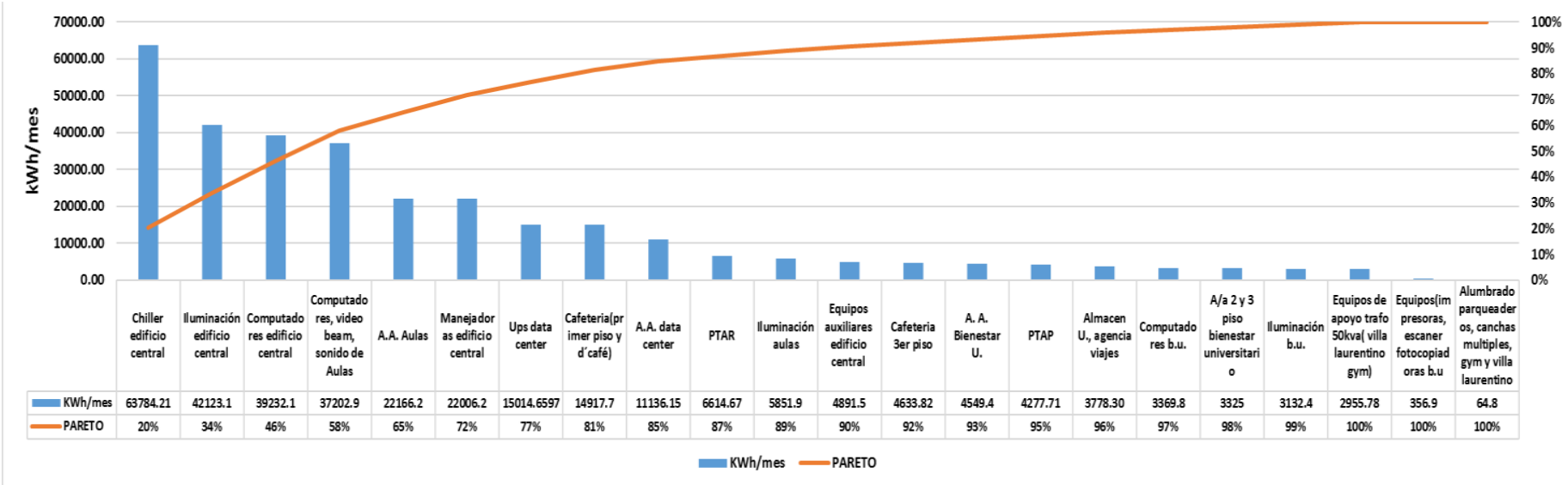

Figura 96. Pareto general de consumo de energía eléctrica UAO

Los equipos, sistemas y/o áreas que representan el $20 \%$ y tienen el $80 \%$ del consumo de energía eléctrica total son: el chiller del edificio central con un $20 \%$; iluminación edificio central con el $14 \%$; con el $12 \%$ están los computadores edificio central y computadores, videobeam y sistemas de sonidos de aulas; con el $7 \%$ se encuentran los aires acondicionado aulas y manejadores del edificio central; y con el $5 \%$ y $4 \%$ respetivamente está la UPS DATA CENTER y la cafetería primer piso y D'café como lo enseñan las figuras 97-102.

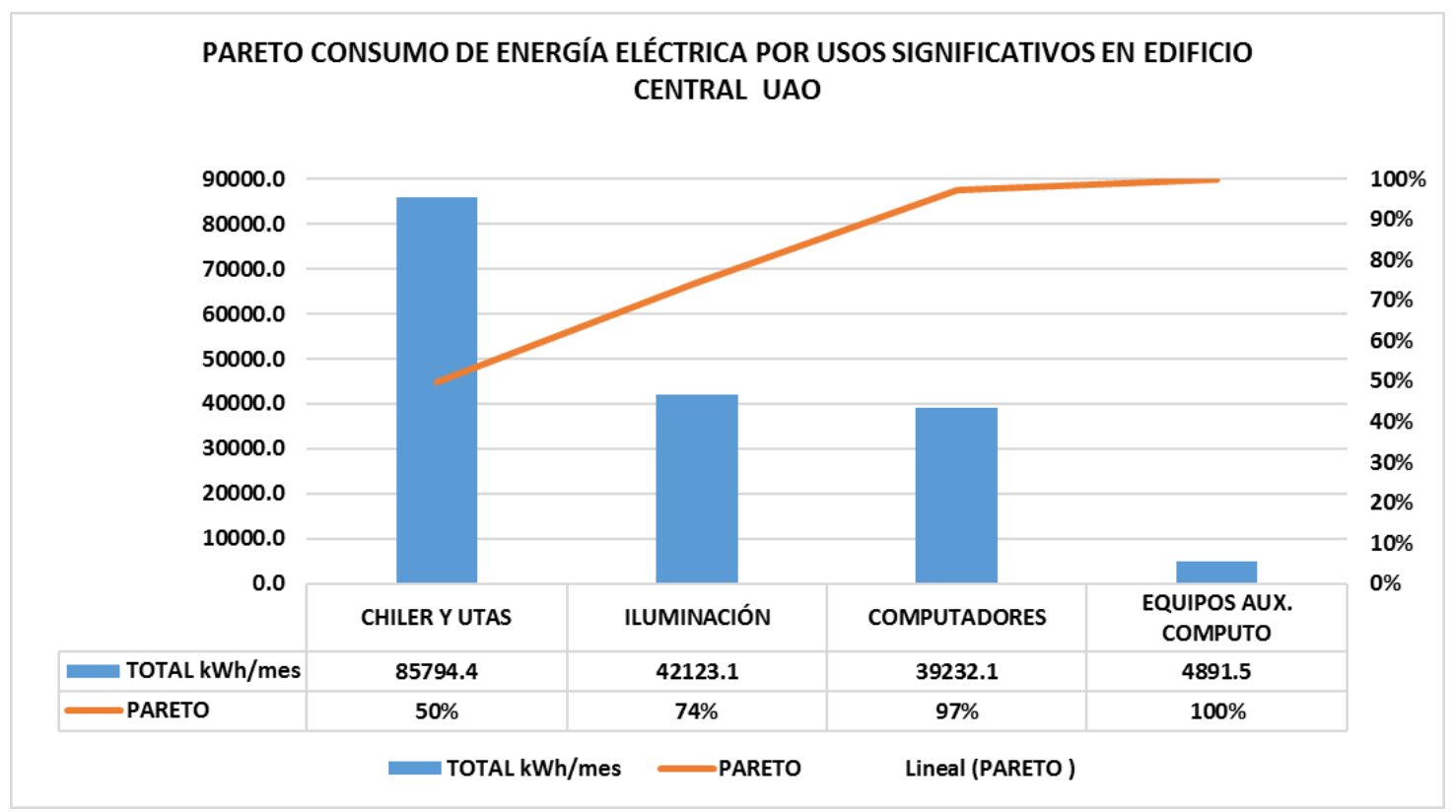

Figura 97. Pareto de consumo de energía eléctrica por usos significativos en edificio central UAO 


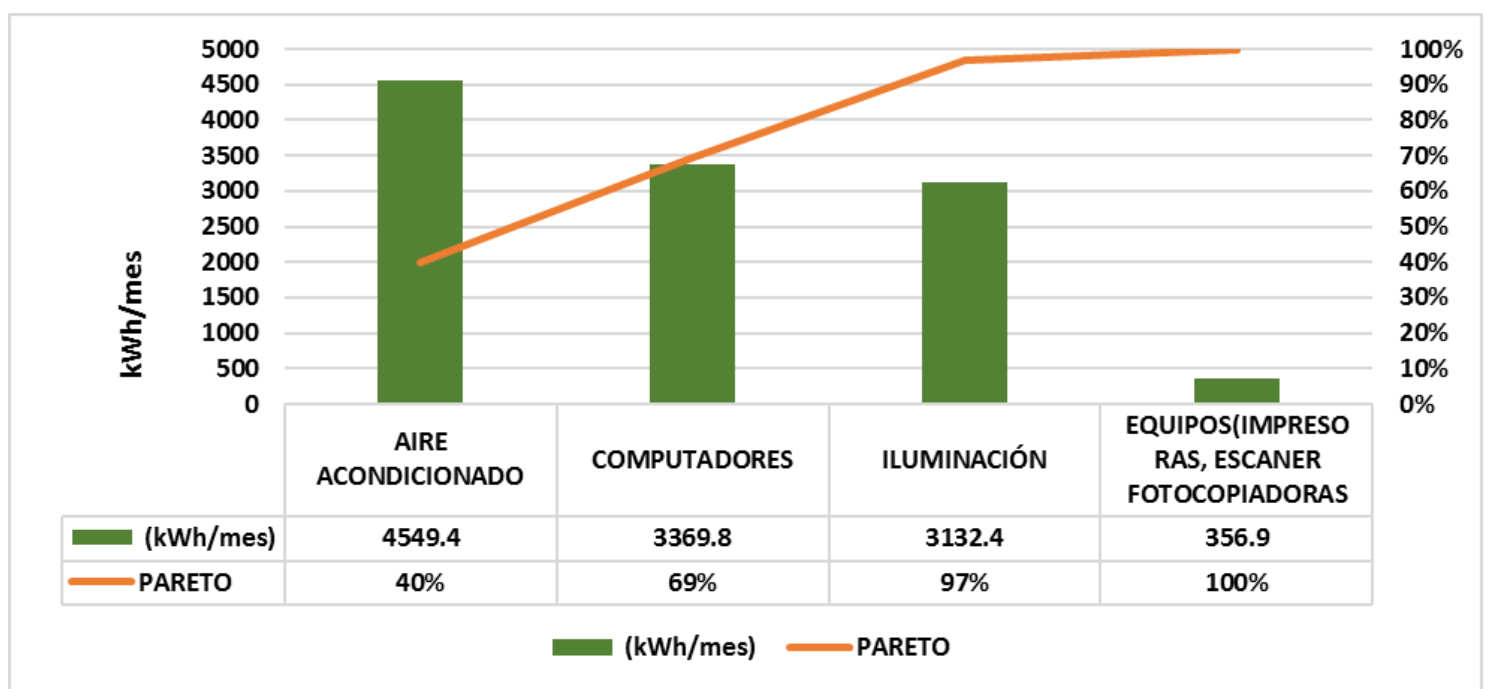

Figura 98. Pareto de consumo de energía eléctrica por usos significativos en bienestar universitario UAO

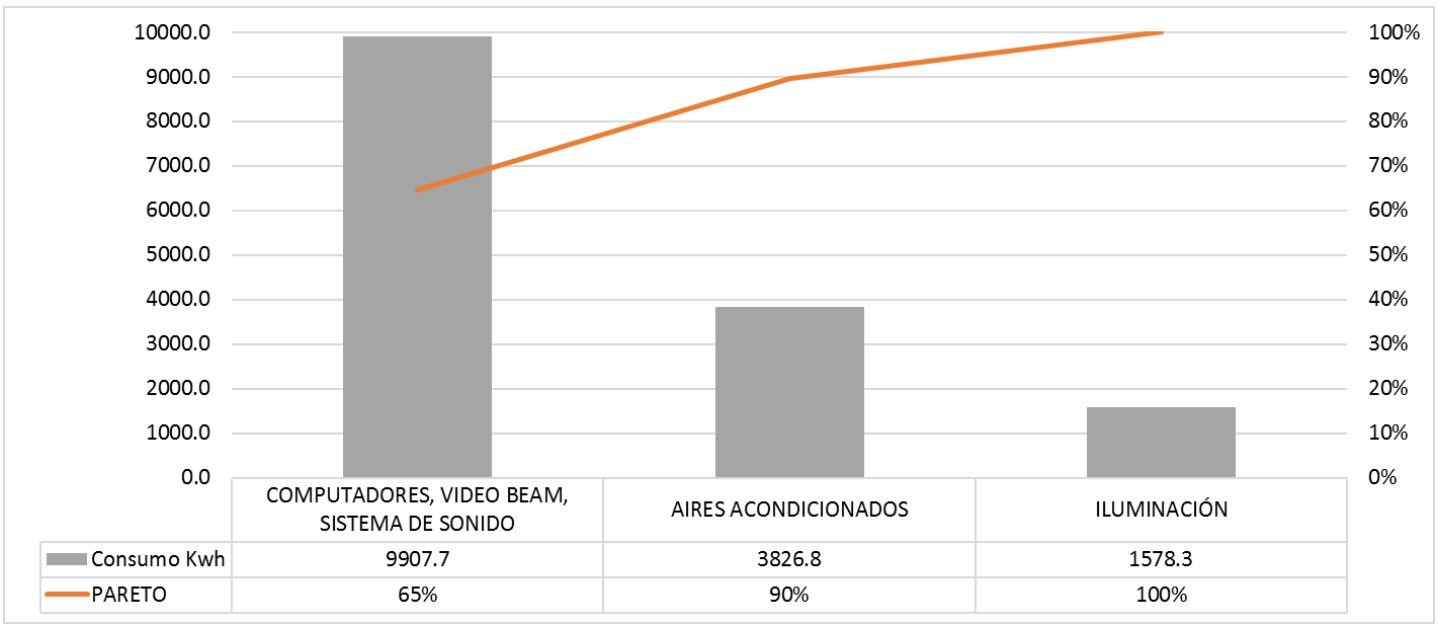

Figura 99. Pareto consumo de energía eléctrica por usos significativos aulas 1

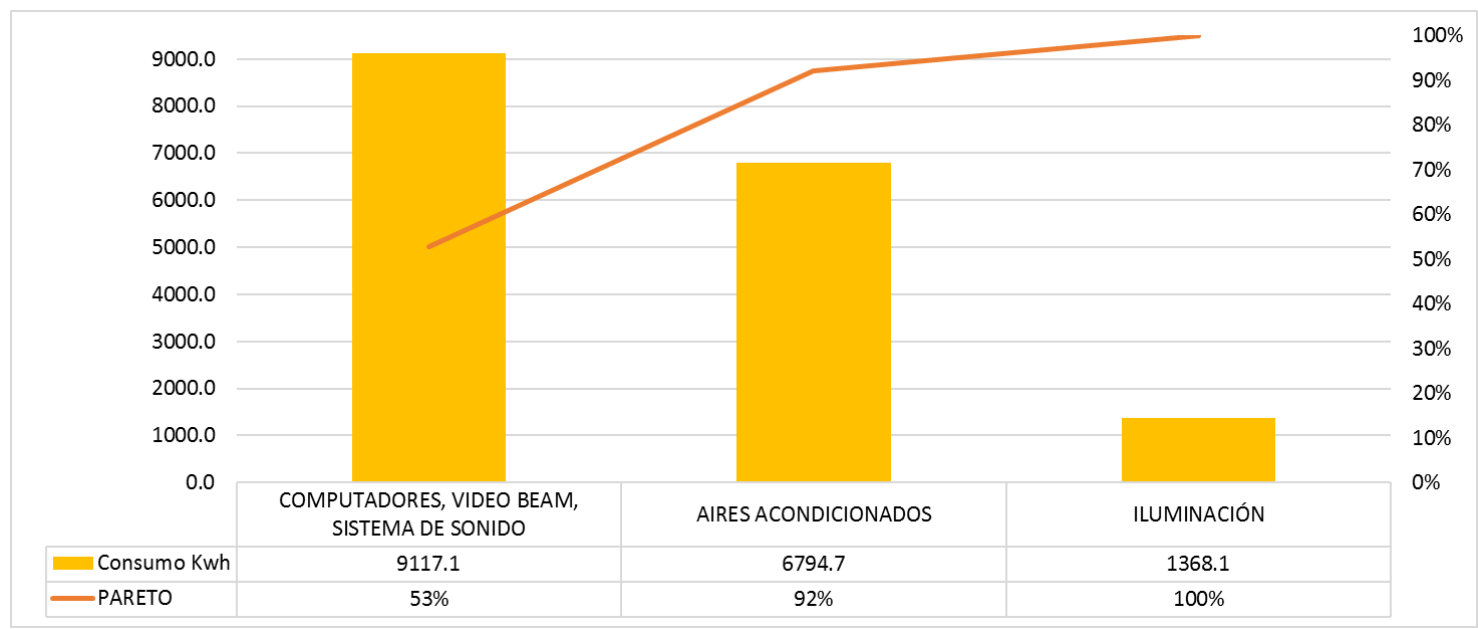

Figura 100. Pareto consumo de energía eléctrica por usos significativos aulas 2 


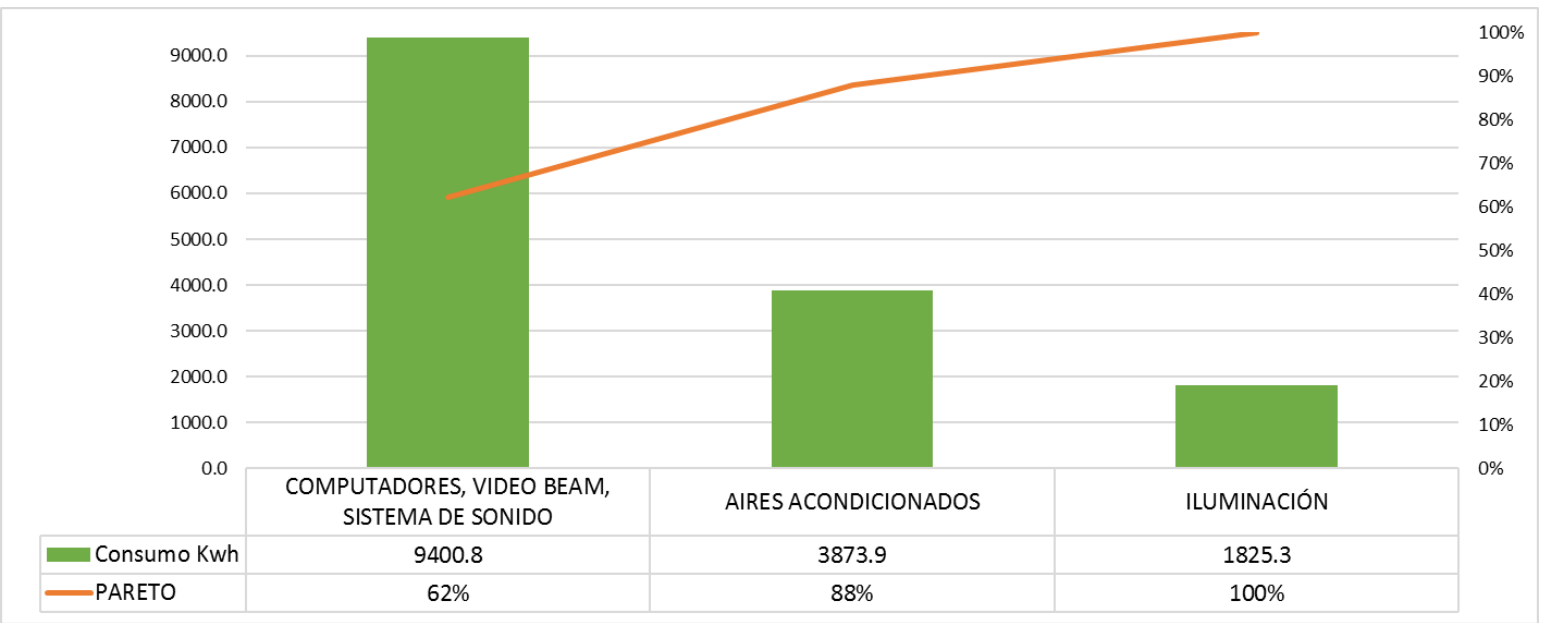

Figura 101. Pareto consumo de energía eléctrica por usos significativos aulas 3

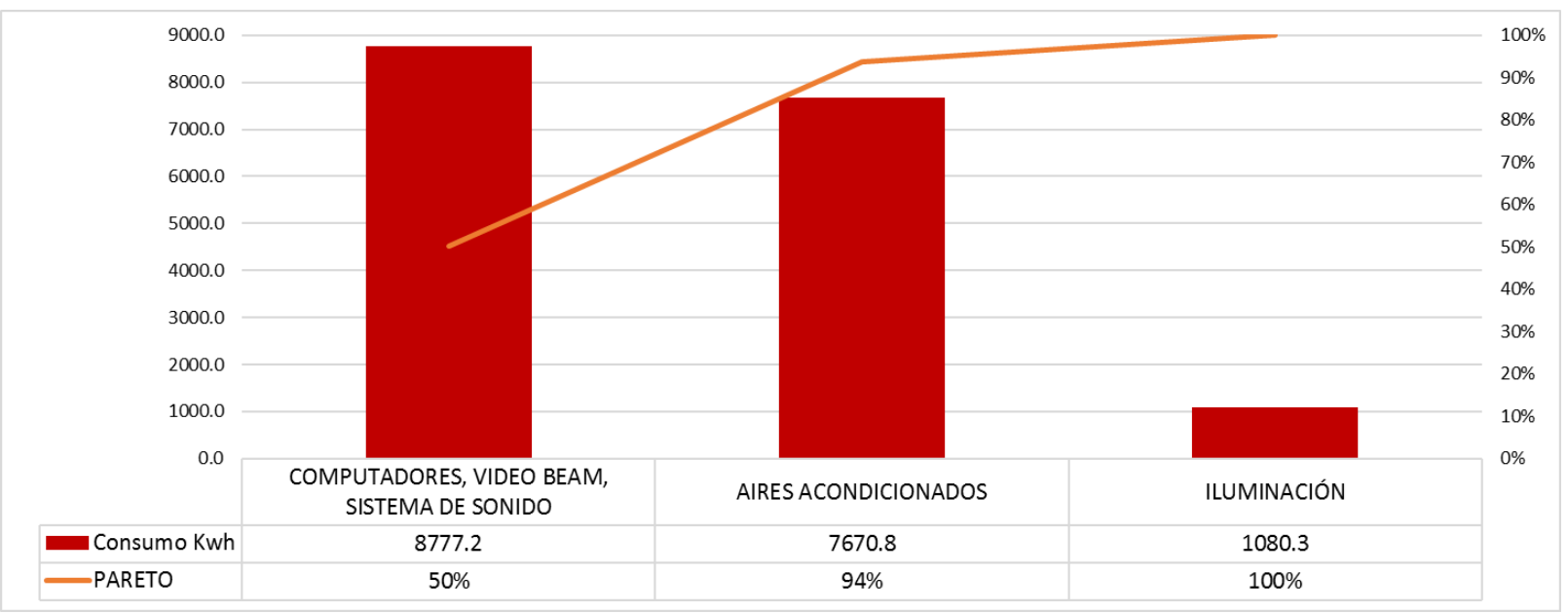

Figura 102. Pareto consumo de energía eléctrica por usos significativos aulas 4 


\section{CAPÍTULO 5: ANÁLISIS Y ESTUDIO ENERGÉTICO DEL EDIFICIO DE AULAS 4 DE LA UNIVERSIDAD AUTÓNOMA DE OCCIDENTE}

En este capítulo se realiza la simulación dinámica del edificio aulario 4 utilizando el software Design Builder y su motor de cálculo energy plus, con el propósito de conocer la situación energética del aulario y describir los aspectos de la eficiencia energética en la edificación, tanto en lo pasivo como activo. Lo anterior, teniendo en cuenta la calibración del modelo utilizando los datos de monitorización continúa del Sistema BMS instalado en la edificación. El campus cuenta con cuatro edificios dedicados a las labores de docencia en pregrado y posgrado, todas las aulas son similares. El edificio Aulario 4 es usado principalmente en actividades de tipo académicas y administrativas, el 68\% de los recintos del edificio (aulas y torreones) son usados para impartir clases de pregrado, posgrados y diversos eventos académicos. Su horario de funcionamiento es de 6:30 am a 9:30 pm de lunes a viernes y, de 7:30 am a 5:00 pm los sábados. Para el análisis energético se seleccionó este Aulario, dado que se tiene proyectado desde la administración hacer actualizaciones de tipo tecnológico.

En este sentido, la simulación energética se constituye en un aporte para evaluar los cambios proyectados, no solo desde medidas activas si no pasivas en aras de conseguir unas medidas de ahorro energético que contribuyan a optimizar la eficiencia, siendo extensivas a las demás edificaciones del campus.

\subsection{SITUACIÓN}

El edificio objeto de estudio energético es el correspondiente a aulas 4 de la Universidad Autónoma de Occidente de Cali, el cual se haya ubicado en el extremo noroeste ubicado en la longitud 3,354149, con latitud $-76,520925$ como puede observarse en la Figura 103, la Figura 104 presenta la localización del edificio de Aulas 4 dentro del campus.

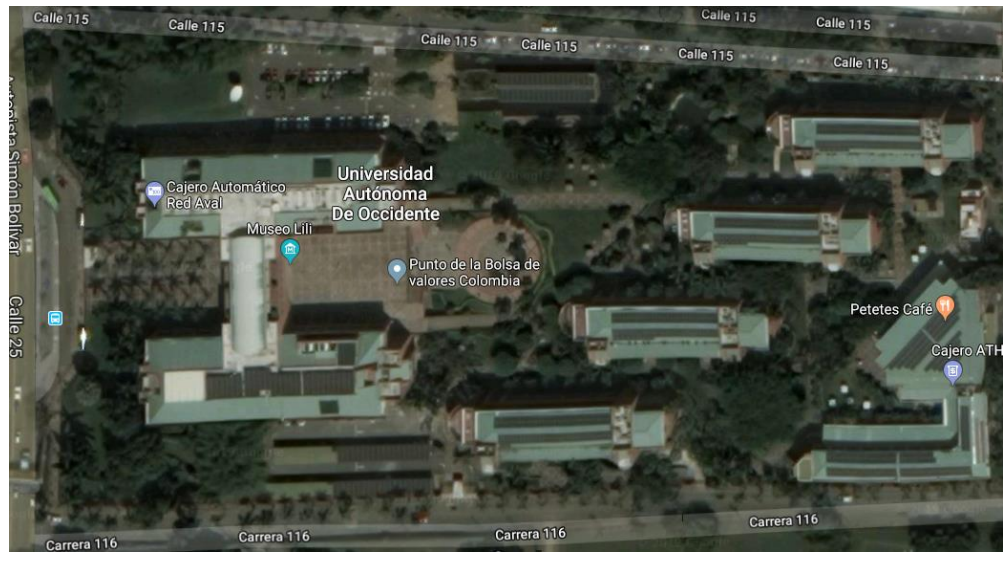

Figura 103. Ubicación Campus Universitario Universidad Autónoma de Occidente Fuente: Google Maps 


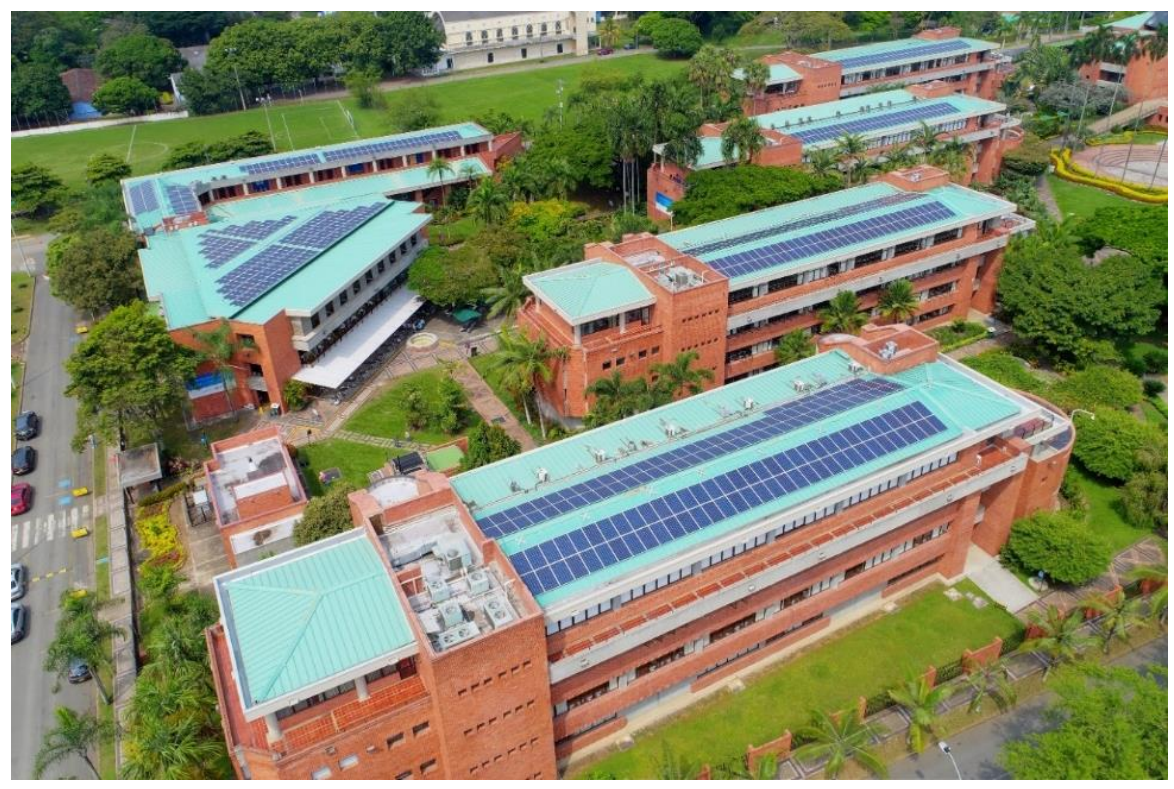

Figura 104. Localización del edificio de aulas 4

\subsection{DESCRIPCIÓN GENERAL Y USO}

El edificio es usado principalmente en actividades de tipo académicas y administrativas, el $68 \%$ de los recintos del edificio (aulas y torreones) son usados para impartir clases de pregrado, posgrados y diversos eventos académicos. Su horario de funcionamiento es de 6:30 am a 9:30 pm de lunes a viernes y, de 7:30 am a 5:00 pm los sábados.

El edificio cuenta con cuatro pisos, en el primer piso existen 3 torreones (aclimatados), dos baños y la oficina de egresados (aclimatada), el segundo piso se compone de 6 aulas, la oficina de TIC (aclimatada), 2 baños y un torreón (aclimatado), el tercer piso alberga la oficina de planta física (aclimatada), 6 aulas, 2 baños y un torreón (aclimatado) y el cuarto piso consta de una oficina (aclimatada), 10 aulas (aclimatadas), 2 baños y un torreón (aclimatado).

A continuación, se adjuntan algunas fotografías de la morfología del edificio (figuras 105 109). 


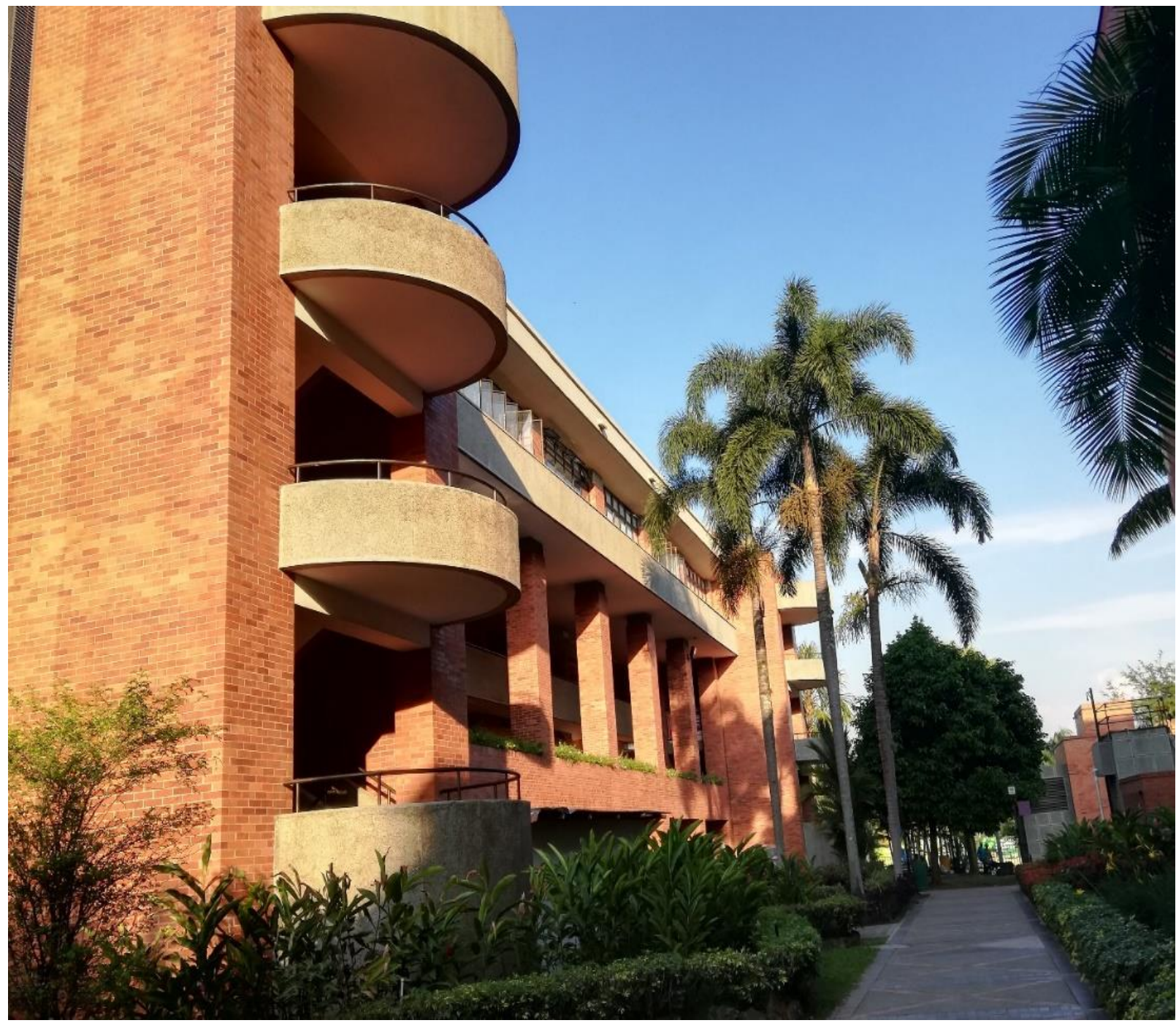

Figura 105. Fachada este del edificio de aulas 4. 


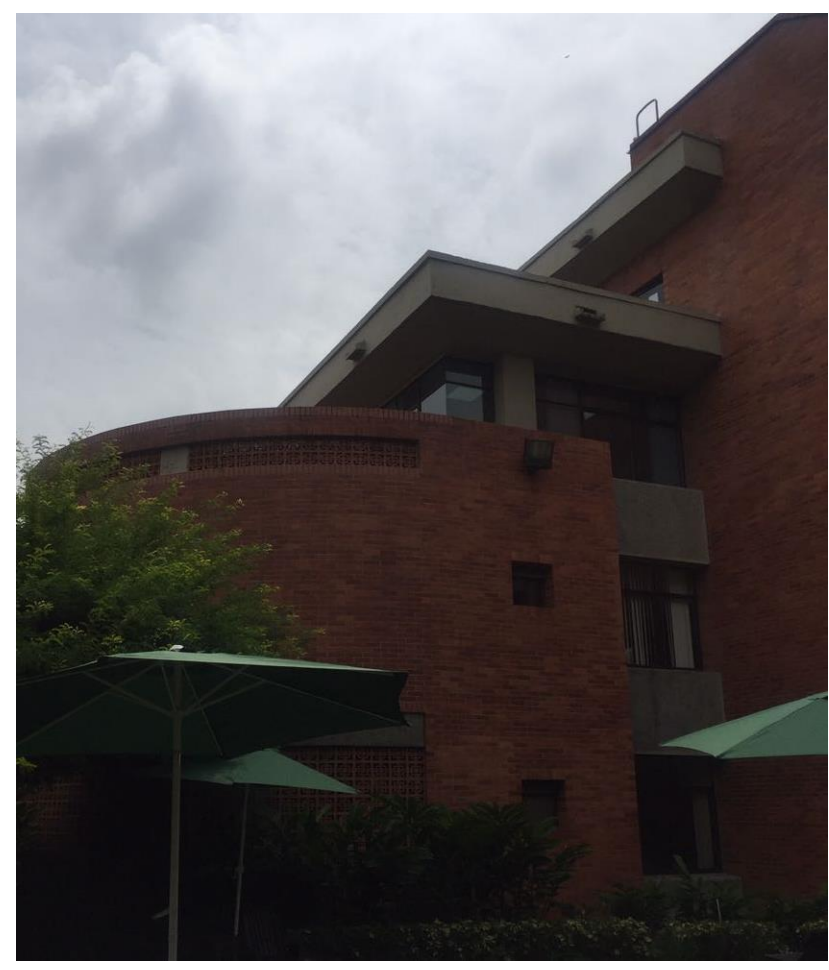

Figura 106. Fachada sureste del edificio de aulas 4.

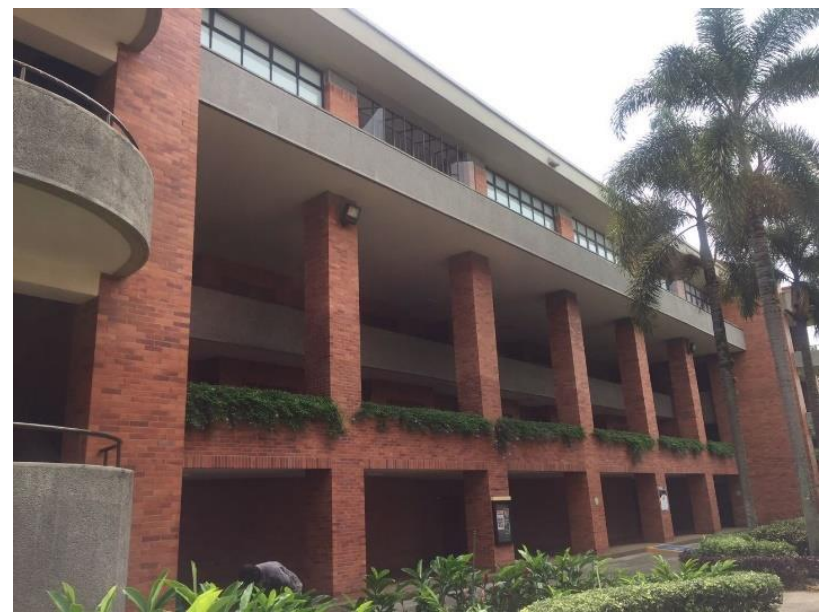

Figura 108. Fachada sur del edificio de aulas 4.

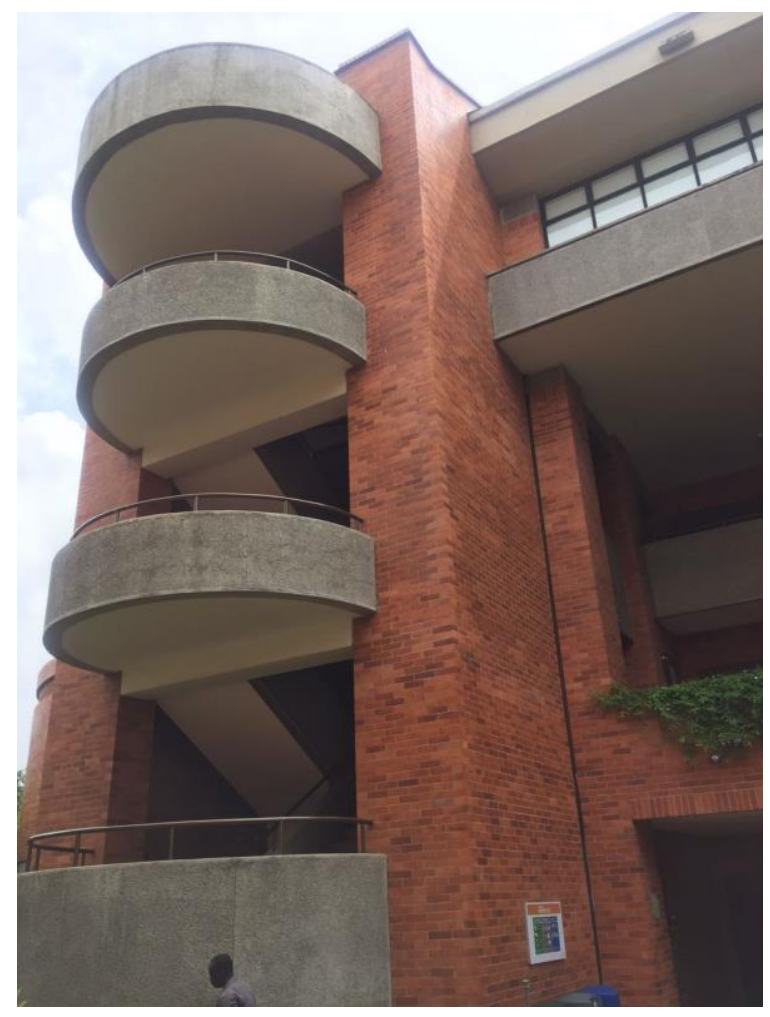

Figura 107. Fachada escaleras del edificio.

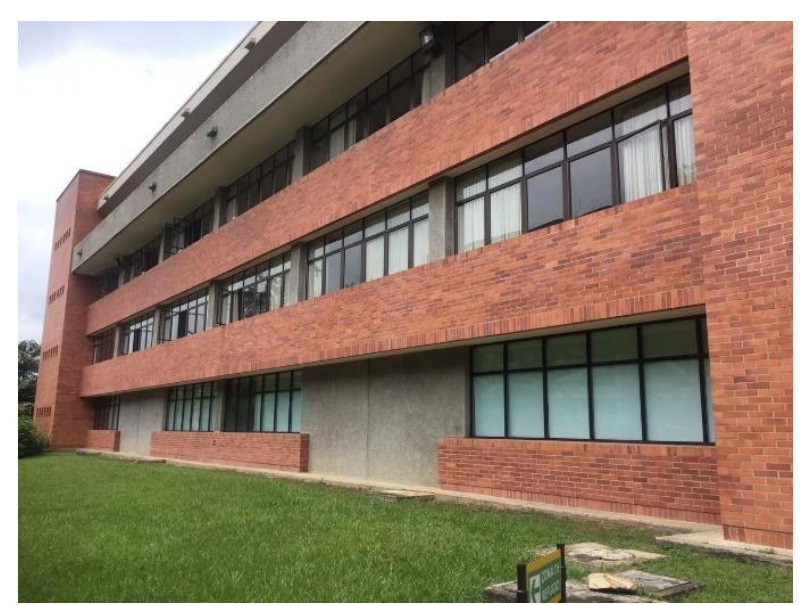

Figura 109. Fachada norte del edificio de aulas 4. 


\subsection{DISTRIBUCIÓN}

El edificio consta de cuatro pisos, en la Tabla 33 se expresan las áreas ocupadas por cada piso y su altura:

Tabla 33. Superficies por pisos.

\begin{tabular}{|c|c|c|}
\hline Piso & Superficie $\left.\mathbf{( m}^{\mathbf{2}}\right)$ & Altura $\mathbf{( m )}$ \\
\hline $\mathbf{1}$ & 878,95 & 2,6 \\
\hline $\mathbf{2}$ & 869,71 & 2,6 \\
\hline $\mathbf{3}$ & 690,74 & 2,6 \\
\hline $\mathbf{4}$ & 648,45 & 2,6 \\
\hline Total & 3087,85 & 2,6 \\
\hline
\end{tabular}

En la Figura 110 y la Tabla 34, se describe el primer piso (planta baja del edificio) que se Compone de $848,29 \mathrm{~m}^{2}$.

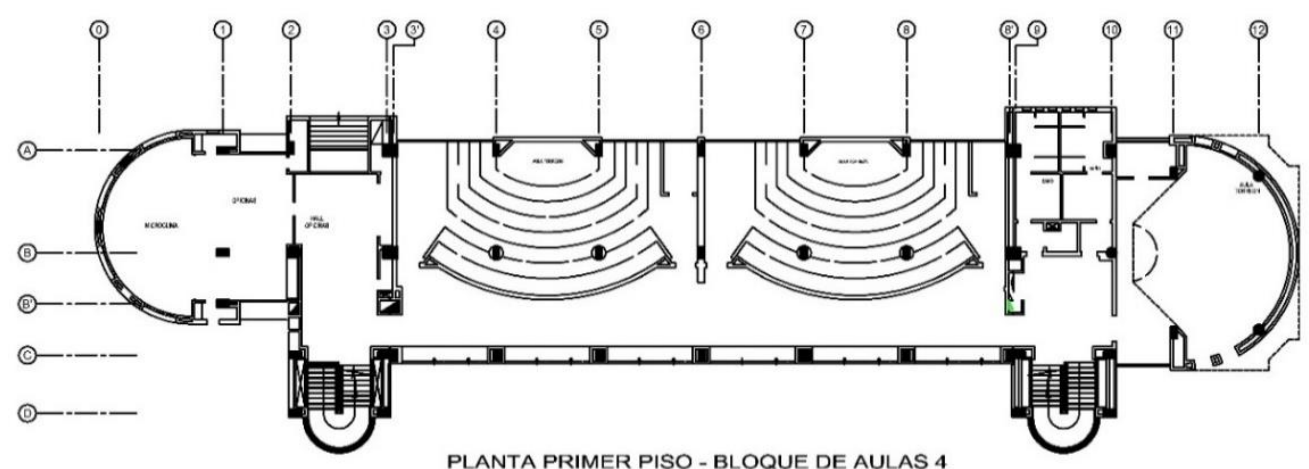

Figura 110. Primer piso.

Tabla 34. Superficies piso 1.

\begin{tabular}{|c|c|}
\hline Recinto & Superficie $\mathbf{( m}^{\mathbf{2}} \mathbf{~}$ \\
\hline Registro académico & 96,55 \\
\hline A4t1 & 111,16 \\
\hline A4T1A & 136,61 \\
\hline A4T1B & 136,59 \\
\hline Baño mujeres p1 & 26,98 \\
\hline Baño hombres p1 & 23,63 \\
\hline Pasillo sur p1 & 158,03 \\
\hline Pasillo este p1 & 40,11 \\
\hline Pasillo oeste p1 & 73,49 \\
\hline Cm. A4T1 & 8,17 \\
\hline Cm. A4T1A & 6,09 \\
\hline Cm. A4T1B & 5,51 \\
\hline Escalera este p1 & 10,71 \\
\hline Escalera oeste p1 & 23,52 \\
\hline Baño mujeres r.a. & 2,83 \\
\hline Baño hombres r.a. & 2,94 \\
\hline
\end{tabular}




\begin{tabular}{|c|c|}
\hline Cuarto técnico $\mathbf{p 1}$ & 3,52 \\
\hline Cuarto multimedios & 12,51 \\
\hline Total & $\mathbf{8 7 8 , 9 5}$ \\
\hline
\end{tabular}

En la Figura 111 y la Tabla 35 , se describe el segundo piso (planta primera del edificio) que se compone de $874,90 \mathrm{~m}^{2}$.

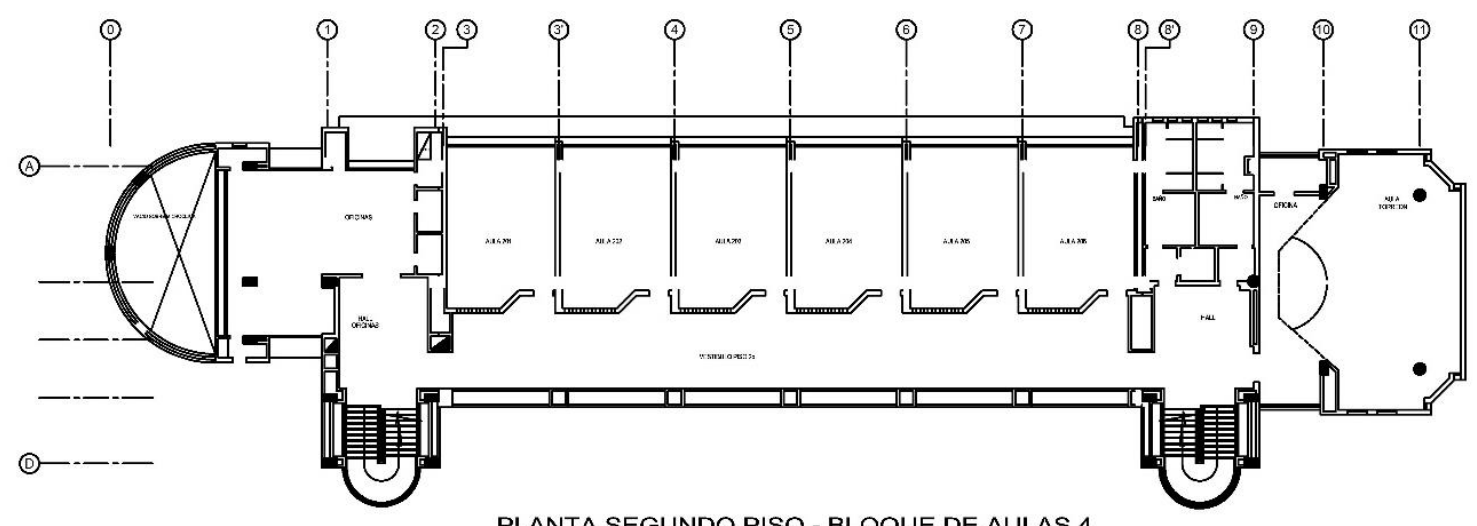

PLANTA SEGUNDO PISO - BLOQUE DE AULAS 4

Figura 111. Segundo piso.

Tabla 35. Superficies piso 2.

\begin{tabular}{|c|c|}
\hline Recinto & Superficie $\left(m^{2}\right)$ \\
\hline TIC norte & 123,88 \\
\hline 4201 & 45,55 \\
\hline 4202 & 46,94 \\
\hline 4203 & 46,94 \\
\hline 4204 & 46,94 \\
\hline 4205 & 47,08 \\
\hline 4206 & 42,85 \\
\hline A4T2 & 126,88 \\
\hline Baño mujeres p2 & 26,97 \\
\hline Baño hombres p2 & 23,63 \\
\hline Pasillo sur p2 & 178,13 \\
\hline Pasillo este p2 & 40,13 \\
\hline Pasillo oeste p2 & 37,61 \\
\hline Cm. A4T2 & 7,98 \\
\hline C. T. TIC 1 & 2,89 \\
\hline C. T. Tic 2 & 3,46 \\
\hline C. T. Tic 3 & 1,49 \\
\hline Escalera este p2 & 12,8 \\
\hline Escalera oeste p2 & 0,03 \\
\hline Baño mujeres TIC & 2,16 \\
\hline Baño hombres TIC & 2,26 \\
\hline Baño auxiliar TIC & 3,11 \\
\hline Total & 869,71 \\
\hline
\end{tabular}


En la Figura 112 y la Tabla 36, se describe el tercer piso (planta segunda del edificio) que se compone de $694,25 \mathrm{~m}^{2}$.

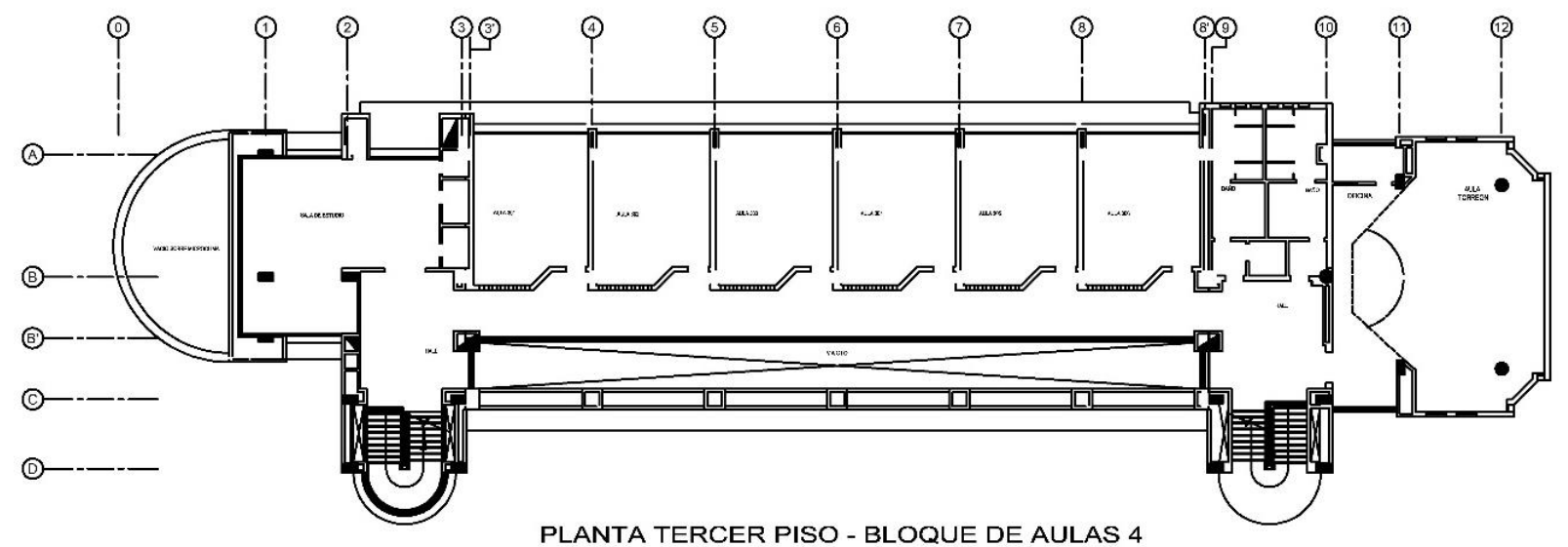

Figura 112. Tercer piso.

Tabla 36. Superficies piso 3.

\begin{tabular}{|c|c|}
\hline Recinto & Superficie $\mathbf{( m}^{\mathbf{2}} \mathbf{~}$ \\
\hline Planta Física & 68,68 \\
\hline $\mathbf{4 3 0 1}$ & 40,77 \\
\hline $\mathbf{4 3 0 2}$ & 40,98 \\
\hline $\mathbf{4 3 0 3}$ & 40,99 \\
\hline $\mathbf{4 3 0 4}$ & 40,99 \\
\hline $\mathbf{4 3 0 5}$ & 41,33 \\
\hline $\mathbf{4 3 0 6}$ & 37,45 \\
\hline A4T3 & 126,88 \\
\hline Baño mujeres p3 & 27 \\
\hline Baño hombres p3 & 23,63 \\
\hline Pasillo sur p3 & 91,65 \\
\hline Pasillo este p3 & 40,19 \\
\hline Pasillo oeste p3 & 37,69 \\
\hline Cm. A4t3 & 7,98 \\
\hline C. T. Planta física 1 & 2,89 \\
\hline C. T. Planta física 2 & 3,46 \\
\hline C. T. Planta física 3 & 1,49 \\
\hline Escalera este p3 & 0,04 \\
\hline Escalera oeste p3 & 0,02 \\
\hline Baño auxiliar planta fi & 3,11 \\
\hline Vacío p3 & 13,52 \\
\hline Total & 690,74 \\
\hline
\end{tabular}

En la Figura 113 y la Tabla 37, se describe el cuarto piso (planta tercera del edificio) que se compone de $634,49 \mathrm{~m}^{2}$. 


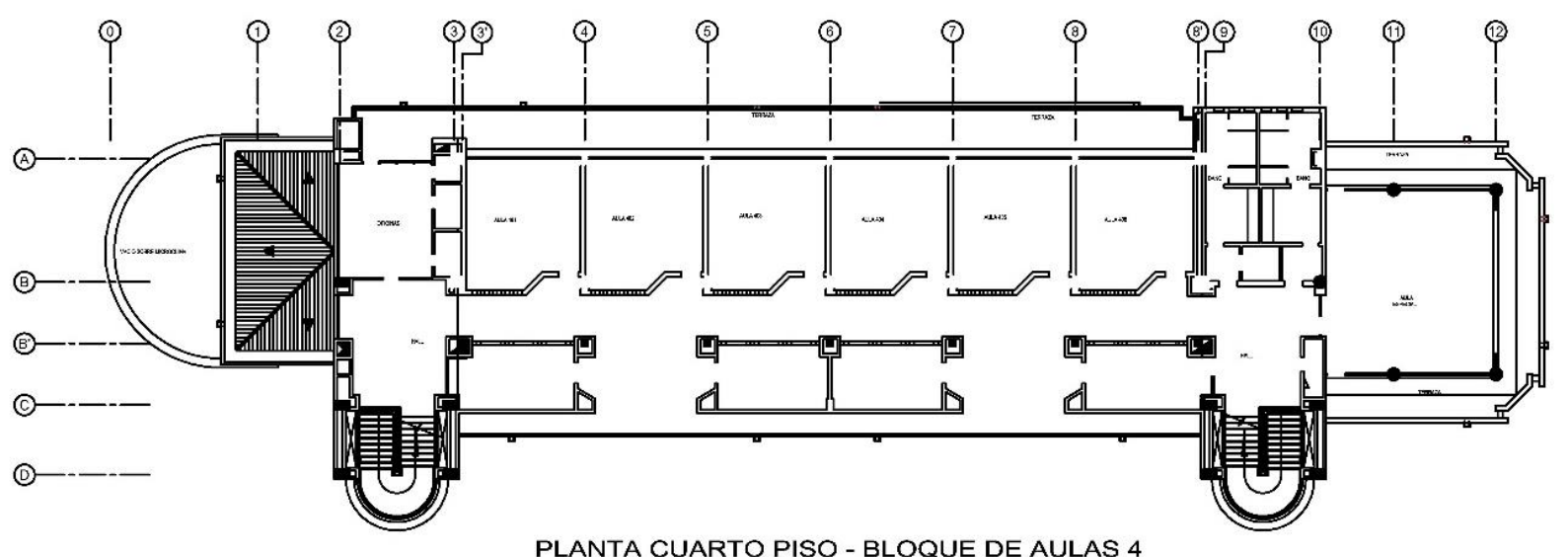

PLANTA CUARTO PISO - BLOQUE DE AULAS 4

Figura 113. Cuarto piso.

Tabla 37. Superficies piso 4.

\begin{tabular}{|c|c|}
\hline Recinto & Superficie $\mathbf{( m}^{\mathbf{2}} \mathbf{~}$ \\
\hline Salón vacío & 25,39 \\
\hline $\mathbf{4 4 0 1}$ & 34,93 \\
\hline $\mathbf{4 4 0 2}$ & 35,09 \\
\hline $\mathbf{4 4 0 3}$ & 35,1 \\
\hline $\mathbf{4 4 0 4}$ & 35,1 \\
\hline $\mathbf{4 4 0 5}$ & 35,39 \\
\hline $\mathbf{4 4 0 6}$ & 32,1 \\
\hline $\mathbf{4 4 0 7}$ & 15,6 \\
\hline $\mathbf{4 4 0 8}$ & 17,07 \\
\hline $\mathbf{4 4 0 9}$ & 17,07 \\
\hline $\mathbf{4 4 1 0}$ & 16,61 \\
\hline A4T4 & 75,97 \\
\hline Baño mujeres p4 & 27,01 \\
\hline Baño hombres p4 & 23,65 \\
\hline Pasillo sur p4 & 134,97 \\
\hline Pasillo este p4 & 39,9 \\
\hline Pasillo oeste p4 & 38,6 \\
\hline C. T. Salón vacío 1 & 3,22 \\
\hline C. T. Salón vacío 2 & 2,22 \\
\hline C. T. Salón vacío 3 & 0,27 \\
\hline Escalera este p4 & 0,06 \\
\hline Escalera oeste p4 & 0,02 \\
\hline Baño salón vacío & 3,11 \\
\hline Total & $\mathbf{6 4 8 , 4 5}$ \\
\hline
\end{tabular}




\subsection{MATERIALES}

En la Tabla 38, se describen los materiales que componen el edificio, registrando sus espesores y en orden descendente, desde la cara más externa a la más interna, con ello se tiene que los cerramientos y particiones se hayan compuestos de la siguiente manera:

Tabla 38. Materiales de construcción de los espacios del Edificio

\begin{tabular}{|c|c|c|c|}
\hline Espacio & Capas & Espesor $(\mathrm{cm})$ & $U(W / m 2-K)$ \\
\hline \multirow{4}{*}{ Fachadas } & Ladrillo interior & 13 & \multirow{4}{*}{1,636} \\
\hline & Concreto fundido & 2 & \\
\hline & Ladrillo interior & 13 & \\
\hline & Mortero & 0,3 & \\
\hline \multirow{2}{*}{ Oficinas } & Ladrillo interior & 13 & \multirow[t]{2}{*}{2,605} \\
\hline & Mortero & 0,3 & \\
\hline \multirow{3}{*}{ Torreones } & Concreto fundido & 2 & \multirow{3}{*}{2,490} \\
\hline & Ladrillo interior & 13 & \\
\hline & Mortero & 0,3 & \\
\hline \multirow{3}{*}{ Balcones } & Concreto fundido & 2 & \multirow{3}{*}{2,409} \\
\hline & Ladrillo interior & 13 & \\
\hline & Cemento & 2 & \\
\hline \multirow{3}{*}{ Baños } & Ladrillo interior & 13 & \multirow{3}{*}{2,579} \\
\hline & Mortero & 0,3 & \\
\hline & Cerámica & 0,5 & \\
\hline \multirow{2}{*}{ Salones } & Ladrillo interior & 13 & \multirow[t]{2}{*}{2,605} \\
\hline & Mortero & 0,3 & \\
\hline Pasillos & Ladrillo interior & 13 & 2,634 \\
\hline
\end{tabular}

La Tabla 39 muestra las características de las ventanas del edificio, estas son todas del mismo tipo con dimensiones de acuerdo con cada abertura.

Tabla 39. Características acristalamientos edificio.

\begin{tabular}{|c|c|c|}
\hline \multicolumn{2}{|c|}{ Características } & U (W/M2-K) \\
\hline Acristalamiento & Simple de $3 \mathrm{~mm}$ & \multirow{2}{*}{3,835} \\
\hline Marco & Metálico & \\
\hline Cemento & 0,5 & \\
\hline
\end{tabular}




\subsection{OCUPACIÓN}

Se dimensiona la ocupación de cada recinto de acuerdo con la cantidad de ocupantes por metro cuadrado, obteniendo los resultados presentados en la Tabla 40.

Tabla 40. Ocupación del Edificio.

\begin{tabular}{|c|c|c|c|c|}
\hline Piso & Recinto & $\begin{array}{l}\text { Área de suelo } \\
\left(\mathrm{m}^{2}\right)\end{array}$ & $\begin{array}{c}\text { Cant. } \\
\text { Personas }\end{array}$ & $\begin{array}{c}\text { Densidad de } \\
\text { ocupación }\left(\mathrm{per} / \mathrm{m}^{2}\right)\end{array}$ \\
\hline \multirow{12}{*}{$\begin{array}{l}\text { Primer piso - } \\
\text { planta baja }\end{array}$} & A4T1A & 136,61 & 35 & 0,2525 \\
\hline & A4T1B & 136,59 & 35 & 0,2526 \\
\hline & A4T1 & 111,16 & 24 & 0,2151 \\
\hline & Escalera este $\mathrm{p} 1$ & 10,71 & 2 & 0,1681 \\
\hline & Multimedios & 12,51 & 1 & 0,0480 \\
\hline & Escalera oeste p1 & 23,52 & 2 & 0,0765 \\
\hline & Baño hombres p1 & 23,63 & 2 & 0,0762 \\
\hline & Baño mujeres p1 & 26,98 & 2 & 0,0667 \\
\hline & Pasillo este p1 & 40,11 & 2 & 0,0449 \\
\hline & Pasillo oeste p1 & 73,49 & 2 & 0,0245 \\
\hline & Pasillo sur p1 & 158,03 & 3 & 0,0190 \\
\hline & Registro & 96,55 & 6 & 0,0622 \\
\hline \multirow{15}{*}{$\begin{array}{c}\text { Segundo piso } \\
\text { - planta } \\
\text { primera }\end{array}$} & Aula 4201 & 45,55 & 24 & 0,5269 \\
\hline & Aula 4202 & 46,94 & 24 & 0,5113 \\
\hline & Aula 4203 & 46,94 & 24 & 0,5113 \\
\hline & Aula 4204 & 46,94 & 24 & 0,5113 \\
\hline & Aula 4205 & 47,08 & 24 & 0,5098 \\
\hline & Aula 4206 & 42,85 & 24 & 0,5601 \\
\hline & A4T2 & 126,88 & 27 & 0,2129 \\
\hline & Escalera este p2 & 12,80 & 2 & 0,1406 \\
\hline & Escalera oeste p2 & 0,03 & 2 & 60,0000 \\
\hline & Baño hombres p2 & 23,63 & 2 & 0,0762 \\
\hline & Baño mujeres p2 & 26,97 & 2 & 0,0667 \\
\hline & Pasillo este $\mathrm{p} 2$ & 40,13 & 2 & 0,0449 \\
\hline & Pasillo oeste p2 & 37,61 & 2 & 0,0479 \\
\hline & Pasillo sur p2 & 178,13 & 3 & 0,0168 \\
\hline & $\mathrm{TIC}$ & 144,74 & 23 & 0,159 \\
\hline \multirow{11}{*}{$\begin{array}{c}\text { Tercer piso- } \\
\text { planta } \\
\text { segunda }\end{array}$} & Aula 4301 & 40,77 & 21 & 0,5223 \\
\hline & Aula 4302 & 40,98 & 21 & 0,5124 \\
\hline & Aula 4303 & 40,99 & 21 & 0,5123 \\
\hline & Aula 4304 & 40,99 & 21 & 0,5123 \\
\hline & Aula 4305 & 41,33 & 21 & 0,5081 \\
\hline & Aula 4306 & 37,45 & 21 & 0,5607 \\
\hline & A4T3 & 126,88 & 27 & 0,2129 \\
\hline & Escalera este $\mathrm{p} 3$ & 0,04 & 2 & 45,0000 \\
\hline & Escalera oeste p3 & 0,02 & 2 & 90,0000 \\
\hline & Baño hombres p3 & 23,63 & 2 & 0,0762 \\
\hline & Baño mujeres p3 & 27,00 & 2 & 0,0667 \\
\hline
\end{tabular}



OCCIDENTE

\begin{tabular}{|c|c|c|c|c|}
\hline & Pasillo este $\mathrm{p3}$ & 40,19 & 2 & 0,0448 \\
\hline & Pasillo oeste p3 & 37,69 & 2 & 0,0478 \\
\hline & Pasillo sur p3 & 91,65 & 3 & 0,0327 \\
\hline & Planta física & 68,68 & 4 & 0,0524 \\
\hline & Vacío p3 & 13,52 & 0 & 0,0000 \\
\hline \multirow{19}{*}{$\begin{array}{l}\text { Cuarto piso - } \\
\text { planta tercera }\end{array}$} & Aula 4401 & 34,93 & 14 & 0,4123 \\
\hline & Aula 4402 & 35,09 & 14 & 0,4104 \\
\hline & Aula 4403 & 35,10 & 14 & 0,4103 \\
\hline & Aula 4404 & 35,10 & 14 & 0,4103 \\
\hline & Aula 4405 & 35,39 & 14 & 0,4069 \\
\hline & Aula 4406 & 32,10 & 14 & 0,4486 \\
\hline & Aula 4407 & 15,60 & 6 & 0,3846 \\
\hline & Aula 4408 & 17,07 & 6 & 0,3515 \\
\hline & Aula 4409 & 17,07 & 6 & 0,3515 \\
\hline & Aula 4410 & 16,61 & 6 & 0,3612 \\
\hline & A4T4 & 75,97 & 8 & 0,1028 \\
\hline & Escalera este p4 & 0,06 & 2 & 30,0000 \\
\hline & Escalera oeste p4 & 0,02 & 2 & 90,0000 \\
\hline & Baño hombres p4 & 23,65 & 2 & 0,0761 \\
\hline & Baño mujeres p4 & 27,01 & 2 & 0,0666 \\
\hline & Pasillo este $\mathrm{p} 4$ & 39,90 & 2 & 0,0451 \\
\hline & Pasillo oeste p4 & 38,60 & 2 & 0,0466 \\
\hline & Pasillo sur p4 & 134,97 & 3 & 0,0222 \\
\hline & Salón vacío & 25,39 & 0 & 0,0000 \\
\hline
\end{tabular}

\subsection{CONDICIONES DE DISEÑO EXTERIORES E INTERIORES}

Para realizar el estudio energético, se tuvo en cuenta las condiciones climáticas de diseño interior y exterior del edificio de acuerdo a su ubicación geográfica, dicha información es arrojada por el software con respecto a los datos climáticos cargado por el programa de simulación dinámica Design Builder y su motor de cálculo Energy Plus, como lo presenta la Figura 114.

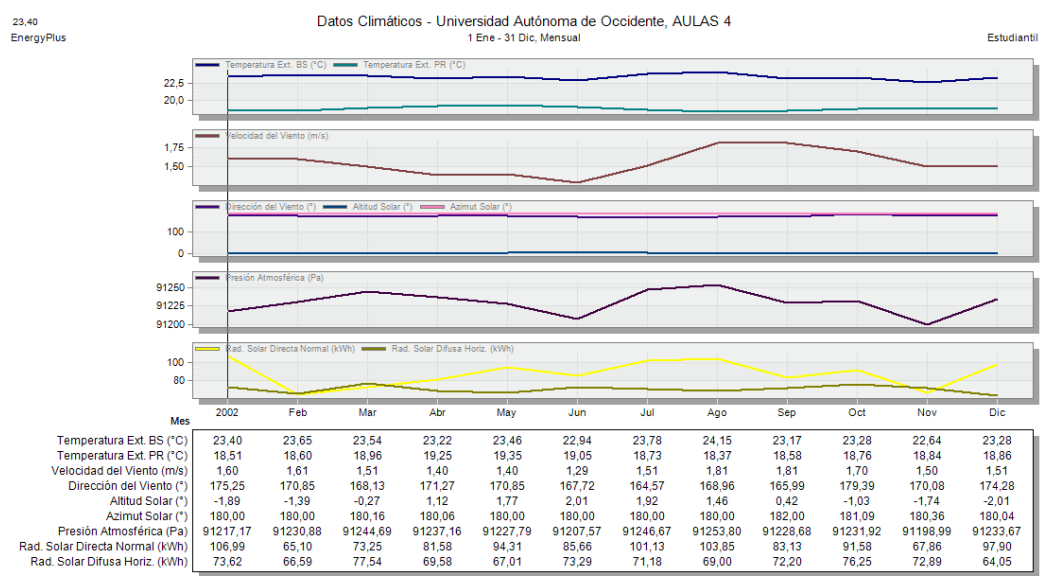

Figura 114. Condiciones de diseño exteriores anuales. 
Las figuras 115 y 116, presentan los parámetros de control del confort para el edificio, en los cuales se tuvo en cuenta la humedad relativa y la temperatura del aire interior, a través del programa de simulación Design Builder.

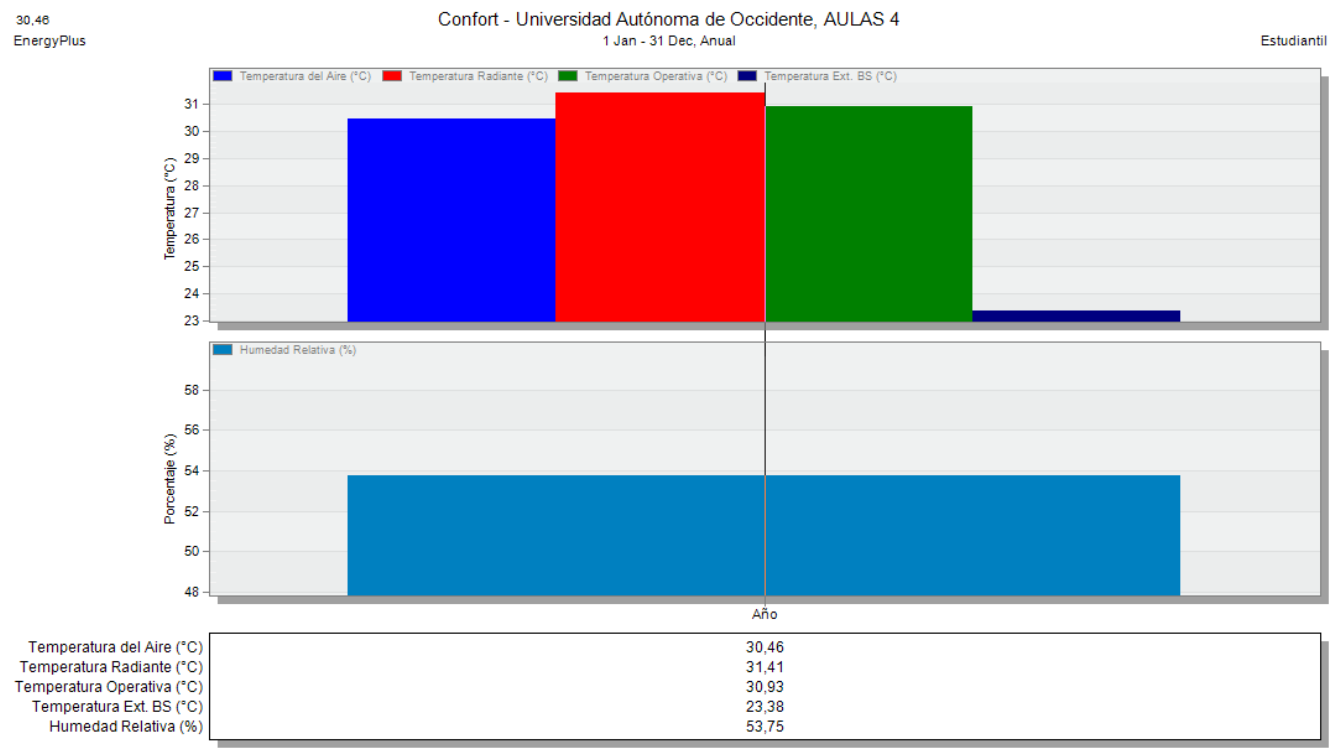

Figura 115. Condiciones de diseño interiores.

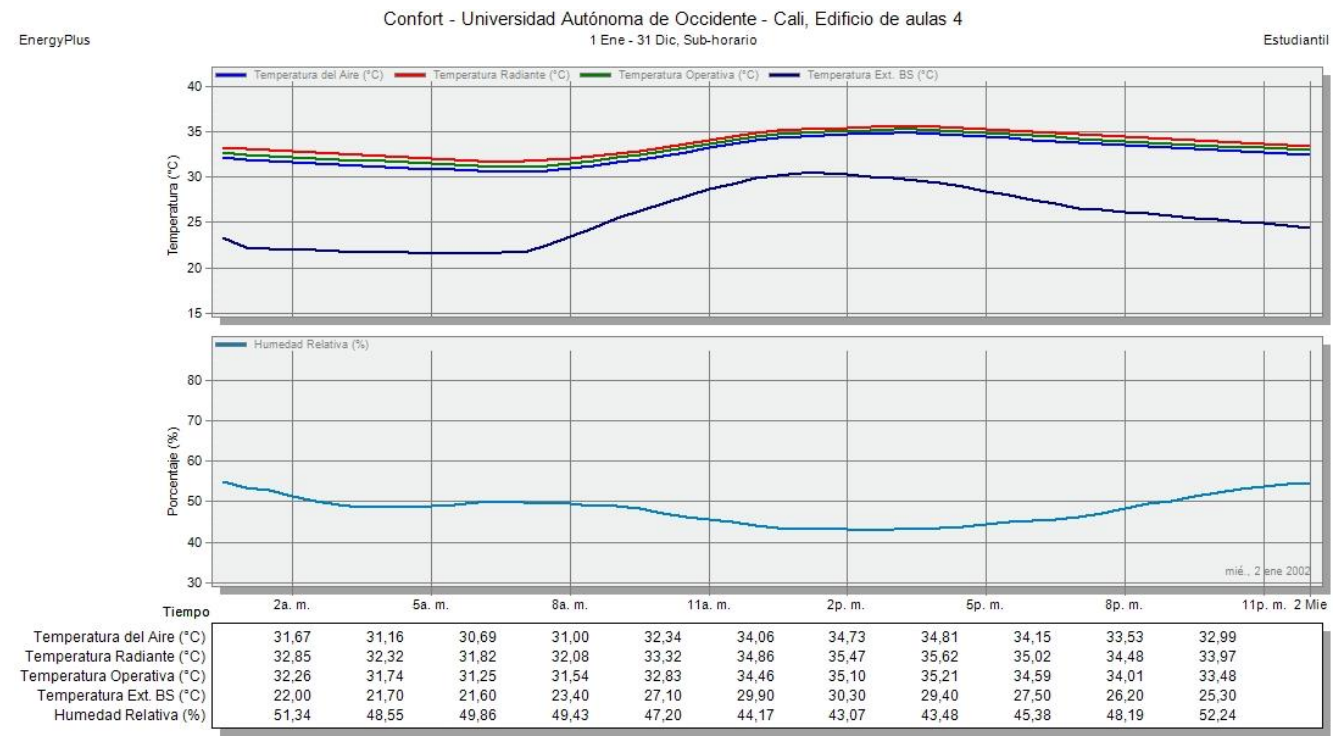

Figura 116. Condiciones de diseño exteriores sub-horario. 


\subsection{DESCRIPCIÓN DE LAS INSTALACIONES}

El edificio de aulas 4 es uno de los 4 Aularios que dispone la Universidad Autónoma de Occidente, El edificio es usado para impartir clases de pregrado y postgrado, actividades académicas de estudiantes de doctorado y alberga las oficinas administrativas de Egresados en el primer piso, TICS en el segundo, y planta física en el tercer piso. El edificio de aulas cuenta con torreones, aulas de clase y oficinas administrativas.

El edificio se encuentra equipado con los equipos de uso final detallado en la Tabla 41. El sistema de iluminación está compuesto en su mayoría por tecnología LED, los equipos ofimáticos compuesto principalmente por computadores, poseen sello de consumo Energy Star que garantizan el uso eficiente de la energía eléctrica y protección del medio ambiente.

El sistema de iluminación de zonas comunes del edificio se encuentra automatizado, el horario de encendido es de 5:30 pm a 10:00 pm para los pasillos internos y de 6:00 pm a 10:00 pm para la iluminación exterior del edificio. Los baños poseen sensores de presencia que activan el encendido de la iluminación.

El sistema de refrigeración del edificio está compuesto por 19 sistemas de aire acondicionado distribuidos en torreones, oficinas y aulas de postgrado (piso 4). Los sistemas son configurados (Setpoints) según el espacio, para las oficinas y torreones la temperatura se configura establecida varía entre 22 y $23^{\circ} \mathrm{C}$, para las aulas de clase el valor se personaliza según el requerimiento de sus ocupantes, estos valores varían de $21^{\circ} \mathrm{C}$ a $25^{\circ} \mathrm{C}$.

Tabla 41. Equipos de uso final del Edificio

\begin{tabular}{|c|c|c|c|}
\hline \multicolumn{4}{|c|}{ Iluminación } \\
\hline Referencia & Cantidad & Potencia [W] & Recintos \\
\hline Bala LED luz cálida - Philips & 8 & 28 & Egresados \\
\hline Bala LED luz blanca - Philips & 12 & 28 & Egresados \\
\hline Panel Cuadrado LED - Sylvana & 160 & 45 & $\begin{array}{c}\text { Egresados, TIC, Planta } \\
\text { física, Salones de } \\
\text { Clase, pasillos }\end{array}$ \\
\hline Bombilla Ahorradora & 104 & 15 & Torreones \\
\hline Tubo Fluorescente & 20 & 32 & Torreones \\
\hline Bala LED luz cálida - Pequeña & 72 & 12 & Salones de clase piso 4 \\
\hline Cinta LED & 20 & 5 & Salones de clase piso 4 \\
\hline Tubos LED & 68 & 17 & Salones de clase piso 4 \\
\hline Referencia & Cquipos Ofimáticos & Potencia [W] & Recintos \\
\hline Computador DELL Optiplex 7450 AIO & 79 & 65 & $\begin{array}{c}\text { Egresados, TIC, Planta } \\
\text { física, Salones de } \\
\text { Clase, torreones }\end{array}$ \\
\hline Scanerjet Interprise 7500 & 1 & 50 & TIC \\
\hline
\end{tabular}



OCCIDENTE

\begin{tabular}{|c|c|c|c|}
\hline Impresora LaserJet P2015dn & 2 & 350 & $\begin{array}{c}\text { Egresados, Planta } \\
\text { física }\end{array}$ \\
\hline Impresora Laserjet 600 M603 & 1 & 950 & TIC \\
\hline $\begin{array}{c}\text { Pantalla interactiva SMART board } \\
6000 \text { pro }\end{array}$ & 10 & 130 & Salones de clase piso 4 \\
\hline Parlantes Behringer MS 16 & 19 & 16 & $\begin{array}{c}\text { Salones de clase, } \\
\text { torreones }\end{array}$ \\
\hline Parlantes BOSÉ & 10 & 40 & Salones de clase piso 4 \\
\hline Televisor Samsung 55" & 5 & 220 & $\begin{array}{c}\text { Egresados, TIC, Planta } \\
\text { física }\end{array}$ \\
\hline Videobeam EPSON Power lite 2250u & 18 & 429 & $\begin{array}{c}\text { Torreones, salones de } \\
\text { clase }\end{array}$ \\
\hline Equipos de Aire Acondicionado & Recintos \\
\hline Referencia & Cantidad & Potencia [W] & Egresados \\
\hline YORK - YNVFYC60BAQDB-X & 1 & 6950 & T1A - T1B \\
\hline Carrier - 40RR014 & 2 & 1079 & T1C \\
\hline Carrier - 40RR012 & 1 & 1034 & T2 - T3 \\
\hline Carrier - 40RR008 & 2 & 900 & TIC - Planta Física \\
\hline Carrier - 38CK060540 & 2 & 2240 & T4 \\
\hline Carrier - E50DJ008 & 1 & 5970 & 4401 al 4406 \\
\hline Blue line - MUB36CR & 6 & 3300 & 4407 al 4410 \\
\hline Blue line - MUB24CR & 4 & 2560 &
\end{tabular}

La energía eléctrica consumida por el edificio proviene de la Red y de energía renovable puesto que, en el techo del edificio se encuentra instalado un sistema solar fotovoltaico compuesto por 144 paneles marca Jinko Solar de 265Wp cada uno, 2 inversores Fronius Symo 17.5 - 3M, para un total de 38,2 kWp instalados. La Figura 117, presenta el plano del SSFV instalado en el techo del edificio.

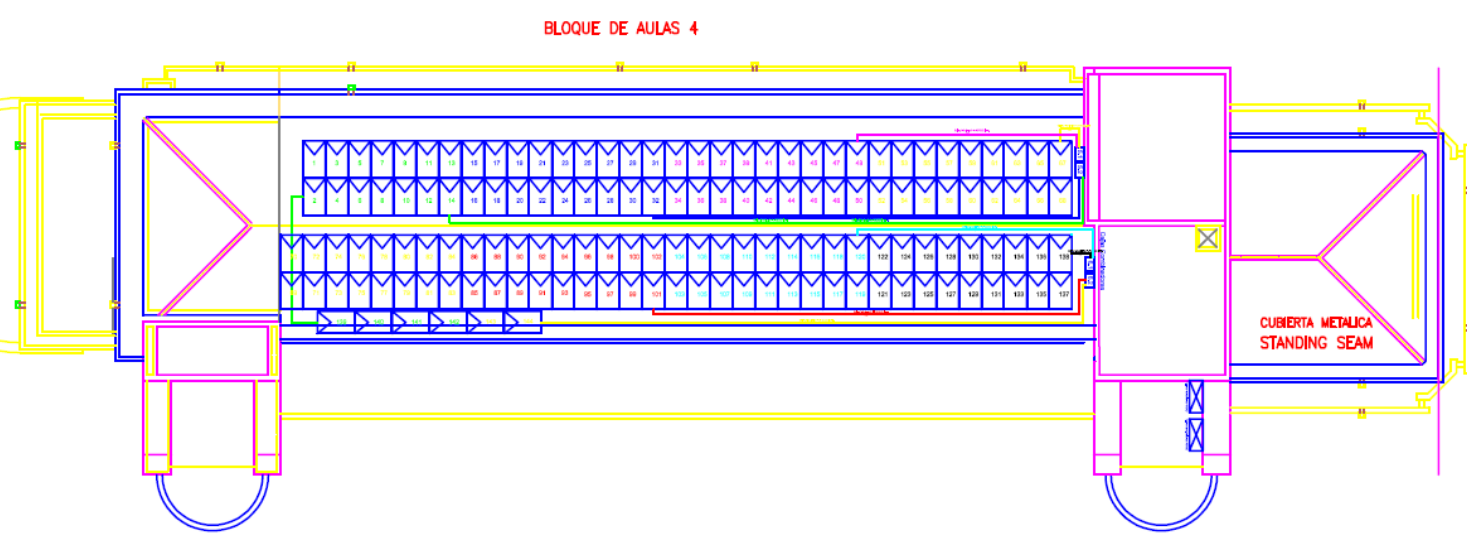

Figura 117. SSFV instalado en el Edificio de aulas 4 


\subsubsection{Consumo de Energía Eléctrica del Edificio}

El edificio posee un medidor de energía eléctrica (Figura 118) que registra su consumo cada 15 minutos, se recopilaron los históricos de consumos del edificio con ayuda del software “Power Monitoring Expert" de la marca "Schneider Electric" de los años 2016, 2017 y 2018.

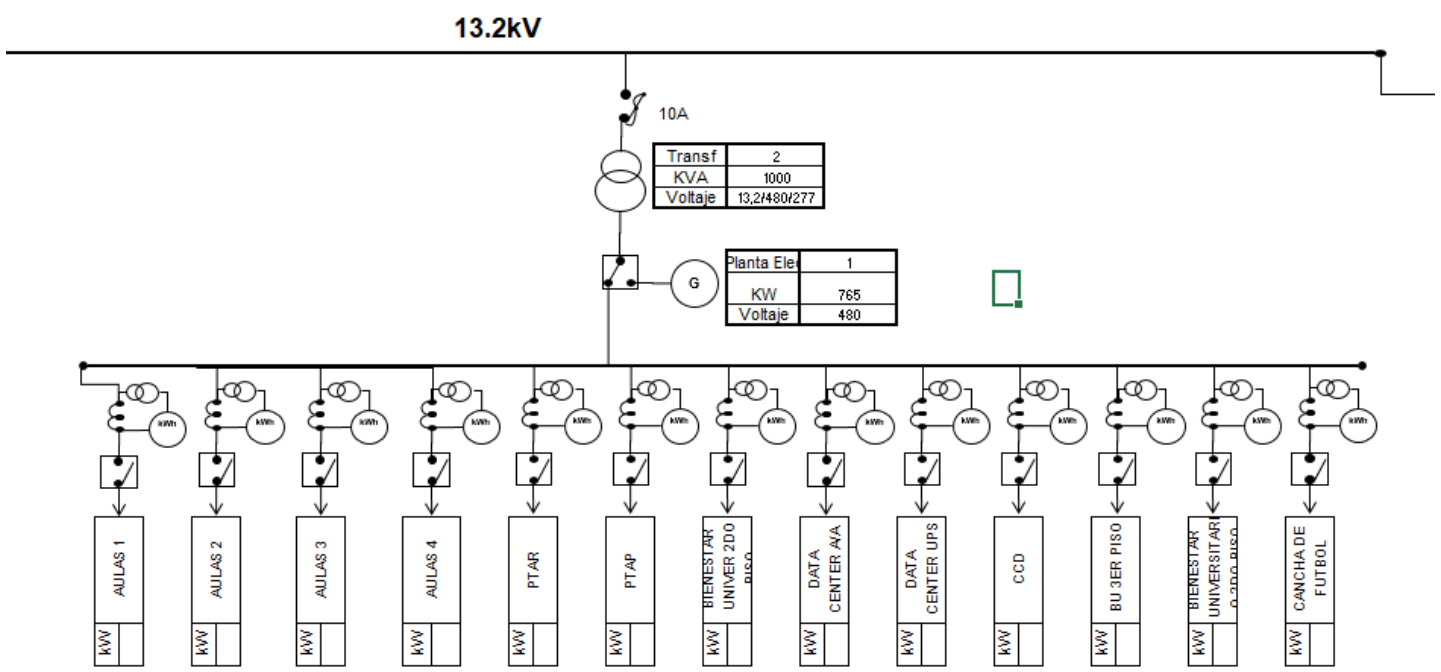

Figura 118. Diagrama Unifilar de subestación 2 con ubicación del medidor del aula 4

La Tabla 42 y las figuras 119 y 120, enseñan el histórico de consumo de energía eléctrica recopilado del edificio de aulas 4 .

Tabla 42. Histórico de consumos de Energía Eléctrica

\begin{tabular}{|c|c|c|c|c|}
\hline \multirow{2}{*}{ Mes } & \multicolumn{4}{|c|}{ Consumo Eléctrico kWh } \\
\cline { 2 - 5 } & $\mathbf{2 0 1 6}$ & $\mathbf{2 0 1 7}$ & $\mathbf{2 0 1 8}$ & $\mathbf{2 0 1 9}$ \\
\hline Enero & 7.511 & 8.621 & 11.968 & 8.157 \\
\hline Febrero & 19.493 & 19.672 & 18.612 & 18.339 \\
\hline Marzo & 16.221 & 20.782 & 17.855 & 19.271 \\
\hline Abril & 18.945 & 17.120 & 18.971 & 15.445 \\
\hline Mayo & 17.404 & 20.919 & 18.237 & 18.876 \\
\hline Junio & 4.998 & 10.869 & 10.451 & 12.135 \\
\hline Julio & 8.360 & 11.163 & 13.730 & 20.271 \\
\hline Agosto & 19.853 & 18.805 & 19.142 & 24.242 \\
\hline Septiembre & 18.574 & 18.620 & 18.290 & 22.723 \\
\hline Octubre & 16.817 & 17.007 & 17.515 & 21.390 \\
\hline Noviembre & 12.879 & 14.861 & 14.198 & 17.109 \\
\hline Diciembre & 5.053 & 8.023 & 9.414 & 10.418 \\
\hline Consumo Año & 166.108 & 186.462 & 188.383 & 208.376 \\
\hline
\end{tabular}




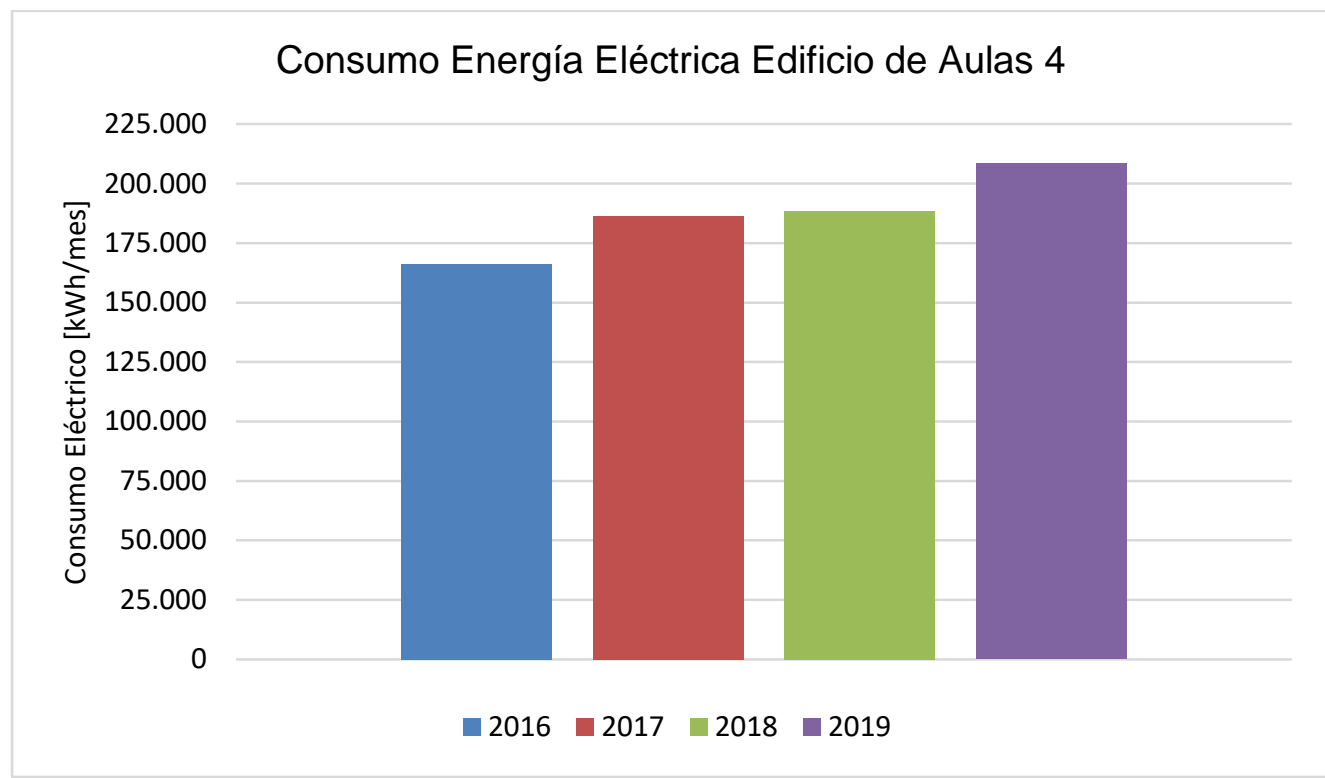

Figura 119. Consumo de Energía Eléctrico anual

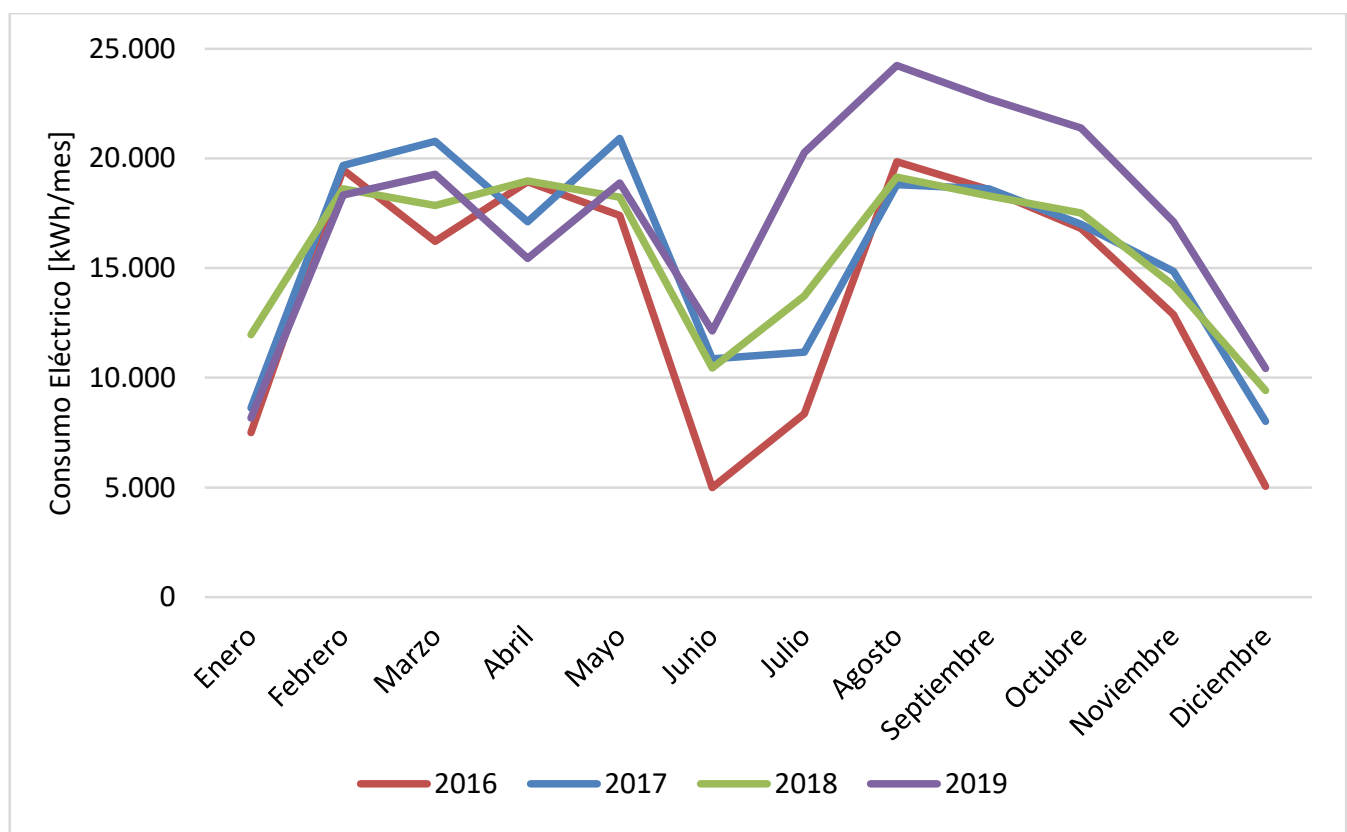

Figura 120. Histórico de consumo de energía eléctrica mensual 2016 - 2019

Analizando el histórico de consumo de energía eléctrica del edificio, se evidencia que el consumo de energía eléctrica en el edificio ha aumentado. El aumento responde a los cambios operativos en el uso de los recintos (uso libre de los torreones desde el 2017) y a cambios constructivos y de mejora adelantados en el mismo (remodelación de aulas de posgrado, de oficinas de egresados y planta física, cambio y adición de equipos de climatización, ascensores, etc.). En el histórico de consumo mensual, se aprecia que el año 2017 tuvo 2 periodos de incremento en el consumo de energía en los meses de marzo y mayo. Los periodos que habitualmente era considerados de bajo consumo, por ser periodo de vacaciones académicas (Junio - Julio y Diciembre - Enero), presentaron incrementos en 
el consumo en 2017 y 2018, dado que en estos periodos se realizaron actividades de remodelación de los espacios del edificio aprovechando su baja o nula ocupación al corresponder a periodos de vacaciones. En el 2019 son normalizadas las actividades del edificio (junio), y con ello se evidencia un aumento en el consumo de energía eléctrica del $10,6 \%$ con respecto al año anterior, debido a la ocupación normal del edificio y a la remodelación y climatización de todos sus espacios.

\subsection{SISTEMAS Y EQUIPOS DEL EDIFICIO}

\subsubsection{Sistema de Aire Acondicionado}

Los sistemas de aire acondicionado del edificio están compuestos por mini Split con sistema de enfriamiento independiente ubicados en la cubierta del edificio con tuberías de conducción de aire directo a las fan coil al interior de cada recinto aclimatado. La Tabla 43 presenta la capacidad de refrigeración instalada en el edificio.

Tabla 43. Potencia de refrigeración kW unidades split

\begin{tabular}{|c|c|c|}
\hline PISO & RECINTO & $\begin{array}{c}\text { CAPACIDAD DE } \\
\text { REFRIGERACIÓN (kW) }\end{array}$ \\
\hline \multirow{11}{*}{$\begin{array}{l}\text { Primer piso - } \\
\text { planta baja }\end{array}$} & A4T1A & 46,77 \\
\hline & A4T1B & 46,77 \\
\hline & A4T1 & 30,6 \\
\hline & Escalera este P1 & N.A. \\
\hline & Escalera oeste P1 & N.A. \\
\hline & Baño hombres P1 & N.A. \\
\hline & Baño mujeres P1 & N.A. \\
\hline & Pasillo este P1 & N.A. \\
\hline & Pasillo oeste P1 & N.A. \\
\hline & Pasillo sur P1 & N.A. \\
\hline & Registro académico & N.A. \\
\hline \multirow{16}{*}{$\begin{array}{l}\text { Segundo piso- } \\
\text { planta primera }\end{array}$} & Aula 4201 & N.A. \\
\hline & Aula 4202 & N.A. \\
\hline & Aula 4203 & N.A. \\
\hline & Aula 4204 & N.A. \\
\hline & Aula 4205 & N.A. \\
\hline & Aula 4206 & N.A. \\
\hline & A4T2 & 28,13 \\
\hline & Escalera este P2 & N.A. \\
\hline & Escalera oeste P2 & N.A. \\
\hline & Baño hombres P2 & N.A. \\
\hline & Baño mujeres P2 & N.A. \\
\hline & Pasillo este P2 & N.A. \\
\hline & Pasillo oeste P2 & N.A. \\
\hline & Pasillo sur P2 & N.A. \\
\hline & TIC & 17,58 \\
\hline & Aula 4301 & N. A \\
\hline
\end{tabular}




\begin{tabular}{|c|c|c|}
\hline \multirow{15}{*}{$\begin{array}{l}\text { Tercer piso- } \\
\text { planta segunda }\end{array}$} & Aula 4302 & N.A. \\
\hline & Aula 4303 & N.A. \\
\hline & Aula 4304 & N.A. \\
\hline & Aula 4305 & N.A. \\
\hline & Aula 4306 & N.A. \\
\hline & A4T3 & 28,13 \\
\hline & Escalera este P3 & N.A. \\
\hline & Escalera oeste P3 & N.A. \\
\hline & Baño hombres P3 & N.A. \\
\hline & Baño mujeres P3 & N.A. \\
\hline & Pasillo este P3 & N.A. \\
\hline & Pasillo oeste P3 & N.A. \\
\hline & Pasillo sur P3 & N.A. \\
\hline & Planta física & 17,58 \\
\hline & Vacío P3 & N.A. \\
\hline \multirow{19}{*}{$\begin{array}{l}\text { Cuarto piso - } \\
\text { planta tercera }\end{array}$} & Aula 4401 & 10,55 \\
\hline & Aula 4402 & 10,55 \\
\hline & Aula 4403 & 10,55 \\
\hline & Aula 4404 & 10,55 \\
\hline & Aula 4405 & 10,55 \\
\hline & Aula 4406 & 10,55 \\
\hline & Aula 4407 & 7,03 \\
\hline & Aula 4408 & 7,03 \\
\hline & Aula 4409 & 7,03 \\
\hline & Aula 4410 & 7,03 \\
\hline & A4T4 & 24,62 \\
\hline & Escalera este P4 & N.A. \\
\hline & Escalera oeste P4 & N.A. \\
\hline & Baño hombres P4 & N.A. \\
\hline & Baño mujeres P4 & N.A. \\
\hline & Pasillo este P4 & N.A. \\
\hline & Pasillo oeste P4 & N.A. \\
\hline & Pasillo sur P4 & N.A. \\
\hline & Salón vacío & N.A. \\
\hline
\end{tabular}

\subsubsection{Sistemas de Iluminación}

La iluminación de los recintos del edificio está instalada de forma superficial y compuesta principalmente por tecnología LED y fluorescente, los recintos poseen diferentes luminarias instaladas (potencia y cantidad) según el requerimiento del espacio, como lo muestra la Tabla 44.

Tabla 44. Sistemas de Iluminación del Edificio.

\begin{tabular}{|c|c|c|c|c|}
\hline \multirow{2}{*}{ Piso } & Recinto & $\begin{array}{c}\text { Área de suelo } \\
\left(\mathbf{m}^{\mathbf{2}} \mathbf{)}\right.\end{array}$ & $\begin{array}{c}\text { Potencia total } \\
\mathbf{( w )}\end{array}$ & $\begin{array}{c}\text { Densidad normalizada } \\
\left(\mathbf{w} / \mathbf{m}^{\mathbf{2}}\right)\end{array}$ \\
\hline \multirow{2}{*}{$\begin{array}{c}\text { Primer piso - } \\
\text { planta baja }\end{array}$} & A4T1A & 136,61 & 625 & 4,575 \\
\cline { 2 - 5 } & A4T1B & 136,59 & 670 & 4,905 \\
\cline { 2 - 5 } & A4T1 & 111,16 & 401 & 3,607 \\
\hline
\end{tabular}



OCCIDENTE

\begin{tabular}{|c|c|c|c|c|}
\hline & Escalera este P1 & 10,71 & N.A. & N.A. \\
\hline & Cuarto multimedios & 12,51 & 64 & 5,116 \\
\hline & Escalera oeste P1 & 23,52 & N.A. & N.A. \\
\hline & Baño hombres P1 & 23,63 & 244 & 10,326 \\
\hline & Baño mujeres P1 & 26,98 & 244 & 9,044 \\
\hline & Pasillo este P1 & 40,11 & 612 & 15,258 \\
\hline & Pasillo oeste P1 & 73,49 & 612 & 8,328 \\
\hline & Pasillo sur P1 & 158,03 & 612 & 3,873 \\
\hline & Registro académico & 96,55 & 550 & 5,697 \\
\hline \multirow{15}{*}{$\begin{array}{l}\text { Segundo piso - } \\
\text { planta primera }\end{array}$} & Aula 4201 & 45,55 & 270 & 5,928 \\
\hline & Aula 4202 & 46,94 & 270 & 5,752 \\
\hline & Aula 4203 & 46,94 & 270 & 5,752 \\
\hline & Aula 4204 & 46,94 & 270 & 5,752 \\
\hline & Aula 4205 & 47,08 & 270 & 5,735 \\
\hline & Aula 4206 & 42,85 & 270 & 6,301 \\
\hline & A4T2 & 126,88 & 394 & 3,105 \\
\hline & Escalera este P2 & 12,80 & N.A. & N.A. \\
\hline & Escalera oeste P2 & 0,03 & N.A. & N.A. \\
\hline & Baño hombres P2 & 23,63 & 224 & 9,479 \\
\hline & Baño mujeres P2 & 26,97 & 224 & 8,306 \\
\hline & Pasillo este P2 & 40,13 & 612 & 15,250 \\
\hline & Pasillo oeste P2 & 37,61 & 612 & 16,272 \\
\hline & Pasillo sur P2 & 178,13 & 612 & 3,436 \\
\hline & TIC & 144,74 & 1687 & 13,618 \\
\hline \multirow{16}{*}{$\begin{array}{l}\text { Tercer piso - } \\
\text { planta segunda }\end{array}$} & 4301 & 40,77 & 225 & 5,519 \\
\hline & 4302 & 40,98 & 225 & 5,490 \\
\hline & 4303 & 40,99 & 225 & 5,489 \\
\hline & 4304 & 40,99 & 225 & 5,489 \\
\hline & 4305 & 41,33 & 225 & 5,444 \\
\hline & 4306 & 37,45 & 225 & 6,008 \\
\hline & A4T3 & 126,88 & 401 & 3,160 \\
\hline & Escalera este P3 & 0,04 & N.A. & N.A. \\
\hline & Escalera oeste P3 & 0,02 & N.A. & N.A. \\
\hline & Baño hombres P3 & 23,63 & 224 & 9,479 \\
\hline & Baño mujeres P3 & 27,00 & 224 & 8,296 \\
\hline & Pasillo este P3 & 40,19 & 612 & 15,228 \\
\hline & Pasillo oeste P3 & 37,69 & 612 & 16,238 \\
\hline & Pasillo sur P3 & 91,65 & 612 & 6,678 \\
\hline & Planta física & 68,68 & 360 & 5,242 \\
\hline & Vacío P3 & 13,52 & N.A. & N.A. \\
\hline \multirow{6}{*}{$\begin{array}{l}\text { Cuarto piso - } \\
\text { planta tercera }\end{array}$} & Aula 4401 & 34,93 & 180 & 5,153 \\
\hline & Aula 4402 & 35,09 & 180 & 5,130 \\
\hline & Aula 4403 & 35,10 & 180 & 5,128 \\
\hline & Aula 4404 & 35,10 & 180 & 5,128 \\
\hline & Aula 4405 & 35,39 & 180 & 5,086 \\
\hline & Aula 4406 & 32,10 & 180 & 5,607 \\
\hline
\end{tabular}



OCCIDENTE

\begin{tabular}{|c|c|c|c|c|}
\hline \multirow{4}{*}{} & Aula 4407 & 15,60 & 90 & 5,769 \\
\cline { 2 - 5 } & Aula 4408 & 17,07 & 180 & 10,545 \\
\cline { 2 - 5 } & Aula 4409 & 17,07 & 180 & 10,545 \\
\cline { 2 - 5 } & Aula 4410 & 16,61 & 180 & 10,837 \\
\cline { 2 - 5 } & A4T4 & 75,97 & 158 & 2,080 \\
\cline { 2 - 5 } & Escalera este P4 & 0,06 & N.A. & N.A. \\
\cline { 2 - 5 } & Escalera oeste P4 & 0,02 & N.A. & 8,293 \\
\cline { 2 - 5 } & Baño hombres P4 & 23,65 & 224 & 5,614 \\
\cline { 2 - 5 } & Baño mujeres P4 & 27,01 & 224 & 17,617 \\
\cline { 2 - 5 } & Pasillo este P4 & 39,90 & 680 & 5,038 \\
\cline { 2 - 5 } & Pasillo oeste P4 & 38,60 & 680 & 26,782 \\
\cline { 2 - 5 } & Pasillo sur P4 & 134,97 & 680 & N.A. \\
\cline { 2 - 5 } & Salón vacío & 25,39 & N.A. & \\
\hline
\end{tabular}

\subsubsection{Equipos Ofimáticos}

Para el inventario de equipos se han tenido en cuenta los aparatos de computación y equipos de oficina para cada recinto, obteniendo así los datos que se muestran en la Tabla 45.

Tabla 45. Equipos de uso ofimático del Edificio.

\begin{tabular}{|c|c|c|c|c|c|}
\hline Piso & Recinto & $\begin{array}{c}\text { Área de } \\
\text { suelo }\left(\mathrm{m}^{2}\right)\end{array}$ & $\begin{array}{l}\text { Potencia } \\
\text { total (w) }\end{array}$ & $\begin{array}{c}\text { Densidad potencia } \\
\text { equipos }\left(w / m^{2}\right)\end{array}$ & Climatizado \\
\hline \multirow{12}{*}{$\begin{array}{l}\text { Primer piso - } \\
\text { planta baja }\end{array}$} & A4T1A & 136,61 & 800 & 5,856 & $\mathrm{Si}$ \\
\hline & A4T1B & 136,59 & 800 & 5,857 & $\mathrm{Si}$ \\
\hline & A4T1 & 111,16 & 800 & 7,197 & $\mathrm{Si}$ \\
\hline & Escalera este P1 & 10,71 & 0 & 0,000 & No \\
\hline & $\begin{array}{c}\text { Cuarto } \\
\text { multimedios }\end{array}$ & 12,51 & 591 & 47,242 & No \\
\hline & Escalera oeste P1 & 23,52 & 0 & 0,000 & No \\
\hline & Baño hombres P1 & 23,63 & 0 & 0,000 & No \\
\hline & Baño mujeres P1 & 26,98 & 0 & 0,000 & No \\
\hline & Pasillo este P1 & 40,11 & 0 & 0,000 & No \\
\hline & Pasillo oeste P1 & 73,49 & 0 & 0,000 & No \\
\hline & Pasillo sur P1 & 158,03 & 0 & 0,000 & No \\
\hline & $\begin{array}{c}\text { Registro } \\
\text { académico }\end{array}$ & 96,55 & 3350 & 34,697 & Si \\
\hline \multirow{9}{*}{$\begin{array}{c}\text { Segundo piso } \\
\text { - planta } \\
\text { primera }\end{array}$} & Aula 4201 & 45,55 & 800 & 17,563 & No \\
\hline & Aula 4202 & 46,94 & 800 & 17,043 & No \\
\hline & Aula 4203 & 46,94 & 800 & 17,043 & No \\
\hline & Aula 4204 & 46,94 & 800 & 17,043 & No \\
\hline & Aula 4205 & 47,08 & 800 & 16,992 & No \\
\hline & Aula 4206 & 42,85 & 800 & 18,670 & No \\
\hline & A4T2 & 126,88 & 800 & 6,305 & $\mathrm{Si}$ \\
\hline & Escalera este P2 & 12,8 & 0 & 0,000 & No \\
\hline & Escalera oeste P2 & 0,03 & 0 & 0,000 & No \\
\hline
\end{tabular}




\begin{tabular}{|c|c|c|c|c|c|}
\hline & Baño hombres P2 & 23,63 & 0 & 0,000 & No \\
\hline & Baño mujeres P2 & 26,97 & 0 & 0,000 & No \\
\hline & Pasillo este P2 & 40,13 & 0 & 0,000 & No \\
\hline & Pasillo oeste P2 & 37,61 & 0 & 0,000 & No \\
\hline & Pasillo sur P2 & 178,13 & 0 & 0,000 & No \\
\hline & TIC & 144,74 & 10118 & 81,676 & $\mathrm{Si}$ \\
\hline \multirow{16}{*}{$\begin{array}{l}\text { Tercer piso - } \\
\text { planta } \\
\text { segunda }\end{array}$} & Aula 4301 & 40,77 & 800 & 19,622 & No \\
\hline & Aula 4302 & 40,98 & 800 & 19,522 & No \\
\hline & Aula 4303 & 40,99 & 800 & 19,517 & No \\
\hline & Aula 4304 & 40,99 & 800 & 19,517 & No \\
\hline & Aula 4305 & 41,33 & 800 & 19,356 & No \\
\hline & Aula 4306 & 37,45 & 800 & 21,362 & No \\
\hline & A4T3 & 126,88 & 800 & 6,305 & Si \\
\hline & Escalera este P3 & 0,04 & 0 & 0,000 & No \\
\hline & Escalera oeste P3 & 0,02 & 0 & 0,000 & No \\
\hline & Baño hombres P3 & 23,63 & 0 & 0,000 & No \\
\hline & Baño mujeres P3 & 27 & 0 & 0,000 & No \\
\hline & Pasillo este P3 & 40,19 & 0 & 0,000 & No \\
\hline & Pasillo oeste P3 & 37,69 & 0 & 0,000 & No \\
\hline & Pasillo sur P3 & 91,65 & 0 & 0,000 & No \\
\hline & Planta física & 68,68 & 4390 & 63,920 & $\mathrm{Si}$ \\
\hline & Vacío P3 & 13,52 & 0 & 0,000 & No \\
\hline \multirow{19}{*}{$\begin{array}{l}\text { Cuarto piso - } \\
\text { planta tercera }\end{array}$} & Aula 4401 & 34,93 & 800 & 22,903 & $\mathrm{Si}$ \\
\hline & Aula 4402 & 35,09 & 800 & 22,796 & $\mathrm{Si}$ \\
\hline & Aula 4403 & 35,1 & 800 & 22,790 & $\mathrm{Si}$ \\
\hline & Aula 4404 & 35,1 & 800 & 22,794 & $\mathrm{Si}$ \\
\hline & Aula 4405 & 35,39 & 800 & 22,609 & Si \\
\hline & Aula 4406 & 32,1 & 800 & 24,928 & $\mathrm{Si}$ \\
\hline & Aula 4407 & 15,6 & 800 & 51,283 & $\mathrm{Si}$ \\
\hline & Aula 4408 & 17,07 & 800 & 46,871 & Si \\
\hline & Aula 4409 & 17,07 & 800 & 46,866 & Si \\
\hline & Aula 4410 & 16,61 & 800 & 48,165 & $\mathrm{Si}$ \\
\hline & A4T4 & 75,97 & 395 & 5,201 & $\mathrm{Si}$ \\
\hline & Escalera este P4 & 0,06 & 0 & 0,000 & No \\
\hline & Escalera oeste P4 & 0,02 & 0 & 0,000 & No \\
\hline & Baño hombres P4 & 23,65 & 0 & 0,000 & No \\
\hline & Baño mujeres P4 & 27,01 & 0 & 0,000 & No \\
\hline & Pasillo este P4 & 39,9 & 0 & 0,000 & No \\
\hline & Pasillo oeste P4 & 38,6 & 0 & 0,000 & No \\
\hline & Pasillo sur P4 & 134,97 & 0 & 0,000 & No \\
\hline & Salón vacío & 25,39 & 0 & 0,000 & No \\
\hline
\end{tabular}




\subsubsection{Régimen de Ocupación y Usos}

Una vez conocidos los elementos y equipos de uso final que generan demanda energética en el edificio, es necesario establecer horarios para las distintas actividades que se realizan en el edificio con el fin de lograr una mayor aproximación y calibración del diseño realizado en el software de simulación dinámica Energy Plus. Las actividades administrativas son llevadas a cabo de lunes a viernes de 7:00 am a 5:00 pm, y las académicas de lunes a viernes de 6:30 am a 9:30 pm y los sábados de 7:30 am a 5:00 pm.

\subsection{COSTE ECONÓMICO DEL CONSUMO ENERGÉTICO E IMPACTO MEDIOAMBIENTAL}

Para obtener el coste económico que genera el consumo de energía eléctrica en el edificio de Aulas 4, se usará la tarifa económica que se tiene pactada con la empresa comercializadora de energía eléctrica CELSIA, donde se factura con una tarifa de $\$ 322,3$ COP/kWh de energía FV consumida y de $\$ 358 \mathrm{COP} / \mathrm{kWh}$ de energía de la RED. Las tarifas son fijas a lo largo del año y fueron establecidas desde el año 2017 que entró en funcionamiento el SSFV del edificio. Para calcular el impacto medioambiental del consumo de energía eléctrica de la Red, se empleará el factor de CO2 para Colombia de 0.0818 [Kg $\mathrm{CO} 2 / \mathrm{Kwh}$. La Tabla 46jError! No se encuentra el origen de la referencia., muestra los costes económicos y el impacto medioambiental del consumo de energía eléctrica en el edificio en los últimos 3 años (2017, 2018, 2019).

Tabla 46. Costes Económicos e Impacto medioambiental Edificio de Aulas 4

\begin{tabular}{|c|c|c|c|c|c|c|c|}
\hline Año & $\begin{array}{c}\text { Mes / } \\
\text { Consumo }\end{array}$ & $\begin{array}{c}\text { Consumo } \\
\text { de Energía } \\
\text { (kWh/mes) }\end{array}$ & $\begin{array}{c}\text { Costo } \\
\text { energía } \\
\text { consumida } \\
\text { de la RED } \\
\text { (COP) }\end{array}$ & $\begin{array}{c}\text { Consumo } \\
\text { Energía } \\
\text { Generada } \\
\text { por el SSFV } \\
\text { (kWh/mes) }\end{array}$ & $\begin{array}{c}\text { Costo } \\
\text { energía } \\
\text { consumida } \\
\text { generada } \\
\text { por el SSFV } \\
\text { (COP) } \\
\end{array}$ & $\begin{array}{c}\text { Costo Total } \\
\text { (COP) }\end{array}$ & $\begin{array}{c}\text { Impacto } \\
\text { Ambiental } \\
\text { (Kg CO2) }\end{array}$ \\
\hline \multirow{13}{*}{$\begin{array}{l}2 \\
0 \\
1 \\
7\end{array}$} & Enero & 8.621 & 3.086 .318 & 0 & 0 & 3.086 .318 & 705,2 \\
\hline & Febrero & 19.672 & 7.042 .576 & 0 & 0 & 7.042 .576 & $1.609,2$ \\
\hline & Marzo & 20.782 & 7.439 .956 & 0 & 0 & 7.439 .956 & $1.700,0$ \\
\hline & Abril & 17.120 & 6.128 .960 & 0 & 0 & 6.128 .960 & $1.400,4$ \\
\hline & Mayo & 18.666 & 6.682 .428 & 2.253 & 726.142 & 7.408 .570 & $1.526,9$ \\
\hline & Junio & 6.475 & 2.318 .050 & 4.394 & 1.416 .186 & 3.734 .236 & 529,7 \\
\hline & Julio & 6.218 & 2.226 .044 & 4.945 & 1.593 .774 & 3.819 .818 & 508,6 \\
\hline & Agosto & 13.872 & 4.966 .176 & 4.933 & 1.589 .906 & 6.556 .082 & $1.134,7$ \\
\hline & Septiembre & 13.622 & 4.876 .676 & 4.998 & 1.610 .855 & 6.487 .531 & $1.114,3$ \\
\hline & Octubre & 12.636 & 4.523 .688 & 4.371 & 1.408 .773 & 5.932 .461 & $1.033,6$ \\
\hline & \begin{tabular}{|l|} 
Noviembre \\
\end{tabular} & 10.400 & 3.723 .200 & 4.461 & 1.437 .780 & 5.160 .980 & 850,7 \\
\hline & Diciembre & 3.546 & 1.269 .468 & 4.477 & 1.442 .937 & 2.712 .405 & 290,1 \\
\hline & Total Año & 151.630 & \begin{tabular}{|l|}
54.283 .540 \\
\end{tabular} & 34.832 & 11.226 .354 & 65.509 .894 & 12.403 \\
\hline
\end{tabular}



OCCIDENTE

\begin{tabular}{|c|c|c|c|c|c|c|c|}
\hline \multirow{13}{*}{$\begin{array}{l}2 \\
0 \\
1 \\
8\end{array}$} & Enero & 7.513 & 2.689 .677 & 4.455 & 1.435 .847 & 4.125 .523 & 614,6 \\
\hline & Febrero & 14.092 & 5.044 .807 & 4.520 & 1.456 .796 & 6.501 .603 & $1.152,7$ \\
\hline & Marzo & 12.991 & 4.650 .840 & 4.864 & 1.567 .667 & 6.218 .507 & $1.062,7$ \\
\hline & Abril & 14.559 & 5.212 .207 & 4.413 & 1.422 .310 & 6.634 .517 & $1.190,9$ \\
\hline & Mayo & 13.861 & 4.962 .143 & 4.376 & 1.410 .385 & 6.372 .528 & $1.133,8$ \\
\hline & Junio & 6.119 & 2.190 .551 & 4.332 & 1.396 .204 & 3.586 .755 & 500,5 \\
\hline & Julio & 9.149 & 3.275 .305 & 4.582 & 1.476 .779 & 4.752 .083 & 748,4 \\
\hline & Agosto & 14.143 & 5.063 .108 & 4.999 & 1.611.178 & 6.674 .286 & $1.156,9$ \\
\hline & Septiembre & 13.619 & 4.875 .514 & 4.671 & 1.505 .463 & 6.380 .977 & $1.114,0$ \\
\hline & Octubre & 12.870 & 4.607 .460 & 4.645 & 1.497 .084 & 6.104 .544 & $1.052,8$ \\
\hline & \begin{tabular}{|l|} 
Noviembre \\
\end{tabular} & 10.208 & 3.654 .285 & 3.990 & 1.285 .977 & 4.940 .262 & 835,0 \\
\hline & \begin{tabular}{|l|} 
Diciembre \\
\end{tabular} & 4.593 & 1.644 .151 & 4.821 & 1.553 .808 & 3.197 .959 & 375,7 \\
\hline & Total Año & 133.715 & \begin{tabular}{|l|}
47.870 .048 \\
\end{tabular} & 54.668 & $\begin{array}{l}17.619 .496 \\
\end{array}$ & 65.489.544 & 10.938 \\
\hline \multirow{13}{*}{$\begin{array}{l}2 \\
0 \\
1 \\
9\end{array}$} & Enero & 3.828 & 1.370 .459 & 4.329 & 1.395 .330 & 2.765 .789 & 313,1 \\
\hline & Febrero & 14.162 & 5.069 .909 & 4.177 & 1.346 .196 & 6.416 .105 & $1.158,4$ \\
\hline & Marzo & 15.825 & 5.665 .265 & 3.446 & 1.110 .675 & 6.775 .940 & $1.294,5$ \\
\hline & Abril & 12.317 & 4.409 .544 & 3.128 & 1.008 .190 & 5.417 .733 & $1.007,5$ \\
\hline & Mayo & 14.751 & 5.280 .716 & 4.125 & 1.329 .517 & 6.610 .232 & $1.206,6$ \\
\hline & Junio & 7.974 & 2.854 .809 & 4.160 & 1.340 .829 & 4.195 .639 & 652,3 \\
\hline & Julio & 15.415 & 5.518 .624 & 4.856 & 1.564 .976 & 7.083 .600 & $1.261,0$ \\
\hline & Agosto & 19.352 & 6.928 .045 & 4.890 & 1.576 .108 & 8.504 .153 & $1.583,0$ \\
\hline & Septiembre & 18.121 & 6.487 .212 & 4.603 & 1.483 .447 & 7.970 .659 & $1.482,3$ \\
\hline & Octubre & 16.500 & 5.907 .138 & 4.890 & 1.576 .050 & 7.483 .188 & $1.349,7$ \\
\hline & \begin{tabular}{|l|} 
Noviembre \\
\end{tabular} & 13.038 & 4.667 .740 & 4.071 & 1.312 .022 & 5.979 .762 & $1.066,5$ \\
\hline & \begin{tabular}{|l|} 
Diciembre \\
\end{tabular} & 6.272 & 2.245 .257 & 4.146 & 1.336 .285 & 3.581 .542 & 513,0 \\
\hline & Total Año & 157.555 & 56.404 .718 & 50.821 & 16.379 .624 & 72.784 .342 & 12.888 \\
\hline
\end{tabular}

\subsection{REPRESENTACIÓN GEOMÉTRICA DEL EDIFICIO EN DESIGNBUILDER}

En las figuras 121 - 139, se muestra la representación geográfica, los pisos o plantas construidas y las diferentes vistas del edificio simulado en Design Builder.

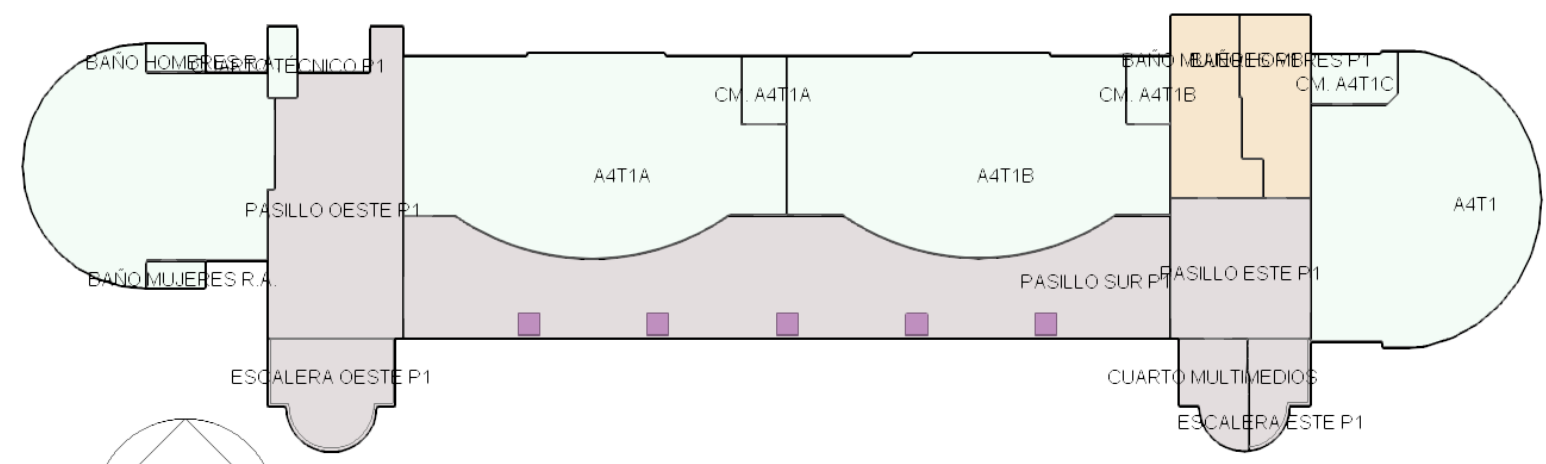

Figura 121. Plantilla de diseño piso 1. 


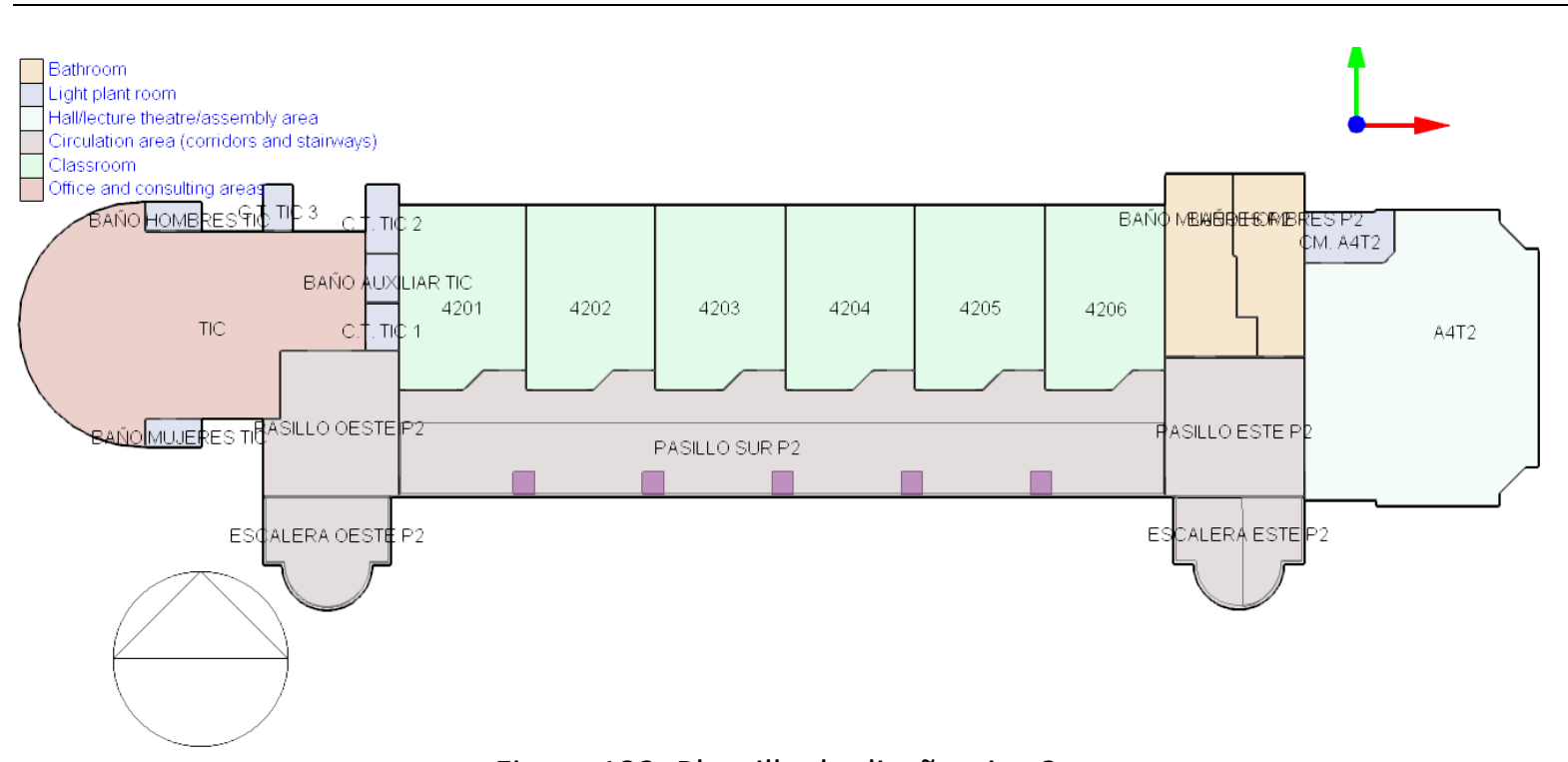

Figura 122. Plantilla de diseño piso 2.

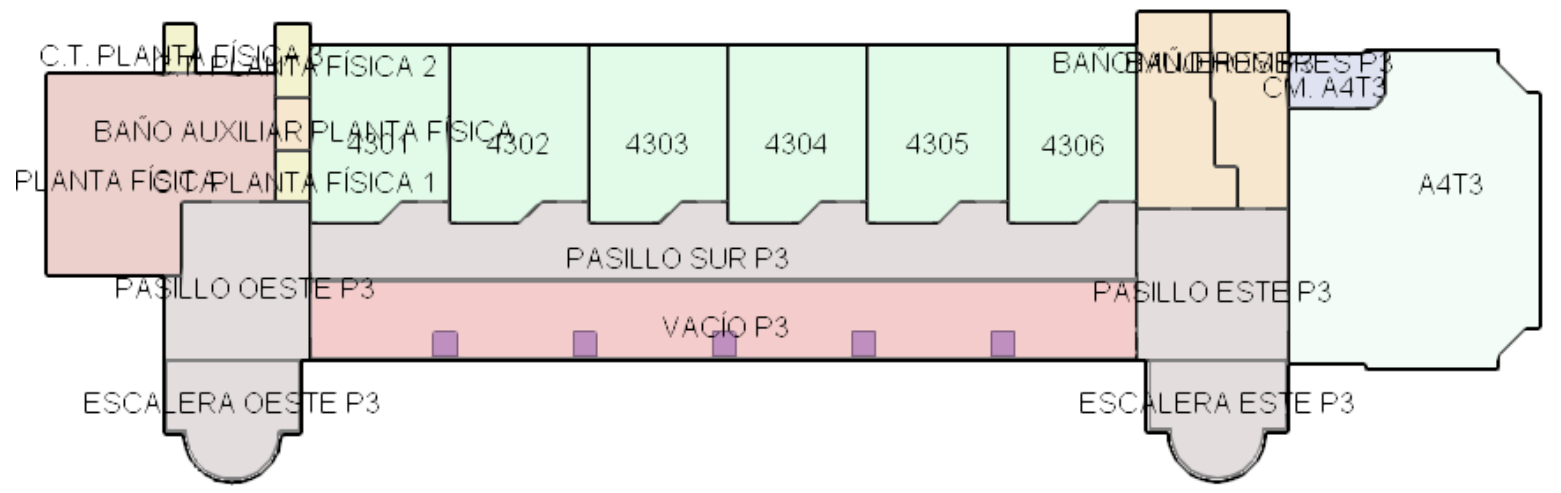

Figura 123. Plantilla de diseño piso 3.

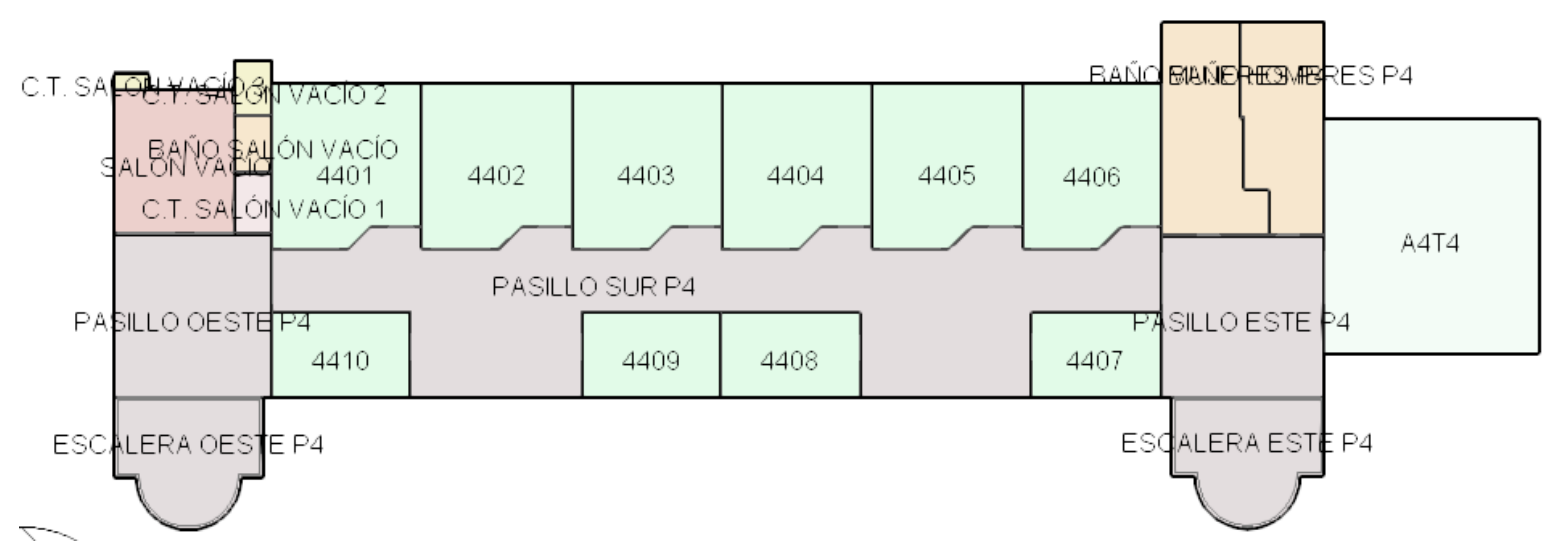

Figura 124. Plantilla de diseño piso 4. 


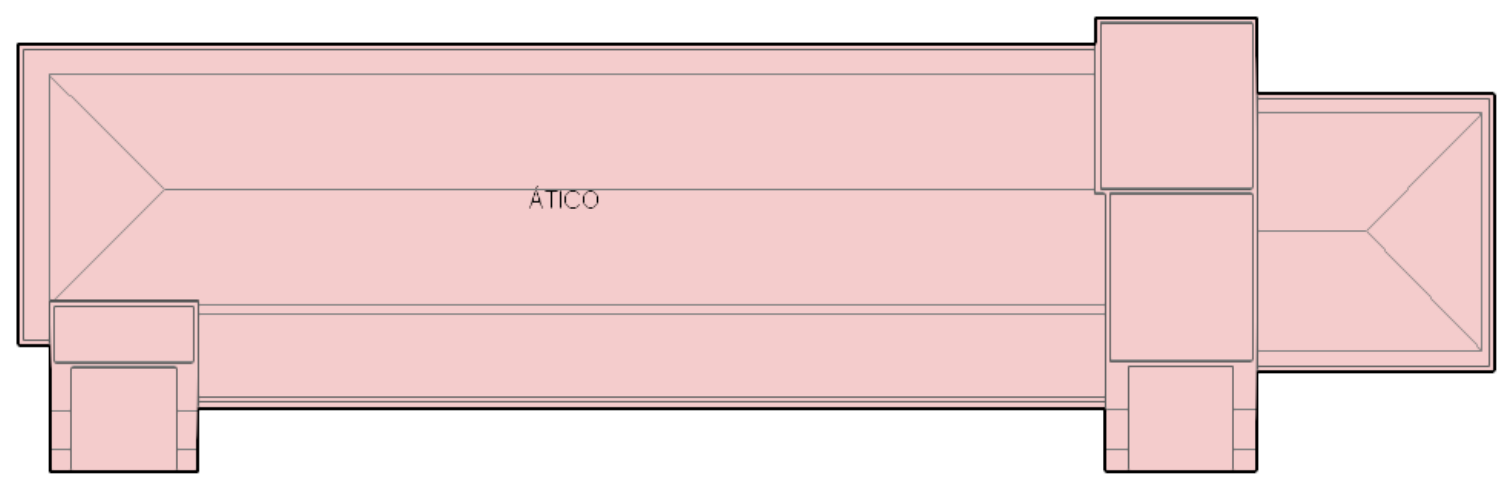

Figura 125. Plantilla de diseño techo.

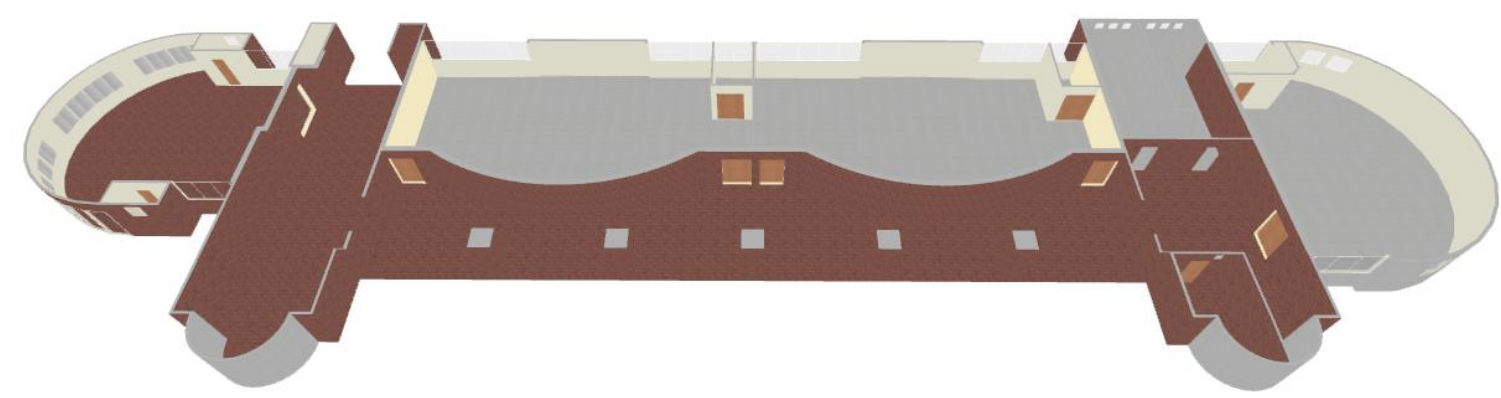

Figura 126. Piso 1.

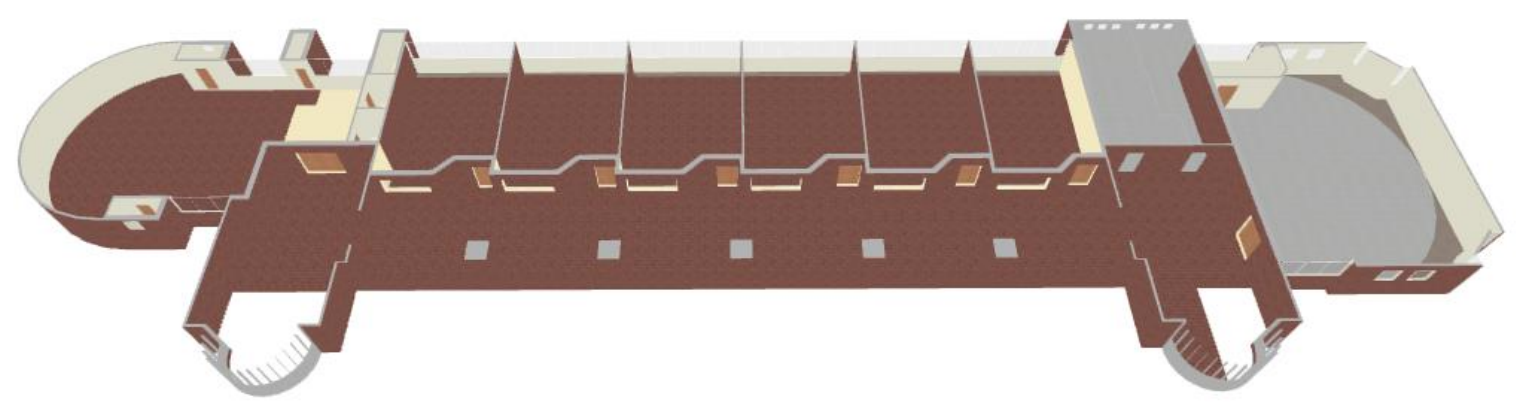

Figura 127. Piso 2.

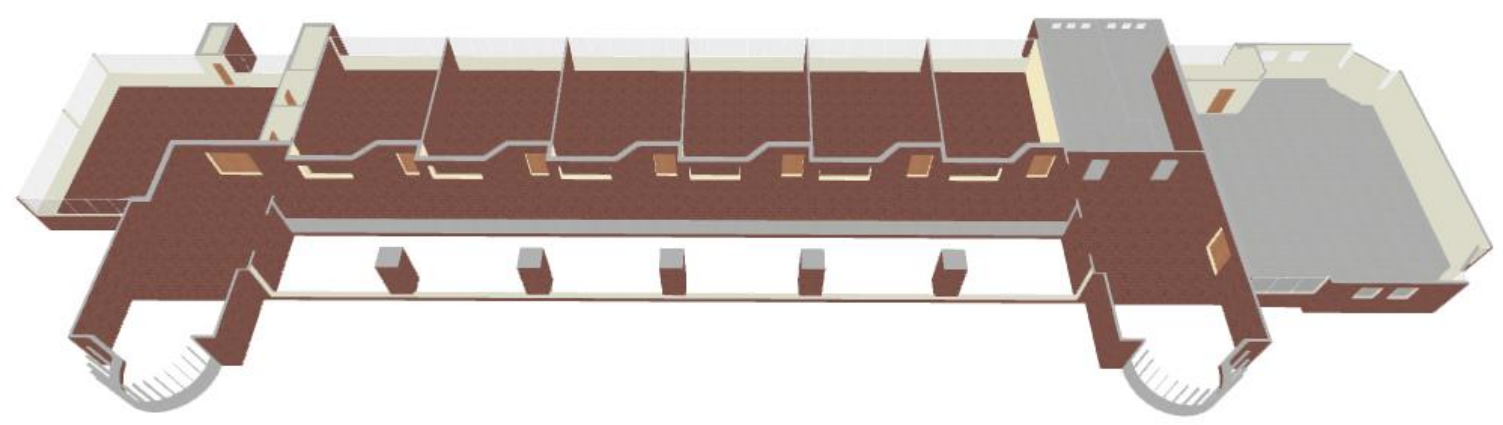

Figura 128. Piso 3. 


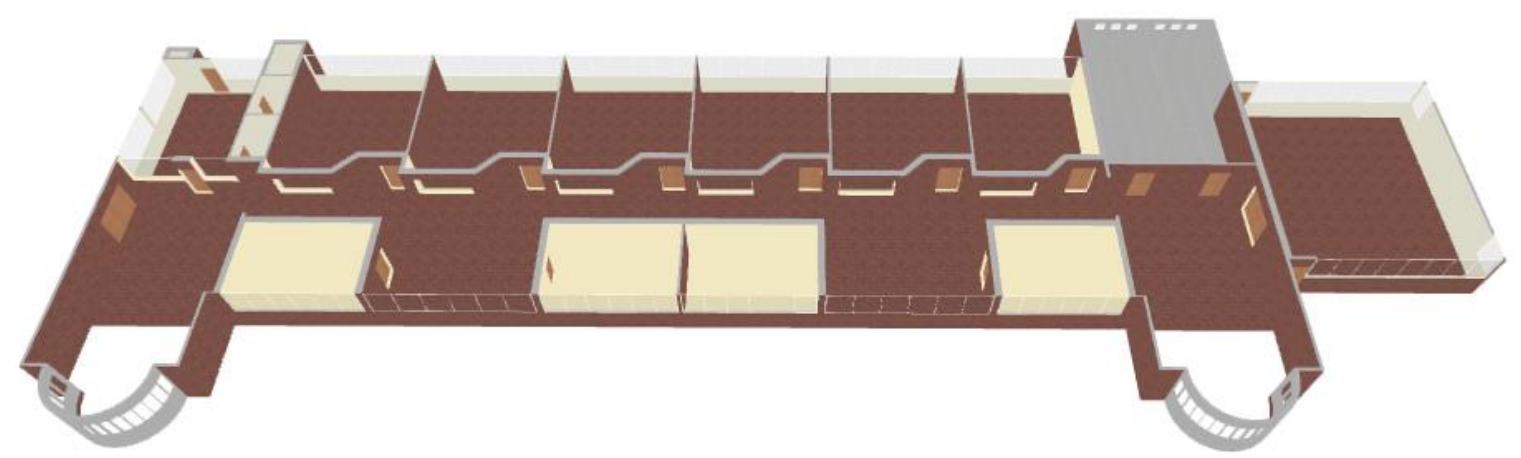

Figura 129. Piso 4.

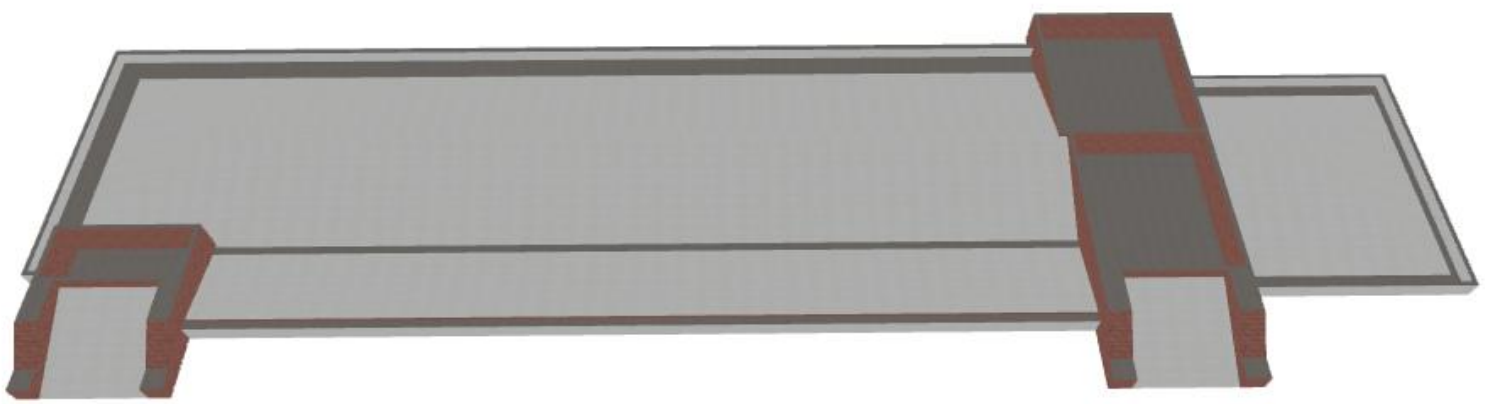

Figura 130. Techo.

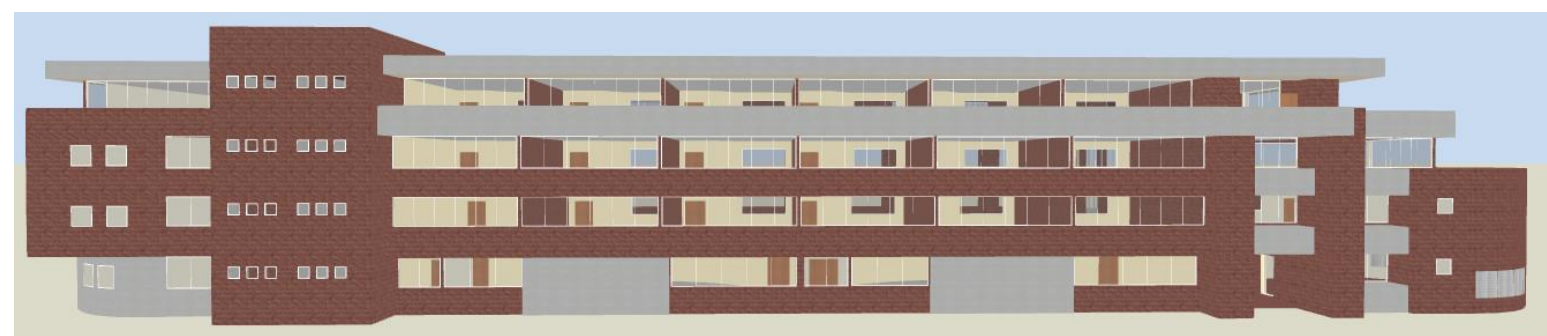

Figura 131. Vista norte del edificio.

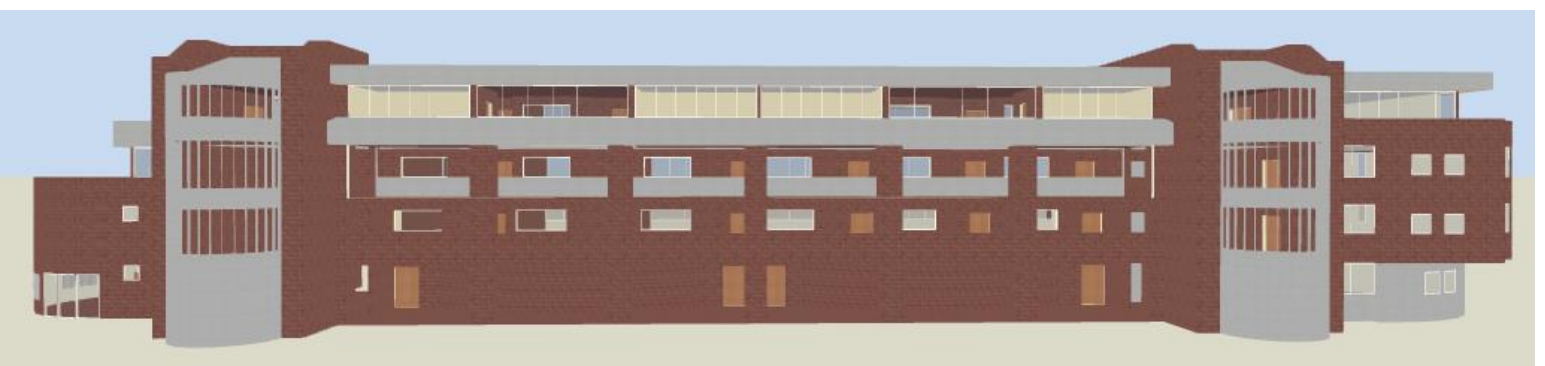

Figura 132. Vista sur del edificio. 


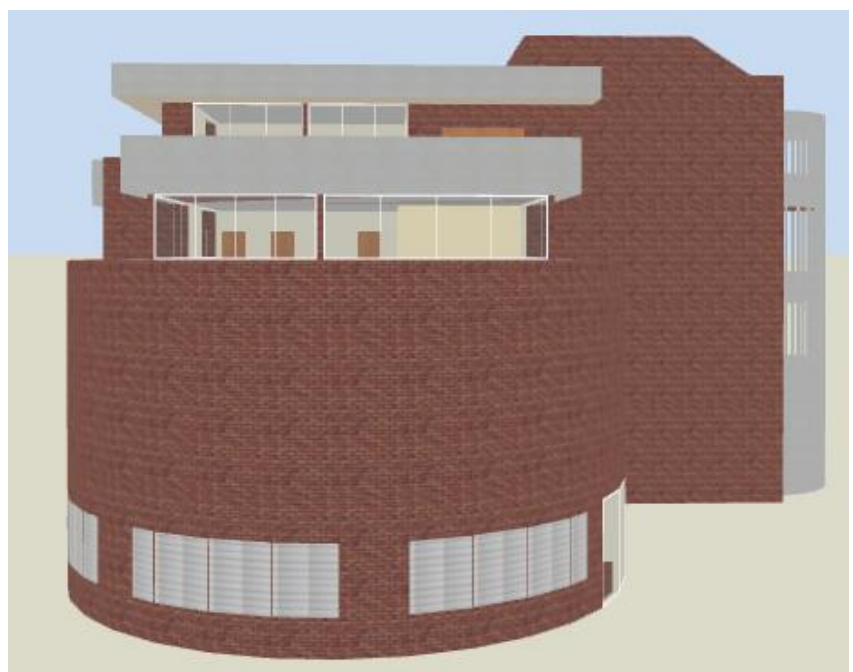

Figura 133. Vista oeste del edificio.

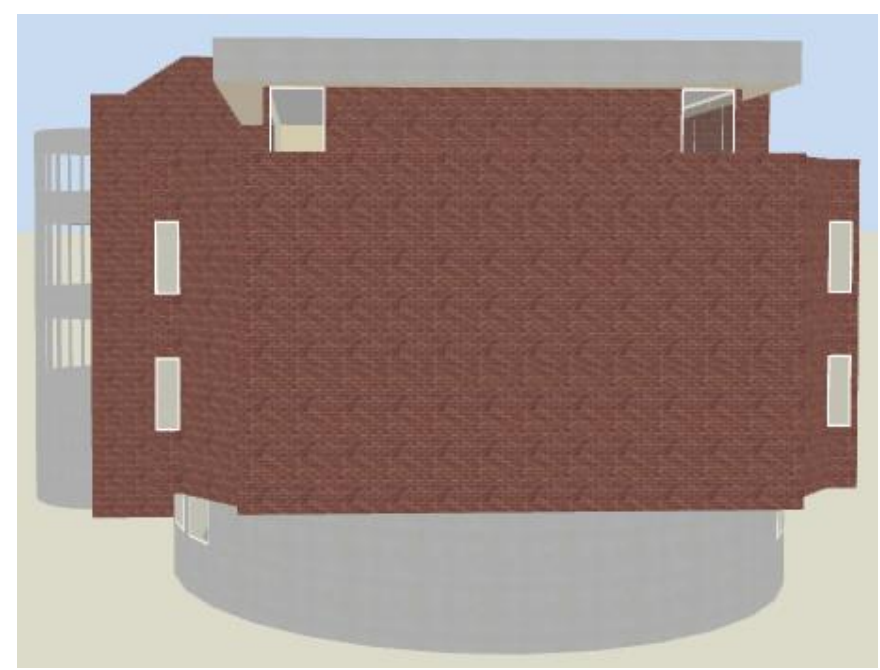

Figura 134. Vista este del edificio.

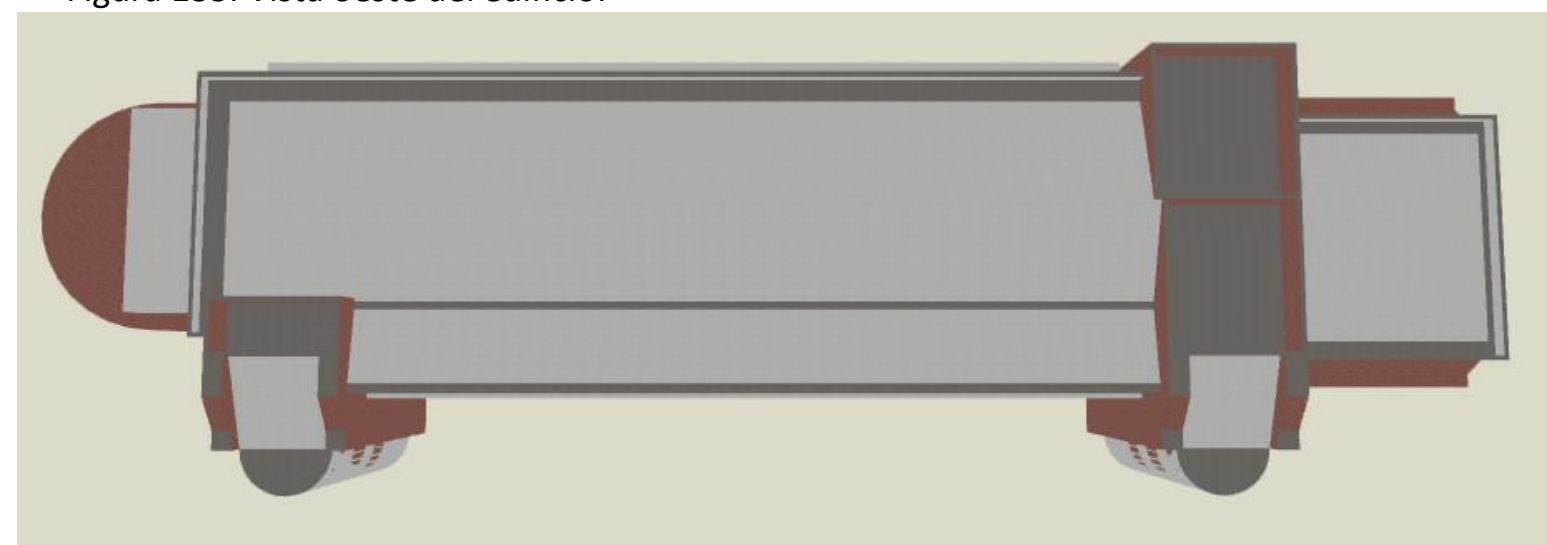

Figura 135. Vista de planta del edificio.

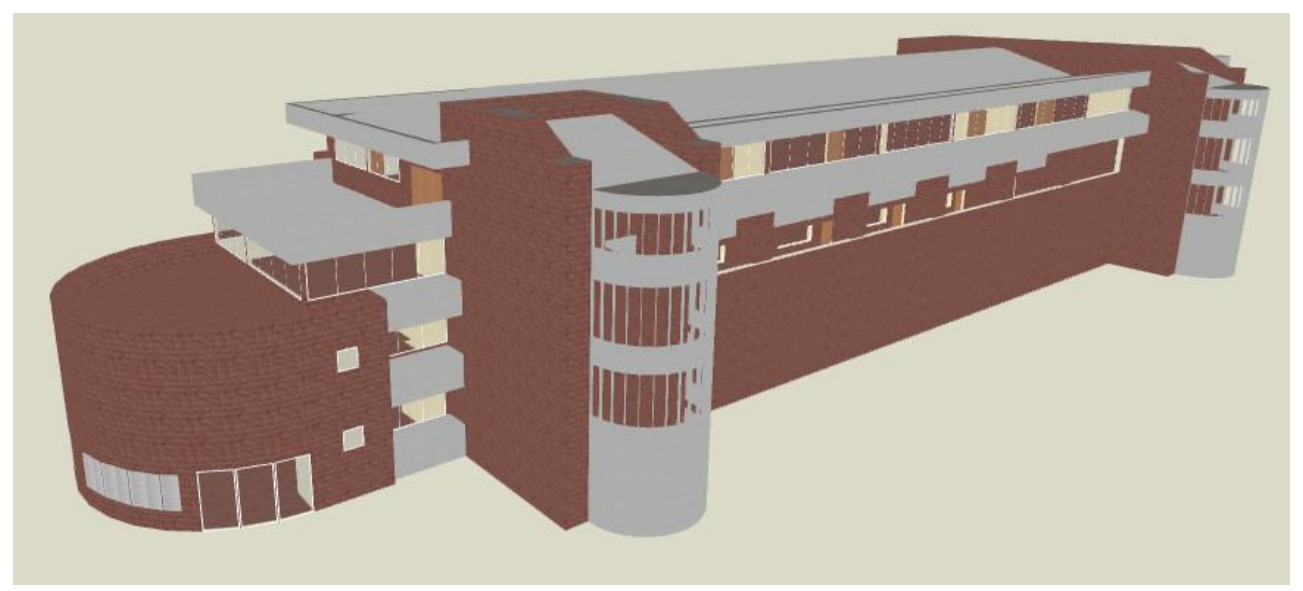

Figura 136. Vista suroeste del edificio. 


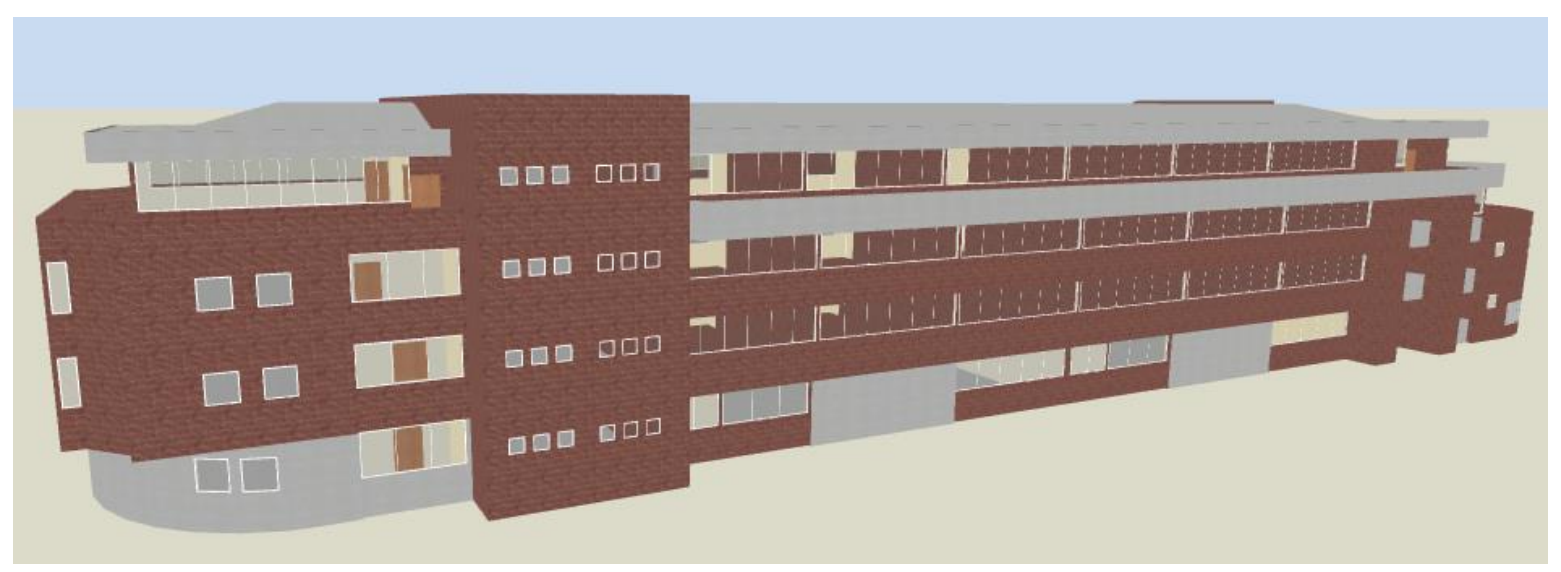

Figura 137. Vista noreste del edificio.

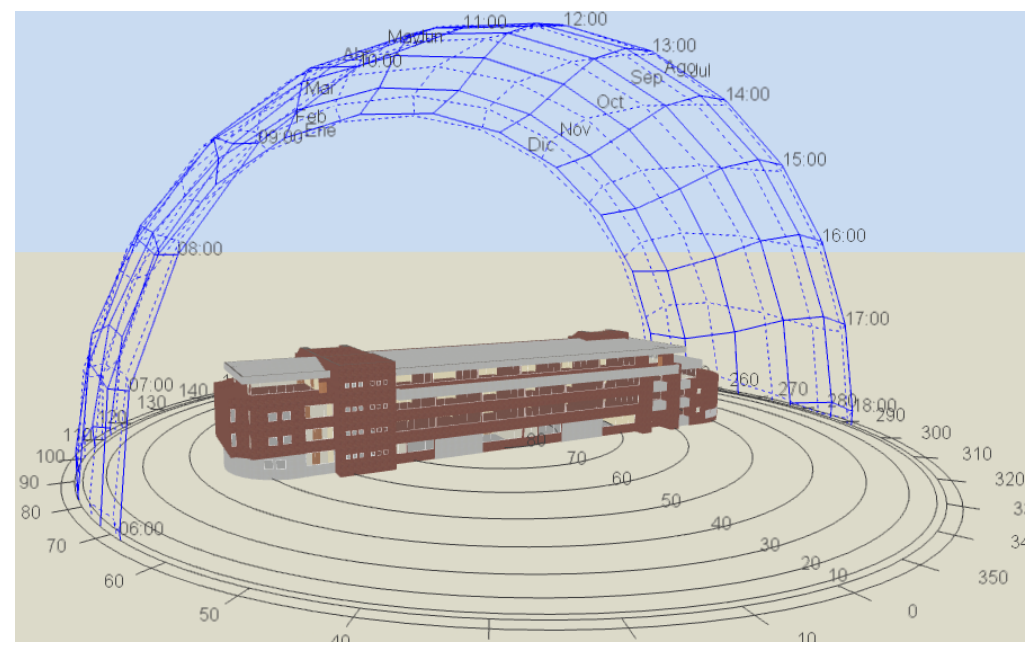

Figura 138. Vista suroeste del edificio con diagrama solar.

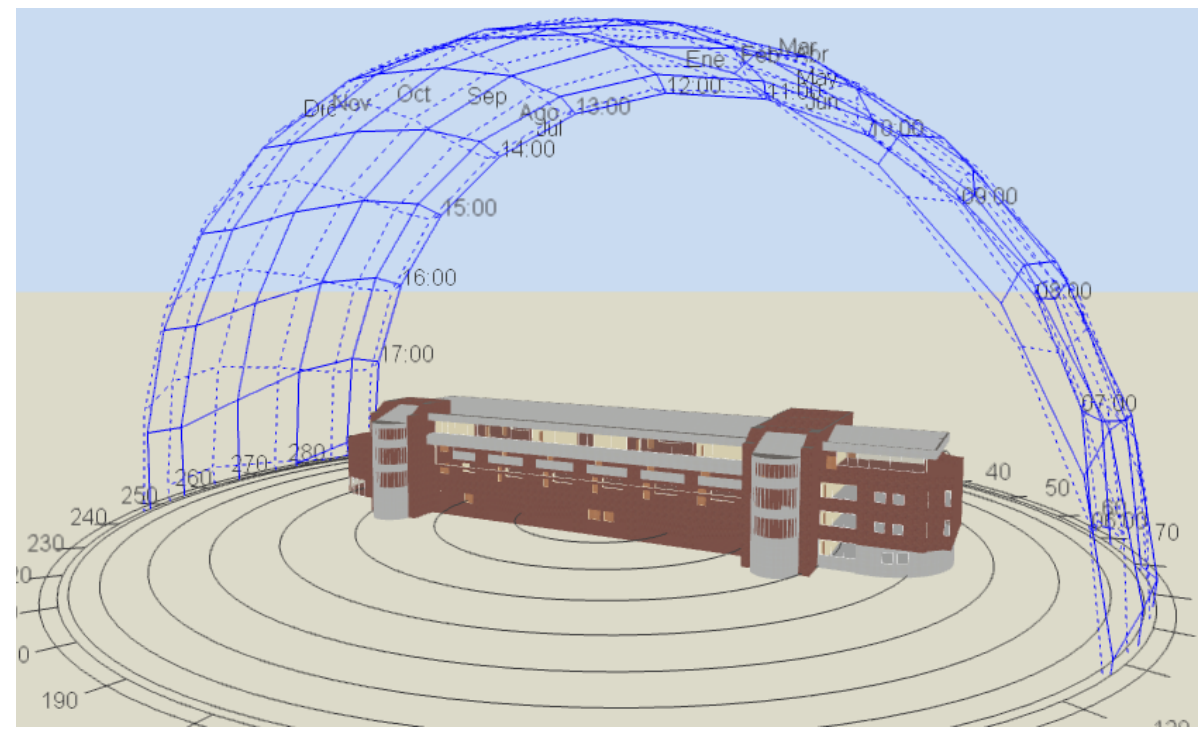

Figura 139. Vista noroeste del edificio con diagrama solar. 


\subsection{COMPARACIÓN DE LOS CONSUMOS ENERGÉTICOS MEDIDOS Y SIMULADOS}

La demanda de energética del edificio se satisface mediante energía eléctrica final, una parte generada con el sistema renovable PV y otra suministrada a través de la red eléctrica. El consumo energético del edificio es únicamente de energía eléctrica, a continuación, se presenta el histórico de consumos del edificio de los años 2016, 2017 y 2018, datos obtenidos a través de la plataforma virtual de los medidores marca SCHNEIDER, instalados en el edificio que permiten una monitorización continua. La Tabla 47 presenta los datos obtenidos al calibrar el modelo simulado en Energy Plus del Edificio.

Tabla 47. Valores de consumo eléctrico reales y simulados

\begin{tabular}{|c|c|c|c|}
\hline Mes & $\begin{array}{c}\text { Consumo } \\
\text { real año } \\
\mathbf{2 0 1 7}\end{array}$ & $\begin{array}{c}\text { Consumo } \\
\text { simulado } \\
\text { año tipo }\end{array}$ & Error \\
\hline Enero & 8621 & 8120 & $5.81 \%$ \\
\hline Febrero & 19672 & 20661 & $5.03 \%$ \\
\hline Marzo & 20782 & 23918 & $15.09 \%$ \\
\hline Abril & 17120 & 17903 & $4.57 \%$ \\
\hline Mayo & 20919 & 18995 & $9.20 \%$ \\
\hline Junio & 10869 & 10040 & $7.63 \%$ \\
\hline Julio & 11163 & 9565 & $14.32 \%$ \\
\hline Agosto & 18805 & 20482 & $8.92 \%$ \\
\hline Septiembre & 18620 & 18943 & $1.74 \%$ \\
\hline Octubre & 17007 & 18807 & $10.59 \%$ \\
\hline Noviembre & 14861 & 13418 & $9.71 \%$ \\
\hline Diciembre & 8023 & 7086 & $11.67 \%$ \\
\hline Total & $\mathbf{1 8 6 4 6 2}$ & $\mathbf{1 8 7 9 3 8}$ & $\mathbf{0 . 7 9 \%}$ \\
\hline
\end{tabular}

\subsubsection{Consumo Total de Energía}

Una vez introducidos los datos de materiales constructivos, geometría, orientación, actividades y sistemas de climatización. Se realizó la simulación energética donde se obtiene el consumo total de energía final anual del edificio. El dato obtenido por simulación fue de $187.938 \mathrm{kWh}$, mientras que el consumo real para el año 2017 (registrado por los medidores) fue de $186.462 \mathrm{kWh}$, la diferencia es de $0.79 \%$, por encima valor aceptable a pesar de que en algunos meses el error se acepta entre 10 y $15 \%$, el valor de diferencia es bastante aceptable, ya que el edificio ha sido simulado para el caso de mayor carga térmica y eléctrica y es por esto que el valor se encuentra por encima del real, ya que para este edificio el sistema operó durante un tiempo a cargas parciales. 
Tabla 48. Energía total consumida.

\begin{tabular}{|c|c|c|}
\hline $\begin{array}{c}\text { Energía total } \\
{[\mathbf{k w h}]}\end{array}$ & $\begin{array}{c}\text { Energía total por } \\
\text { área construida } \\
{\left[\mathbf{k w h} / \mathbf{m}^{2}\right]}\end{array}$ & $\begin{array}{c}\text { Energía total por área } \\
\text { climatizada construida } \\
{\left[\mathbf{k w h} / \mathbf{m}^{2}\right]}\end{array}$ \\
\hline $\mathbf{1 8 7 . 9 3 8}$ & 68,63 & 159,17 \\
\hline
\end{tabular}

Si comparamos el indicador de consumo de energía $\mathrm{kWh} / \mathrm{m}^{2}$, considerando la superficie en un caso el área total del edificio útil y en otro caso sólo la superficie climatizada del edificio se comprueba que este último es el doble.

En la Tabla 48., se comprueba que el consumo energético es más del doble solo teniendo en cuenta el área total climatizada. Sin embrago esta es la situación más real porque el resto de superficie no climatizada son espacios abiertos.

En la Figura 140 se muestra la evolución del consumo de energía del edificio por meses, en un año meteorológico tipo comparado con el real del año 2017 y observándose que los meses de menor consumo energético corresponden a enero, junio y diciembre debido a una época vacacional.

Consumos totales año 2017 y año tipo simulado

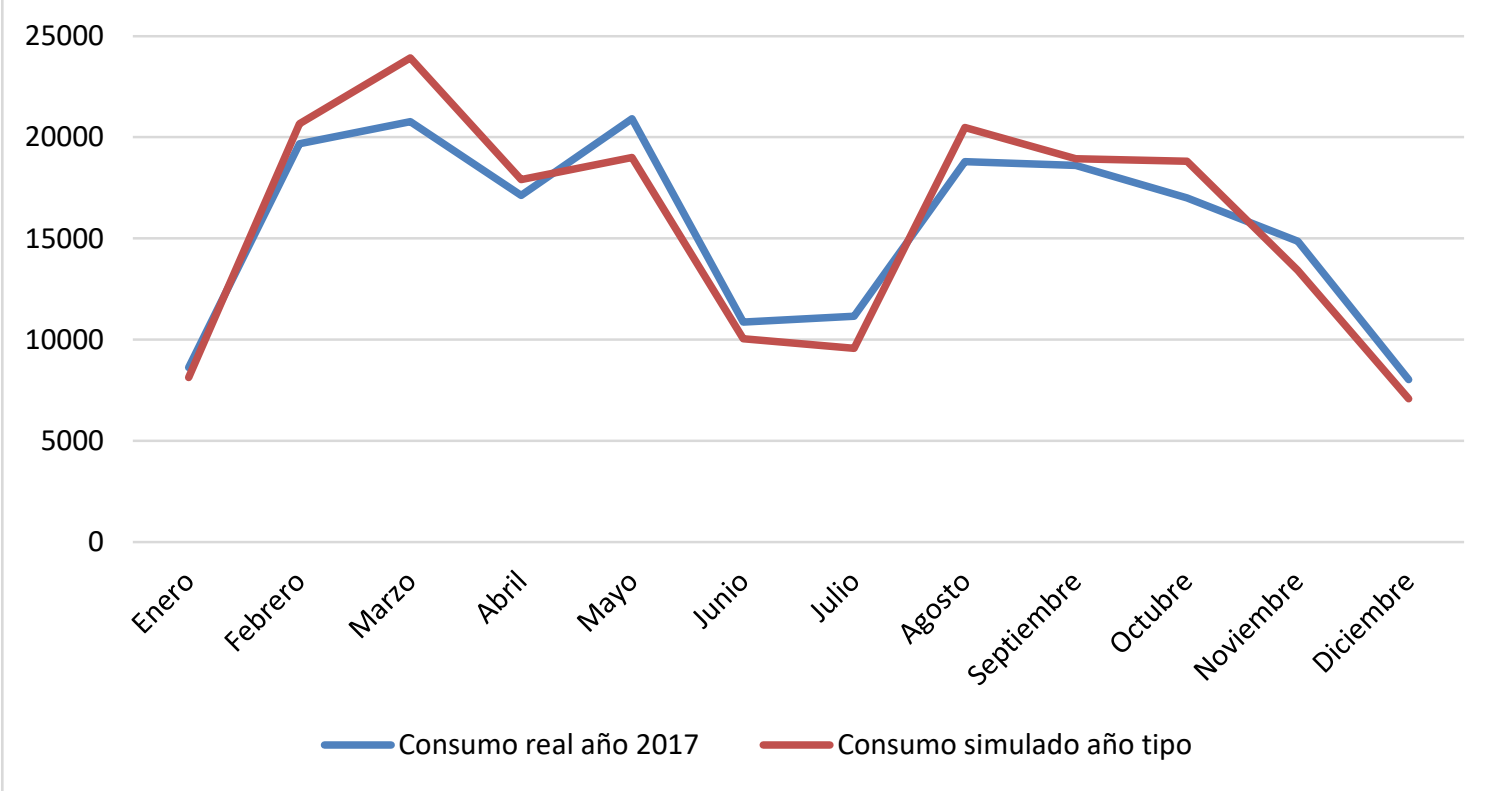

Figura 140. Consumo energético anual simulado y real. 


\subsubsection{Consumo de Energía por Usos}

A continuación, se desglosa el consumo total anual de energía final simulado del edificio de acuerdo con el tipo de uso como lo presentan la Tabla 49 y la Table 50. Se observa que el porcentaje de consumo mayor es la refrigeración, seguido de los equipos ofimáticos.

Tabla 49. Distribución de consumos energéticos por uso.

\begin{tabular}{|c|c|c|}
\hline Tipo de uso & Electricidad (Kwh) & Porcentaje de carga (\%) \\
\hline Enfriamiento & 91558,35 & 48,72 \\
\hline Iluminación interior & 10014,02 & 5,33 \\
\hline Iluminación exterior & 1735,82 & 0,92 \\
\hline Equipos interiores & 84630,13 & 45,03 \\
\hline Consumo Total (Kwh) & $\mathbf{1 8 7 9 3 8 , 3 2}$ & $\mathbf{1 0 0}$ \\
\hline
\end{tabular}

Tabla 50. Distribución de consumos energéticos desglosados mes a mes por uso.

\begin{tabular}{|c|c|c|c|c|c|c|c|}
\hline Mes & Refrigeración & $\begin{array}{c}\text { Iluminación } \\
\text { interior }\end{array}$ & $\begin{array}{c}\text { Iluminación } \\
\text { exterior }\end{array}$ & Equipos & $\begin{array}{c}\text { Total } \\
\text { (kwh) }\end{array}$ & $\begin{array}{c}\text { Consumo } \\
\text { kwh/día }\end{array}$ & $\begin{array}{c}\% \\
\text { consumo } \\
\text { mes }\end{array}$ \\
\hline Enero & 3561.25 & 341.51 & 53.58 & 4163.75 & 8120.09 & 261.94 & $4.3 \%$ \\
\hline Febrero & 10437.90 & 1149.70 & 214.30 & 8859.06 & 20660.96 & 737.89 & $11.0 \%$ \\
\hline Marzo & 12164.65 & 1326.59 & 246.44 & 10179.94 & 23917.62 & 771.54 & $12.7 \%$ \\
\hline Abril & 9586.68 & 1184.71 & 214.30 & 6916.94 & 17902.63 & 596.75 & $9.5 \%$ \\
\hline Mayo & 9463.18 & 962.87 & 160.72 & 8407.74 & 18994.51 & 612.73 & $10.1 \%$ \\
\hline Junio & 2433.77 & 144.42 & 0.00 & 7461.88 & 10040.07 & 334.67 & $5.3 \%$ \\
\hline Julio & 4330.96 & 380.47 & 53.58 & 4799.50 & 9564.51 & 308.53 & $5.1 \%$ \\
\hline Agosto & 11388.65 & 1316.33 & 246.44 & 7531.07 & 20482.49 & 660.73 & $10.9 \%$ \\
\hline Septiembre & 10267.62 & 1238.83 & 225.01 & 7211.90 & 18943.36 & 631.45 & $10.1 \%$ \\
\hline Octubre & 9995.76 & 1272.47 & 235.73 & 7303.31 & 18807.27 & 606.69 & $10.0 \%$ \\
\hline Noviembre & 6357.02 & 602.63 & 85.72 & 6373.07 & 13418.44 & 432.85 & $7.1 \%$ \\
\hline Diciembre & 1570.91 & 93.49 & 0.00 & 5421.97 & 7086.37 & 236.21 & $3.8 \%$ \\
\hline
\end{tabular}

Las figuras 141 y 142., muestran la distribución de consumo anual simulado y la distribución porcentual por consumos para el año 2017 respectivamente. 


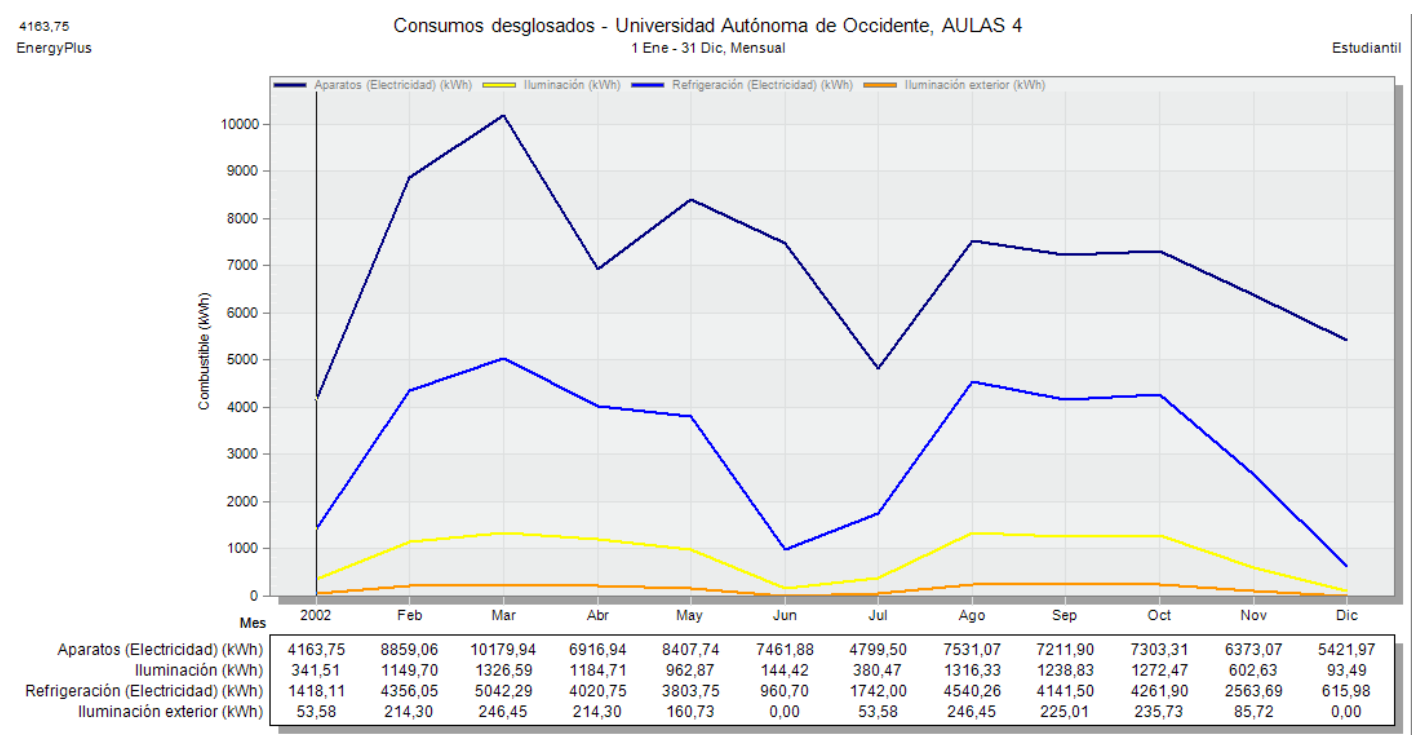

Figura 141. Distribución de consumo energético mensual desglosado por uso final.

\section{Consumo Energético por Uso Final}

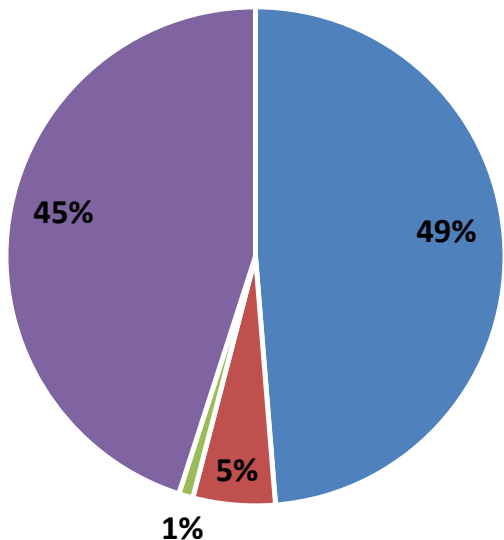

Refrigeración

- Iluminación interior

- Iluminación exterior

Equipos

Figura 142. Distribución porcentual de consumo energético por uso final.

Como se observa en la Figura 143 los consumos energéticos del edificio se encuentran distribuidos en: iluminación exterior con 1.735,83 kWh (0,92\%), iluminación interior con 10.014,03 kWh (5,33\%), equipos ofimáticos con 84630,14 kWh (45,03\%), climatización con $91.558,35 \mathrm{kWh}(48,72 \%)$. 


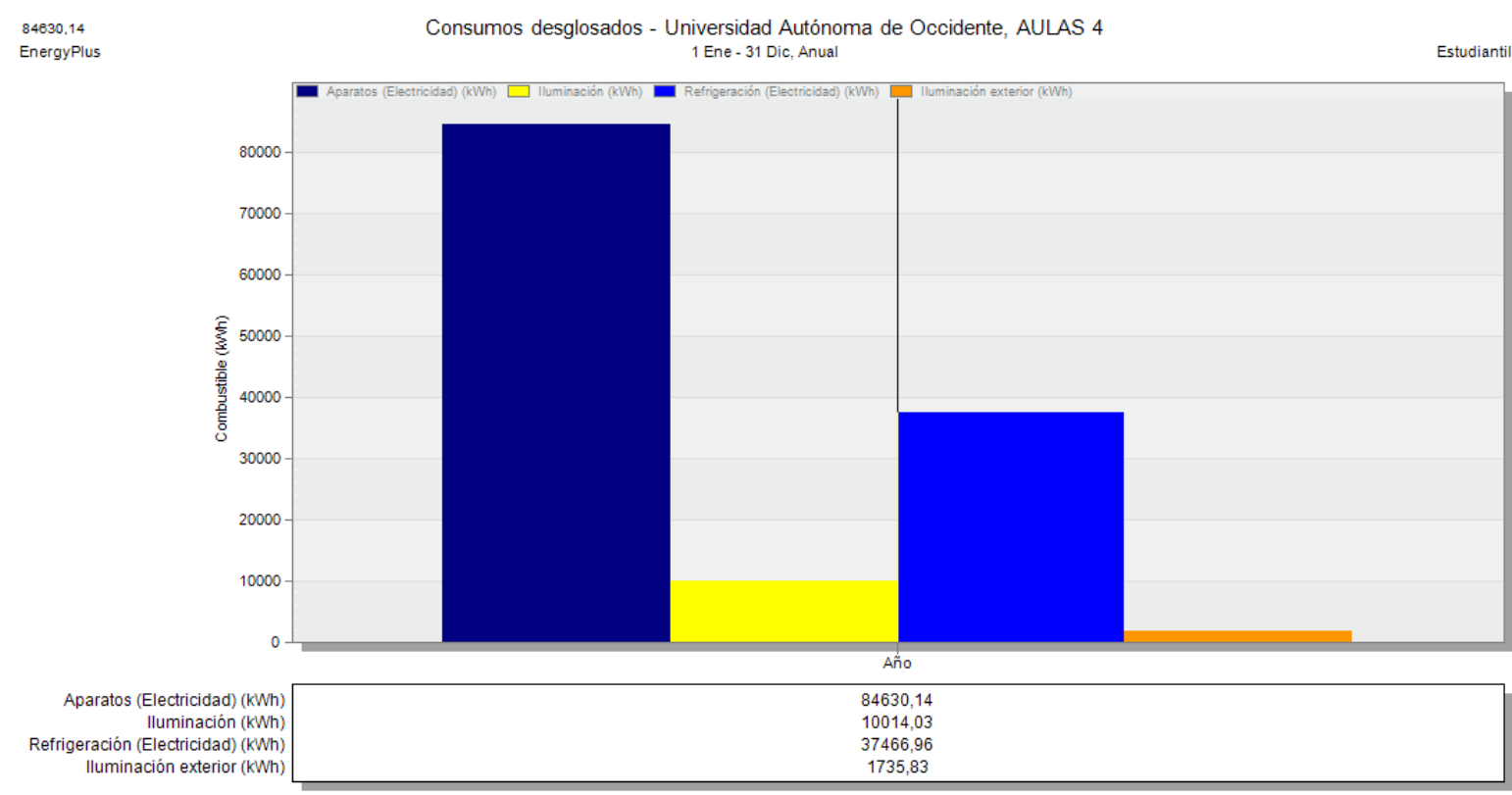

Figura 143. Diagrama de barras distribución del consumo energético anual.

\subsubsection{Impacto Medioambiental - Emisiones de $\mathrm{CO}_{2}$}

Se obtienen las emisiones de $\mathrm{kg}$ de $\mathrm{CO}_{2}$ generados por las instalaciones, presentado de forma mensual y anual en la ¡Error! No se encuentra el origen de la referencia. y la ¡Error! se encuentra el origen de la referencia..

Tabla 51. Producción mensual y anual de $\mathrm{kg}$ de $\mathrm{CO}_{2}$

\begin{tabular}{|c|c|}
\hline Mes & kg de $\mathbf{C O}_{\mathbf{2}}$ \\
\hline Enero & 3622,03 \\
\hline Febrero & 8834,94 \\
\hline Marzo & 10177,92 \\
\hline Abril & 7476,04 \\
\hline Mayo & 8081,05 \\
\hline Junio & 5191,60 \\
\hline Julio & 4227,17 \\
\hline Agosto & 8262,26 \\
\hline Septiembre & 7767,25 \\
\hline Octubre & 7922,48 \\
\hline Noviembre & 5832,81 \\
\hline Diciembre & 3715,65 \\
\hline Total & 81111,2 \\
\hline
\end{tabular}

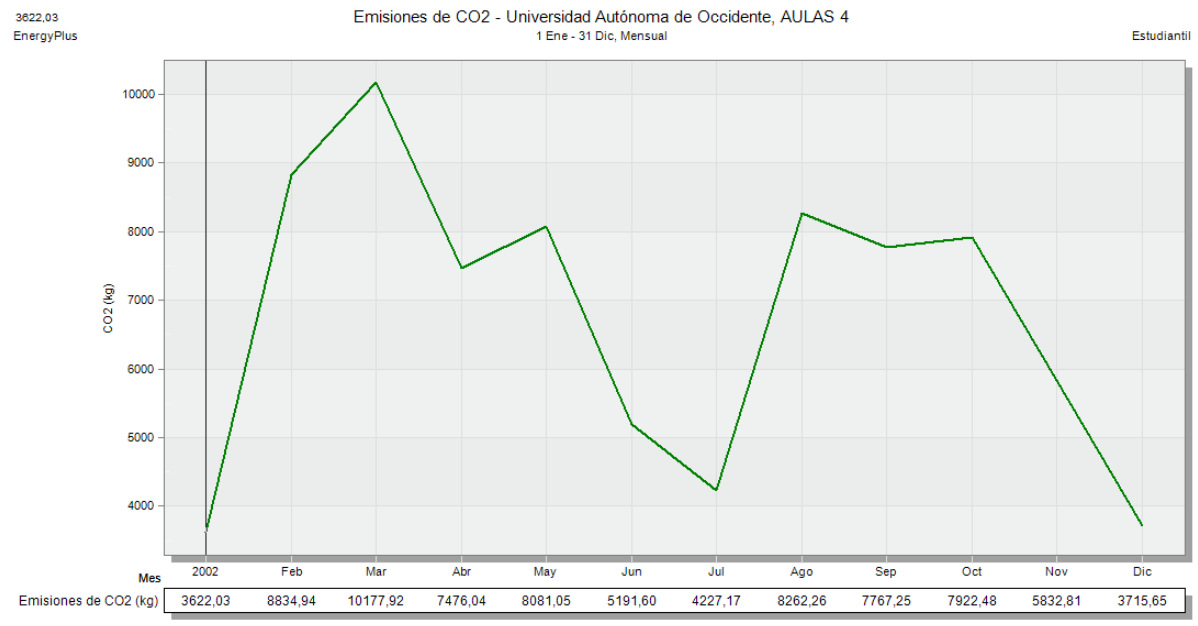

Figura 144. Emisiones de $\mathrm{CO}_{2}$ mensual para el edificio 


\section{CAPÍTULO 6: PROPUESTAS DE MAE'S PARA EL EDIFICIO DE AULAS 4 MEDIANTE SIMULACIÓN ENERGÉTICA}

Las medidas de ahorro energético MAE's que se proponen en este capitulo, son unas de tipo pasivo que afectan a la reducción de la demanda de energía del edificio y otras activas que se aplican a las instalaciones térmicas y eléctricas.

El tipo de MAE's propuestas son:

1. Sistemas de Aire Acondicionado más eficiente energéticamente

2. Rediseño del sistema de iluminación interior

3. Filtros Solares y sombras

- Vidrio electrocrómico

- Voladizos

- Persianas reflectivas

- Películas Protectoras

4. Implementación de todas las MAE's propuestas

5. Sistema de respaldo de baterías para el sistema de iluminación

\subsection{MAE I - SISTEMA DE AIRE ACONDICIONADO MÁS EFICIENTE.}

En este apartado se analiza y simula energéticamente el edificio de aulas 4 implementando la propuesta de acondicionamiento de los recintos del edificio, en la cual se mejoran los sistemas de aire acondicionado del edificio, reemplazando los equipos existentes por equipos de tecnología VRF, en aras de incrementar la eficiencia energética del edificio por medio de la reducción del consumo de energía eléctrica. Además, se propone la adición de refrigeración a recintos no aclimatados, esto con el fin de mejorar el confort en cada una de las áreas del edificio. Las tablas 52 - 54, presentan las características técnicas de los equipos a instalar, el listado de los recintos a acondicionar junto con el flujo y las características técnicas de los equipos interiores y exteriores de aire acondicionado.

Tabla 52. Características técnicas extractores

\begin{tabular}{|c|c|c|}
\hline Recinto & Aumento de presión (Pa) & Caudal máximo $\left.\mathbf{~ m}^{\mathbf{3}} \mathbf{/ s}\right)$ \\
\hline Baño hombres r.a. & 49,8 & 0,0472 \\
\hline Baño mujeres r.a. & 49,8 & 0,0472 \\
\hline Baño hombres p1 & 104,5 & 0,2737 \\
\hline Baño mujeres p1 & 102 & 0,2265 \\
\hline Baño auxiliar TIC & 49,8 & 0,0472 \\
\hline Baño hombres TIC & 49,8 & 0,0472 \\
\hline Baño mujeres TIC & 49,8 & 0,0472 \\
\hline Baño hombres p2 & 104,5 & 0,2737 \\
\hline
\end{tabular}




\begin{tabular}{|c|c|c|}
\hline Baño mujeres p2 & 102 & 0,2265 \\
\hline Baño auxiliar planta física & 49,8 & 0,0472 \\
\hline Baño hombres p3 & 104,5 & 0,2737 \\
\hline Baño mujeres p3 & 102 & 0,2265 \\
\hline C.t. Salón vacío 3 & 49,8 & 0,0566 \\
\hline Baño hombres p4 & 104,5 & 0,2737 \\
\hline Baño mujeres p4 & 102 & 0,2265 \\
\hline
\end{tabular}

Tabla 53. Características técnicas de los equipos de acondicionamiento de recintos

\begin{tabular}{|c|c|c|c|c|c|c|c|}
\hline $\begin{array}{c}\text { Condensadora } \\
\text { de aire }\end{array}$ & $\begin{array}{c}\text { Capacidad } \\
\text { (btu/h) }\end{array}$ & $\begin{array}{l}\text { Cant. } \\
\text { Módulos }\end{array}$ & $\begin{array}{l}\text { Capacidad } \\
\text { refrigeración } \\
(\mathbf{k W})\end{array}$ & $\begin{array}{l}\text { Fan-coil } \\
\text { asociados }\end{array}$ & Piso & $\begin{array}{l}\text { Caudal } \\
\left(\mathrm{m}^{3} / \mathrm{s}\right)\end{array}$ & $\begin{array}{l}\text { Temperatura } \\
\text { referencia }\left({ }^{\circ} \mathrm{C}\right)\end{array}$ \\
\hline \multirow{2}{*}{$\begin{array}{c}\text { UCA \# 1-B4- } \\
\text { N1 }\end{array}$} & \multirow{2}{*}{408000} & \multirow{2}{*}{2} & \multirow{2}{*}{119,6} & A4T1A & 1 & 1,557 & 25 \\
\hline & & & & A4T1B & 1 & 1,557 & 25 \\
\hline \multirow{7}{*}{$\begin{array}{c}\text { UCA \# 2-B4- } \\
\text { N2 }\end{array}$} & \multirow{7}{*}{408000} & \multirow{7}{*}{3} & \multirow{7}{*}{119,6} & TIC Sur & 2 & 0,649 & 25 \\
\hline & & & & 4201 & 2 & 0,649 & 25 \\
\hline & & & & 4202 & 2 & 0,649 & 25 \\
\hline & & & & 4203 & 2 & 0,649 & 25 \\
\hline & & & & 4204 & 2 & 0,649 & 25 \\
\hline & & & & 4205 & 2 & 0,649 & 25 \\
\hline & & & & 4206 & 2 & 0,649 & 25 \\
\hline \multirow{8}{*}{$\begin{array}{c}\text { UCA \# 3-B1- } \\
\text { N3 }\end{array}$} & \multirow{8}{*}{432000} & \multirow{8}{*}{3} & \multirow{8}{*}{126,6} & Planta Física & 3 & 0,765 & 24 \\
\hline & & & & Planta Física & 3 & 0,649 & 25 \\
\hline & & & & 4301 & 3 & 0,649 & 25 \\
\hline & & & & 4302 & 3 & 0,649 & 25 \\
\hline & & & & 4303 & 3 & 0,649 & 25 \\
\hline & & & & 4304 & 3 & 0,649 & 25 \\
\hline & & & & 4305 & 3 & 0,649 & 25 \\
\hline & & & & 4306 & 3 & 0,649 & 25 \\
\hline \multirow{8}{*}{$\begin{array}{c}\text { UCA \# 4-B4- } \\
\text { N4 }\end{array}$} & \multirow{8}{*}{408000} & \multirow{8}{*}{3} & \multirow{8}{*}{119,6} & Salón vacío & 4 & 0,316 & 24 \\
\hline & & & & Salón vacío & 4 & 0,316 & 24 \\
\hline & & & & 4401 & 4 & 0,765 & 24 \\
\hline & & & & 4402 & 4 & 0,765 & 24 \\
\hline & & & & 4403 & 4 & 0,765 & 24 \\
\hline & & & & 4404 & 4 & 0,765 & 24 \\
\hline & & & & 4405 & 4 & 0,765 & 24 \\
\hline & & & & 4406 & 4 & 0,765 & 24 \\
\hline \multirow{5}{*}{$\begin{array}{c}\text { UCA \# 5-B1- } \\
\text { N4-2 }\end{array}$} & \multirow{5}{*}{360000} & \multirow{5}{*}{3} & \multirow{5}{*}{105,5} & 4407 & 4 & 0,533 & 24 \\
\hline & & & & 4408 & 4 & 0,533 & 24 \\
\hline & & & & 4409 & 4 & 0,533 & 24 \\
\hline & & & & 4410 & 4 & 0,533 & 24 \\
\hline & & & & A4T4 & 4 & 1,586 & 24 \\
\hline \multirow{3}{*}{$\begin{array}{l}\text { UCA \# 6-B4- } \\
\text { SALONES } \\
\text { TORREONES } \\
\text { N1-N2-N3 }\end{array}$} & \multirow{3}{*}{408000} & \multirow{3}{*}{3} & \multirow{3}{*}{119,6} & A4T1 & 1 & 1,472 & 24 \\
\hline & & & & A4T2 & 2 & 1,472 & 24 \\
\hline & & & & A4T3 & 3 & 1,699 & 24 \\
\hline
\end{tabular}


Tabla 54. Resumen datos recintos climatizados actualizados del edificio.

\begin{tabular}{|c|c|c|c|c|}
\hline Nivel & Recinto & Área $(\mathrm{m} 2)$ & Volumen (m3) & Climatizado \\
\hline \multirow{18}{*}{$\begin{array}{l}\text { Primer } \\
\text { piso - } \\
\text { planta } \\
\text { baja }\end{array}$} & Egresados & 96,55 & 251,04 & No \\
\hline & A4t1 & 111,16 & 289,01 & $\mathrm{Si}$ \\
\hline & A4t1A & 136,61 & 355,19 & $\mathrm{Si}$ \\
\hline & A4t1B & 136,59 & 355,13 & $\mathrm{Si}$ \\
\hline & Baño mujeres p1 & 26,98 & 70,14 & $\mathrm{Si}$ \\
\hline & Baño hombres p1 & 23,63 & 61,45 & $\mathrm{Si}$ \\
\hline & Pasillo sur p1 & 158,03 & 410,88 & No \\
\hline & Pasillo este $\mathrm{p} 1$ & 40,11 & 104,29 & No \\
\hline & Pasillo oeste p1 & 73,49 & 191,07 & No \\
\hline & Cm. A4t1 & 8,17 & 21,24 & No \\
\hline & Cm. A4t1A & 6,09 & 15,84 & No \\
\hline & Cm. A4t1B & 5,51 & 14,32 & No \\
\hline & Escalera este p1 & 10,71 & 27,84 & No \\
\hline & Escalera oeste p1 & 23,52 & 61,16 & No \\
\hline & Baño mujeres egresados & 2,83 & 7,35 & $\mathrm{Si}$ \\
\hline & Baño hombres egresados & 2,94 & 7,65 & $\mathrm{Si}$ \\
\hline & Cuarto tecnico p1 & 3,52 & 9,14 & No \\
\hline & Cuarto multimedios & 12,51 & 32,53 & No \\
\hline \multirow{23}{*}{$\begin{array}{c}\text { Segundo } \\
\text { piso - } \\
\text { planta } \\
\text { primera }\end{array}$} & TIC sur & 72,41 & 167,99 & $\mathrm{Si}$ \\
\hline & TIC norte & 49,8 & 115,54 & $\mathrm{Si}$ \\
\hline & 4201 & 45,55 & 105,67 & $\mathrm{Si}$ \\
\hline & 4202 & 46,94 & 108,89 & $\mathrm{Si}$ \\
\hline & 4203 & 46,94 & 108,89 & $\mathrm{Si}$ \\
\hline & 4204 & 46,94 & 108,89 & $\mathrm{Si}$ \\
\hline & 4205 & 47,08 & 109,22 & $\mathrm{Si}$ \\
\hline & 4206 & 42,85 & 99,41 & $\mathrm{Si}$ \\
\hline & A4T2 & 126,88 & 310,85 & $\mathrm{Si}$ \\
\hline & Baño hombres p2 & 23,63 & 56,01 & $\mathrm{Si}$ \\
\hline & Baño mujeres p2 & 26,97 & 63,93 & $\mathrm{Si}$ \\
\hline & Pasillo sur p2 & 178,13 & 413,26 & No \\
\hline & Pasillo este p2 & 40,13 & 93,1 & No \\
\hline & Pasillo oeste p2 & 37,61 & 87,25 & No \\
\hline & Cm. A4T2 & 7,98 & 19,55 & No \\
\hline & C. T. TIC 1 & 2,89 & 6,66 & No \\
\hline & C. T. TIC 2 & 3,46 & 7,99 & No \\
\hline & C. T. TIC 3 & 1,49 & 3,46 & No \\
\hline & Escalera este p2 & 12,8 & 55,1 & No \\
\hline & Escalera oeste p2 & 0,03 & 54,57 & No \\
\hline & Baño mujeres TIC & 2,16 & 5,02 & $\mathrm{Si}$ \\
\hline & Baño hombres TIC & 2,26 & 5,25 & $\mathrm{Si}$ \\
\hline & Baño auxiliar TIC & 3,11 & 7,18 & $\mathrm{Si}$ \\
\hline \multirow{3}{*}{$\begin{array}{l}\text { Tercer } \\
\text { piso - }\end{array}$} & Planta física sur & 34 & 78,88 & $\mathrm{Si}$ \\
\hline & Planta física norte & 33,67 & 78,11 & $\mathrm{Si}$ \\
\hline & 4301 & 40,77 & 94,59 & $\mathrm{Si}$ \\
\hline
\end{tabular}




\begin{tabular}{|c|c|c|c|c|}
\hline \multirow{19}{*}{$\begin{array}{c}\text { planta } \\
\text { segunda }\end{array}$} & 4302 & 40,98 & 95,08 & $\mathrm{Si}$ \\
\hline & 4303 & 40,99 & 95,1 & $\mathrm{Si}$ \\
\hline & 4304 & 40,99 & 95,1 & $\mathrm{Si}$ \\
\hline & 4305 & 41,33 & 95,88 & $\mathrm{Si}$ \\
\hline & 4306 & 37,45 & 86,88 & $\mathrm{Si}$ \\
\hline & $\mathrm{A} 4 \mathrm{t} 3$ & 126,88 & 310,85 & $\mathrm{Si}$ \\
\hline & Baño hombres p3 & 23,63 & 56,01 & $\mathrm{Si}$ \\
\hline & Baño mujeres p3 & 27 & 64 & $\mathrm{Si}$ \\
\hline & Pasillo sur p3 & 91,65 & 212,63 & No \\
\hline & Pasillo este $\mathrm{p} 3$ & 40,19 & 93,23 & No \\
\hline & Pasillo oeste $\mathrm{p3}$ & 37,69 & 87,45 & No \\
\hline & $\mathrm{Cm} . \mathrm{A} 4 \mathrm{t} 3$ & 7,98 & 19,55 & No \\
\hline & C. T. Planta física 1 & 2,89 & 6,7 & No \\
\hline & C. T. Planta física 2 & 3,46 & 8,03 & No \\
\hline & C. T. Planta física 3 & 1,49 & 3,46 & No \\
\hline & Escalera este $\mathrm{p3}$ & 0,04 & 55,1 & No \\
\hline & Escalera oeste p3 & 0,02 & 54,57 & No \\
\hline & Baño auxiliar planta física & 3,11 & 7,22 & $\mathrm{Si}$ \\
\hline & Vacío p3 & 13,52 & 253,96 & No \\
\hline \multirow{24}{*}{$\begin{array}{l}\text { Cuarto } \\
\text { piso - } \\
\text { planta } \\
\text { tercera }\end{array}$} & Investigadores norte & 13,04 & 30,25 & $\mathrm{Si}$ \\
\hline & Investigadores sur & 11,87 & 27,54 & $\mathrm{Si}$ \\
\hline & 4401 & 34,93 & 81,04 & $\mathrm{Si}$ \\
\hline & 4402 & 35,09 & 81,42 & $\mathrm{Si}$ \\
\hline & 4403 & 35,1 & 81,44 & $\mathrm{Si}$ \\
\hline & 4404 & 35,1 & 81,44 & $\mathrm{Si}$ \\
\hline & 4405 & 35,39 & 82,1 & $\mathrm{Si}$ \\
\hline & 4406 & 32,1 & 74,47 & $\mathrm{Si}$ \\
\hline & 4407 & 15,6 & 36,01 & $\mathrm{Si}$ \\
\hline & 4408 & 17,07 & 39,4 & $\mathrm{Si}$ \\
\hline & 4409 & 17,07 & 39,4 & $\mathrm{Si}$ \\
\hline & 4410 & 16,61 & 38,33 & $\mathrm{Si}$ \\
\hline & $\mathrm{A} 4 \mathrm{t} 4$ & 75,97 & 176,25 & $\mathrm{Si}$ \\
\hline & Baño mujeres p4 & 27,01 & 64,02 & $\mathrm{Si}$ \\
\hline & Baño hombres p4 & 23,65 & 56,05 & $\mathrm{Si}$ \\
\hline & Pasillo sur p4 & 134,97 & 313,14 & No \\
\hline & Pasillo este $\mathrm{p} 4$ & 39,9 & 92,56 & No \\
\hline & Pasillo oeste p4 & 38,6 & 89,54 & No \\
\hline & C. T. Investigadores 1 & 3,22 & 7,46 & No \\
\hline & C. T. Investigadores 2 & 2,22 & 5,15 & No \\
\hline & C.t. Investigadores 3 & 0,27 & 0,62 & $\mathrm{Si}$ \\
\hline & Escalera este $\mathrm{p} 4$ & 0,06 & 55,1 & No \\
\hline & Escalera oeste p4 & 0,02 & 54,57 & No \\
\hline & Baños investigadores & 3,11 & 7,22 & No \\
\hline Techo & Techo: Ático & 836,74 & 258,17 & No \\
\hline
\end{tabular}


A continuación, se presentan los datos obtenidos al realizar la simulación energética de esta propuesta de mejora. La Figura 145 muestra la evolución del consumo de energía del edificio por meses, en un año meteorológico tipo y observándose que los meses de menor consumo energético corresponden a enero, junio, Julio y diciembre debido a una época vacacional.

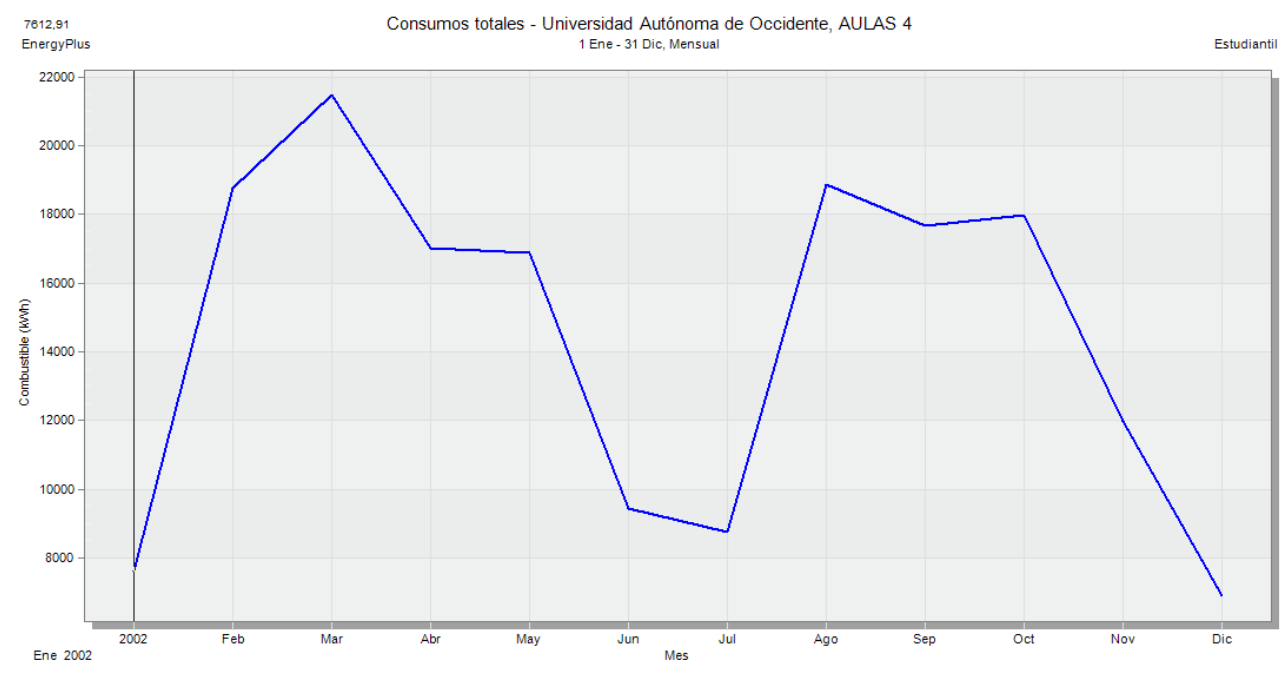

Figura 145. Distribución de consumo energético anual.

A continuación, se desglosa el consumo total anual de energía del edificio con el nuevo sistema VRF de acuerdo con el tipo de uso, como lo muestra la Tabla 55. La Tabla 56, presenta la distribución de consumos energéticos desglosados mes a mes, donde se observa que el porcentaje de consumo mayor es de equipos ofimáticos, seguido de la refrigeración.

Tabla 55. Distribución de consumos energéticos por uso.

\begin{tabular}{|c|c|c|}
\hline TIPO DE USO & ELECTRICIDAD (kWh) & PORCENTAJE DE CARGA (\%) \\
\hline Enfriamiento & 71088,69 & 41,26 \\
\hline Iluminación interior & 10014,02 & 5,81 \\
\hline Iluminación exterior & 1735,82 & 1,01 \\
\hline Equipos interiores & 84633,13 & 49,12 \\
\hline Extractores & 7836,77 & 2,81 \\
\hline CONSUMO TOTAL (kWh) & $\mathbf{1 7 2 3 0 8 , 4 3}$ & $\mathbf{1 0 0}$ \\
\hline
\end{tabular}

Tabla 56. Distribución de consumos energéticos desglosados mes a mes por uso.

\begin{tabular}{|c|c|c|c|c|c|c|c|c|}
\hline Mes & Refrigeración & $\begin{array}{c}\text { Iluminación } \\
\text { interior }\end{array}$ & $\begin{array}{c}\text { Iluminación } \\
\text { exterior }\end{array}$ & Equipos & Extractores & $\begin{array}{c}\text { Total } \\
\text { (kwh) }\end{array}$ & $\begin{array}{c}\text { Consumo } \\
\text { kwh/día }\end{array}$ & $\begin{array}{c}\text { Consumo } \\
\text { mes }\end{array}$ \\
\hline Enero & 2867.76 & 341.51 & 53.58 & 4163.75 & 168.33 & 7594.93 & 245.00 & $4.4 \%$ \\
\hline Febrero & 7786.41 & 1149.70 & 214.30 & 8859.06 & 601.00 & 18610.47 & 664.66 & $10.8 \%$ \\
\hline Marzo & 8893.91 & 1326.59 & 246.44 & 10179.94 & 686.25 & 21333.13 & 688.17 & $12.4 \%$ \\
\hline Abril & 7947.96 & 1184.71 & 214.30 & 6919.94 & 623.19 & 16890.10 & 563.00 & $9.8 \%$ \\
\hline Mayo & 6812.15 & 962.87 & 160.72 & 8407.74 & 484.01 & 16827.49 & 542.82 & $9.8 \%$ \\
\hline Junio & 1793.86 & 144.42 & 0.00 & 7461.88 & 48.06 & 9448.22 & 314.94 & $5.5 \%$ \\
\hline
\end{tabular}




\begin{tabular}{|c|c|c|c|c|c|c|c|c|} 
Julio & 3325.46 & 380.47 & 53.58 & 4799.50 & 181.27 & 8740.28 & 281.94 & $5.1 \%$ \\
\hline Agosto & 9102.03 & 1316.33 & 246.44 & 7531.07 & 683.23 & 18879.10 & 609.00 & $11.0 \%$ \\
\hline Septiembre & 8325.95 & 1238.83 & 225.01 & 7211.90 & 650.09 & 17651.78 & 588.39 & $10.2 \%$ \\
\hline Octubre & 8290.90 & 1272.47 & 235.73 & 7303.31 & 658.26 & 17760.67 & 572.92 & $10.3 \%$ \\
\hline Noviembre & 4591.34 & 602.63 & 85.72 & 6373.07 & 21.99 & 11674.75 & 376.60 & $6.8 \%$ \\
\hline Diciembre & 1350.96 & 93.49 & 0.00 & 5421.97 & 31.09 & 6897.51 & 229.92 & $4.0 \%$ \\
\hline
\end{tabular}

Las figuras 146 y 147, muestran la distribución de consumo anual simulado y la distribución porcentual por consumos para el año 2017 respectivamente.

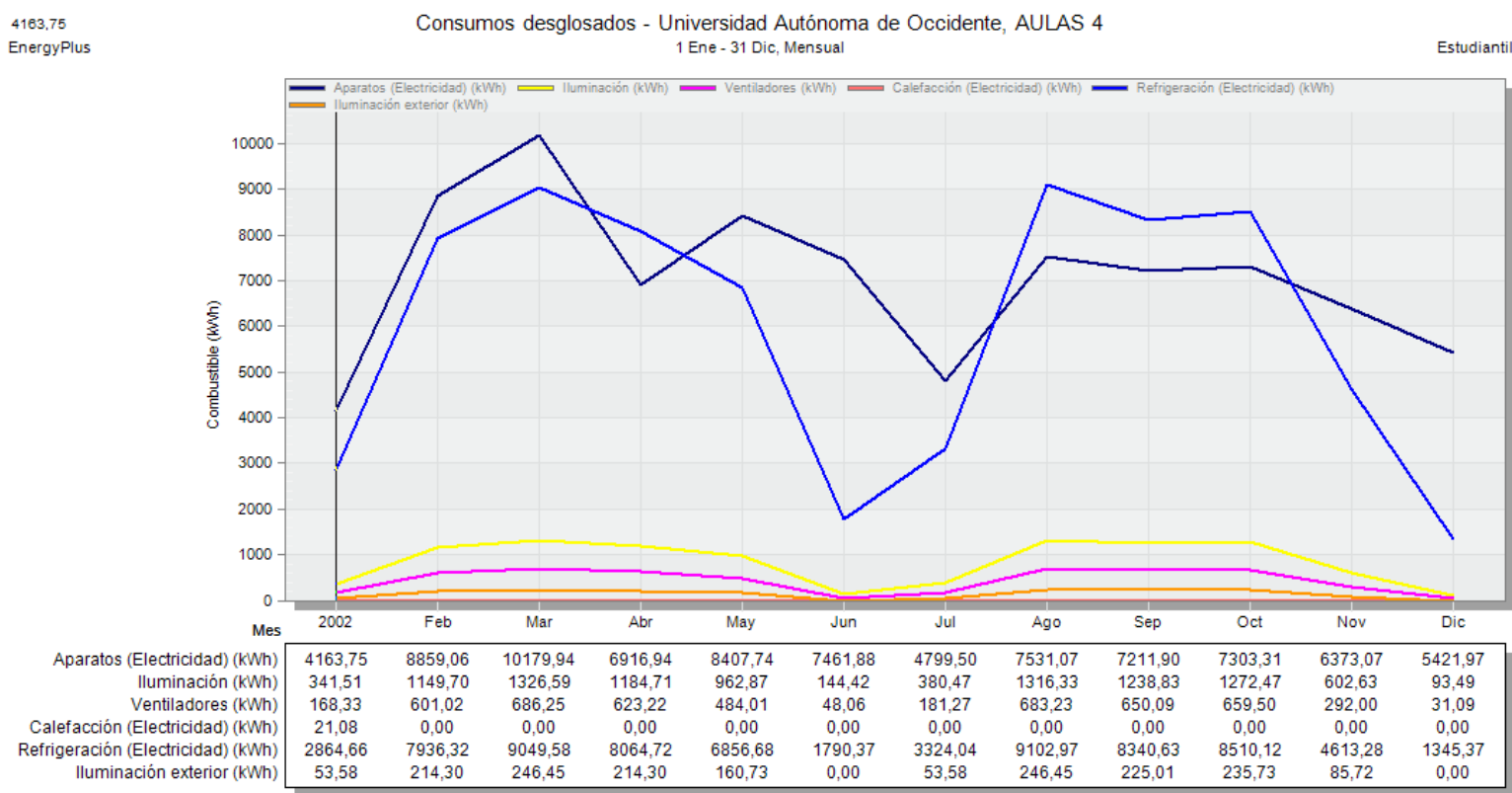

Figura 146. Distribución de consumo energético anual desglosado por uso final para MAE I

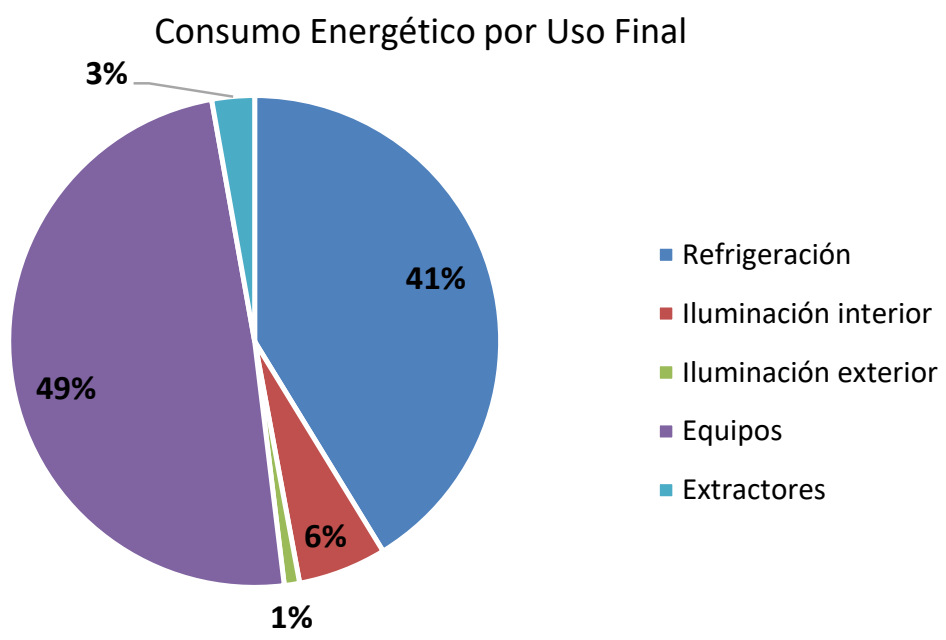

Figura 147. Distribución porcentual de consumo energético por uso final para MAE I 
La Figura 148 presenta los consumos energéticos del edificio según cada uso final y su porcentaje de participación, de donde se obtiene que el consumo por iluminación exterior es de 1.735,82 kWh (1,01\%), iluminación interior 10.014,02 kWh (5,81\%), consumo por equipos ofimáticos de $84.633,13 \mathrm{kWh}$ (49,12\%), y el consumo por climatización de $71.088,69 \mathrm{kWh}$ y extractores de $4.836,77 \mathrm{kWh}$ que supone un $44,06 \%$.

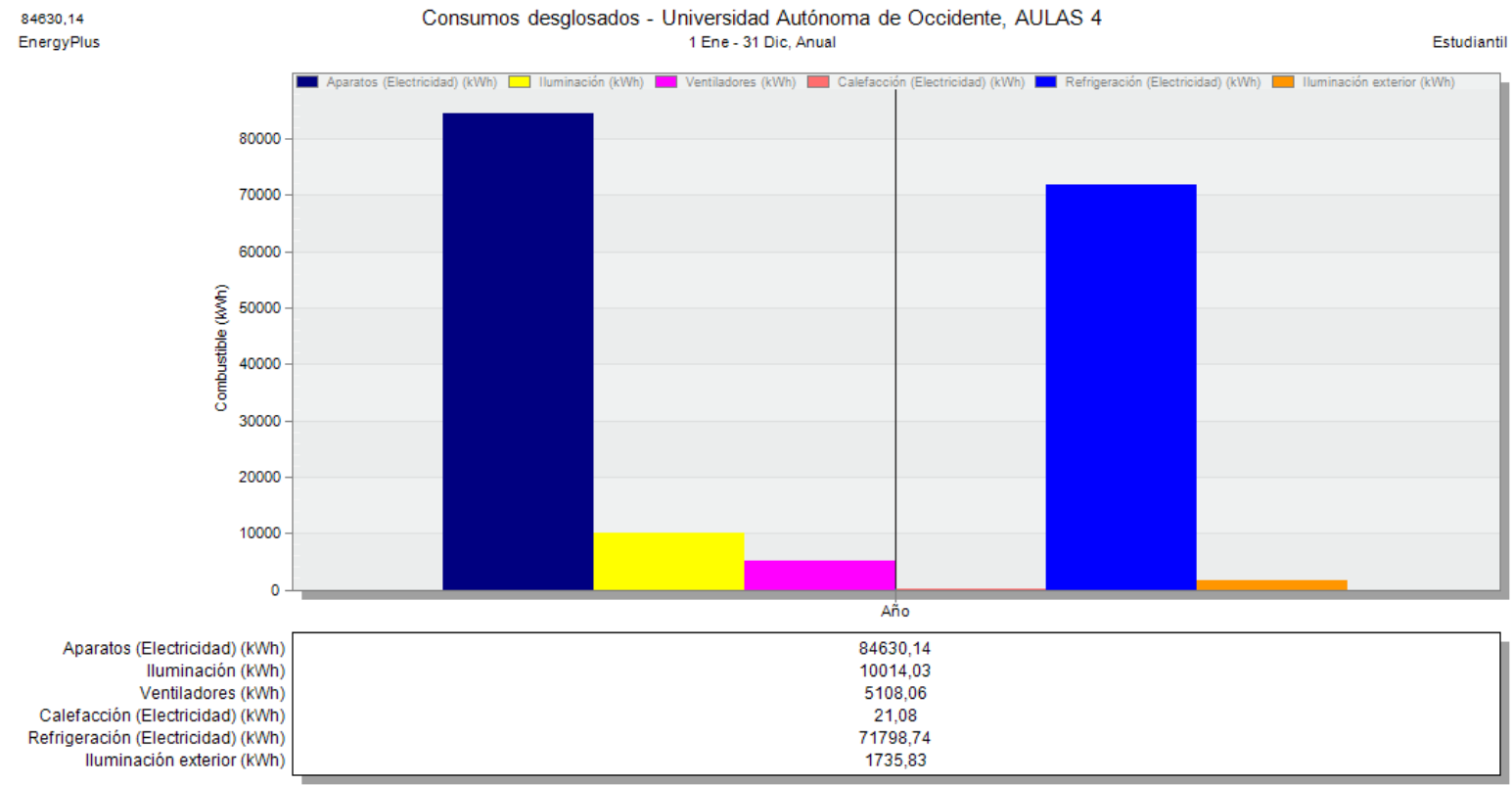

Figura 148. Diagrama de barras distribución del consumo energético anual.

\section{Impacto Medioambiental - Emisiones de $\mathrm{CO} 2$}

Se obtienen las emisiones de $\mathrm{kg}$ de $\mathrm{CO}_{2}$ generados por las instalaciones, presentado de forma mensual y anual en la tabla 57 y la Figura 149. 
Tabla 57. Producción mensual y anual de $\mathrm{kg}$ de $\mathrm{CO}_{2}$ con MAE I

\begin{tabular}{|c|c|}
\hline Mes & kg de $\mathbf{C O}_{\mathbf{2}}$ \\
\hline Enero & 4613,42 \\
\hline Febrero & 11368,8 \\
\hline Marzo & 13022,2 \\
\hline Abril & 10304,35 \\
\hline Mayo & 10224,44 \\
\hline Junio & 5723,5 \\
\hline Julio & 5295,74 \\
\hline Agosto & 11441,29 \\
\hline Septiembre & 10705,87 \\
\hline Octubre & 10896,56 \\
\hline Noviembre & 7251,81 \\
\hline Diciembre & 4176,5 \\
\hline Total & 105024,48 \\
\hline \multicolumn{2}{|c}{} \\
\hline
\end{tabular}

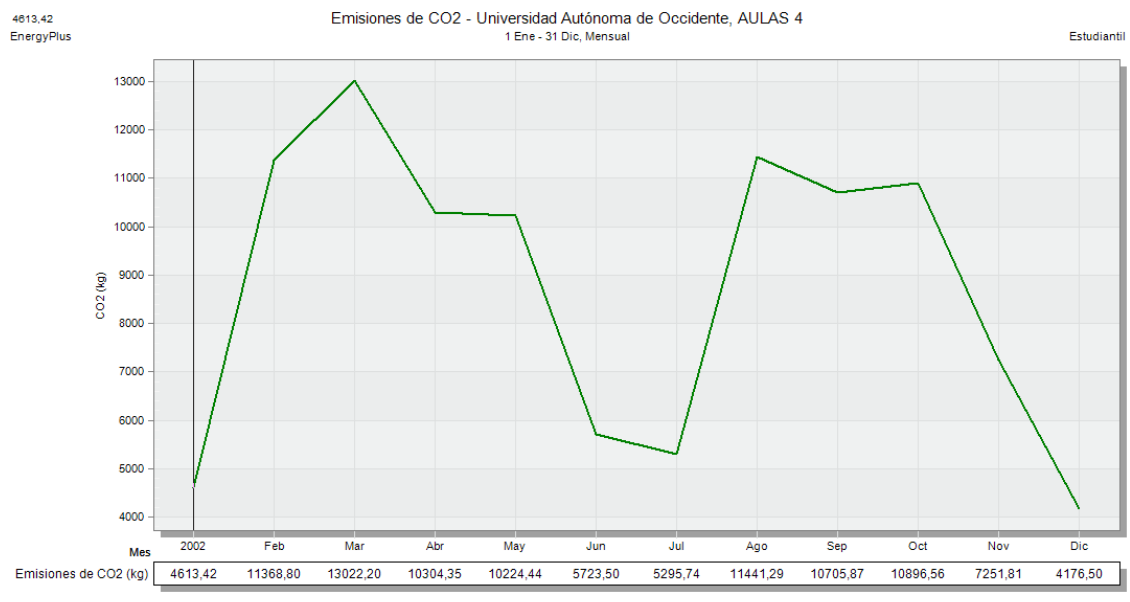

Figura 149. Emisiones de $\mathrm{CO}_{2}$ mensual para el edificio con la MAE I

\subsubsection{Análisis comparativo de consumos energéticos del edificio base vs el edificio con la MAE I}

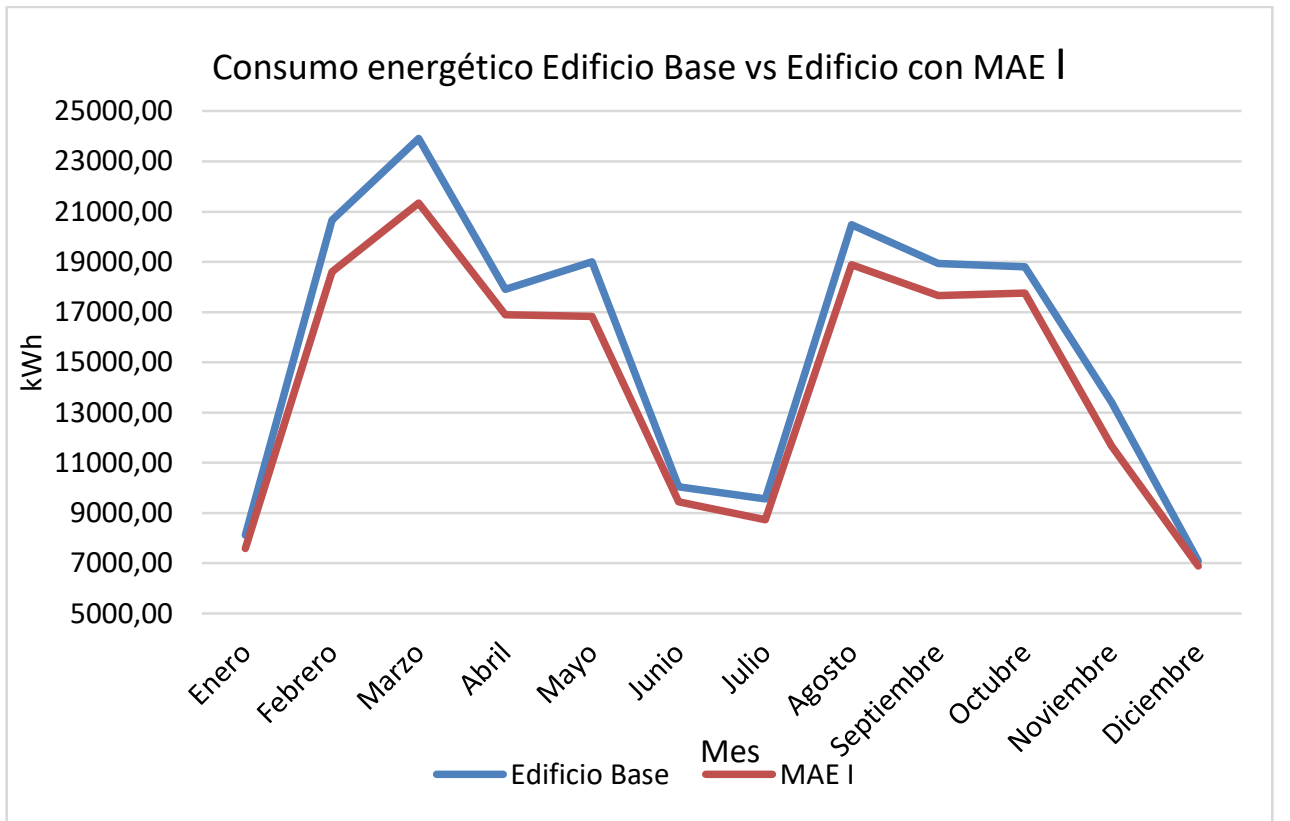

Figura 150. Consumo energético mensual Edificio Base y Edificio con MAE I. 


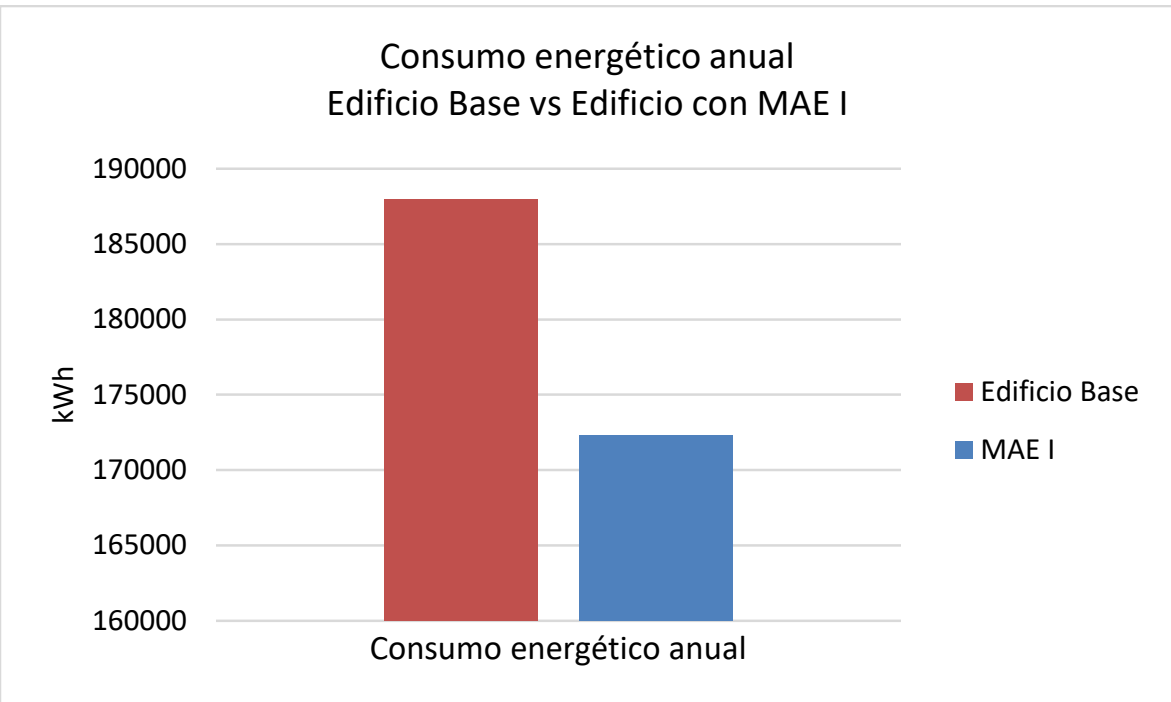

Figura 151. Consumo energético anual Edificio Base y Edificio con MAE I

Comparando los datos obtenidos del Edificio base y el Edificio con la Medida de Ahorro Energético I, se puede destacar que en el edificio con el MAE I (nuevo sistema VRF) son integrados y climatiza todos los recintos del edificio, con cambio de tecnología en los sistemas de refrigeración y se logra una disminución de consumo energético anual del 8,316\%. En la Figura 150 se observa la evolución del consumo anual de energía en el edificio es el mismo, pero con un consumo menor del HVAC, en la Figura 151 se puede observar que debido a que solo se realizó un rediseño del sistema de HVAC para el edificio, todos los otros consumos conservan su comportamiento y consumo anual, mientras que el consumo por refrigeración se reduce en un 22,36\% (20469,66 kWh) con respecto al consumo energético del antiguo HVAC, generando así una reducción considerable y tomando como referencia esta como una muy buena estrategia de mejora de la eficiencia energética en el edificio.

\subsection{MAE II - REDISEÑO DEL SISTEMA DE ILUMINACIÓN INTERIOR.}

En este caso se realiza el diseño de iluminación en el software Dialux con el fin de que los nuevos diseños cumplieran con la reglamentación colombiana, este es un software gratuito de que permite crear proyectos de iluminación profesionales. Este software es reconocido internacionalmente en iluminación, y facilita la tarea de diseñar sistemas de iluminación tanto para interiores como exteriores.

A continuación, se presenta la relación de recintos a los que se le realizo diseño previo de simulación en el software Dialux. 
TORREONES A4T1B Y A4T1C

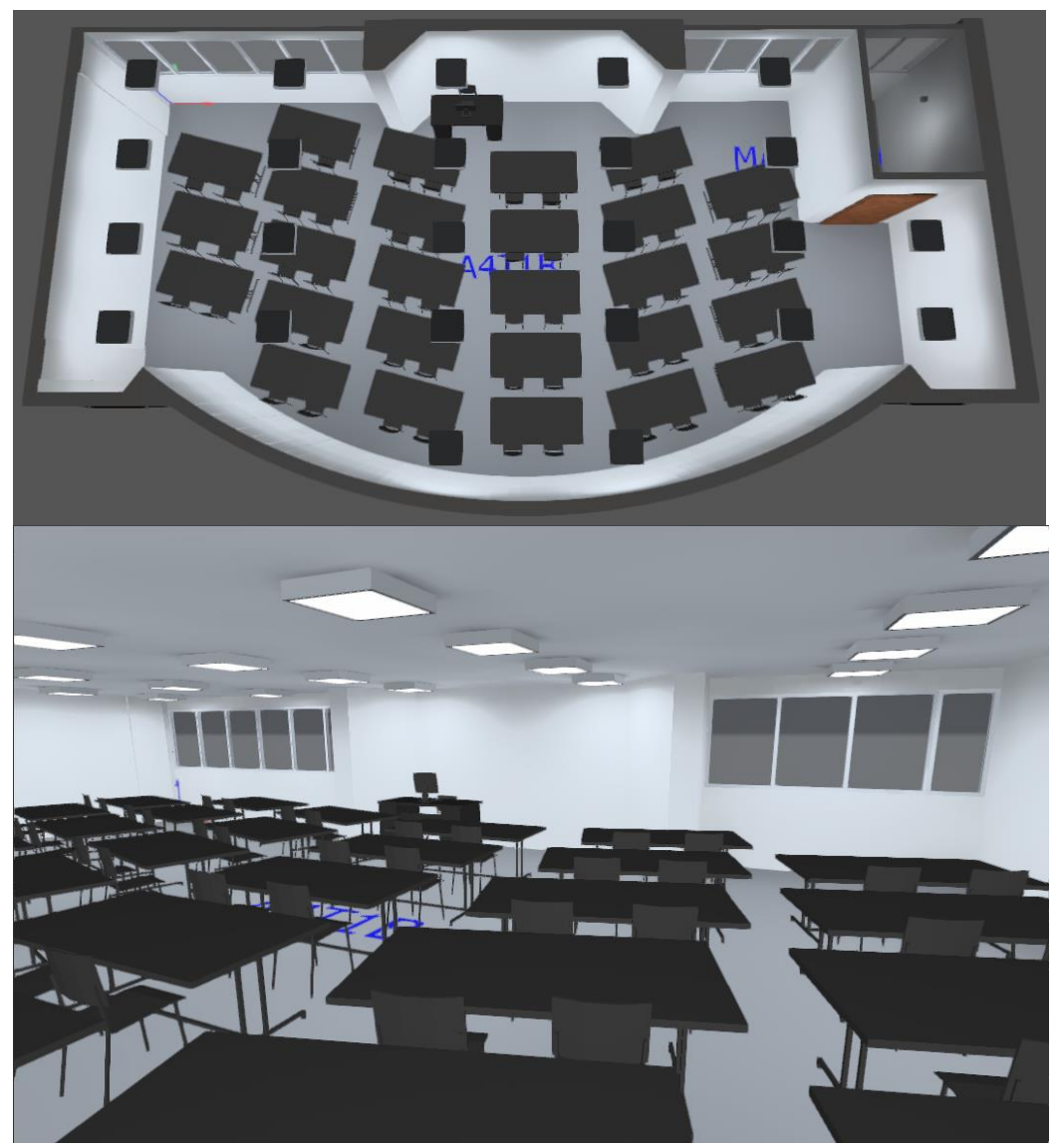

\section{OFICINA DE EGRESADOS}

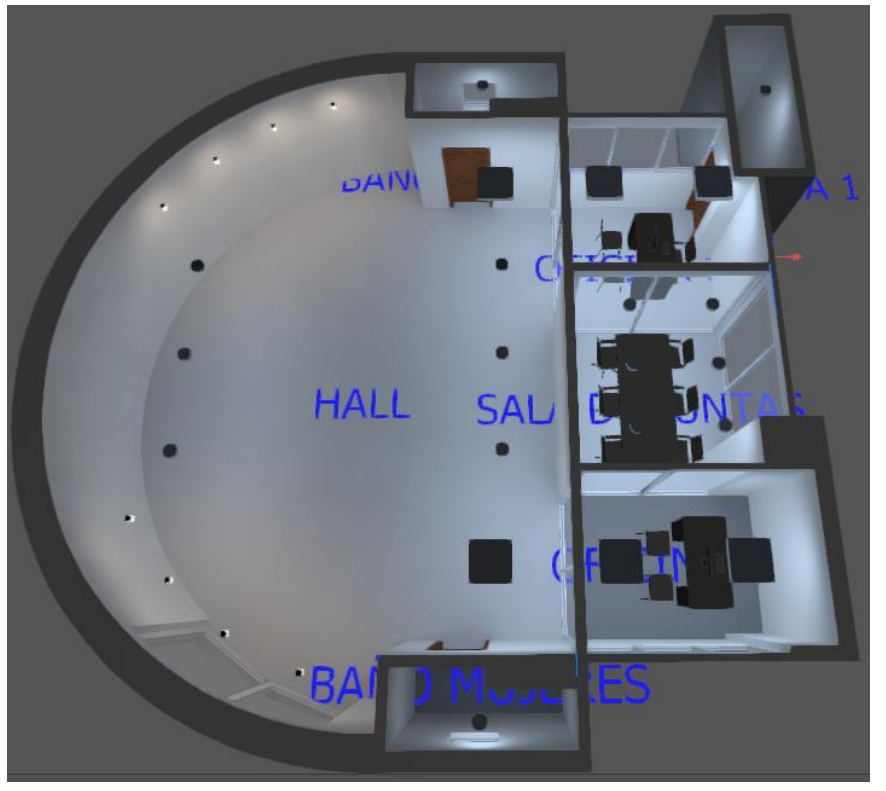

Oficina Investigadores
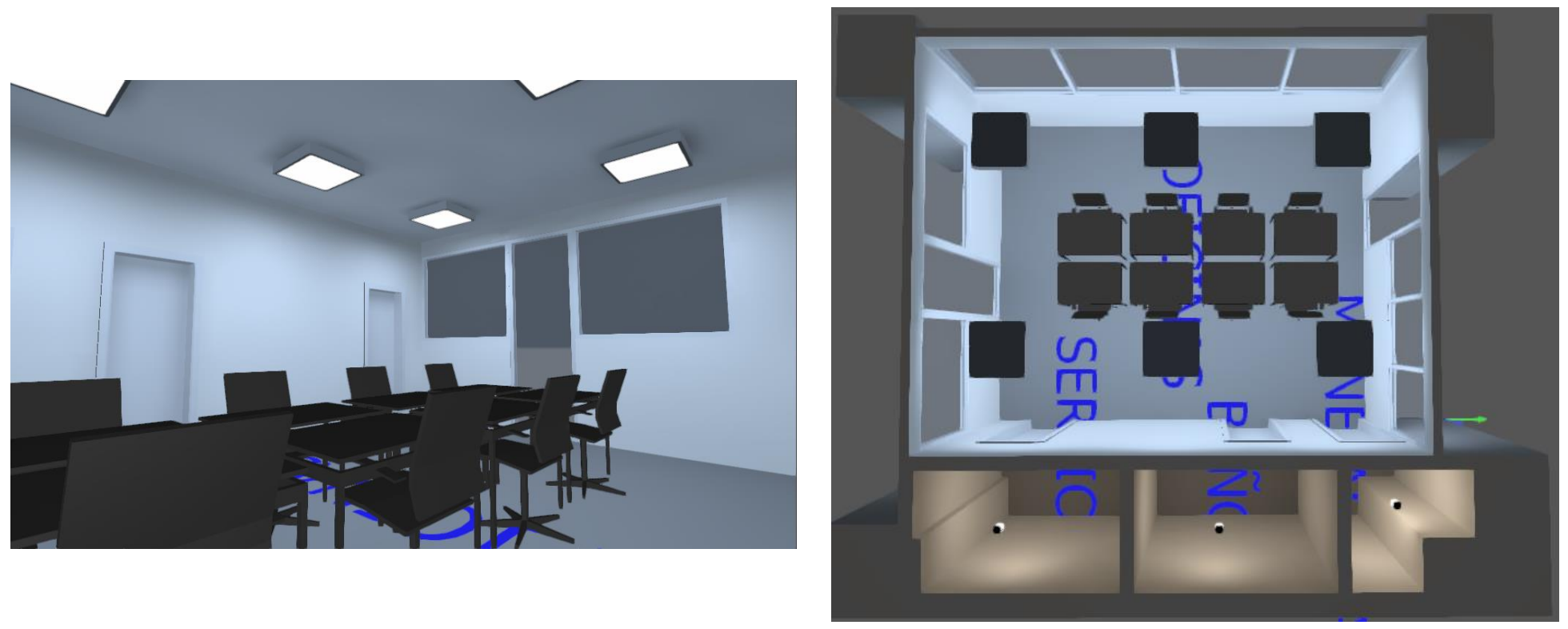

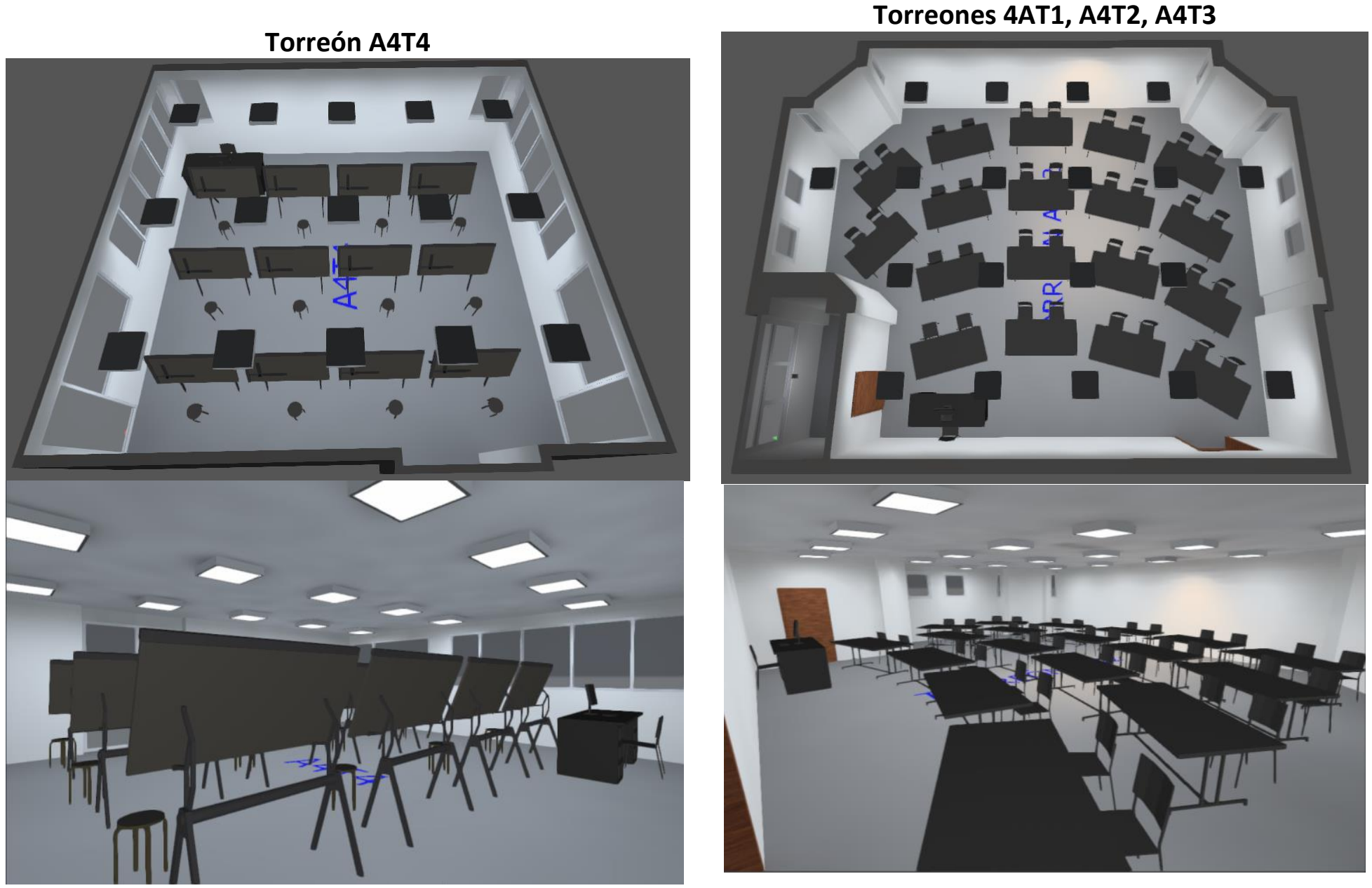

\section{Aulas Piso 2}
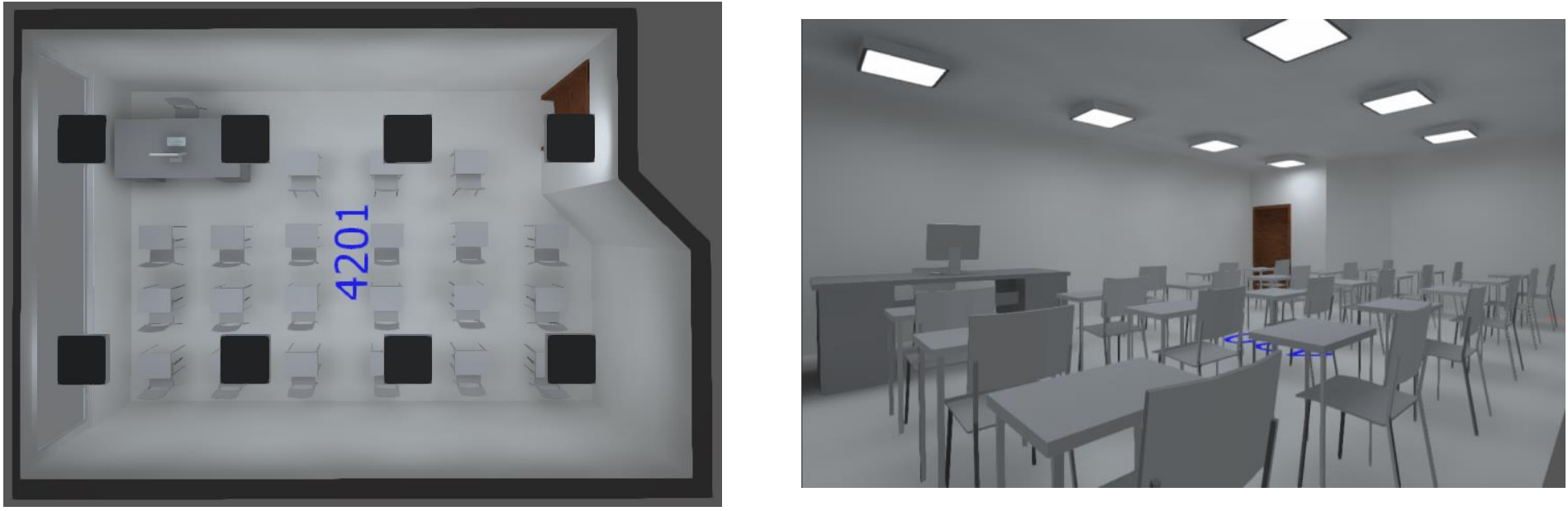

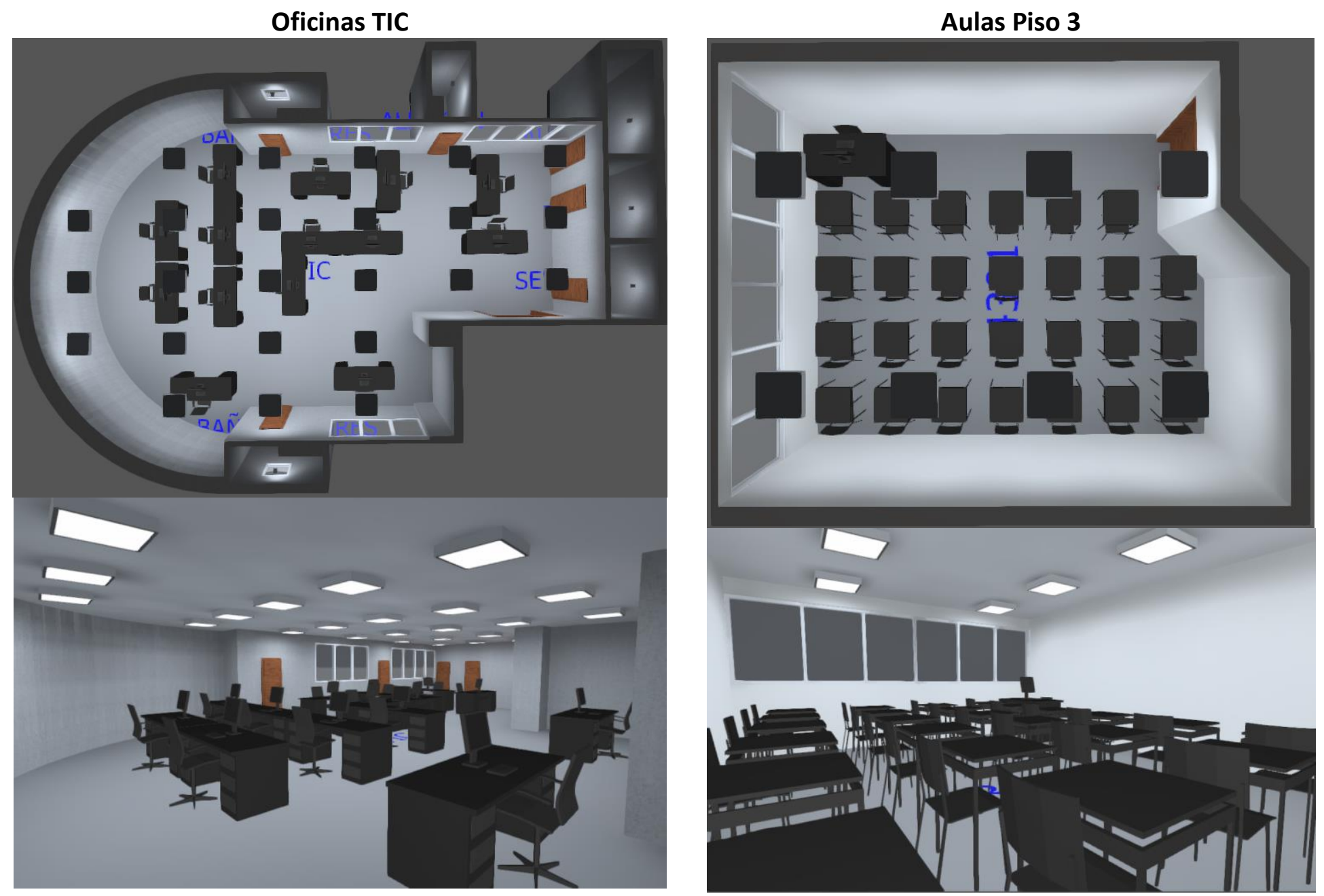

\section{Planta Física}
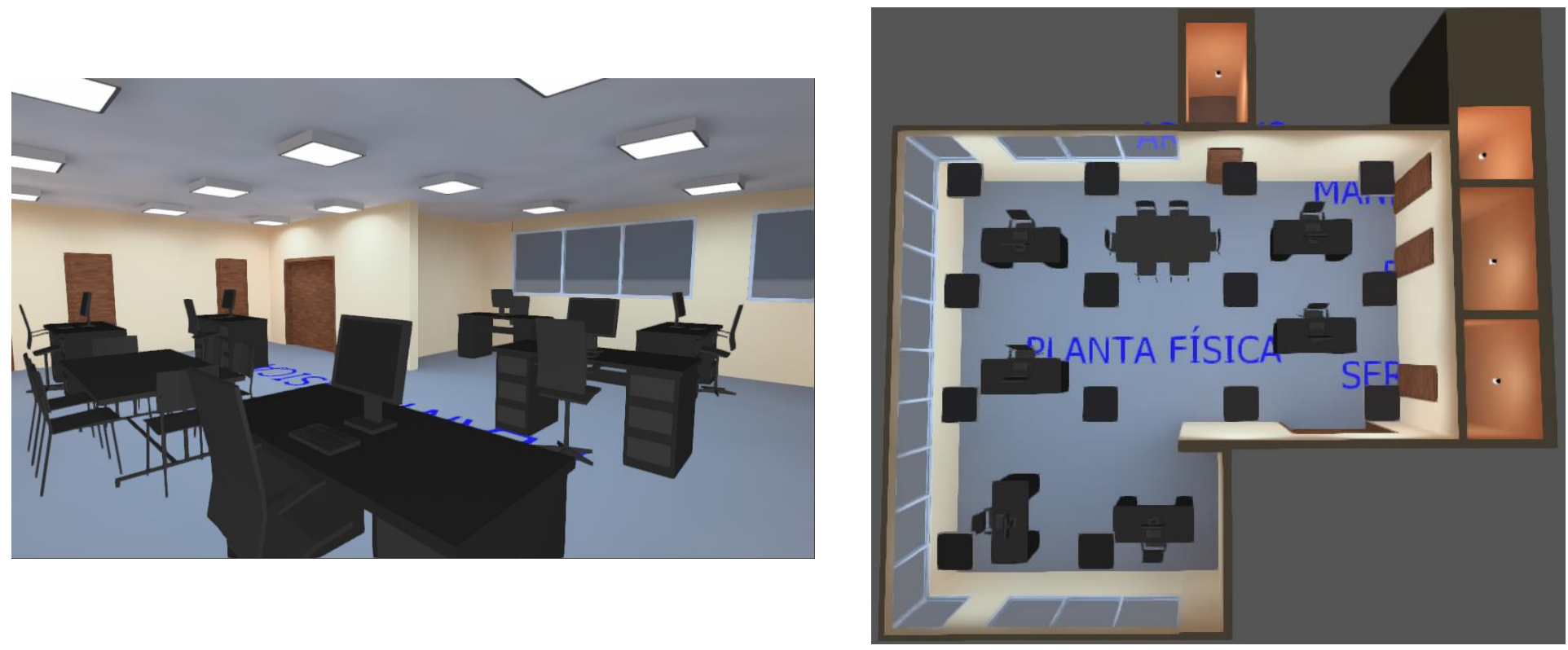
AULAS 4401 a 4406

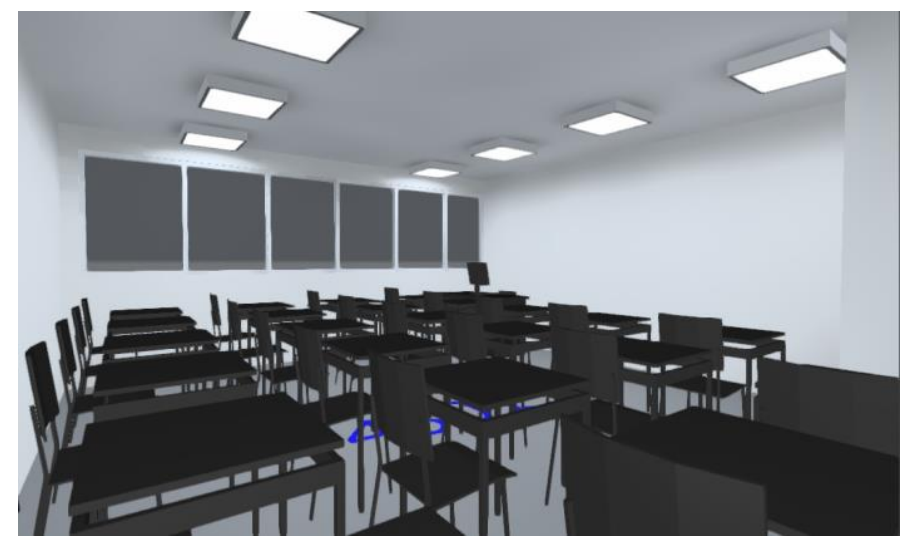

AULAS 4407 a 4410

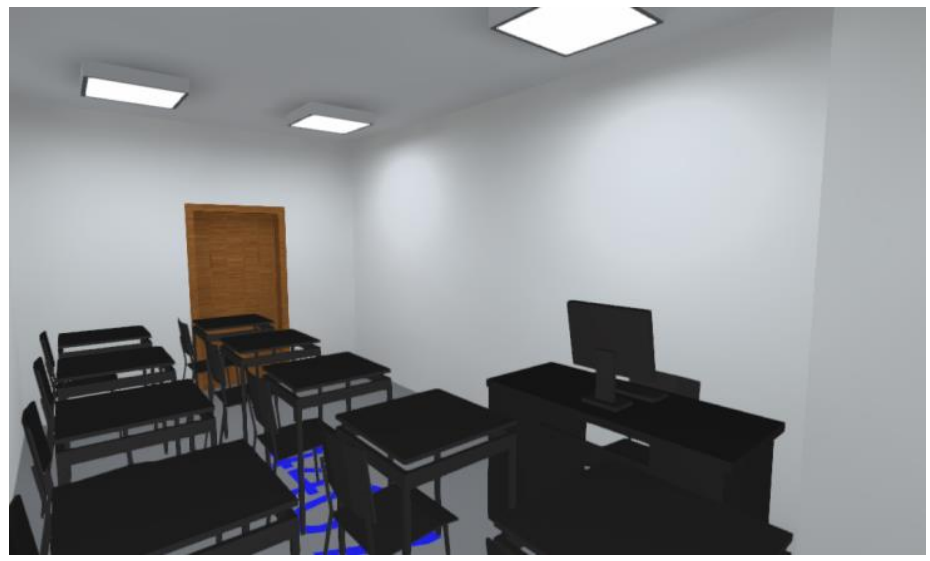

En la Tabla 58, se presenta el resumen de luminarias usadas en el rediseño de iluminación.

Tabla 58. Resumen de luminarias

\begin{tabular}{|c|c|c|c|c|c|}
\hline Recinto & $\begin{array}{c}\text { Marca } \\
\text { luminaria }\end{array}$ & $\begin{array}{c}\text { Referencia } \\
\text { luminaria }\end{array}$ & $\begin{array}{c}\text { Potencia } \\
\text { luminaria } \\
\text { (W) }\end{array}$ & Cantidad & $\begin{array}{c}\text { Potencia total } \\
\text { luminarias } \\
\text { (W) }\end{array}$ \\
\hline $\begin{array}{c}\text { Torreones } \\
\text { A4T1A y B }\end{array}$ & Sylvania & $\begin{array}{c}\text { Start panel led 625 } \\
\text { nw 0047573 }\end{array}$ & 45 & 24 & 1080 \\
\hline $\begin{array}{c}\text { Torreones } \\
\text { A4T1, 2 y 3 }\end{array}$ & Sylvania & $\begin{array}{c}\text { Start panel led 625 } \\
\text { nw 0047573 }\end{array}$ & 45 & 19 & 855 \\
\hline Aulas piso 2 & Sylvania & $\begin{array}{c}\text { Start panel led 625 } \\
\text { nw 0047573 }\end{array}$ & 45 & 8 & 360 \\
\hline TIC & Sylvania & $\begin{array}{c}\text { Start panel led 625 } \\
\text { nw 0047573 }\end{array}$ & 45 & 24 & 1080 \\
\hline Aulas piso 3 & Sylvania & $\begin{array}{c}\text { Start panel led 625 } \\
\text { nw 0047573 }\end{array}$ & 45 & 860 \\
\hline Planta física & Sylvania & $\begin{array}{c}\text { Start panel led 625 } \\
\text { nw 0047573 }\end{array}$ & 45 & 14 & 630 \\
\hline Aulas 4401 a & Sylvania & $\begin{array}{c}\text { Start panel led 625 } \\
\text { nw 0047573 }\end{array}$ & 45 & 8 & 360 \\
\hline $\begin{array}{c}\text { Aulas 4407 a } \\
\text { 4410 }\end{array}$ & Sylvania & $\begin{array}{c}\text { Start panel led 625 } \\
\text { nw 0047573 }\end{array}$ & 45 & 4 & 180 \\
\hline
\end{tabular}


La Tabla 59, presenta los niveles de iluminancia obtenidos en cada recinto a partir del rediseño del sistema de iluminación.

Tabla 59. Niveles de iluminancia con la propuesta de diseño de iluminación

\begin{tabular}{|c|c|c|c|c|}
\hline \multirow{2}{*}{ Recinto } & $\begin{array}{c}\text { Tipo de } \\
\text { recinto }\end{array}$ & $\begin{array}{c}\text { Iluminancia } \\
\text { según normativa } \\
\text { (lux) }\end{array}$ & $\begin{array}{c}\text { Nivel de } \\
\text { iluminancia } \\
\text { obtenido (lux) }\end{array}$ & $\begin{array}{c}\text { Estado de } \\
\text { normativa }\end{array}$ \\
\hline Torreón A4TA & Torreón & 500 & 597 & Si cumple \\
\hline \multirow{2}{*}{ Oficina egresados } & Hall & 100 & 327 & Si cumple \\
\cline { 2 - 5 } & Oficina 1 & 500 & 558 & Si cumple \\
\cline { 2 - 5 } & Oficina 2 & 500 & 552 & Si cumple \\
\cline { 2 - 5 } & Sala juntas & 500 & 544 & Si cumple \\
\hline Torreones A4T1A y B & Torreón & 500 & 563 & Si cumple \\
\hline Torreones A4T1, 2 y 3 & Torreón & 500 & 578 & Si cumple \\
\hline Aulas piso 2 & Aula & 500 & 562 & Si cumple \\
\hline TIC & Oficina & 500 & 568 & Si cumple \\
\hline Aulas piso 3 & Aula & 500 & 556 & Si cumple \\
\hline Planta física & Oficina & 500 & 551 & Si cumple \\
\hline Aulas 4401 a 4406 & Aula & 500 & 619 & Si cumple \\
\hline Aulas 4407 a 4410 & Aula & 500 & 610 & Si cumple \\
\hline
\end{tabular}

En la Tabla 60, se comparan los consumos de energía mes a mes simulado en Design Builder entre el Edificio Base y el edificio con el nuevo diseño de iluminación.

Tabla 60. Consumo Kwh diseño de iluminación nuevo vs actual

\begin{tabular}{|c|c|c|c|}
\hline Mes & $\begin{array}{c}\text { Consumo en iluminación } \\
\text { Edificio Base (kWh) }\end{array}$ & $\begin{array}{c}\text { Consumo en iluminación } \\
\text { Edificio con MAE II (kWh) }\end{array}$ & $\begin{array}{c}\text { Diferencia } \\
\text { (kWh) }\end{array}$ \\
\hline Enero & 8120.09 & 8251.52 & 131.43 \\
\hline Febrero & 20660.96 & 21309.50 & 648.54 \\
\hline Marzo & 23917.62 & 24656.94 & 739.32 \\
\hline Abril & 17902.63 & 18582.32 & 679.69 \\
\hline Mayo & 18994.51 & 19521.40 & 526.89 \\
\hline Junio & 10040.07 & 10054.81 & 14.74 \\
\hline Julio & 9564.51 & 9694.65 & 130.14 \\
\hline Agosto & 20482.49 & 21220.60 & 738.11 \\
\hline Septiembre & 18943.36 & 19659.58 & 716.22 \\
\hline Octubre & 18807.27 & 19525.75 & 718.48 \\
\hline Noviembre & 13418.44 & 13703.60 & 285.16 \\
\hline Diciembre & 7086.37 & 7092.87 & 6.5 \\
\hline Total anual & 187938.32 & 193273.54 & 5335.22 \\
\hline
\end{tabular}




\section{Impacto Medioambiental - Emisiones de $\mathrm{CO}_{2}$}

Se obtienen las emisiones de $\mathrm{kg}$ de $\mathrm{CO}_{2}$ generados por las instalaciones, presentado de forma mensual y anual en la Tabla 61 y la Figura 152.

Tabla 61. Producción mensual y anual de $\mathrm{kg}$ de $\mathrm{CO}_{2}$ con MAE II

\begin{tabular}{|c|c|}
\hline Mes & kg de $\mathbf{C O}_{\mathbf{2}}$ \\
\hline Enero & 3687.59 \\
\hline Febrero & 9139.86 \\
\hline Marzo & 10532.22 \\
\hline Abril & 7800.63 \\
\hline Mayo & 8329.05 \\
\hline Junio & 5195.78 \\
\hline Julio & 4292.76 \\
\hline Agosto & 8610.47 \\
\hline Septiembre & 8104.60 \\
\hline Octubre & 8262.96 \\
\hline Noviembre & 5970.00 \\
\hline Diciembre & 3714.64 \\
\hline Total & $\mathbf{8 3 6 4 0 . 5 6}$ \\
\hline
\end{tabular}

Emisiones de CO2 - Universidad Autónoma de Occidente, AULAS 4
1 Ene-31 Dic, Mensual
EnergyPlus

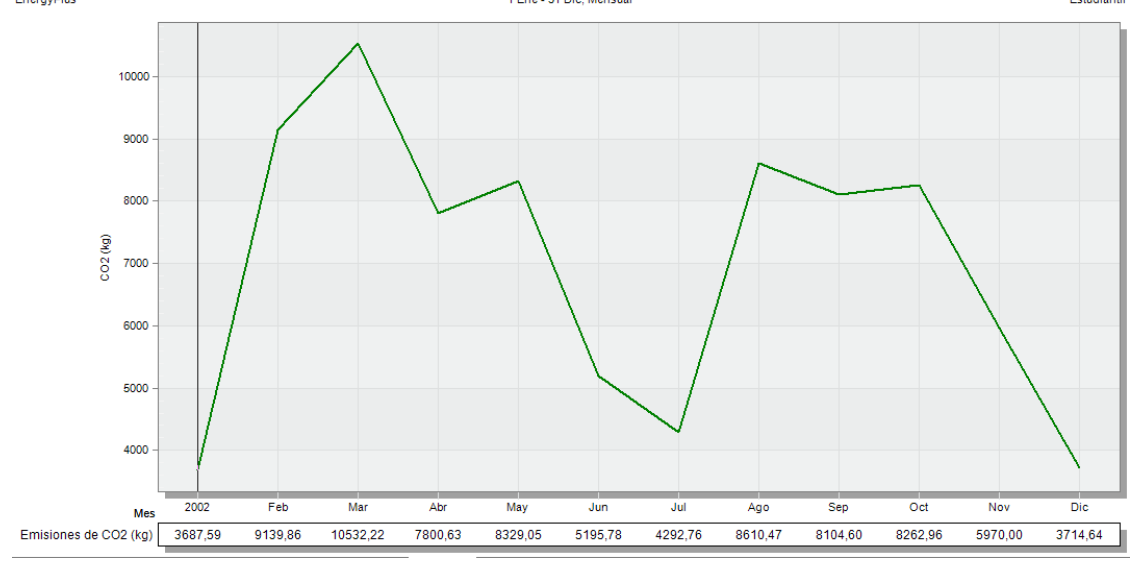

Figura 152. Emisiones de $\mathrm{CO}_{2}$ mensual para el edificio con la MAE II

En el desarrollo de esta MAE se optó inicialmente por la sustitución tecnológica de los sistemas de iluminación actuales por sistemas de iluminación más eficiente. Sin embargo, se buscó no solo realizar una actualización tecnológica, si no, cumplir con la normatividad colombiana que exige niveles mínimos de iluminación para promover una buena calidad ambiental interior y confort lumínico, lo cual dio como resultado que el edificio bajo este escenario tuviera un consumo de energía mayor. Finalmente, no se presentan ahorros energéticos (menor consumo de energía eléctrica), pero se está teniendo confort visual para los usuarios del edificio. 


\subsection{MAE III - FILTROS SOLARES Y SOMBRAS - LAMAS}

Otra estrategia que implementar en aras de la mejora de la eficiencia energética es la implementación de sistemas de lamas en la cubierta exterior del edificio. Las Figuras 153 156, presentan la simulación energética del edificio con la implementación de lamas.

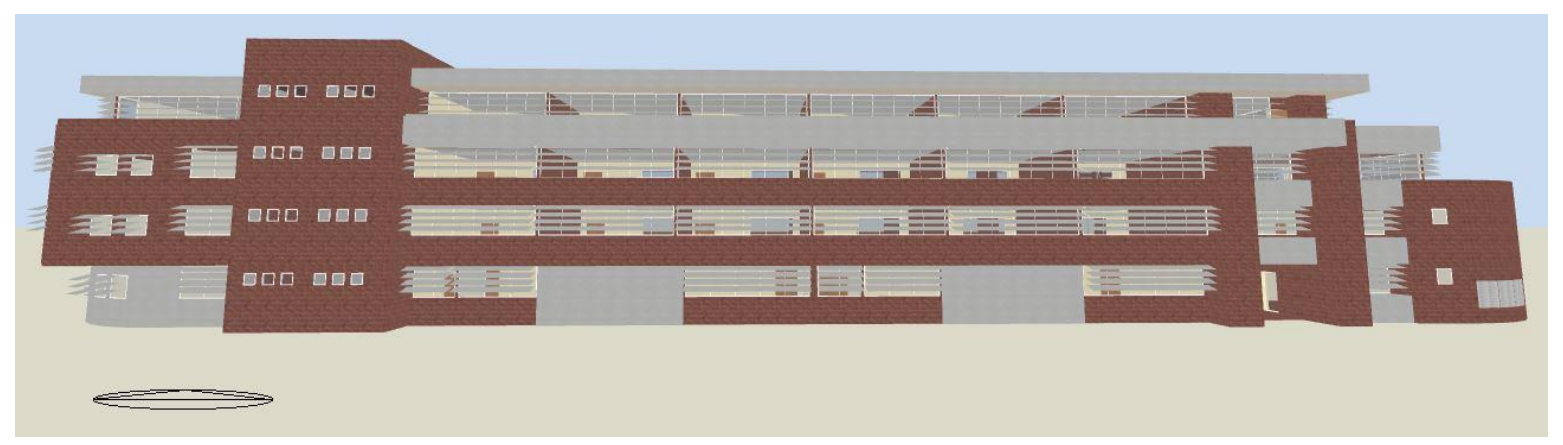

Figura 153. Vista norte del edificio con implementación de lamas

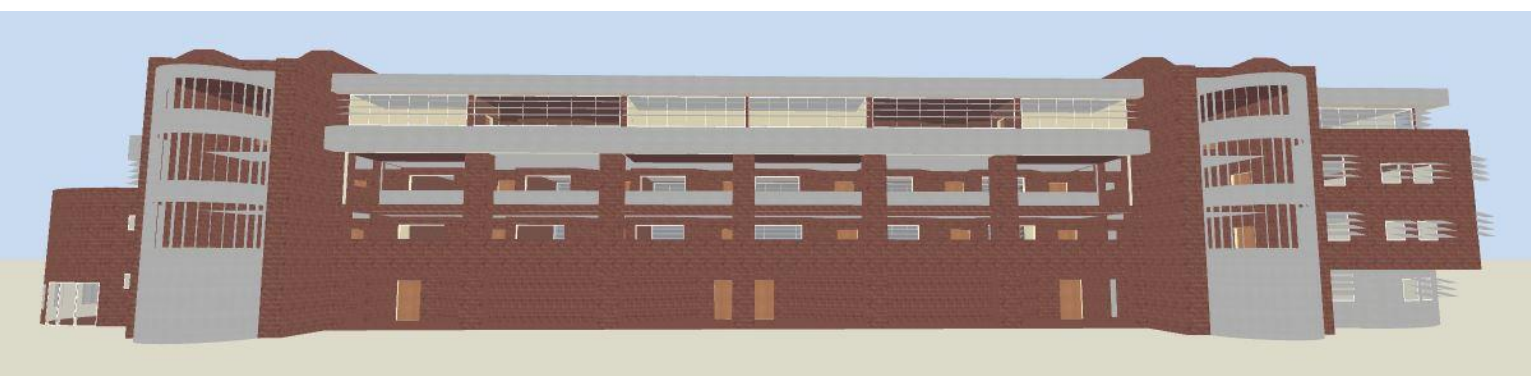

Figura 154. Vista sur del edificio con implementación de lamas

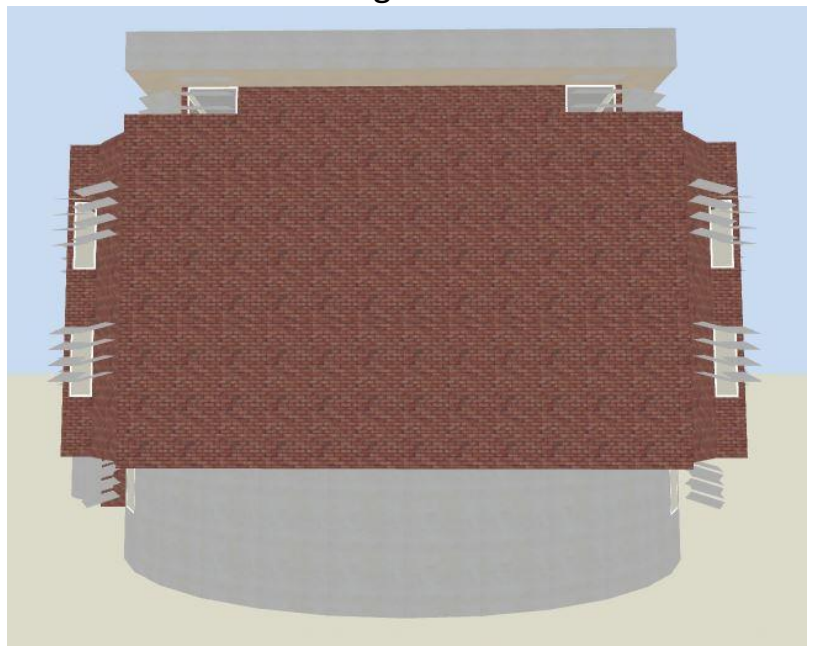

Figura 155. Vista este del edificio con implementación de lamas

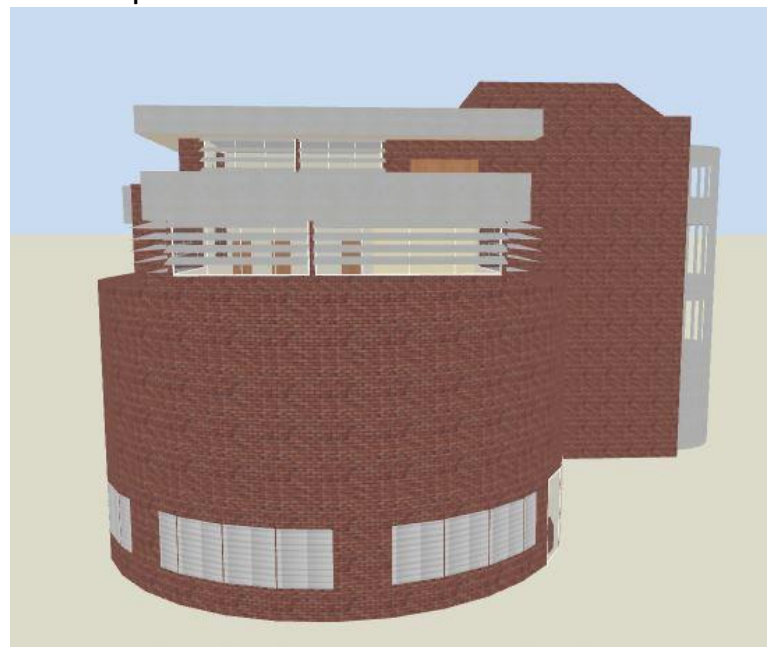

Figura 156. Vista oeste del Edificio con implementación de lamas

A continuación, se presentan los datos obtenidos al realizar la simulación energética de esta propuesta de mejora. La Figura 157 muestra la evolución del consumo de energía del edificio por meses, en un año meteorológico tipo y observándose que los meses de menor consumo energético corresponden a enero, junio, julio y diciembre debido a una época vacacional. 


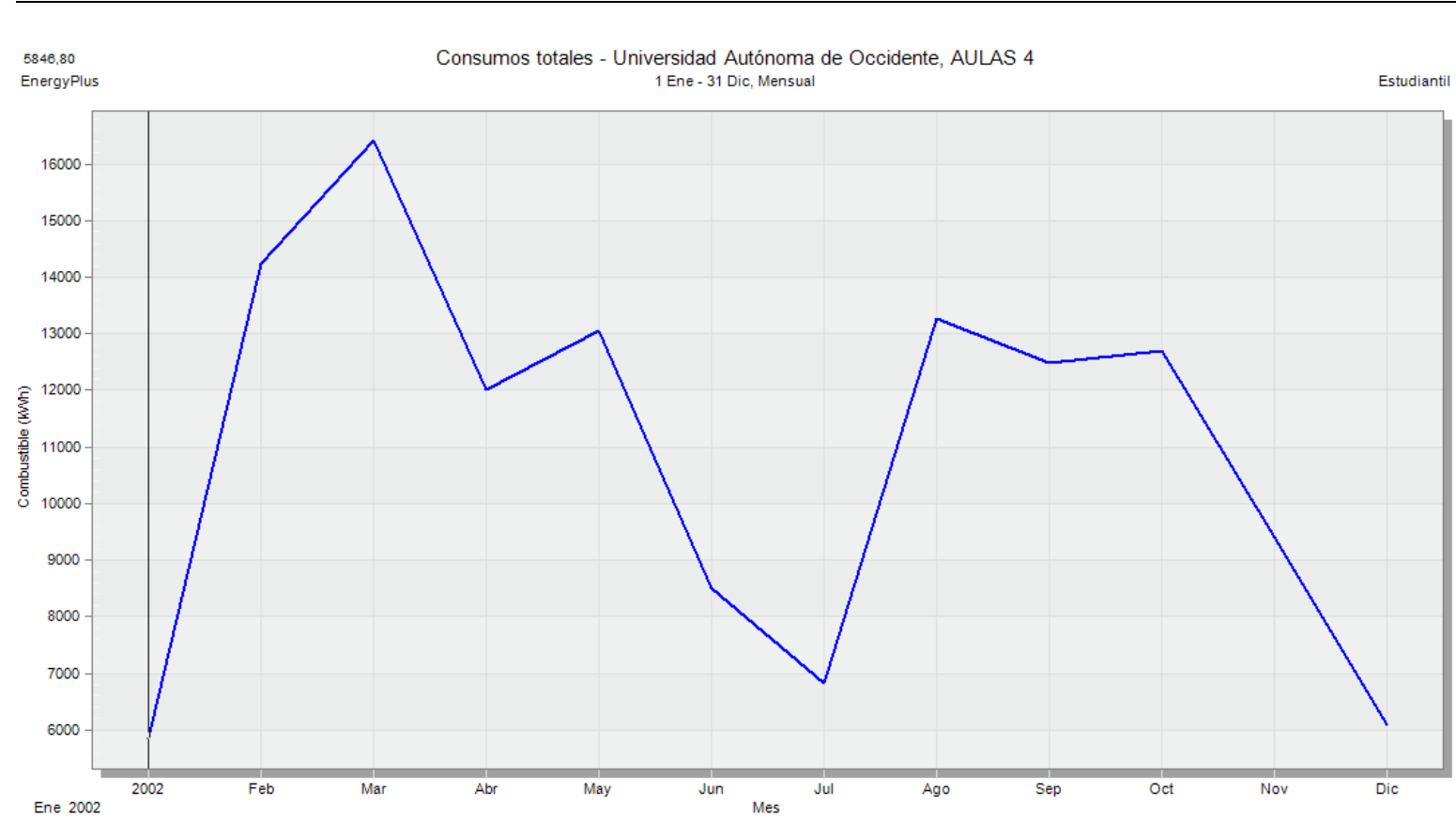

Figura 157. Distribución de consumo energético anual edificio con MAE III.

A continuación, se desglosa el consumo total anual de energía del edificio con la implementación de lamas de acuerdo con el tipo de uso, como lo muestra la Tabla 62. La Tabla 63, presenta la distribución de consumos energéticos desglosados mes a mes, donde se observa que el porcentaje de consumo de equipos ofimáticos es casi igual al consumo de refrigeración, y son los mayores.

Tabla 62. Distribución de consumos energéticos por uso.

\begin{tabular}{|c|c|c|}
\hline TIPO DE USO & ELECTRICIDAD (kWh) & PORCENTAJE DE CARGA (\%) \\
\hline Refrigeración & 84056,58 & 46,59 \\
\hline Iluminación interior & 10014,02 & 5,55 \\
\hline Iluminación exterior & 1735,82 & 0,96 \\
\hline Equipos interiores & 84633,13 & 46,90 \\
\hline CONSUMO TOTAL (kWh) & $\mathbf{1 8 0 4 3 6 , 5 5}$ & $\mathbf{1 0 0}$ \\
\hline
\end{tabular}

Tabla 63. Distribución de consumos energéticos desglosados mes a mes por uso.

\begin{tabular}{|c|c|c|c|c|c|c|c|}
\hline Mes & Refrigeración & $\begin{array}{c}\text { Iluminación } \\
\text { interior }\end{array}$ & $\begin{array}{c}\text { Iluminación } \\
\text { exterior }\end{array}$ & Equipos & $\begin{array}{c}\text { Total } \\
\mathbf{( k w h )}\end{array}$ & $\begin{array}{c}\text { Consumo } \\
\text { kwh/día }\end{array}$ & $\begin{array}{c}\text { consumo } \\
\text { mes }\end{array}$ \\
\hline Enero & 3229.77 & 341.51 & 53.58 & 4163.75 & 7788.61 & 251.25 & $4.3 \%$ \\
\hline Febrero & 9626.16 & 1149.70 & 214.30 & 8859.06 & 19849.22 & 708.90 & $11.0 \%$ \\
\hline Marzo & 11271.52 & 1326.59 & 246.44 & 10179.94 & 23024.49 & 742.73 & $12.8 \%$ \\
\hline Abril & 8748.89 & 1184.71 & 214.30 & 6916.94 & 17064.84 & 568.83 & $9.5 \%$ \\
\hline Mayo & 8757.48 & 962.87 & 160.72 & 8407.74 & 18288.81 & 589.96 & $10.1 \%$ \\
\hline Junio & 2264.14 & 144.42 & 0.00 & 7461.88 & 9870.44 & 329.01 & $5.5 \%$ \\
\hline Julio & 3961.91 & 380.47 & 53.58 & 4799.50 & 9195.46 & 296.63 & $5.1 \%$ \\
\hline
\end{tabular}




\begin{tabular}{|c|c|c|c|c|c|c|c|} 
Agosto & 10499.10 & 1316.33 & 246.44 & 7531.07 & 19592.94 & 632.03 & $10.9 \%$ \\
\hline Septiembre & 9384.40 & 1238.83 & 225.01 & 7211.90 & 18060.14 & 602.00 & $10.0 \%$ \\
\hline Octubre & 9040.71 & 1272.47 & 235.73 & 7303.31 & 17852.22 & 575.88 & $9.9 \%$ \\
\hline Noviembre & 5788.15 & 602.63 & 85.72 & 6373.07 & 12849.57 & 414.50 & $7.1 \%$ \\
\hline Diciembre & 1484.35 & 93.49 & 0.00 & 5421.97 & 6999.81 & 233.33 & $3.9 \%$ \\
\hline
\end{tabular}

Las Figuras 158 y 159., muestran la distribución de consumo anual simulado y la distribución porcentual por consumos para el año 2017 respectivamente del edificio con MAE III.

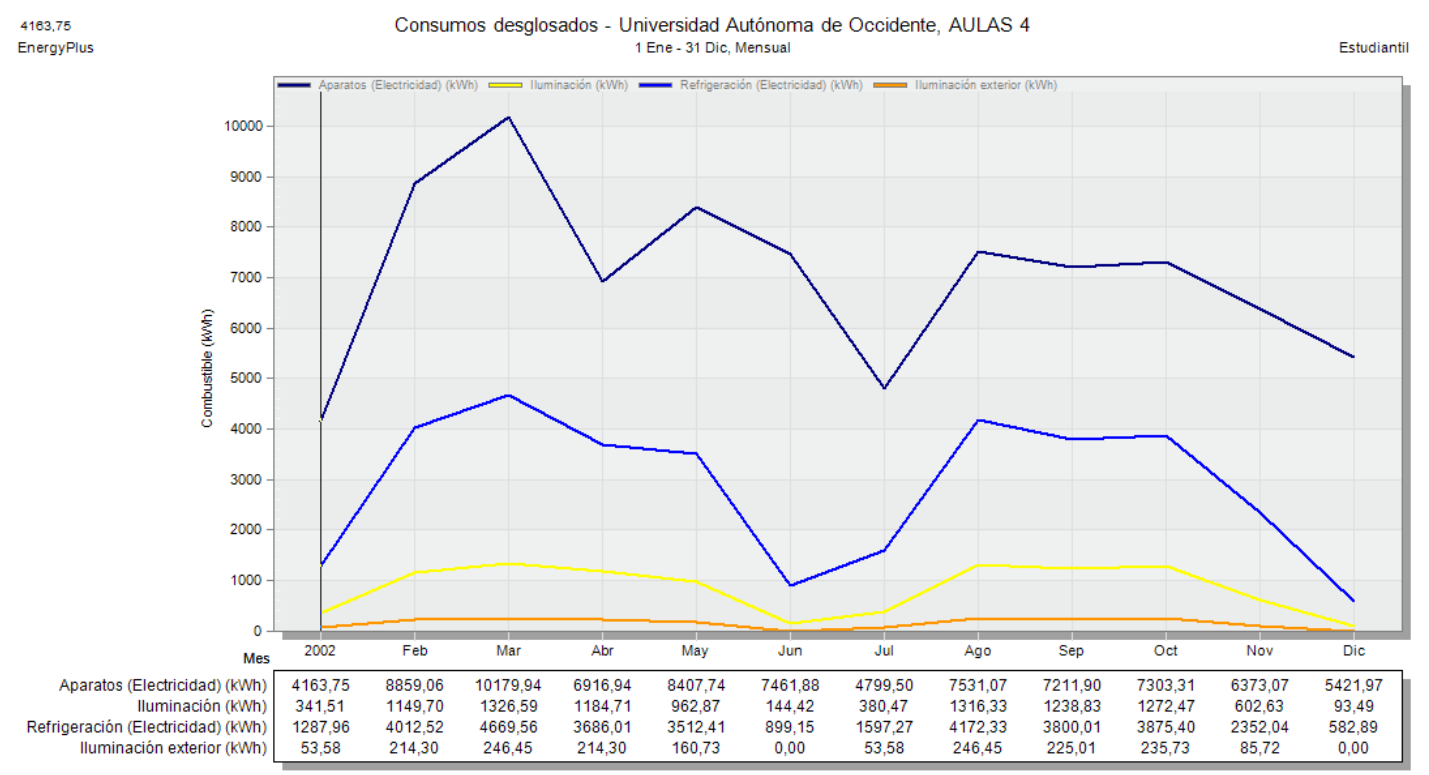

Figura 158. Distribución de consumo energético anual desglosado por uso final para MAE III

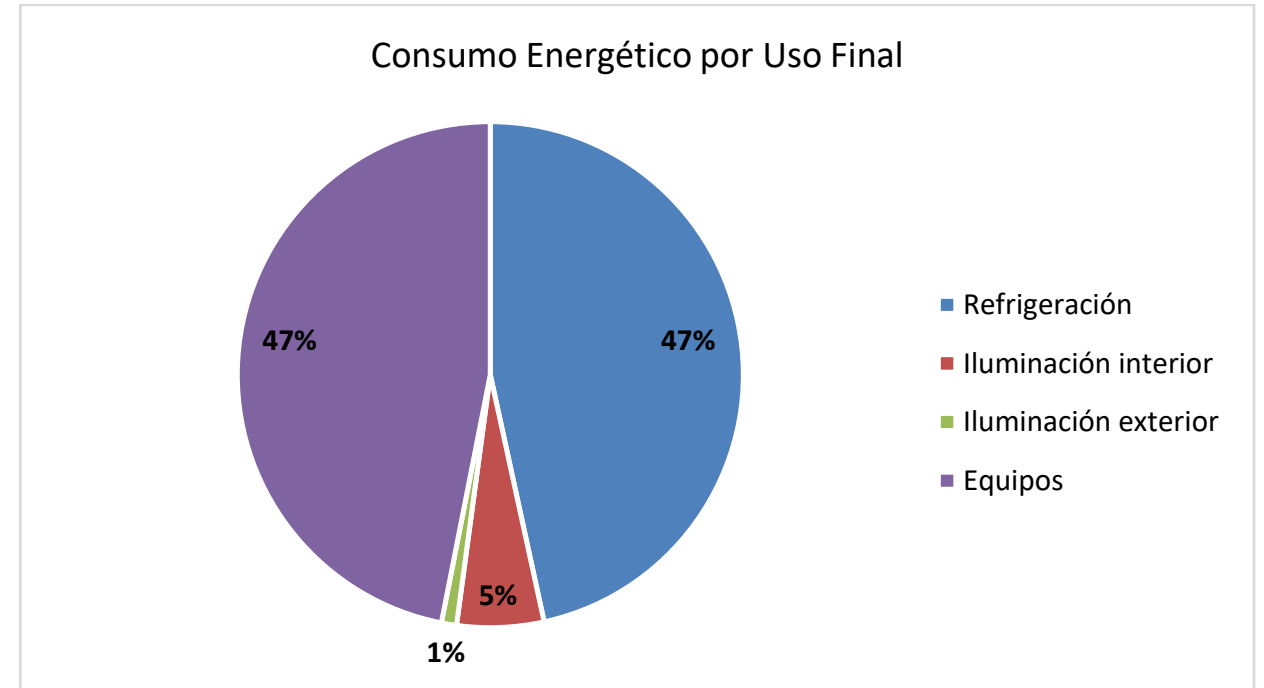

Figura 159. Distribución porcentual de consumo energético por uso final para MAE III 
La Figura 160 presenta los consumos energéticos del edificio según cada uso final y su porcentaje de participación, de donde se obtiene que el consumo por iluminación exterior es de 1.735,82 kWh (0,96\%), iluminación interior 10.014,02 kWh (5,55\%), consumo por equipos ofimáticos de 84.630,13 kWh (46,90\%), y el consumo por climatización de $84.056,58$ kWh $(46,59 \%)$.

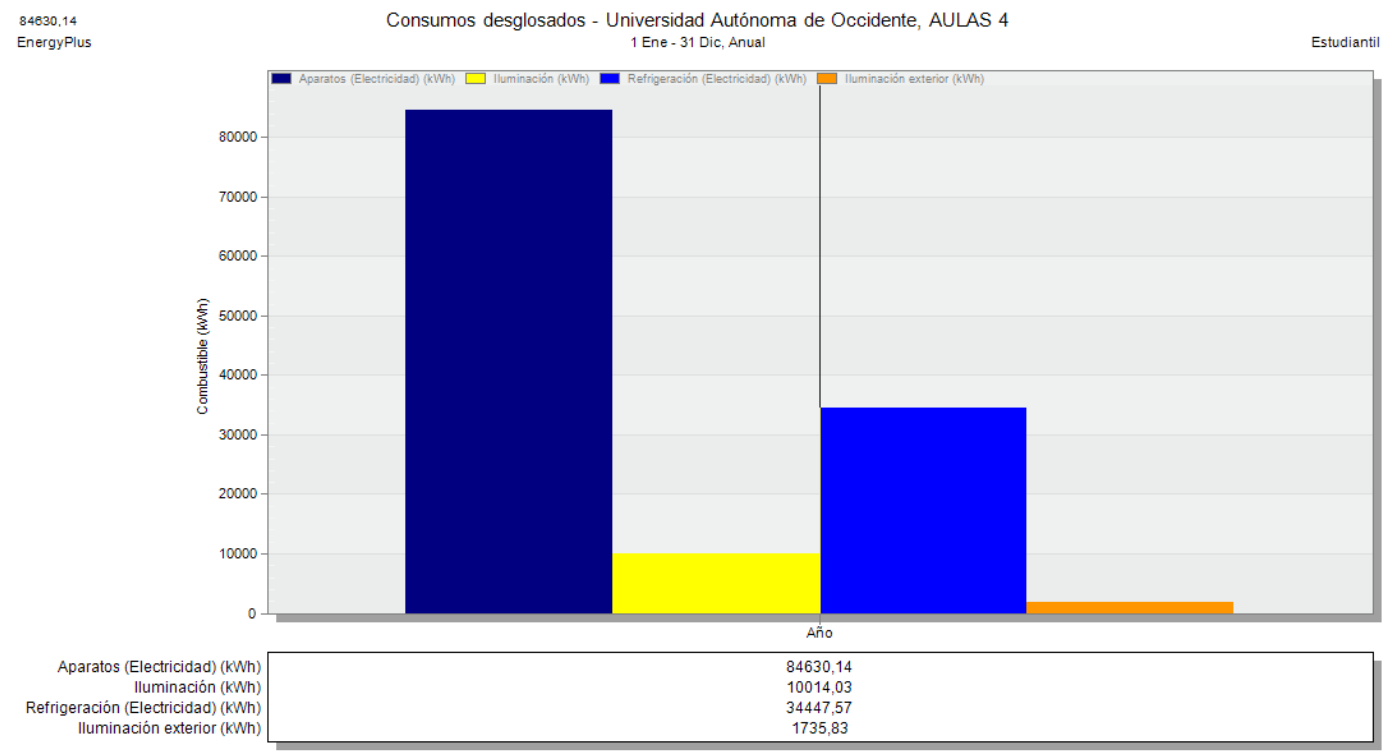

Figura 160. Diagrama de barras distribución del consumo energético anual con MAE III.

\section{Impacto Medioambiental - Emisiones de $\mathrm{CO}_{2}$}

Se obtienen las emisiones de $\mathrm{kg}$ de $\mathrm{CO}_{2}$ generados por las instalaciones, presentado de forma mensual y anual en la Tabla 64 y la Figura 161.

Tabla 64. Producción mensual y anual de $\mathrm{kg}$ de $\mathrm{CO}_{2}$ con MAE III

\begin{tabular}{|c|c|}
\hline Mes & kg de $\mathbf{C O}_{\mathbf{2}}$ \\
\hline Enero & 3543.16 \\
\hline Febrero & 8626.76 \\
\hline Marzo & 9952.05 \\
\hline Abril & 7273.19 \\
\hline Mayo & 7904.5 \\
\hline Junio & 5154.3 \\
\hline Julio & 4139.47 \\
\hline Agosto & 8039.29 \\
\hline Septiembre & 7560.31 \\
\hline Octubre & 7688.26 \\
\hline Noviembre & 5704.55 \\
\hline Diciembre & 3695.6 \\
\hline Total & 79281.44 \\
\hline
\end{tabular}

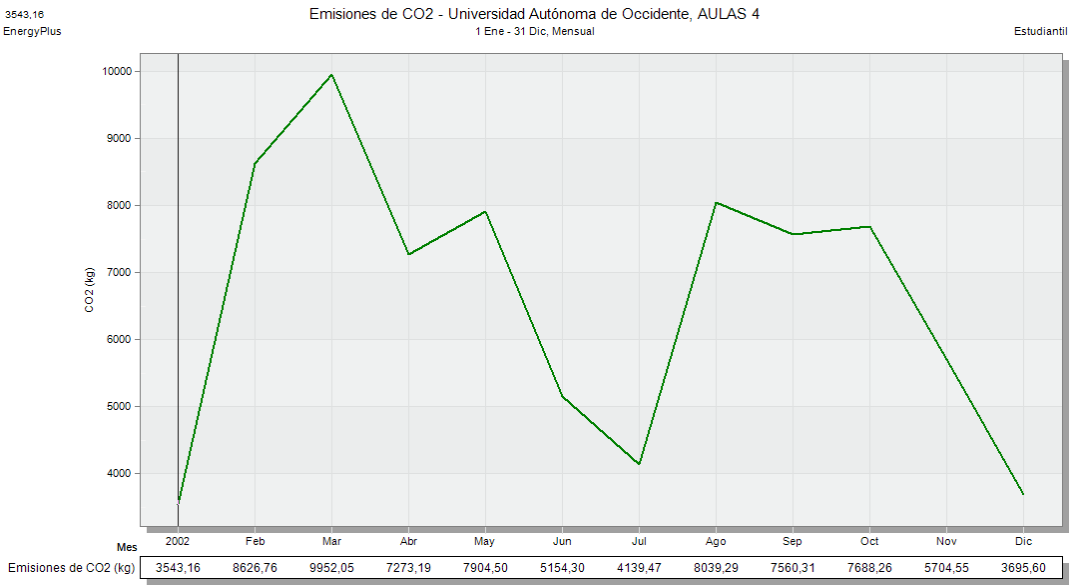

Figura 161. Emisiones de $\mathrm{CO}_{2}$ mensual para el edificio con la MAE III 


\subsubsection{Análisis comparativo de consumos energéticos del edificio base vs el edificio con la MAE III}

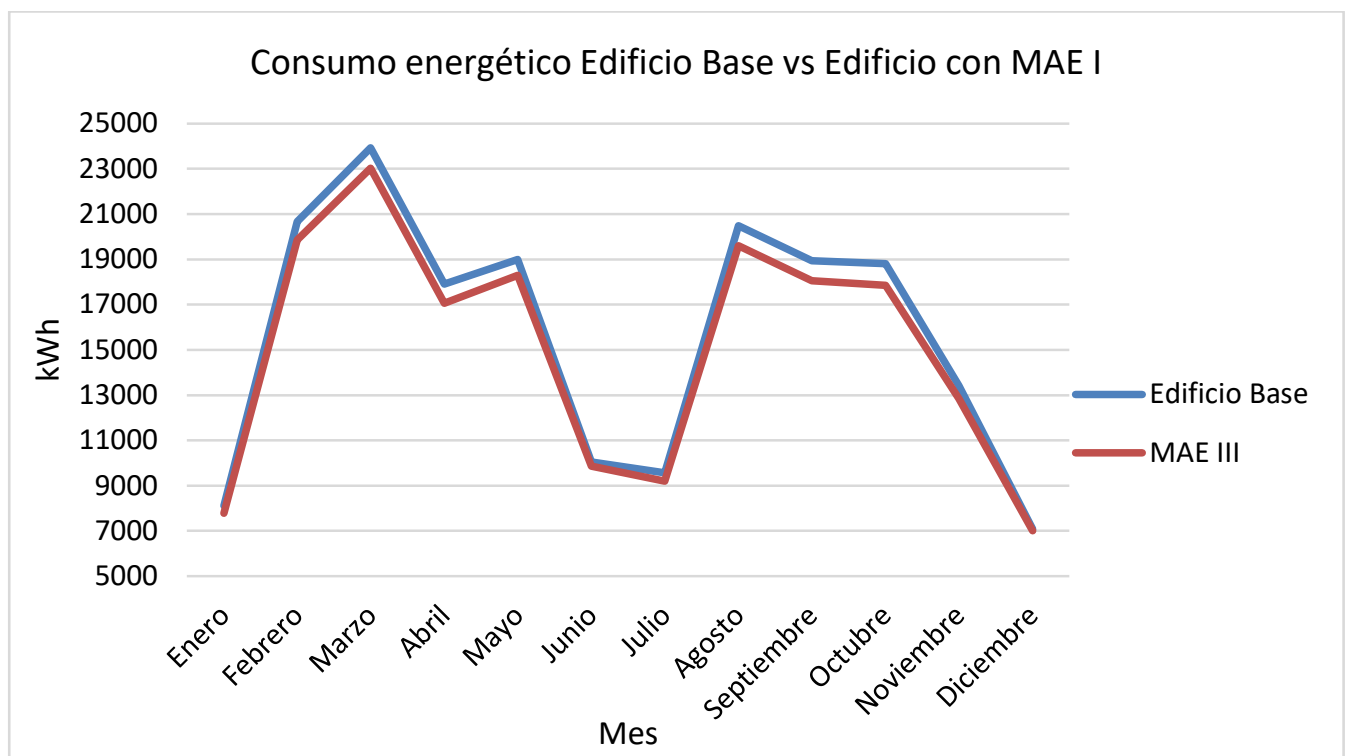

Figura 162. Consumo energético mensual Edificio Base y Edificio con MAE III.

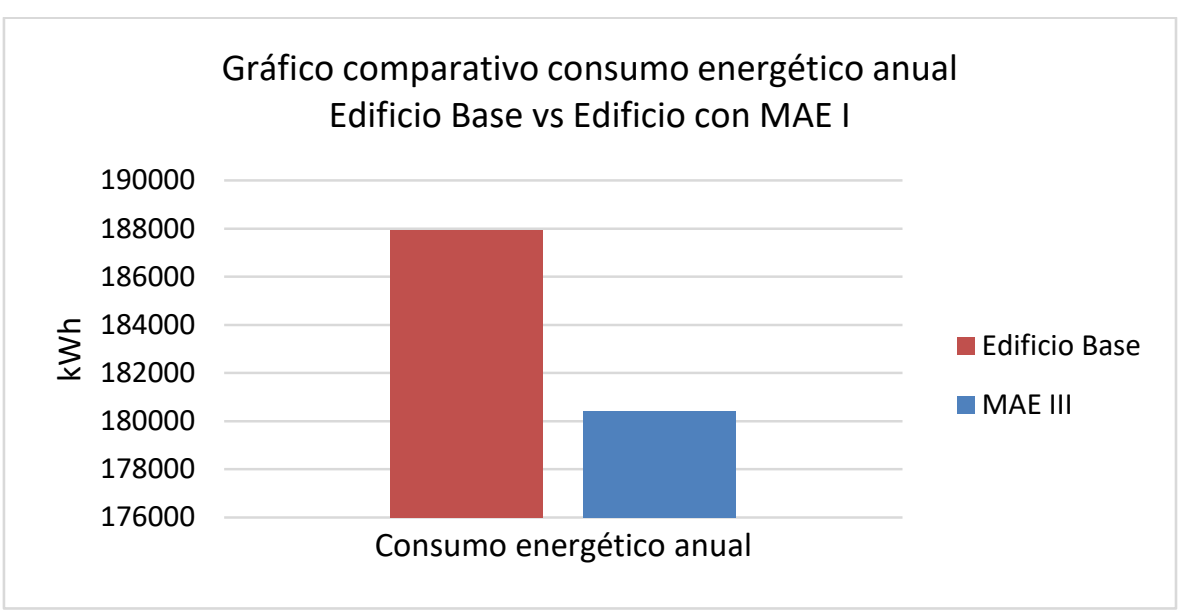

Figura 163. Consumo energético anual Edificio Base y Edificio con MAE III

Una vez implementado y simulado el edificio con la Medida de Ahorro Energético III, que consiste en el sistema de lamas en algunas zonas del edificio, se obtiene una reducción del $3,99 \%$ del consumo energético anual del edificio $(7501,77 \mathrm{kWh} / \mathrm{Año})$ relacionados con el HVAC del edificio base.

Este ahorro energético es debido a que las lamas reducen el impacto directo de la radiación solar a la fachada del edificio donde se sitúan los vidrios de las aulas, logrando así una reducción del calor transferido al interior de los recintos, lo cual significa una reducción de la temperatura interior de los mismos y por lo tanto una reducción significativa en el consumo de aire acondicionado. Es por esto que se debe tener en cuenta como una medida de mejora de la eficiencia energética en el edificio de Aulas 4 de la UAO. 


\subsection{MAE IV - FILTROS SOLARES Y SOMBRAS - VIDRIO ELECTROCRÓMICO}

Otra propuesta que se implementó en aras de mejorar la eficiencia energética del edificio fue la implementación de vidrio electrocrómico en los acristalamientos del edificio, se realizó la simulación energética de este con las configuraciones realizadas, obteniendo los resultados de la Tabla 65 y la Tabla 66, donde se observa que el porcentaje de consumo mayor es de refrigeración, seguido de la refrigeración:

Tabla 65. Distribución de consumos energéticos por uso.

\begin{tabular}{|c|c|c|}
\hline TIPO DE USO & ELECTRICIDAD (kWh) & PORCENTAJE DE CARGA (\%) \\
\hline Refrigeración & 88979.93 & 48.00 \\
\hline Iluminación interior & 10014.02 & 5.40 \\
\hline Iluminación exterior & 1735.82 & 0.94 \\
\hline Equipos interiores & 84630.13 & 45.66 \\
\hline CONSUMO TOTAL (kWh) & $\mathbf{1 8 5 3 5 9 . 9 0}$ & $\mathbf{1 0 0}$ \\
\hline
\end{tabular}

Tabla 66. Distribución de consumos energéticos desglosados mes a mes por uso.

\begin{tabular}{|c|c|c|c|c|c|c|c|}
\hline Mes & Refrigeración & $\begin{array}{c}\text { Iluminación } \\
\text { interior }\end{array}$ & $\begin{array}{c}\text { Iluminación } \\
\text { exterior }\end{array}$ & Equipos & $\begin{array}{c}\text { Total } \\
\text { (kwh) }\end{array}$ & $\begin{array}{c}\text { Consumo } \\
\text { kwh/día }\end{array}$ & $\begin{array}{c}\text { consumo } \\
\text { mes }\end{array}$ \\
\hline Enero & 3466.17 & 341.51 & 53.58 & 4163.75 & 8025.01 & 258.87 & $4.3 \%$ \\
\hline Febrero & 10154.10 & 1149.70 & 214.30 & 8859.06 & 20377.16 & 727.76 & $11.0 \%$ \\
\hline Marzo & 11841.93 & 1326.59 & 246.44 & 10179.94 & 23594.90 & 761.13 & $12.7 \%$ \\
\hline Abril & 9272.34 & 1184.71 & 214.30 & 6916.94 & 17588.29 & 586.28 & $9.5 \%$ \\
\hline Mayo & 9235.71 & 962.87 & 160.72 & 8407.74 & 18767.04 & 605.39 & $10.1 \%$ \\
\hline Junio & 2385.01 & 144.42 & 0.00 & 7461.88 & 9991.31 & 333.04 & $5.4 \%$ \\
\hline Julio & 4241.35 & 380.47 & 53.58 & 4799.50 & 9474.90 & 305.64 & $5.1 \%$ \\
\hline Agosto & 11033.20 & 1316.33 & 246.44 & 7531.07 & 20127.04 & 649.26 & $10.9 \%$ \\
\hline Septiembre & 9952.06 & 1238.83 & 225.01 & 7211.90 & 18627.80 & 620.93 & $10.0 \%$ \\
\hline Octubre & 9693.37 & 1272.47 & 235.73 & 7303.31 & 18504.88 & 596.93 & $10.0 \%$ \\
\hline Noviembre & 6165.89 & 602.63 & 85.72 & 6373.07 & 13227.31 & 426.69 & $7.1 \%$ \\
\hline Diciembre & 1538.80 & 93.49 & 0.00 & 5421.97 & 7054.26 & 235.14 & $3.8 \%$ \\
\hline
\end{tabular}

Las Figuras 164 y 165., muestran la distribución de consumo anual simulado y la distribución porcentual por consumos para el año 2017 respectivamente del edificio con la implementación de vidrios electrocrómicos como MAE IV. 


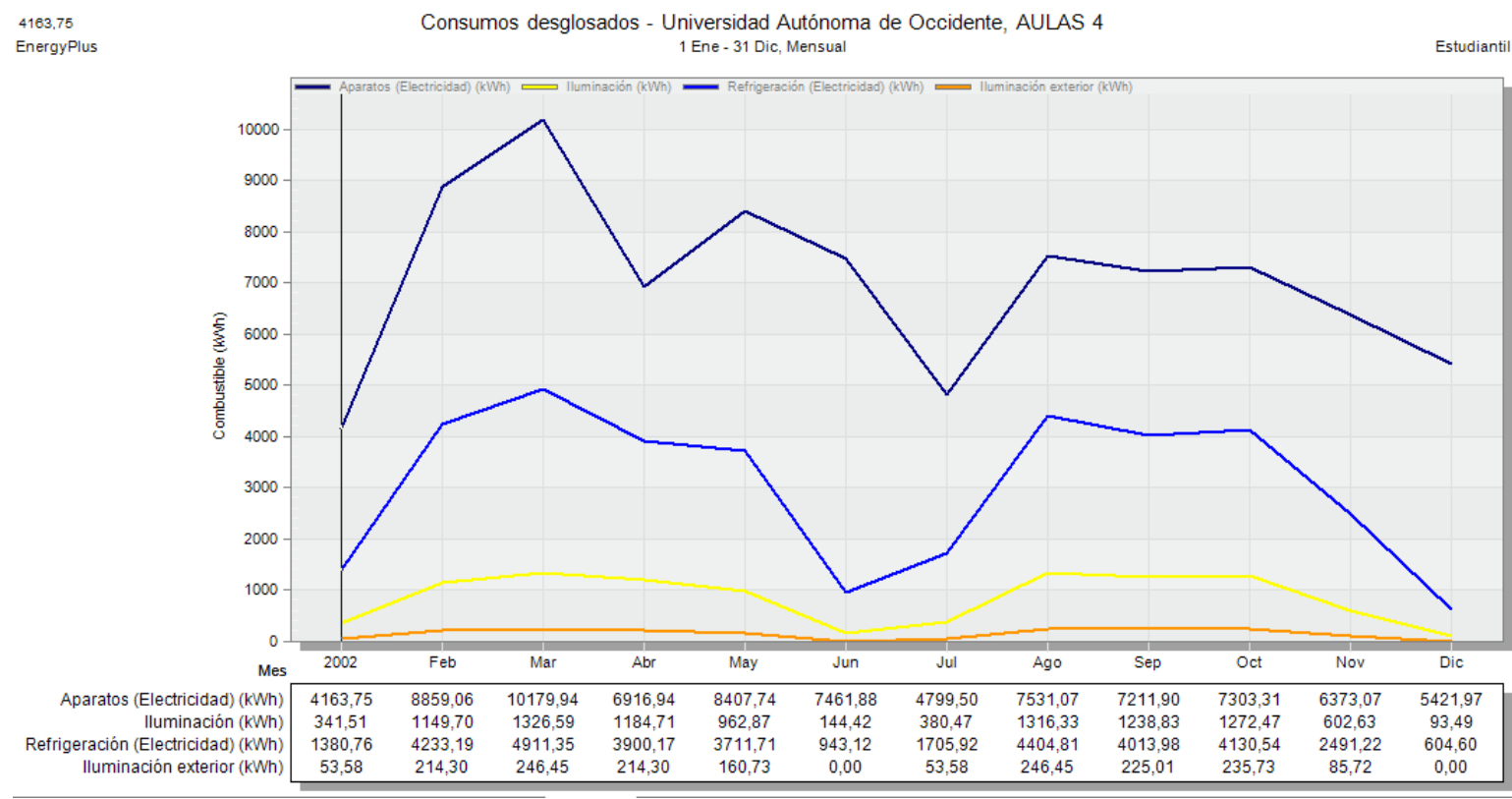

Figura 164. Distribución de consumo energético anual desglosado por uso final para MAE IV

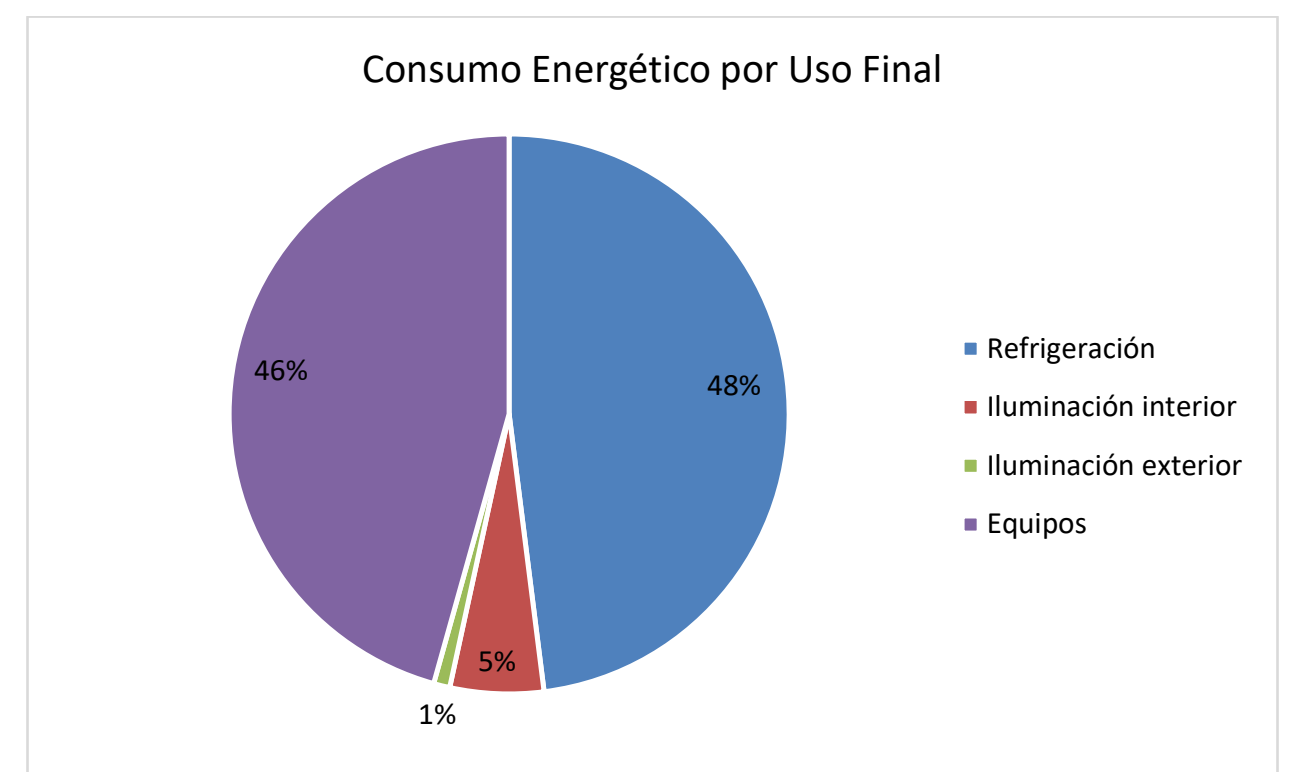

Figura 165. Distribución porcentual de consumo energético por uso final para MAE I

La Figura 166 muestra los consumos energéticos del edificio según cada uso final y su porcentaje de participación, de donde se obtiene que el consumo por iluminación exterior es de $1.735,82 \mathrm{kWh}(0,94 \%)$, iluminación interior 10.014,02 kWh $(5,40 \%)$, consumo por equipos ofimáticos de $84.630,13 \mathrm{kWh}(45,66 \%)$, y el consumo por climatización de $88.979,93 \mathrm{kWh}(48, \%)$. 


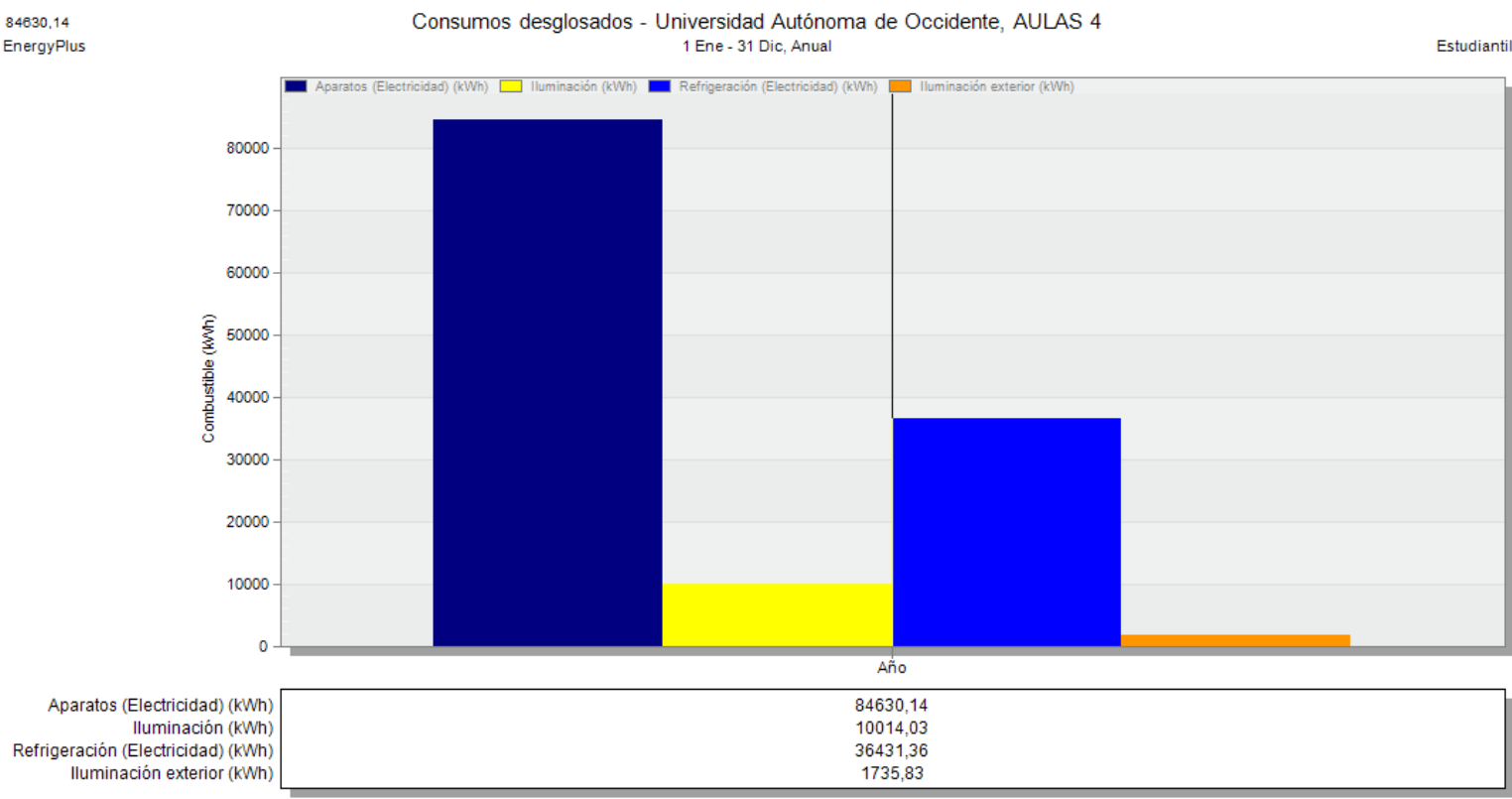

Figura 166. Diagrama de barras distribución del consumo energético anual.

\section{Impacto Medioambiental - Emisiones de $\mathrm{CO}_{2}$}

Se obtienen las emisiones de kg de $\mathrm{CO} 2$ generados por las instalaciones, presentado de forma mensual y anual en la tabla 67 y la Figura 168.

Tabla 67. Producción mensual y anual de $\mathrm{kg}$ de $\mathrm{CO}_{2}$ con MAE IV

\begin{tabular}{|c|c|}
\hline Mes & kg de $\mathbf{C O}_{\mathbf{2}}$ \\
\hline Enero & 3599.4 \\
\hline Febrero & 8760.48 \\
\hline Marzo & 10098.57 \\
\hline Abril & 7402.97 \\
\hline Mayo & 8025.27 \\
\hline Junio & 5180.94 \\
\hline Julio & 4205.31 \\
\hline Agosto & 8180.18 \\
\hline Septiembre & 7689.97 \\
\hline Octubre & 7842.87 \\
\hline Noviembre & 5788.89 \\
\hline Diciembre & 3708.75 \\
\hline Total & 80483.6 \\
\hline
\end{tabular}

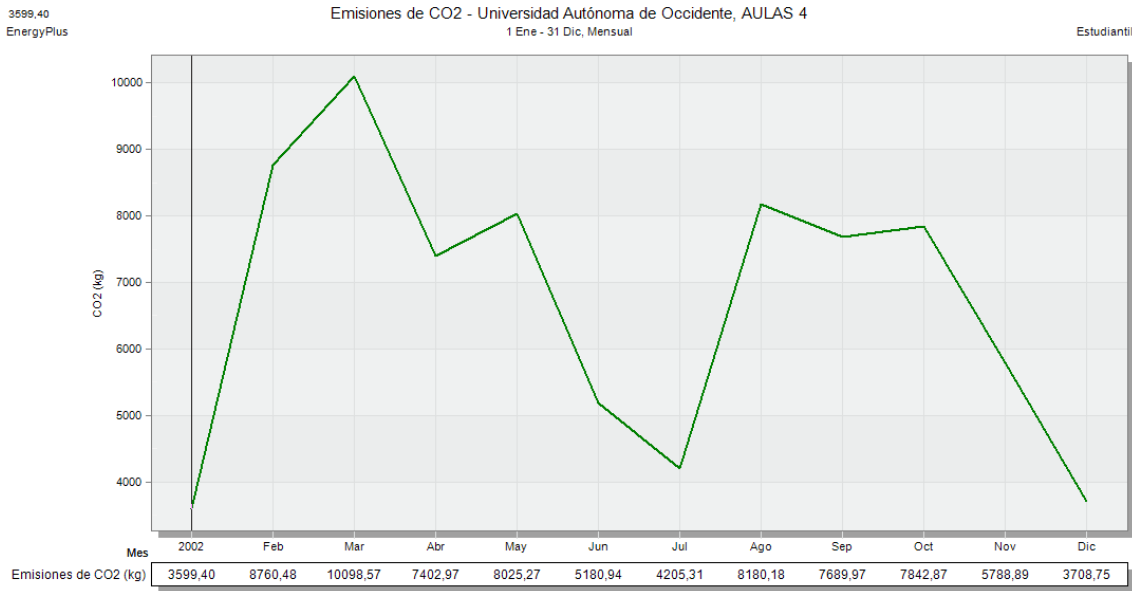

Figura 167. Emisiones de $\mathrm{CO}_{2}$ mensual para el edificio con la MAE IV 


\subsubsection{Análisis comparativo de consumos energéticos del edificio base vs el edificio con la MAE IV}

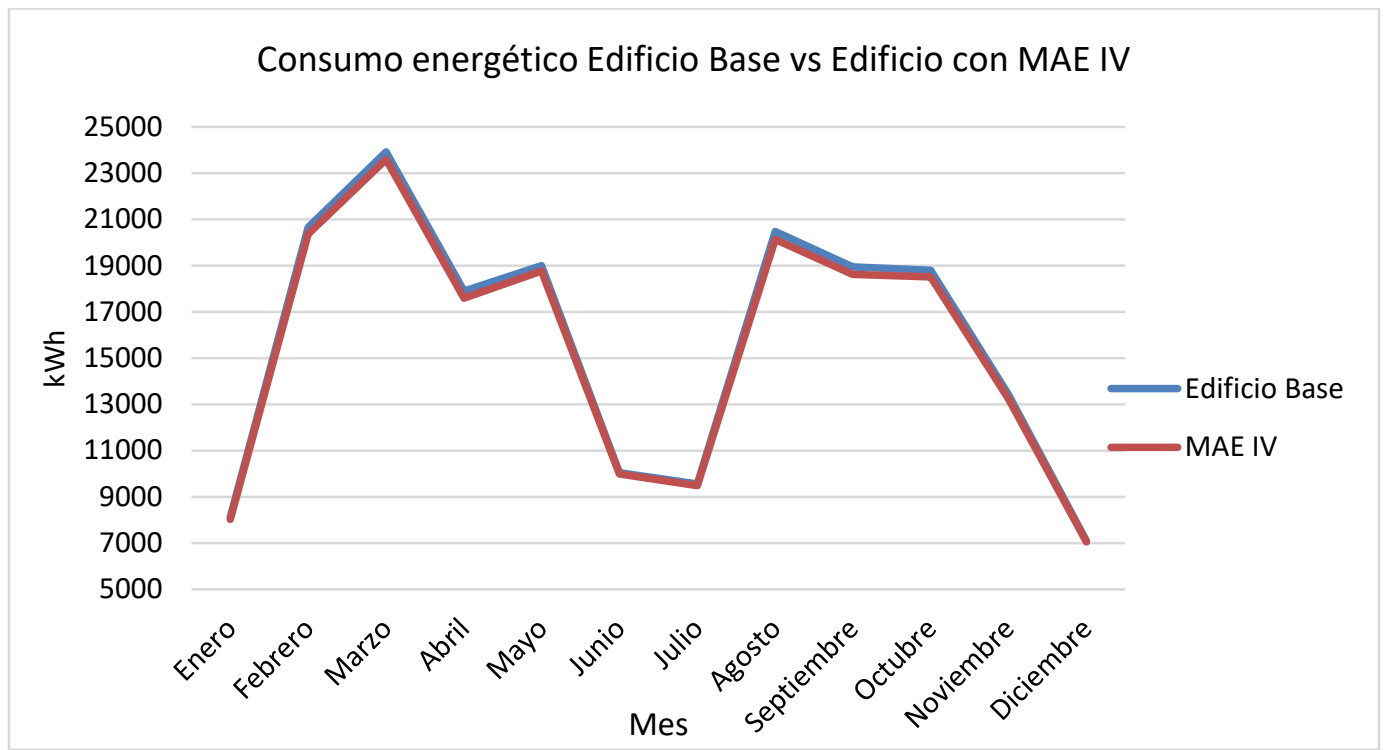

Figura 168. Consumo energético mensual Edificio Base y Edificio con MAE IV.

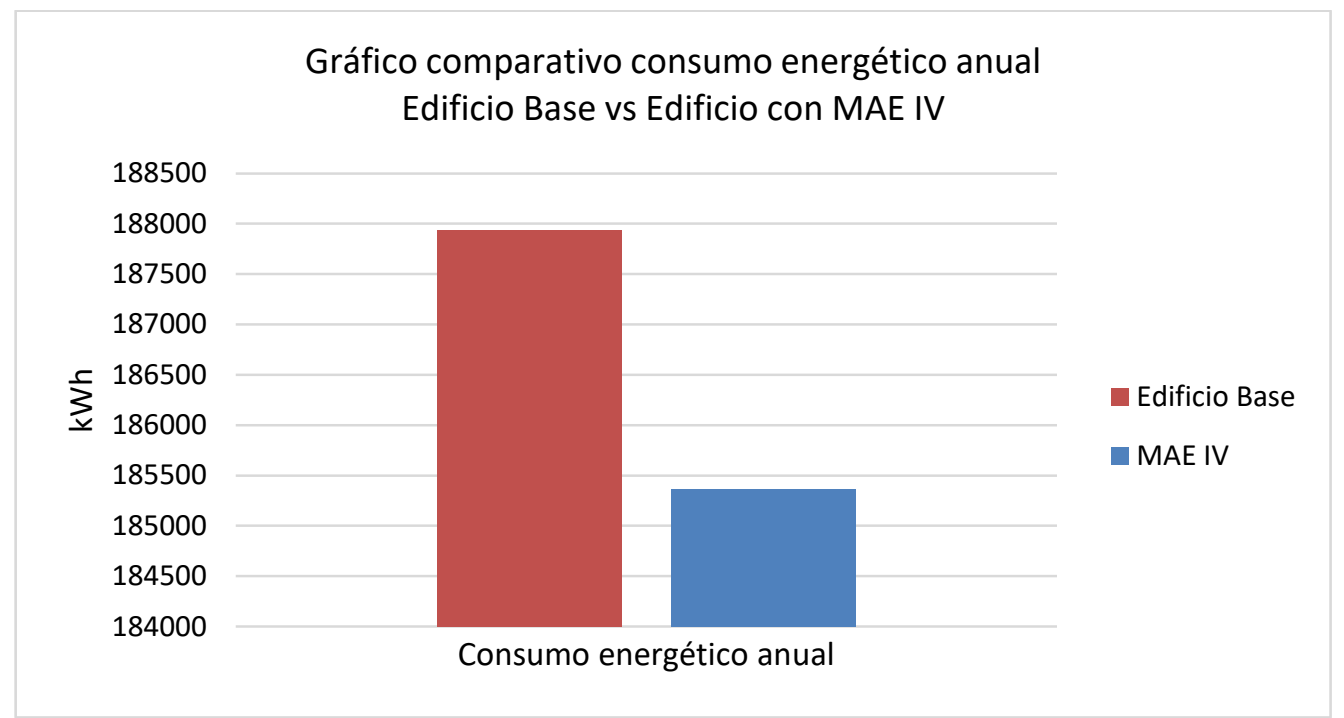

Figura 169. Consumo energético anual Edificio Base y Edificio con MAE IV

De acuerdo con los datos obtenidos, se observa una reducción en el consumo por aire acondicionado, ya que se reduce la carga térmica mediante el sombreado de los acristalamientos mediante vidrio electrocrómico, logrando así una reducción del 1,37\% del consumo total anual del edificio lo que se traduce a casi la mitad del consumo energético total presentado en el mes de diciembre del mismo año, dejando entrever la importancia y lo conveniente de la implementación de esta solución a la mejora de la eficiencia energética. 


\subsection{MAE V - FILTROS SOLARES Y SOMBRAS - VOLADIZOS}

En aras de mejorar la eficiencia energética del edificio, se implementaron voladizos por encima de las ventanas con el fin de reducir el impacto de los rayos UV en el acristalamiento del edificio y así reducir la carga térmica interna del mismo. A continuación, se presentan en las Figuras 170 - 173 los resultados obtenidos al realizar la simulación energética de esta propuesta.

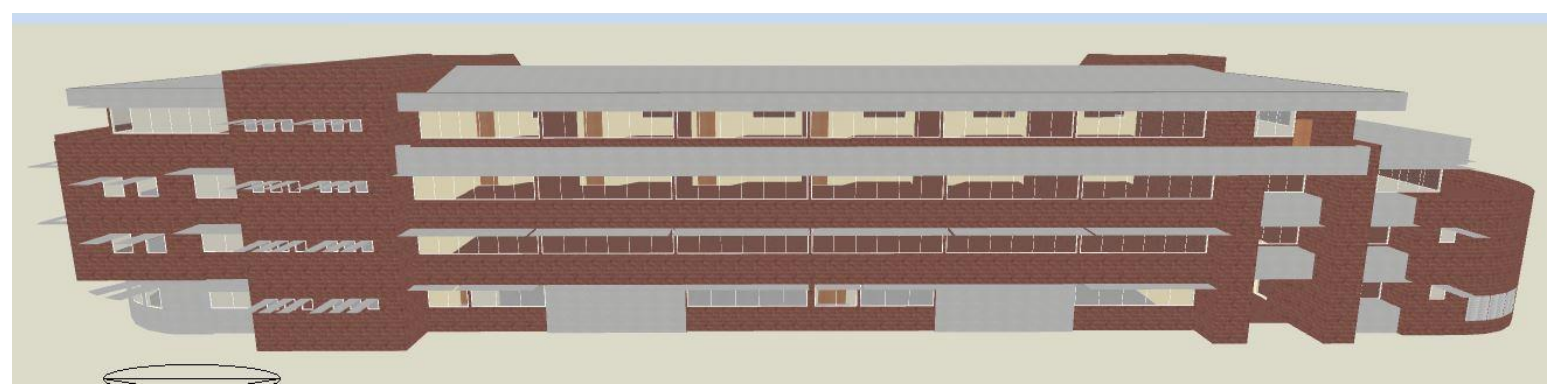

Figura 170. Vista norte del edificio con implementación de voladizos

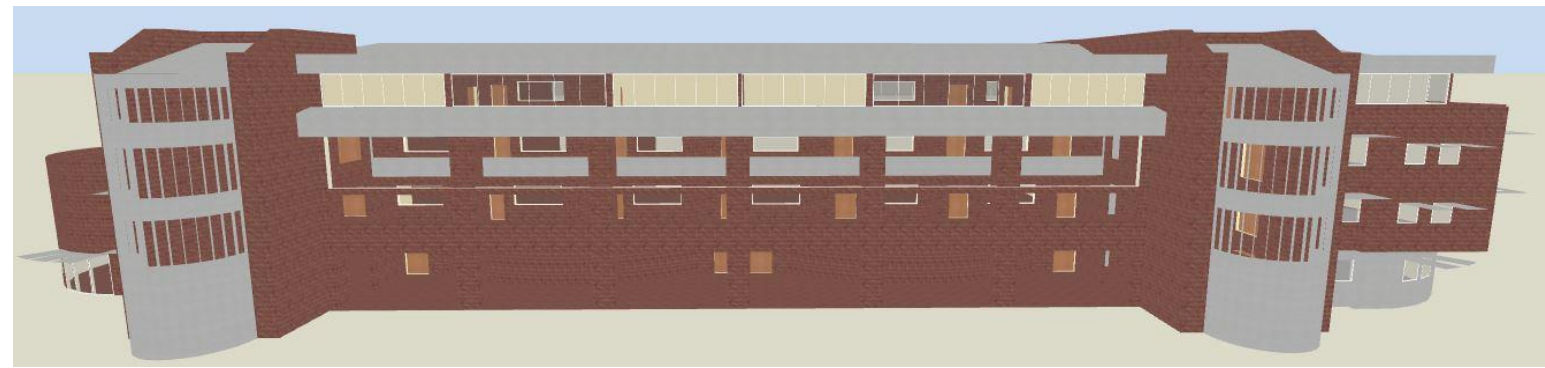

Figura 171. Vista sur del edificio con implementación de voladizos

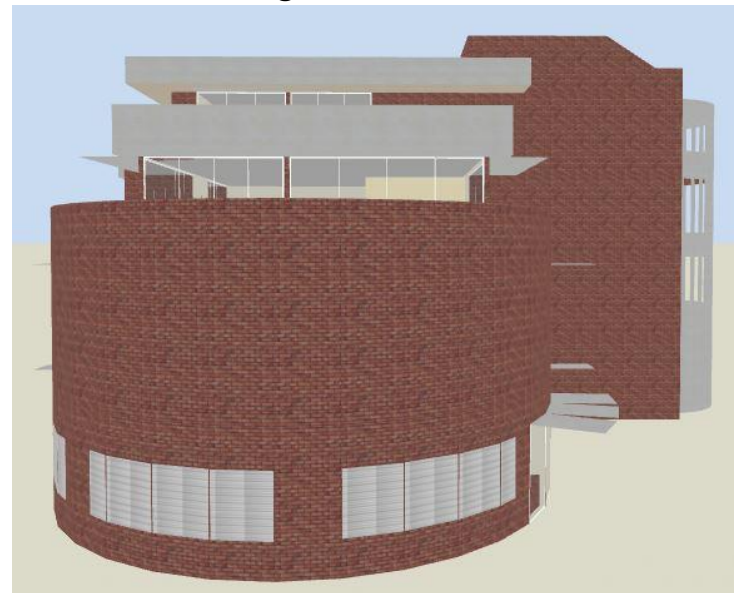

Figura 172. Vista oeste del edificio con implementación de voladizos

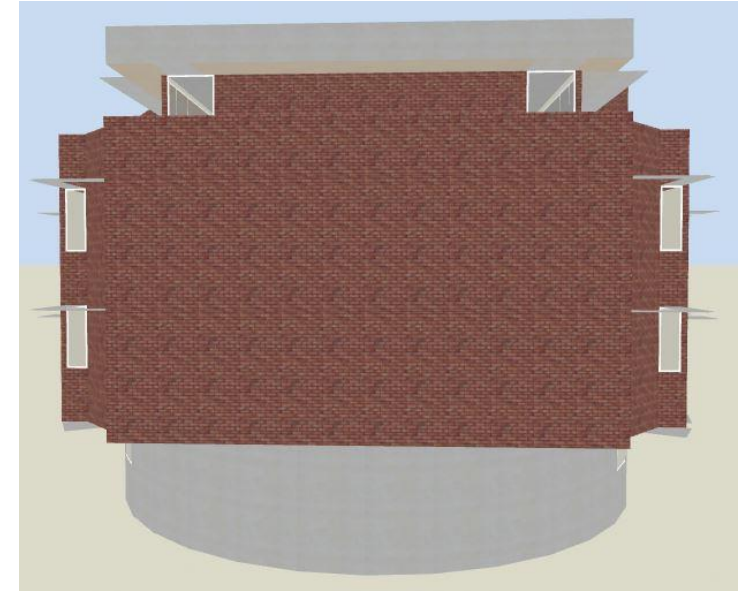

Figura 173. Vista este del edificio con implementación de voladizos

La Figura 174 presenta la evolución del consumo de energía del edificio por meses bajo la implementación de voladizos, en un año meteorológico tipo y observándose que los meses de menor consumo energético corresponden a enero, junio, Julio y diciembre debido a una época vacacional. 


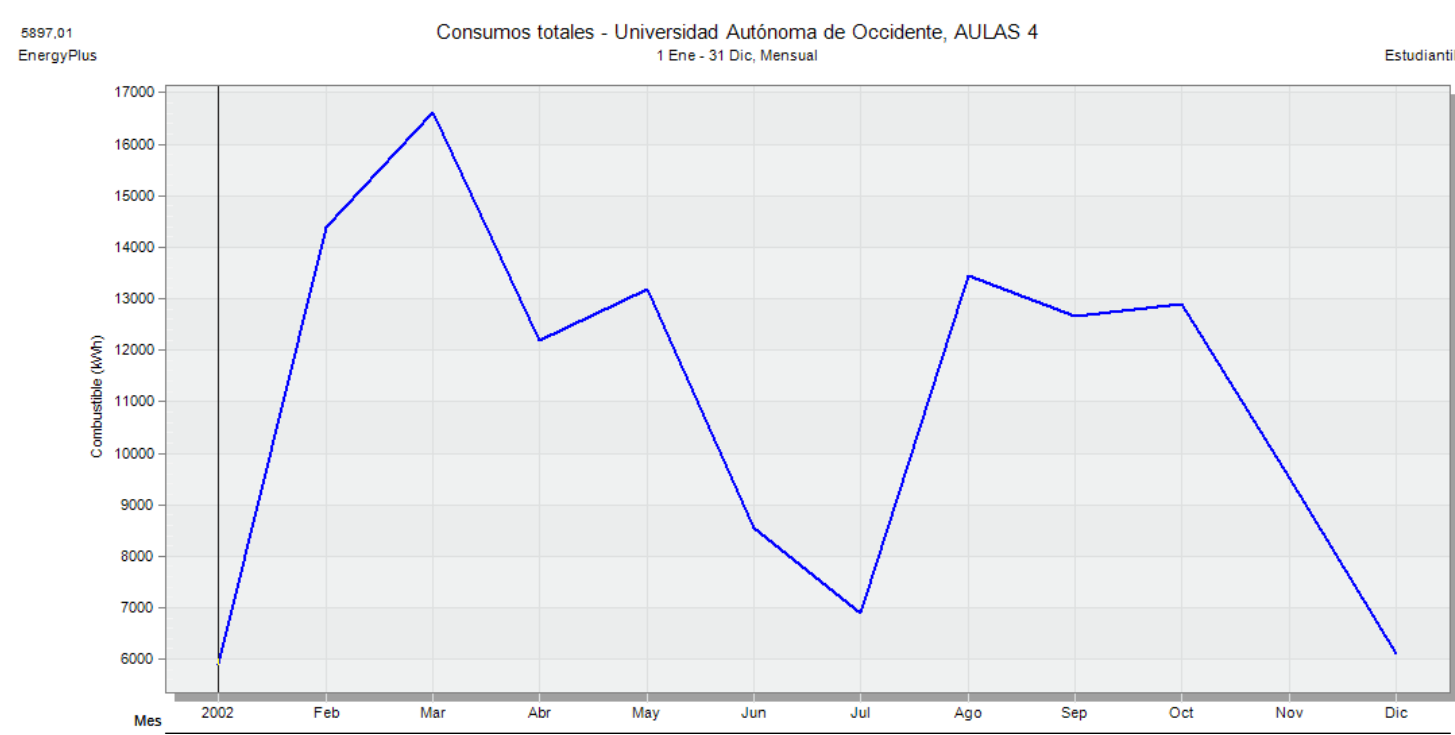

Figura 174. Distribución de consumo energético anual con MAE V implementada

La Tabla 68 desglosa el consumo total anual de energía del edificio con la implementación de voladizos según el tipo de uso. En la Tabla 69, se presenta la distribución de consumos energéticos desglosados mes a mes, donde se observa que el porcentaje de mayor consumo son los equipos de refrigeración.

Tabla 68. Distribución de consumos energéticos por uso.

\begin{tabular}{|c|c|c|}
\hline TIPO DE USO & ELECTRICIDAD (kWh) & PORCENTAJE DE CARGA (\%) \\
\hline Enfriamiento & 87768.23 & 47.66 \\
\hline Iluminación interior & 10014.02 & 5.44 \\
\hline Iluminación exterior & 1735.82 & 0.94 \\
\hline Equipos interiores & 84630.10 & 45.96 \\
\hline CONSUMO TOTAL (kWh) & $\mathbf{1 8 4 1 4 8 . 1 7}$ & $\mathbf{1 0 0}$ \\
\hline
\end{tabular}

Tabla 69. Distribución de consumos energéticos desglosados mes a mes por uso.

\begin{tabular}{|c|c|c|c|c|c|c|c|}
\hline Mes & Refrigeración & $\begin{array}{c}\text { Iluminación } \\
\text { interior }\end{array}$ & $\begin{array}{c}\text { Iluminación } \\
\text { exterior }\end{array}$ & Equipos & $\begin{array}{c}\text { Total } \\
\text { (kwh) }\end{array}$ & $\begin{array}{c}\text { Consumo } \\
\text { kwh/día }\end{array}$ & $\begin{array}{c}\text { consumo } \\
\text { mes }\end{array}$ \\
\hline Enero & 3355.98 & 341.51 & 53.58 & 4163.72 & 7914.79 & 255.32 & $4.3 \%$ \\
\hline Febrero & 10009.33 & 1149.70 & 214.30 & 8859.06 & 20232.39 & 722.59 & $11.0 \%$ \\
\hline Marzo & 11726.61 & 1326.59 & 246.44 & 10179.94 & 23479.58 & 757.41 & $12.8 \%$ \\
\hline Abril & 9189.81 & 1184.71 & 214.30 & 6916.94 & 17505.76 & 583.53 & $9.5 \%$ \\
\hline Mayo & 9110.39 & 962.87 & 160.72 & 8407.74 & 18641.72 & 601.35 & $10.1 \%$ \\
\hline Junio & 2351.26 & 144.42 & 0.00 & 7461.88 & 9957.56 & 331.92 & $5.4 \%$ \\
\hline Julio & 4121.41 & 380.47 & 53.58 & 4799.50 & 9354.96 & 301.77 & $5.1 \%$ \\
\hline Agosto & 10926.50 & 1316.33 & 246.44 & 7531.07 & 20020.34 & 645.82 & $10.9 \%$ \\
\hline Septiembre & 9880.83 & 1238.83 & 225.01 & 7211.90 & 18556.57 & 618.55 & $10.1 \%$ \\
\hline Octubre & 9525.09 & 1272.47 & 235.73 & 7303.31 & 18336.60 & 591.50 & $10.0 \%$ \\
\hline Noviembre & 6052.74 & 602.63 & 85.72 & 6373.07 & 13114.16 & 423.04 & $7.1 \%$ \\
\hline Diciembre & 1518.28 & 93.49 & 0.00 & 5421.97 & 7033.74 & 234.46 & $3.8 \%$ \\
\hline
\end{tabular}


Las Figuras 175 y 176., muestran la distribución de consumo anual simulado y la distribución porcentual por consumos para el año 2017 bajo la implementación de voladizos respectivamente.

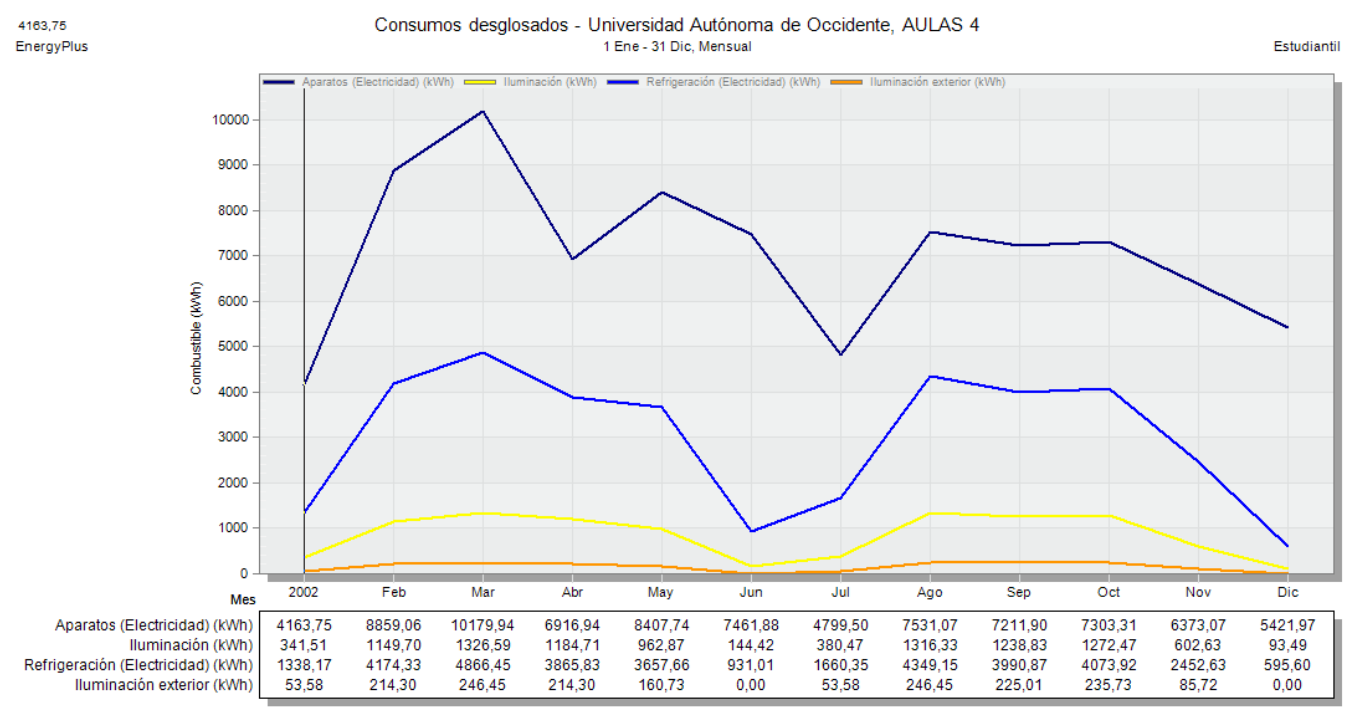

Figura 175. Distribución de consumo energético anual desglosado por uso final para MAE V

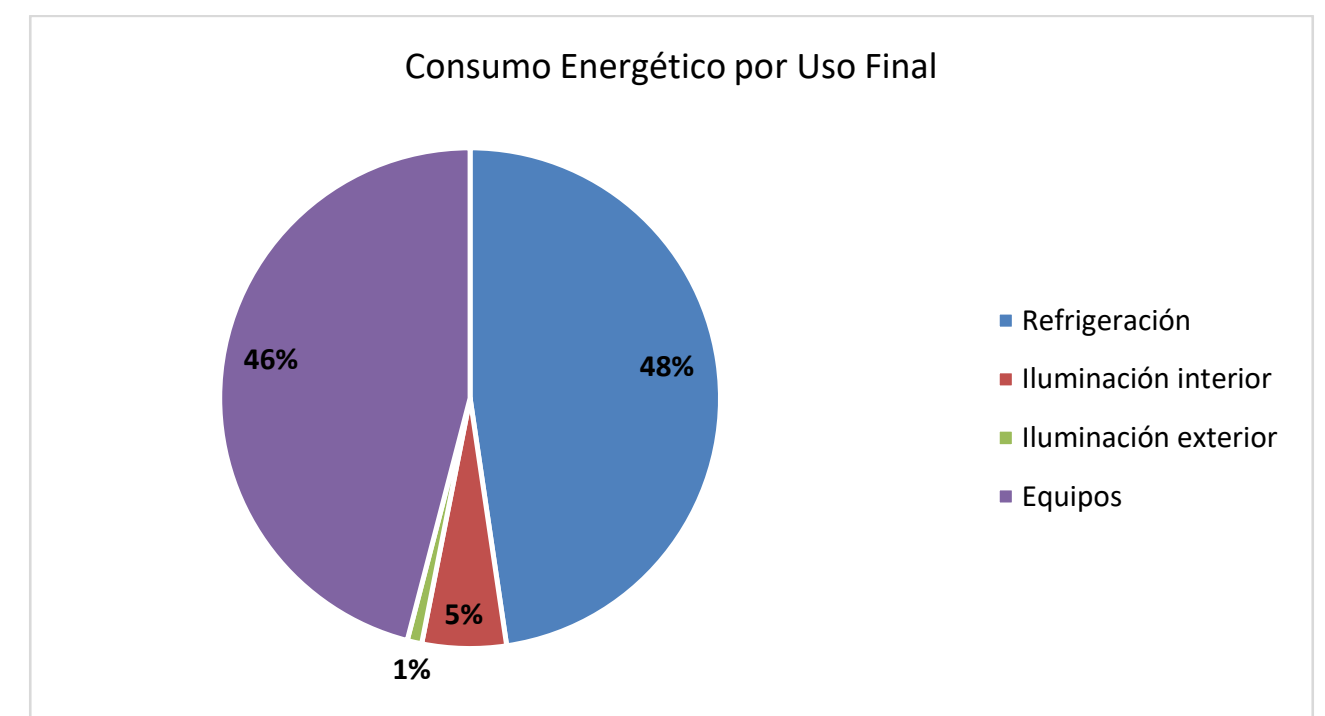

Figura 176. Distribución porcentual de consumo energético por uso final para MAE V

La Figura 177 muestra los consumos energéticos del edificio según cada uso final y su porcentaje de participación, de donde se obtiene que el consumo por iluminación exterior es de 1.735,82 kWh (0,94\%), iluminación interior 10.014,02 kWh (5,44\%), consumo por equipos ofimáticos de $84.630,13 \mathrm{kWh}$ (45,96\%), y el consumo por climatización de $87.768,23$ que representa el $47,66 \%$. 


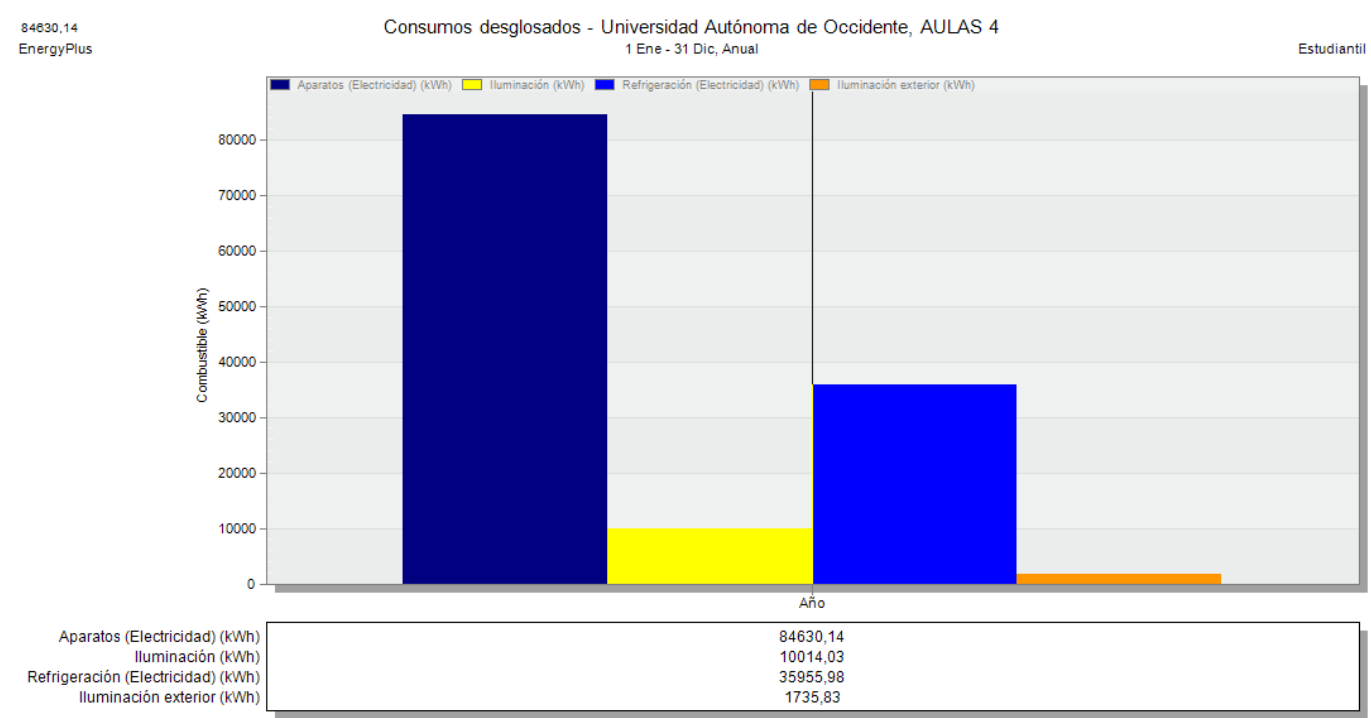

Figura 177. Diagrama de barras distribución del consumo energético anual implementando MAE V.

\section{Impacto Medioambiental - Emisiones de $\mathrm{CO}_{2}$}

Se obtienen las emisiones de $\mathrm{kg}$ de $\mathrm{CO}_{2}$ generados por las instalaciones, presentado de forma mensual y anual en la tabla y la Figura 178.

Tabla 70. Producción mensual y anual de $\mathrm{kg}$ de $\mathrm{CO}_{2}$ con MAE V

\begin{tabular}{|c|c|}
\hline Mes & kg de $\mathbf{C O}_{\mathbf{2}}$ \\
\hline Enero & 3573.59 \\
\hline Febrero & 8724.82 \\
\hline Marzo & 10071.36 \\
\hline Abril & 7382.16 \\
\hline Mayo & 7992.52 \\
\hline Junio & 5173.61 \\
\hline Julio & 4177.69 \\
\hline Agosto & 8146.44 \\
\hline Septiembre & 7675.96 \\
\hline Octubre & 7808.57 \\
\hline Noviembre & 5765.51 \\
\hline Diciembre & 3703.3 \\
\hline Total & 80195.53 \\
\hline
\end{tabular}

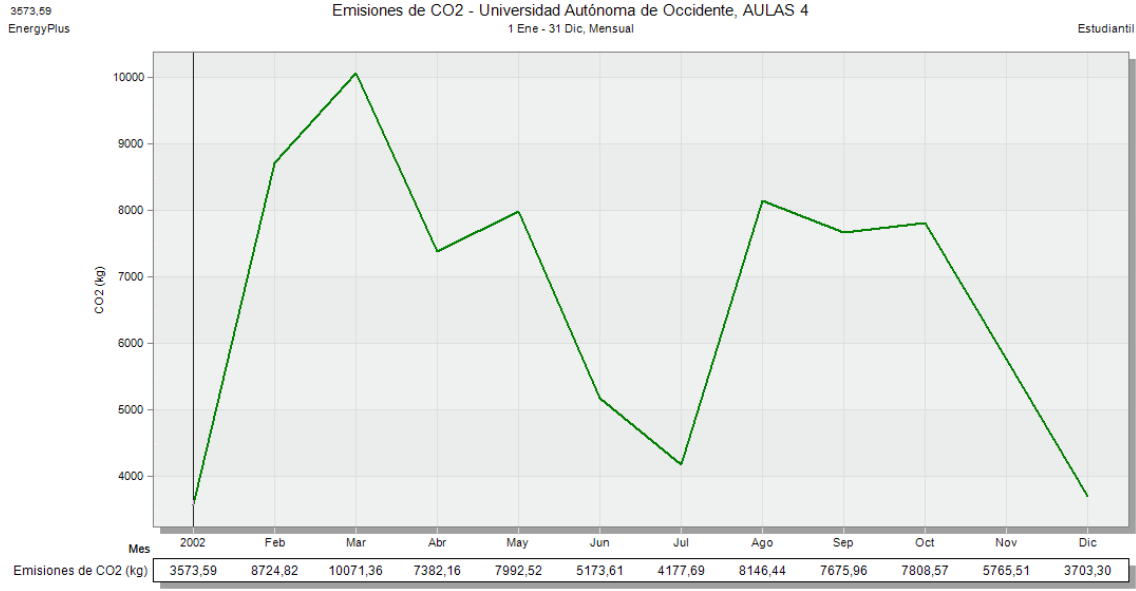

Figura 178. Emisiones de $\mathrm{CO}_{2}$ mensual para el edificio con la MAE V 


\subsubsection{Análisis comparativo de consumos energéticos del edificio base vs el edificio con la MAE V}

Las Figuras 179 y 180 comparan los consumos energéticos del Edificio base y el Edificio con la Medida de Ahorro Energético V (implementación de voladizos)

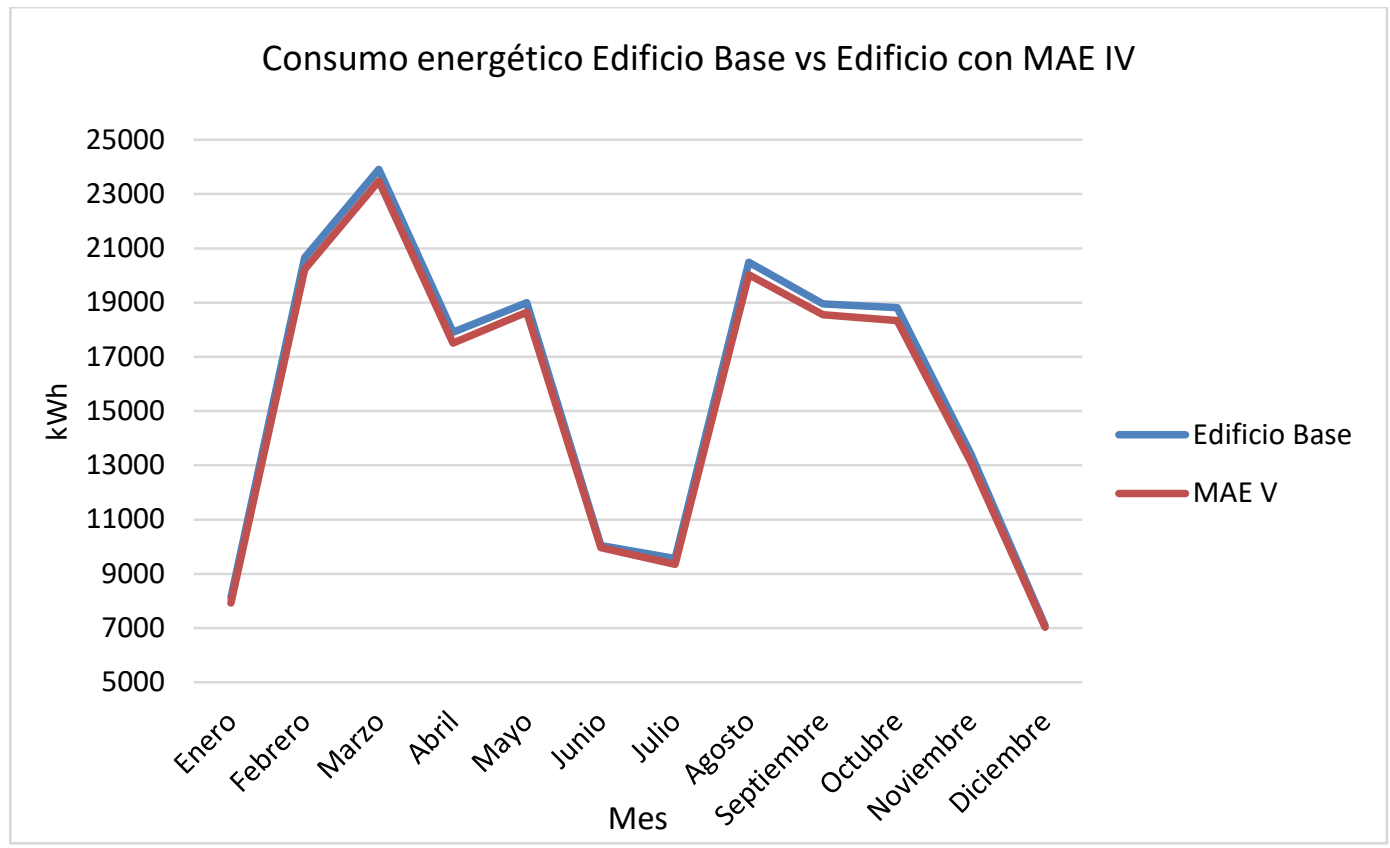

Figura 179. Consumo energético mensual Edificio Base y Edificio con la MAE V.

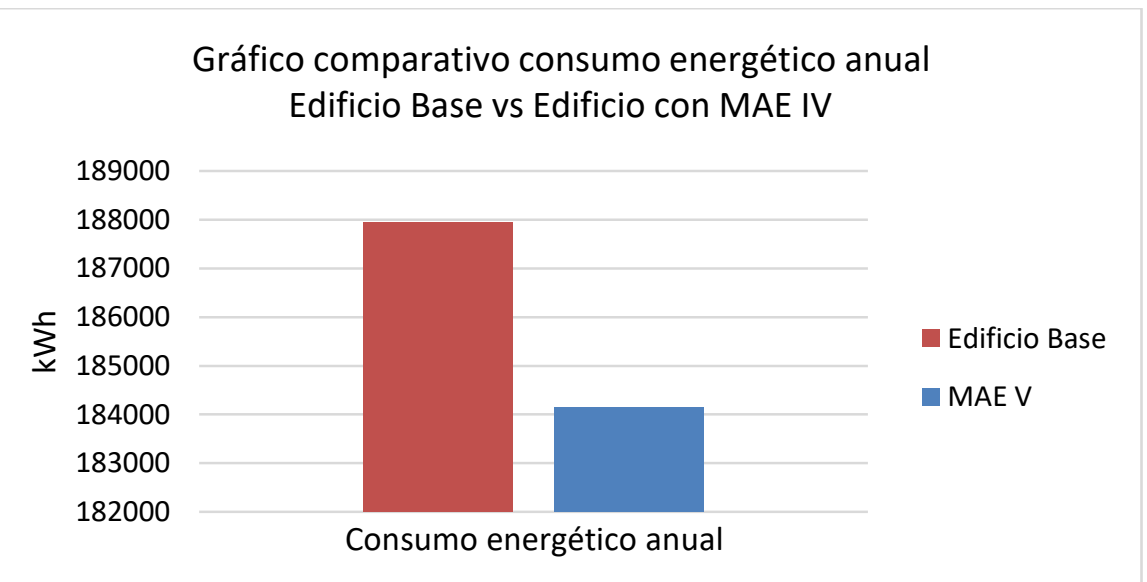

Figura 180. Consumo energético anual Edificio Base y Edificio con la MAE V.

Al implementar la estrategia de voladizos, se obtuvo una reducción en el consumo por aire acondicionado del 2,42\% del consumo total anual del edificio lo que se traduce a un poco más del consumo energético total presentado en el mes de diciembre del mismo año, dejando entrever la importancia y lo conveniente de la implementación de esta solución a la mejora de la eficiencia energética. 


\subsection{MAE VI - FILTROS SOLARES Y SOMBRAS - PERSIANAS REFLECTIVAS}

Otra estrategia que implementar en aras de la mejora de la eficiencia energética es la implementación de persianas reflectivas ubicadas en el interior de los recintos para reducir el impacto de los rayos UV en el acristalamiento del edificio y así reducir la carga térmica interna del edificio. Se realizó la simulación energética implementando las persianas reflectivas y se obtuvo que febrero y marzo fueron los meses de mayor consumo bajo esta $\mathrm{MAE}$, como lo muestra la Figura 181.

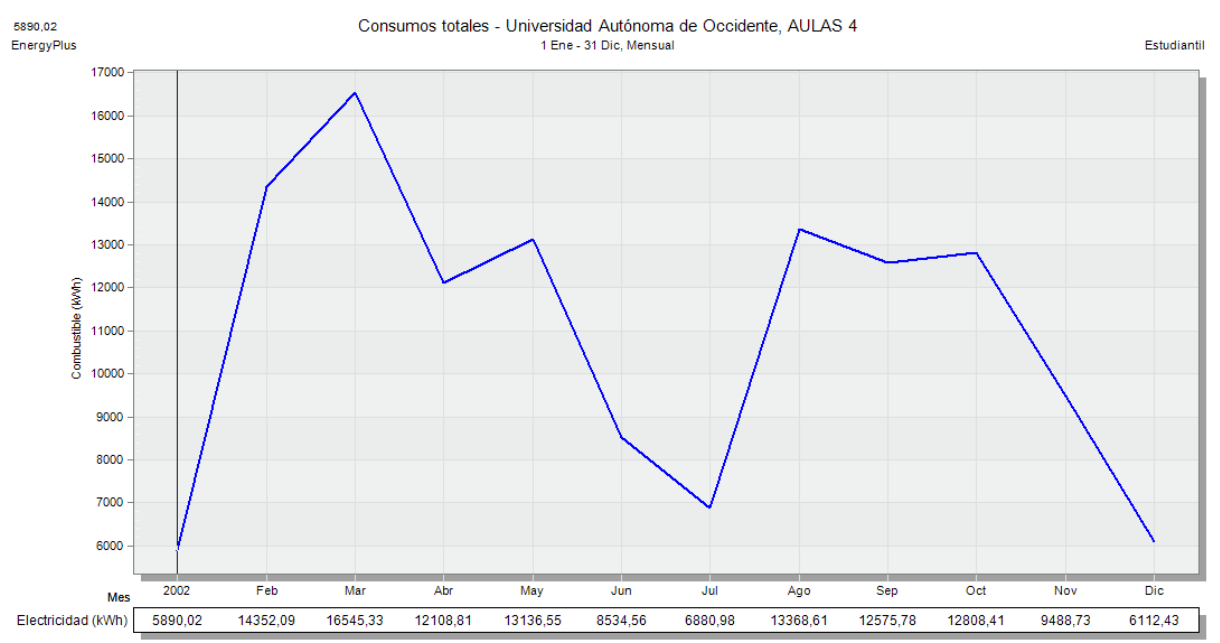

Figura 181. Distribución de consumo energético anual con MAE VI.

A continuación, se desglosa el consumo total anual de energía del edificio con la implementación de persianas reflectivas según el tipo de uso, como lo muestra la Tabla 71. La Tabla 72, muestra la distribución de consumos energéticos desglosados mes a mes, donde se observa que el mayor consumo de energía es de los equipos de refrigeración.

Tabla 71. Distribución de consumos energéticos por uso.

\begin{tabular}{|c|c|c|}
\hline TIPO DE USO & ELECTRICIDAD (kWh) & PORCENTAJE DE CARGA (\%) \\
\hline Enfriamiento & 86492,26 & 47,30 \\
\hline Iluminación interior & 10014,02 & 5,48 \\
\hline Iluminación exterior & 1735,82 & 0,95 \\
\hline Equipos interiores & 84630,13 & 46,28 \\
\hline CONSUMO TOTAL (kWh) & $\mathbf{1 8 2 8 7 2 , 2 3}$ & $\mathbf{1 0 0}$ \\
\hline
\end{tabular}

Tabla 72. Distribución de consumos energéticos desglosados mes a mes por uso.

\begin{tabular}{|c|c|c|c|c|c|c|c|}
\hline Mes & Refrigeración & $\begin{array}{c}\text { Iluminación } \\
\text { interior }\end{array}$ & $\begin{array}{c}\text { Iluminación } \\
\text { exterior }\end{array}$ & Equipos & $\begin{array}{c}\text { Total } \\
\text { (kwh) }\end{array}$ & $\begin{array}{c}\text { Consumo } \\
\text { kwh/día }\end{array}$ & $\begin{array}{c}\text { consumo } \\
\text { mes }\end{array}$ \\
\hline Enero & 3340.47 & 341.51 & 53.58 & 4163.75 & 7899.31 & 254.82 & $4.3 \%$ \\
\hline Febrero & 9922.68 & 1149.70 & 214.30 & 8859.06 & 20145.74 & 719.49 & $11.0 \%$ \\
\hline Marzo & 11564.19 & 1326.59 & 246.44 & 10179.94 & 23317.16 & 752.17 & $12.8 \%$ \\
\hline Abril & 9005.64 & 1184.71 & 214.30 & 6916.94 & 17321.59 & 577.39 & $9.5 \%$ \\
\hline
\end{tabular}


CAPÍTULO 6: PROPUESTAS DE MAE'S PARA EL EDIFICIO DE AULAS 4 MEDIANTE SIMULACIÓN ENERGÉTICA

\begin{tabular}{|c|c|c|c|c|c|c|c|} 
Mayo & 8995.12 & 962.87 & 160.72 & 8407.74 & 18526.45 & 597.63 & $10.1 \%$ \\
\hline Junio & 2340.99 & 144.42 & 0.00 & 7461.88 & 9947.29 & 331.58 & $5.4 \%$ \\
\hline Julio & 4091.94 & 380.47 & 53.58 & 4799.50 & 9325.49 & 300.82 & $5.1 \%$ \\
\hline Agosto & 10727.70 & 1316.33 & 246.44 & 7531.07 & 19821.54 & 639.40 & $10.8 \%$ \\
\hline Septiembre & 9654.07 & 1238.83 & 225.01 & 7211.90 & 18329.81 & 610.99 & $10.0 \%$ \\
\hline Octubre & 9334.32 & 1272.47 & 235.73 & 7303.31 & 18145.83 & 585.35 & $9.9 \%$ \\
\hline Noviembre & 5993.43 & 602.63 & 85.72 & 6373.07 & 13054.85 & 421.12 & $7.1 \%$ \\
\hline Diciembre & 1521.71 & 93.49 & 0.00 & 5421.97 & 7037.17 & 234.57 & $3.8 \%$ \\
\hline
\end{tabular}

Las figuras 182 y 183, presentan la distribución de consumo anual simulado y la distribución porcentual por consumos bajo la implementación de persianas reflectivas en el edificio para el año 2017 respectivamente.

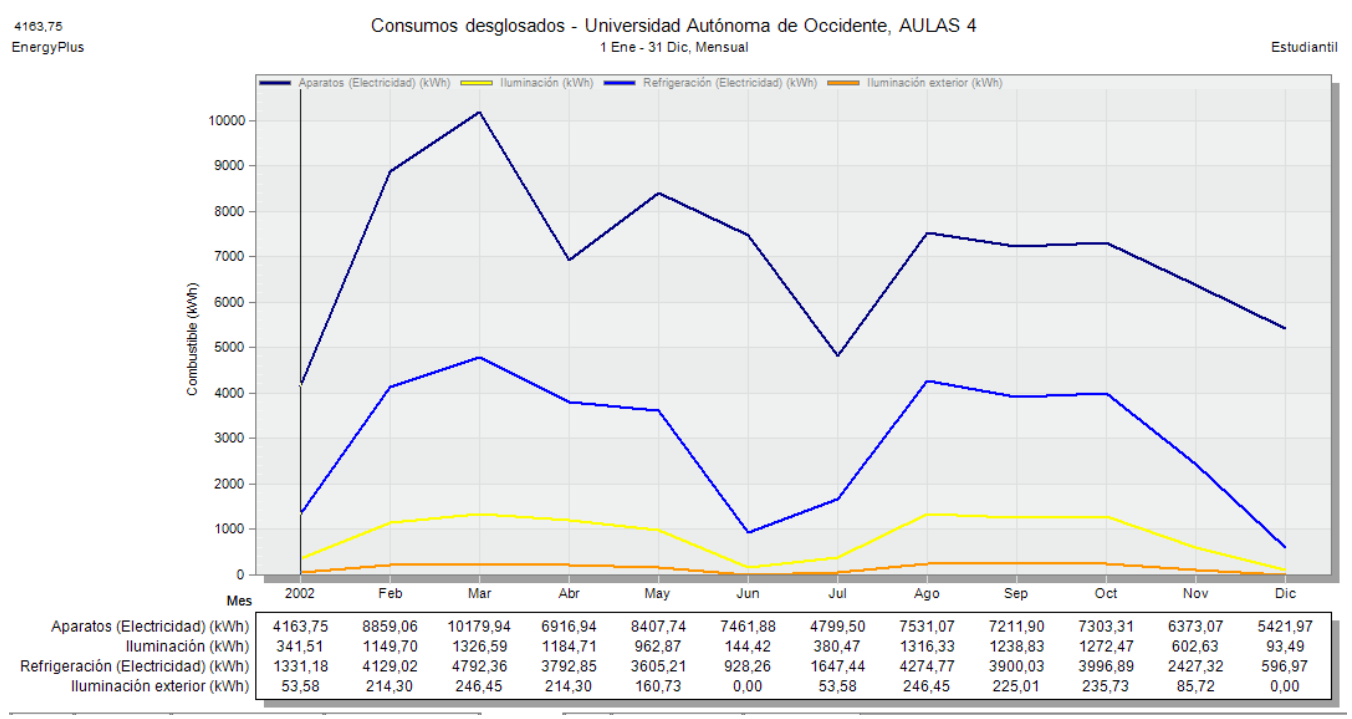

Figura 182. Distribución de consumo energético anual desglosado por uso final para MAE VI

Consumo Energético por Uso Final

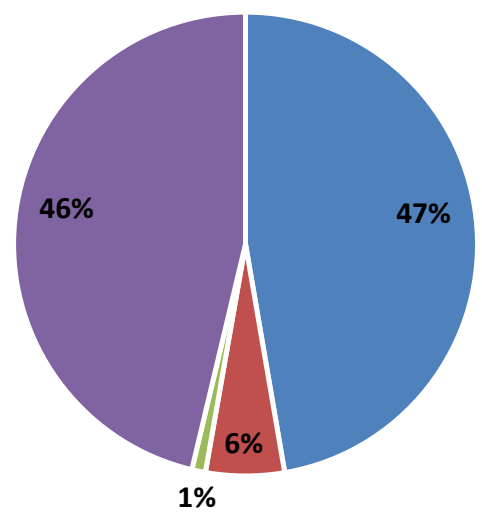

- Refrigeración

- Iluminación interior

- lluminación exterior

- Equipos

Figura 183. Distribución porcentual de consumo energético por uso final para MAE VI 
La Figura 184 presenta los consumos energéticos del edificio según cada uso final y su porcentaje de participación, donde se obtiene que el consumo por iluminación exterior es de $1.735,82 \mathrm{kWh}(0,95 \%)$, iluminación interior 10.014,02 kWh $(5,48 \%)$, consumo por equipos ofimáticos de 84.630,13 kWh (46,28\%), y el consumo por climatización de 86492,26 que supone un $47,30 \%$.

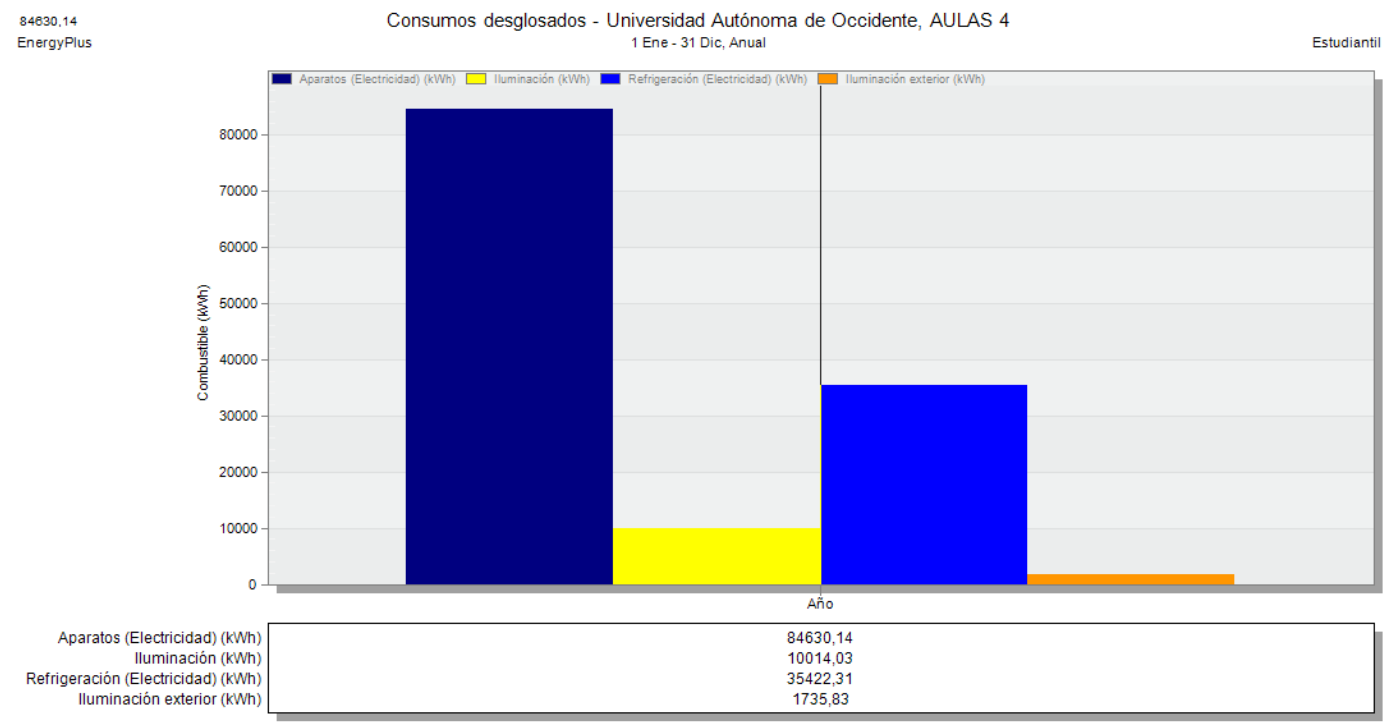

Figura 184. Diagrama de barras distribución del consumo energético anual.

\section{Impacto Medioambiental - Emisiones de $\mathrm{CO}_{2}$}

Se obtienen las emisiones de $\mathrm{kg}$ de $\mathrm{CO}_{2}$ generados por las instalaciones, presentado de forma mensual y anual en la Figura 185 y la tabla 73.

Tabla 73. Producción mensual y anual de $\mathrm{kg}$ de $\mathrm{CO}_{2}$ con MAE VI

\begin{tabular}{|c|c|}
\hline Mes & kg de $\mathbf{C O}_{\mathbf{2}}$ \\
\hline Enero & 3569.35 \\
\hline Febrero & 8697.36 \\
\hline Marzo & 10026.46 \\
\hline Abril & 7337.93 \\
\hline Mayo & 7960.74 \\
\hline Junio & 5171.94 \\
\hline Julio & 4169.87 \\
\hline Agosto & 8101.37 \\
\hline Septiembre & 7620.92 \\
\hline Octubre & 7761.89 \\
\hline Noviembre & 5750.17 \\
\hline Diciembre & 3701.13 \\
\hline Total & 79869.13 \\
\hline
\end{tabular}

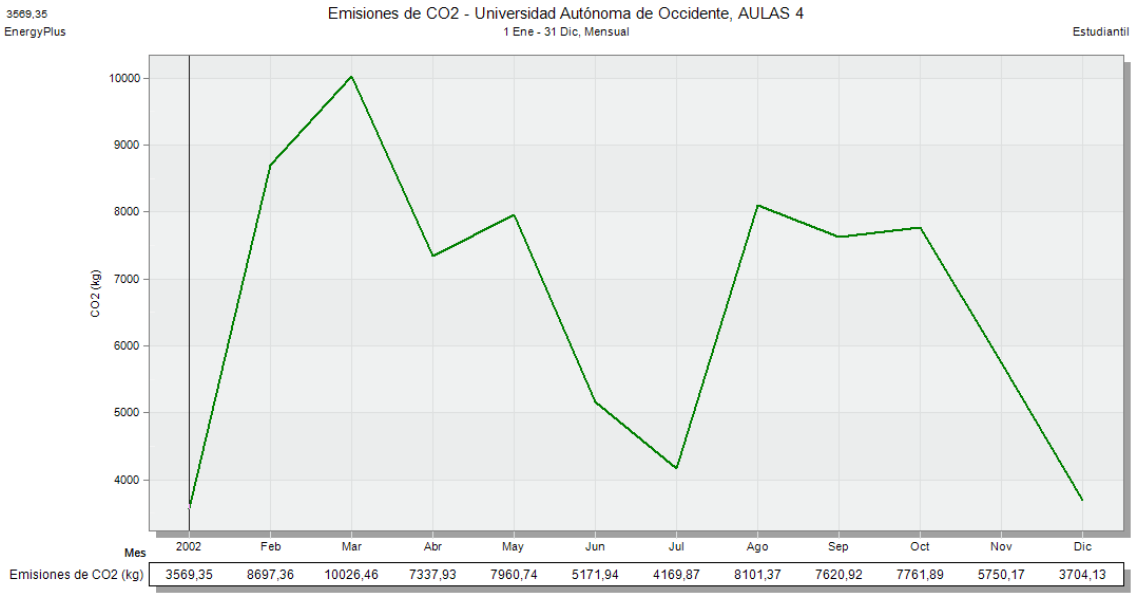

Figura 185. Emisiones de $\mathrm{CO}_{2}$ mensual para el edificio con la MAE VI 


\subsubsection{Análisis comparativo de consumos energéticos del edificio base vs el edificio con la MAE VI}

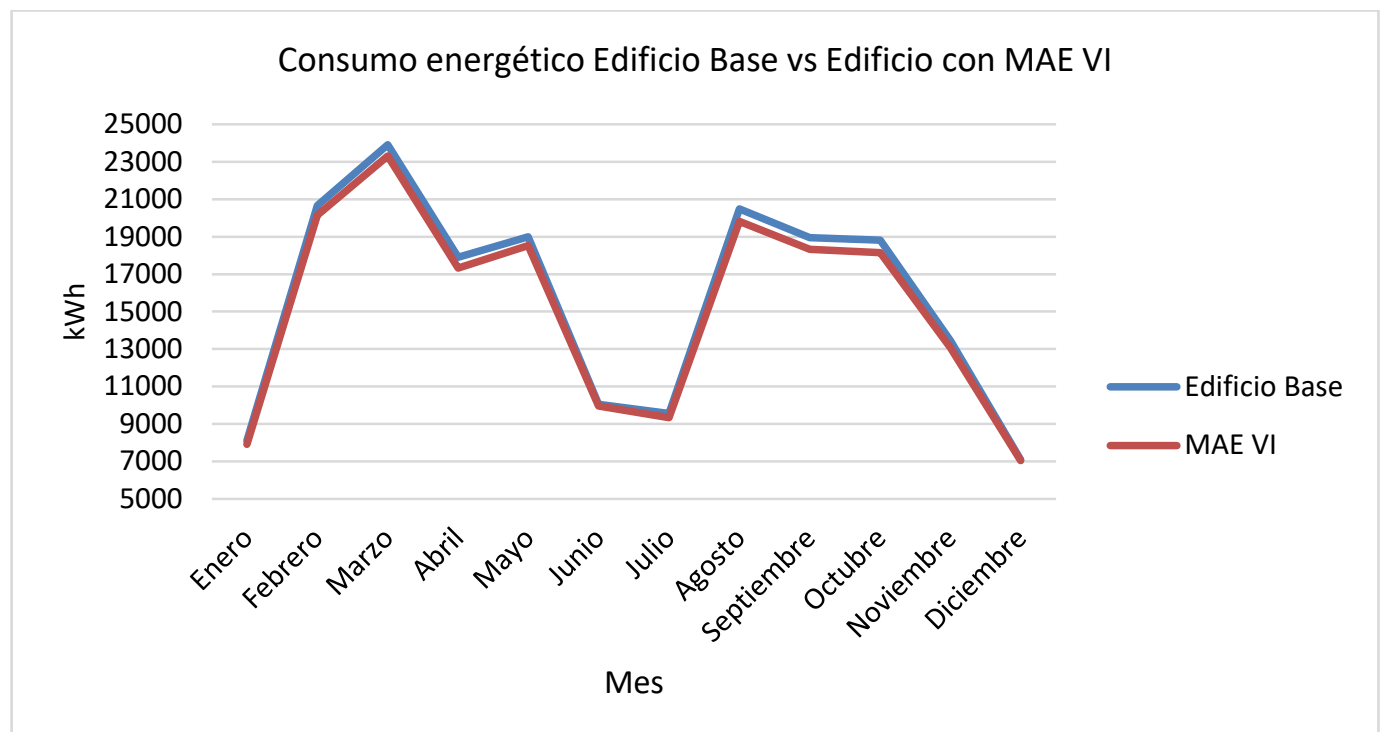

Figura 186. Consumo energético mensual Edificio Base y Edificio con MAE VI.

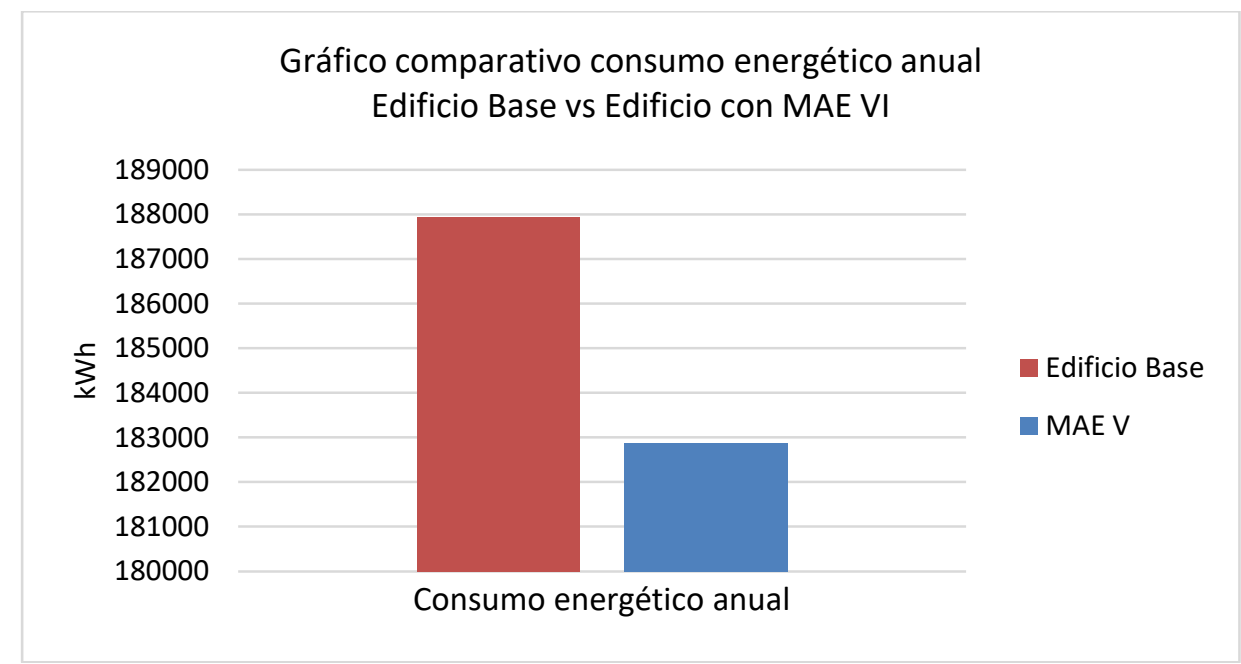

Figura 187. Consumo energético anual Edificio Base y Edificio con MAE VI

Los resultados presentados en las Figuras 186 y 187 muestran que al implementar esta estrategia, se obtiene una reducción en el consumo por aire acondicionado, pues se ha reducido la carga térmica debida al sombreado de los acristalamientos al usar los sistemas de persianas reflectivas, logrando una reducción del 2,70\% del consumo total anual del edificio lo que se traduce a un poco más del consumo energético total presentado en el mes de diciembre del mismo año, dejando entrever la importancia y lo conveniente de la implementación de esta solución a la mejora de la eficiencia energética. 


\subsection{MAE VII - FILTROS SOLARES Y SOMBRAS - PELICULAS PROTECTORAS}

Otra estrategia que se implementó en aras de la mejora de la eficiencia energética son las películas protectoras en el acristalamiento del edificio, para reducir la radiación solar en el edificio, evitando así el incremento de la carga térmica de cada recinto. Al implementar y simular esta estrategia, se obtuvo la curva de consumo energético anual presentado en la Figura 188.

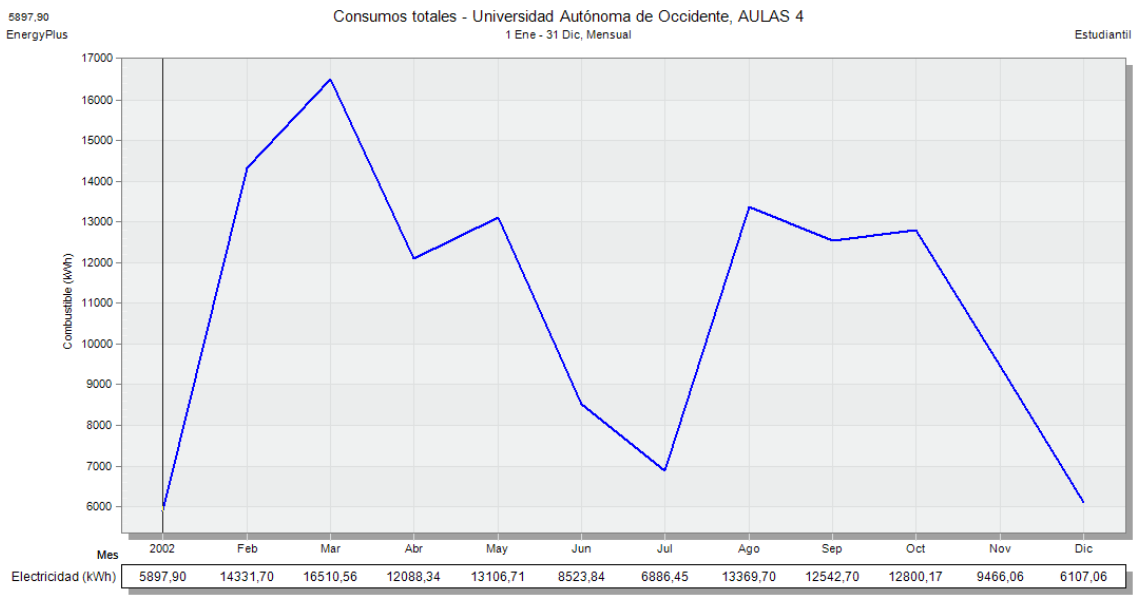

Figura 188. Distribución de consumo energético anual con MAE VII.

A continuación, se desglosa el consumo total anual de energía del edificio con la implementación de películas protectoras según el tipo de uso, como lo muestra la Tabla 74. La Tabla 74, muestra la distribución de consumos energéticos desglosados mes a mes, donde se observa que el mayor consumo de energía es de los equipos de refrigeración.

Tabla 74. Distribución de consumos energéticos por uso.

\begin{tabular}{|c|c|c|}
\hline TIPO DE USO & ELECTRICIDAD (kWh) & PORCENTAJE DE CARGA (\%) \\
\hline Refrigeración & 86292,56 & 47,24 \\
\hline Iluminación interior & 10014,02 & 5,48 \\
\hline Iluminación exterior & 1735,82 & 0,95 \\
\hline Equipos interiores & 84630,76 & 46,33 \\
\hline CONSUMO TOTAL (kWh) & $\mathbf{1 8 2 6 7 3 , 1 6}$ & $\mathbf{1 0 0}$ \\
\hline
\end{tabular}

Tabla 75. Distribución de consumos energéticos desglosados mes a mes por uso.

\begin{tabular}{|c|c|c|c|c|c|c|c|}
\hline Mes & Refrigeración & $\begin{array}{c}\text { Iluminación } \\
\text { interior }\end{array}$ & $\begin{array}{c}\text { Iluminación } \\
\text { exterior }\end{array}$ & Equipos & $\begin{array}{c}\text { Total } \\
\text { (kwh) }\end{array}$ & $\begin{array}{c}\text { Consumo } \\
\text { kwh/día }\end{array}$ & $\begin{array}{c}\text { consumo } \\
\text { mes }\end{array}$ \\
\hline Enero & 3362.41 & 341.51 & 53.58 & 4163.75 & 7921.25 & 255.52 & $4.3 \%$ \\
\hline Febrero & 9891.50 & 1149.70 & 214.30 & 8859.06 & 20114.56 & 718.38 & $11.0 \%$ \\
\hline Marzo & 11502.45 & 1326.59 & 246.44 & 10179.94 & 23255.42 & 750.17 & $12.7 \%$ \\
\hline Abril & 8997.63 & 1184.71 & 214.30 & 6916.94 & 17313.58 & 577.12 & $9.5 \%$ \\
\hline Mayo & 8927.20 & 962.87 & 160.72 & 8407.74 & 18458.53 & 595.44 & $10.1 \%$ \\
\hline Junio & 2318.25 & 144.42 & 0.00 & 7461.88 & 9924.55 & 330.82 & $5.4 \%$ \\
\hline
\end{tabular}


CAPÍTULO 6: PROPUESTAS DE MAE'S PARA EL EDIFICIO DE AULAS 4 MEDIANTE SIMULACIÓN ENERGÉTICA

\begin{tabular}{|c|c|c|c|c|c|c|c|} 
Julio & 4116.05 & 380.47 & 53.58 & 4799.50 & 9349.60 & 301.60 & $5.1 \%$ \\
\hline Agosto & 10725.86 & 1316.33 & 246.44 & 7531.07 & 19819.70 & 639.35 & $10.8 \%$ \\
\hline Septiembre & 9588.30 & 1238.83 & 225.01 & 7211.90 & 18264.04 & 608.80 & $10.0 \%$ \\
\hline Octubre & 9401.19 & 1272.47 & 235.73 & 7303.31 & 18212.70 & 587.51 & $10.0 \%$ \\
\hline Noviembre & 5956.27 & 602.63 & 85.72 & 6373.70 & 13018.32 & 419.95 & $7.1 \%$ \\
\hline Diciembre & 1505.45 & 93.49 & 0.00 & 5421.97 & 7020.91 & 234.03 & $3.8 \%$ \\
\hline
\end{tabular}

En las Figuras 189 y 190, se presentan la distribución de consumo anual simulado y la distribución porcentual por consumos bajo la implementación de películas protectoras en el edificio para el año 2017 respectivamente.

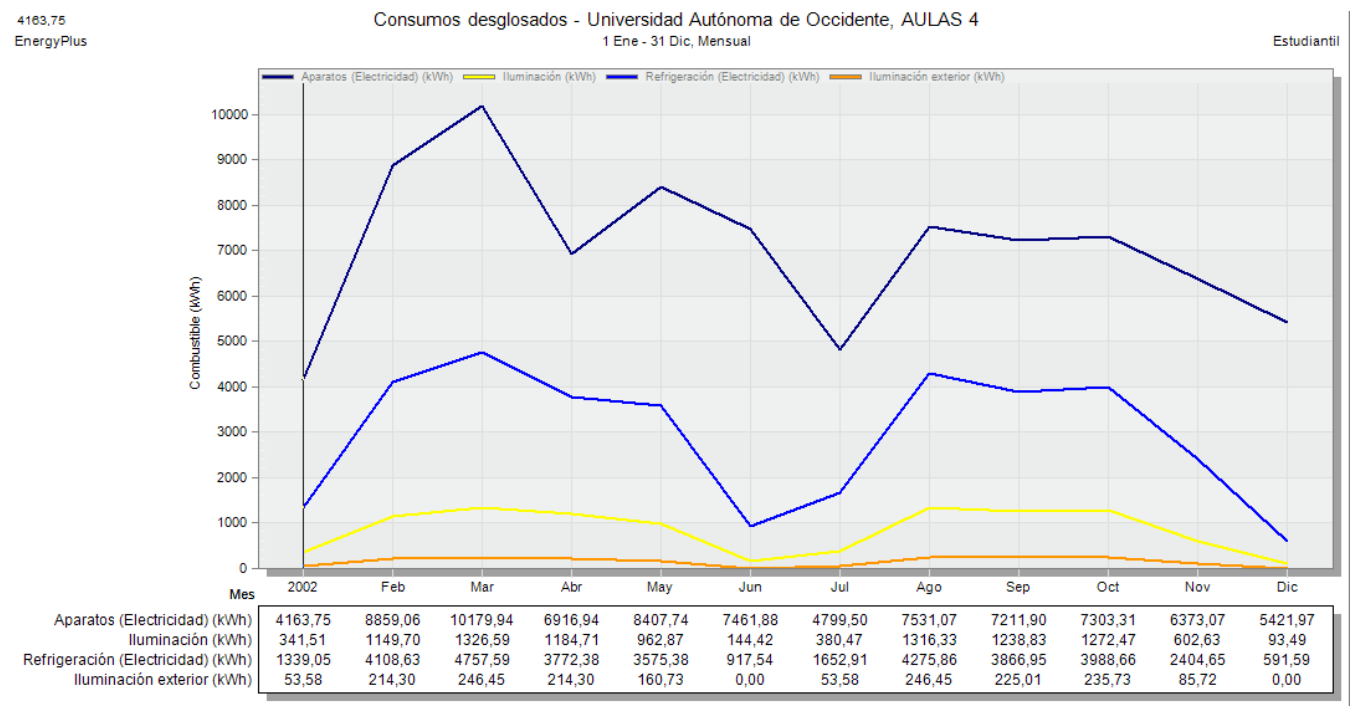

Figura 189. Distribución de consumo energético anual desglosado por uso final para MAE VII

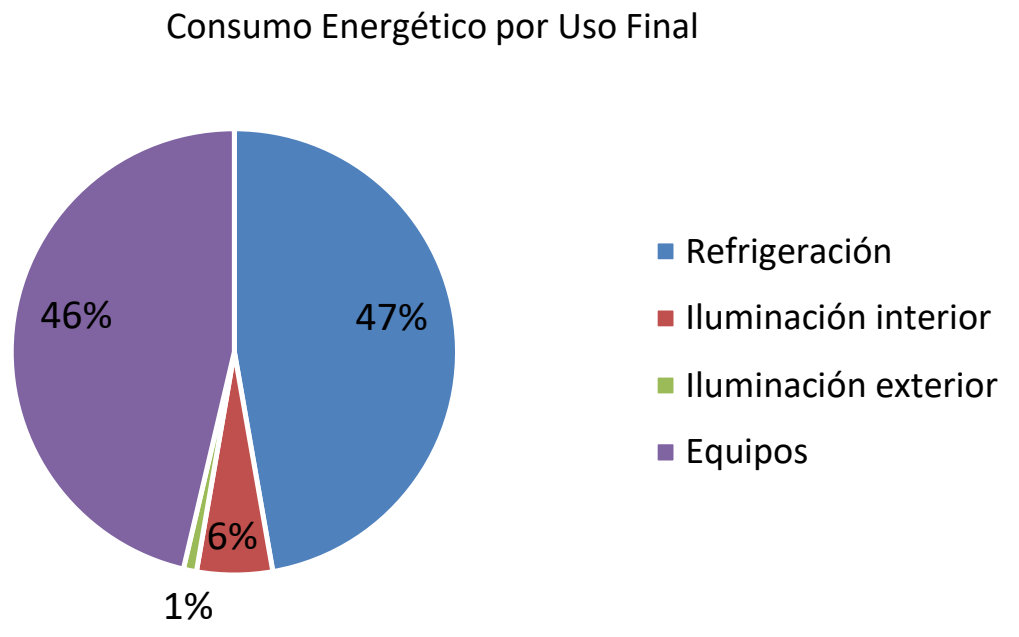

Figura 190. Distribución porcentual de consumo energético por uso final para MAE VII 
La Figura 191 presenta los consumos energéticos del edificio según cada uso final y su porcentaje de participación, donde se obtiene que el consumo por iluminación exterior es de $1.735,82 \mathrm{kWh}(0,95 \%)$, iluminación interior 10.014,02 kWh $(5,48 \%)$, consumo por equipos ofimáticos de 84.630,76 kWh (46,33\%), y el consumo por climatización de 86292,56 que representa el $47,24 \%$.

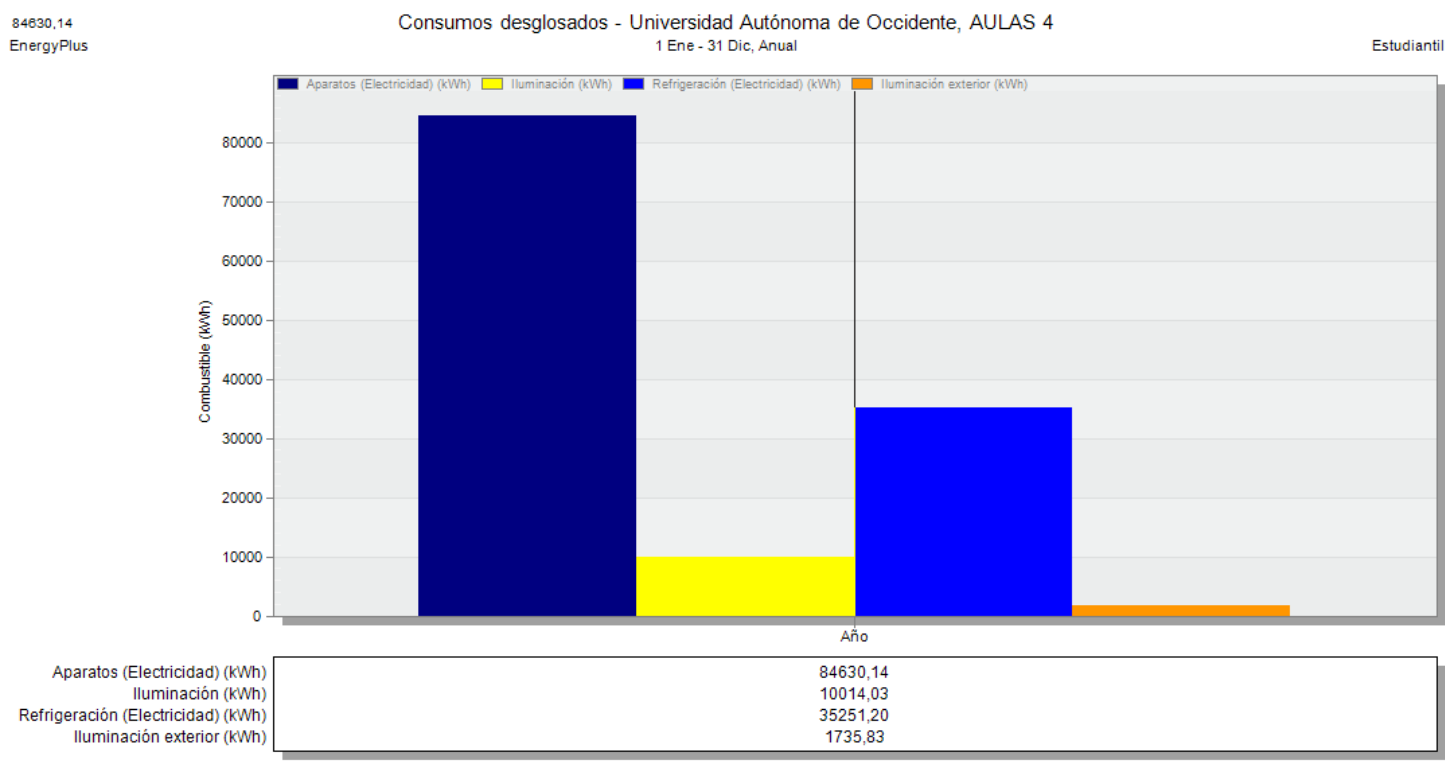

Figura 191. Diagrama de barras distribución del consumo energético anual.

\section{Impacto Medioambiental - Emisiones de $\mathrm{CO}_{2}$}

Se obtienen las emisiones de $\mathrm{kg}$ de $\mathrm{CO}_{2}$ generados por las instalaciones, presentado de forma mensual y anual en la Tabla 76 y la Figura 192.

Tabla 76. Producción mensual y anual de $\mathrm{kg}$ de $\mathrm{CO}_{2}$ con MAE VII

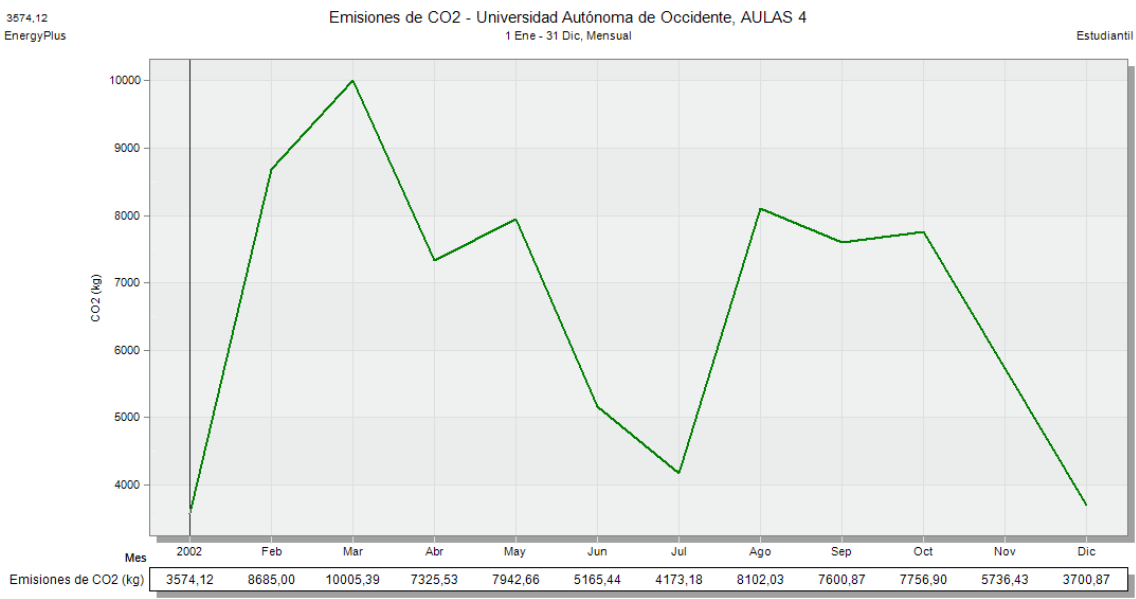

Figura 192. Emisiones de $\mathrm{CO}_{2}$ mensual para el edificio con la MAE VII 


\subsubsection{Análisis comparativo de consumos energéticos del edificio base vs el edificio con la MAE VII}

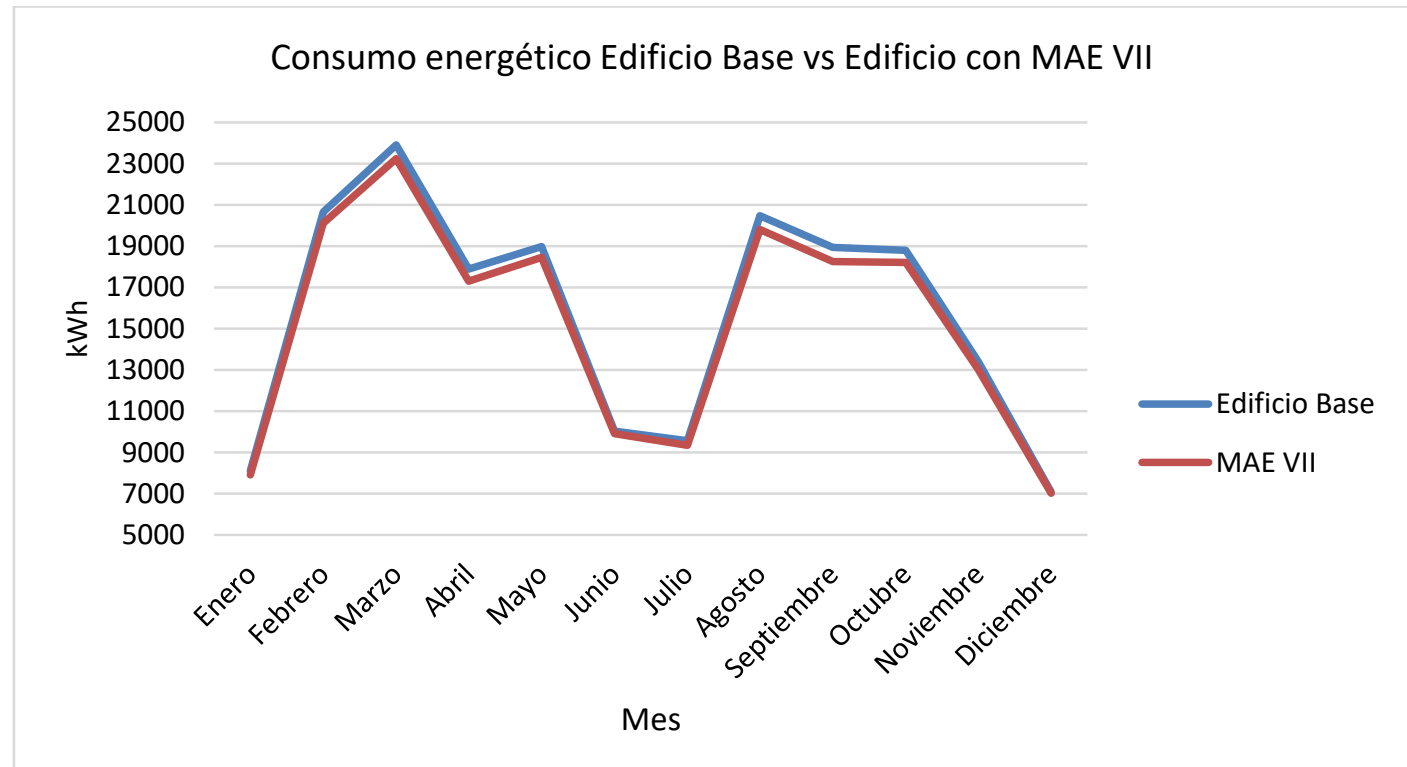

Figura 193. Consumo energético mensual Edificio Base y Edificio con MAE VII.

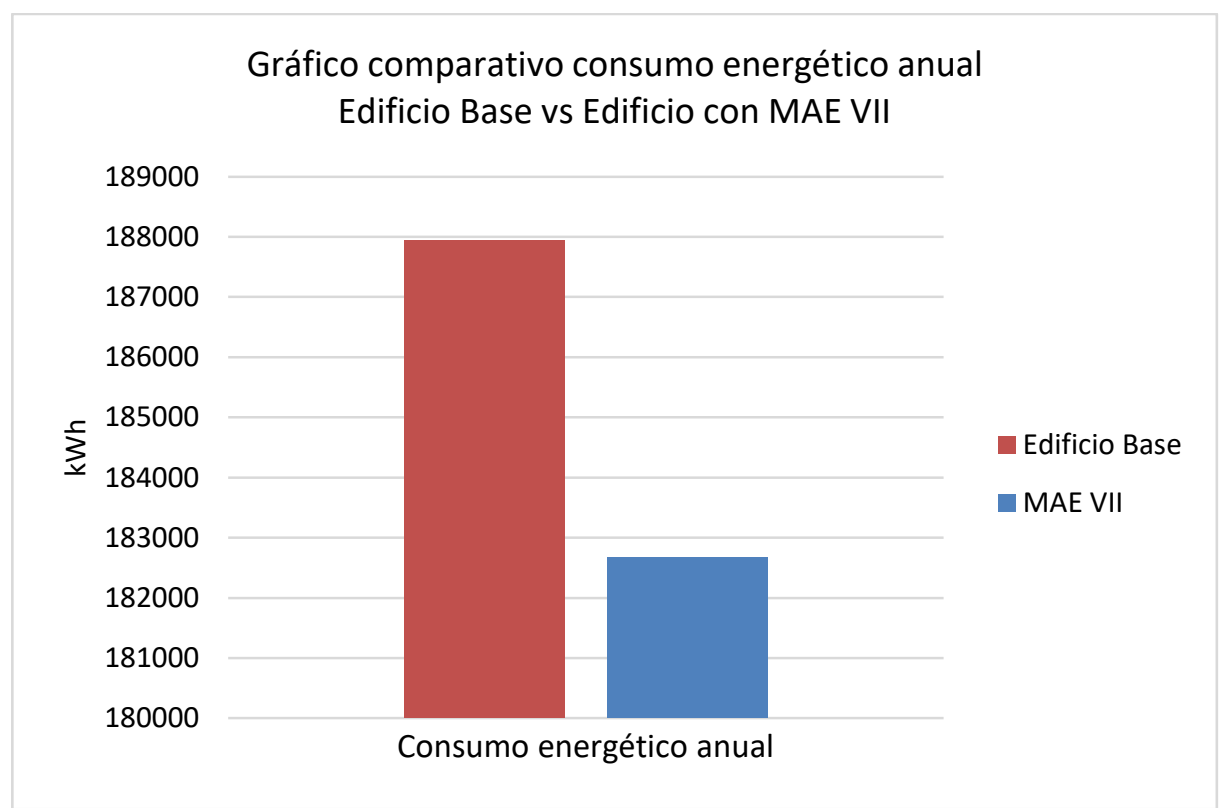

Figura 194. Consumo energético anual Edificio Base y Edificio con MAE VII

De acuerdo con los datos obtenidos y presentados en las Figuras 193 y 194 se observa una reducción en el consumo por aire acondicionado, pues se redujo la carga térmica debida al sombreado de los acristalamientos, obteniendo una reducción del 2,80\% del consumo total anual del edificio lo que se traduce a un poco más del consumo energético total presentado en el mes de diciembre del mismo año, dejando entrever la importancia y lo conveniente de la implementación de esta solución a la mejora de la eficiencia energética. 


\subsection{MAE VIII - IMPLEMENTACIÓN DE TODAS LAS MAE'S PROPUESTAS}

Como etapa final de simulación, se implementaron las 6 MAE's y el rediseño del sistema de iluminación interior presentadas anteriormente en el edificio de aulas 4 (Acondicionamiento de todas las aulas y oficinas del edificio, rediseño del sistema de iluminación, sistema de lamas, vidrio electrocrómico, voladizos, persianas reflectivas y película protectora).

La Figura 195 presenta los datos obtenidos al realizar la simulación energética del edificio con las propuestas de mejora, donde se muestra la evolución del consumo de energía del edificio por meses, en un año meteorológico tipo y observándose que los meses de menor consumo energético corresponden a enero, junio, Julio y diciembre debido a una época vacacional y el de mayor consumo para los meses de febrero y marzo.

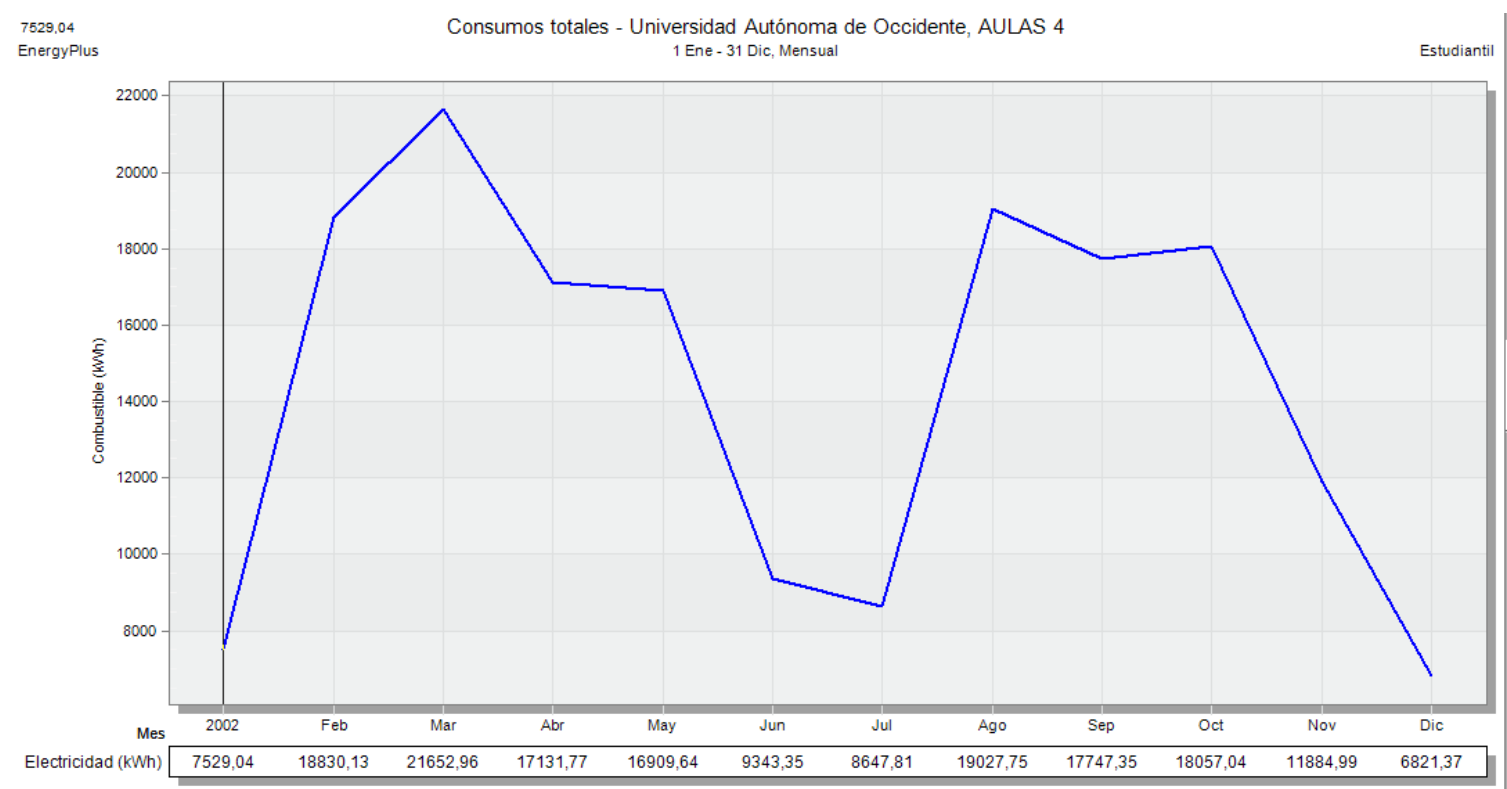

Figura 195. Distribución de consumo energético anual.

A continuación, se desglosa el consumo total anual de energía del edificio con la implementación de las 6 MAE's y la inclusión del rediseño de iluminación por calidad ambiental de acuerdo con el tipo de uso, como lo muestra la Tabla 77. En la Tabla 78, se presenta la distribución de consumos energéticos desglosados mes a mes, donde se observa que el porcentaje de consumo mayor es de equipos ofimáticos, seguido de la refrigeración. Dicha distribución se repite en la mayor parte de los casos vistos anteriormente.

Tabla 77. Distribución de consumos energéticos por uso.

\begin{tabular}{|c|c|c|}
\hline TIPO DE USO & ELECTRICIDAD (kWh) & PORCENTAJE DE CARGA (\%) \\
\hline Enfriamiento & 68004,88 & 39,3 \\
\hline Iluminación interior & 13421,92 & 7,8 \\
\hline Iluminación exterior & 1735,82 & 1,0 \\
\hline
\end{tabular}




\begin{tabular}{|c|c|c|}
\hline Equipos interiores & 84630,13 & 49,0 \\
\hline Extractores & 5036,31 & 2,9 \\
\hline CONSUMO TOTAL (kWh) & $\mathbf{1 7 2 8 2 9 , 0 6}$ & $\mathbf{1 0 0}$ \\
\hline
\end{tabular}

Tabla 78. Distribución de consumos energéticos desglosados mes a mes por uso.

\begin{tabular}{|c|c|c|c|c|c|c|c|c|}
\hline Mes & Refrigeración & $\begin{array}{c}\text { Iluminación } \\
\text { interior }\end{array}$ & $\begin{array}{c}\text { Iluminación } \\
\text { exterior }\end{array}$ & Equipos & Extractores & $\begin{array}{c}\text { Total } \\
\text { (kwh) }\end{array}$ & $\begin{array}{c}\text { Consumo } \\
\text { kwh/día }\end{array}$ & $\begin{array}{c}\text { consumo } \\
\text { mes }\end{array}$ \\
\hline Enero & 2696.62 & 434.10 & 53.58 & 4163.75 & 164.36 & 7512.41 & 242.34 & $4.3 \%$ \\
\hline Febrero & 7452.42 & 1558.53 & 214.30 & 8859.06 & 595.31 & 18679.62 & 667.13 & $10.8 \%$ \\
\hline Marzo & 8608.06 & 1800.53 & 246.44 & 10179.94 & 679.57 & 21514.54 & 694.02 & $12.4 \%$ \\
\hline Abril & 7631.23 & 1616.52 & 214.30 & 6916.94 & 617.23 & 16996.22 & 566.54 & $9.8 \%$ \\
\hline Mayo & 6534.43 & 1296.92 & 160.72 & 8407.74 & 477.08 & 16876.89 & 544.42 & $9.8 \%$ \\
\hline Junio & 1688.27 & 155.11 & 0.00 & 7461.88 & 42.96 & 9348.22 & 311.61 & $5.4 \%$ \\
\hline Julio & 3135.46 & 473.79 & 53.58 & 4799.50 & 175.86 & 8638.19 & 278.65 & $5.0 \%$ \\
\hline Agosto & 8796.07 & 1783.25 & 246.44 & 7531.07 & 676.49 & 19033.32 & 613.98 & $11.0 \%$ \\
\hline Septiembre & 7951.33 & 1688.99 & 225.01 & 7211.90 & 643.84 & 17721.07 & 590.70 & $10.3 \%$ \\
\hline Octubre & 7915.66 & 1728.06 & 235.73 & 7303.31 & 650.77 & 17833.53 & 575.28 & $10.3 \%$ \\
\hline Noviembre & 4309.32 & 790.86 & 85.72 & 6373.07 & 285.29 & 11844.26 & 382.07 & $6.9 \%$ \\
\hline Diciembre & 1286.01 & 95.26 & 0.00 & 5421.97 & 27.55 & 6830.79 & 227.69 & $4.0 \%$ \\
\hline
\end{tabular}

Las Figuras 196 y 197, muestran la distribución de consumo anual simulado y la distribución porcentual por consumos para el año 2017 respectivamente.

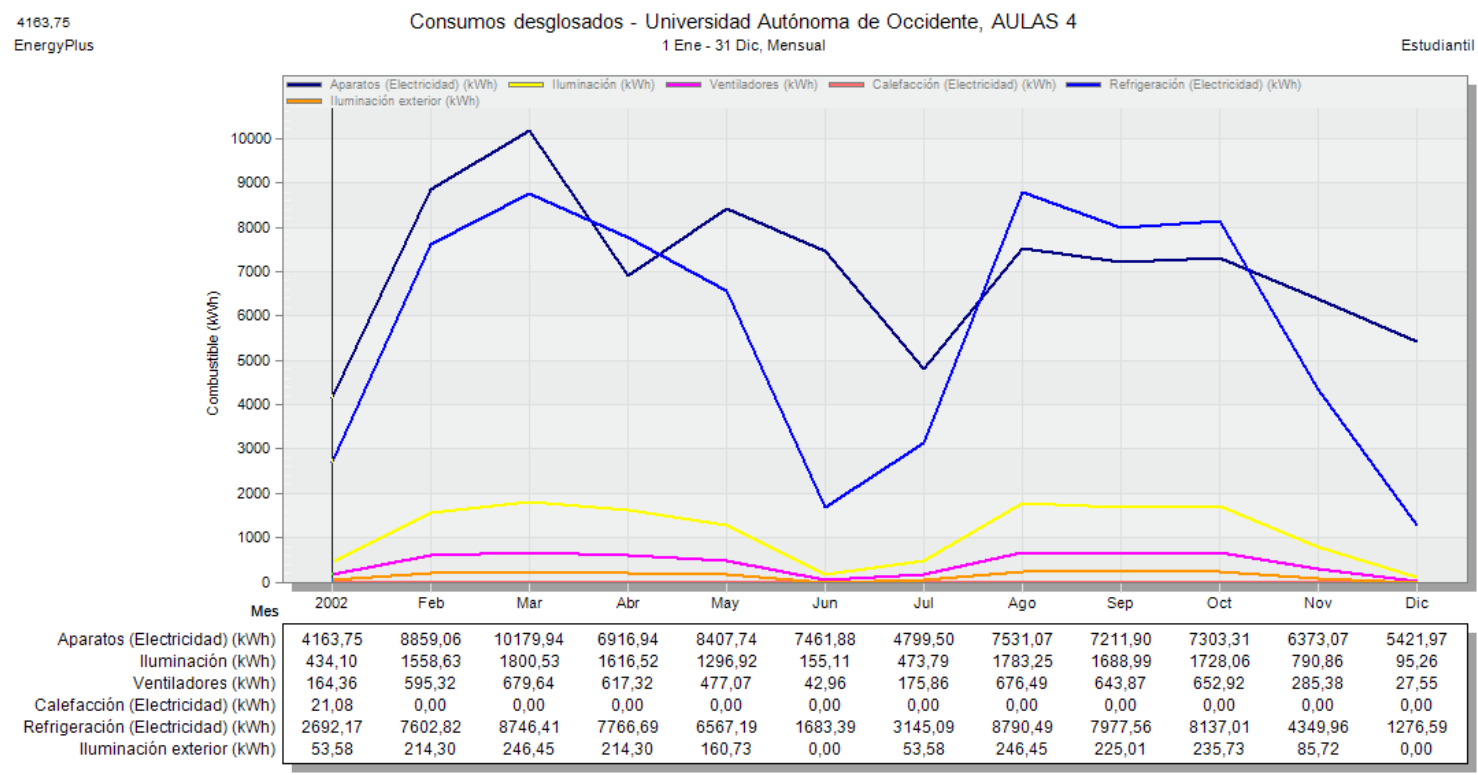

Figura 196. Distribución de consumo energético anual desglosado por uso final para MAE VIII 


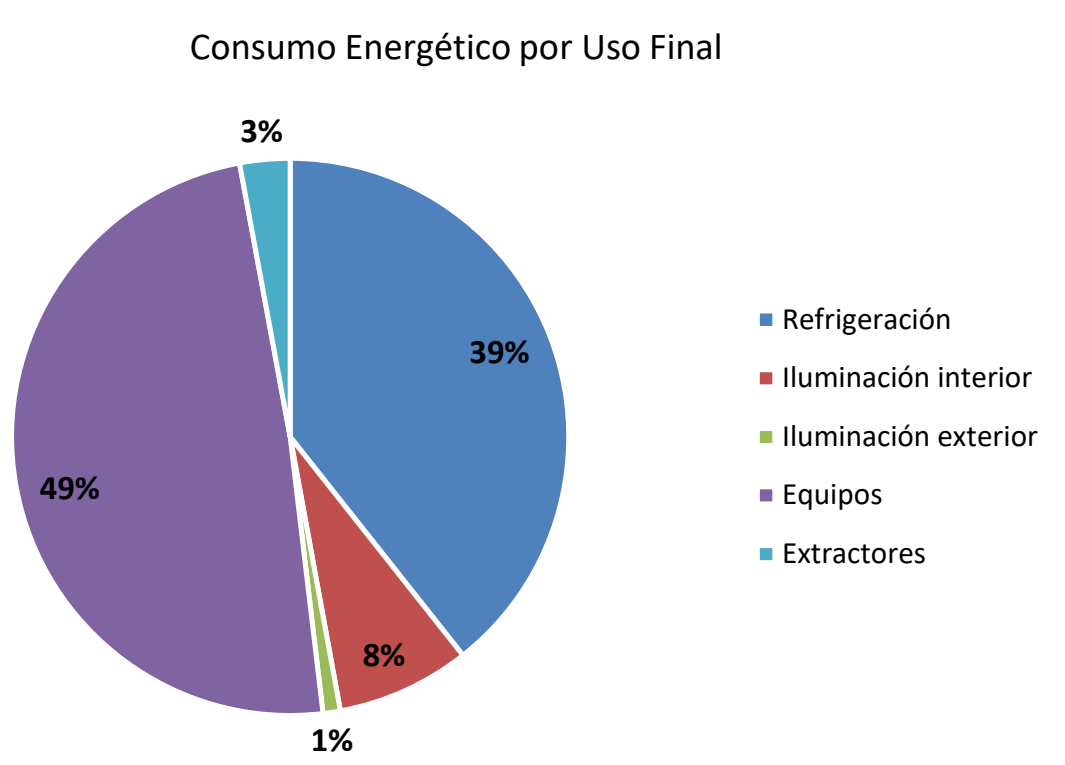

Figura 197. Distribución porcentual de consumo energético por uso final para MAE VIII

La Figura 198 presenta los consumos energéticos del edificio según cada uso final y su porcentaje de participación, de donde se obtiene que el consumo por iluminación exterior es de $1.735,82 \mathrm{kWh}(1,0 \%)$, iluminación interior 13.421,92 kWh (7,8\%), consumo por equipos ofimáticos de $84.630,13 \mathrm{kWh}(49,0 \%)$, y el consumo por climatización de $68.004,88$ kWh y extractores de $5.036,31 \mathrm{kWh}$ que representa el supone un $42,3 \%$.

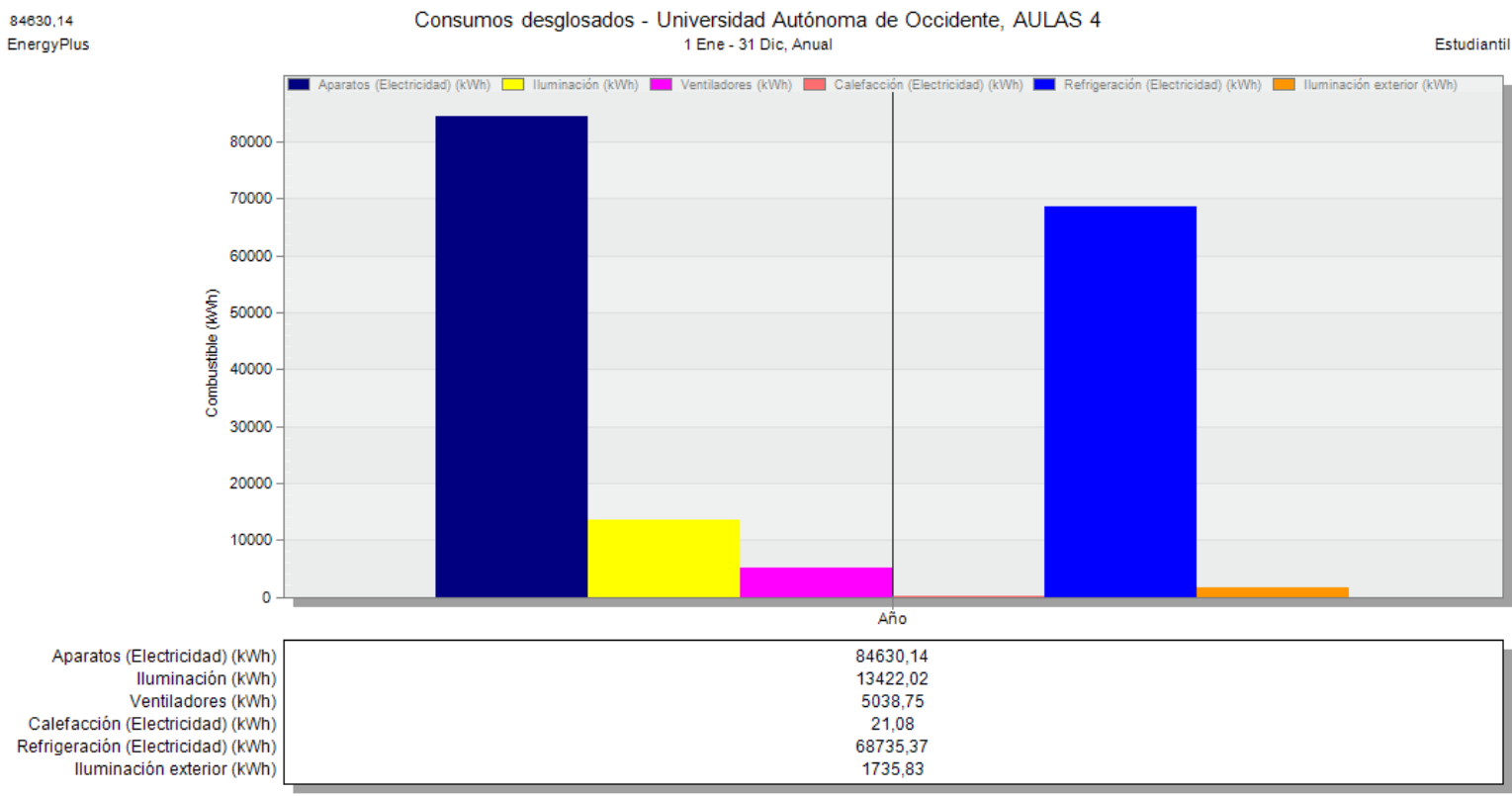

Figura 198. Diagrama de barras distribución del consumo energético anual. 


\section{Impacto Medioambiental - Emisiones de $\mathrm{CO}_{2}$}

A continuación, se presentan las emisiones de $\mathrm{kg}$ de $\mathrm{CO}_{2}$ generados por las instalaciones, presentado de forma mensual y anual en la Figura 199 y Tabla 79.

Tabla 79. Producción mensual y anual de $\mathrm{kg}$ de $\mathrm{CO}_{2}$ con MAE VIII

\begin{tabular}{|c|c|}
\hline Mes & kg de $\mathbf{C O}_{\mathbf{2}}$ \\
\hline Enero & 4562.59 \\
\hline Febrero & 11411.05 \\
\hline Marzo & 13121.68 \\
\hline Abril & 10381.84 \\
\hline Mayo & 10247.23 \\
\hline Junio & 5662.06 \\
\hline Julio & 5240.57 \\
\hline Agosto & 11530.8 \\
\hline Septiembre & 10754.88 \\
\hline Octubre & 10942.55 \\
\hline Noviembre & 7202.3 \\
\hline Diciembre & 4133.74 \\
\hline Total & 105191.29 \\
\hline
\end{tabular}

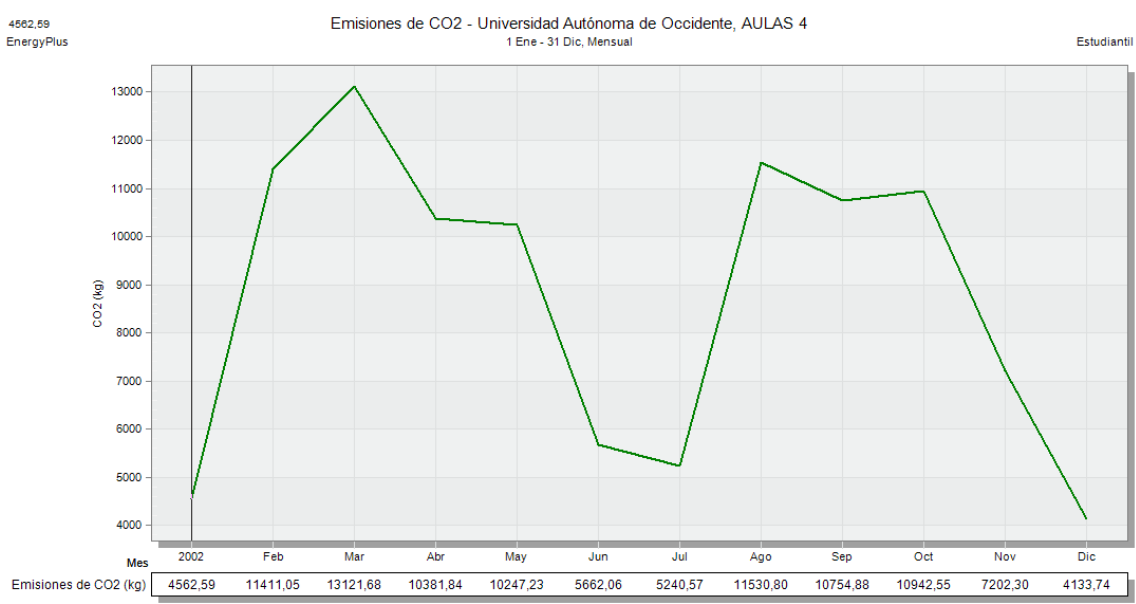

Figura 199. Emisiones de $\mathrm{CO}_{2}$ mensual para el edificio con la MAE VIII

\subsubsection{Análisis comparativo de consumos energéticos del edificio base vs el edificio con la MAE VIII}

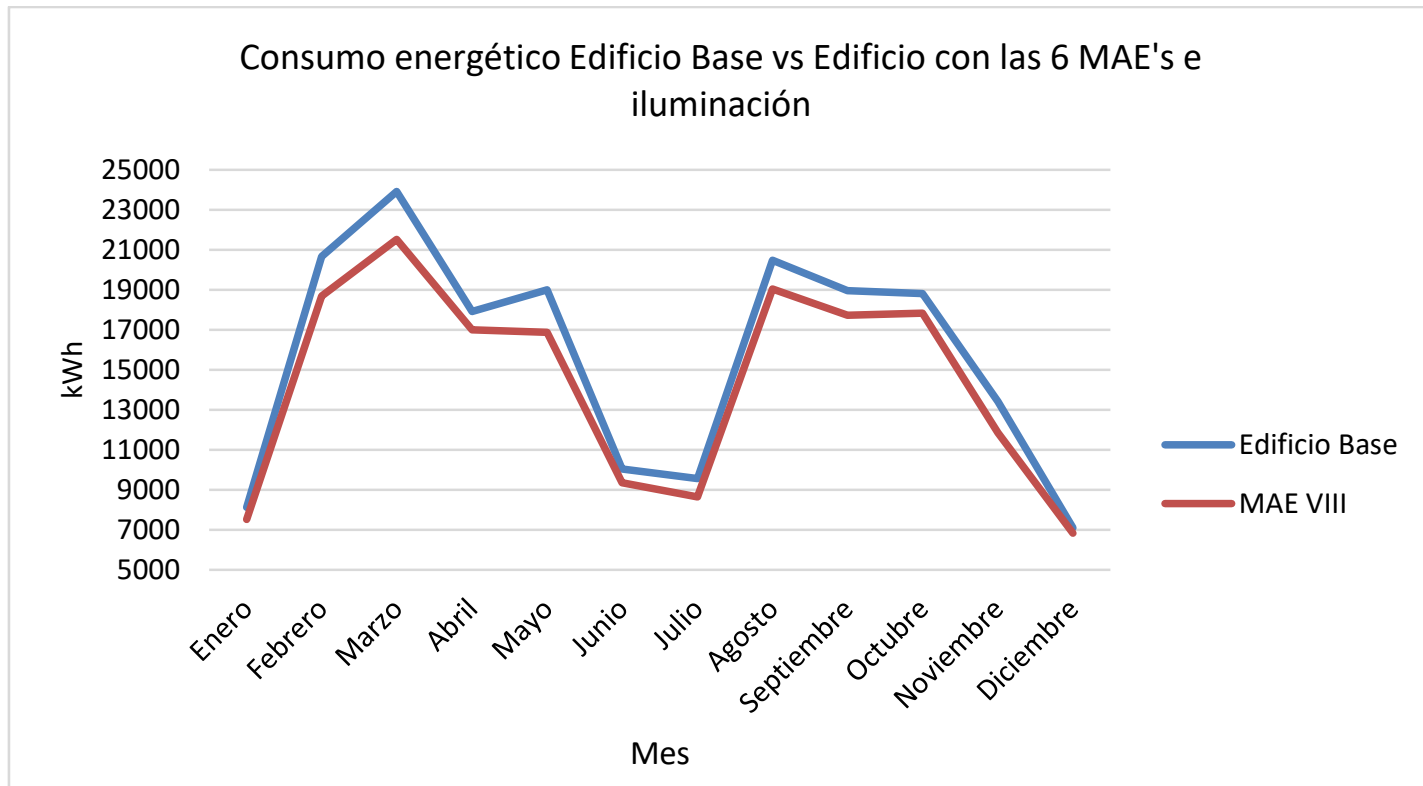

Figura 200. Consumo energético mensual Edificio Base y Edificio con las 6 MAE’s e iluminación. 


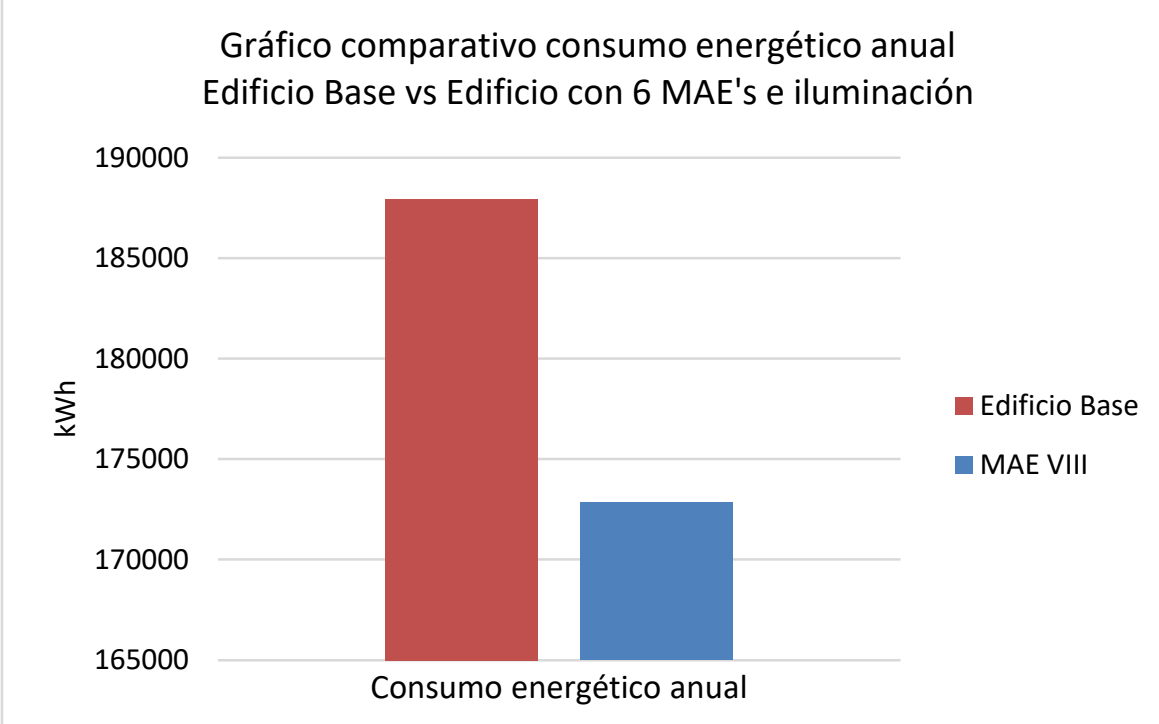

Figura 201. Consumo energético anual Edificio Base y Edificio con 6 MAE's e iluminación

Al comparar los datos obtenidos del Edificio base y el Edificio con las 6 MAE's e iluminación, se resalta que el edificio obtiene una reducción del consumo energético anual del 8,04\%. La Figura 200 presenta la diferencia entre los consumos energéticos para el edificio base y el edificio con las 6 MAE's e iluminación implementadas, donde se evidencia que el comportamiento de consumo es el mismo, pero con un consumo menor.

En la Figura 201 se observa que el comportamiento del consumo anual de energía en el edificio es el mismo, pero con un consumo reducido al $8 \%$ influyendo más la MAE de refrigeración.

La tabla 80, presenta en resumen los ahorros de consumo energético y de emisiones de CO2 obtenidos con las MAE's propuestas y aplicadas al edificio simulado.

Tabla 80. Resumen ahorros de las MAE's aplicadas al edificio

\begin{tabular}{|c|c|c|c|c|}
\hline & $\begin{array}{c}\text { Consumo } \\
\text { Energético Anual } \\
{[\mathrm{kWh}]}\end{array}$ & Ahorro [\%] & $\begin{array}{c}\text { Producción de } \\
\text { CO2 [kg] }\end{array}$ & $\begin{array}{c}\text { Ahorro en } \\
\text { Emisiones de } \\
\text { CO2 }\end{array}$ \\
\hline Edificio Base & 187938.32 & & 81111.2 & \\
\hline MAE I & 172308.43 & $8.3 \%$ & 105024.48 & 23913.28 \\
\hline Iluminación & 193273.54 & $-2.8 \%$ & 83640.56 & 2529.36 \\
\hline MAE III & 180436.55 & $4.0 \%$ & 79281.44 & -1829.76 \\
\hline MAE IV & 185359.9 & $1.4 \%$ & 79281.44 & -1829.76 \\
\hline MAE V & 184148.17 & $2.0 \%$ & 80195.53 & -915.67 \\
\hline MAE VI & 182872.23 & $2.7 \%$ & 79869.13 & -1242.07 \\
\hline MAE VII & 182673.16 & $2.8 \%$ & 79768.42 & -1342.78 \\
\hline 6 MAE's e & 172829.06 & $8.0 \%$ & 105191.29 & 24080.09 \\
\hline iluminación & & &
\end{tabular}




\section{PROPUESTA DE ALMACENAMIENTO PARA EL SISTEMA DE ILUMINACIÓN}

Como propuesta adicional se plantea el dimensionado de un sistema de baterías para el SSFV instalado en el edificio y que este, sea capaz de suplir el consumo eléctrico de los sistemas de iluminación interior y exterior del mismo. Los sistemas de iluminación del edificio, representan el 6,25\% del consumo total de energía el edificio.

Para realizar el dimensionado de las baterías a usar, se trabajará con baterías del tipo OpZs que son las más adecuadas para este tipo de implementación, gracias a su durabilidad, tecnología y fácil mantenimiento. Para conocer su capacidad, se debe tener en cuenta la cantidad total de energía consumida en un año y el equivalente de promedio mensual y diario. El sistema de iluminación interior y exterior del edificio tiene un consumo de energía anual de $11.749,87 \mathrm{kWh} /$ Año. Los promedios de consumo mensual y diario son de 979,15 $\mathrm{kWh} / \mathrm{mes}$ y $32,19 \mathrm{kWh} /$ día respectivamente.

Una vez conocidos los valores de consumo, se selecciona el nivel de tensión al que operará el sistema de baterías, dependiendo de la potencia total a atender y lo establecido en la Tabla 81. En este caso la potencia a atender es mayor a $5 \mathrm{~kW}$, por lo que el nivel de tensión del sistema será de 48 VDC.

Tabla 81. Potencia Total atendida y Nivel de tensión para sistemas de acumulación de energía

\begin{tabular}{|c|c|}
\hline Potencia Total Atendida (W) & Nivel de Tensión (VDC) \\
\hline $\mathrm{P}<500$ & 12 \\
\hline $500=>P<2500$ & 24 \\
\hline $2500=>P<=5000$ & 48 \\
\hline
\end{tabular}

Para garantizar el cumplimiento del sistema ante la demanda de energía (teniendo en cuenta que el dimensionado se realiza con el valor promedio diario y no teniendo en cuenta valores picos máximos), se diseñará el sistema con una autonomía de 1 día completo que su vez garantiza la duración de las baterías cercana a los 10 años según la curva de ciclaje del proveedor. Para el tipo de baterías OpZs, se recomienda tener una profundidad de descarga del $40 \%$ que garantiza unos 4800 ciclos de carga y descarga y daría un tiempo de vida útil de 13,15 años.

Conociendo los datos necesarios, se calcula la capacidad de las baterías como se presenta a continuación:

$$
\operatorname{Cap}_{\text {Bat }}=\frac{\text { Econs }_{\text {día }} * \text { Autonomía }}{\operatorname{Prof}_{\text {desc }} * V D C}=\frac{32,19 \frac{\mathrm{kWh}}{\text { día }} * 1 \text { día }}{40 \% * 48 \mathrm{Vdc}}=1.676,6 \mathrm{Ah}
$$

El valor obtenido de la capacidad de las baterías no es comercial, se busca en el catálogo del proveedor, y se opta por el uso de la marca Victron Batteries, y se selecciona Victron OpZs Solar 1830 Ah que brinda capacidad suficiente para el suministro y alimentación de las cargas requeridas, en la Figura 202 se presenta el tipo y forma de batería seleccionada. 


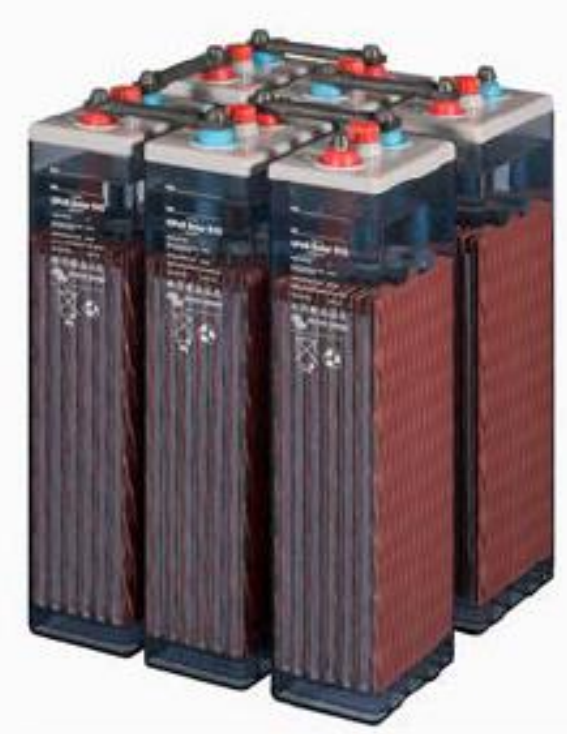

Figura 202. Victron OpZs Solar 1830 Ah

Los requerimientos para albergar las baterías son un recinto bajo techo, cubierto de la intemperie, cerca al inversor de carga, las dimensiones de las baterías dadas por la ficha técnica del proveedor VICTRON ENERGY es de $21 \mathrm{~cm}$ de altura, 27,5 cm de ancho por 71,1 cm de profundidad, cabe destacar también que se debe tener en cuenta la construcción de losa de soporte de hasta $0,1732 \mathrm{~kg} / \mathrm{m} 2$, esto para que se garantice el soporte del peso de la unidad de baterías.

Son baterías de mantenimiento reducido, en condiciones normales de funcionamiento y a $20{ }^{\circ} \mathrm{C}$, se le debe añadir agua destilada cada $2-3$ años.

La batería tiene un costo aproximado de 5.026,45 € (información obtenida en: http://mercasolar.com/product/bateria-victron-opzs-solar-1830-ah/) 


\section{CAPÍTULO 7: DESARROLLO DE LA METODOLOGÍA PARA ESTIMAR LÍNEAS BASES E INDICADORES}

En este capítulo se describe una metodología, implementada en la selección y aplicación de modelos para la estimación de líneas bases e indicadores energéticos en edificios. Se parte de un análisis de datos y variables que afectan el consumo de energía, a fin de seleccionar el modelo más adecuado que cumpla con los estándares normativos propios de la implementación de un sistema de gestión energética. En este sentido, se describen modelos que van desde las series de tiempo hasta modelos de regresión lineales y multivariable, en los cuales se detalla el procedimiento matemático y estadístico, así como el empleo del software $R$ estudio para el procesamiento de los datos. De igual forma, se realizan los cálculos necesarios para validar la capacidad de pronóstico de los modelos y el porcentaje de error de los mismos, con el objetivo de mostrar la importancia que tiene la implementación de un sistema de gestión energética en un edificio, y permitir alternativas en conseguir ahorros energéticos mediante las líneas bases e indicadores energéticos.

\subsection{METOdología PARA LA SELECCIÓN DE MODELOS DE LINEA BASE E INDICADORES}

Se presenta un esquema metodológico (Figura 203), que simplifica las etapas a tener en cuenta en la selección de un modelo para establecer líneas bases e indicadores energéticos. La determinación de la mejora en el rendimiento energético en una edificación, implica la cuantificación del consumo de energía, la normalización de las variables relevantes que puedan afectar dicho consumo, los modelos utilizados para establecer la línea base e indicadores, siguiendo las respectivas validaciones estadística y, por último, el cálculo de las mejoras del rendimiento energético con fines de cuantificar ahorros energéticos y niveles de eficiencia. 


\section{Metodología para la selección de modelos de Linea Base e indicadores}

Seleccionar limite de instalación - Periodo de reporte de la línea base

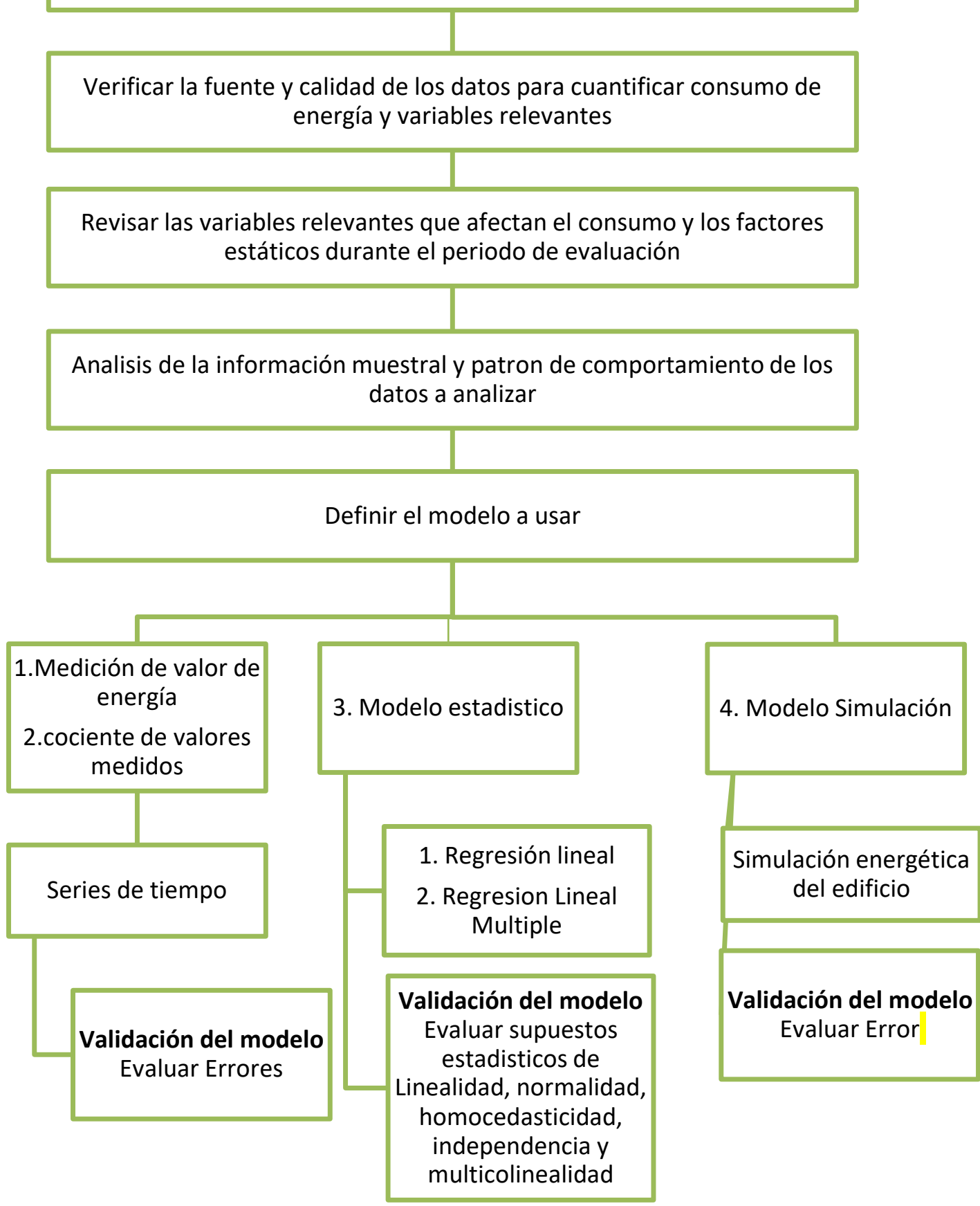

Figura 203. Metodología para la selección de modelos de líneas bases e indicadores 


\subsubsection{Seleccionar límite de instalación - Periodo de reporte de la línea LBEn}

Los límites de una instalación pueden ser físicos o de lugar y/o de organización. La selección de los límites de la instalación y el periodo temporal correspondiente a la construcción de una línea de base energética LBEn, son fundamentales a la hora de iniciar acciones encaminadas a implementar un sistema de gestión de la energía o trabajar en función de la eficiencia energética.

En ese sentido, es importante tener en cuenta la contabilidad energética presente en los límites establecidos en la instalación de cada organización. Con respecto a los períodos de tiempo seleccionados como referencia de análisis de la LBEn, se recomienda una duración de al menos 12 meses consecutivos ( 1 año) para considerar las variaciones operacionales y estacionales.

El ahorro de energía está determinado por la diferencia en el consumo de energía entre dos tiempos comparables (un período de referencia y un período de reporte de la línea base) siendo equivalentes en el periodo de tiempo seleccionado. Los períodos de tiempo se pueden clasificar de la siguiente manera:

- Menos de un año: se puede usar un período más corto cuando el consumo de energía es estacional.

- Un año: cuando el consumo de energía es sensible al clima, se usa comúnmente un período anual.

- Más de un año: puede ser cuando no hay un año que se considera típico

Los cambios significativos en el uso del consumo de energía deben tenerse en cuenta y documentarse.

\subsubsection{Verificar la fuente y calidad de los datos para cuantificar el consumo de energía y las variables relevantes}

La planificación de la recopilación de los múltiples datos, el modo de cómo hacerlo y con qué frecuencia, permite obtener el diagnóstico energético, efectuar un análisis en el seguimiento de los procesos y la evaluación de la medición. En este sentido, es importante incluir en la contabilidad energética no solo la cuantificación del consumo de energía, sino el de las variables relevantes que pueden afectarlo. Lo anterior, nos permite aumentar la verificación y certeza de los ahorros de energía calculados y garantizar que satisfagan las necesidades de la organización [1].

Algunos de los factores que se deben tener en cuenta en la determinación adecuada de la calidad de los datos incluyen los siguientes aspectos:

La recopilación de datos de consumo, se refiriere a lecturas de manuales o información automática enviadas a un centro de recopilación de datos centralizado. En este sentido, se 
consideran verificables solo los datos tomados de los sistemas de control y / o medición precisos y los medidores calibrados regularmente. También es aceptable, la cuantificación del consumo de energía o de una variable relevante, mediante la resta de lecturas de dos o más medidores calibrados. Los datos deben recopilarse de manera consistente durante la línea de base y los períodos de informe. Otros datos a considerar pueden referirse a:

La fuente de datos de estaciones meteorológicas (para cálculos de días de grado). La frecuencia de la recopilación de datos, es decir, que abarca todos los turnos, por hora, día, mes, horas de trabajo y temporadas. La precisión de medidores y equipos de medición, precisión (incertidumbre de medición con respecto al sesgo, linealidad, resolución). La repetibilidad de datos de la fuente de datos y, por último, la validación de los datos.

De tal forma, la integridad de los datos incluye garantizar un período de tiempo adecuado para que los mismos se recopilen en toda la organización y se realicen los cálculos de ahorro de energía.

Por otra parte, todas las mediciones tienen una incertidumbre inherente y esto puede limitarse utilizando los cálculos y fórmulas correctas para la normalización o el modelado. En cuanto a la calibración de los medidores deberá seguir las recomendaciones del fabricante. Esto implica documentar los registros de calibración y registros de reparaciones a medidores calibrados. Sin embargo, los registros de calibración para medidores de servicios públicos no son responsabilidad de la organización y, en general, no requieren mantenimiento.

El consumo de energía y los datos de las variables relevantes deben analizarse en busca de valores anómalos, se hace referencia a que no son representativos de las condiciones de operación típicas. En caso de presentarse alta variabilidad, no es necesario eliminar los valores atípicos.

No obstante, el efecto de los valores atípicos afecta la fiabilidad de las estimaciones del modelo, lo que implica investigar las causas para eliminarlos o mantener el registro. Se recomienda tratar los períodos de parada separados de los períodos de operación. Si se opera de esta manera, las mediciones para ambos períodos se tratarán y modelarán por separado.

\subsubsection{Revisar las variables relevantes que afectan el consumo y los factores estáticos durante el periodo de evaluación}

Las variables relevantes corresponden a variables que afectan directamente la cantidad de energía consumida dentro de los límites de la instalación y, en particular, se utilizan para normalizar el consumo de energía como parte de un modelo de ajuste. Al desarrollar un modelo de ajuste, se debe tener en cuenta:

1. No omitir las variables relevantes que afectan el consumo de energía

2. Evitar incluir variables que no son relevantes para el consumo de energía. Las variables se excluyen del modelo si no hay un mecanismo lógico por el cual la variable afectaría el consumo de los tipos de energía que se están modelando. 
Se recopilan los datos que cuantifican las variables relevantes, siendo parte del proceso de contabilidad de energía. Así, las variables relevantes se refieren a cantidades físicas características.

Para cualquier tipo de instalación (industrial o comercial) se tendrá en cuenta:

- Nivel de actividad (por ejemplo, ocupación, horas de operación).

- Clima (por ejemplo, grado de calentamiento día, grado de enfriamiento día y humedad).

En la misma dirección, otro de los elementos importantes a considerar en el establecimiento y análisis de una LBEn, son los factores estáticos que impactan significativamente en el desempeño energético $y$, generalmente, son factores fijos inherentes a la tecnología existente y los cuales determinan la eficiencia energética de la tecnología en uso.

Hacen referencia a los cambios en la ocupación de edificios - Un edificio tiene un número relativamente estable de ocupantes. Si el número de ocupantes aumenta significativamente o disminuye, este puede requerir una revisión en los factores estáticos definidos, dado que afecta las LBEn e IDE. De igual manera se presenta, cuando existen modificaciones en el área de los edificios.

Cuando hay cambios importantes en los factores estáticos, se relacionan con variaciones en la tecnología y la organización deberá revisar las líneas de base energética que fueron elaboradas antes de esos cambios.

\subsubsection{Análisis de la información muestral y patrón de comportamiento de los datos a analizar}

Se trata del análisis previo de los datos en función de establecer condiciones de ciclicidad, estacionalidad, tendencia y aleatoriedad de los datos.

La tendencia en una serie de tiempo es el cambio del nivel de los datos a largo plazo. Si para un periodo prolongado la serie se mueve hacia arriba, se dice que los datos muestran tendencia positiva. Si el nivel de los datos disminuye con el tiempo, responde a una tendencia negativa. Por otro lado, los datos se consideran estacionarios cuando no hay tendencia positiva ni negativa (es decir, la serie es en esencia plana a largo plazo).

Cuando se presenta una variación regular del nivel de los datos que se repite cada año para el mismo periodo, se explica por la presentación de un patrón estacional en una serie de tiempo. Por ejemplo, el consumo de energía en países con verano e invierno intensos y la venta de útiles escolares. Otro análisis corresponde a un patrón cíclico, se representa mediante movimiento de los datos hacia arriba y hacia abajo, similar a un a onda alrededor de la tendencia a largo plazo. Las fluctuaciones cíclicas son de mayor duración y son menos regulares que las fluctuaciones estacionales. Un ejemplo de este tipo de variación son los 
ciclos comerciales cuyos períodos recurrentes dependen de la condición de oferta y demanda y de factores como el clima o las costumbres sociales.

En cuanto a la aleatoriedad, no responde a ningún patrón de comportamiento y se asocia a factores fortuitos o aleatorios que inciden de forma aislada en una serie de tiempo [2],[3].

\subsubsection{Definir un modelo para su utilización}

El patrón existente de los datos, corresponde a un aspecto importante para definir el modelo o técnica a utilizar en la estimación de la LBEn. Estos abarcan modelos cuantitativos como las series de tiempo, hasta modelos causales, como regresiones univariable, o multivariables.

En este sentido, determinar el modelo más indicado para su uso depende de criterios como el comportamiento de los datos, la selección de herramientas de análisis estadísticos que permitan dar validez al modelo, así como evaluar su capacidad descriptiva y predictiva (métricas de error). Todos, constituyen uno de los elementos importantes a la hora de establecer los criterios de selección de los modelos útiles para establecer una línea de base energética y posteriormente un ahorro.

En este sentido, la parametrización de los modelos implica evaluar la estructura matemática que identifique, tanto las entradas y salidas de cada modelo, como llegar a establecer las condiciones iniciales y los parámetros o magnitudes que describen las características físicas y funcionales del modelo. De otro lado, es importante comprobar que el modelo estadístico se ajusta correctamente a los datos establecidos. Esto implica someterse a pruebas estadísticas de bondad de ajuste, para verificar que reproducen el valor medido y, a su vez, permitir el uso con propósitos del pronóstico de valores futuros, siendo importante considerar que su esquema no cambiara en el tiempo de validez del modelo. Dichos elementos hacen parte de la evaluación de la capacidad descriptiva del modelo. Por otra parte, la validación del modelo, definido como la comparación de las estimaciones del modelo con los valores observados del sistema real, son tenidos en cuenta para determinar la validez del mismo.

Como parte del análisis para aplicación de estos modelos, se incluye la identificación de las variables relevantes que afectan el consumo de energía. En este sentido, el concepto de normalización se recomienda para mitigar los efectos asociados a los valores anormales de las variables relevantes que afectan el consumo de energía. Esto se hace al comparar entre el período de referencia y los períodos de informe, definidos para reportar la línea base. Por ejemplo, para las condiciones climáticas cambiantes, los grados día se pueden usar como una variable relevante para normalizar el consumo de energía en los edificios, donde una proporción significativa de la energía utilizada en el mismo corresponde a calefacción o refrigeración de espacios.

Las pruebas estadísticas (por ejemplo, el criterio del valor $\mathrm{p}$ ) pueden ser útiles para decidir si las variables relevantes afectan significativamente el consumo de energía y si deben ser utilizadas para la normalización. 
La normalización del consumo de energía mediante el uso de modelos de ajuste, se realizará de manera que los períodos de referencia y de información se puedan comparar, es decir, como si todas las variables relevantes fueran las mismas en los dos períodos. El período de referencia normalizado y / o el consumo de energía del período de notificación, se calcula utilizando uno o más modelos de ajuste. Estos, abarcan modelos cuantitativos utilizando las series de tiempo hasta modelos causales como regresiones univariable, multivariables.

\subsection{APLICACIÓN DE LA METODOLOGIA PROPUESTA AL EDIFICIO DE AULAS DE LA UNIVERSIDAD AUTONOMA DE OCCIDENTE.}

\section{Descripción de cuáles son los limites}

El límite corresponde al edificio de aulas cuatro de la Universidad Autónoma de Occidente, el periodo de análisis corresponde a los años 2017, 2018, 2019.

\section{La obtención de los datos}

Los datos utilizados para el análisis de los distintos métodos aplicados a la obtención de una línea base energética corresponden a:

- Datos historias del contador de energía desde el año 2016 hasta 2019 con frecuencia de registro de cada 15 min por variable.

- Datos de la estación meteorología instalada en la Universidad desde el año 2017 a 2019 y la estación meteorológica del IDEAN.

- Datos de ocupación de 2017 a 2019. En este caso se trata de la programación semestral de clases y ocupación de auditorios y demás espacios del aula.

\section{Las variables relevantes y factores estáticos para analizar}

El análisis de las variables relevantes y factores estáticos comprende la información suministrada durante el periodo 2017 - 2019. En su conjunto, incluye datos de estaciones meteorológicas instalada en la UAO que permiten disponer de las variables climatológicas, así como la información de planificación docente, relacionada con ocupación de salones, auditorios, oficinas y datos de consumo de energía del edificio.

Consumo de energía final Total: Es el consumo de energía final del edificio y en este caso constituye la variable dependiente. Comprende el consumo del medidor eléctrico ubicado en el edificio más la energía que se genera por los paneles fotovoltaicos (PV) instalados en la cubierta de la edificación. Se cuenta con la información diaria desde estas fuentes que permite totalizar el consumo de energía en kWh.

Temperatura: Es la temperatura seca media diaria del aire exterior en ${ }^{\circ} \mathrm{C}$ calculada a partir de la información horaria de que se dispone de la estación meteorológica.

Humedad: Es la humedad relativa media diaria, del aire exterior en \%, que se dispone de la estación meteorológica. 
Radiación: Es la radiación solar media, calculada considerando el tiempo de radiación diaria (radiación directa y difusa).

Ocupación: Es la ocupación de personas en los recintos de pregrado y postgrado expresada en el tiempo en que están siendo utilizados en cada espacio. Se determina a partir de la planificación existente sumando las horas de todos los recintos mensualmente.

Algunos factores estáticos en el aula se relacionan con actividades diarias en el aula, o bien con el data center ubicado en el edificio y algunos equipos que permanecen encendidos. Los consumos relacionados con los elementos mencionados anteriormente se pueden evidenciar en las gráficas de tendencia del edificio, son consumos fijos que se identifican aun sin ocupación en la edificación.

\section{Análisis de la información y patrón de comportamiento de los datos a analizar}

El análisis y comportamiento de los datos constituye uno de los elementos iniciales de mayor importancia en la decisión de usar un determinado modelo de línea base, en atención a la procedencia y verificación de los datos, la frecuencia de estos y las posibles alteraciones en cuanto al registro de la información.

A continuación, se presenta en la Figura 204 el comportamiento histórico del consumo de energía del edificio de Aulas 4 de la Universidad Autónoma de Occidente en adelante UAO.

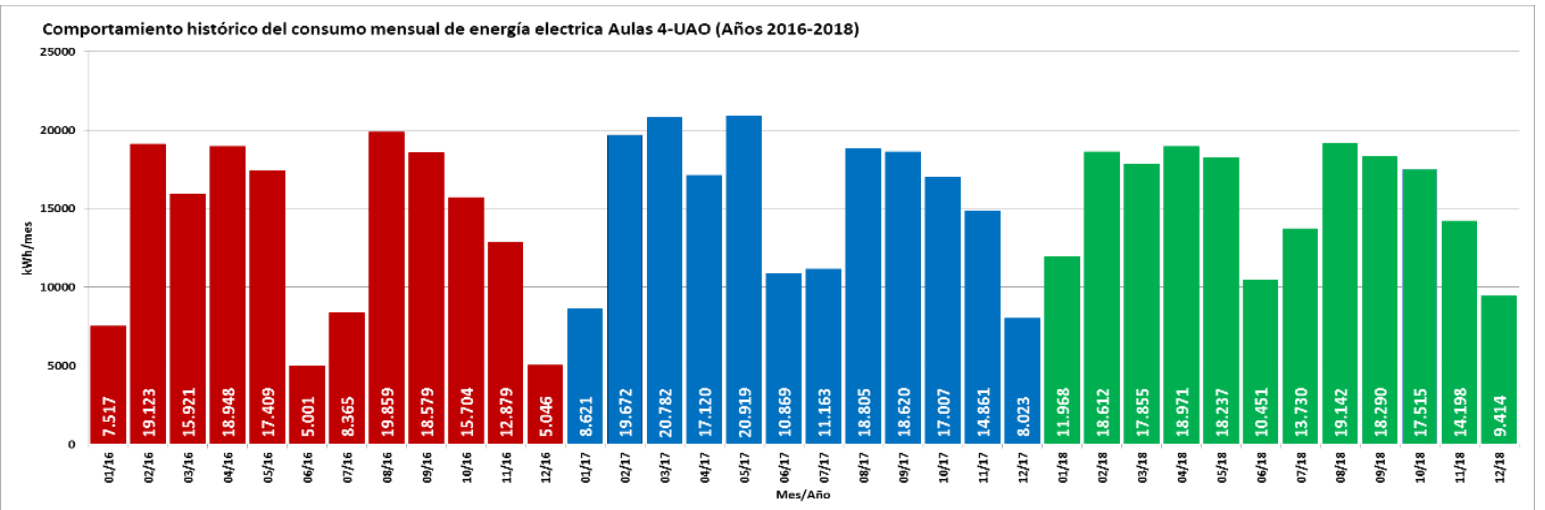

Figura 204. Comportamiento histórico del consumo mensual de energía eléctrica del edificio aulas 4

El análisis de la información histórica del consumo mensual de energía eléctrica en Aulas 4 (Figura 205) muestra un comportamiento estacional anual, con una ligera alteración entre los meses de marzo y abril que depende del mes donde se presenta la semana santa (semana en que la universidad no está operativa). De igual forma, se evidencia un incremento anual del consumo de energía (Figura 206) que logra ser explicado por la renovación tecnológica progresiva de las instalaciones en las aulas 4, y para el 2017 representó un 13,5\% con respecto al año anterior y en el 2018 fue tan solo del 1,0\%. 


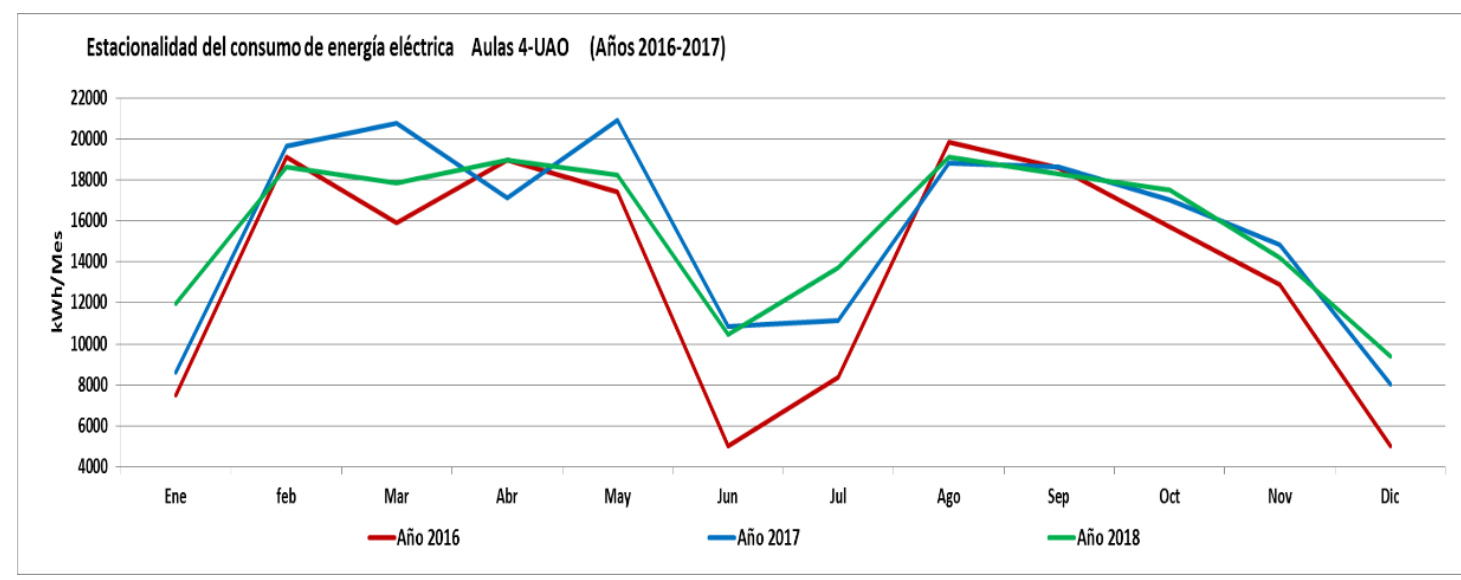

Figura 205. Grafica comportamiento estacional del edificio de aulas 4

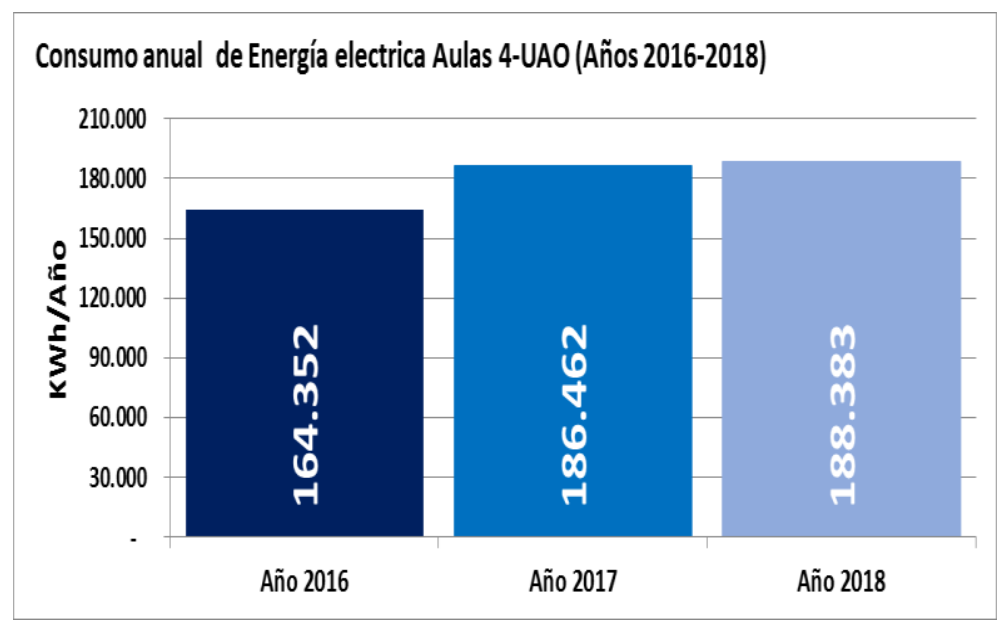

Figura 206. Grafica consumo anual del edificio de aulas 4

A continuación, se muestra la utilización de los modelos de series de tiempo aplicados a la obtención de una línea de base energética, como propuesta para la validación de los modelos de medición de valor de energía y cociente de valores medidos, propuestos por la norma ISO 50006 [4].

En el contexto de los sistemas de gestión de la energía, el propósito fundamental de una línea de base energética, parte de proporcionar una referencia cuantitativa que provee la base de comparación del desempeño energético. Es decir, un valor del consumo de energía eléctrico o térmico, que permita medir ahorros como una referencia antes y después de implementar las acciones de mejora. Considerando lo anterior como un pronóstico o valor de referencia de consumo de cualquier tipo de energía, el análisis de series de tiempo se ajusta de manera adecuada como modelos mencionados previamente. 


\subsubsection{Modelos de Series de Tiempo}

A continuación, se presenta la aplicación al caso de estudio del edificio de aulas 4 del campus universitario, partiendo de modelos sencillos hasta los modelos que consideran la estacionalidad y el análisis segmentado de los datos.

\section{Modelo 1: Promedio del consumo mensual histórico}

Este primer modelo de línea base energética para el año 2019, se obtiene a partir de la observación del comportamiento de los datos, donde el valor pronosticado para el consumo de energía de un mes específico del mismo año (por ej. Enero-2019) se adquiere a partir del cálculo del promedio del consumo de energía eléctrica para el mismo mes. Esto, considerando el histórico de 3 años atrás (es decir, el promedio de los consumos de Ene2016, Ene-2017 y Ene-2018). En este caso no se tienen en cuenta las mejoras tecnológicas realizadas en años anteriores.

En la Figura 207, se presenta la línea de base energética obtenida, ilustrada como una línea de color negro. Los valores obtenidos como línea base son presentados en la Tabla 82.

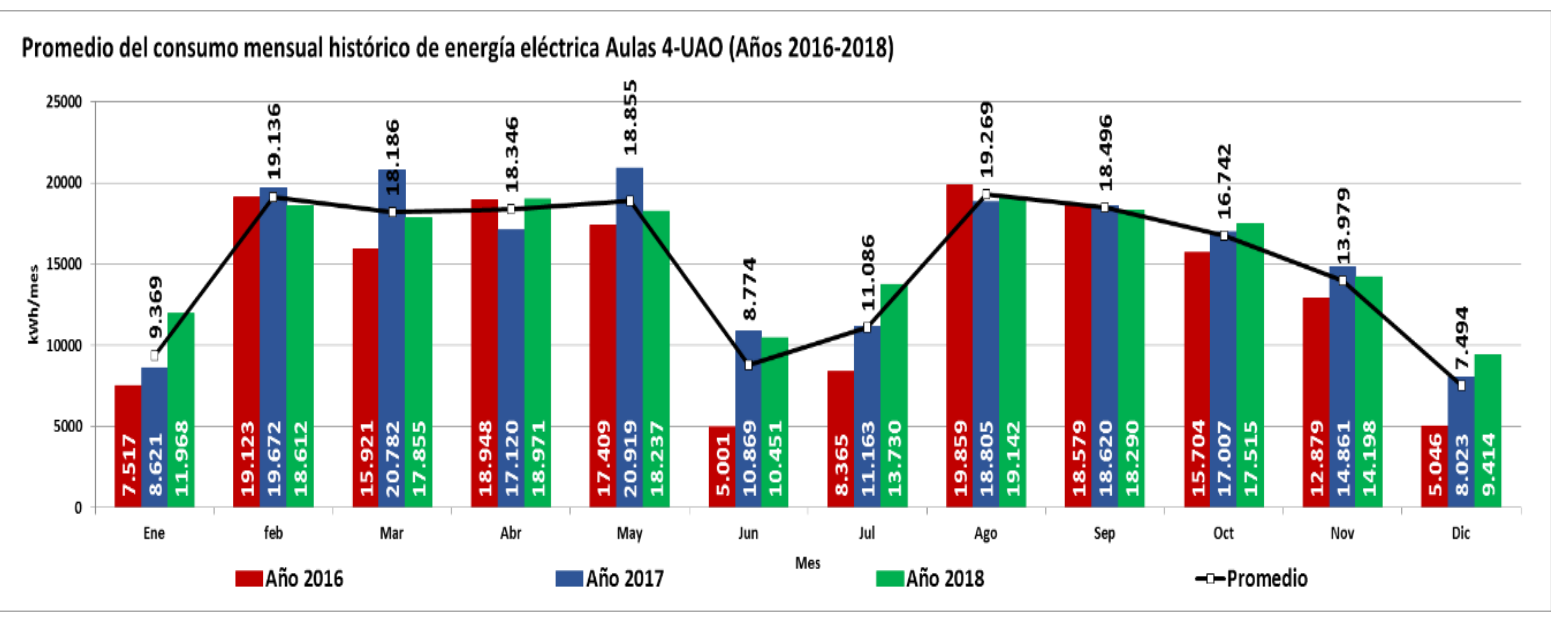

Figura 207. Promedio del consumo mensual histórico de energía Eléctrica (2016 - 2018)

Tabla 82. Línea base - Promedio del consumo mensual histórico

\begin{tabular}{|c|c|c|c|c|}
\hline kWh/mes & Año 2016 & Año 2017 & Año 2018 & Línea Base 2019 \\
\hline Ene & 7517 & 8621 & 11968 & 9369 \\
\hline Feb & 19123 & 19672 & 18612 & 19136 \\
\hline Mar & 15921 & 20782 & 17855 & 18186 \\
\hline Abr & 18948 & 17120 & 18971 & 18346 \\
\hline May & 17409 & 20919 & 18237 & 18855 \\
\hline Jun & 5001 & 10869 & 10451 & 8774 \\
\hline Jul & 8365 & 11163 & 13730 & 11086 \\
\hline Ago & 19859 & 18805 & 19142 & 19269 \\
\hline Sep & 18579 & 18620 & 18290 & 18496 \\
\hline Oct & 15704 & 17007 & 17515 & 16742 \\
\hline Nov & 12879 & 14861 & 14198 & 13979 \\
\hline Dic & 5046 & 8023 & 9414 & 7494 \\
\hline
\end{tabular}




\section{Modelo 2: Promedio ponderado del consumo mensual histórico}

El segundo modelo propuesto de línea base energética para el año 2019, se construye a partir del valor pronosticado de consumo de energía de un mes específico del mismo año (por ej. Enero-2019). Se trata del cálculo del promedio ponderado del consumo de energía eléctrica, para el mismo mes y considerando el histórico de 3 años atrás (es decir, el promedio de los consumos de Ene-2016, Ene-2017 y Ene-2018), dándole mayor peso a los consumos de energía del último año. Tal como se muestra en la siguiente ecuación.

$$
E_{\text {mes } x-2019}=\frac{E_{\text {mes } x-2016}+2 * E_{\text {mes } x-2017}+3 * E_{\text {mes } x-2018}}{6}
$$

En este análisis, como en el modelo 1, no se han considerado los cambios tecnológicos realizados durante los últimos 3 años.

En la Tabla 83, se presenta la línea base Energética propuesta y en la Figura 208 se ilustra como una línea negra en la gráfica.

Tabla 83. Línea base - Promedio ponderado del consumo mensual histórico

\begin{tabular}{|c|c|c|c|c|}
\hline $\mathbf{k W h} / \mathbf{m e s}$ & Año 2016 & Año 2017 & Año 2018 & Línea Base 2019 \\
\hline Ene & 7517 & 8621 & 11968 & 10110 \\
\hline Feb & 19123 & 19672 & 18612 & 19050 \\
\hline Mar & 15921 & 20782 & 17855 & 18508 \\
\hline Abr & 18948 & 17120 & 18971 & 18350 \\
\hline May & 17409 & 20919 & 18237 & 18993 \\
\hline Jun & 5001 & 10869 & 10451 & 9682 \\
\hline Jul & 8365 & 11163 & 13730 & 11980 \\
\hline Ago & 19859 & 18805 & 19142 & 19149 \\
\hline Sep & 18579 & 18620 & 18290 & 18448 \\
\hline Oct & 15704 & 17007 & 17515 & 17044 \\
\hline Nov & 12879 & 14861 & 14198 & 14199 \\
\hline Dic & 5046 & 8023 & 9414 & 8222 \\
\hline
\end{tabular}

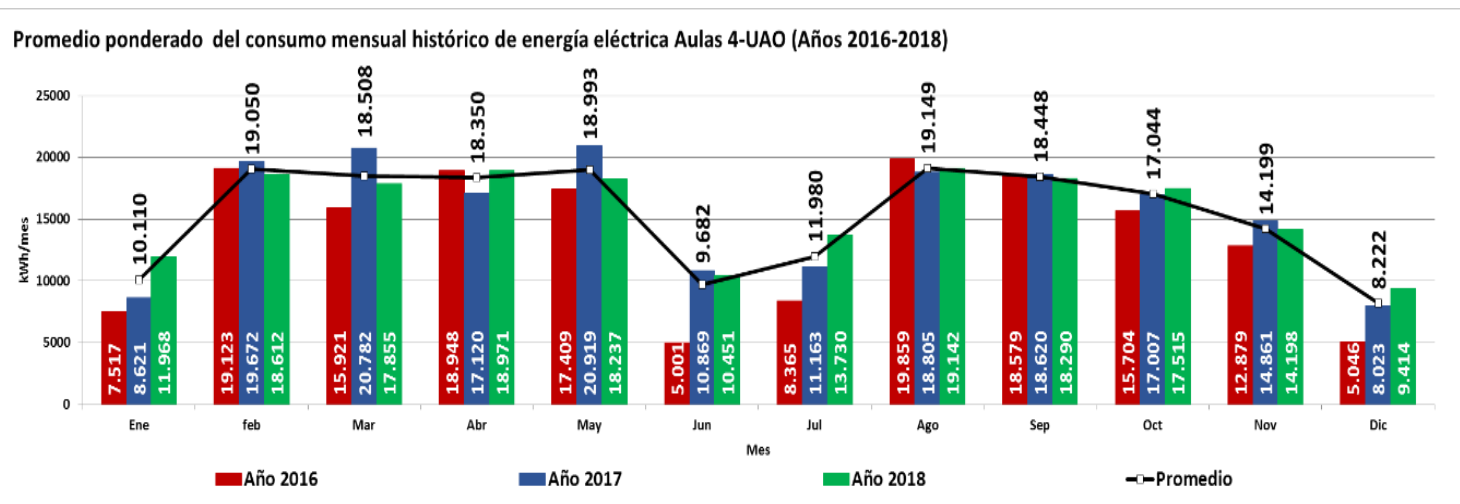

Figura 208. Promedio ponderado del consumo mensual histórico de energía Eléctrica (2016 2018) 


\section{Modelo 3: Índices de estacionalidad}

En este tercer modelo la línea de base energética propuesta, tiene en cuenta la estacionalidad anual del consumo de energía y un incremento del consumo de energía para el año 2019 del 1\% respecto al año anterior (incremento mínimo de los últimos tres años). De tal forma, el modelo de línea de base energética obtenido para el año 2019, considera los índices de estacionalidad con la información histórica de los últimos tres años. Los resultados se presentan en la Tabla 84 y de forma gráfica en la Figura 209.

Tabla 84. Línea base - Índices de estacionalidad

\begin{tabular}{|c|r|c|c|r|}
\multicolumn{7}{c|}{ Cálculo de índices de estacionalidad } \\
\hline kWh/mes & Año 2016 & Año 2017 & Año 2018 & \multicolumn{1}{c|}{ Suma } \\
\hline Ene & 7.517 & 8.621 & 11.968 & $\mathbf{2 8 . 1 0 6}$ \\
\hline feb & 19.123 & 19.672 & 18.612 & $\mathbf{5 7 . 4 0 7}$ \\
\hline Mar & 15.921 & 20.782 & 17.855 & $\mathbf{5 4 . 5 5 8}$ \\
\hline Abr & 18.948 & 17.120 & 18.971 & $\mathbf{5 5 . 0 3 9}$ \\
\hline May & 17.409 & 20.919 & 18.237 & $\mathbf{5 6 . 5 6 5}$ \\
\hline Jun & 5.001 & 10.869 & 10.451 & $\mathbf{2 6 . 3 2 1}$ \\
\hline Jul & 8.365 & 11.163 & 13.730 & $\mathbf{3 3 . 2 5 8}$ \\
\hline Ago & 19.859 & 18.805 & 19.142 & $\mathbf{5 7 . 8 0 6}$ \\
\hline Sep & 18.579 & 18.620 & 18.290 & $\mathbf{5 5 . 4 8 9}$ \\
\hline Oct & 15.704 & 17.007 & 17.515 & $\mathbf{5 0 . 2 2 6}$ \\
\hline Nov & 12.879 & 14.861 & 14.198 & $\mathbf{4 1 . 9 3 8}$ \\
\hline Dic & 5.046 & 8.023 & 9.414 & $\mathbf{2 2 . 4 8 3}$ \\
\hline Suma & 164.352 & 186.462 & 188.383 & $\mathbf{5 3 9 . 1 9 7}$ \\
\hline & & & L & Incremento: \\
\cline { 2 - 5 } & & &
\end{tabular}

\begin{tabular}{|r|c|}
\hline \multicolumn{1}{c|}{$\begin{array}{c}\text { Índice } \\
\text { Estacional }\end{array}$} & $\begin{array}{c}\text { Línea Base } \\
\text { Año 2019 }\end{array}$ \\
\hline $\mathbf{5 , 2 1 \%}$ & 9.918 \\
\hline $10,65 \%$ & 20.257 \\
\hline $10,12 \%$ & 19.252 \\
\hline $10,21 \%$ & 19.422 \\
\hline $10,49 \%$ & 19.960 \\
\hline $4,88 \%$ & 9.288 \\
\hline $6,17 \%$ & 11.736 \\
\hline $10,72 \%$ & 20.398 \\
\hline $10,29 \%$ & 19.581 \\
\hline $9,31 \%$ & 17.723 \\
\hline $7,78 \%$ & 14.799 \\
\hline $4,17 \%$ & 7.934 \\
\hline $100,00 \%$ & 190.267 \\
\hline $1,00 \%$ & $\mathbf{1}$ \\
\hline
\end{tabular}

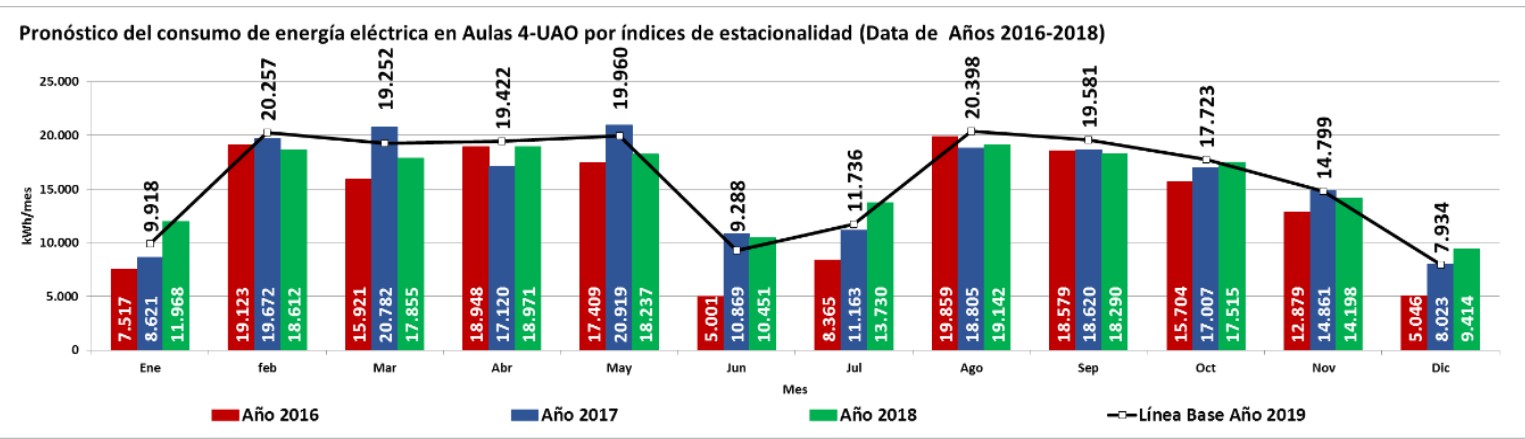

Figura 209. Línea base - Índices de estacionalidad

\section{Modelo 4: Media móvil de orden 12}

A partir de la estacionalidad anual del consumo de energía y los incrementos históricos que se han venido presentando en el consumo, se puede obtener un cuarto modelo de línea de base energética para el año 2019, aplicando el cálculo de la media móvil de orden 12 (estacionalidad de 12 meses). Los mismos, en atención a que los métodos de pronósticos 
móvil tienen como objeto dar relevancia a los datos más recientes para obtener la previsión, así se elige la media móvil 12.

Cada punto de una media móvil de una serie temporal es la media aritmética de un número de puntos consecutivos de la serie, donde el número de puntos es elegido de tal manera que los efectos estacionales y / o irregulares sean eliminados [45].

En la Tabla 85, se muestran los valores de la línea base estimada bajo la modelo media móvil 12, la cual requiere un histórico de 12 datos para estimar el dato siguiente. La Figura 210 presenta de forma gráfica la línea base obtenida.

Tabla 85. Línea base - Media móvil de orden 12

\begin{tabular}{|c|c|c|}
\hline Año-mes & $\begin{array}{c}\text { Consumo } \\
{[\mathbf{k W h} / \mathrm{mes}]}\end{array}$ & $\begin{array}{c}\text { Media móvil } \\
\mathbf{n}=12\end{array}$ \\
\hline ene-16 & 7517 & \\
\hline feb-16 & 19123 & \\
\hline mar-16 & 15921 & \\
\hline abr-16 & 18948 & \\
\hline may-16 & 17409 & \\
\hline jun-16 & 5001 & \\
\hline jul-16 & 8365 & \\
\hline ago-16 & 19859 & \\
\hline sep-16 & 18579 & \\
\hline oct-16 & 15704 & \\
\hline nov-16 & 12879 & \\
\hline dic-16 & 5046 & \\
\hline ene-17 & 8621 & 13696 \\
\hline feb-17 & 19672 & 13788 \\
\hline mar-17 & 20782 & 13834 \\
\hline abr-17 & 17120 & 14239 \\
\hline may-17 & 20919 & 14086 \\
\hline jun-17 & 10869 & 14379 \\
\hline jul-17 & 11163 & 14868 \\
\hline ago-17 & 18805 & 15101 \\
\hline sep-17 & 18620 & 15013 \\
\hline oct-17 & 17007 & 15017 \\
\hline nov-17 & 14861 & 15125 \\
\hline dic-17 & 8023 & 15290 \\
\hline
\end{tabular}

\begin{tabular}{|c|c|c|}
\hline Año-mes & $\begin{array}{c}\text { Consumo } \\
{[\mathbf{k W h / m e s}]}\end{array}$ & $\begin{array}{c}\text { Media móvil } \\
\mathbf{n}=12\end{array}$ \\
\hline ene-18 & 11968 & 15539 \\
\hline feb-18 & 18612 & 15817 \\
\hline mar-18 & 17855 & 15729 \\
\hline abr-18 & 18971 & 15485 \\
\hline may-18 & 18237 & 15639 \\
\hline jun-18 & 10451 & 15416 \\
\hline jul-18 & 13730 & 15381 \\
\hline ago-18 & 19142 & 15595 \\
\hline sep-18 & 18290 & 15623 \\
\hline oct-18 & 17515 & 15596 \\
\hline nov-18 & 14198 & 15638 \\
\hline dic-18 & 9414 & 15583 \\
\hline ene-19 & 8157 & 15699 \\
\hline feb-19 & 18339 & 15381 \\
\hline mar-19 & 19271 & 15358 \\
\hline abr-19 & 15445 & 15476 \\
\hline may-19 & 18876 & 15182 \\
\hline jun-19 & 12135 & 15236 \\
\hline jul-19 & 20271 & 15376 \\
\hline ago-19 & 24242 & 15921 \\
\hline sep-19 & 22723 & 16346 \\
\hline oct-19 & 21390 & 16715 \\
\hline nov-19 & 17109 & 17038 \\
\hline dic-19 & 10418 & 17281 \\
\hline
\end{tabular}




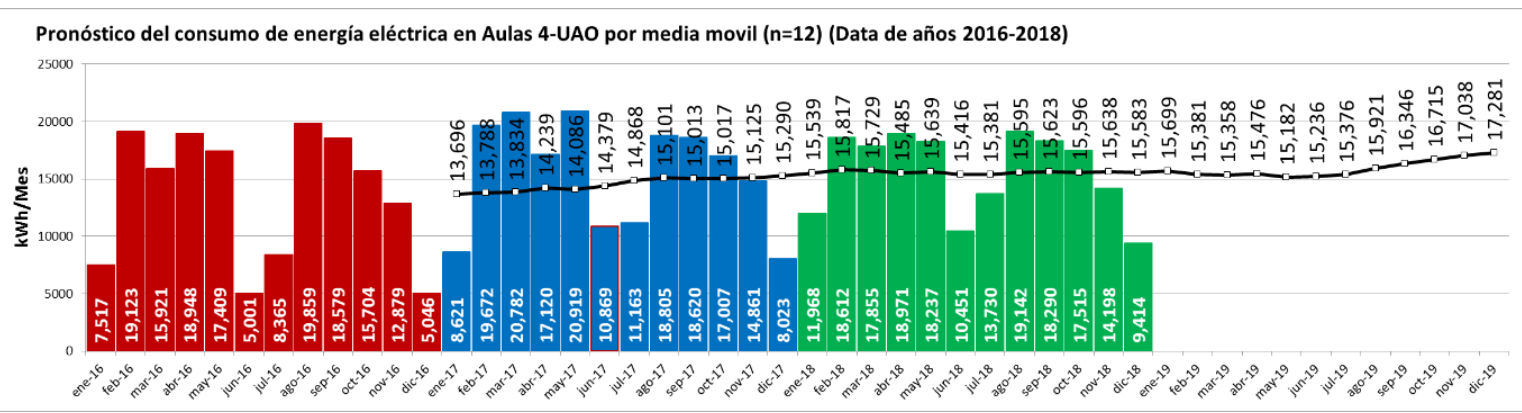

Figura 210. Línea base - Media móvil de orden 12

Nota: Este modelo además de subestimar el consumo, presenta mucho desfase en el pronóstico para los meses de bajo consumo.

Es posible obtener modelos más afinados, si se tienen en cuenta variables relevantes que afectan el consumo energético en el tiempo. Por ejemplo, para este caso de estudio la programación de la operación del campus universitario, es una variable relevante a considerar para acercarnos más al pronóstico. Esta programación que realiza la universidad de forma anual, estima actividades para un numero de semanas estándar (semestres regulares, de verano y de invierno, vacaciones, semana santa) que involucran a otras variables que pueden afectar el consumo, tales como la ocupación y algunos factores climáticos relacionados con la estacionalidad, muchos de ellos coinciden con patrones repetitivos año tras año, como se puede apreciar en las figuras $211-213$ :

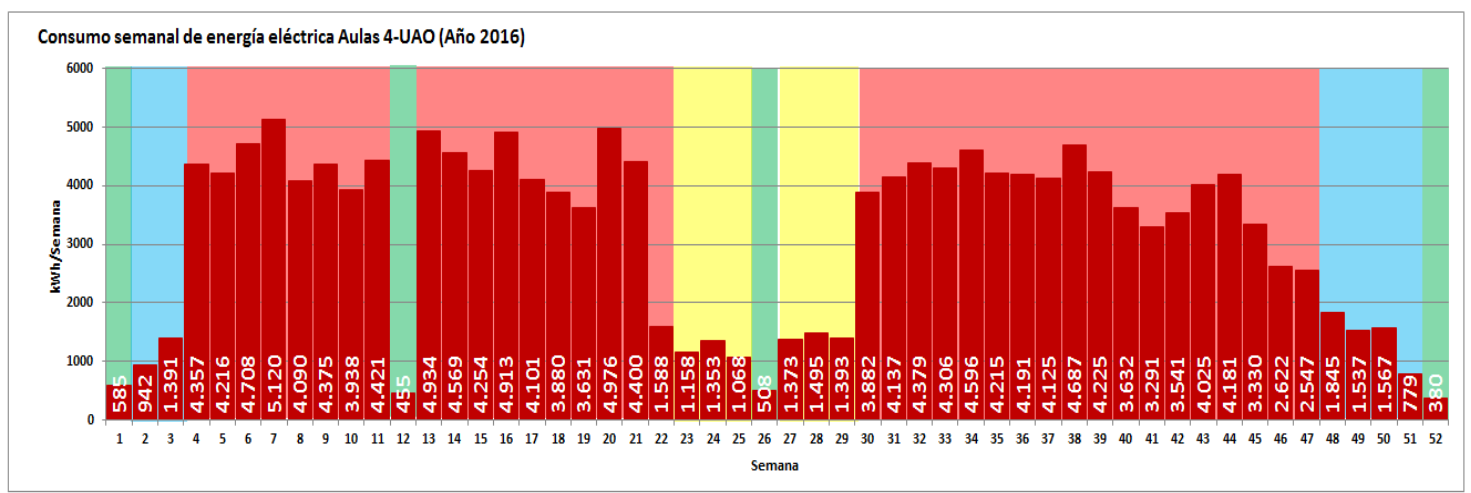

Figura 211. Consumo semanal de energía eléctrica para el año 2016

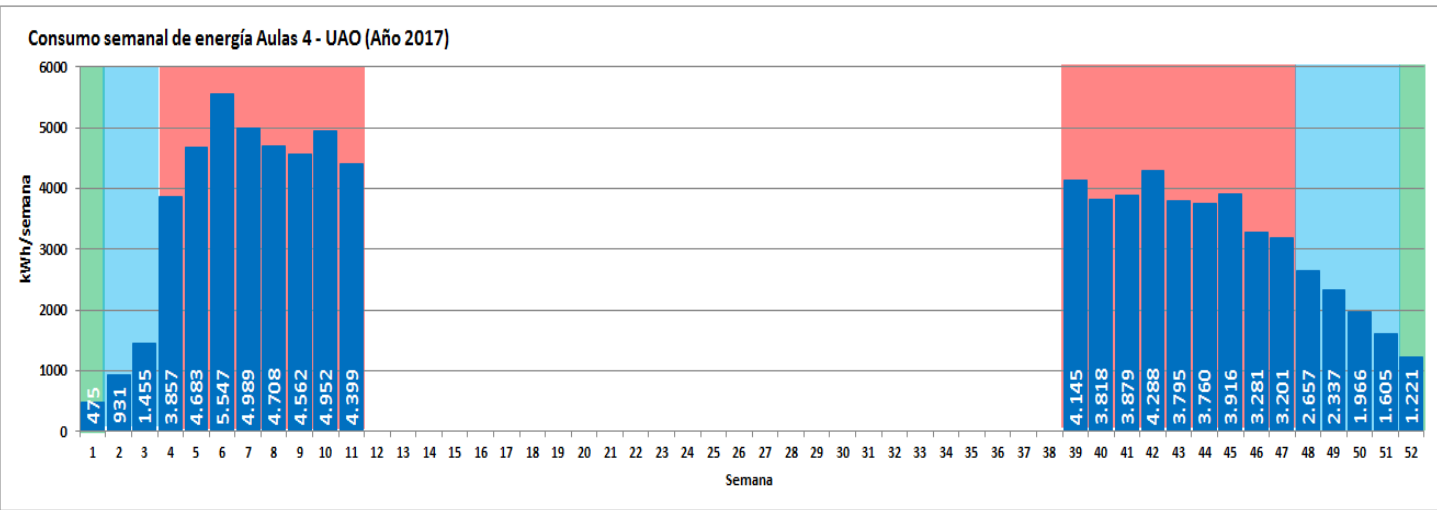

Figura 212. Consumo semanal de energía eléctrica para el año 2016 


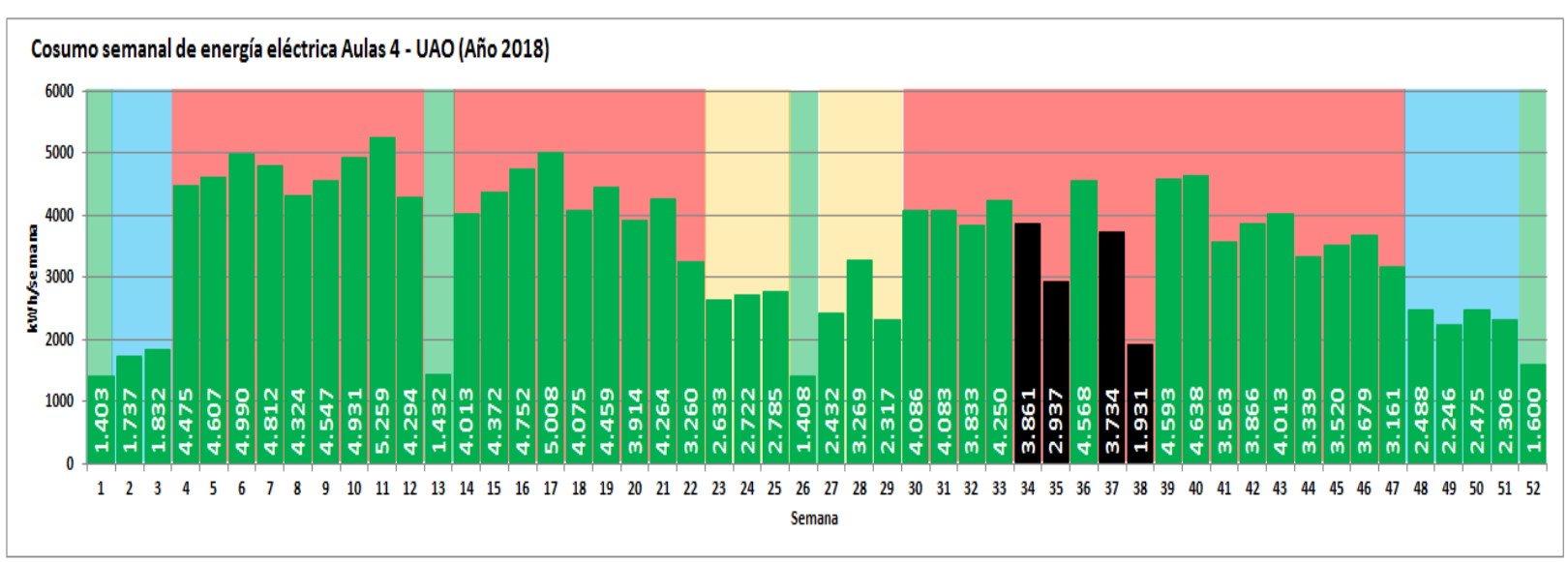

Figura 213. Consumo semanal de energía eléctrica para el año 2016

Las franjas verdes corresponden a vacaciones colectivas y semana santa, las franjas rosadas a los semestres regulares, las franjas azules al semestre intermedio de invierno, y las franjas amarillas al semestre intermedio de verano.

Para el año 2017, se tuvo problemas con el sistema de medición y no se cuenta con datos de consumo eléctrico del edificio de las semanas 12 a la 38. Así mismo, en el 2018 se presentaron inconvenientes de registro para las semanas 34, 35, 37 y 38.

Teniendo en cuenta estas variaciones en el consumo energético, se puede plantear un modelo más preciso que considere dichos cambios para tener un pronóstico más cercano y acorde a la programación académica de la universidad para el año 2019:

\section{Modelo 5: Considerando la programación académica}

Es posible obtener un quinto modelo de línea de base energética para el año 2019, cuando se considera la variación que tienen los consumos energéticos en algunos periodos definidos en la programación anual de la universidad (semestres regulares, de verano y de invierno, vacaciones, semana santa). Estos generan las cimas y los valles en la estacionalidad anual del consumo de energía, como se ilustra en las figuras $214-218$.

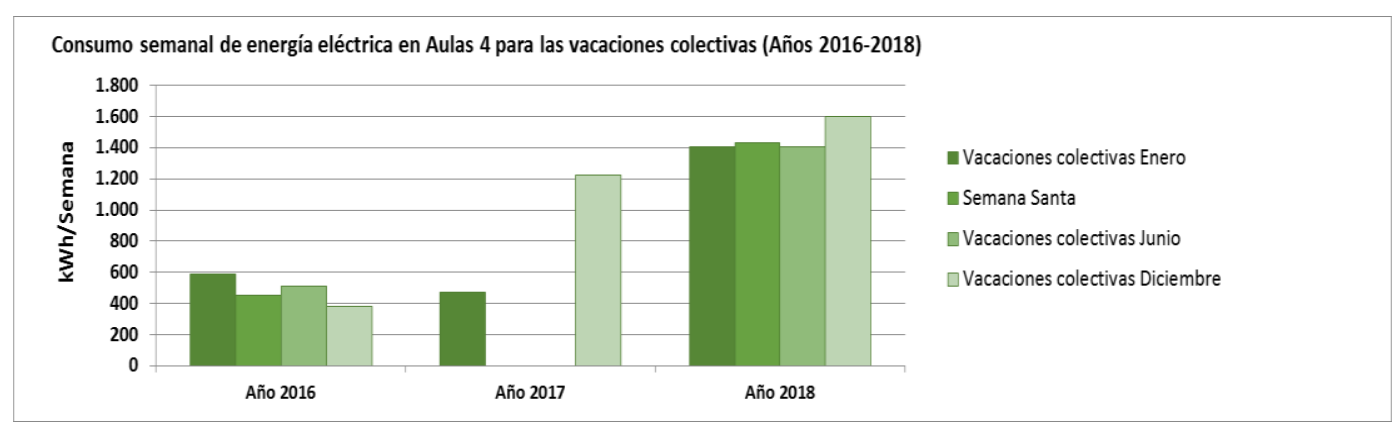

Figura 214. Consumo semanal de energía para el periodo de vacaciones (Años 2016 - 2018) 


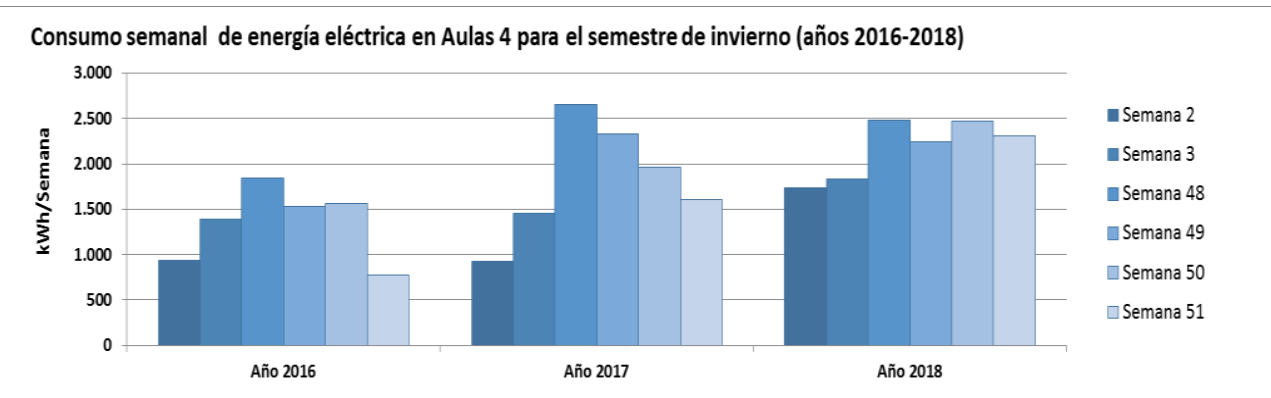

Figura 215. Consumo semanal de energía para el periodo de invierno (Años 2016 - 2018)

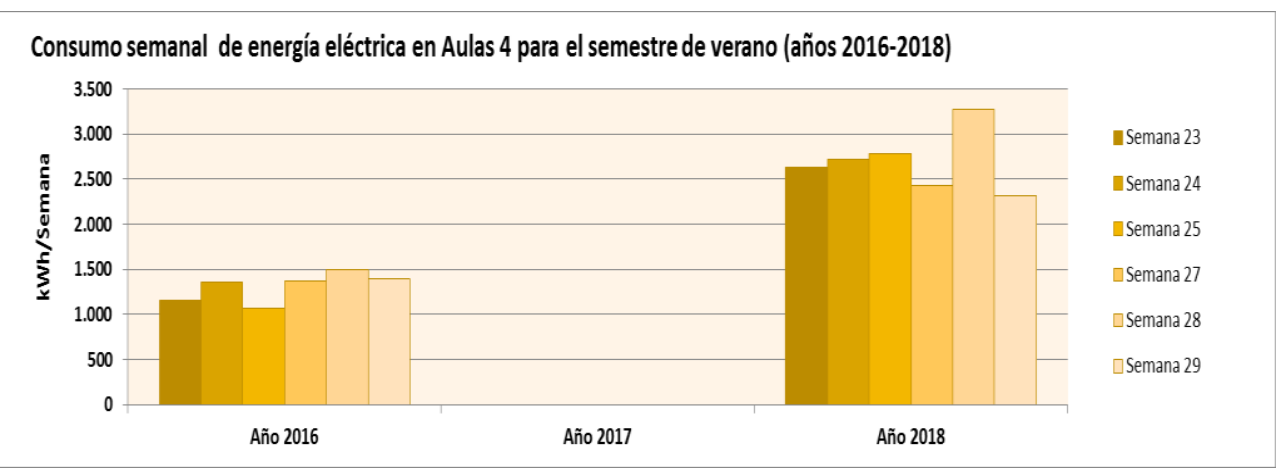

Figura 216. Consumo semanal de energía para el periodo de verano (Años 2016 - 2018)

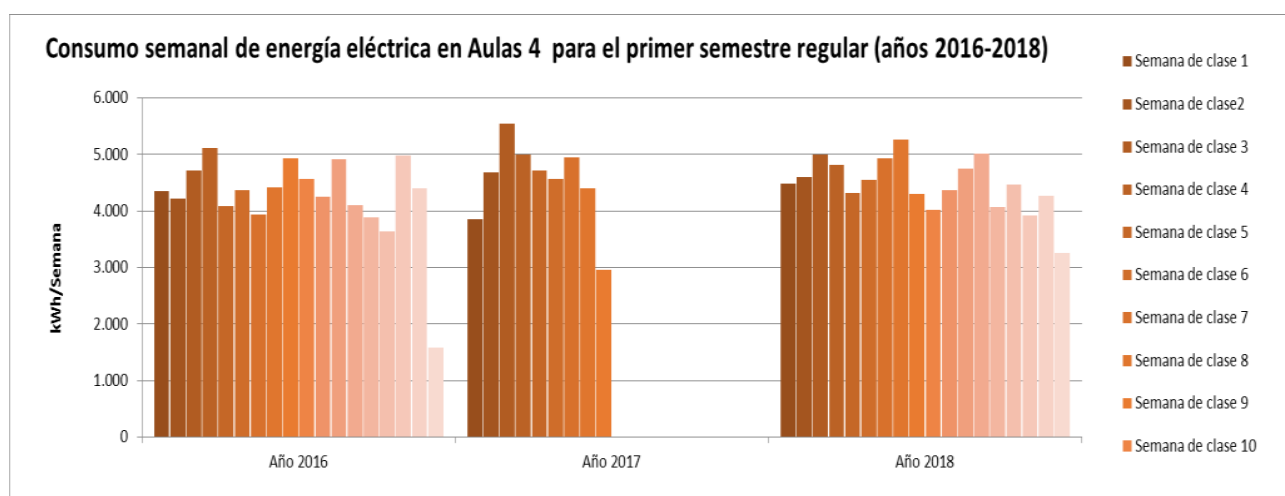

Figura 217. Consumo semanal de energía para el primer semestre (Años 2016 - 2018)

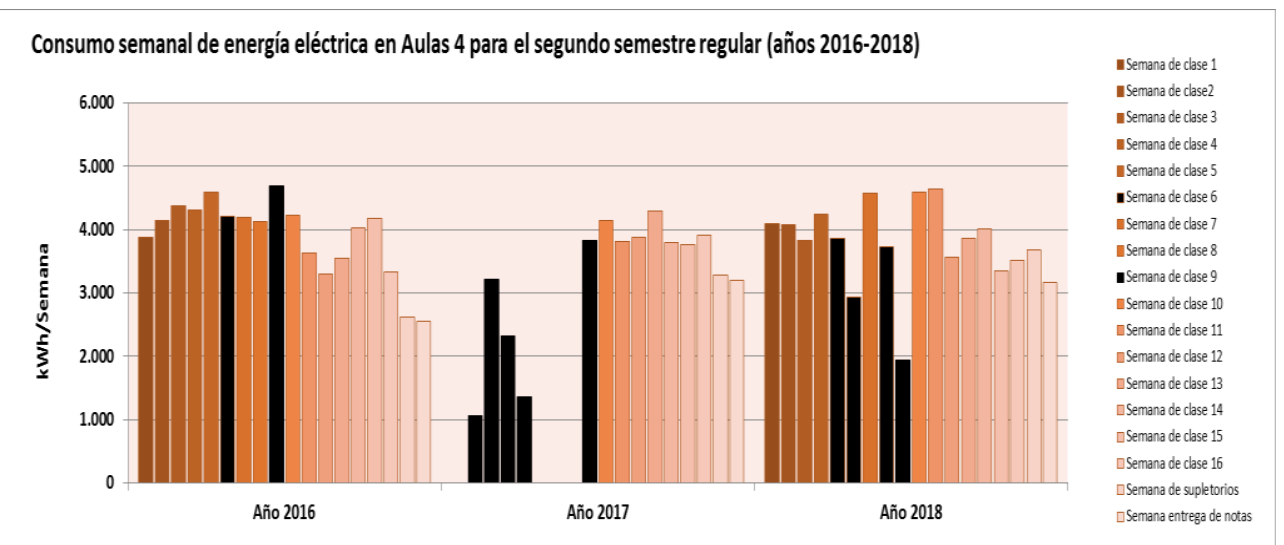

Figura 218. Consumo semanal de energía para el segundo semestre (Años 2016 - 2018) 
Tomando los consumos promedio del año 2018 y los eventos programados, se propone construir la línea base mensual que da cuenta del consumo esperado en el año 2019. Así se muestra en la siguiente Figura 219.

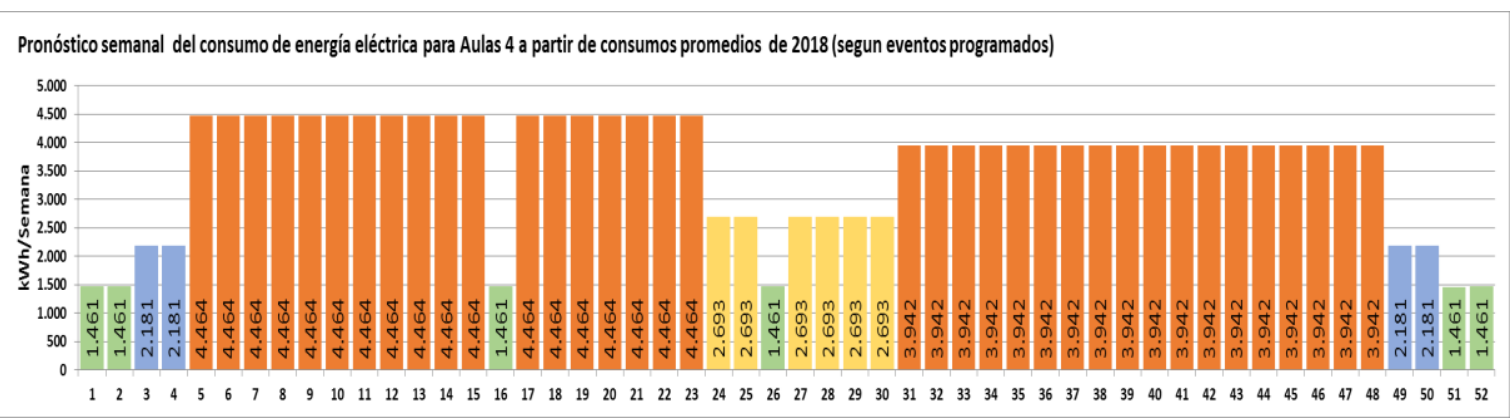

Figura 219. Consumo promedio según programación académica

A partir del pronóstico semanal obtenido anteriormente, se puede levantar el pronóstico mensual presentado en la Tabla 86 y la Figura 220.

Tabla 86. Línea base - consumo promedio según programación académica

\begin{tabular}{|c|c|}
\hline \multicolumn{2}{|c|}{$\begin{array}{c}\text { Línea de base energética } \\
\text { mensual Año 2019 }\end{array}$} \\
\hline Mes & kWh/Mes \\
\hline ene-19 & 10,054 \\
\hline feb-19 & 17,857 \\
\hline mar-19 & 19,770 \\
\hline abr-19 & 16,129 \\
\hline may-19 & 19,770 \\
\hline jun-19 & 12,334 \\
\hline jul-19 & 12,640 \\
\hline ago-19 & 17,459 \\
\hline sep-19 & 16,896 \\
\hline oct-19 & 17,459 \\
\hline nov-19 & 16,896 \\
\hline dic-19 & 7,909 \\
\hline
\end{tabular}

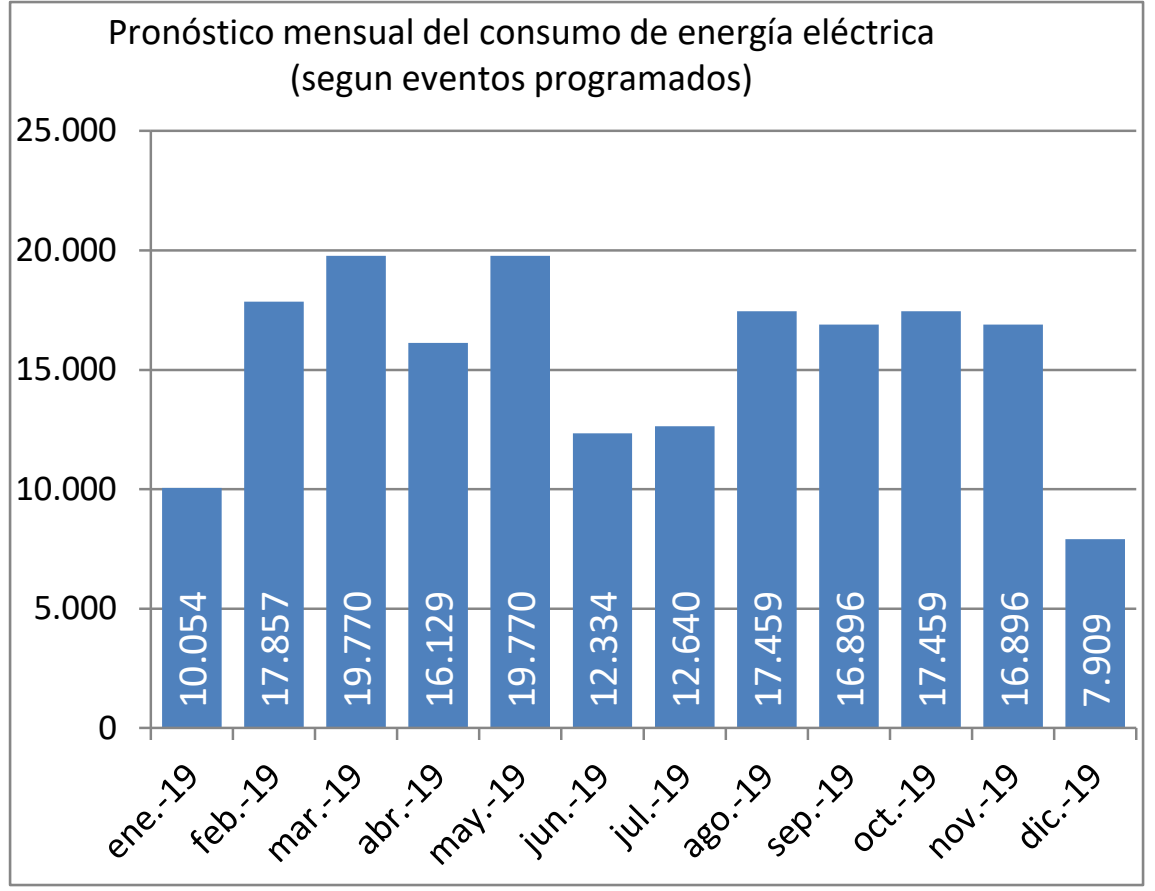

Figura 220. Línea base - consumo promedio según programación académica

\section{Modelo 6: Considerando la curva de consumo promedio diario.}

Es posible obtener un modelo de línea base más aproximado, si se considera el comportamiento del consumo de energía para cada día de la semana. Lo anterior, dado que la universidad los días sábados labora hasta las 3 p.m. y el día domingo no tiene actividad 
académica. Esto permite analizar el comportamiento de la curva semanal de consumo energético en el 2018, según eventos considerados, como se presentan en las Figuras 221 y 222.

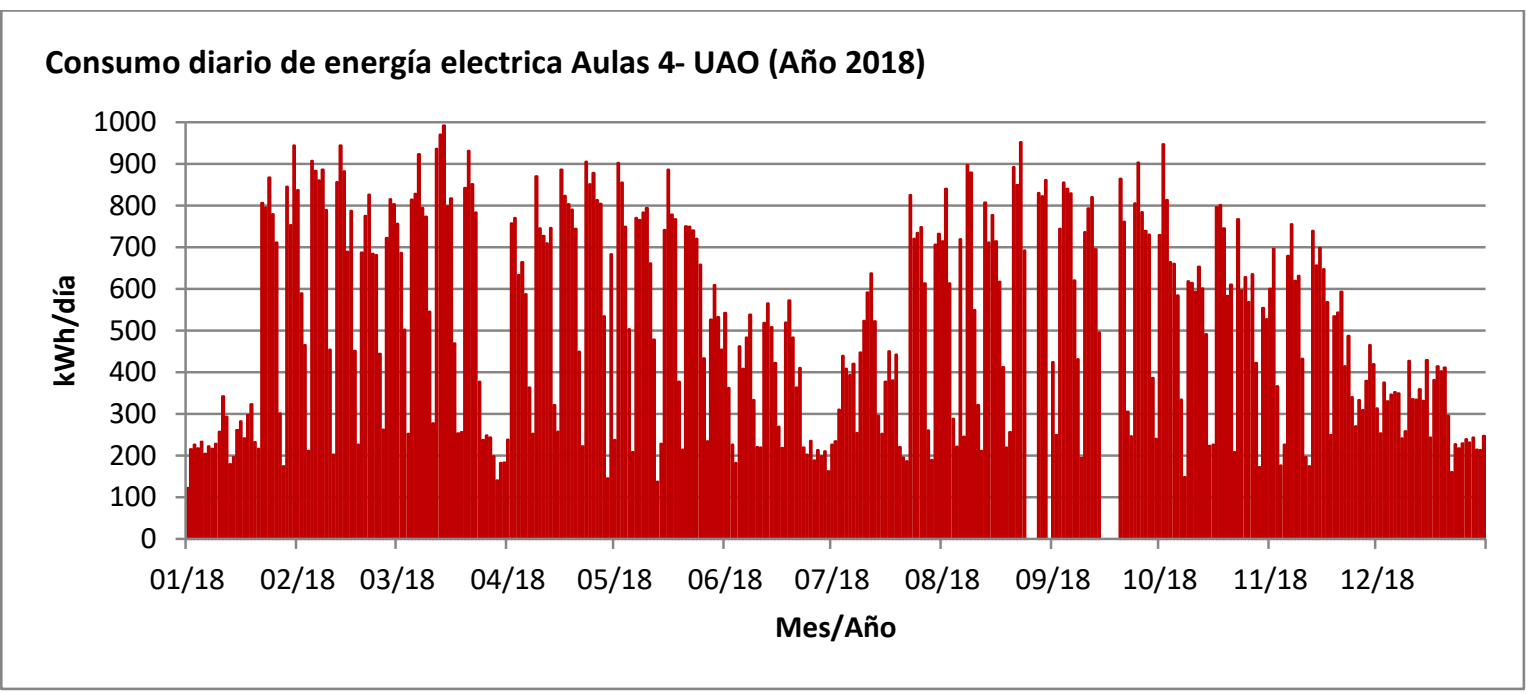

Figura 221. Consumo de energía diario para el año 2018

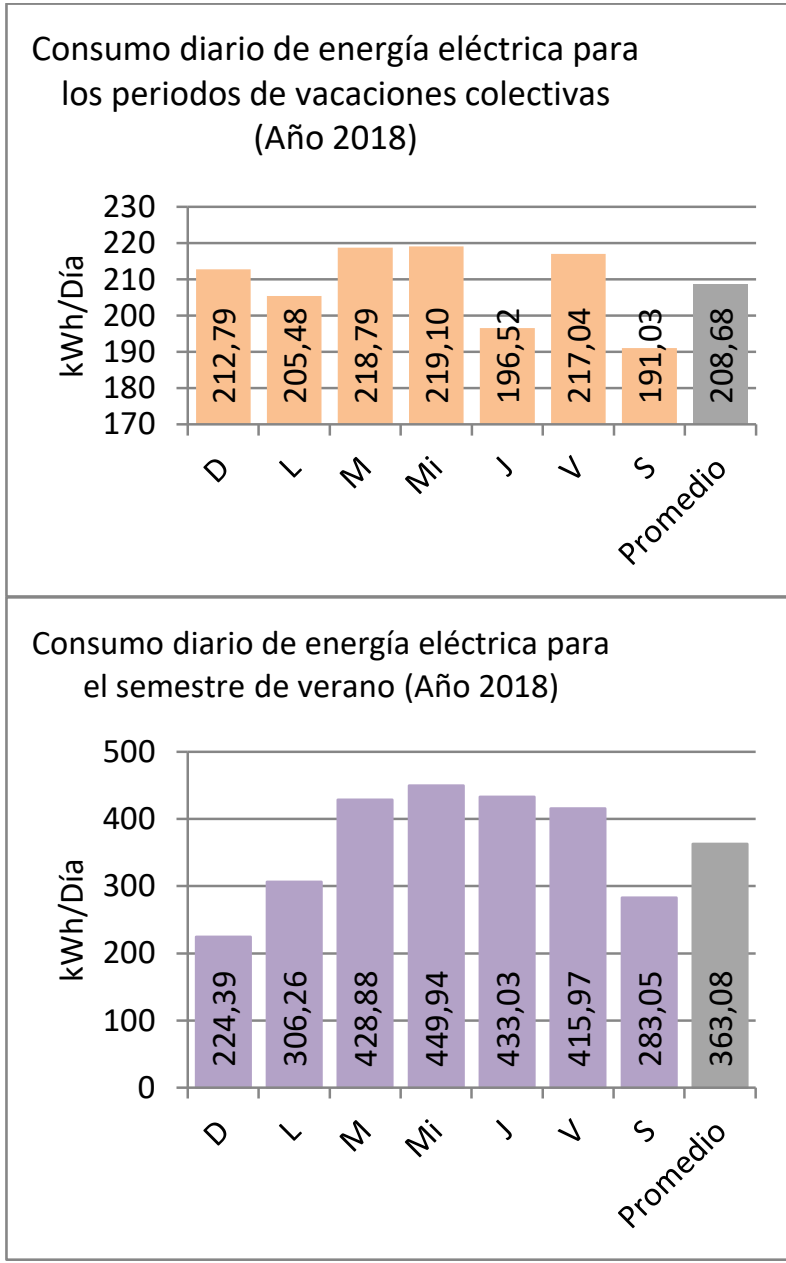

Consumo diario de energía eléctrica para el semestre de invierno (Año 2018)

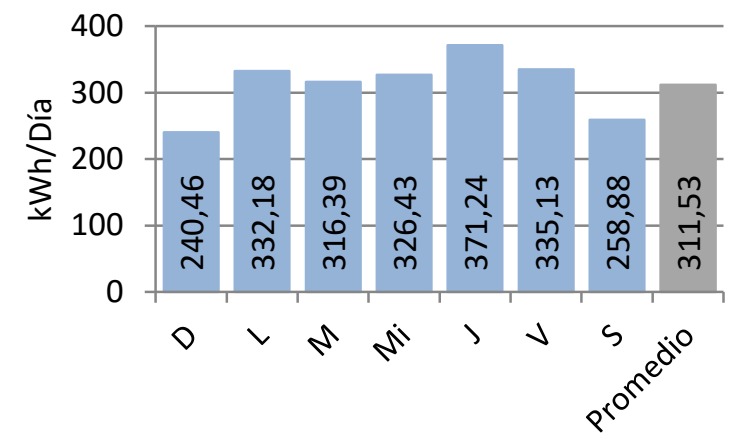

Consumo diario de energía eléctrica para

el primer semestre regular (Año 2018)

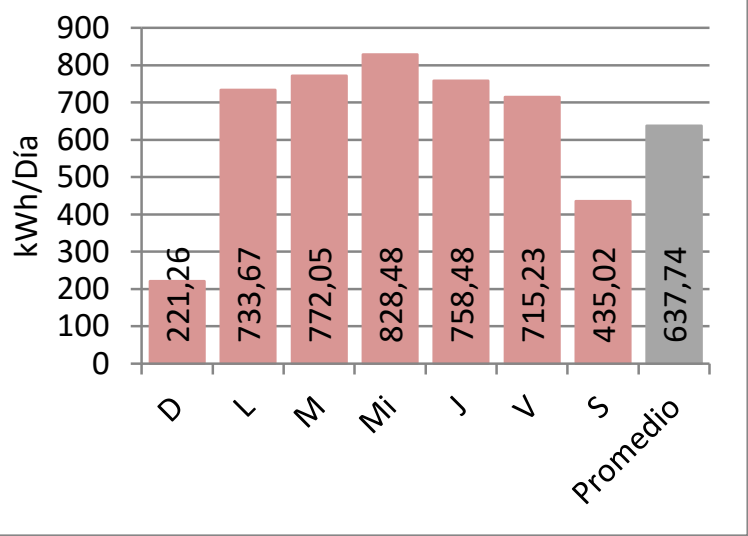




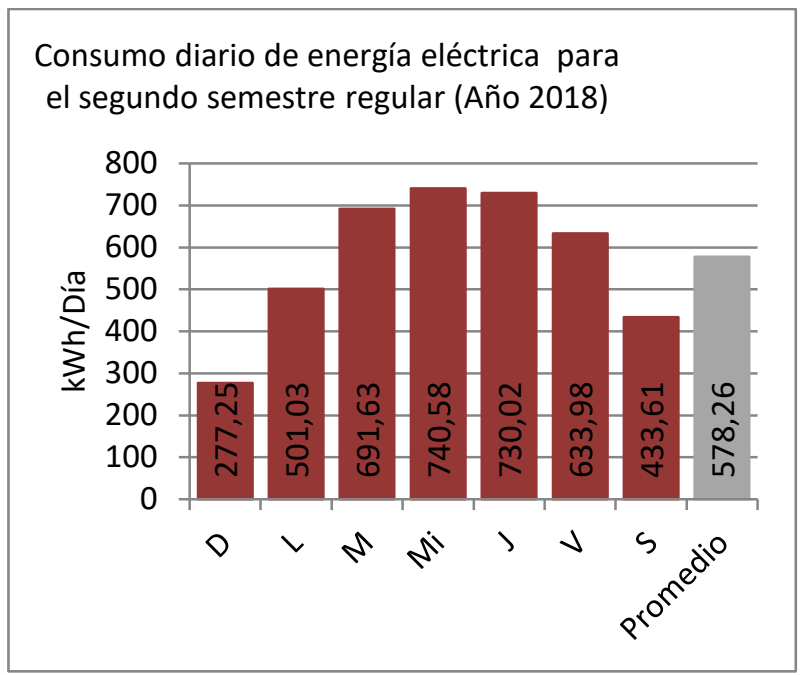

Figura 222. Consumo de energía diario promedio por distintos periodos del 2018,

A partir del comportamiento diario del consumo energético del 2018, se establece el pronóstico de los consumos diarios para los diferentes periodos del año 2019, como lo muestra la Figura 223.

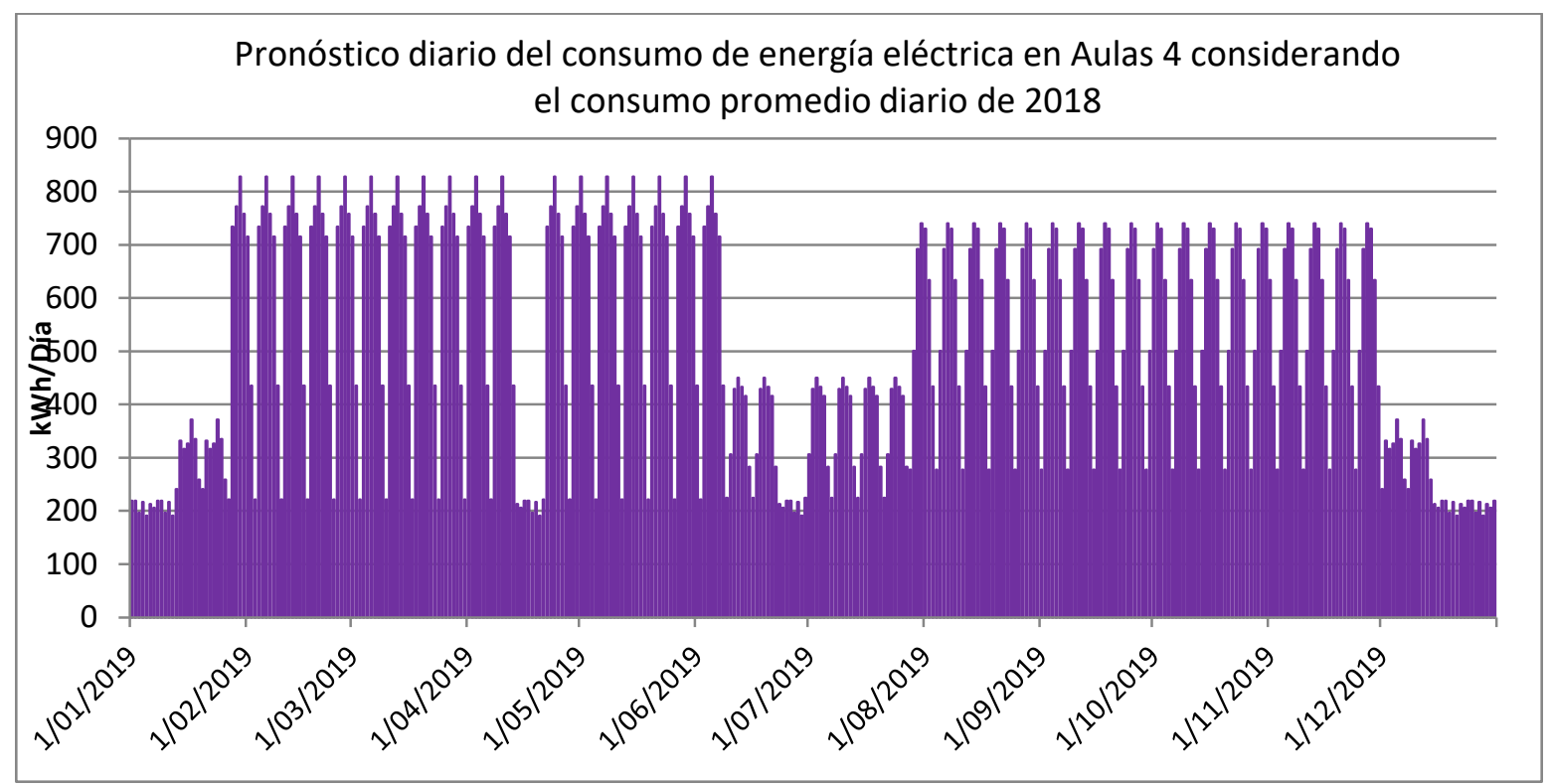

Figura 223. Pronóstico diario del consumo de energía eléctrica considerando el consumo promedio diario de 2018

Semanalmente se espera que los consumos energéticos sean los presentados en la Figura 224. 
Pronóstico semanal del consumo de energía eléctrica en Aulas 4 considerando el consumo promedio diario de 2018

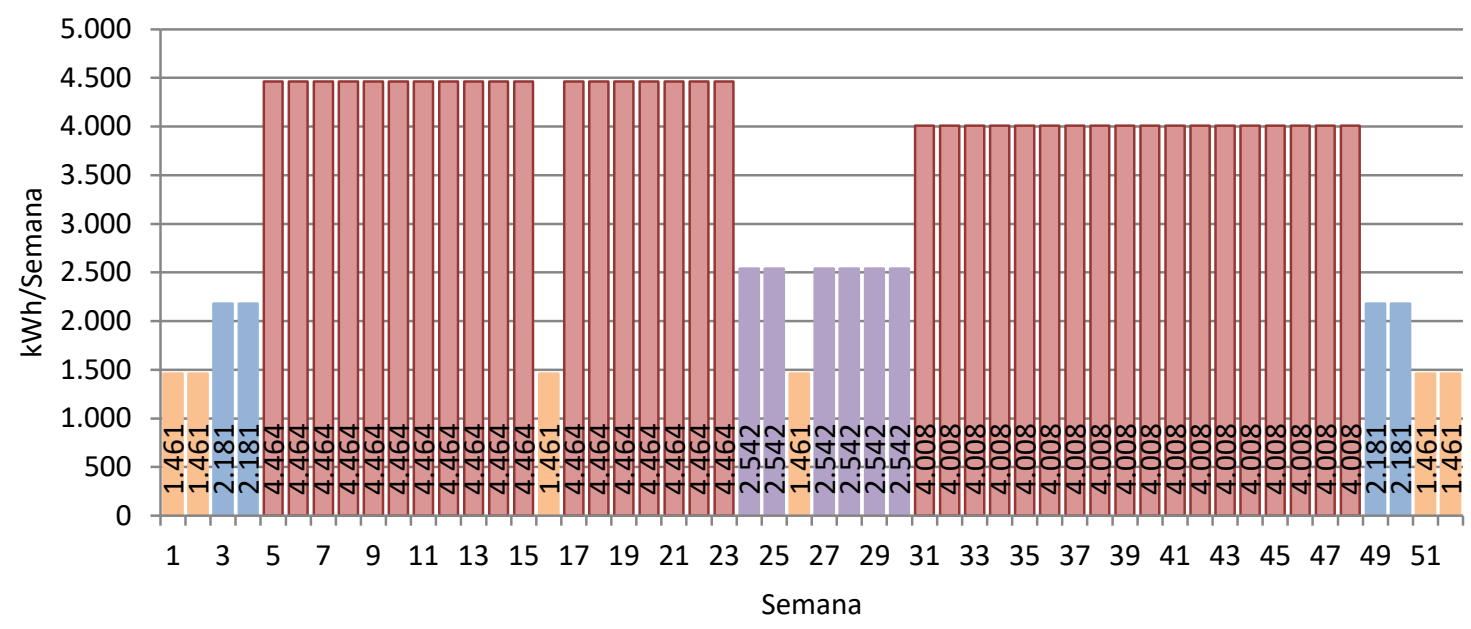

Figura 224. Pronóstico semanal del consumo de energía eléctrica considerando el consumo promedio diario de 2018

A partir del pronóstico semanal obtenido anteriormente, se puede estimar el pronóstico mensual presentado en la Tabla 87 y la Figura 225.

Tabla 87. Línea base - consumo promedio según programación

\begin{tabular}{|c|c|}
\multicolumn{2}{|c|}{$\begin{array}{c}\text { Línea de base energética } \\
\text { mensual Año 2019 }\end{array}$} \\
\hline Mes & kWh/Mes \\
\hline ene-19 & 10178,62 \\
\hline feb-19 & 17856,71 \\
\hline mar-19 & 19228,21 \\
\hline abr-19 & 16359,01 \\
\hline may-19 & 20158,89 \\
\hline jun-19 & 11667,40 \\
\hline jul-19 & 12152,20 \\
\hline ago-19 & 17830,02 \\
\hline sep-19 & 16810,70 \\
\hline oct-19 & 16724,73 \\
\hline nov-19 & 17100,00 \\
\hline dic-19 & 7920,03 \\
\hline
\end{tabular}

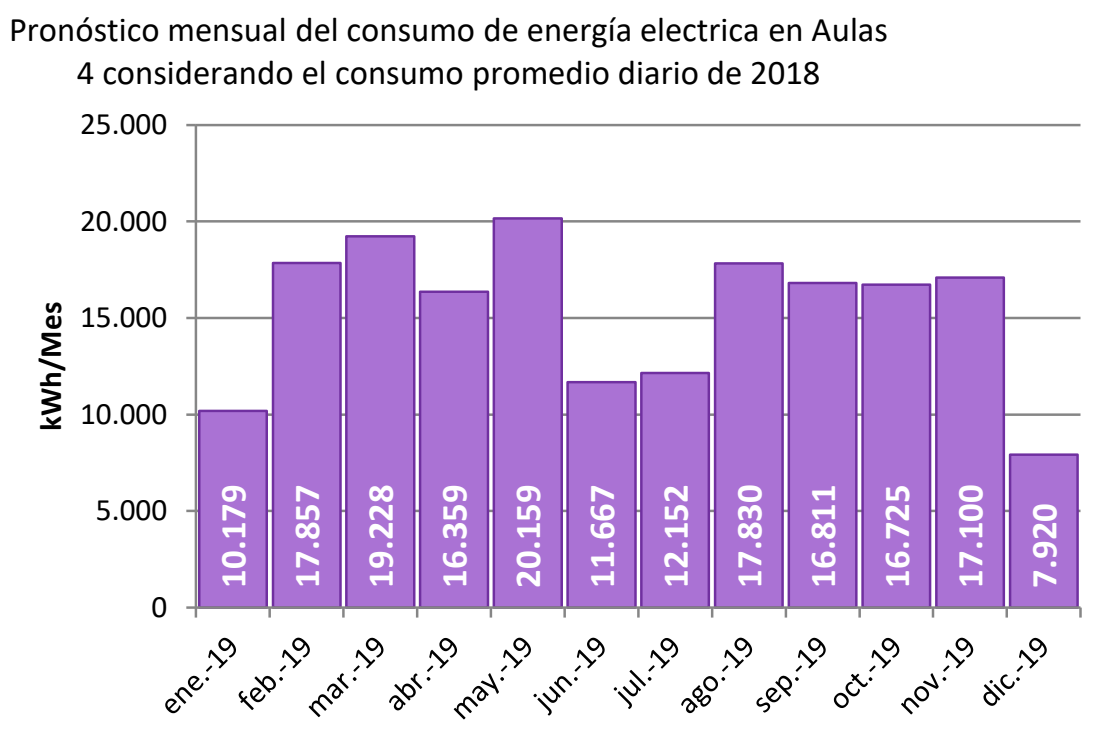

Figura 225. Línea base - consumo promedio según programación académica 
A continuación, se presentan de forma resumida los 6 modelos de series de tiempo obtenidos para el pronóstico mensual del consumo de energía en el edificio de Aulas. La Tabla 88 y la Figura 226 presentan los valores obtenidos en los diferentes modelos comparados con el consumo de energía real.

Tabla 88. Modelos de pronósticos implementados para determinar el consumo de energía de Aulas 4 en el 2019

\begin{tabular}{|c|c|c|c|c|c|c|c|c|c|c|c|c|c|}
\hline No & Enero & Febrero & Marzo & Abril & Mayo & Junio & Julio & Agosto & Sept & Oct & Nov & Dic & $\begin{array}{c}\text { Método } \\
\text { utilizado }\end{array}$ \\
\hline $\mathbf{1}$ & 9.369 & 19.136 & 18.186 & 18,346 & 18.855 & 8.774 & 11.086 & 19.269 & 18.496 & 16.742 & 13.979 & 7.494 & $\begin{array}{c}\text { Promedio } \\
\text { mensual } \\
\text { histórico }\end{array}$ \\
\hline $\mathbf{2}$ & 10.110 & 19.050 & 18.508 & 18.350 & 18.993 & 9.682 & 11.980 & 19.149 & 18.448 & 17.044 & 14.199 & 8.222 & $\begin{array}{c}\text { Promedio } \\
\text { mensual } \\
\text { histórico } \\
\text { ponderado }\end{array}$ \\
\hline $\mathbf{3}$ & 9.918 & 20.257 & 19.252 & 19.422 & 19.960 & 9.288 & 11.736 & 20.398 & 19.581 & 17.723 & 14.799 & 7.934 & $\begin{array}{c}\text { Índices de } \\
\text { estacionalidad }\end{array}$ \\
\hline $\mathbf{4}$ & 15.699 & 15.381 & 15.358 & 15.476 & 15.182 & 15.236 & 15.376 & 15.921 & 16.346 & 16.715 & 17.038 & 17.281 & $\begin{array}{c}\text { Media móvil } \\
\text { (n=12) }\end{array}$ \\
\hline $\mathbf{5}$ & 10.054 & 17.857 & 19.770 & 16.129 & 19.770 & 12.334 & 12.640 & 17.459 & 16.896 & 17.459 & 16.896 & 7.909 & $\begin{array}{c}\text { Considerando } \\
\text { programación } \\
\text { semanal }\end{array}$ \\
\hline $\mathbf{6}$ & 10.179 & 17.857 & 19.228 & 16.359 & 20.159 & 11.667 & 12.152 & 17.830 & 16.811 & 16.725 & 17.100 & 7.920 & $\begin{array}{c}\text { Consumos } \\
\text { diarios }\end{array}$ \\
\hline $\begin{array}{l}\text { Valor } \\
\text { Real }\end{array}$ & 8.157 & 18.339 & 19.271 & 15.445 & 18.876 & 12.135 & 20.271 & 24.242 & 22.723 & 21.390 & 17.109 & 10.418 & $\begin{array}{c}\text { Mediciones } \\
\text { mensuales } \\
\text { (Año 2019) }\end{array}$ \\
\hline
\end{tabular}

Resultados obtenidos con los diferentes métodos de pronóstico utilizados para obtener una línea de base energética 2019 de Aulas 4-UAO

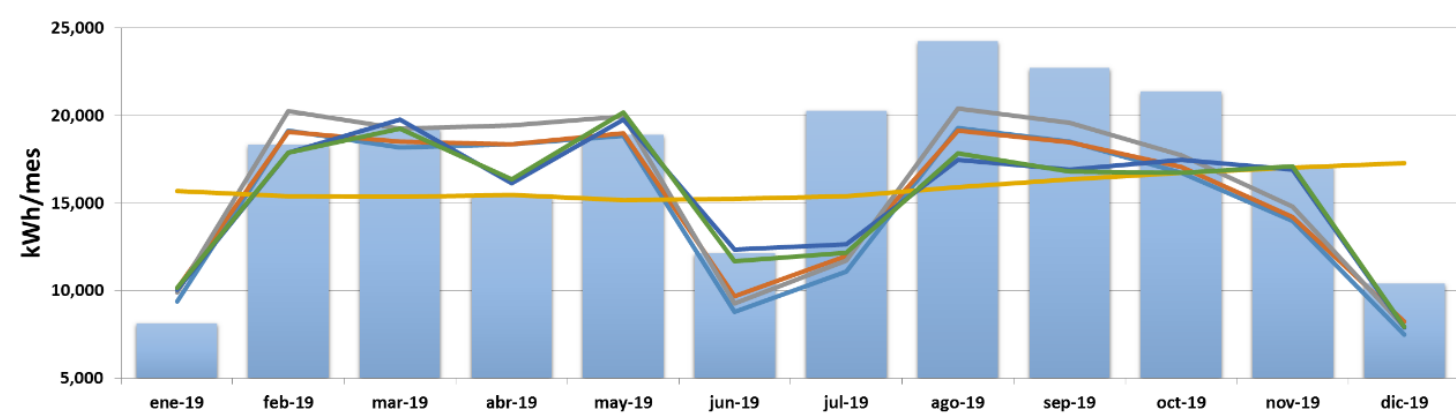

- Valor Real (Año 2019)

—Media movil (n=12)

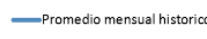

—Promedio mensual historico ponderado

—indices de estacionalidad

Figura 226. Resultados obtenidos con los diferentes métodos de pronóstico utilizados para obtener una línea de base energética 2019 de Aulas 4-UAO

Para realizar una comparación entre los distintos modelos de pronósticos utilizados se utilizó el error porcentual medio absoluto (MAPE) que entrega la desviación en términos porcentuales y se presenta en la Tabla 89. 
CAPÍTULO 7: DESARROLLO DE LA METODOLOGÍA PARA ESTIMAR LÍNEAS BASES E INDICADORES

Tabla 89. Error Absoluto Porcentual MAPE de los modelos de series de tiempo

\begin{tabular}{|c|c|c|c|c|c|c|c|c|c|c|c|c|c|}
\hline \multirow[b]{2}{*}{2019} & \multirow{2}{*}{$\begin{array}{c}\text { Consumo } \\
\text { Real }\end{array}$} & \multicolumn{2}{|c|}{ Modelo 1} & \multicolumn{2}{|c|}{ Modelo 2} & \multicolumn{2}{|c|}{ Modelo 3} & \multicolumn{2}{|c|}{ Modelo 4} & \multicolumn{2}{|c|}{ Modelo 5} & \multicolumn{2}{|c|}{ Modelo 6} \\
\hline & & $\begin{array}{l}\text { Consumo } \\
\text { Estimado }\end{array}$ & MAPE & $\begin{array}{l}\text { Consumo } \\
\text { Estimado }\end{array}$ & MAPE & $\begin{array}{l}\text { Consumo } \\
\text { Estimado }\end{array}$ & MAPE & $\begin{array}{l}\text { Consumo } \\
\text { Estimado } \\
\end{array}$ & MAPE & $\begin{array}{l}\text { Consumo } \\
\text { Estimado }\end{array}$ & MAPE & $\begin{array}{l}\text { Consumo } \\
\text { Estimado }\end{array}$ & MAPE \\
\hline Ene & 8157 & 9369 & $14,9 \%$ & 10110 & $23,9 \%$ & 9918 & $21,6 \%$ & 15699 & $92,5 \%$ & 10054 & $23,3 \%$ & 10179 & $24,8 \%$ \\
\hline Feb & 18339 & 19136 & $4,3 \%$ & 19050 & $3,9 \%$ & 20257 & $10,5 \%$ & 15381 & $16,1 \%$ & 17857 & $2,6 \%$ & 17857 & $2,6 \%$ \\
\hline Mar & 19271 & 18186 & $5,6 \%$ & 18508 & $4,0 \%$ & 19252 & $0,1 \%$ & 15358 & $20,3 \%$ & 19770 & $2,6 \%$ & 19228 & $0,2 \%$ \\
\hline Abr & 15445 & 18346 & $18,8 \%$ & 18350 & $18,8 \%$ & 19422 & $25,7 \%$ & 15476 & $0,2 \%$ & 16129 & $4,4 \%$ & 16359 & $5,9 \%$ \\
\hline May & 18876 & 18855 & $0,1 \%$ & 18993 & $0,6 \%$ & 19960 & $5,7 \%$ & 15182 & $19,6 \%$ & 19770 & $4,7 \%$ & 20159 & $6,8 \%$ \\
\hline Jun & 12135 & 8774 & $27,7 \%$ & 9682 & $20,2 \%$ & 9288 & $23,5 \%$ & 15236 & $25,6 \%$ & 12334 & $1,6 \%$ & 1667 & $3,8 \%$ \\
\hline Jul & 20271 & 11086 & $45,3 \%$ & 11980 & $40,9 \%$ & 11736 & $42,1 \%$ & 15376 & $24,1 \%$ & 12640 & $37,6 \%$ & 152 & $40,1 \%$ \\
\hline Ago & 24242 & 19269 & $20,5 \%$ & 149 & $21,0 \%$ & 20398 & $15,9 \%$ & 15921 & $34,3 \%$ & 459 & $28,0 \%$ & 830 & $26,5 \%$ \\
\hline Sep & 22723 & 18496 & $18,6 \%$ & 3448 & $18,8 \%$ & 19581 & $13,8 \%$ & 16346 & $28,1 \%$ & 896 & $25,6 \%$ & 811 & $26,0 \%$ \\
\hline Oct & 21390 & 742 & $21,7 \%$ & 7044 & $20,3 \%$ & 7723 & $17,1 \%$ & 16715 & $21,9 \%$ & כנJ4 & $18,4 \%$ & 725 & $21,8 \%$ \\
\hline Nov & 17109 & 13979 & $18,3 \%$ & 14199 & $17,0 \%$ & 14799 & $13,5 \%$ & 17038 & $0,4 \%$ & 16896 & $1,2 \%$ & 17100 & $0,1 \%$ \\
\hline Dic & 10418 & 494 & $28,1 \%$ & 22 & $21,1 \%$ & 34 & $23,8 \%$ & 7281 & $65,9 \%$ & 909 & $24,1 \%$ & 920 & $24,0 \%$ \\
\hline \multicolumn{2}{|c|}{$\begin{array}{l}\text { Medida de } \\
\text { Error }\end{array}$} & \multicolumn{2}{|c|}{ MAPE } & \multicolumn{2}{|c|}{ MAPE } & \multicolumn{2}{|c|}{ MAPE } & \multicolumn{2}{|c|}{ MAPE } & \multicolumn{2}{|c|}{ MAPE } & \multicolumn{2}{|c|}{ MAPE } \\
\hline \multicolumn{2}{|r|}{ Valor } & \multicolumn{2}{|c|}{$18,66 \%$} & \multicolumn{2}{|c|}{$17,55 \%$} & \multicolumn{2}{|c|}{$17,78 \%$} & \multicolumn{2}{|c|}{$29,08 \%$} & \multicolumn{2}{|c|}{$14,52 \%$} & \multicolumn{2}{|c|}{$15,21 \%$} \\
\hline
\end{tabular}

\subsubsection{Modelos de Regresión Lineal y Multivariable}

Para construir un modelo de regresión confiable, primero se debe identificar las variables independientes que pueden tener una alta relación con la variable que se pretende explicar. Con ayuda del software R Studio se obtuvieron los niveles de correlación [5] - [7] de las variables independientes (Temperatura, Humedad, Radiación, Ocupación Total) que se presenta en la Tabla 90 con respecto a la variable dependiente (Consumo de energía final Total).

Tabla 90. Información mensual de variables monitoreadas en el edificio para el 2017

\begin{tabular}{|c|c|c|c|c|c|}
\hline Mes/Variable & $\begin{array}{c}\text { Temperatura } \\
{\left[{ }^{\circ} \mathbf{C}\right]}\end{array}$ & $\begin{array}{c}\text { Humedad } \\
{[\%]}\end{array}$ & $\begin{array}{c}\text { Radiación } \\
{[\mathbf{W} / \mathbf{m} 2]}\end{array}$ & $\begin{array}{c}\text { Ocupación } \\
{[\text { horas] }}\end{array}$ & $\begin{array}{c}\text { Consumo Total } \\
{[\mathbf{k W h}]}\end{array}$ \\
\hline Enero & 24,129 & 75,093 & 365,254 & 5756,67 & 8621 \\
\hline Febrero & 24,905 & 69,847 & 392,134 & 19698,50 & 19672 \\
\hline Marzo & 23,537 & 78,989 & 367,483 & 18293,17 & 20782 \\
\hline Abril & 23,637 & 78,141 & 400,491 & 22503,40 & 17120 \\
\hline Mayo & 23,495 & 79,716 & 399,974 & 25312,50 & 20919 \\
\hline Junio & 24,461 & 75,431 & 396,705 & 2498,20 & 10869 \\
\hline Julio & 24,221 & 74,353 & 399,624 & 4835,00 & 11163 \\
\hline Agosto & 26,768 & 64,531 & 480,902 & 6859,50 & 18805 \\
\hline Septiembre & 25,122 & 73,537 & 458,310 & 8278,50 & 18620 \\
\hline
\end{tabular}




\begin{tabular}{|c|c|c|c|c|c|} 
Octubre & 24,080 & 77,239 & 361,803 & 18036,17 & 17007 \\
\hline Noviembre & 24,015 & 78,182 & 376,114 & 17375,33 & 14861 \\
\hline Diciembre & 24,126 & 77,246 & 362,676 & 1238,50 & 8023 \\
\hline
\end{tabular}

La Figura 227, presenta la correlación entre las variables, donde se evidencia que la variable independiente que mayor correlación tiene con la variable dependiente, es la ocupación total, con una correlación del 75\%, seguida de la radiación con el 38\% de correlación.

\begin{tabular}{lrrrrr}
\multicolumn{7}{l}{ round(cor(X2017_Mensua1), 2) } & & & \\
\multicolumn{1}{l}{ Temperatura } & Humedad & Radiación & Ocupación & Tota1 & Consumo Tota1 \\
Temperatura & 1.00 & -0.95 & 0.80 & -0.42 & 0.12 \\
Humedad & -0.95 & 1.00 & -0.70 & 0.36 & -0.11 \\
Radiación & 0.80 & -0.70 & 1.00 & -0.17 & 0.38 \\
Ocupación Tota1 & -0.42 & 0.36 & -0.17 & 1.00 & 0.75 \\
Consumo Tota1 & 0.12 & -0.11 & 0.38 & 0.75 & 1.00
\end{tabular}

Figura 227. Correlación entre variables - Software R Studio

La Figura 228 presenta gráficamente la relación entre las variables y su significancia estadística (asteriscos rojos). La variable con mayor relación y significancia estadística, que permite describir la variable Consumo de energía Total, es la variable independiente Ocupación Total.

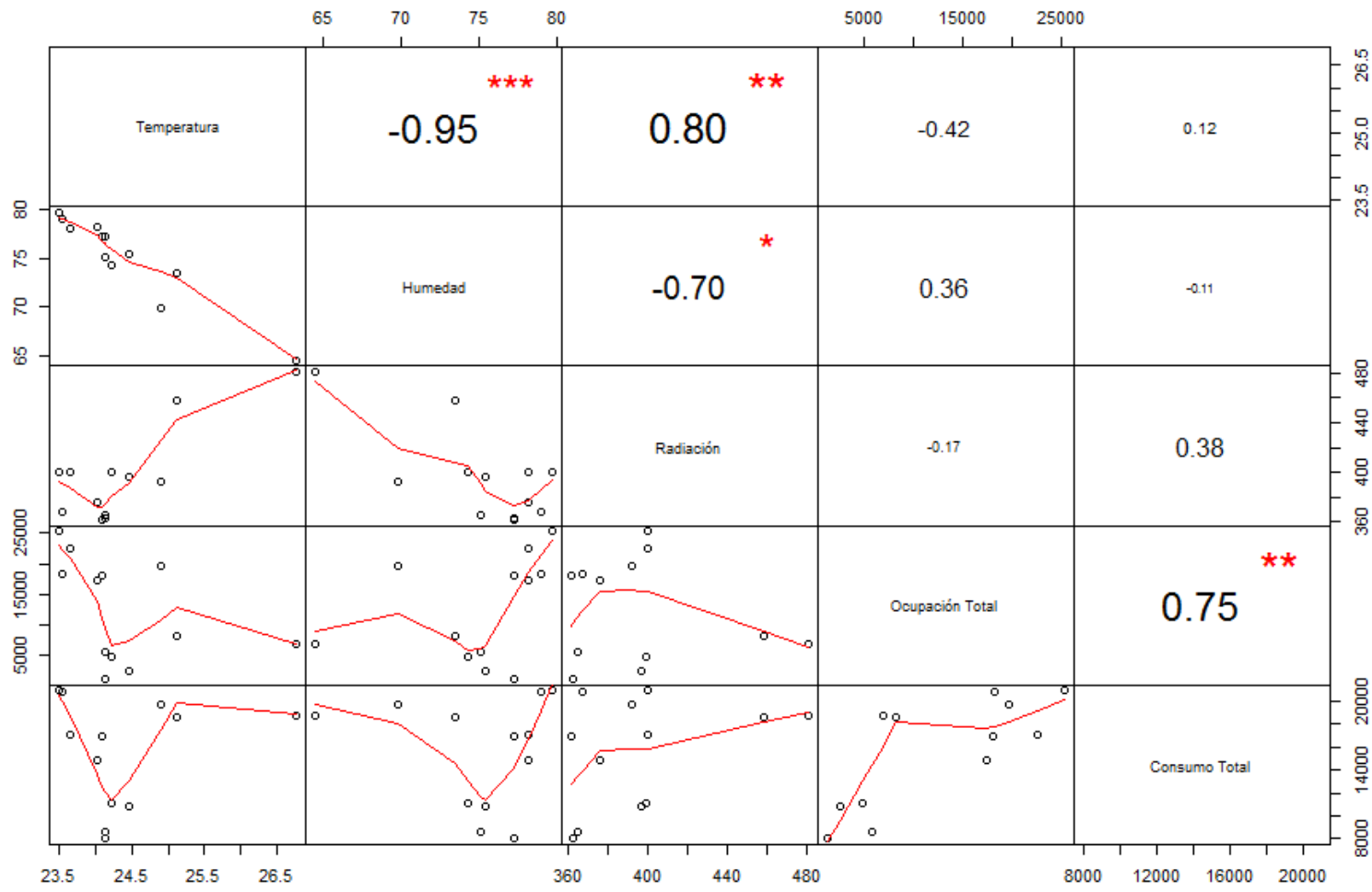

Figura 228. Correlación entre el Consumo de energía final Total y las variables independientes Software R Studio 
Para continuar con el análisis se parte de la construcción de unos modelos de pronóstico que utiliza datos de consumo de energía eléctrica y de variables relevantes para el período de referencia, bajo el siguiente modelo:

$$
\text { Electricidad }_{\text {lineabase }}=\beta_{0} X+\beta+\varepsilon_{i}
$$

Donde:

Electricidad $_{\text {lineabase }}=$ Consumo de electricidad observado durante el período de referencia.

$\beta=$ intercepción del modelo de pronóstico.

$\beta_{0}=$ coeficiente de la variable independiente en el modelo de pronóstico.

$X_{\text {lineaBase }}=$ valor observado en el período de referencia de la variable.

$\varepsilon_{i}=$ término de error del modelo de pronóstico.

Para garantizar que el modelo de pronóstico desarrollado tenga validez [8], se realizan una serie de pruebas estadísticas que tienen en cuenta:

$\checkmark$ La función de regresión es no lineal.

$\checkmark$ Los términos de error no se distribuyen normalmente.

$\checkmark$ Los términos de error tienen varianza no constante.

$\checkmark$ Los términos de error no son independientes.

$\checkmark$ Las variables independientes no se relacionan entre sí (para el caso multivariable)

La Tabla 91. presenta los detalles de cumplimiento de los diferentes supuestos estadísticos, según su prueba y representación gráfica.

Tabla 91. Supuestos y pruebas de verificación para los modelos de regresión

\begin{tabular}{|c|c|c|}
\hline Supuestos & Prueba & Cumplimiento de la Prueba \\
\hline Linealidad & Gráfica & $\begin{array}{c}\text { Distribución aleatoria con } \\
\text { respecto al } 0\end{array}$ \\
\hline Normalidad & Shapiro Wilks & P.value $\geq 0,05$ \\
\hline Homocedasticidad & Breusch Pagan & P.value $\geq 0,05$ \\
\hline Independencia & Durbin Watson & P.value $\geq 0,05$ \\
\hline Multicolinealidad & $\begin{array}{c}\text { Factor de inflación de la varianza } \\
\text { (FIV) }\end{array}$ & FIV $\leq 10$ \\
\hline
\end{tabular}

Con ayuda de la herramienta estadística R Studio [9], [10], se realizó la construcción y validación de los modelos de regresión lineal univariable y multivariable. 


\subsubsection{Modelo de Regresión Lineal Univariable}

Se construyeron 4 modelos de regresión lineal univariable, con las diferentes variables (Temperatura, Humedad, Radiación y Ocupación Total). Esto, con el fin de validar lo obtenido en la Figura 228. donde se obtuvo que la variable más relevante es la Ocupación Total.

\section{Modelo 1:}

Variable dependiente: Consumo Total Variable independiente: Temperatura

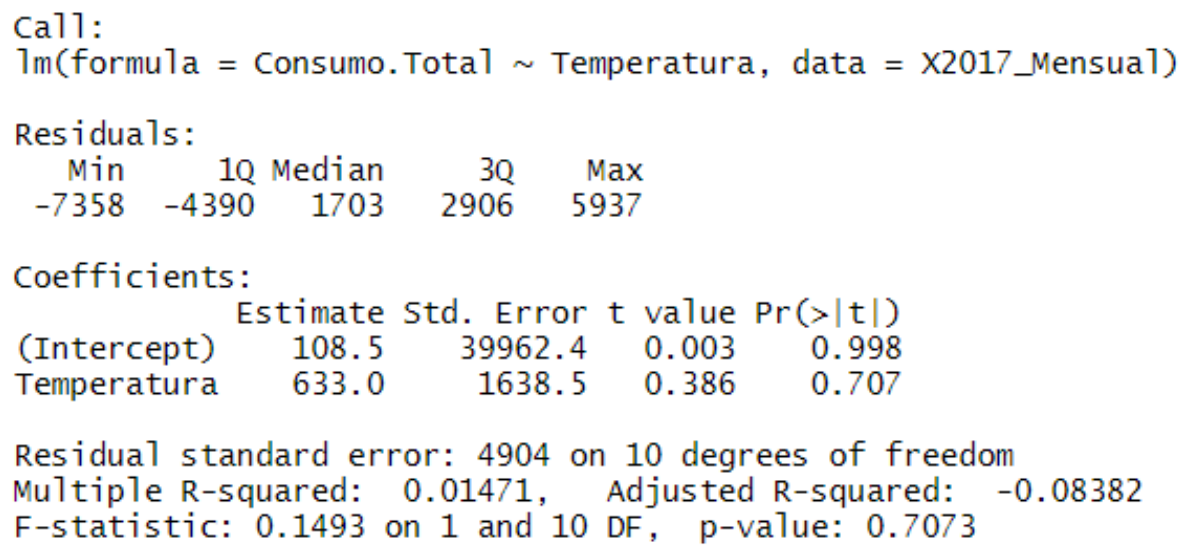

El modelo desarrollado se describe como:

$$
\text { Electricidad }_{\text {lineabase }}=633,0 \cdot \text { Temperatura }+108,5+\varepsilon_{i}
$$

El modelo tiene un coeficiente de determinación $R^{2}=0,0147$ que indica que el modelo explica el $1,47 \%$ de la variabilidad de las observaciones (datos). Al tener un valor de $R^{2} \tan$ bajo (el valor varía entre $0 \%$ y $100 \%$ ), indicando que el modelo no se ajusta de buena forma a los datos $y$, por lo tanto, la Temperatura no describe significativamente el comportamiento del Consumo Total. 


\section{Modelo 2:}

Variable dependiente: Consumo Total

Variable independiente: Humedad

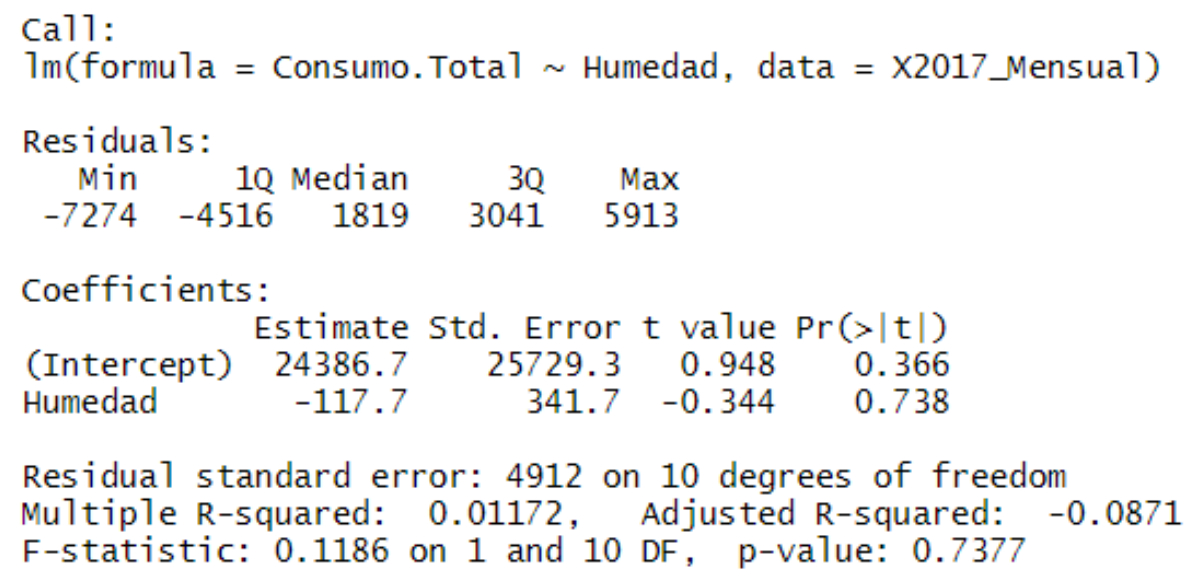

El modelo desarrollado se describe como:

$$
\text { Electricidad }_{\text {lineabase }}=-117,7 \cdot \text { Humedad }+24,86,7+\varepsilon_{i}
$$

El modelo tiene un coeficiente de determinación $R^{2}=0,0117$, lo que indica que el mismo solo explica el $1,17 \%$ de la variabilidad de las observaciones (datos). Al tener un valor de $R^{2}$ tan bajo (el valor de varía entre $0 \%$ y $100 \%$ ), enseña que el modelo no se ajusta de buena forma a los datos $y$, por lo tanto, la Humedad no describe significativamente el comportamiento del Consumo Total.

\section{Modelo 3:}

Variable dependiente: Consumo Total

Variable independiente: Radiación

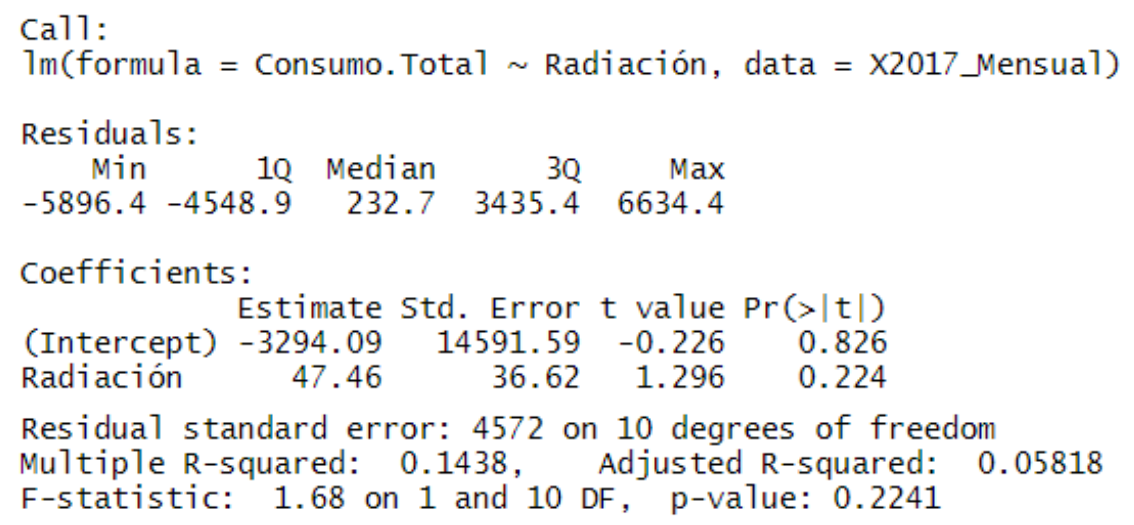

El modelo desarrollado se describe como:

$$
\text { Electricidad }_{\text {lineabase }}=47,46 \cdot \text { Radiación }-3294,09+\varepsilon_{i}
$$


El modelo tiene un coeficiente de determinación $R^{2}=0,1438$ que indica que el modelo alcanza a explicar el $14,38 \%$ de la variabilidad de las observaciones (datos). Al tener un valor de $R^{2}$ tan bajo (el valor de varía entre $0 \%$ y $100 \%$ ), indica que el modelo no se ajusta de buena forma a los datos y, por lo tanto, la Radiación no describe significativamente el comportamiento del Consumo Total.

\section{Modelo 4:}

Variable dependiente: Consumo Total

Variable independiente: Ocupación

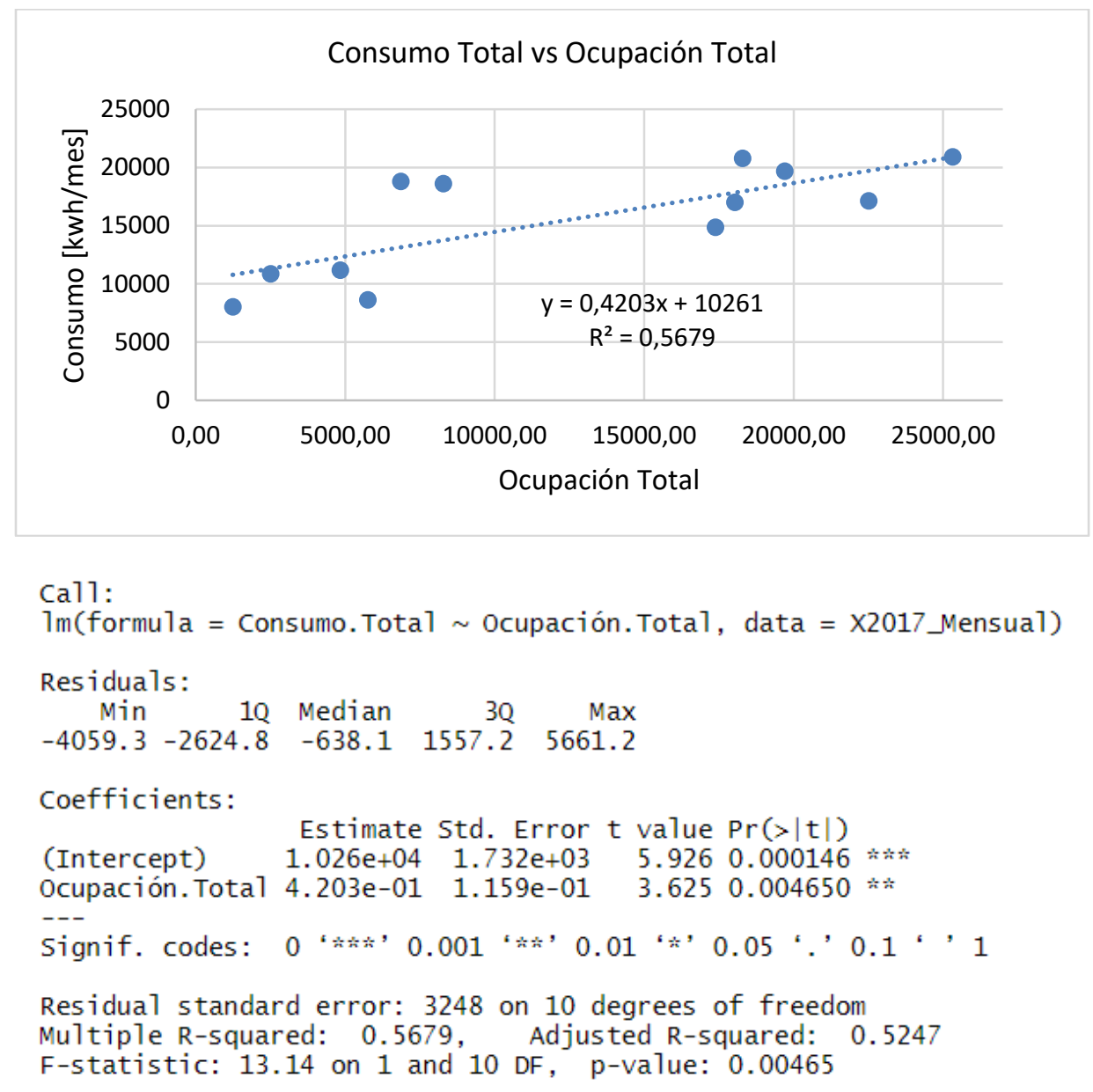

El modelo desarrollado se describe como:

$$
\text { Electricidad }_{\text {lineabase }}=0,4203 \cdot \text { Ocupación }+10260+\varepsilon_{i}
$$

El modelo tiene un coeficiente de determinación $R^{2}=0,5679$ que indica que el modelo logra explicar el $56,79 \%$ de la variabilidad de las observaciones (datos). Un valor p de 0,00465 para el estadístico $\mathrm{F}$ que indica que la relación lineal es estadísticamente significativa $(0,00465<0,05)$. 
Como se esperaba, tras el análisis de correlación entre variables el modelo que mejor se ajusta y explica el comportamiento del Consumo Total de Energía corresponde a la variable independiente la Ocupación Total. Sin embargo, este modelo posee un coeficiente de determinación un poco bajo. Por tal razón, se aplicó el método de los residuales con el fin de filtrar algunos datos atípicos y conseguir que el coeficiente de determinación $R^{2}$ mejorara. La técnica de los residuales para el filtrado consiste en calcular los residuos, los cuales se definen como la diferencia entre el valor observado $y$, que en este caso corresponde al valor medido del consumo real de la energía y el valor estimado por la línea base energética (LBEn) calculada, a partir de la regresión lineal, Ver anexo aplicación de la técnica de residuales [11].
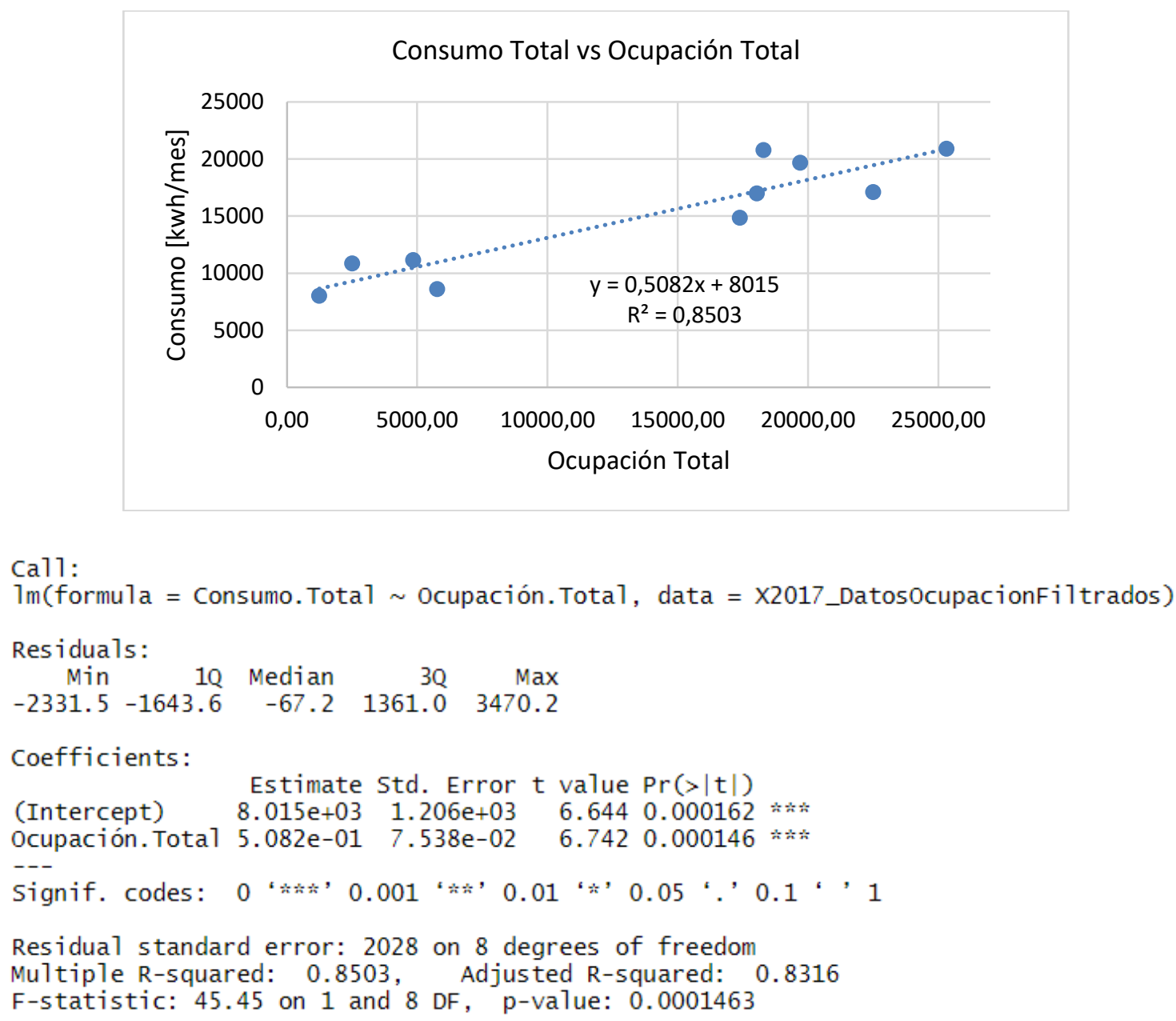

Ahora, el modelo desarrollado se describe como:

$$
\text { Electricidad }_{\text {lineabase }}=0,5082 \cdot \text { Ocupación }+8015+\varepsilon_{i}
$$

El modelo de regresión realizando procesos de filtrado, como el método de los residuales, permite aumentar el nivel de correlación a $R^{2}=0,8503$. En esta ocasión, el modelo permitió 
explicar el 85,03\% de la variabilidad de las observaciones (datos). De igual forma, se analizó el valor de $p$ de 0,0001 para el estadístico $F$, que indica que la relación lineal es estadísticamente significativa $(0,0001<0,05)$.

Los intervalos de confianza del modelo con un nivel de significancia entre 2,5\%- 97,5\%, Es decir un intervalo entre los cuales puede variar el modelo de regresión lineal univariable.

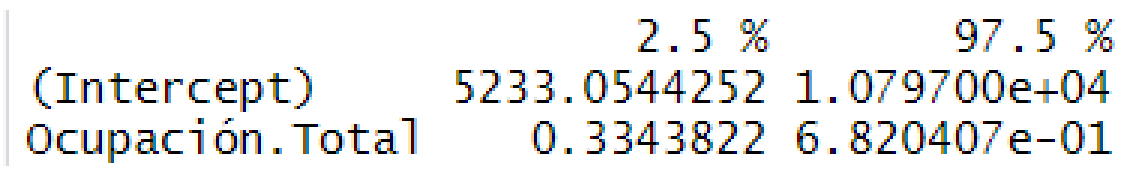

$$
\begin{aligned}
& \text { Electricidad }_{\text {lineabase }(2,5 \%)}=0,3343 \cdot \text { Ocupación }+5233,05+\varepsilon_{i} \\
& \text { Electricidad }_{\text {lineabase }(97,5 \%)}=0,6820 \cdot \text { Ocupación }+10797+\varepsilon_{i}
\end{aligned}
$$

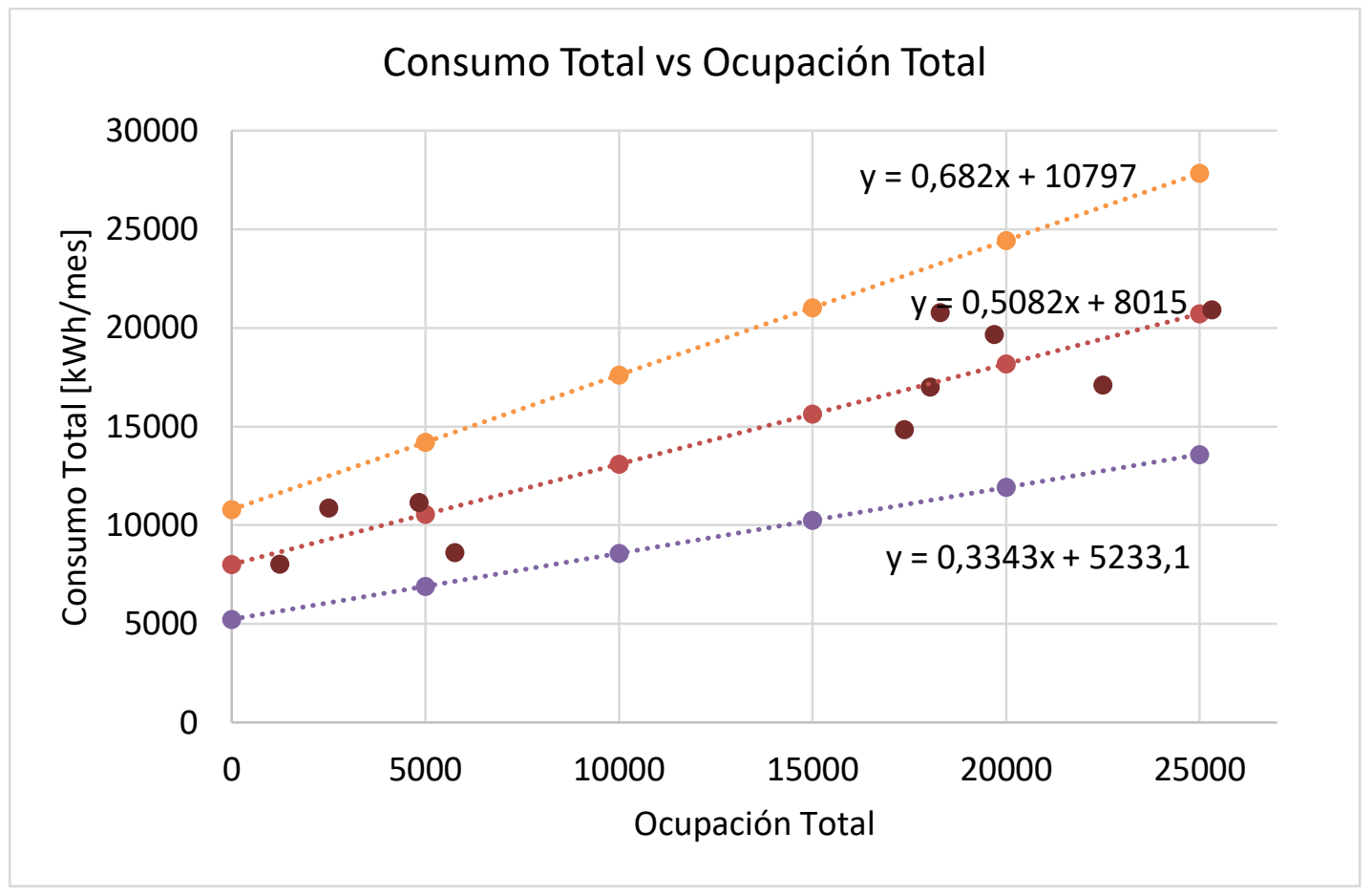

Para garantizar que el modelo desarrollado anteriormente es válido, se realizan las pruebas de los supuestos estadísticos mencionados. 


\section{a. Linealidad}

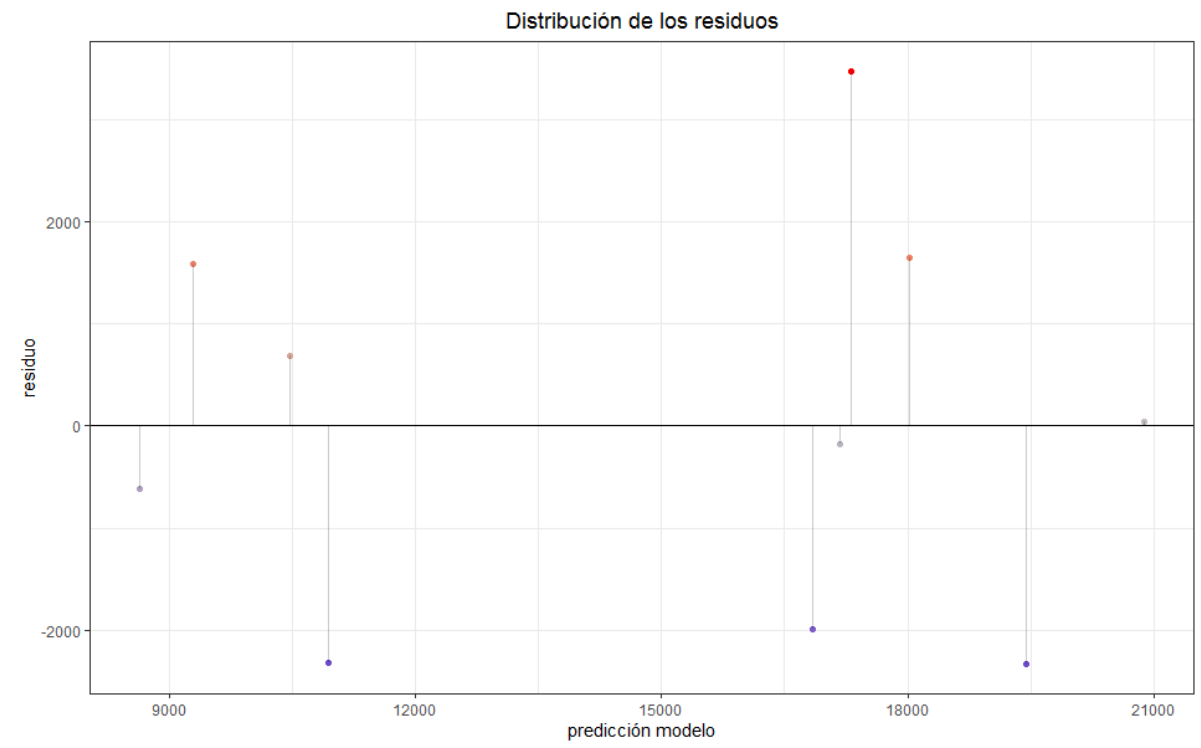

La gráfica de distribución de los residuos, muestra que los mismos se distribuyen de forma aleatoria en torno al 0 , por lo que se acepta el supuesto de linealidad.

\section{b. Normalidad}
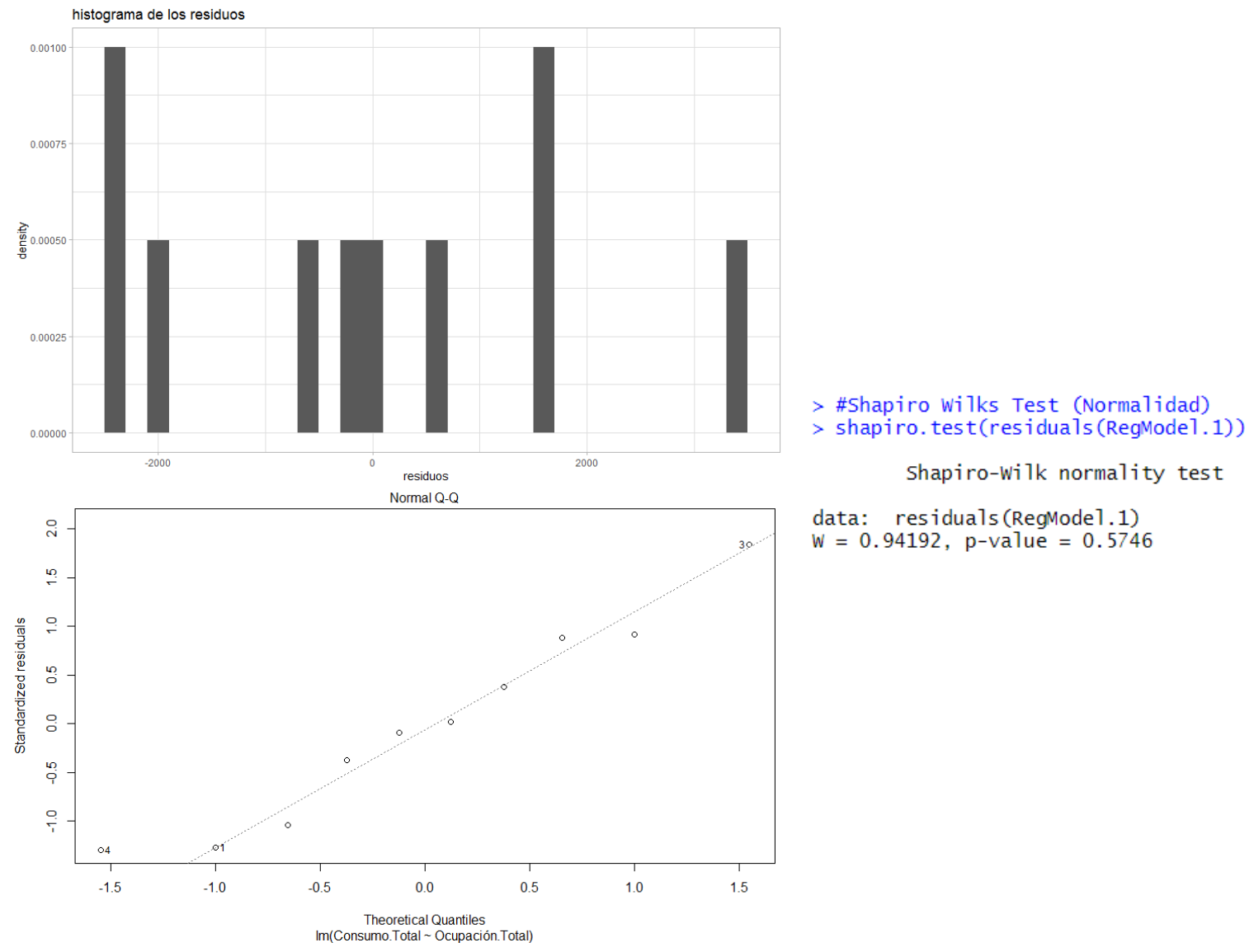

data: residuals (RegMode1.1) $\mathrm{W}=0.94192, \mathrm{p}$-value $=0.5746$ 
A través del histograma se presenta que los residuos se distribuyen de forma normal con media 0 . El gráfico Q-Q que ubica los cuartiles de la distribución de la muestra respecto a los cuartiles del modelo de distribución normal, presenta que ambas distribuciones siguen un comportamiento sobre una línea recta y, por ende, se acepta el supuesto de linealidad, Además, el estadístico Shapiro Wilks obtiene un $P$ value de 0,5746 que resulta $\geq 0,05$.

Tanto la representación gráfica como el contraste de hipótesis confirman la distribución normal de los residuos.

\section{c. Homocedasticidad}

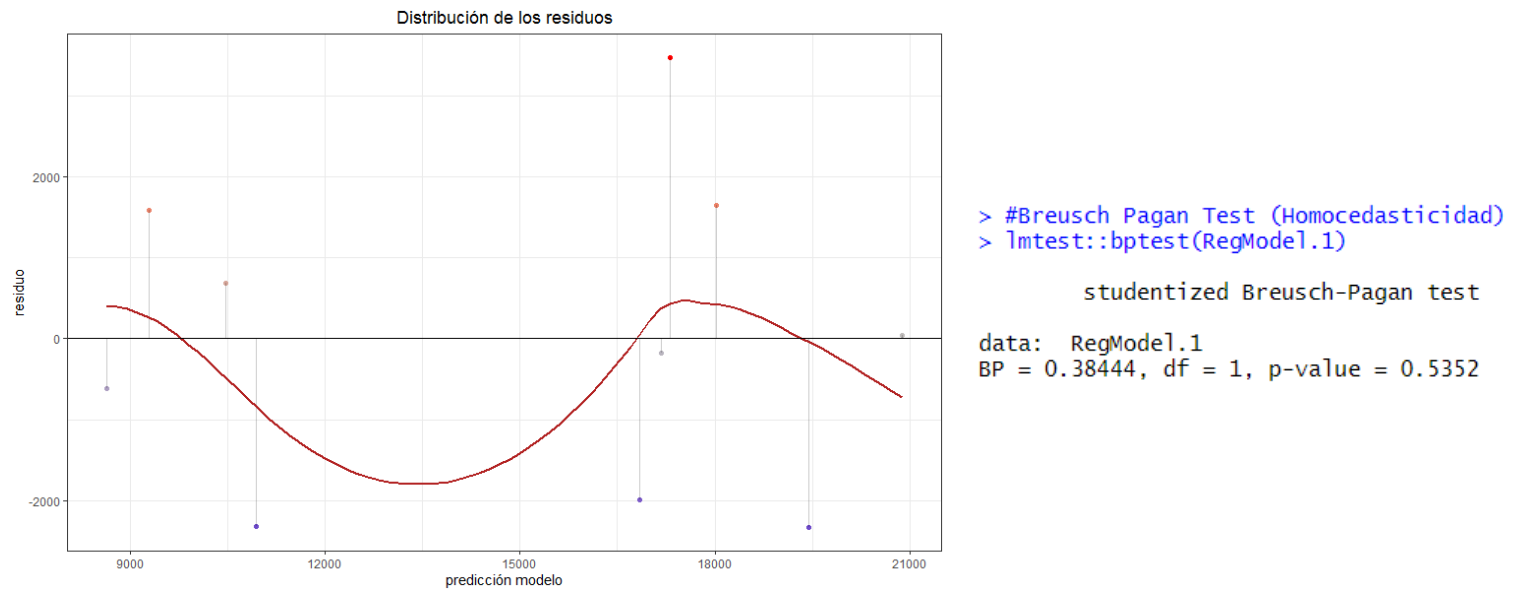

El análisis de la gráfica de distribución de los residuos visualiza que la variabilidad de los residuos es constante a lo largo del eje $X$ (el tamaño de los residuos no aumenta ni disminuye de forma sistémica ni significativa con variaciones de y) y la prueba estadística de Breusch Pagan, arroja un $P$ value de 0,5352 que resulta $\geq 0,05$.

$\mathrm{Ni}$ la representación gráfica ni el contraste de hipótesis muestran evidencias sobre la falta de homocedasticidad.

\section{d. Independencia}

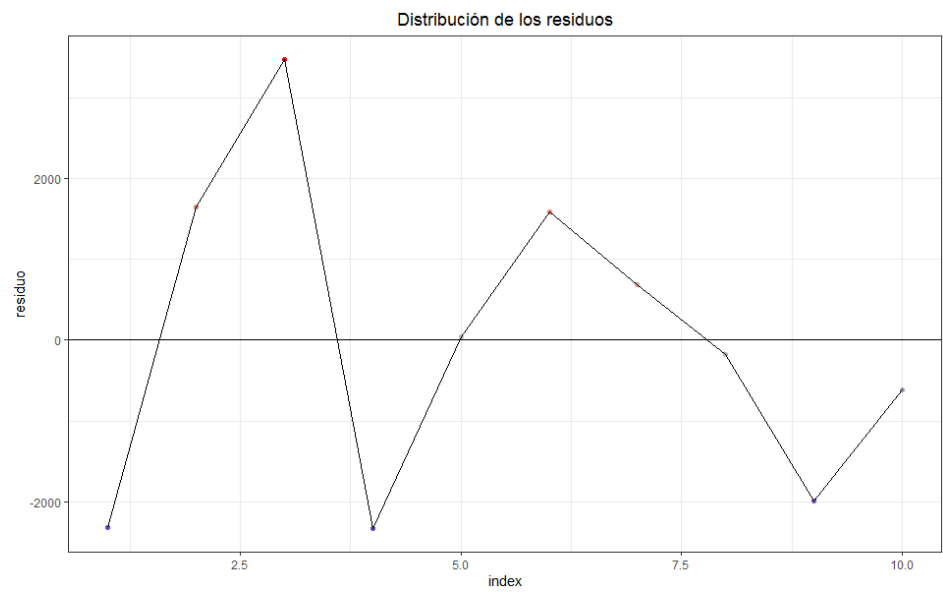

$>$ \#Durbin Watson Test (Independencia)

$>$ dwtest(RegMode1.1)

Durbin-watson test

data: RegModel.1

$\mathrm{DW}=2.048, \mathrm{p}$-value $=0.5002$ 
La representación gráfica de los residuos muestra que los residuos no tienen ninguna tendencia marcada y no poseen algún tipo de autocorrelación entre ellos, es decir, que son independientes. El estadístico de Durbin Watson, confirma que no hay problemas de independencia al obtenerse un $\mathrm{P}$ value de 0,5002 $\geq 0,05$.

Otra forma de verificar el cumplimiento de los supuestos estadísticos requeridos para que el modelo de regresión lineal univariable sea válido, es el uso de la herramienta gvima [12] (paquete en R Studio) que realiza una prueba global sobre el modelo lineal.

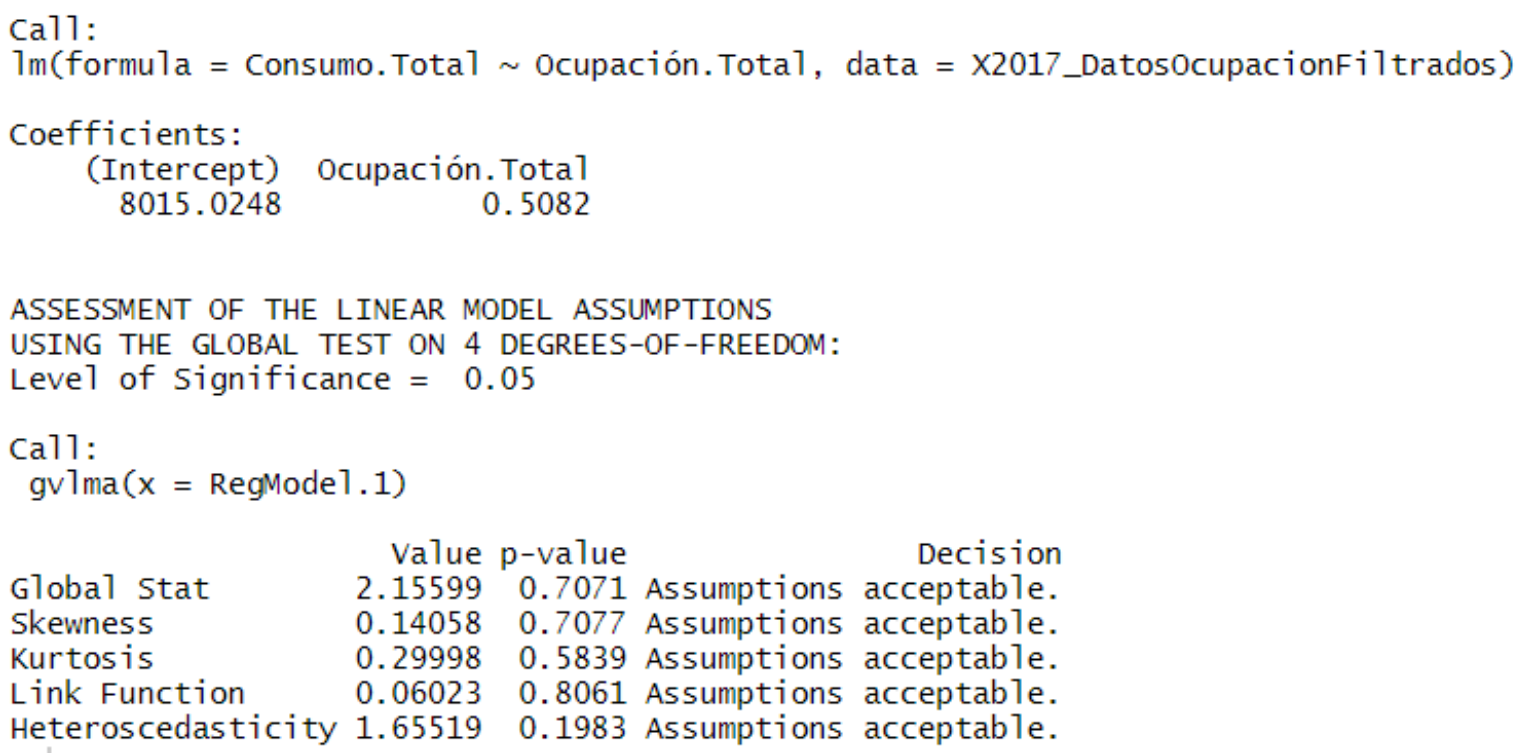

Los resultados de la prueba global (gvlma) confirman que todos los supuestos del modelo de regresión lineal univariable están comprobados. Es válido usar el modelo de regresión lineal para cuantificar el consumo de energía en función de la variable relevante independiente ("ocupación Total"). 


\subsubsection{Modelo de Regresión Lineal Multivariable}

Se construyó un modelo de regresión lineal multivariable con todas las variables disponibles (Temperatura, Humedad, Radiación y Ocupación Total)

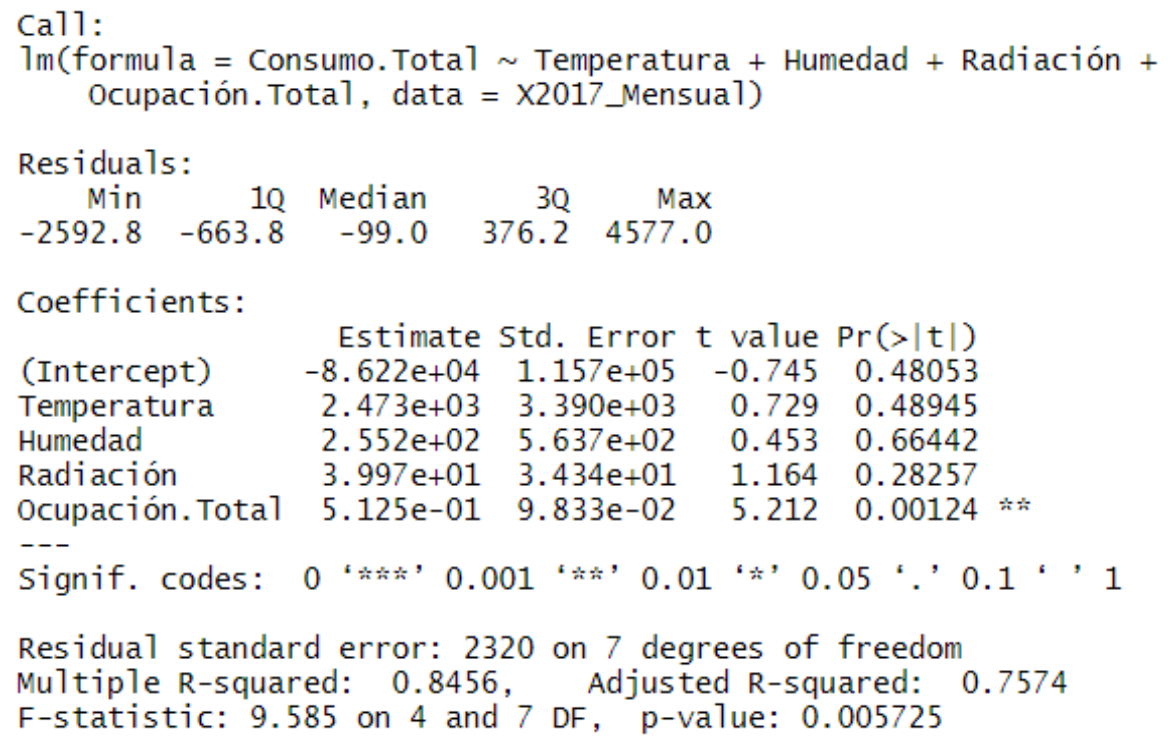

El análisis estadístico de las variables, muestra que las variables Temperatura, Humedad y Radiación no son significativas en el modelo, dado que su p value es mayor a 0,05. En este caso, la única variable significativa en el modelo es la variable ocupación.

Sin embargo, en este caso se busca obtener un modelo de regresión que integre más de 1 variable independiente, para conocer que variables son las más apropiadas para definir el modelo de regresión multivariable. De tal forma, se empleó la función step del software estadístico R Studio que permite realizar una regresión gradual, en tanto agrega y elimina iterativamente predictores (variables independientes) en el modelo de regresión. Lo anterior, para encontrar el subconjunto de variables que da como resultado el modelo con mejor rendimiento, siendo un modelo que reduce el error de predicción.

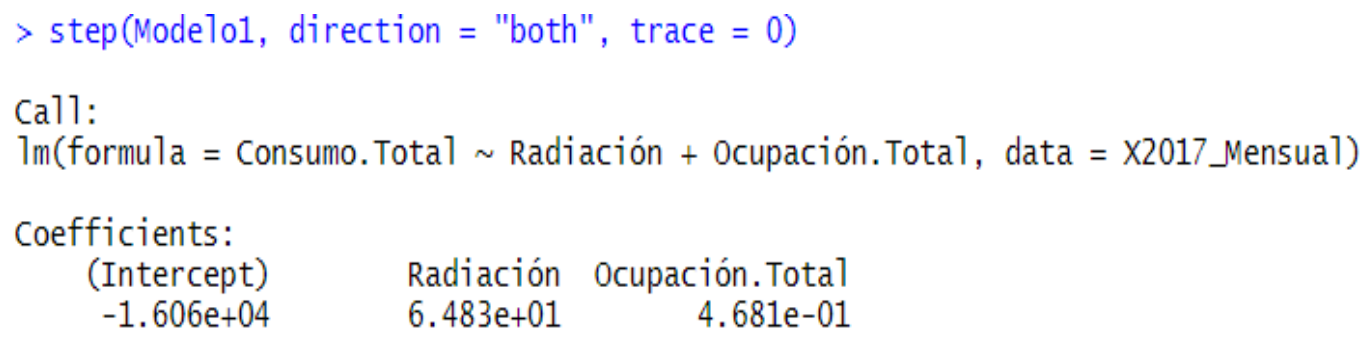

Empleando la función en los datos del modelo, se obtuvo que el mejor modelo de regresión lineal multivariable es el compuesto por las variables Radiación y Ocupación Total, dando así lugar al siguiente modelo: 


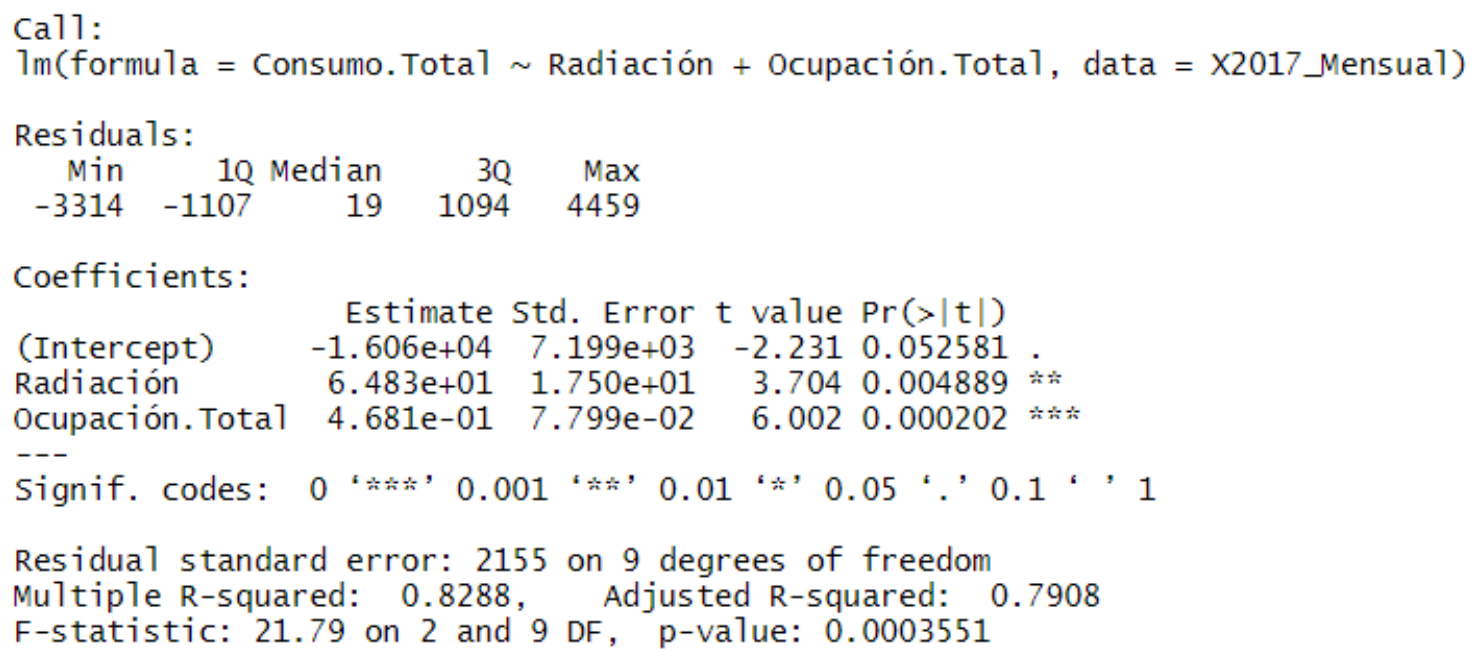

Ahora, el modelo desarrollado se describe como:

$$
\text { Electricidad }_{\text {lineabase }}=64,83 \cdot \text { Radiación }+0,4681 \cdot \text { Ocupación }-16060+\varepsilon_{i}
$$

El modelo tiene un $R^{2}$ Ajustado=0,7908 indica que el modelo explica el $79,08 \%$ de la variabilidad de las observaciones (datos). El valor de $R^{2}$ ajustado mide el porcentaje de la variación en la respuesta siendo explicada por el modelo, sin embargo, se ajusta al número de variables predictoras en el modelo. El modelo tiene un valor $p$ de 0,00035 para el estadístico $\mathrm{F}$ que indica que la relación lineal es estadísticamente significativa $(0,00035<0,05)$.

Otro elemento analizado son los intervalos de confianza del modelo que nos permite contar con dos ecuaciones, en la cual podría estar el rango de pronóstico del modelo de regresión lineal multivariable.

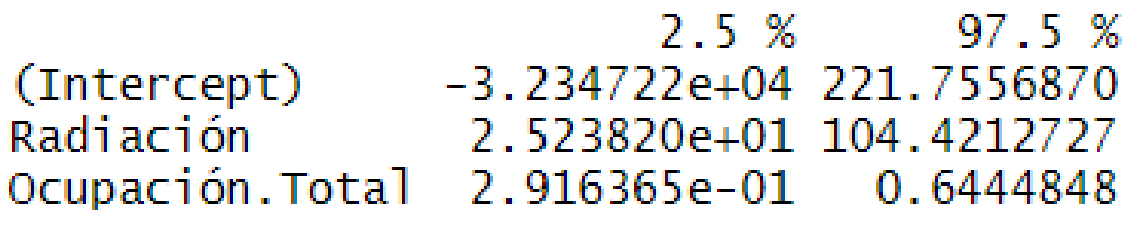

Electricidad $_{\text {lineabase }(2,5 \%)}=25,2382 \cdot$ Radiación $+0,2916 \cdot$ Ocupación $-32347,22+\varepsilon_{i}$ Electricidad $_{\text {lineabase }(97,5 \%)}=104,421 \cdot$ Radiación $+0,6444 \cdot$ Ocupación $+221,7556+\varepsilon_{i}$

Para garantizar que el modelo desarrollado es válido, se prueban los mismos supuestos estadísticos que para el modelo de regresión lineal univariable, adicionando la prueba de multicolinealidad. 


\section{a. Linealidad}

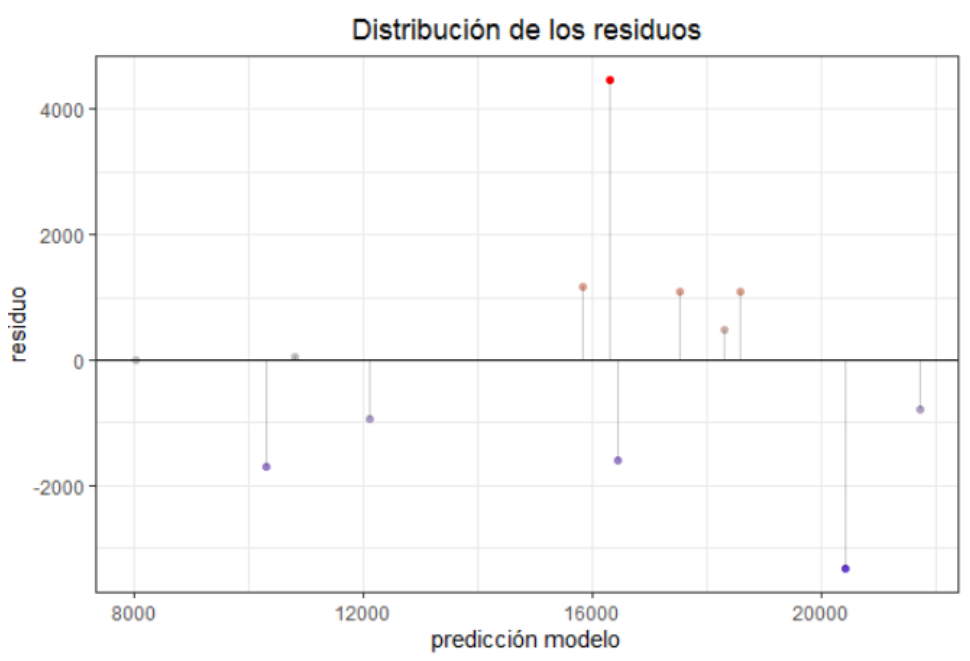

La gráfica de distribución de los residuos, muestra que los residuos se distribuyen de forma aleatoria en torno al 0 lo que permite aceptar el supuesto de linealidad.

\section{b. Normalidad:}
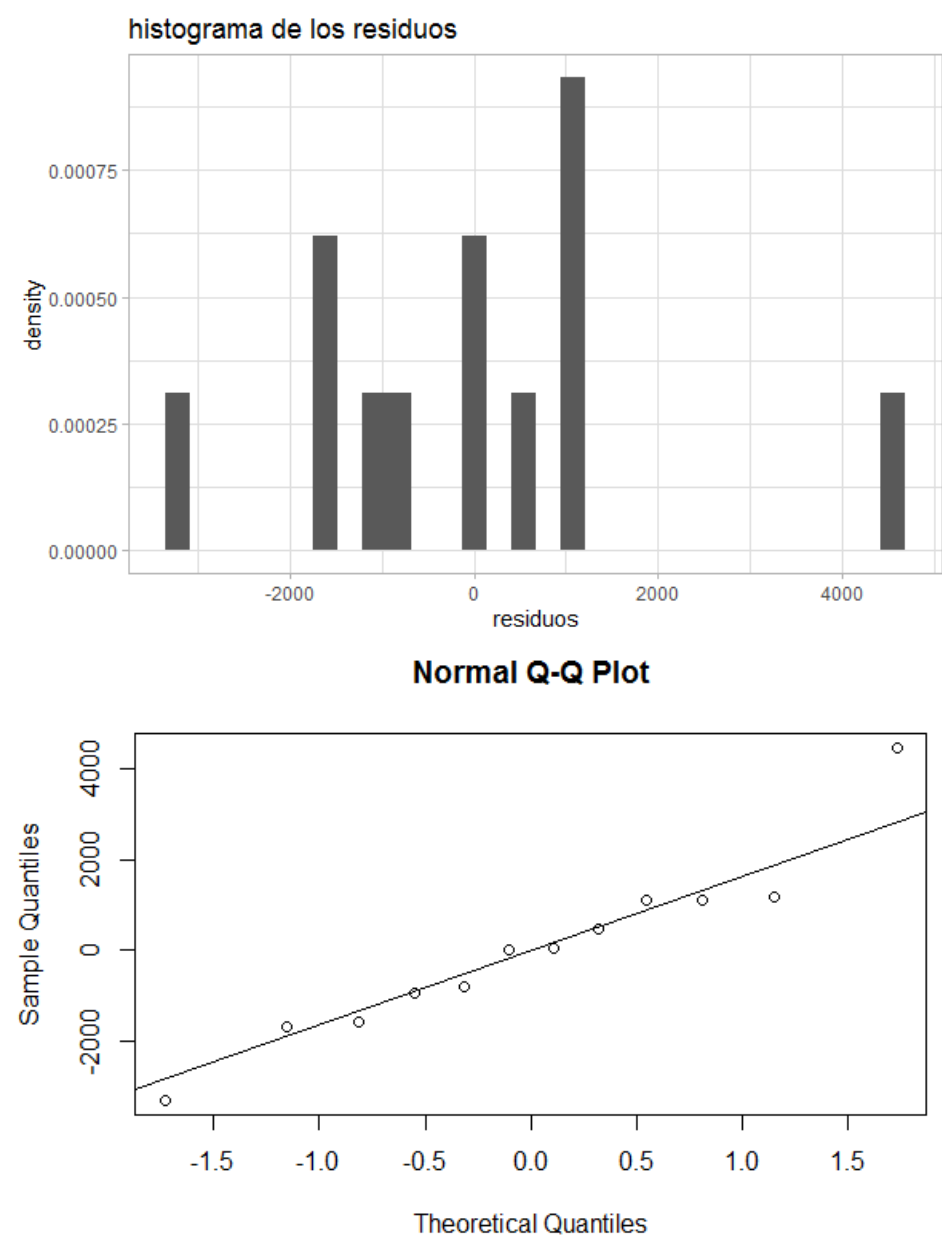

$>$ \#Shapiro wilks Test (Normalidad) $>$ shapiro.test(residuals (Modelo3)) Shapiro-wilk normality test data: residuals(Modelo3) $\mathrm{W}=0.94408, \mathrm{p}$-value $=0.5527$ 
Por medio del histograma se presenta los residuos en su distribución de forma normal con media 0 . El gráfico Q-Q que sitúa los cuartiles de la distribución de la muestra respecto a los cuartiles del modelo de distribución normal, presenta que ambas distribuciones siguen un comportamiento sobre una línea recta y se acepta el supuesto de linealidad. Además, el estadístico Shapiro Wilks obtiene un $\mathrm{P}$ value de 0,5527 que resulta $\geq 0,05$.

Tanto la representación gráfica como el contraste de hipótesis confirman la distribución normal de los residuos.

\section{c. Homocedasticidad}

El análisis de la gráfica de distribución de los residuos visualiza que la variabilidad de los residuos es constante a lo largo del eje $X$ (el tamaño de los residuos no aumenta ni disminuye de forma sistémica ni significativa con variaciones de y) y la prueba estadística de Breusch Pagan, arroja un $P$ value de 0,2914 que resulta $\geq 0,05$.

$\mathrm{Ni}$ la representación gráfica ni el contraste de hipótesis muestran evidencias sobre la falta de homocedasticidad.

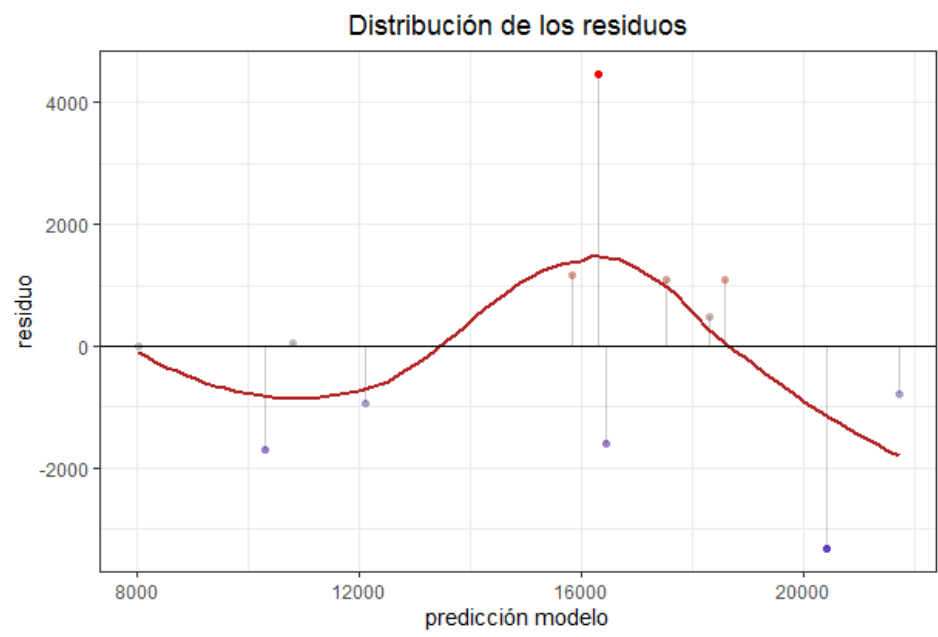

$>$ 7mtest: :bptest(Mode103)

studentized Breusch-Pagan test

data: Modelo3

$\mathrm{BP}=2.4661, \mathrm{df}=2, \mathrm{p}$-value $=0.2914$

\section{d. Independencia}

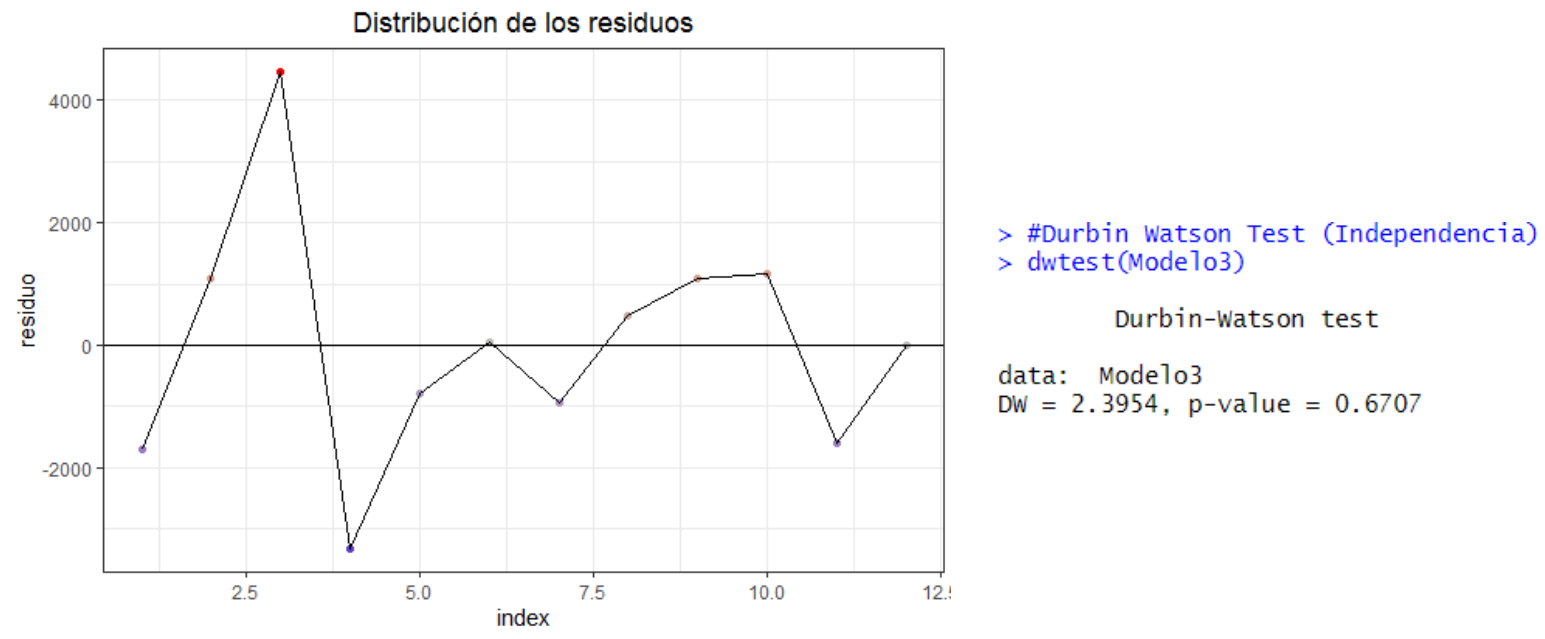


La representación gráfica de los residuos muestra que los residuos no tienen ninguna tendencia marcada y no poseen algún tipo de autocorrelación entre ellos, es decir, que son independientes, El estadístico de Durbin Watson, confirma que no hay problemas de independencia al obtenerse un $P$ value de $0,6707 \geq 0,05$.

\section{e. Multicolinealidad}

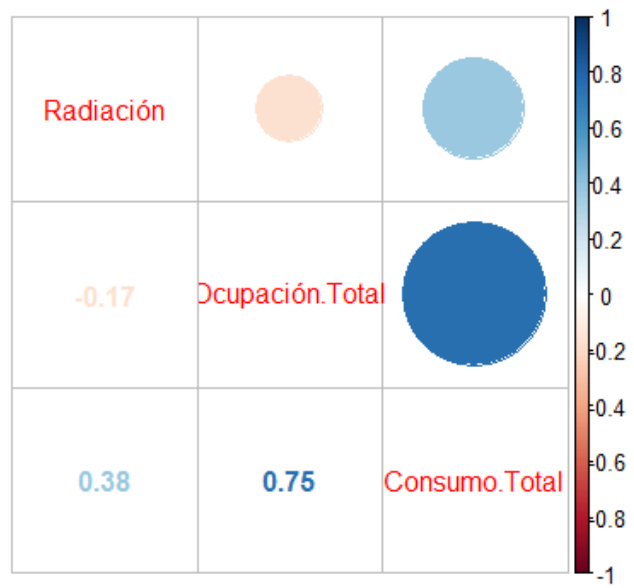

> \#Prueba VIF de multicolinealidad

$>$ vif(Modelo3)

Radiación Ocupación. Tota1

$1.028107 \quad 1.028107$

La figura de correlación de variables presenta el diagrama y los coeficientes de correlación entre las variables independientes del modelo (Radiación y Ocupación Total), donde se evidencia que la dependencia entre las variables es baja. Entre más pequeño el valor de $R$ menor es la dependencia entre las variables, para este caso, la correlación entre ellas es de $-0,17$. Además, como los valores de VIF (Factor de Inflación de Varianza) para cada variable es menor a 10, el modelo no presenta problemas de multicolinealidad.

En la Tabla 92 se resumen los modelos de regresión lineal obtenidos y el cumplimiento de los supuestos estadísticos que validan el modelo.

Tabla 92. Consolidado cumplimiento de supuestos estadísticos de los modelos de Regresión

\begin{tabular}{|c|c|c|c|c|c|}
\hline$\gamma^{2}$ & 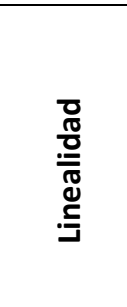 & 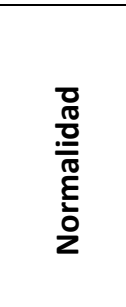 & 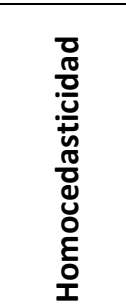 & 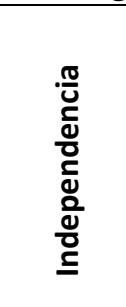 & 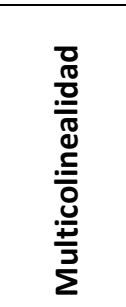 \\
\hline $\begin{array}{l}\text { Univariable } \\
\text { Electricidad }_{L B}=0,5082 \cdot \text { Ocupación }+8015\end{array}$ & Cumple & Cumple & Cumple & Cumple & $\begin{array}{c}\text { No } \\
\text { Aplica }\end{array}$ \\
\hline $\begin{array}{l}\text { Multivariable } \\
\begin{array}{l}\text { Electricidad }_{L B}=64,83 \cdot \text { Radiación }+0,4681 \\
\cdot \text { Ocupación }-16060\end{array}\end{array}$ & Cumple & Cumple & Cumple & Cumple & Cumple \\
\hline
\end{tabular}




\section{Ajuste de bondad de los modelos de regresión lineal}

En la Tabla 93 se presenta la prueba de bondad de ajuste de los modelos de regresión lineal univariable y multivariable. Esta prueba se realiza, empleando la ecuación obtenida y los datos originales con los que fue creado el modelo, su fin es obtener el error porcentual absoluto medio (MAPE) de cada modelo y así conocer que también se ajusta a sus datos originales. El MAPE indica el tamaño del error del pronóstico debido a que se toma sólo la magnitud del error (valor absoluto), lo cual da la idea de la exactitud esperada del pronóstico.

Para el modelo de regresión lineal univariable el MAPE es del 15,16\% y para el modelo de regresión lineal multivariable es del 8,73\%. Según los valores obtenidos por cada modelo de regresión lineal para la serie de datos iniciales, el modelo que mejor pronostica en el modelo de regresión múltiple.

Tabla 93. Ajuste de bondad de los modelos de regresión lineal

\begin{tabular}{|c|c|c|c|c|c|c|}
\hline \multirow{2}{*}{ Mes/Año } & \multicolumn{3}{|c|}{ Modelo Univariable 2017 } & \multicolumn{3}{c|}{ Modelo Multivariable 2017 } \\
\cline { 2 - 8 } & $\begin{array}{c}\text { Consumo } \\
\text { Estimado }\end{array}$ & Diferencia & Error & $\begin{array}{c}\text { Consumo } \\
\text { Estimado }\end{array}$ & Diferencia & Error \\
\hline Enero & 10940,54 & $-2319,54$ & $26,9 \%$ & 10314,11 & $-1693,11$ & $19,6 \%$ \\
\hline Febrero & 18025,78 & 1646,22 & $8,4 \%$ & 18582,92 & 1089,08 & $5,5 \%$ \\
\hline Marzo & 17311,59 & 3470,41 & $16,7 \%$ & 16326,96 & 4455,04 & $21,4 \%$ \\
\hline Abril & 19451,23 & $-2331,23$ & $13,6 \%$ & 20437,67 & $-3317,67$ & $19,4 \%$ \\
\hline Mayo & 20878,81 & 40,19 & $0,2 \%$ & 21719,10 & $-800,10$ & $3,8 \%$ \\
\hline Junio & 9284,59 & 1584,41 & $14,6 \%$ & 10827,79 & 41,21 & $0,4 \%$ \\
\hline Julio & 10472,15 & 690,85 & $6,2 \%$ & 12110,89 & $-947,89$ & $8,5 \%$ \\
\hline Agosto & 11501,00 & 7304,00 & $38,8 \%$ & 18327,81 & 477,19 & $2,5 \%$ \\
\hline Septiembre & 12222,13 & 6397,87 & $34,4 \%$ & 17527,40 & 1092,60 & $5,9 \%$ \\
\hline Octubre & 17180,98 & $-173,98$ & $1,0 \%$ & 15838,42 & 1168,58 & $6,9 \%$ \\
\hline Noviembre & 16845,14 & $-1984,14$ & $13,4 \%$ & 16456,86 & $-1595,86$ & $10,7 \%$ \\
\hline Diciembre & 8644,41 & $-621,41$ & $7,7 \%$ & 8032,03 & $-9,03$ & $0,1 \%$ \\
\hline RMSE & \multicolumn{7}{|c|}{3255,665934} & & 1865,953174 & \\
\hline MAPE & \multicolumn{7}{|c|}{$15,16 \%$} & $8,73 \%$ & \\
\hline
\end{tabular}

\section{Validación de los modelos y capacidad de pronóstico}

La información que se utilizó para crear los modelos corresponde al 2017, para realizar la validación de los mismos se usaron los datos de los 3 meses siguientes (enero, febrero y marzo de 2018) equivalente a un $25 \%$ de datos con los que se establecieron los modelos. En cada uno de ellos se evalúa el error porcentual absoluto medio (MAPE) y a partir del 4 mes se presentan los valores en los que variará el pronóstico de valores de la LBE. 


\section{Modelo univariable}

La Tabla 94 presenta los valores obtenidos al evaluar la capacidad de pronóstico del modelo de regresión lineal univariable, con un MAPE del 28,18\% que representa el error de pronóstico del modelo.

Tabla 94. Capacidad de pronóstico del modelo de Regresión lineal univariable

\begin{tabular}{|c|c|c|c|c|c|c|}
\hline \multirow[b]{2}{*}{ Mes/Año } & \multicolumn{6}{|c|}{2018} \\
\hline & $\begin{array}{c}\text { Consumo } \\
\text { Real }\end{array}$ & $\begin{array}{l}\text { Consumo } \\
\text { Estimado }\end{array}$ & Error & $\begin{array}{c}\text { Error } \\
\text { Porcentual }\end{array}$ & $\begin{array}{c}\text { Error } \\
\text { Absoluto }\end{array}$ & $\begin{array}{c}\text { Error Absoluto } \\
\text { Porcentual }\end{array}$ \\
\hline Enero & 11968 & 11235,72 & 732,28 & $6,12 \%$ & 732,28 & $6,1 \%$ \\
\hline Febrero & 18612 & 10321,97 & 8290,03 & $44,54 \%$ & 8290,03 & $44,5 \%$ \\
\hline Marzo & 17855 & 11805,16 & 6049,84 & $33,88 \%$ & 6049,84 & $33,9 \%$ \\
\hline \multicolumn{3}{|c|}{ Medidas de Error de Pronóstico } & ME & MPE & MAE & MAPE \\
\hline \multicolumn{3}{|c|}{ Valores } & 5024,05 & $28,18 \%$ & 5024,05 & $28,18 \%$ \\
\hline \multicolumn{3}{|c|}{ Capacidad de Pronóstico del Modelo } & \multicolumn{2}{|c|}{ Exactitud } & \multicolumn{2}{|c|}{ Nivel de Incertidumbre } \\
\hline
\end{tabular}

El modelo de pronóstico univariable sobrestima el consumo total de energía con un sesgo promedio e incertidumbre de $\pm 5024,05 \mathrm{kWh} / \mathrm{mes}$ (que representa un $28,18 \%$ del valor real) como es presentado en la Tabla 95 y la Figura 229.

Tabla 95. Capacidad de pronóstico modelo univariable

\begin{tabular}{|c|c|c|c|c|}
\hline Mes & $\begin{array}{c}\text { Consumo } \\
\text { Real }\end{array}$ & Sesgo & $\begin{array}{c}\text { Error } \\
\text { Máximo }\end{array}$ & $\begin{array}{c}\text { Error } \\
\text { Mínimo }\end{array}$ \\
\hline Enero & 11968 & & & \\
\hline Febrero & 18612 & & & \\
\hline Marzo & 17855 & & & \\
\hline Abril & 18971 & 23995,05 & 23995,05 & 13946,95 \\
\hline Mayo & 18237 & 23261,05 & 23261,05 & 13212,95 \\
\hline Junio & 10451 & 15475,05 & 15475,05 & 5426,95 \\
\hline Julio & 13730 & 18754,05 & 18754,05 & 8705,95 \\
\hline Agosto & 19142 & 24166,05 & 24166,05 & 14117,95 \\
\hline Septiembre & 18290 & 23314,05 & 23314,05 & 13265,95 \\
\hline Octubre & 17515 & 22539,05 & 22539,05 & 12490,95 \\
\hline Noviembre & 14198 & 19222,05 & 19222,05 & 9173,95 \\
\hline Diciembre & 9414 & 14438,05 & 14438,05 & 4389,95 \\
\hline
\end{tabular}

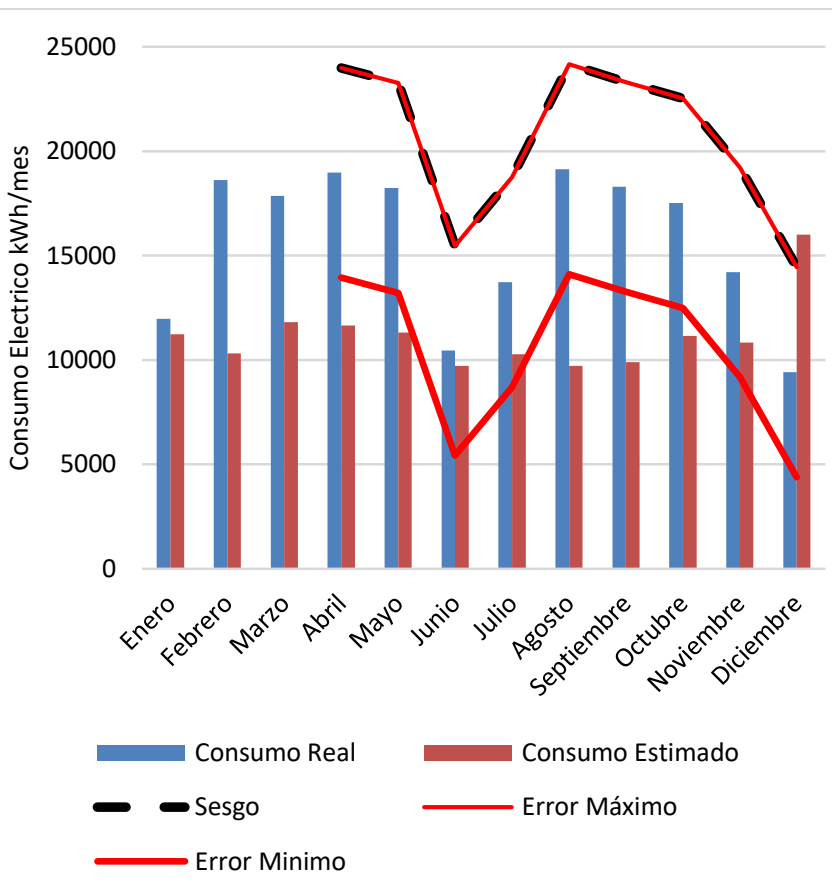

Figura 229. Capacidad de pronóstico modelo univariable 


\section{Modelo Multivariable}

La Tabla 96, presenta los valores obtenidos al evaluar la capacidad de pronóstico del modelo de regresión lineal multivariable, con un MAPE del 22,85\% que representa el error de pronóstico del modelo.

Tabla 96. Capacidad de pronóstico del modelo de Regresión lineal multivariable

\begin{tabular}{|c|c|c|c|c|c|c|}
\hline \multirow[b]{2}{*}{ Mes/Año } & \multicolumn{6}{|c|}{2018} \\
\hline & $\begin{array}{c}\text { Consumo } \\
\text { Real }\end{array}$ & $\begin{array}{l}\text { Consumo } \\
\text { Estimado }\end{array}$ & Error & $\begin{array}{c}\text { Error } \\
\text { Porcentual }\end{array}$ & $\begin{array}{c}\text { Error } \\
\text { Absoluto }\end{array}$ & $\begin{array}{c}\text { Error Absoluto } \\
\text { Porcentual }\end{array}$ \\
\hline Enero & 11968 & 10261,94 & 1706 & $14,26 \%$ & 1706,06 & $14,26 \%$ \\
\hline Febrero & 18612 & 12106,34 & 6506 & $34,95 \%$ & 6505,66 & $34,95 \%$ \\
\hline Marzo & 17855 & 14399,28 & 3456 & $19,35 \%$ & 3455,72 & $19,35 \%$ \\
\hline \multicolumn{3}{|c|}{ Medidas de Error de Pronóstico } & ME & MPE & MAE & MAPE \\
\hline \multicolumn{3}{|c|}{ Valores } & 3889,14 & $22,85 \%$ & 3889,14 & $22,85 \%$ \\
\hline \multicolumn{3}{|c|}{$\begin{array}{l}\text { Capacidad de Pronóstico del } \\
\text { Modelo }\end{array}$} & \multicolumn{2}{|c|}{ Exactitud } & \multicolumn{2}{|c|}{ Nivel de Incertidumbre } \\
\hline
\end{tabular}

El modelo de pronóstico sobrestima el consumo total de energía con un sesgo promedio e incertidumbre de $\pm 3889,14 \mathrm{kWh} /$ mes (que representa un $28,18 \%$ del valor real), como es presentado en la Tabla 97 y la Figura 230.

Tabla 97. Capacidad de pronóstico modelo multivariable

\begin{tabular}{|c|c|c|c|c|}
\hline Mes & $\begin{array}{c}\text { Consumo } \\
\text { Real }\end{array}$ & Sesgo & $\begin{array}{c}\text { Error } \\
\text { Máximo }\end{array}$ & $\begin{array}{c}\text { Error } \\
\text { Mínimo }\end{array}$ \\
\hline Enero & 11968 & & & \\
\hline Febrero & 18612 & & & \\
\hline Marzo & 17855 & & & \\
\hline Abril & 18971 & 22860,14 & 22860,14 & 15081,86 \\
\hline Mayo & 18237 & 22126,14 & 22126,14 & 14347,86 \\
\hline Junio & 10451 & 14340,14 & 14340,14 & 6561,86 \\
\hline Julio & 13730 & 17619,14 & 17619,14 & 9840,86 \\
\hline Agosto & 19142 & 23031,14 & 23031,14 & 15252,86 \\
\hline Septiembre & 18290 & 22179,14 & 22179,14 & 14400,86 \\
\hline Octubre & 17515 & 21404,14 & 21404,14 & 13625,86 \\
\hline Noviembre & 14198 & 18087,14 & 18087,14 & 10308,86 \\
\hline Diciembre & 9414 & 13303,14 & 13303,14 & 5524,86 \\
\hline
\end{tabular}

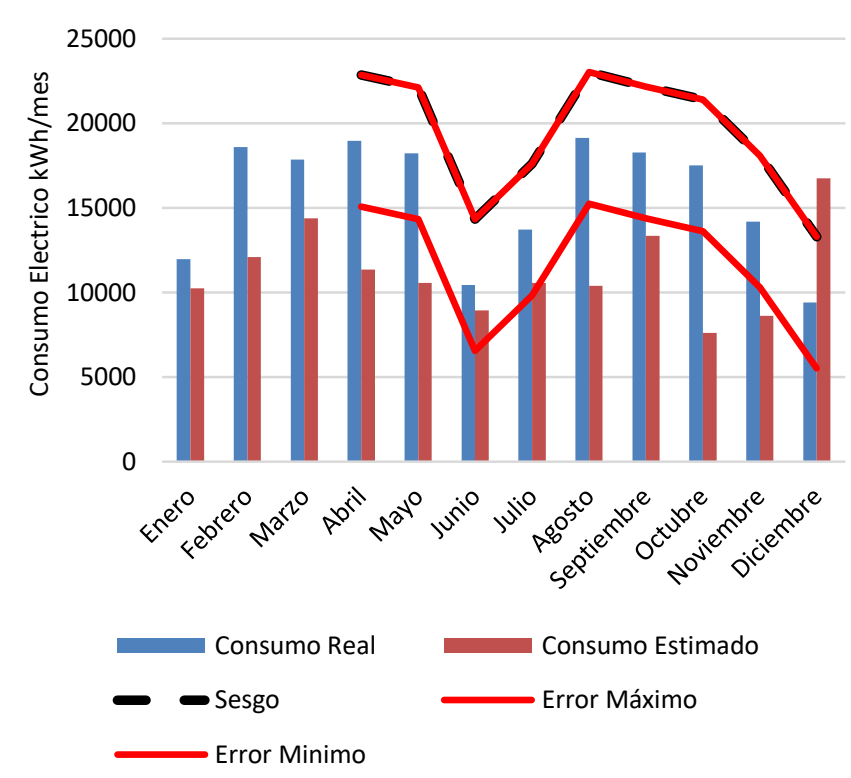

Figura 230. Capacidad de pronóstico modelo multivariable 


\subsubsection{Modelo de Regresión Lineal para el año 2018}

Con información disponible del año 2018 (Tabla 98), se construyó el modelo de regresión lineal multivariable con todas las variables disponibles (Temperatura, Humedad, Radiación y Ocupación Total).

Tabla 98. Información mensual de variables monitoreadas en el edificio para el 2018

\begin{tabular}{|c|c|c|c|c|c|}
\hline Mes/Variable & $\begin{array}{c}\text { Temperatura } \\
{\left[{ }^{\circ} \mathbf{C}\right]}\end{array}$ & $\begin{array}{c}\text { Humedad } \\
{[\%]}\end{array}$ & $\begin{array}{c}\text { Radiación } \\
{[\mathbf{W} / \mathbf{m} 2]}\end{array}$ & $\begin{array}{c}\text { Ocupación } \\
{[\text { horas] }}\end{array}$ & $\begin{array}{c}\text { Consumo } \\
\text { Total }[\mathbf{k W h}]\end{array}$ \\
\hline Enero & 23,533 & 77,879 & 360,255 & 6337,50 & 11968 \\
\hline Febrero & 24,755 & 73,395 & 401,687 & 4539,50 & 18612 \\
\hline Marzo & 25,187 & 73,040 & 415,983 & 7458,00 & 17855 \\
\hline Abril & 23,700 & 78,738 & 371,425 & 7160,00 & 18971 \\
\hline Mayo & 23,698 & 80,082 & 363,996 & 6490,00 & 18237 \\
\hline Junio & 24,908 & 74,671 & 361,735 & 3340,50 & 10451 \\
\hline Julio & 25,137 & 71,986 & 378,773 & 4443,83 & 13730 \\
\hline Agosto & 24,846 & 70,698 & 383,925 & 3339,17 & 19142 \\
\hline Septiembre & 25,496 & 68,678 & 426,743 & 3720,50 & 18290 \\
\hline Octubre & 24,290 & 74,760 & 207,902 & 6157,00 & 17515 \\
\hline Noviembre & 23,899 & 80,624 & 340,688 & 5544,33 & 14198 \\
\hline Diciembre & 24,500 & 75,626 & 392,649 & 15711,00 & 9414 \\
\hline
\end{tabular}

Ca11:

$1 \mathrm{~m}$ (formula = Consumo_Total $\sim$ Temperatura + Humedad + Radiacion + OcupTota1, data $=$ X2018_Mensua1)

Residuals:

Min 1Q Median 3Q Max

$\begin{array}{lllll}-5258.3 & -2161.6 & 792.1 & 2212.4 & 3528.4\end{array}$

\section{Coefficients:}

$\begin{array}{lrrrr} & \text { Estimate } & \text { Std. Error } & \mathrm{t} \text { value } & \operatorname{Pr}(>|\mathrm{t}|) \\ \text { (Intercept) } & 1.404 \mathrm{e}+05 & 1.570 \mathrm{e}+05 & 0.895 & 0.401 \\ \text { Temperatura } & -3.276 \mathrm{e}+03 & 4.348 \mathrm{e}+03 & -0.753 & 0.476 \\ \text { Humedad } & -5.854 \mathrm{e}+02 & 7.552 \mathrm{e}+02 & -0.775 & 0.464 \\ \text { Radiacion } & 5.465 \mathrm{e}+00 & 2.327 \mathrm{e}+01 & 0.235 & 0.821 \\ \text { OcupTotal } & -4.180 \mathrm{e}-01 & 3.724 \mathrm{e}-01 & -1.122 & 0.299\end{array}$

Residual standard error: 3865 on 7 degrees of freedom Multiple R-squared: 0.2491 , Adjusted R-squared: -0.1799 F-statistic: 0.5806 on 4 and 7 DF, p-value: 0.6867

El análisis estadístico de las variables muestra que ninguna de estas es realmente significativa para el modelo de regresión, en tanto todas tienen un p value mayor a 0,05. Además, el valor de $R^{2}$ ajustado del modelo es negativo $(-0,1799)$, lo que indica que el modelo obtenido explica en un $0 \%$ la variabilidad de las observaciones (datos), es decir, que las variables no describen el comportamiento de la variable consumo. 


\section{Modelo de Regresión Lineal con información semanal}

Con el fin de obtener un modelo de regresión lineal multivariable, un poco más depurado o detallado y, según la información disponible, se realizó un modelo con datos semanales del año 2018. Se encontró que a lo largo del año (52 semanas), se presentan diferentes tipos de "semana" según el periodo académico, como lo presentan la

Tabla 99 y la Figura 231.

Tabla 99. Distribución del tipo de semana para el año 2018

\begin{tabular}{|c|c|c|}
\hline Periodo & Detalle & Semanas \\
\hline Invierno & $\begin{array}{c}\text { Vacaciones de semestre 2 } \\
\text { (entre diciembre y enero) }\end{array}$ & $2,3,49,50,51$ \\
\hline Semestre 1 & Periodo de clases académicas & $4-22$ (Excepto la Sem 13) \\
\hline Vacaciones & $\begin{array}{c}\text { Periodo que la Universidad se } \\
\text { encuentra totalmente cerrada }\end{array}$ & 1,13 (Semana Santa), 26, 52 \\
\hline Verano & $\begin{array}{c}\text { Vacaciones de semestre 1 } \\
\text { (entre junio y Julio) }\end{array}$ & $23,24,25,27,28,29$ \\
\hline Semestre 2 & Periodo de clases académicas & $30-48$ \\
\hline
\end{tabular}

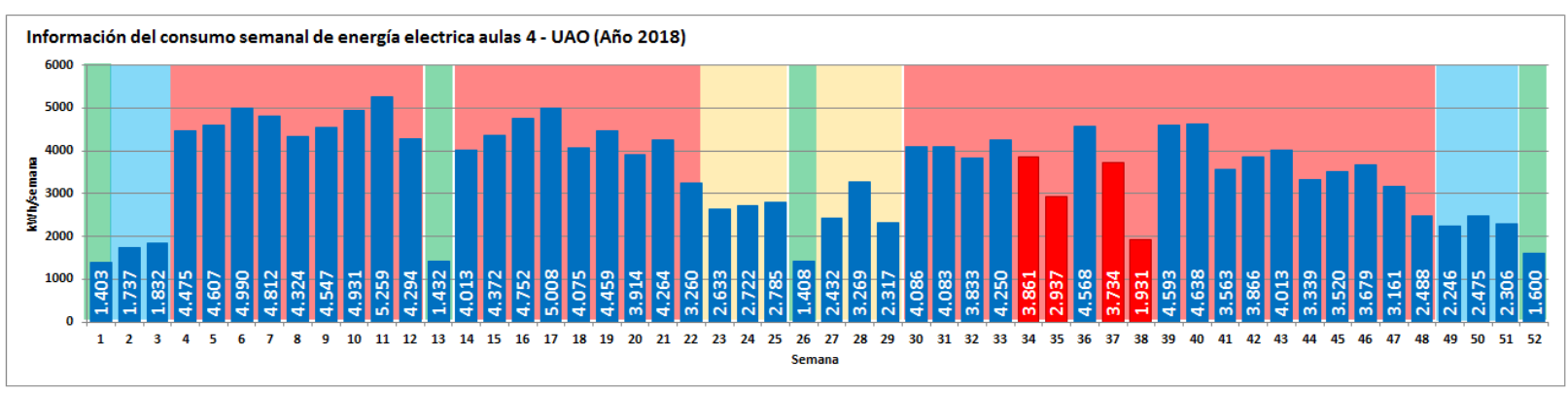

Figura 231. Distribución del tipo de semana para el año 2018

Al procesar los datos medidos de consumo de energía se encontró que el medidor presentó problemas y no registró información en varios momentos de las semanas 34, 35, 37 y 38 (Semanas en rojo en la Figura 231). Por lo tanto, la información de estas semanas fue excluida en los análisis realizados.

Para la obtención del modelo de regresión lineal multivariable, se utilizó la información del tipo de semana clasificada como semestre, pues son los periodos con mayor consumo de energía y, donde se realizan las actividades académicas.

La Tabla 100. Presenta la información de las semanas clasificadas como semestre. 
Tabla 100. Datos semanales - Periodo Semestre del año 2018.

\begin{tabular}{|c|c|c|c|c|c|c|}
\hline Semana & $\begin{array}{c}\text { Temperatura } \\
{\left[{ }^{\circ} \mathrm{C}\right]}\end{array}$ & $\begin{array}{l}\text { Humedad } \\
\text { [\%] }\end{array}$ & $\begin{array}{l}\text { Radiación } \\
{[W / m 2]}\end{array}$ & $\begin{array}{c}\text { Ocupación } \\
\text { [horas] }\end{array}$ & $\begin{array}{c}\text { Consumo } \\
\text { Total } \\
\text { [kWh] }\end{array}$ & $\begin{array}{l}\text { Tipo de } \\
\text { Semana }\end{array}$ \\
\hline 4 & 24,59 & 74,85 & 341,06 & 380,50 & 4432,777 & Semestre \\
\hline 5 & 25,32 & 73,02 & 348,18 & 596,00 & 4644,356 & Semestre \\
\hline 6 & 25,34 & 73,14 & 389,64 & 1004,50 & 4981,32 & Semestre \\
\hline 7 & 24,69 & 75,58 & 389,60 & 1132,50 & 4836,71 & Semestre \\
\hline 8 & 23,98 & 74,57 & 412,97 & 1211,50 & 4359,954 & Semestre \\
\hline 9 & 24,87 & 69,54 & 452,53 & 1731,50 & 4537,477 & Semestre \\
\hline 10 & 26,04 & 69,44 & 423,77 & 1722,00 & 4955,343 & Semestre \\
\hline 11 & 26,08 & 67,26 & 470,15 & 1643,50 & 5234,621 & Semestre \\
\hline 12 & 24,48 & 76,72 & 418,05 & 1658,50 & 4277,57 & Semestre \\
\hline 14 & 22,66 & 80,75 & 379,72 & 1612,00 & 4027,239 & Semestre \\
\hline 15 & 23,56 & 77,46 & 401,31 & 1626,50 & 4376,808 & Semestre \\
\hline 16 & 24,61 & 76,98 & 362,71 & 1708,50 & 4717,731 & Semestre \\
\hline 17 & 23,93 & 79,79 & 325,64 & 1907,00 & 4930,622 & Semestre \\
\hline 18 & 24,22 & 78,48 & 416,59 & 1522,50 & 4137,512 & Semestre \\
\hline 19 & 23,05 & 82,28 & 322,40 & 1323,50 & 4388,022 & Semestre \\
\hline 20 & 23,71 & 79,80 & 363,80 & 1473,50 & 3990,811 & Semestre \\
\hline 21 & 23,94 & 78,78 & 356,55 & 1486,50 & 4284,221 & Semestre \\
\hline 22 & 24,14 & 80,08 & 360,68 & 1301,50 & 3251,571 & Semestre \\
\hline 30 & 24,29 & 75,86 & 355,96 & 619,50 & 4088,809 & Semestre \\
\hline 31 & 23,64 & 77,97 & 359,43 & 644,17 & 4115,94 & Semestre \\
\hline 32 & 24,15 & 70,53 & 333,94 & 771,50 & 3822,71 & Semestre \\
\hline 33 & 25,08 & 70,17 & 390,96 & 818,00 & 4257,771 & Semestre \\
\hline 36 & 25,28 & 68,41 & 384,73 & 1006,50 & 4512,883 & Semestre \\
\hline 39 & 25,66 & 68,40 & 422,90 & 1160,50 & 4586,678 & Semestre \\
\hline 40 & 25,10 & 70,62 & 456,87 & 1178,00 & 4732,091 & Semestre \\
\hline 41 & 23,31 & 76,17 & 386,45 & 1218,00 & 3718,854 & Semestre \\
\hline 42 & 24,53 & 73,81 & 393,36 & 1353,50 & 3985,087 & Semestre \\
\hline 43 & 24,39 & 76,15 & 394,03 & 1554,50 & 3825,184 & Semestre \\
\hline 44 & 23,65 & 80,55 & 358,06 & 1618,50 & 3093,856 & Semestre \\
\hline 45 & 23,76 & 80,51 & 373,16 & 1692,00 & 3539,902 & Semestre \\
\hline 46 & 24,49 & 78,84 & 359,11 & 1553,00 & 3732,104 & Semestre \\
\hline 47 & 24,24 & 79,82 & 332,53 & 1310,00 & 3182,082 & Semestre \\
\hline 48 & 22,85 & 83,66 & 322,75 & 1111,33 & 2471,073 & Semestre \\
\hline
\end{tabular}

Se realizó el modelo de regresión lineal multivariable con las variables disponibles y se encontró que para los datos fuente del modelo, ninguna de las variables es realmente significativa dado que todas tienen en el modelo un $p$ value mayor a 0,05. Por lo anterior, era de esperar que el modelo desarrollado no tuviera un buen $R^{2}$ ajustado, así el valor de 
0,3622 indica que el modelo explica apenas el 36,22\% de la variabilidad de las observaciones (datos).

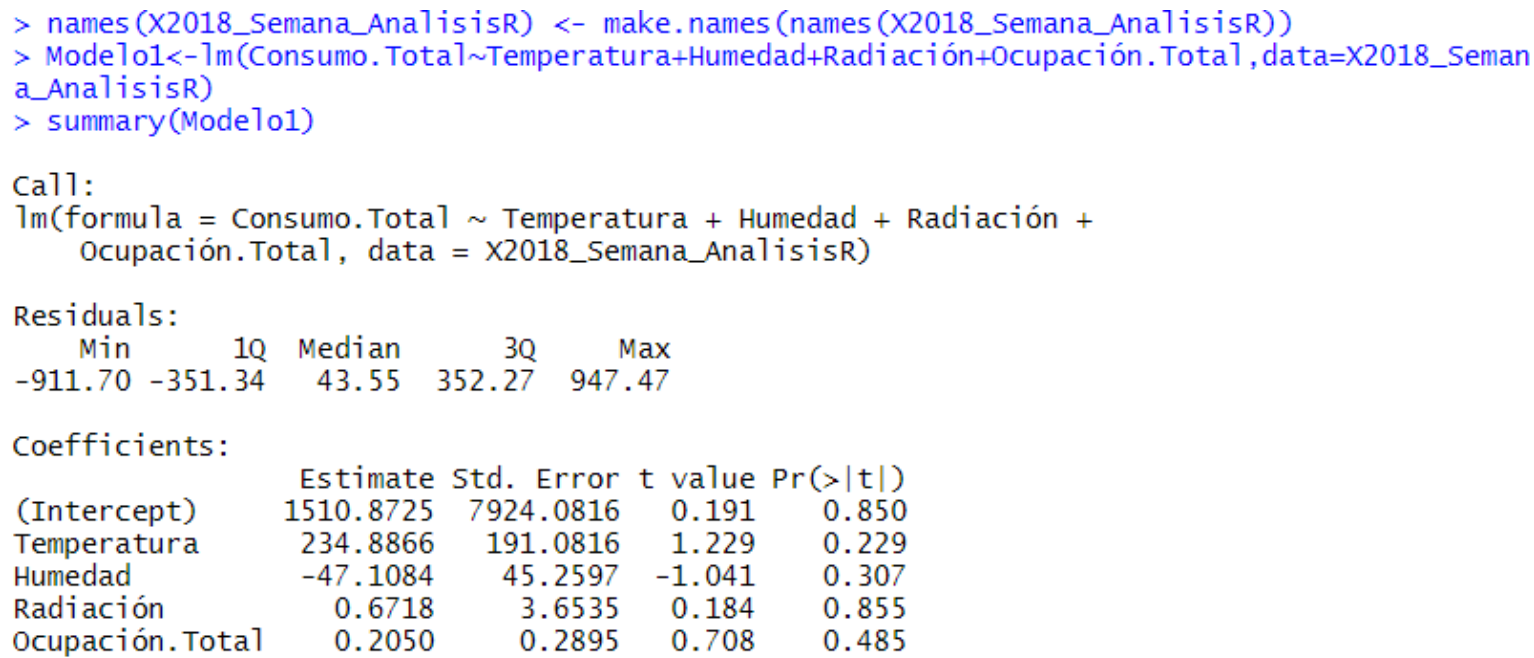

Residua 1 standard error: 487.3 on 28 degrees of freedom Multiple R-squared: 0.4419 , Adjusted R-squared: 0.3622

F-statistic: 5.543 on 4 and 28 DF, p-value: 0.002044

Asi mismo, se realizaron las pruebas para verificar el cumplimiento de los supuestos estadisticos por parte del modelo desarrollado. Se hizo uso de la prueba global (gvima de R Studio) y de la prueba VIF para descartar multicolinealidad, de esta menara se obtuvo que el modelo cumple con los supuestos estadisticos.

ASSESSMENT OF THE LINEAR MODEL ASSUMPTIONS

USING THE GLOBAL TEST ON 4 DEGREES-OF-FREEDOM:

Level of Significance $=0.05$

Ca11:

$\operatorname{gvlma}(x=$ Modelo1)

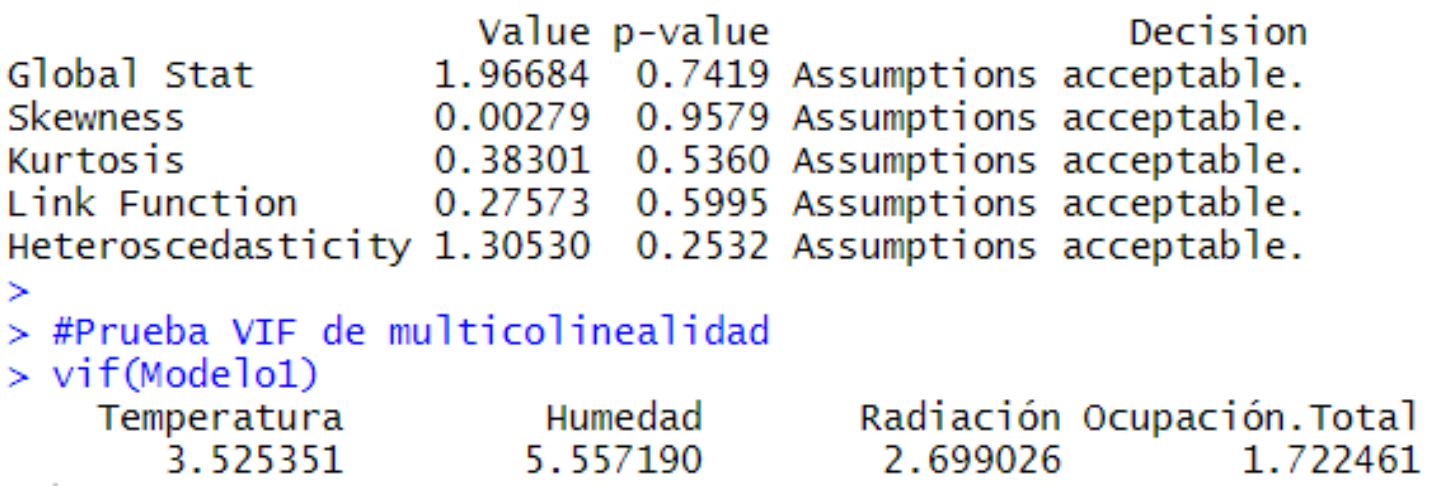

Sin embargo, el modelo desarrollado anteriormente no es un buen modelo, pues el nivel de correlación es muy bajo para usarse como herramienta de pronóstico. Solo describe el $36,22 \%$ de variación o comportamiento de los datos. 
Teniendo en cuenta las características de los datos y de los periodos semestrales del año 2018, se decidió partir la información y trabajar modelos de regresión por periodo semestral 2018 - 1 y periodo semestral $2018-3$.

Periodo $2018-1$

La Tabla 101. Presenta los datos medidos para el periodo $2018-1$.

Tabla 101. Datos semanales - Semestre 1 del 2018.

\begin{tabular}{|c|c|c|c|c|c|c|}
\hline Semana & $\begin{array}{c}\text { Temperatura } \\
{\left[{ }^{\circ} \mathbf{C}\right]}\end{array}$ & $\begin{array}{c}\text { Humedad } \\
{[\mathbf{\%}]}\end{array}$ & $\begin{array}{c}\text { Radiación } \\
{[\mathbf{W} / \mathbf{m} \mathbf{}]}\end{array}$ & $\begin{array}{c}\text { Ocupación } \\
{[\text { horas }]}\end{array}$ & $\begin{array}{c}\text { Consumo } \\
\text { Total } \\
{[\mathbf{k W h}]}\end{array}$ & $\begin{array}{c}\text { Tipo de } \\
\text { Semana }\end{array}$ \\
\hline $\mathbf{4}$ & 24,59 & 74,85 & 341,06 & 380,50 & 4432,777 & Semestre \\
\hline $\mathbf{5}$ & 25,32 & 73,02 & 348,18 & 596,00 & 4644,356 & Semestre \\
\hline $\mathbf{6}$ & 25,34 & 73,14 & 389,64 & 1004,50 & 4981,32 & Semestre \\
\hline $\mathbf{7}$ & 24,69 & 75,58 & 389,60 & 1132,50 & 4836,71 & Semestre \\
\hline $\mathbf{8}$ & 23,98 & 74,57 & 412,97 & 1211,50 & 4359,954 & Semestre \\
\hline $\mathbf{9}$ & 24,87 & 69,54 & 452,53 & 1731,50 & 4537,477 & Semestre \\
\hline $\mathbf{1 0}$ & 26,04 & 69,44 & 423,77 & 1722,00 & 4955,343 & Semestre \\
\hline $\mathbf{1 1}$ & 26,08 & 67,26 & 470,15 & 1643,50 & 5234,621 & Semestre \\
\hline $\mathbf{1 2}$ & 24,48 & 76,72 & 418,05 & 1658,50 & 4277,57 & Semestre \\
\hline $\mathbf{1 4}$ & 22,66 & 80,75 & 379,72 & 1612,00 & 4027,239 & Semestre \\
\hline $\mathbf{1 5}$ & 23,56 & 77,46 & 401,31 & 1626,50 & 4376,808 & Semestre \\
\hline $\mathbf{1 6}$ & 24,61 & 76,98 & 362,71 & 1708,50 & 4717,731 & Semestre \\
\hline $\mathbf{1 7}$ & 23,93 & 79,79 & 325,64 & 1907,00 & 4930,622 & Semestre \\
\hline $\mathbf{1 8}$ & 24,22 & 78,48 & 416,59 & 1522,50 & 4137,512 & Semestre \\
\hline $\mathbf{1 9}$ & 23,05 & 82,28 & 322,40 & 1323,50 & 4388,022 & Semestre \\
\hline $\mathbf{2 0}$ & 23,71 & 79,80 & 363,80 & 1473,50 & 3990,811 & Semestre \\
\hline $\mathbf{2 1}$ & 23,94 & 78,78 & 356,55 & 1486,50 & 4284,221 & Semestre \\
\hline $\mathbf{2 2}$ & 24,14 & 80,08 & 360,68 & 1301,50 & 3251,571 & Semestre \\
\hline
\end{tabular}

Se realizó el modelo de regresión lineal multivariable con las variables disponibles y se encontró que para los datos fuente del modelo, la variable Humedad resulta realmente significativa para un modelo de regresión con un $p$ value de 0,0475 . El modelo desarrollado con todas las variables posee un $R^{2}$ Ajustado de 0,449 , es decir, que el modelo explica el $44,9 \%$ de la variabilidad de las observaciones (datos). 


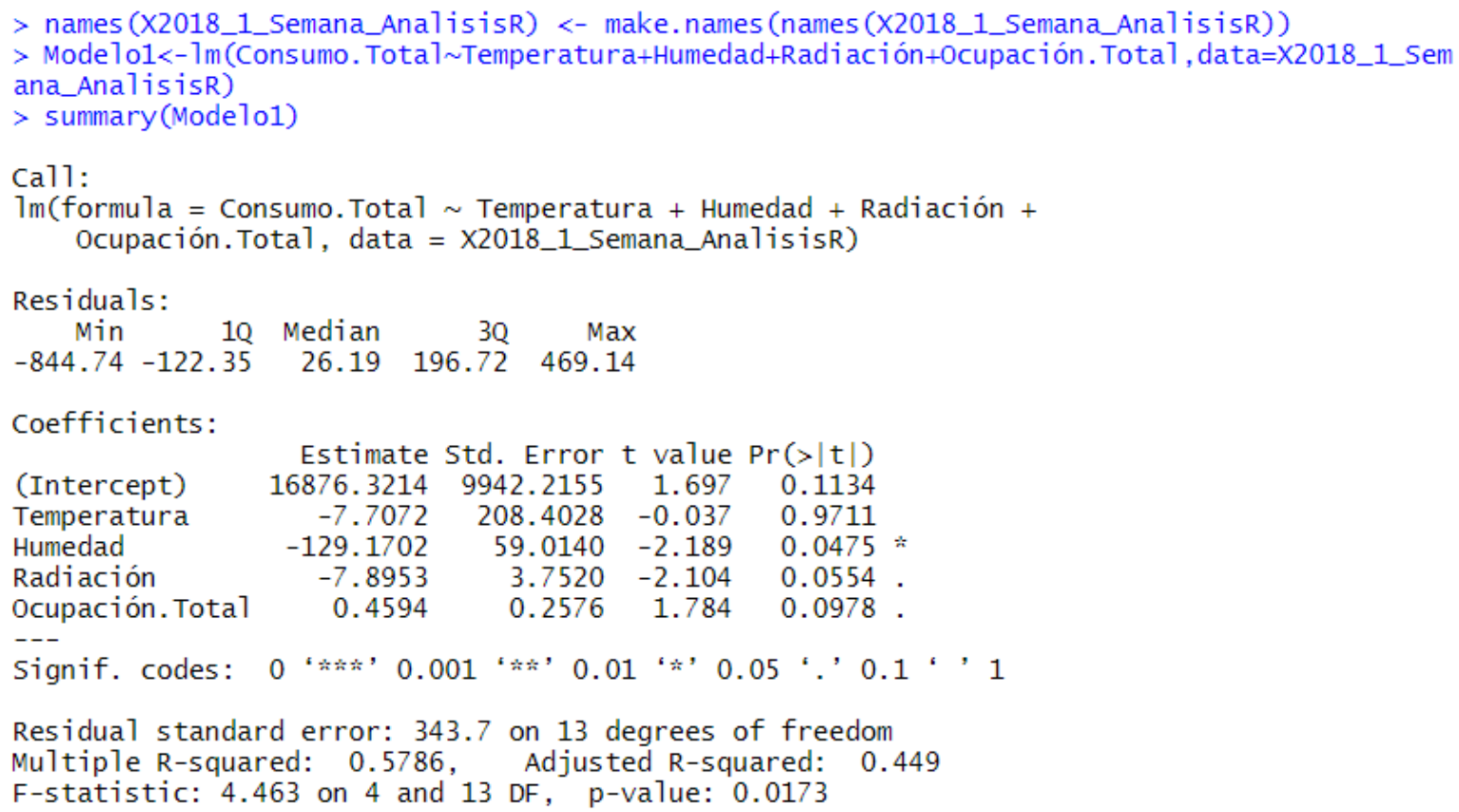

Al realizar las pruebas para verificar el cumplimiento de los supuestos estadisticos por parte del modelo desarrollado (Prueba global (gvlma de R Studio) y prueba VIF), se encontró que el modelo no cumple en su totalidad con los supuestos estadisticos.

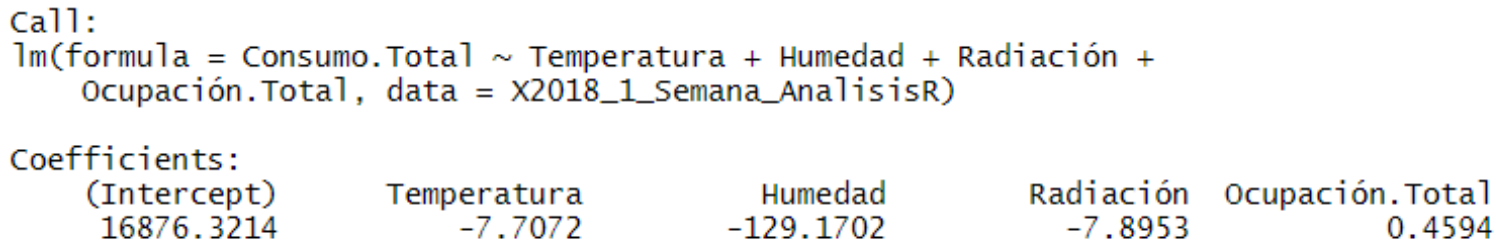

$3.526093 \quad 1.560588$




\section{Periodo $2018-3$}

La Tabla 102. Presenta los datos medidos para el periodo 2018 - 3.

Tabla 102. Datos semanales - Semestre 3 del 2018.

\begin{tabular}{|c|c|c|c|c|c|c|}
\hline Semana & $\begin{array}{c}\text { Temperatura } \\
{\left[{ }^{\circ} \mathbf{C}\right]}\end{array}$ & $\begin{array}{c}\text { Humedad } \\
{[\mathbf{\%}]}\end{array}$ & $\begin{array}{c}\text { Radiación } \\
{[\mathbf{W} / \mathbf{m} \mathbf{}]}\end{array}$ & $\begin{array}{c}\text { Ocupación } \\
{[\text { horas }]}\end{array}$ & $\begin{array}{c}\text { Consumo } \\
\text { Total } \\
{[\mathbf{k W h}]}\end{array}$ & $\begin{array}{c}\text { Tipo de } \\
\text { Semana }\end{array}$ \\
\hline $\mathbf{3 0}$ & $\mathbf{2 4 , 2 9}$ & 75,86 & 355,96 & 619,50 & 4088,809 & Semestre \\
\hline $\mathbf{3 1}$ & 23,64 & 77,97 & 359,43 & 644,17 & 4115,94 & Semestre \\
\hline $\mathbf{3 2}$ & 24,15 & 70,53 & 333,94 & 771,50 & 3822,71 & Semestre \\
\hline $\mathbf{3 3}$ & 25,08 & 70,17 & 390,96 & 818,00 & 4257,771 & Semestre \\
\hline $\mathbf{3 6}$ & 25,28 & 68,41 & 384,73 & 1006,50 & 4512,883 & Semestre \\
\hline $\mathbf{3 9}$ & $\mathbf{2 5 , 6 6}$ & 68,40 & 422,90 & 1160,50 & 4586,678 & Semestre \\
\hline $\mathbf{4 0}$ & 25,10 & 70,62 & 456,87 & 1178,00 & 4732,091 & Semestre \\
\hline $\mathbf{4 1}$ & 23,31 & 76,17 & 386,45 & 1218,00 & 3718,854 & Semestre \\
\hline $\mathbf{4 2}$ & 24,53 & 73,81 & 393,36 & 1353,50 & 3985,087 & Semestre \\
\hline $\mathbf{4 3}$ & 24,39 & 76,15 & 394,03 & 1554,50 & 3825,184 & Semestre \\
\hline $\mathbf{4 4}$ & 23,65 & 80,55 & 358,06 & 1618,50 & 3093,856 & Semestre \\
\hline $\mathbf{4 5}$ & 23,76 & 80,51 & 373,16 & 1692,00 & 3539,902 & Semestre \\
\hline $\mathbf{4 6}$ & 24,49 & 78,84 & 359,11 & 1553,00 & 3732,104 & Semestre \\
\hline $\mathbf{4 7}$ & 24,24 & 79,82 & 332,53 & 1310,00 & 3182,082 & Semestre \\
\hline $\mathbf{4 8}$ & 22,85 & 83,66 & 322,75 & 1111,33 & 2471,073 & Semestre \\
\hline
\end{tabular}

Se construyó un modelo de regresión lineal multivariable con todas las variables disponibles (Temperatura, Humedad, Radiación y Ocupación Total).

Cal1:

$1 \mathrm{~m}$ (formu1a $=$ Consumo. Total $\sim$ Temperatura + Humedad + Radiación + Ocupación.Tota1, data $=$ X2018_3_Semana_Fi1trado_1_85)

Residuals:

Min 10 Median $30 \quad$ Max

$\begin{array}{lllll}-204.476 & -55.812 & -4.824 & 145.446 & 219.503\end{array}$

Coefficients:

(Intercept)

Temperatura

Humedad

Radiación

Ocupación. Total

---

Signif. codes: 0 ' $* * * 0.001$

Estimate Std. Error $\mathrm{t}$ value $\operatorname{Pr}(>|\mathrm{t}|)$

$\begin{array}{lll}-2881.2476 & 4573.5470 & -0.630\end{array}$

191.8413

$-6.2413$

9.0069

124.0978

24.1854

2.7077

1.546

$-0.258$

3.326

$0.1964-3.434$

0.5463

0.1607

0.8029

$0.0104 *$

$0.0089 * *$

Residual standard error: 177.3 on 8 degrees of freedom Multiple R-squared: 0.8965 , Adjusted R-squared: 0.8447

F-statistic: 17.31 on 4 and 8 DF, p-value: 0.0005272 
El análisis estadístico de las variables, muestra que las variables Temperatura y Humedad no son significativas en el modelo, dado que su $p$ value es mayor a 0,05. En este caso, las variables significativas para describir el comportamiento del Consumo Total de energía son Ocupación Total y Radiación.

Para obtener las variables más apropiadas para definir el modelo de regresión multivariable, se utilizó la función step del software estadístico $\mathrm{R}$ Studio, que permite realizar una regresión gradual que agrega y elimina iterativamente predictores (variables independientes) en el modelo de regresión, para encontrar el subconjunto de variables que da como resultado el modelo con mejor rendimiento, siendo un modelo que reduce el error de predicción.

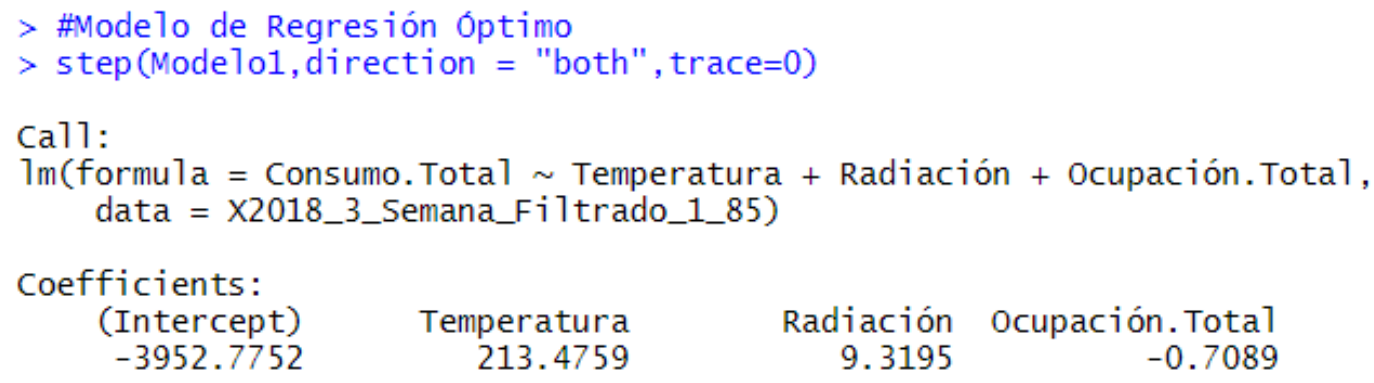

Empleando la función en los datos del modelo, se obtuvo que el mejor modelo de regresión lineal multivariable es el compuesto por las variables Temperatura, Radiación y Ocupación Total, dando así lugar al siguiente modelo:

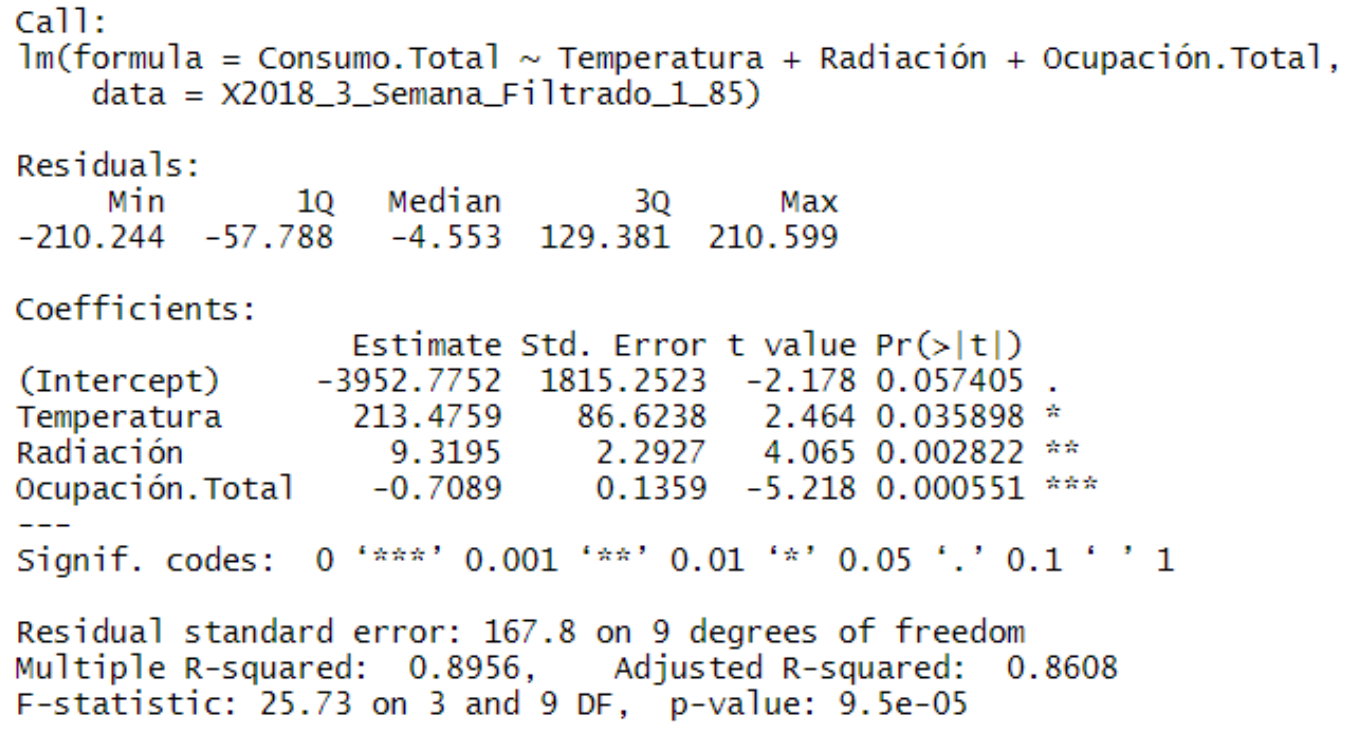

Ahora, el modelo desarrollado se describe como:

Electricidad $_{\text {lineabase }}$

$$
=213,47 \cdot \text { Temperatura }+9,31 \cdot \text { Radiación }-0,708 \cdot \text { Ocupación }-3952,7+\varepsilon_{i}
$$


El modelo tiene un $R^{2}$ Ajustado=0,8608 que indica que el modelo explica el $86,08 \%$ de la variabilidad de las observaciones (datos), el valor de $R^{2}$ Ajustado mide el porcentaje de la variación en la respuesta que es explicada por el modelo, pero ajustado al número de variables predictoras del mismo. El modelo tiene un valor $\mathrm{p}$ de $9,5 \times 10^{-3}$ para el estadístico $\mathrm{F}$ que indica que la relación lineal es estadísticamente significativa $\left(9,5 \times 10^{-3}<0,05\right)$.

En cuanto a los intervalos de confianza del modelo se presenta el rango o nivel de significancia del mismo en las siguientes ecuaciones que describen el modelo de regresión lineal multivariable.

$>$ confint(Modelo2)

$\begin{array}{lrr}\text { (Intercept) } & 2.5 \% & 97.5 \% \\ \text { Temperatura } & -8059.161339 & 153.6108630 \\ \text { Radiación } & 17.519291 & 409.4325911 \\ \text { Ocupación. Total } & 4.132961 & 14.5059728 \\ & -1.016190 & -0.4015549\end{array}$

Electricidad $_{L B(2,5 \%)}$

$$
\begin{array}{r}
=17,52 \cdot \text { Temperatura }+4,13 \cdot \text { Radiación }-1,02 \cdot \text { Ocupación }-8059,16+\varepsilon_{i} \\
\text { Electricidad }_{L B(97,5 \%)} \\
=409,43 \cdot \text { Temperatura }+14,51 \cdot \text { Radiación }-0,40 \cdot \text { Ocupación }+153,61+\varepsilon_{i}
\end{array}
$$

Para garantizar que el modelo desarrollado es válido, se prueban los mismos supuestos estadísticos que para el modelo de regresión lineal univariable, adicionando la prueba de multicolinealidad.

\section{a. Linealidad}

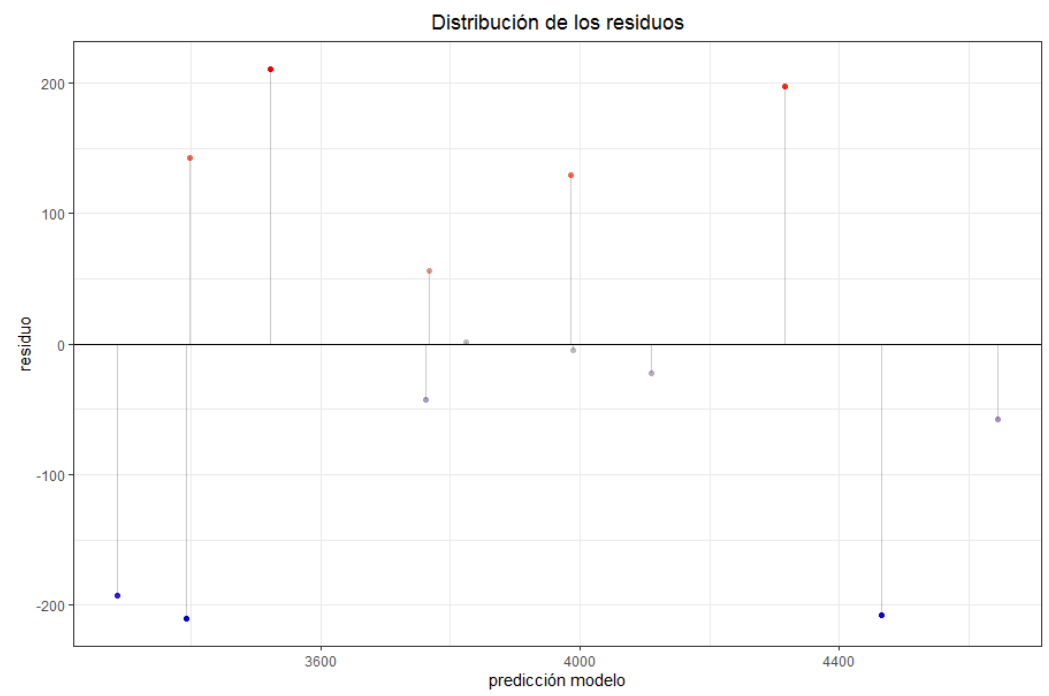

La gráfica de distribución de los residuos, muestra que los residuos se distribuyen de forma aleatoria entorno al 0 por lo que se acepta el supuesto de linealidad. 


\section{b. Normalidad:}

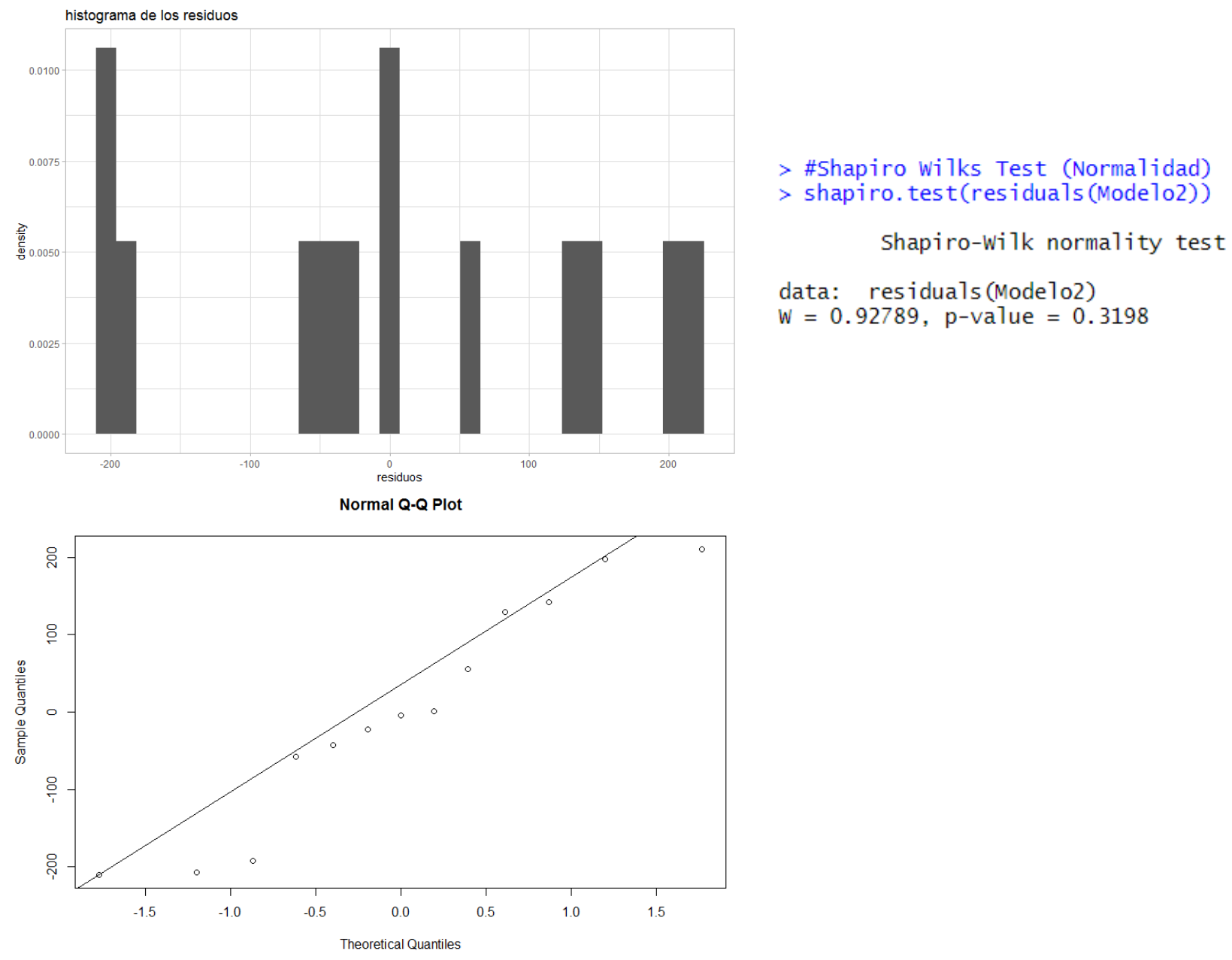

La representación por medio del histograma presenta que los residuos se distribuyen de forma normal con media 0 . El gráfico $Q-Q$ que sitúa los cuartiles de la distribución de la muestra respecto a los cuartiles del modelo de distribución normal, presenta que ambas distribuciones siguen un comportamiento sobre una línea recta y se acepta el supuesto de linealidad. Además, el estadístico Shapiro Wilks obtiene un $\mathrm{P}$ value de 0,3198 que resulta $\geq$ 0,05 .

Tanto la representación gráfica como el contraste de hipótesis confirman la distribución normal de los residuos. 


\section{c. Homocedasticidad}

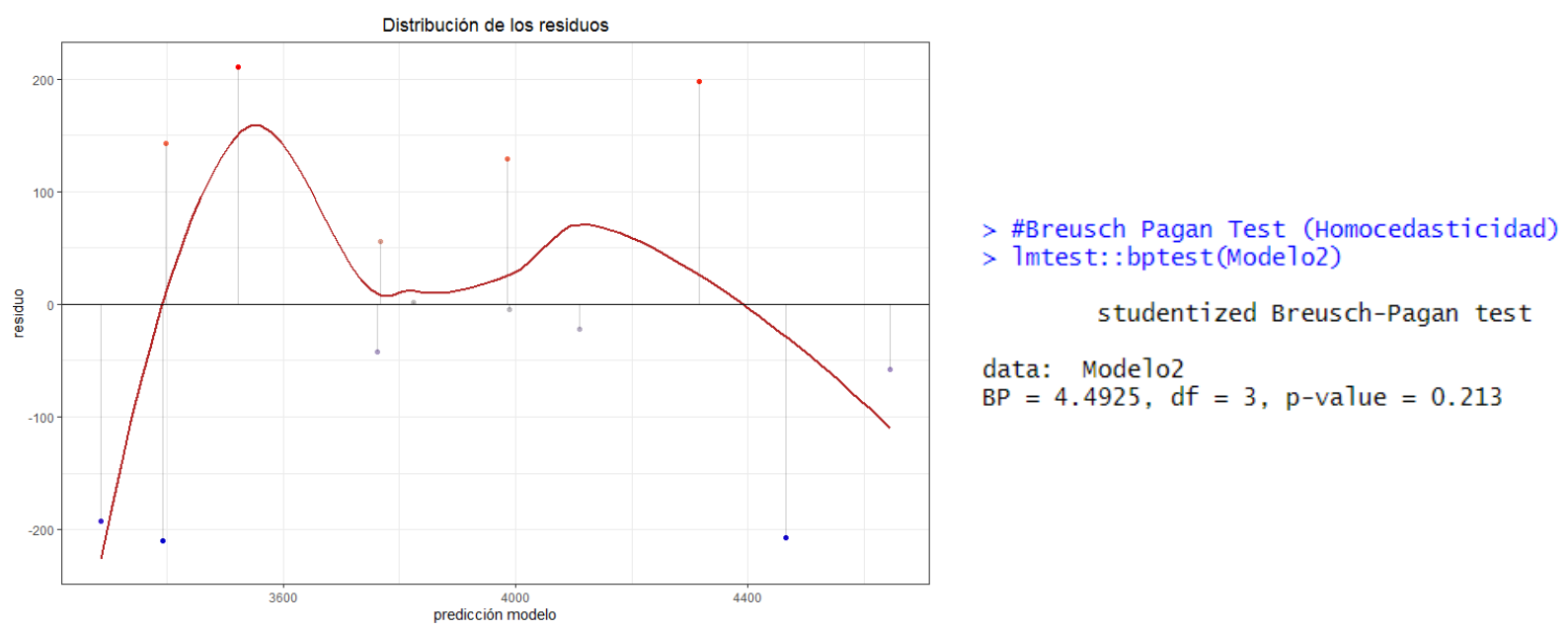

El análisis de la gráfica de distribución de los residuos muestra que la variabilidad de los residuos es constante a lo largo del eje $X$ (el tamaño de los residuos no aumenta ni disminuye de forma sistémica ni significativa con variaciones de y) y la prueba estadística de Breusch Pagan arroja un $P$ value de 0,213 que resulta $\geq 0,05$.

$\mathrm{Ni}$ la representación gráfica ni el contraste de hipótesis muestran evidencias sobre la falta de homocedasticidad.

\section{d. Independencia}

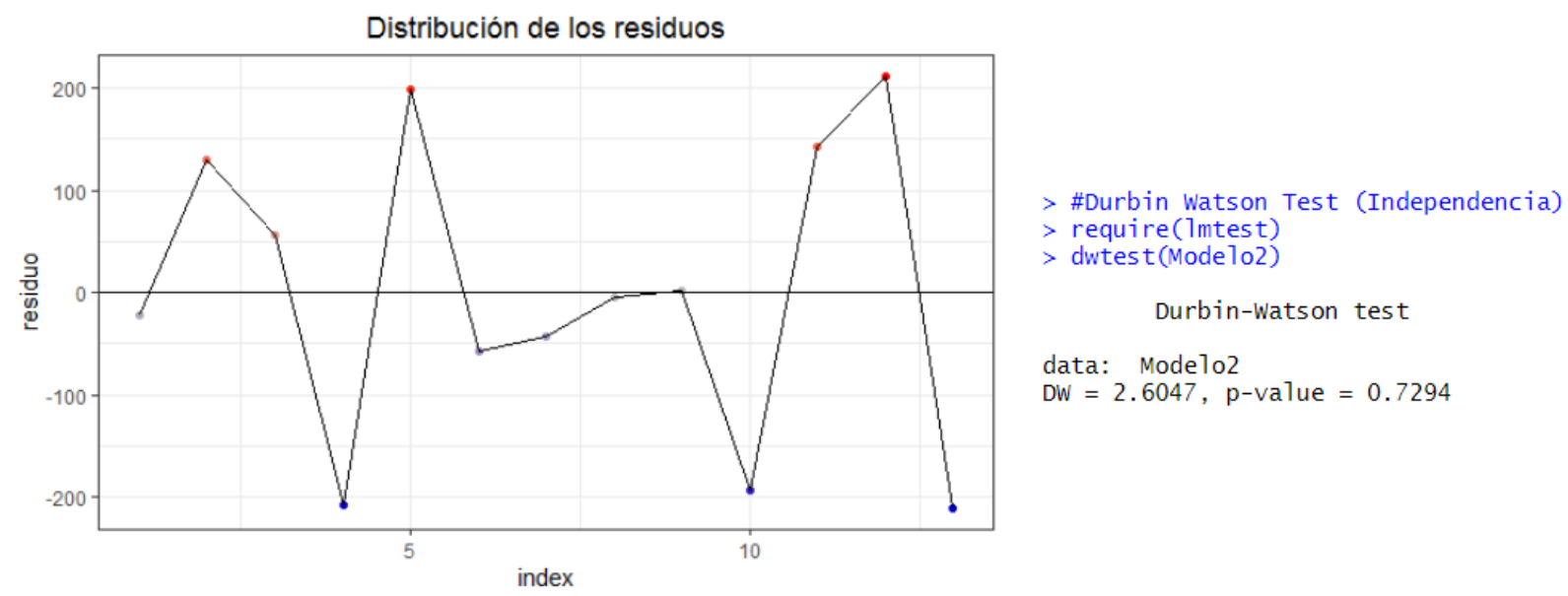

La representación gráfica de los residuos muestra que los residuos no tienen ninguna tendencia marcada y no poseen algún tipo de autocorrelación entre ellos, es decir, que son independientes, El estadístico de Durbin Watson, confirma que no hay problemas de independencia al obtenerse un $P$ value de $0,7294 \geq 0,05$. 


\section{e. Multicolinealidad}

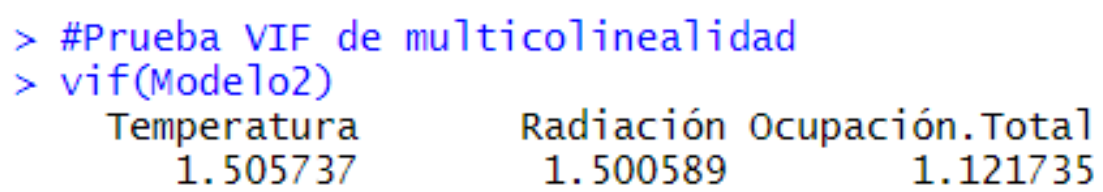

Como los valores de VIF (Factor de Inflación de Varianza) para cada variable es menor a 10, el modelo no presenta problemas de multicolinealidad.

\section{Ajuste de bondad del modelo de regresión lineal}

En la Tabla 103, se presenta la prueba de bondad de ajuste del modelo de regresión lineal multivariable. Esta prueba se realiza empleando la ecuación obtenida y los datos originales con los que fue creado el modelo, su fin es obtener el error porcentual absoluto medio (MAPE) del modelo y así conocer que también se ajusta a sus datos originales. EI MAPE indica el tamaño del error del pronóstico debido a que se toma sólo la magnitud del error (valor absoluto), lo cual da la idea de la exactitud esperada del pronóstico. El modelo desarrollado tiene un MAPE del 13,15\%.

Tabla 103. Ajuste de bondad del modelo de regresión lineal

\begin{tabular}{|c|c|c|c|c|c|c|}
\hline \multirow[b]{2}{*}{ Semana } & \multicolumn{6}{|c|}{$2018-3$} \\
\hline & $\begin{array}{c}\text { Consumo } \\
\text { Real }\end{array}$ & $\begin{array}{l}\text { Consumo } \\
\text { Estimado }\end{array}$ & Error & $\begin{array}{c}\text { Error } \\
\text { Porcentual }\end{array}$ & Error Absoluto & $\begin{array}{c}\text { Error } \\
\text { Absoluto } \\
\text { Porcentual }\end{array}$ \\
\hline 30 & 4088,809 & 4107,868 & $-19,06$ & $-0,47 \%$ & 19,06 & $0,5 \%$ \\
\hline 31 & 4115,94 & 3983,952 & 131,99 & $3,21 \%$ & 131,99 & $3,2 \%$ \\
\hline 32 & 3822,71 & 3765,36 & 57,35 & $1,50 \%$ & 57,35 & $1,5 \%$ \\
\hline 33 & 4257,771 & 4461,821 & $-204,05$ & $-4,79 \%$ & 204,05 & $4,8 \%$ \\
\hline 36 & 4512,883 & 4313,056 & 199,83 & $4,43 \%$ & 199,83 & $4,4 \%$ \\
\hline 39 & 4586,678 & 4640,505 & $-53,83$ & $-1,17 \%$ & 53,83 & $1,2 \%$ \\
\hline 40 & 4732,091 & 4824,833 & $-92,74$ & $-1,96 \%$ & 92,74 & $2,0 \%$ \\
\hline 41 & 3718,854 & 3758,791 & $-39,94$ & $-1,07 \%$ & 39,94 & $1,1 \%$ \\
\hline 42 & 3985,087 & 3987,623 & $-2,54$ & $-0,06 \%$ & 2,54 & $0,1 \%$ \\
\hline 43 & 3825,184 & 3821,667 & 3,52 & $0,09 \%$ & 3,52 & $0,1 \%$ \\
\hline 44 & 3093,856 & 3283,506 & $-189,65$ & $-6,13 \%$ & 189,65 & $6,1 \%$ \\
\hline 45 & 3539,902 & 3395,531 & 144,37 & $4,08 \%$ & 144,37 & $4,1 \%$ \\
\hline 46 & 3732,104 & 3518,97 & 213,13 & $5,71 \%$ & 213,13 & $5,7 \%$ \\
\hline 47 & 3182,082 & 3390,187 & $-208,11$ & $-6,54 \%$ & 208,11 & $6,5 \%$ \\
\hline 48 & 2471,073 & 3143,07 & $-672,00$ & $-27,19 \%$ & 672,00 & $27,2 \%$ \\
\hline \multicolumn{3}{|c|}{ Medidas de Error de Pronóstico } & ME & MPE & MAE & MAPE \\
\hline \multicolumn{3}{|c|}{ Valores } & $-222,32$ & $-9,34 \%$ & 364,41 & $13,15 \%$ \\
\hline
\end{tabular}




\section{Validación del modelo y capacidad de pronóstico}

La información que se utilizó para crear el modelo corresponde al tercer semestre del 2018, para realizar la validación del mismo se usaron los datos de las 3 semanas del semestre siguiente 2019 - 1. Para el modelo, se evalúa el error porcentual absoluto medio (MAPE) y se usa como referencia para conocer el error de pronóstico del modelo.

La Tabla 104. Presenta los valores obtenidos al evaluar la capacidad de pronóstico del modelo de regresión lineal multivariable semanal, con un MAPE del 6,95\% que representa el error de pronóstico del modelo.

Tabla 104. Capacidad de pronóstico del modelo de Regresión lineal multivariable semanal

\begin{tabular}{|c|c|c|c|c|c|c|}
\hline $\begin{array}{l}\text { Semana } \\
2019 \text { - } 1\end{array}$ & $\begin{array}{c}\text { Consumo } \\
\text { Real }\end{array}$ & $\begin{array}{l}\text { Consumo } \\
\text { Estimado }\end{array}$ & Error & $\begin{array}{c}\text { Error } \\
\text { Porcentual }\end{array}$ & $\begin{array}{c}\text { Error } \\
\text { Absoluto }\end{array}$ & $\begin{array}{c}\text { Error } \\
\text { Absoluto } \\
\text { Porcentual }\end{array}$ \\
\hline 6 & 4430,55 & 3845,18 & 585,37 & $13,21 \%$ & 585,37 & $13,2 \%$ \\
\hline 7 & 4881,30 & 4829,09 & 52,21 & $1,07 \%$ & 52,21 & $1,1 \%$ \\
\hline 8 & 4743,08 & 4432,16 & 310,92 & $6,56 \%$ & 310,92 & $6,6 \%$ \\
\hline \multicolumn{3}{|c|}{ Medidas de Error de Pronóstico } & ME & MPE & MAE & MAPE \\
\hline \multicolumn{3}{|c|}{ Valores } & 316,16 & $6,95 \%$ & 316,16 & $6,95 \%$ \\
\hline
\end{tabular}

Los resultados obtenidos en cada uno de los modelos nos muestran algunas ventajas relacionadas con la preparación de los datos y el tiempo de reporte de la información de la de la línea de base energética para una edificación, desde la utilización de datos mensuales, semanales y diarios. De igual forma los resultados que este análisis puede aportar a los ahorros energéticos y seguimiento de indicadores que se pueden obtener en una edificación cuando se emplea tratamiento estadístico y validación a los resultados obtenidos. Elemento que constituyen un aporte para la implementación de sistemas de gestión energética.

\subsubsection{Modelos de Regresión Lineal para el año 2019}

Una vez obtenidos los datos climáticos, de ocupación y consumo del año 2019 se desarrollaron varios modelos de regresión lineal según los datos y la periodicidad de los mismos.

\section{Modelo Mensual}

La Tabla 105. Presenta la información mensual de las variables monitoreadas para el edificio para el año 2019. 
Tabla 105. Información mensual de variables monitoreadas en el edificio para el 2019

\begin{tabular}{|c|c|c|c|c|c|}
\hline Mes/Variable & $\begin{array}{c}\text { Temperatura } \\
{\left[{ }^{\circ} \mathbf{C}\right]}\end{array}$ & $\begin{array}{c}\text { Humedad } \\
{[\%]}\end{array}$ & $\begin{array}{c}\text { Radiación } \\
{[\mathbf{W} / \mathbf{m} 2]}\end{array}$ & $\begin{array}{c}\text { Ocupación } \\
{[\text { horas] }}\end{array}$ & $\begin{array}{c}\text { Consumo Total } \\
{[\mathbf{k W h}]}\end{array}$ \\
\hline Enero & 24,36 & 73,75 & 401,43 & 694,00 & 8157,39 \\
\hline Febrero & 24,79 & 74,98 & 391,62 & 3776,00 & 18338,60 \\
\hline Marzo & 24,75 & 75,21 & 391,16 & 3893,50 & 19270,85 \\
\hline Abril & 26,16 & 72,55 & 394,59 & 3259,00 & 15445,27 \\
\hline Mayo & 25,56 & 74,20 & 354,94 & 4223,00 & 18875,69 \\
\hline Junio & 24,32 & 79,25 & 363,57 & 2249,00 & 12134,52 \\
\hline Julio & 24,72 & 71,83 & 399,34 & 4188,00 & 20270,80 \\
\hline Agosto & 25,29 & 65,39 & 453,03 & 5340,00 & 24242,27 \\
\hline Septiembre & 24,96 & 69,86 & 414,62 & 5711,50 & 22723,39 \\
\hline Octubre & 23,62 & 77,72 & 402,03 & 6395,50 & 21390,40 \\
\hline Noviembre & 23,79 & 78,55 & 365,73 & 5424,80 & 17109,19 \\
\hline Diciembre & 24,31 & 76,44 & 364,82 & 1053,50 & 10417,76 \\
\hline
\end{tabular}

Se construyó el modelo de regresión lineal óptimo en el software estadístico R Studio.

Cal1:

1m(formula $=$ Consumo.Eléctrico $\sim$ Humedad + Ocupación, data $=$ X2019_Mensua1)

Residuals:

Min 10 Median $3 Q$ Max

$\begin{array}{lllll}-2126.8 & -796.1 & 180.2 & 803.3 & 2236.3\end{array}$

Coefficients:

$\begin{array}{lrrrrr} & \text { Estimate } & \text { Std. Error } \mathrm{t} \text { value } \operatorname{Pr}(>|\mathrm{t}|) & \\ \text { (Intercept) } & 38239.9325 & 9145.2804 & 4.181 & 0.00237 & * \\ \text { Humedad } & -401.6449 & 119.3429 & -3.365 & 0.00832 & * * \\ \text { Ocupación } & 2.3123 & 0.2596 & 8.908 & 9.28 \mathrm{e}-06 & * * *\end{array}$

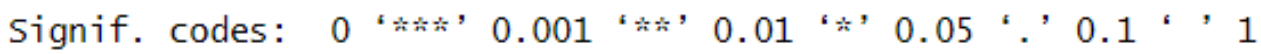

Residual standard error: 1505 on 9 degrees of freedom

Multiple R-squared: 0.9249 , Adjusted R-squared: 0.9082

F-statistic: 55.44 on 2 and 9 DF, p-value: $8.705 \mathrm{e}-06$

El modelo desarrollado se describe como:

$$
\text { Electricidad }_{\text {lineabase }}=-401,64 \cdot \text { Humedad }+2,31 \cdot \text { Ocupación }+38239,93+\varepsilon_{i}
$$

El modelo tiene un $R^{2}$ Ajustado=0,9082 indica que el modelo explica el $90,82 \%$ de la variabilidad de las observaciones (datos), El valor de $R^{2}$ ajustado mide el porcentaje de la variación en la respuesta siendo explicada por el modelo, sin embargo, se ajusta al número de variables predictoras en el modelo, El modelo tiene un valor $p$ de $8,7 \times 10^{-6}$ para el estadístico $\mathrm{F}$ que indica que la relación lineal es estadísticamente significativa $\left(8,7 \times 10^{-6}<0,05\right)$. 
Para garantizar que el modelo desarrollado es válido, se realizó la prueba global de supuestos estadísticos y la prueba de multicolinealidad.

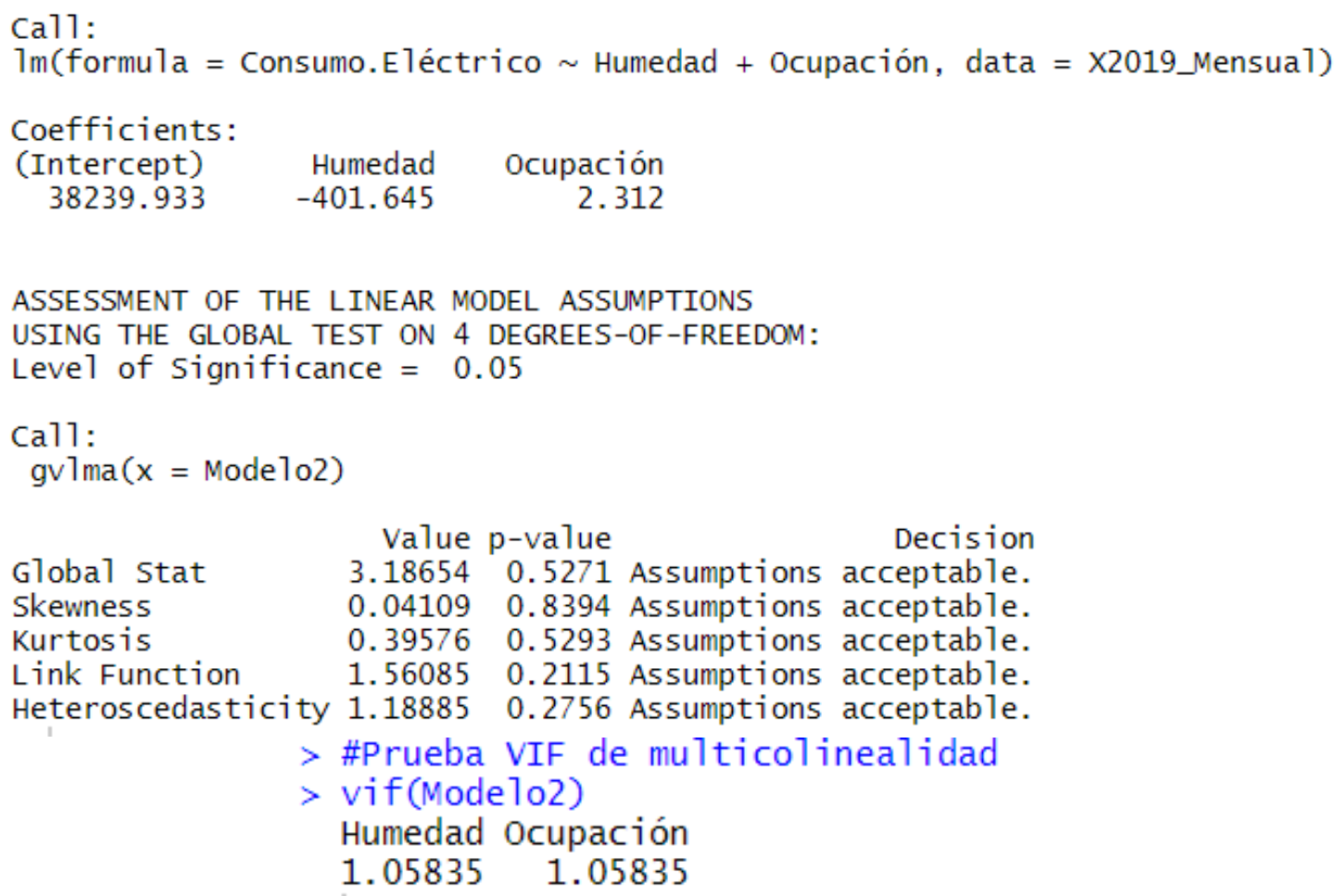

Los resultados de la prueba global (gvlma) y la prueba VIF para multicolinealidad, confirman que el modelo de regresión desarrollado cumple con los supuestos estadísticos y es válido para cuantificar el consumo de energía en función de las variables relevantes "humedad" y "ocupación Total".

\section{Modelo Semanal}

La Tabla 106, presenta la información semanal de las variables monitoreadas para el edificio para el año 2019.

Tabla 106. Información semanal de las variables monitoreadas en el edificio para el año 2019

\begin{tabular}{|c|c|c|c|c|c|}
\hline Semana & $\begin{array}{c}\text { Temperatura } \\
{\left[{ }^{\mathbf{C}} \mathbf{C}\right]}\end{array}$ & $\begin{array}{c}\text { Humedad } \\
{[\%]}\end{array}$ & $\begin{array}{c}\text { Radiación } \\
{[\mathbf{W} / \mathbf{m} \mathbf{2}]}\end{array}$ & $\begin{array}{c}\text { Ocupación } \\
{[\text { horas] }}\end{array}$ & $\begin{array}{c}\text { Consumo Total } \\
{[\mathbf{k W h}]}\end{array}$ \\
\hline $\mathbf{1}$ & 24,91 & 69,73 & 477,03 & 0,00 & 1352,01 \\
\hline $\mathbf{2}$ & 22,57 & 80,20 & 302,76 & 0,00 & 1282,69 \\
\hline $\mathbf{3}$ & 24,29 & 74,33 & 355,27 & 0,00 & 1760,23 \\
\hline $\mathbf{4}$ & 25,63 & 69,90 & 498,10 & 0,00 & 1970,34 \\
\hline $\mathbf{5}$ & 24,24 & 76,55 & 366,78 & 852,00 & 2688,81 \\
\hline $\mathbf{6}$ & 24,76 & 75,31 & 341,03 & 934,50 & 4430,55 \\
\hline $\mathbf{7}$ & 25,54 & 70,43 & 429,74 & 948,00 & 4881,30 \\
\hline $\mathbf{8}$ & 24,64 & 77,61 & 410,04 & 979,00 & 4743,08 \\
\hline $\mathbf{9}$ & 24,37 & 74,14 & 415,42 & 962,50 & 4664,74 \\
\hline
\end{tabular}




\begin{tabular}{|c|c|c|c|c|c|}
\hline 10 & 25,59 & 70,78 & 434,79 & 950,00 & 4763,52 \\
\hline 11 & 24,86 & 75,40 & 384,66 & 961,50 & 4600,34 \\
\hline 12 & 23,47 & 81,07 & 318,53 & 960,00 & 4452,79 \\
\hline 13 & 25,33 & 74,10 & 410,54 & 816,00 & 4142,01 \\
\hline 14 & 25,36 & 74,68 & 350,57 & 968,00 & 4495,67 \\
\hline 15 & 27,20 & 67,22 & 483,71 & 977,50 & 4522,65 \\
\hline 16 & 25,46 & 76,08 & 352,19 & 0,00 & 1151,32 \\
\hline 17 & 26,35 & 72,92 & 404,77 & 966,50 & 4276,74 \\
\hline 18 & 27,79 & 66,15 & 401,73 & 782,00 & 3970,04 \\
\hline 19 & 26,43 & 71,72 & 338,52 & 941,50 & 4257,00 \\
\hline 20 & 25,37 & 74,85 & 334,78 & 957,50 & 4553,22 \\
\hline 21 & 24,58 & 77,91 & 373,33 & 991,50 & 4570,51 \\
\hline 22 & 23,57 & 80,92 & 329,27 & 981,50 & 4003,17 \\
\hline 23 & 24,13 & 79,59 & 348,42 & 809,00 & 2632,40 \\
\hline 24 & 24,15 & 81,12 & 372,54 & 394,00 & 3831,92 \\
\hline 25 & 24,78 & 77,95 & 352,43 & 624,50 & 3319,15 \\
\hline 26 & 24,37 & 78,04 & 378,87 & 337,50 & 1911,52 \\
\hline 27 & 24,77 & 72,22 & 380,29 & 1155,50 & 3883,44 \\
\hline 28 & 24,65 & 70,76 & 396,25 & 936,50 & 4338,04 \\
\hline 29 & 25,08 & 70,06 & 430,69 & 748,00 & 5634,30 \\
\hline 30 & 24,22 & 74,90 & 371,03 & 730,50 & 4364,22 \\
\hline 31 & 25,08 & 71,10 & 414,40 & 1190,00 & 5471,80 \\
\hline 32 & 25,55 & 67,06 & 469,17 & 1029,00 & 5370,51 \\
\hline 33 & 25,22 & 61,92 & 452,15 & 1302,50 & 5959,31 \\
\hline 34 & 25,05 & 64,17 & 476,28 & 1115,50 & 5033,77 \\
\hline 35 & 25,50 & 65,04 & 434,95 & 1320,50 & 5949,49 \\
\hline 36 & 25,75 & 64,98 & 430,62 & 1354,00 & 6178,90 \\
\hline 37 & 26,30 & 64,62 & 406,20 & 1365,50 & 6276,09 \\
\hline 38 & 23,46 & 76,48 & 352,93 & 1417,00 & 4718,13 \\
\hline 39 & 24,50 & 72,04 & 459,89 & 1348,00 & 4899,27 \\
\hline 40 & 23,30 & 78,70 & 400,92 & 1426,00 & 4557,72 \\
\hline 41 & 23,92 & 76,36 & 423,16 & 1550,00 & 5365,00 \\
\hline 42 & 23,43 & 77,93 & 433,47 & 1218,00 & 4529,88 \\
\hline 43 & 23,45 & 79,60 & 384,64 & 1403,50 & 4636,99 \\
\hline 44 & 24,28 & 74,59 & 384,33 & 1373,00 & 5048,91 \\
\hline 45 & 24,23 & 77,19 & 442,11 & 1217,00 & 5009,57 \\
\hline 46 & 22,72 & 84,52 & 278,50 & 1229,50 & 3762,01 \\
\hline 47 & 23,18 & 79,19 & 375,78 & 1369,30 & 3252,12 \\
\hline 48 & 24,97 & 74,72 & 358,54 & 1261,00 & 4173,76 \\
\hline 49 & 24,05 & 75,47 & 355,36 & 558,00 & 3279,15 \\
\hline 50 & 23,65 & 77,02 & 352,04 & 322,50 & 2552,07 \\
\hline
\end{tabular}




\begin{tabular}{|l|c|c|c|c|c|}
\hline $\mathbf{5 1}$ & 24,24 & 78,01 & 361,22 & 173,00 & 2309,01 \\
\hline $\mathbf{5 2}$ & 25,31 & 74,29 & 371,43 & 0,00 & 1597,90 \\
\hline
\end{tabular}

Se construyó el modelo de regresión lineal óptimo en el software estadístico R Studio.

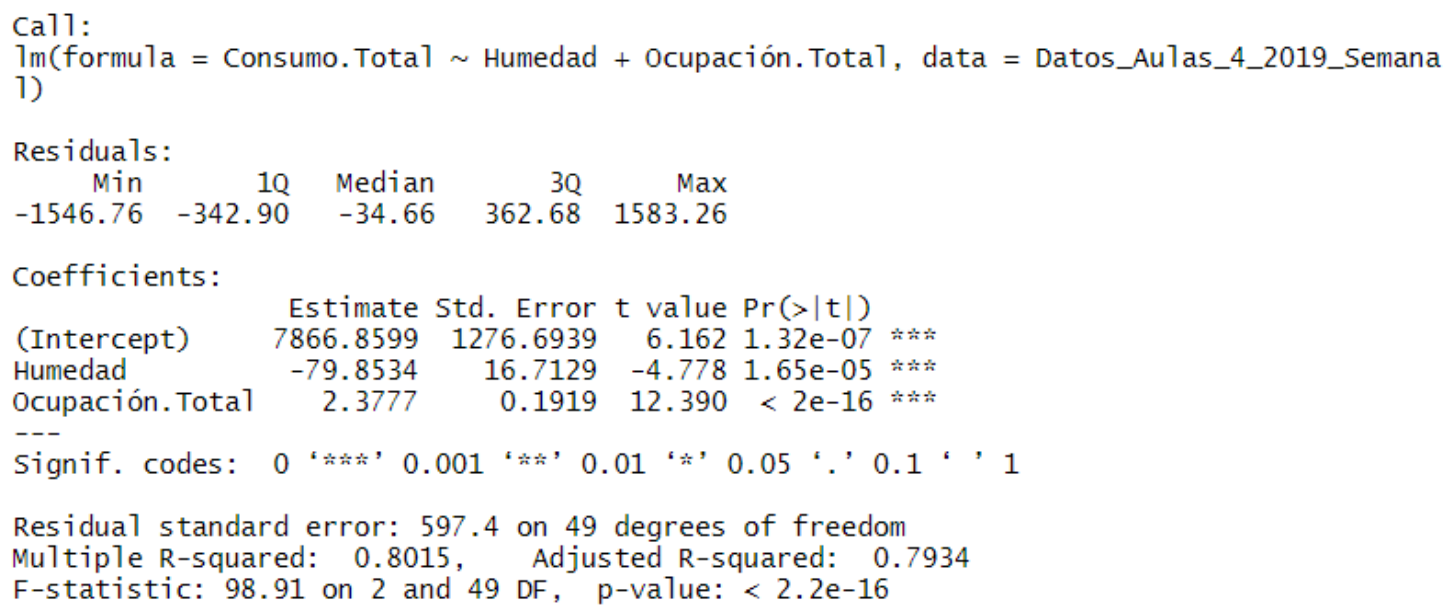

El modelo desarrollado se describe como:

$$
\text { Electricidad }_{\text {lineabase }}=-79,85 \cdot \text { Humedad }+2,37 \cdot \text { Ocupación }+7866,86+\varepsilon_{i}
$$

El modelo tiene un $R^{2}$ Ajustado=0,7934 indica que el modelo explica el $79,34 \%$ de la variabilidad de las observaciones (datos), El valor de $R^{2}$ ajustado mide el porcentaje de la variación en la respuesta siendo explicada por el modelo, sin embargo, se ajusta al número de variables predictoras en el modelo, El modelo tiene un valor $p<2,2 \times 10^{-16}$ para el estadístico $\mathrm{F}$ que indica que la relación lineal es estadísticamente significativa $\left(2,2 \times 10^{-16}<0,05\right)$.

Para garantizar que el modelo desarrollado es válido, se realizó la prueba global de supuestos estadísticos y la prueba de multicolinealidad.

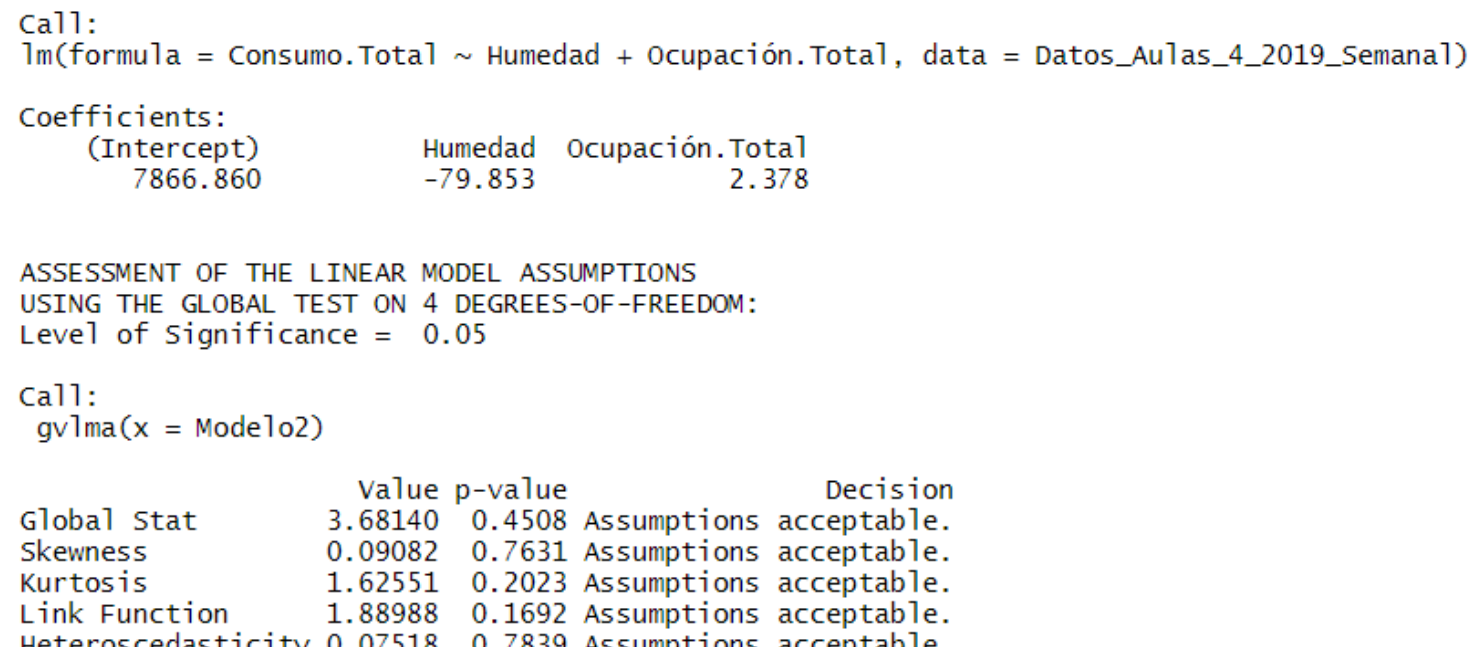




\section{$>$ \#Prueba VIF de multicolinealidad \\ $>\operatorname{vif(Modelo2)}$ \\ Humedad Ocupación. Total \\ $1.021707 \quad 1.021707$}

Los resultados de la prueba global (gvlma) y la prueba VIF para multicolinealidad, confirman que el modelo de regresión desarrollado cumple con los supuestos estadísticos y es válido para cuantificar el consumo de energía en función de las variables relevantes "humedad" y "ocupación Total".

\section{Modelo Diario}

Con la información diaria disponible se desarrollaron modelos de regresión lineal para cada mes iniciando desde febrero (enero no se tuvo en cuenta, pues la ocupación del edificio es casi nula). Para cada mes se obtuvo el modelo de regresión óptimo y la validación de los supuestos estadísticos como se presenta a continuación para el mes de marzo.

La Tabla 107, presenta la información diaria de las variables monitoreadas para el edificio para marzo de 2019.

Tabla 107. Información diaria de las variables monitoreadas para marzo

\begin{tabular}{|c|c|c|c|c|c|}
\hline Día & $\begin{array}{c}\text { Temperatura } \\
{\left[{ }^{\circ} \mathbf{C}\right]}\end{array}$ & $\begin{array}{c}\text { Humedad } \\
{[\%]}\end{array}$ & $\begin{array}{c}\text { Radiación } \\
{[\mathbf{W} / \mathbf{m} \mathbf{]}]}\end{array}$ & $\begin{array}{c}\text { Ocupación } \\
{[\text { horas] }}\end{array}$ & $\begin{array}{c}\text { Consumo Total } \\
{[\mathbf{k W h}]}\end{array}$ \\
\hline $\mathbf{1 / 0 3 / 2 0 1 9}$ & 24,19 & 74,87 & 397,58 & 131,50 & 683,29 \\
\hline $\mathbf{2 / 0 3 / 2 0 1 9}$ & 24,41 & 72,62 & 460,41 & 74,50 & 467,61 \\
\hline $\mathbf{3 / 0 3 / 2 0 1 9}$ & 24,00 & 74,59 & 428,35 & 0,00 & 183,44 \\
\hline $\mathbf{4 / 0 3 / 2 0 1 9}$ & 25,01 & 70,74 & 479,00 & 164,00 & 689,30 \\
\hline $\mathbf{5 / 0 3 / 2 0 1 9}$ & 24,64 & 74,18 & 370,57 & 193,50 & 779,28 \\
\hline $\mathbf{6 / 0 3 / 2 0 1 9}$ & 25,31 & 71,29 & 458,18 & 199,00 & 914,51 \\
\hline $\mathbf{7 / 0 3 / 2 0 1 9}$ & 25,83 & 70,29 & 396,72 & 192,50 & 876,22 \\
\hline $\mathbf{8 / 0 3 / 2 0 1 9}$ & 25,94 & 70,23 & 488,64 & 130,50 & 768,01 \\
\hline $\mathbf{9 / 0 3 / 2 0 1 9}$ & 26,82 & 67,22 & 548,95 & 70,50 & 601,52 \\
\hline $\mathbf{1 0 / 0 3 / 2 0 1 9}$ & 25,60 & 71,51 & 301,45 & 0,00 & 134,68 \\
\hline $\mathbf{1 1 / 0 3 / 2 0 1 9}$ & 25,24 & 71,45 & 438,03 & 160,50 & 832,47 \\
\hline $\mathbf{1 2 / 0 3 / 2 0 1 9}$ & 23,36 & 86,00 & 223,19 & 193,00 & 779,22 \\
\hline $\mathbf{1 3 / 0 3 / 2 0 1 9}$ & 25,34 & 74,24 & 499,58 & 199,50 & 913,60 \\
\hline $\mathbf{1 4 / 0 3 / 2 0 1 9}$ & 23,38 & 80,93 & 248,74 & 190,50 & 679,32 \\
\hline $\mathbf{1 5 / 0 3 / 2 0 1 9}$ & 24,57 & 73,72 & 403,94 & 131,00 & 722,08 \\
\hline $\mathbf{1 6 / 0 3 / 2 0 1 9}$ & 26,31 & 68,70 & 530,41 & 87,00 & 540,20 \\
\hline $\mathbf{1 7 / 0 3 / 2 0 1 9}$ & 25,77 & 72,74 & 348,75 & 0,00 & 133,45 \\
\hline $\mathbf{1 8 / 0 3 / 2 0 1 9}$ & 25,19 & 72,09 & 415,96 & 160,50 & 868,38 \\
\hline $\mathbf{1 9 / 0 3 / 2 0 1 9}$ & 21,62 & 90,52 & 129,49 & 202,00 & 769,97 \\
\hline $\mathbf{2 0 / 0 3 / 2 0 1 9}$ & 23,51 & 80,08 & 439,82 & 199,50 & 716,45 \\
\hline $\mathbf{2 1 / 0 3 / 2 0 1 9}$ & 24,10 & 76,89 & 469,92 & 193,50 & 830,15 \\
\hline $\mathbf{2 2 / 0 3 / 2 0 1 9}$ & 23,05 & 82,73 & 299,13 & 128,00 & 575,84 \\
\hline & & & & & \\
\hline
\end{tabular}




\begin{tabular}{|l|c|c|c|c|c|}
$\mathbf{2 3 / 0 3 / 2 0 1 9}$ & 24,34 & 77,91 & 302,72 & 76,50 & 527,48 \\
\hline $\mathbf{2 4 / 0 3 / 2 0 1 9}$ & 22,50 & 87,29 & 172,70 & 0,00 & 164,52 \\
\hline $\mathbf{2 5 / 0 3 / 2 0 1 9}$ & 24,14 & 76,09 & 483,39 & 0,00 & 245,10 \\
\hline $\mathbf{2 6 / 0 3 / 2 0 1 9}$ & 24,94 & 73,35 & 402,49 & 191,50 & 855,69 \\
\hline $\mathbf{2 7 / 0 3 / 2 0 1 9}$ & 26,06 & 69,50 & 506,45 & 205,50 & 866,25 \\
\hline $\mathbf{2 8 / 0 3 / 2 0 1 9}$ & 25,63 & 73,44 & 426,42 & 199,00 & 951,00 \\
\hline $\mathbf{2 9 / 0 3 / 2 0 1 9}$ & 22,39 & 88,76 & 240,75 & 130,50 & 627,13 \\
\hline $\mathbf{3 0 / 0 3 / 2 0 1 9}$ & 26,56 & 70,75 & 392,56 & 89,50 & 347,42 \\
\hline $\mathbf{3 1 / 0 3 / 2 0 1 9}$ & 27,55 & 66,83 & 421,73 & 0,00 & 249,42 \\
\hline
\end{tabular}

Se construyó el modelo de regresión lineal óptimo en el software estadístico R Studio.

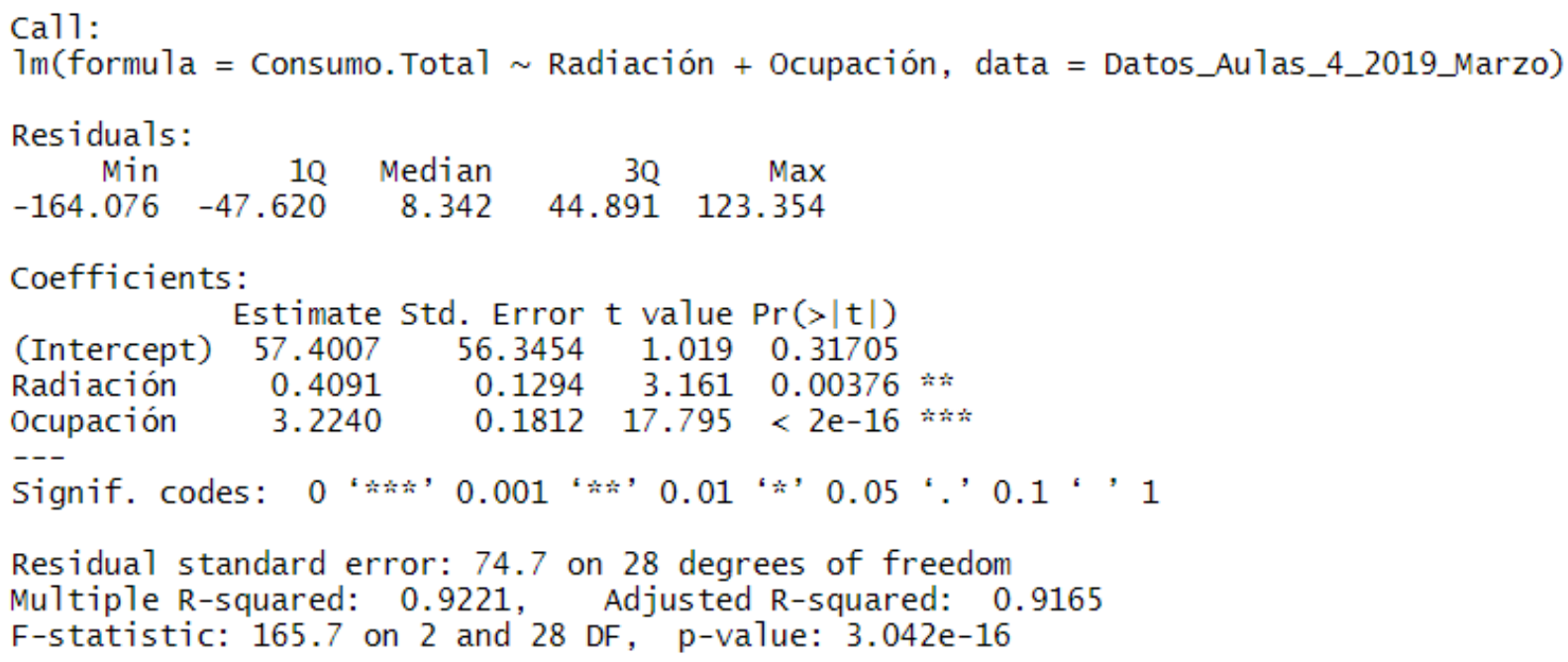

El modelo desarrollado se describe como:

$$
\text { Electricidad }_{\text {lineabase }}=0,409 \cdot \text { Radiación }+3,22 \cdot \text { Ocupación }+57,40+\varepsilon_{i}
$$

El modelo tiene un $R^{2}$ Ajustado=0,9165 indica que el modelo explica el $91,65 \%$ de la variabilidad de las observaciones (datos), El valor de $R^{2}$ ajustado mide el porcentaje de la variación en la respuesta siendo explicada por el modelo, sin embargo, se ajusta al número de variables predictoras en el modelo, El modelo tiene un valor $\mathrm{p}$ de $3,04 \times 10^{-16}$ para el estadístico $\mathrm{F}$ que indica que la relación lineal es estadísticamente significativa $(3,04$ x 10-16 $<0,05)$.

Para garantizar que el modelo desarrollado es válido, se realizó la prueba global de supuestos estadísticos y la prueba de multicolinealidad. 


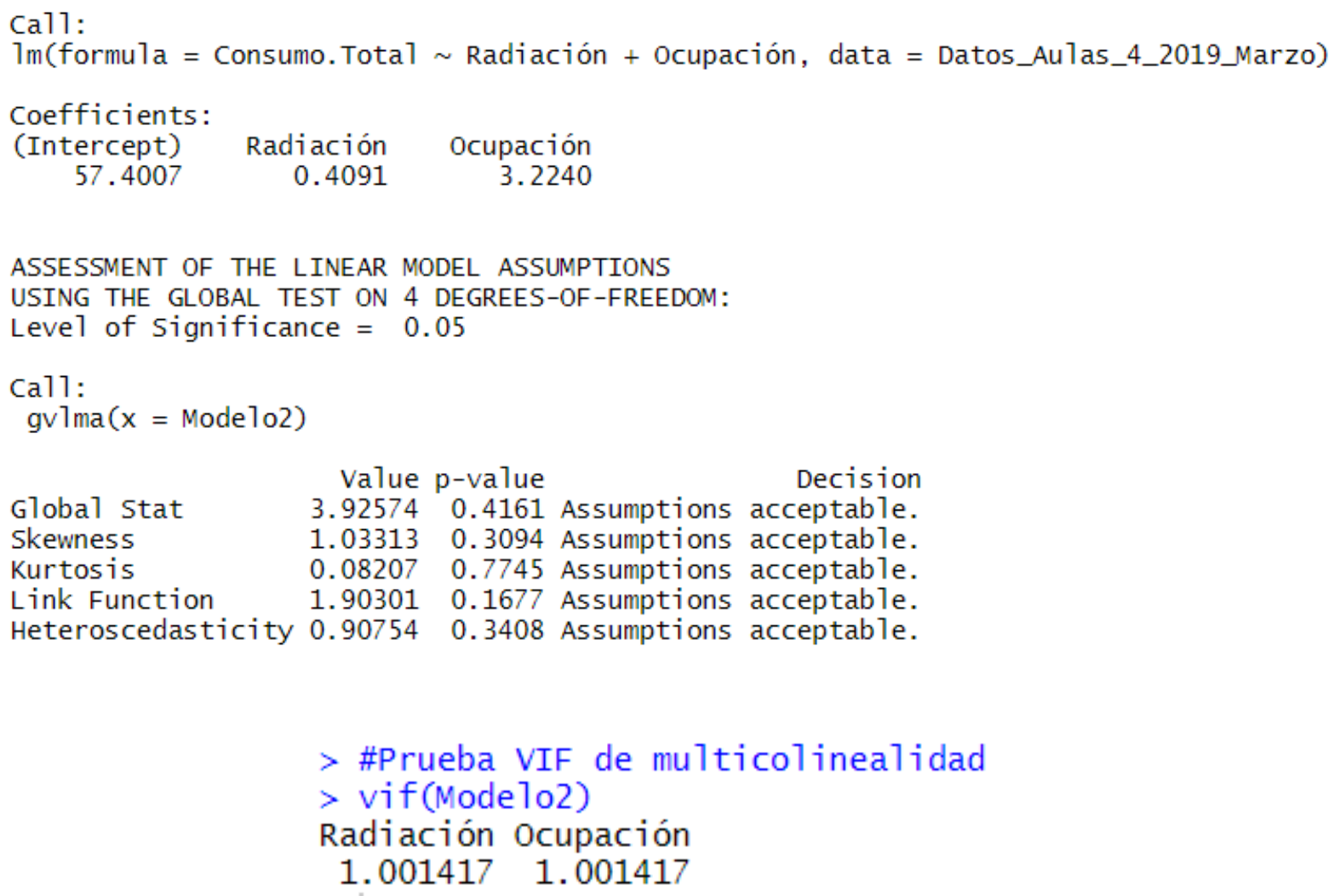

Los resultados de la prueba global (gvlma) y la prueba VIF para multicolinealidad, confirman que el modelo de regresión desarrollado cumple con los supuestos estadísticos y es válido para cuantificar el consumo de energía en función de las variables relevantes "Radiación" y "Ocupación Total".

La Tabla 108, recopila los modelos de regresión desarrollados para el año 2019. Donde se presenta el modelo y su ecuación, el valor de R2 ajustado y el cumplimiento de los supuestos estadísticos.

En general, los modelos de regresión obtenidos poseen un nivel de correlación aceptable (mayor al 75\%), a excepción de los modelos diarios de los meses de Junio y Julio que presentan valores de correlación baja $(25,66 \%$ y $29,91 \%$ respectivamente) esto debido a que son meses de baja ocupación, la mayor parte del tiempo es de vacaciones y por la dinámica del edificio, la variable que resulta ser más representativa e importante al momento de desarrollar un modelo de regresión para estimar el consumo eléctrico es la Ocupación. 
Tabla 108. Modelos de regresión lineal multivariable para el 2019

\begin{tabular}{|c|c|c|c|c|c|}
\hline \multicolumn{3}{|c|}{ MODELO } & LBE & $\begin{array}{c}\mathrm{R}^{2} \\
\text { AJUST. }\end{array}$ & $\begin{array}{l}\text { SUPUESTOS } \\
\text { ESTADÍSTICOS }\end{array}$ \\
\hline \multicolumn{3}{|c|}{ MENSUAL } & $\begin{array}{c}\text { Consumo }=-401,64 * \text { Hum }+2,31 * \text { Ocup } \\
+38239,93\end{array}$ & $90,82 \%$ & Si cumple \\
\hline \multicolumn{3}{|c|}{ SEMANAL } & $\begin{array}{c}\text { Consumo }=-79,85 * \text { Hum }+2,37 * \text { Ocup } \\
+7866,86\end{array}$ & $79,34 \%$ & Si cumple \\
\hline \multirow{11}{*}{$\begin{array}{l}\text { D } \\
\text { I } \\
\text { A } \\
\text { R }\end{array}$} & \multirow{11}{*}{$\begin{array}{c}M \\
E \\
S\end{array}$} & Ene & Consumo $=0,28 * \operatorname{Rad}+1,27 *$ Ocup $+120,5$ & $82,12 \%$ & Si cumple \\
\hline & & Feb & $\begin{array}{c}\text { Consumo }=43,3 * \text { Temp }+3,03 * \text { Ocup } \\
-830,11\end{array}$ & $90,94 \%$ & Si cumple \\
\hline & & Mar & Consumo $=0,40 * \operatorname{Rad}+3,22 *$ Ocup $+57,4$ & $91,65 \%$ & Si cumple \\
\hline & & Abr & Consumo $=2,22 *$ Ocup $+328,48$ & $87,91 \%$ & Si cumple \\
\hline & & May & $\begin{array}{c}\text { Consumo }=104,79 * \text { Temp }+19,98 * \text { Hum } \\
+2,83 * \text { Ocup }-3925,08\end{array}$ & $76,63 \%$ & Si cumple \\
\hline & & Jun & $\begin{array}{c}\text { Consumo }=183,83 * \text { Temp }+43,36 * \text { Hum } \\
+1,41 * \text { Ocup }-7574,07\end{array}$ & $25,66 \%$ & Si cumple \\
\hline & & Jul & Consumo $=2,17 *$ Ocup $+385,29$ & $29,91 \%$ & Si cumple \\
\hline & & Ago & $\begin{array}{c}\text { Consumo }=106,89 * \text { Temp }+2,50 * \text { Ocup } \\
-2337,38\end{array}$ & $79,38 \%$ & Si cumple \\
\hline & & Sep & $\begin{array}{c}\text { Consumo }=-17,98 * \text { Hum }+2,88 * \text { Ocup } \\
+1475,58\end{array}$ & $91,01 \%$ & Si cumple \\
\hline & & Oct & $\begin{array}{c}\text { Consumo }=-13,66 * \text { Hum }+2,19 * \text { Ocup } \\
+1316,64\end{array}$ & $89,34 \%$ & Si cumple \\
\hline & & Nov & $\begin{aligned} \text { Consumo }=132,97 * \text { Temp }+23,77 * \text { Hum } \\
+0,87 * \text { Rad }+1,55-5064,31\end{aligned}$ & $71,63 \%$ & Si cumple \\
\hline
\end{tabular}

Una vez obtenidos los modelos de regresión lineal con datos diarios, semanal y mensual. Se realizó el pronóstico del consumo de energía eléctrica para los diferentes meses del año. El proceso realizado para cada mes es ilustrado con el mes de marzo en la Tabla 109. 
Tabla 109. Pronóstico de consumo de energía eléctrica para el mes de marzo de 2019 utilizando las LBE obtenidas.

\section{Pronóstico con modelo diario de LBE}

LBE Mes de Febrero: Consumo $=43,3 *$ Temp $+3,03 *$ Ocup $-830,11$

\begin{tabular}{|c|c|c|c|c|c|c|}
\hline Fecha & Temperatura & Humedad & Radiación & Ocupación & $\begin{array}{c}\text { Consumo } \\
\text { Real }\end{array}$ & $\begin{array}{c}\text { Consumo } \\
\text { Estimado }\end{array}$ \\
\hline $1 / 03 / 2019$ & 24,19 & 74,87 & 397,58 & 131,50 & 683,29 & 616,61 \\
\hline $2 / 03 / 2019$ & 24,41 & 72,62 & 460,41 & 74,50 & 467,61 & 453,31 \\
\hline $3 / 03 / 2019$ & 24,00 & 74,59 & 428,35 & 0,00 & 183,44 & 209,25 \\
\hline $4 / 03 / 2019$ & 25,01 & 70,74 & 479,00 & 164,00 & 689,30 & 751,00 \\
\hline $5 / 03 / 2019$ & 24,64 & 74,18 & 370,57 & 193,50 & 779,28 & 824,56 \\
\hline $6 / 03 / 2019$ & 25,31 & 71,29 & 458,18 & 199,00 & 914,51 & 870,52 \\
\hline $7 / 03 / 2019$ & 25,83 & 70,29 & 396,72 & 192,50 & 876,22 & 873,26 \\
\hline $8 / 03 / 2019$ & 25,94 & 70,23 & 488,64 & 130,50 & 768,01 & 689,36 \\
\hline $9 / 03 / 2019$ & 26,82 & 67,22 & 548,95 & 70,50 & 601,52 & 545,34 \\
\hline $10 / 03 / 2019$ & 25,60 & 71,51 & 301,45 & 0,00 & 134,68 & 278,38 \\
\hline $11 / 03 / 2019$ & 25,24 & 71,45 & 438,03 & 160,50 & 832,47 & 750,35 \\
\hline $12 / 03 / 2019$ & 23,36 & 86,00 & 223,19 & 193,00 & 779,22 & 767,90 \\
\hline $13 / 03 / 2019$ & 25,34 & 74,24 & 499,58 & 199,50 & 913,60 & 873,34 \\
\hline $14 / 03 / 2019$ & 23,38 & 80,93 & 248,74 & 190,50 & 679,32 & 761,02 \\
\hline $15 / 03 / 2019$ & 24,57 & 73,72 & 403,94 & 131,00 & 722,08 & 631,93 \\
\hline $16 / 03 / 2019$ & 26,31 & 68,70 & 530,41 & 87,00 & 540,20 & 573,54 \\
\hline $17 / 03 / 2019$ & 25,77 & 72,74 & 348,75 & 0,00 & 133,45 & 285,71 \\
\hline $18 / 03 / 2019$ & 25,19 & 72,09 & 415,96 & 160,50 & 868,38 & 748,20 \\
\hline $19 / 03 / 2019$ & 21,62 & 90,52 & 129,49 & 202,00 & 769,97 & 719,66 \\
\hline $20 / 03 / 2019$ & 23,51 & 80,08 & 439,82 & 199,50 & 716,45 & 793,91 \\
\hline $21 / 03 / 2019$ & 24,10 & 76,89 & 469,92 & 193,50 & 830,15 & 801,41 \\
\hline $22 / 03 / 2019$ & 23,05 & 82,73 & 299,13 & 128,00 & 575,84 & 556,82 \\
\hline $23 / 03 / 2019$ & 24,34 & 77,91 & 302,72 & 76,50 & 527,48 & 456,20 \\
\hline $24 / 03 / 2019$ & 22,50 & 87,29 & 172,70 & 0,00 & 164,52 & 144,15 \\
\hline $25 / 03 / 2019$ & 24,14 & 76,09 & 483,39 & 0,00 & 245,10 & 215,30 \\
\hline $26 / 03 / 2019$ & 24,94 & 73,35 & 402,49 & 191,50 & 855,69 & 831,74 \\
\hline $27 / 03 / 2019$ & 26,06 & 69,50 & 506,45 & 205,50 & 866,25 & 922,44 \\
\hline $28 / 03 / 2019$ & 25,63 & 73,44 & 426,42 & 199,00 & 951,00 & 884,29 \\
\hline $29 / 03 / 2019$ & 22,39 & 88,76 & 240,75 & 130,50 & 627,13 & 535,94 \\
\hline $30 / 03 / 2019$ & 26,56 & 70,75 & 392,56 & 89,50 & 347,42 & 591,89 \\
\hline $31 / 03 / 2019$ & 27,55 & 66,83 & 421,73 & 0,00 & 249,42 & 362,74 \\
\hline
\end{tabular}

Consumo Real (kWh/mes): 19292,99

Consumo Estimado (kWh/mes): 19320,08 


\section{Pronóstico con modelo semanal de LBE}

LBE Semanal: Consumo $=-79,85 * H u m+2,37 *$ Ocup $+7866,86$

\begin{tabular}{|c|c|c|c|c|c|c|}
\hline Semana & Temperatura & Humedad & Radiación & Ocupación & $\begin{array}{c}\text { Consumo } \\
\text { Real }\end{array}$ & $\begin{array}{c}\text { Consumo } \\
\text { Estimado }\end{array}$ \\
\hline 9 & 24,20 & 74,02 & 428,78 & 206,00 & 1334,35 & 2445,6282 \\
\hline 10 & 25,59 & 70,78 & 434,79 & 950,00 & 4763,52 & 4473,8846 \\
\hline 11 & 24,86 & 75,40 & 384,66 & 961,50 & 4600,34 & 4132,4898 \\
\hline 12 & 23,47 & 81,07 & 318,53 & 960,00 & 4452,79 & 3675,9225 \\
\hline 13 & 25,33 & 74,10 & 410,54 & 816,00 & 4142,01 & 3889,854 \\
\hline
\end{tabular}

Consumo Real (kWh/mes): 19292,99

Consumo Estimado (kWh/mes): 18617, 78

\section{Pronóstico con modelo mensual de LBE}

LBE Mensual: Consumo $=-401,64 *$ Hum $+2,31 *$ Ocup $+38239,93$

\begin{tabular}{|c|c|c|c|c|c|c|}
\hline Mes & Temperatura & Humedad & Radiación & Ocupación & $\begin{array}{c}\text { Consumo } \\
\text { Real }\end{array}$ & $\begin{array}{c}\text { Consumo } \\
\text { Estimado }\end{array}$ \\
\hline Marzo & 24,75 & 75,21 & 391,16 & 3893,50 & 19292,99 & 17034,4489 \\
\hline
\end{tabular}

Consumo Real (kWh/mes): 19292,99

Consumo Estimado (kWh/mes): 17034,45

\begin{tabular}{|c|c|c|c|}
\hline \multirow{2}{*}{$\begin{array}{c}\text { Consumo } \\
\text { Real }\end{array}$} & \multicolumn{3}{|c|}{ Consumo Estimado LBE } \\
\cline { 2 - 4 } & $\begin{array}{c}\text { Mod } \\
\text { Diario }\end{array}$ & $\begin{array}{c}\text { Mod } \\
\text { Semanal }\end{array}$ & $\begin{array}{c}\text { Mod } \\
\text { Mensual }\end{array}$ \\
\hline 19292,99 & 19320,08 & 18617,78 & 17034,45 \\
\hline Diferencia & $-27,09$ & 675,21 & 2258,54 \\
\hline MAPE & $0,1 \%$ & $3,5 \%$ & $11,7 \%$ \\
\hline
\end{tabular}

La

Tabla 110, presenta las estimaciones realizadas para cada mes con su respectivo valor MAPE. 
Tabla 110. Pronóstico de consumo eléctrico mes a mes empleando LBE diarias, semanales y mensual para el 2019.

\begin{tabular}{|c|c|c|c|c|c|c|c|c|c|c|c|}
\hline \multirow[b]{3}{*}{ Mes } & \multirow{3}{*}{$\begin{array}{c}\text { Consumo } \\
\text { Real } \\
\text { [kWh] }\end{array}$} & \multicolumn{10}{|c|}{ Consumo Estimado LBE } \\
\hline & & \multicolumn{4}{|c|}{ Mod Diario } & \multicolumn{3}{|c|}{ Mod Semanal } & \multicolumn{3}{|c|}{ Mod Mensual } \\
\hline & & \begin{tabular}{|c|} 
Consumo \\
Estimado LBE \\
{$[\mathrm{kWh}]$}
\end{tabular} & Mes LBE & $\begin{array}{c}\text { Diferencia } \\
\text { [kWh] }\end{array}$ & MAPE & \begin{tabular}{|c} 
Consumo \\
Estimado LBE \\
{$[\mathrm{kWh}]$}
\end{tabular} & $\begin{array}{c}\text { Diferencia } \\
\text { [kWh] }\end{array}$ & MAPE & $\begin{array}{l}\text { Consumo } \\
\text { Estimado } \\
\text { LBE }[k W h]\end{array}$ & $\begin{array}{c}\text { Diferencia } \\
\text { [kWh] }\end{array}$ & MAPE \\
\hline Febrero & 18282,015 & 11297,14 & Enero & 6984,88 & $38,2 \%$ & 16805,22 & 1476,80 & $8,1 \%$ & 16856,33 & 1425,69 & $7,8 \%$ \\
\hline Marzo & 19292,99 & 19320,08 & Febrero & $-27,09$ & $0,1 \%$ & 18617,78 & 675,21 & $3,5 \%$ & 17034,45 & 2258,54 & $11,7 \%$ \\
\hline Abril & 14801,464 & 15661,49 & Marzo & $-860,03$ & $5,8 \%$ & 16463,64 & $-1662,18$ & $11,2 \%$ & 16635,44 & $-1833,98$ & $12,4 \%$ \\
\hline Mayo & 19172,776 & 19572,97 & Abril & $-400,20$ & $2,1 \%$ & 19812,89 & $-640,11$ & $3,3 \%$ & 18203,96 & 968,82 & $5,1 \%$ \\
\hline Junio & 12369,744 & 12604,90 & Mayo & $-235,15$ & $1,9 \%$ & 12983,70 & $-613,95$ & $5,0 \%$ & 11610,77 & 758,98 & $6,1 \%$ \\
\hline Julio & 21059,361 & 8580,08 & Junio & 12479,28 & $59,3 \%$ & 20677,71 & 381,65 & $1,8 \%$ & 19072,51 & 1986,85 & $9,4 \%$ \\
\hline Agosto & 24720,47 & 23569,17 & Julio & 1151,30 & $4,7 \%$ & 25720,67 & $-1000,19$ & $4,0 \%$ & 24325,69 & 394,78 & $1,6 \%$ \\
\hline Septiembre & 23052,766 & 24225,25 & Agosto & $-1172,48$ & $5,1 \%$ & 22300,83 & 751,94 & $3,3 \%$ & 23387,98 & $-335,21$ & $1,5 \%$ \\
\hline Octubre & 21967,904 & 20865,54 & Septiembre & 1102,37 & $5,0 \%$ & 23574,53 & $-1606,62$ & $7,3 \%$ & 21814,02 & 153,88 & $0,7 \%$ \\
\hline Noviembre & 17373,539 & 19237,61 & Octubre & $-1864,07$ & $10,7 \%$ & 18298,91 & $-925,37$ & $5,3 \%$ & 19235,86 & $-1862,32$ & $10,7 \%$ \\
\hline Diciembre & 10455,589 & 11075,96 & Noviembre & $-620,37$ & $5,9 \%$ & 9634,64 & 820,95 & $7,9 \%$ & 9973,85 & 481,73 & $4,6 \%$ \\
\hline
\end{tabular}

La Tabla 111 presenta los modelos de LBE propuestos como ideales para realizar el pronóstico de consumo de energía mes a mes del año 2019.

Tabla 111. Modelos de LBE propuestos para pronosticar 2019

\begin{tabular}{|c|c|c|c|}
\hline MES & MODELO & LBE & MAPE (\%) \\
\hline FEB & Semanal & Consumo $=-79,85 *$ Hum $+2,37 *$ Ocup $+7866,86$ & 8,1 \\
\hline MAR & Diario & Consumo $=43,3 *$ Temp $+3,03 *$ Ocup $-830,11$ & 0,1 \\
\hline ABR & Diario & Consumo $=0,40 *$ Rad $+3,22 *$ Ocup $+57,4$ & 5,8 \\
\hline MAY & Diario & Consumo $=2,22 *$ Ocup $+328,48$ & 2,1 \\
\hline JUN & Diario & $\begin{array}{c}\text { Consumo }=104,79 * \text { Temp }+19,98 * \text { Hum }+2,83 * \text { Ocup } \\
-3925,08\end{array}$ & 1,9 \\
\hline JUL & Semanal & Consumo $=-79,85 *$ Hum $+2,37 *$ Ocup $+7866,86$ & 1,8 \\
\hline AGO & Diario & Consumo $=2,17 *$ Ocup $+385,29$ & 4,7 \\
\hline SEP & Diario & Consumo $=106,89 *$ Temp $+2,50 *$ Ocup $-2337,38$ & 5,1 \\
\hline OCT & Diario & Consumo $=-17,98 *$ Hum $+2,88 *$ Ocup $+1475,58$ & 5,0 \\
\hline NOV & Diario & Consumo $=-13,66 *$ Hum $+2,19 *$ Ocup $+1316,64$ & 10,7 \\
\hline DIC & Diario & $\begin{array}{c}\text { Consumo }=132,97 * \text { Temp }+23,77 * \text { Hum }+0,87 * \text { Rad } \\
+1,55-5064,31\end{array}$ & 5,9 \\
\hline
\end{tabular}

De acuerdo a los resultados obtenidos se realiza la construcción y prueba de 3 modelos de regresión lineal, con el fin de encontrar el modelo de mejor capacidad de pronóstico (menor MAPE). Al revisar los modelos y sus errores MAPE, se encuentra que para el funcionamiento normal del edificio (semestre corriente) el modelo diario funciona adecuadamente y presenta bajos errores. Mientras que para los periodos de vacaciones donde la ocupación es baja, el modelo diario no es el que mejor modela el consumo, en este caso, el modelo 
semanal se ajusta mejor que el diario. Es decir, en ciertos meses el error MAPE es menor con otros modelos (por ej. Nov el modelo mensual es menor que el diario).

Lo que se busca es plantear un modelo homogéneo con la misma periodicidad de datos necesarios para su construcción siempre y cuando el análisis de datos lo permita. Lo anterior, con el fin de que el modelo planteado sea funcional para la persona encargada de realizar seguimiento a las líneas bases e indicadores propuestos en el edificio (gestor energético, personal de mantenimiento etc.).

Finalmente, los 3 modelos propuestos funcionan para estimar la línea base (LBE), la selección de uno u otro depende de los niveles de erros e incertidumbre y la disposición de los datos para la estimación de cada uno.

\subsubsection{Modelo de Simulación}

Uno de los modelos propuestos por la norma ISO50006, para estimar líneas bases es el modelo de simulación. En este caso la propuesta es utilizar la simulación energética como herramienta para estimar los valores de línea base LBE e indicadores. Lo anterior, teniendo en cuenta que modelar es analizar en función del tiempo las necesidades energéticas de un edificio, al proporcionar unas condiciones básicas de confort, según su diseño y su entorno condicionado por variables como la radiación solar, la ocupación, orientación del edificio o caracterización térmica de sus componentes arquitectónicos. En ese sentido, se trata de analizar la situación actual del edificio aulario (aulas 4), referente al consumo energético, mediante los datos obtenidos a través del programa de simulación dinámica Design Builder que previamente ha sido calibrado con los datos experimentales de monitorización continua con un sistema BMS. El objetivo de plantear la simulación energética como alternativa para estimar líneas base energética, parte de contar con pronósticos de consumo. Estos se pueden analizar según los niveles de ocupación y de esa forma tener un rango de estimación para distintos escenarios en los que, incluso, se podría realizar mejoras energéticas que permitan contar con la actualización de una línea base en distintos momentos en los que se tiene en cuenta horas de operación, sistemas de climatización (HVAC) distribuidos vs centralizados, variación en las necesidades de los ocupantes y cambios tecnológicos y arquitectónicos. Elementos necesarios para actualizar una línea base energética.

\subsection{INDICADORES ENERGÉTICOS Y AMBIENTALES APLICADOS A EDIFICIOS}

El objetivo principal de los indicadores de eficiencia energética (EEI) [13] [15] es obtener una comprensión de las principales influencias en el consumo final de energía tanto de manera global, como por subsectores. A su vez, son usados como herramienta que permiten la evaluación de resultados alcanzados, la evaluación de objetivos, entre otros, cuando se han establecido políticas de eficiencia energética. 
Entre los antecedentes relacionados con indicadores de desempeño, Pérez et al. [16] establece que la eficiencia energética es un objetivo central para la política energética y una piedra angular para el desarrollo sostenible. Sin embargo, la falta de un conjunto válido de indicadores de eficiencia energética (EEI) suficientemente precisos, robustos y repetibles está afectando significativamente el éxito de tales políticas y causando confusión y especulación en este campo. Por lo tanto, es crucial identificar métodos adecuados para medir la eficiencia energética y lograr un consenso sobre el uso de un conjunto válido de EEl. Alves et al. [17] estableció diferentes indicadores para evaluar el rendimiento energético de los sistemas HVAC, en los que encontró diferencia al cambiar la ubicación geográfica y las condiciones climáticas que afectan a los sistemas, lo que puede llevar a conceptos erróneos sobre la eficiencia energética, pues es importante utilizar correctamente los indicadores que mejor se ajustan a la ubicación. Perroni et al. [18] presenta un estudio sobre el rendimiento energético de una empresa representado por un marco, un mapa de indicadores, y un modelo de proceso de entrada / salida longitudinal, en el cual establece que los indicadores de rendimiento pueden integrarse en tres niveles jerárquicos: eficiencia energética por fuente; eficiencia energética del proceso; y la eficiencia energética de la empresa extendida. Estudios encontrados presentan el uso de indicadores de eficiencia energética (EEI) en edificaciones, en el artículo "Buildings energy consumption generation gap: A post-occupancy assessment in a case study of three higher education buildings" Bordeau et al. [19] realizó un estudio comparativo del consumo de energía de tres edificios de campus universitarios en Paris que cubren más de 50,000 m2 de superficie útil, el histórico de datos utilizado fue de 3 años, se usaron herramientas estadísticas para su posterior análisis, donde se encontró que el principal propulsor del consumo de energía eléctrica es la Ocupación. Khoshbakht et al. [20] estudió las características de uso de energía en diferentes edificios de 80 campus universitarios en Australia, basado en el método estadístico análisis de frontera estocástico (SFA) obtuvieron los valores de referencia de la intensidad del uso de energía (EUI) que para el campus en general fue de $216 \mathrm{kWh} / \mathrm{m} 2$, edificios de actividades académicas $137 \mathrm{kWh} / \mathrm{m} 2$, edificios de ciencias $164 \mathrm{kWh} / \mathrm{m} 2$, edificio de salud $136 \mathrm{kWh} / \mathrm{m} 2$.

Ocampo et al. [21] desarrolla una metodología que considera las recomendaciones de ISO 50001: 2011 e ISO 50006: 2014 para establecer líneas de base de energía e indicadores de rendimiento energético en edificios de instituciones de educación para identificar potenciales de reducción de consumo de energía eléctrica en edificios y establecer estrategias de gestión de energía relacionadas con la electricidad, se estudiaron tres edificios de la Universidad Federal de Itajubá, los resultados mostraron que los posibles ahorros anuales en el consumo de energía eléctrica para el campus podrían ser de alrededor del $9,6 \%$.

En esta tesis doctoral los indicadores que vamos a seleccionar para realizar el estudio energético, económico y ambiental para un edifico son los presentados en la Tabla 112. 
Tabla 112. Indicadores

\begin{tabular}{|c|c|c|c|}
\hline INDICADOR & \multicolumn{3}{|c|}{ FÓRMULA } \\
\hline $\begin{array}{l}\text { Intensidad } \\
\text { Energética }\end{array}$ & \multicolumn{3}{|c|}{$I E=\frac{k W h}{m^{2}{ }_{a \tilde{n} o}}$} \\
\hline $\begin{array}{l}\text { Indicadores de Uso } \\
\text { Final }\end{array}$ & $\begin{array}{l}\boldsymbol{I E}_{\text {iluminación }} \\
=\frac{k W h_{\text {iluminación }}}{m^{2}{ }_{\text {año iluminado }}}\end{array}$ & $\begin{array}{l}\boldsymbol{I E}_{\text {refrigeración }} \\
=\frac{k W h_{\text {refrigeración }}}{m^{2}{ }_{\text {año }} \text { refrigerado }}\end{array}$ & $\begin{array}{l}\text { IE } \boldsymbol{E}_{\text {ofimáticos }} \\
=\frac{k W h_{\text {ofimáticos }}}{m^{2} \text { año }_{\text {ofimáticos }}}\end{array}$ \\
\hline $\begin{array}{l}\text { Indicador IE referido } \\
\text { al consumo de } \\
\text { energía primaria. } \\
\text { Edificios nZEB }\end{array}$ & \multicolumn{3}{|c|}{ 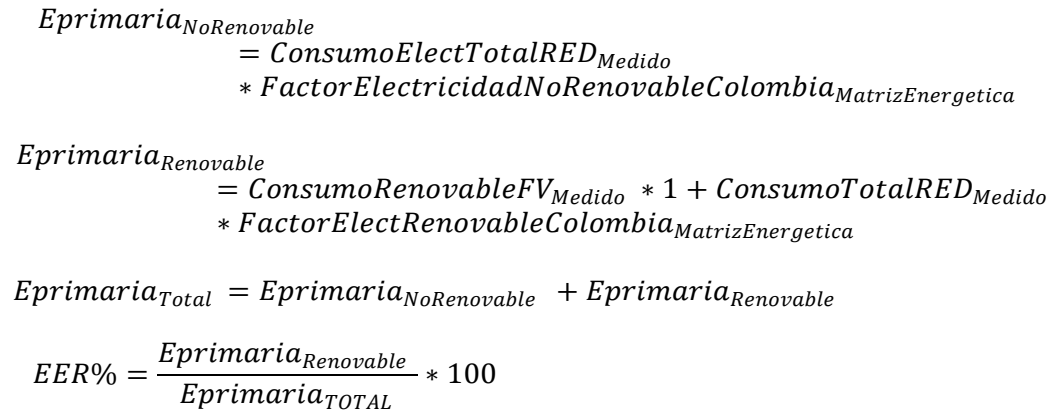 } \\
\hline Impacto Ambiental & \multicolumn{3}{|c|}{$I_{M}=\frac{C_{\text {final }} * \text { FactorElectricidad }}{\mathrm{CO} 2_{2}}$} \\
\hline Eficiencia Energética & \multicolumn{3}{|c|}{$I E E=\frac{E_{\text {medida }}}{E_{\text {Base }}}$} \\
\hline $\begin{array}{c}\text { Sumas acumulativas } \\
\text { CUSUM }\end{array}$ & \multicolumn{3}{|c|}{ CUSUM $=\left[\left(E_{\text {medida }}-E_{\text {tendencia }}\right)_{i}+\left(E_{\text {medida }}-E_{\text {tendencia }}\right)_{i-1}\right.$} \\
\hline
\end{tabular}

\subsubsection{Indicador de Intensidad Energética IE.}

Es un indicador de eficiencia energética, que permite explicar las razones de un buen o mal comportamiento energético del edificio y proporcionan información útil sobre los aspectos a tener en cuenta a la hora de proponer recomendaciones que mejoren dicho comportamiento. Este indicador, en base anual y referidos a la unidad de superficie útil del edificio, se obtendrá de la energía final consumida por el edificio para satisfacer, en unas condiciones climáticas determinadas, las necesidades asociadas a unas condiciones normales de funcionamiento y ocupación, que incluirá la energía consumida en: calefacción, refrigeración, ventilación, producción de agua caliente sanitaria e iluminación; a fin de mantener las condiciones de confort térmico y lumínico así como la calidad del aire interior. Las unidades empleadas para expresar este indicador serán: el $\mathrm{kWh} / \mathrm{m} 2$ de superficie útil del edificio, para valores de consumo de energía. 


$$
I E=\frac{k W h}{m^{2} \text { año }}
$$

Las tablas 113 y 114, enseñan los Indicadores de Eficiencia Energética (IE) por vectores energéticos y por servicios de uso final de los años 2017 - 2019. La Tabla 115 y las Figuras 232 - 233, presentan los indicadores de Generación de Energía Solar FV y Consumo de Energía Eléctrica Total.

Tabla 113. Indicadores de Eficiencia Energética por vectores energéticos en el Campus UAO de los años $2017-2019$

\begin{tabular}{|c|c|c|c|}
\hline \multicolumn{4}{|c|}{ Consumo de energía eléctrica total } \\
\hline Año & 2017 & 2018 & 2019 \\
\hline Consumo Total [kWh/año] & 3.737 .623 & 3.545 .597 & 3.658 .441 \\
\hline Área campus [m2] & \multicolumn{3}{|c|}{49.798} \\
\hline IE [kwh/m2 Año] & 75,06 & 71,20 & 73,47 \\
\hline \multicolumn{4}{|c|}{ Consumo de energía de Gas Natural } \\
\hline Año & 2017 & 2018 & 2019 \\
\hline Consumo Total [m3] & 15.662 & 24.220 & \\
\hline Área campus [m2] & \multicolumn{3}{|c|}{49.798} \\
\hline IE [kwh/m2 Año] & 0,31 & 0,49 & $\begin{array}{c}----- \\
\end{array}$ \\
\hline \multicolumn{4}{|c|}{ Generación de energía renovable mediante solar fotovoltaica-FV } \\
\hline Año & 2017 & 2018 & 2019 \\
\hline Generación FV [kWh/año] & 424.450 & 545.660 & 537.160 \\
\hline Área campus [m2] & \multicolumn{3}{|c|}{49.798} \\
\hline IE [kwh/m2 Año] & 8,52 & 10,96 & 10,79 \\
\hline
\end{tabular}

Tabla 114. Indicadores de Eficiencia Energética por servicios de uso final en el Campus UAO de los años $2017-2019$

\begin{tabular}{|c|c|c|}
\hline Tipo de uso & Electricidad (Kwh) & Indicador IE (kWh/m2 año) \\
\hline Refrigeración & 1.504 .561 & 30,21 \\
\hline Iluminación & 606.389 & 12,18 \\
\hline Equipos Ofimáticos & 440.559 & 8,85 \\
\hline Equipos Auxiliares & 1.185 .805 & 23,81 \\
\hline
\end{tabular}

Tabla 115. Indicadores de Eficiencia Energética de Generación FV y consumo de energía eléctrica total del Campus UAO de los años $2017-2019$

\begin{tabular}{|c|c|c|c|c|c|c|c|c|c|c|c|c|}
\hline \multirow{3}{*}{\begin{tabular}{|c|} 
Año \\
Mes/Consumo
\end{tabular}} & \multicolumn{4}{|c|}{2017} & \multicolumn{4}{|c|}{2018} & \multicolumn{4}{|c|}{2019} \\
\hline & \multicolumn{2}{|c|}{ Generación Sistema FV } & \multicolumn{2}{|c|}{ Consumo Eléctrico } & \multicolumn{2}{|c|}{ Generación Sistema FV } & \multicolumn{2}{|c|}{ Consumo Eléctrico } & \multicolumn{2}{|c|}{ Generación Sistema FV } & \multicolumn{2}{|c|}{ Consumo Eléctrico } \\
\hline & KWh/mes & IE & KWh/mes & IE & KWh/mes & IE & KWh/mes & IE & KWh/mes & IE & KWh/mes & IE \\
\hline Enero & 14.490 & 0,29 & 280.370 & 5,63 & 45.889 & 0,92 & 260.424 & 5,23 & 44.154 & 0,89 & 193.481 & 3,89 \\
\hline Febrero & 16.880 & 0,34 & 344.658 & 6,92 & 46.453 & 0,93 & 322.472 & 6,48 & 43.081 & 0,87 & 262.178 & 5,26 \\
\hline Marzo & 17.340 & 0,35 & 350.748 & 7,04 & 50.768 & 1,02 & 302.893 & 6,08 & 45.354 & 0,91 & 283.337 & 5,69 \\
\hline Abril & 17.580 & 0,35 & 296.426 & 5,95 & 43.382 & 0,87 & 315.173 & 6,33 & 42.641 & 0,86 & 247.512 & 4,97 \\
\hline Mayo & 28.210 & 0,57 & 342.111 & 6,87 & 42.996 & 0,86 & 324.232 & 6,51 & 41.529 & 0,83 & 307.745 & 6,18 \\
\hline Junio & 43.970 & 0,88 & 254.574 & 5,11 & 40.330 & 0,81 & 236.592 & 4,75 & 43.131 & 0,87 & 203.416 & 4,08 \\
\hline Julio & 49.670 & 1,00 & 289.544 & 5,81 & 43.397 & 0,87 & 281.635 & 5,66 & 48.891 & 0,98 & 253.210 & 5,08 \\
\hline Agosto & 48.990 & 0,98 & 346.242 & 6,95 & 48.193 & 0,97 & 332.242 & 6,67 & 50.617 & 1,02 & 300.874 & 6,04 \\
\hline Septiembre & 51.230 & 1,03 & 366.798 & 7,37 & 47.643 & 0,96 & 321.359 & 6,45 & 47.446 & 0,95 & 298.430 & 5,99 \\
\hline Octubre & 44.810 & 0,90 & 344.414 & 6,92 & 47.875 & 0,96 & 333.627 & 6,70 & 47.149 & 0,95 & 312.343 & 6,27 \\
\hline Noviembre & 45.388 & 0,91 & 315.131 & 6,33 & 40.099 & 0,81 & 287.228 & 5,77 & 40.582 & 0,81 & 277.115 & 5,56 \\
\hline Diciembre & 45.892 & 0,92 & 206.608 & 4,15 & 48.635 & 0,98 & 227.720 & 4,57 & 42.585 & 0,86 & 181.639 & 3,65 \\
\hline
\end{tabular}


IE Consumo Electrico Total

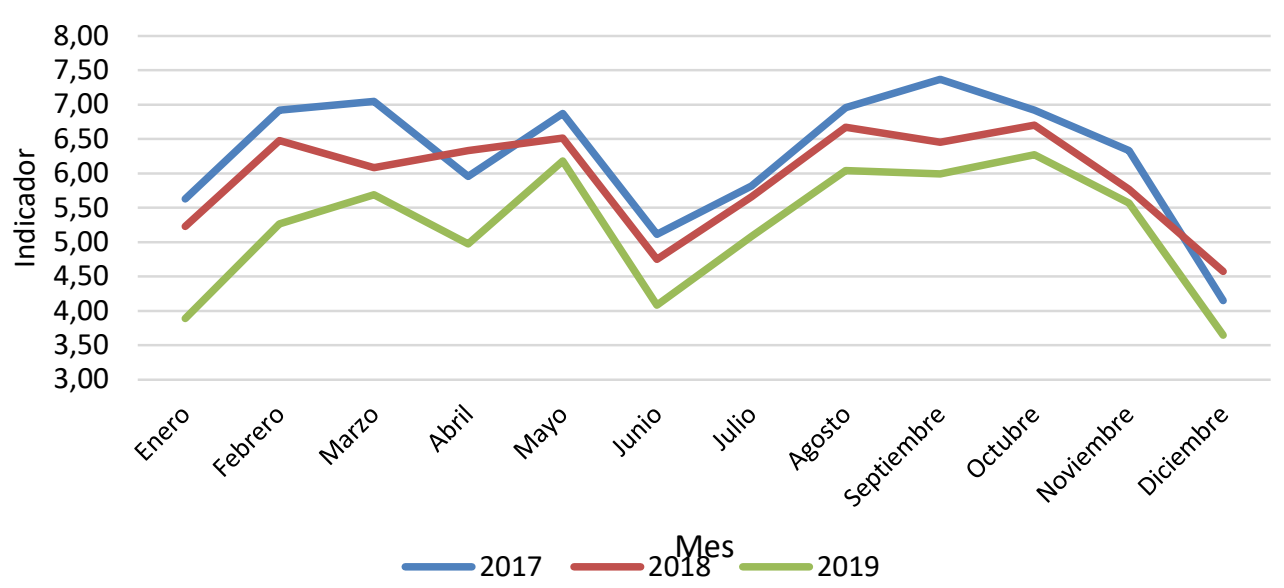

Figura 232. Indicadores de Eficiencia Energética del consumo de energía eléctrica total del Campus UAO de los años $2017-2019$

\section{IE Generación FV}

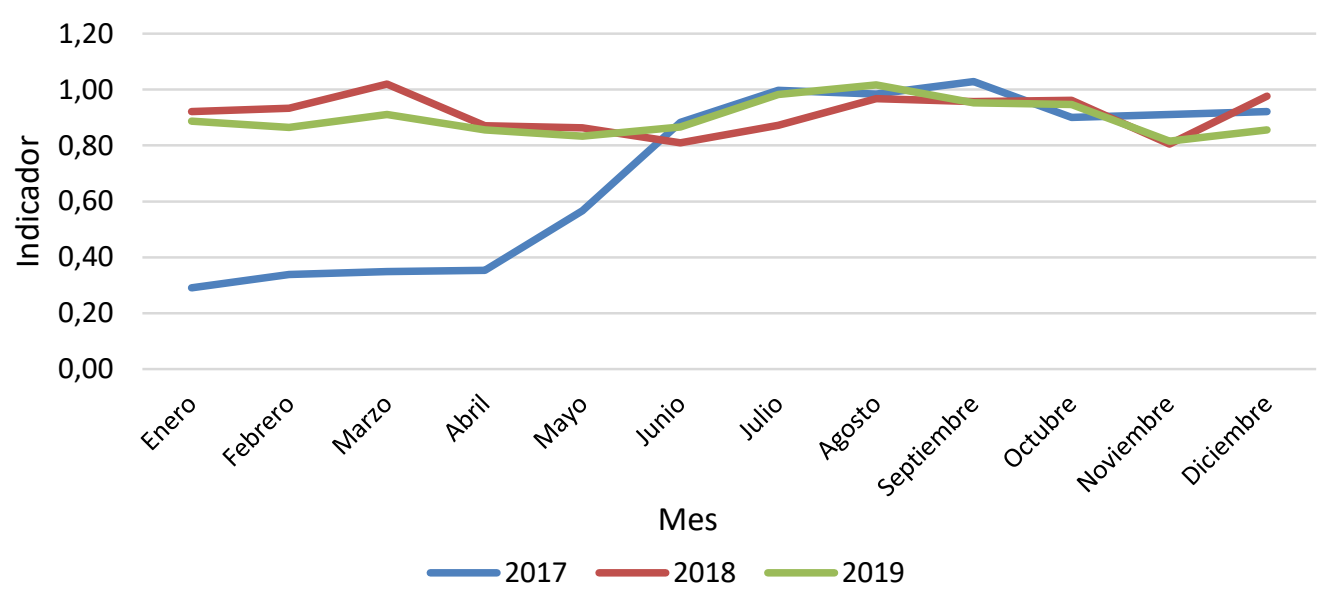

Figura 233. Indicadores de Eficiencia Energética de Generación FV del Campus UAO de los años $2017-2019$

Durante el periodo comprendido entre 2017 a 2019 la producción de energía del sistema solar FV se conserva inalterable, por efecto de la condición climática del lugar donde se encuentra instalado el sistema solar FV. Recordemos que el sistema se encuentra en zona tropical ubicado a unos 30 de latitud norte, cercano a la línea ecuatorial donde las condiciones climáticas del valle interandino donde se encuentra la ciudad de Cali, ofrecen unas características bimodales del clima: dos temporadas secas y dos temporadas lluviosas al año unido a una alta disponibilidad de recurso solar todo el año. Por ejemplo, para el año 2019 el comportamiento bimodal del clima evidencia una mayor producción de energía del sistema solar durante los meses secos (enero - marzo y agosto - octubre) y se reduce en los demás meses del año cuando se presenta la temporada de lluvias. 
Del mismo modo, se presentan en las tablas 116 - 118 y en las figuras 234 y 235 os indicadores anteriores para el edificio de Aulas 4.

Tabla 116. Indicadores de Eficiencia Energética por energéticos en el Edificio de Aulas 4 de los años

$$
2017-2019
$$

\begin{tabular}{|c|c|c|c|}
\hline \multicolumn{4}{|c|}{ Consumo de energía eléctrica total } \\
\hline Año & 2017 & 2018 & 2019 \\
\hline Consumo Total [kWh/año] & 186.462 & 188.381 & 208.376 \\
\hline Área útil [m2] & \multicolumn{3}{|c|}{$3.087,85$} \\
\hline IE [kwh/m2 Año] & 60,39 & 61,01 & 67,48 \\
\hline \multicolumn{4}{|c|}{ Generación de energía renovable mediante solar fotovoltaica-FV } \\
\hline Año & 2017 & 2018 & 2019 \\
\hline Generación FV [kWh/año] & 34.832 & 54.666 & 50.821 \\
\hline IE [kwh/m2 Año] & 11,28 & 17,70 & 16,46 \\
\hline
\end{tabular}

Tabla 117. Indicadores de Eficiencia Energética por servicios de uso final en el Edificio de Aulas 4 de los años 2017 - 2019

\begin{tabular}{|c|c|c|}
\hline Tipo de uso & Consumo eléctrico (Kwh) & Indicador IE kWh/m2 año \\
\hline Enfriamiento & $91.558,4$ & 29,65 \\
\hline Iluminación interior & $10.014,0$ & 3,24 \\
\hline Iluminación exterior & $1.735,8$ & 0,56 \\
\hline Equipos Ofimáticos & $84.630,1$ & 27,41 \\
\hline Área útil [m2] & \multicolumn{2}{|c|}{$3.087,85$} \\
\hline
\end{tabular}

Tabla 118. Indicadores de Eficiencia Energética de Generación FV y consumo de energía eléctrica total del Campus UAO de los años 2017 - 2019

\begin{tabular}{|c|c|c|c|c|c|c|c|c|c|c|c|c|}
\hline \multirow{3}{*}{ Mes/Consumo } & \multicolumn{4}{|c|}{2017} & \multicolumn{4}{|c|}{2018} & \multicolumn{4}{|c|}{2019} \\
\hline & \multicolumn{2}{|c|}{ Generación Sistema FI } & \multicolumn{2}{|c|}{ Consumo Eléctrico } & \multicolumn{2}{|c|}{ Generación Sistema FY } & \multicolumn{2}{|c|}{ Consumo Eléctrico } & \multicolumn{4}{|c|}{ Generación Sistema FY Consumo Eléctrico } \\
\hline & KWh/mes & IE & KWh/mes & IE & KWh/mes & IE & KWh/mes & IE & KWh/mes & IE & KWh/mes & IE \\
\hline Enero & 0 & 0,00 & 8.621 & 2,79 & 4.455 & 1,44 & 11.968 & 3,88 & 4.329 & 1,40 & 8.157 & 2,64 \\
\hline Febrero & 0 & 0,00 & 19.672 & 6,37 & 4.520 & 1,46 & 18.612 & 6,03 & 4.177 & 1,35 & 18.339 & 5,94 \\
\hline Marzo & 0 & 0,00 & 20.782 & 6,73 & 4.864 & 1,58 & 17.855 & 5,78 & 3.446 & 1,12 & 19.271 & 6,24 \\
\hline Abril & 0 & 0,00 & 17.120 & 5,54 & 4.412 & 1,43 & 18.971 & 6,14 & 3.128 & 1,01 & 15.445 & 5,00 \\
\hline Mayo & 2.253 & 0,73 & 20.919 & 6,77 & 4.376 & 1,42 & 18.237 & 5,91 & 4.125 & 1,34 & 18.876 & 6,11 \\
\hline Junio & 4.394 & 1,42 & 10.869 & 3,52 & 4.332 & 1,40 & 10.451 & 3,38 & 4.160 & 1,35 & 12.135 & 3,93 \\
\hline Julio & 4.945 & 1,60 & 11.163 & 3,62 & 4.581 & 1,48 & 13.730 & 4,45 & 4.856 & 1,57 & 20.271 & 6,56 \\
\hline Agosto & 4.933 & 1,60 & 18.805 & 6,09 & 4.999 & 1,62 & 19.142 & 6,20 & 4.890 & 1,58 & 24.242 & 7,85 \\
\hline Septiembre & 4.998 & 1,62 & 18.620 & 6,03 & 4.671 & 1,51 & 18.290 & 5,92 & 4.603 & 1,49 & 22.723 & 7,36 \\
\hline Octubre & 4.371 & 1,42 & 17.007 & 5,51 & 4.645 & 1,50 & 17.515 & 5,67 & 4.890 & 1,58 & 21.390 & 6,93 \\
\hline Noviembre & 4.461 & 1,44 & 14.861 & 4,81 & 3.990 & 1,29 & 14.198 & 4,60 & 4.071 & 1,32 & 17.109 & 5,54 \\
\hline Diciembre & 4.477 & 1,45 & 8.023 & 2,60 & 4.821 & 1,56 & 9.414 & 3,05 & 4.146 & 1,34 & 10.418 & 3,37 \\
\hline
\end{tabular}




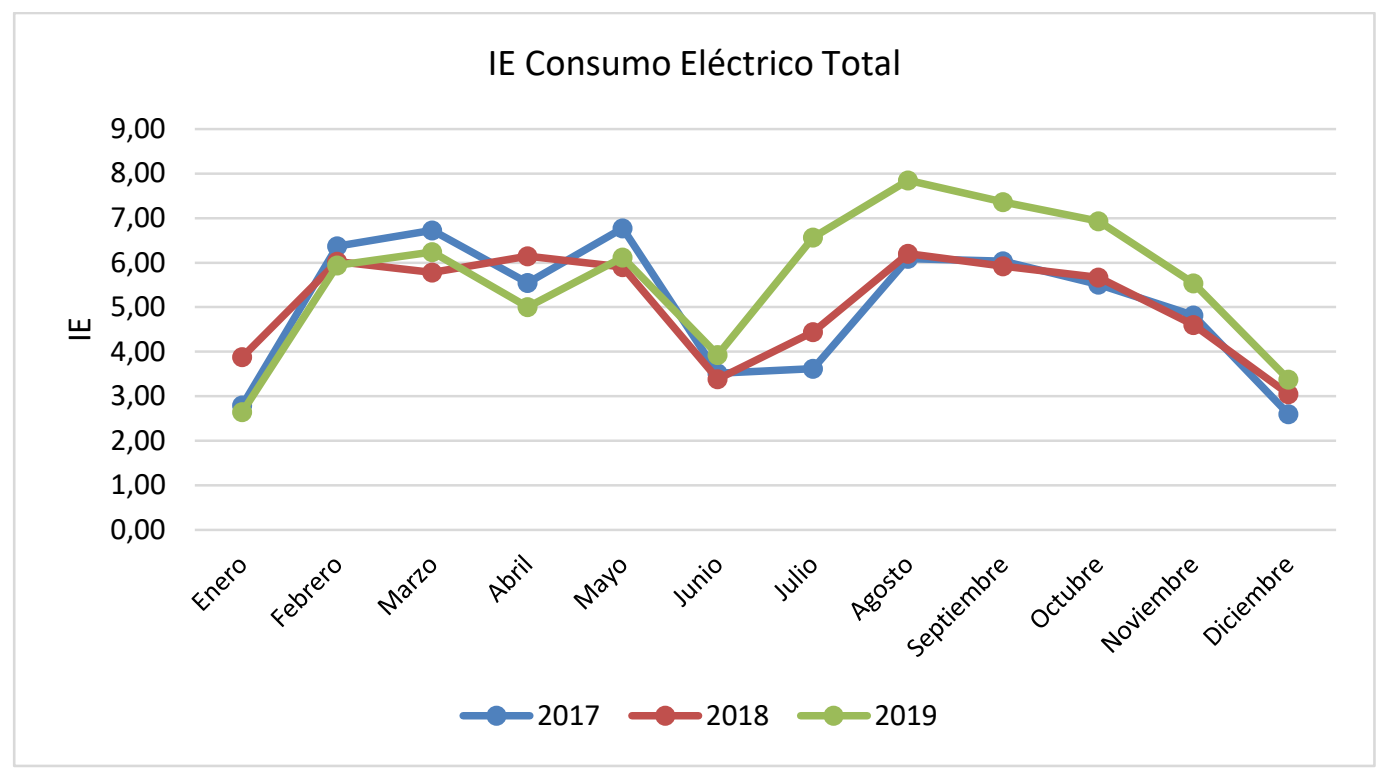

Figura 234. Indicadores de Eficiencia Energética del consumo de energía eléctrica total del Edificio de Aulas 4 de los años 2017 - 2019

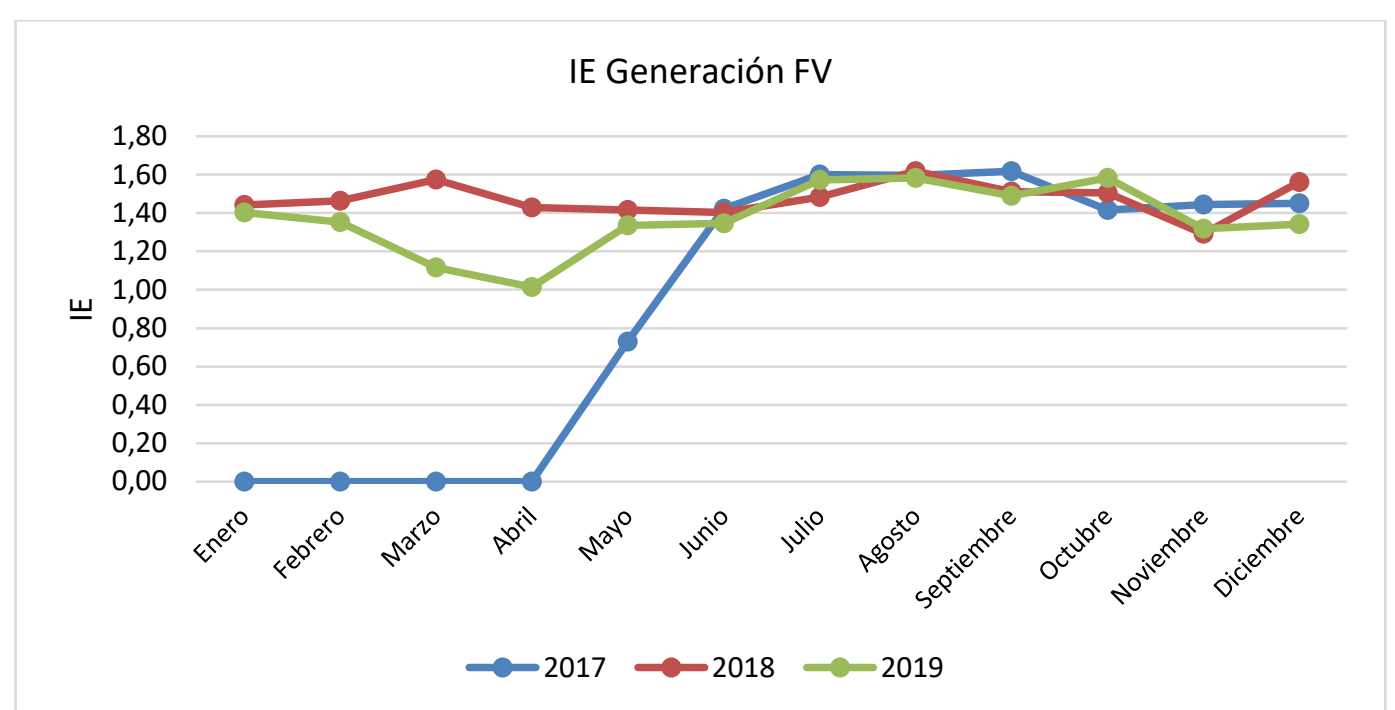

Figura 235. Indicadores de Eficiencia Energética de la generación de Energía Solar FV en el Edificio de Aulas 4 de los años 2017 - 2019

Si consideramos las medidas MAE's que hemos integrado al edificio aulas 4 el cálculo de los nuevos indicadores IE por servicio resultan unos valores que se muestran en la Tabla 119, donde se observa que ha habido una reducción en el sistema de refrigeración que era el más consumidor de energía , lo que demuestra, que se ha conseguido una optimización de la eficiencia energética del edifico y eso significa un mayor ahorro de energía y costes económicos, así como una mayor descarbonización y mejora del medioambiente.

Tabla 119. Escenario de IE con implementación de MAE's en el edificio de aulas 4 


\begin{tabular}{|c|c|c|}
\hline Tipo de uso & Electricidad (Kwh) & Indicador IE kWh/m2 año \\
\hline Enfriamiento & $73.041,19$ & 23,65 \\
\hline Iluminación interior & $13.421,92$ & 4,35 \\
\hline Iluminación exterior & $1.735,82$ & 0,56 \\
\hline Equipos Ofimáticos & $84.630,13$ & 27,41 \\
\hline Área útil [m2] & \multicolumn{2}{|c|}{$3.087,85$} \\
\hline
\end{tabular}

\subsubsection{Indicador IE referido al consumo de Energía primaria Edificios nZEB}

Energía primaria: Energía suministrada al edificio procedente de fuentes renovables y no renovables, que no ha sufrido ningún proceso previo de conversión o transformación. Es la energía contenida en los combustibles y otras fuentes de energía e incluye la energía necesaria para generar la energía final consumida, incluyendo las perdidas por su transporte hasta el edificio, almacenamiento, etc. (Figura 236)

Energía primaria = Energía final + Pérdidas en transformación + Pérdidas en transporte

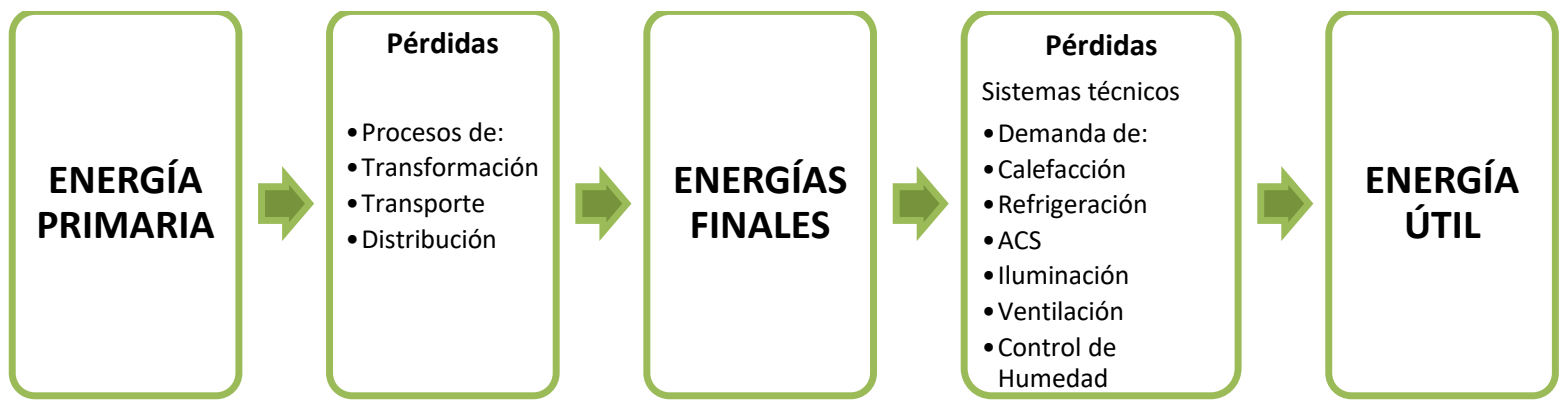

Figura 236. Etapas de Energía primaria a Energía Útil

La energía primaria puede descomponerse en energía primaria procedente de fuentes renovables, o energía primaria renovable, y en energía primaria procedente de fuentes no renovables o energía primaria no renovable, de acuerdo con la Directiva de Energías Renovables (2009/28/CE).

De forma simplificada, la relación entre energía final y primaria se puede expresar con un coeficiente de paso que refleja, para una zona geográfica determinada, el efecto de las perdidas en transformación y transporte en cada una de las partes de la energía primaria (renovable y no renovable) de cada vector energético.

Energía procedente de fuentes renovables: energía procedente de fuentes renovables no fósiles, es decir, energía eólica, solar aerotérmica, geotérmica, hidrotérmica y oceánica, hidráulica, biomasa, gases de vertedero, gases de plantas de depuración y biogás. Debe tenerse en cuenta que no toda la energía generada a partir de fuentes renovables puede ser considerada renovables. La energía generada a partir de fuentes renovables puede tener, en algunos casos, un componente de energía no renovable que debe ser tratado como tal en el cálculo energético [22][46]. 
Las ecuaciones de cálculo para nuestros edificios se expresan como:

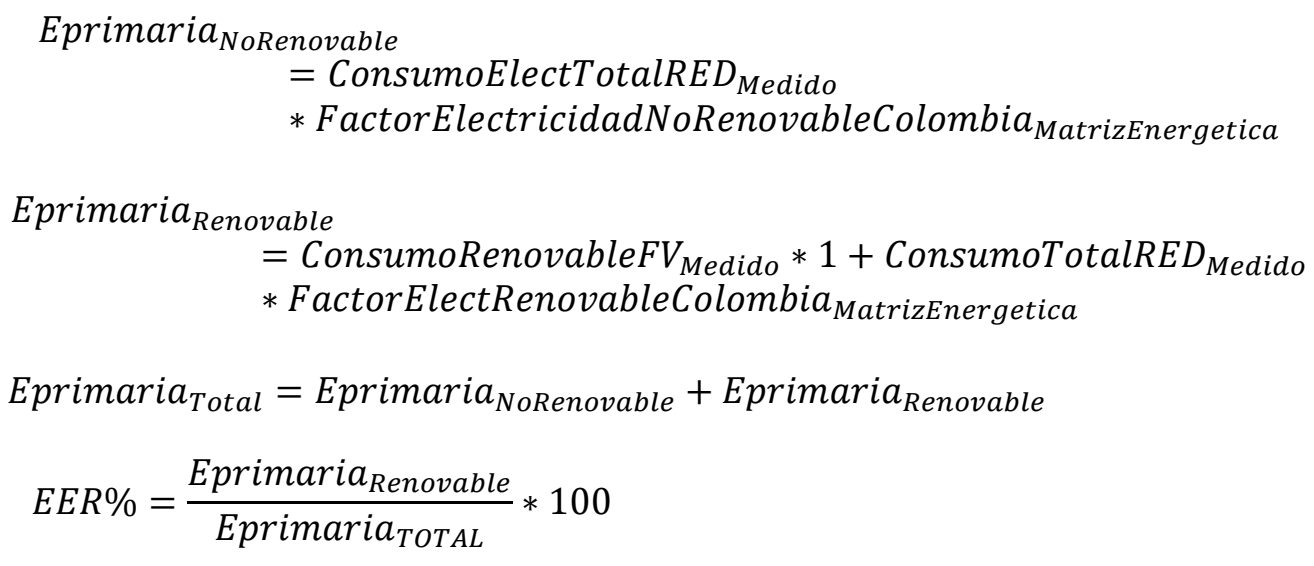

Estudiaremos dos casos para obtener el factor de paso de energía final a energía primaria en función de la matriz de generación energética. El primer caso sería obtener el factor de paso en Colombia y el segundo caso sería en España un país de la EU.

\section{A) Caso Colombia}

En Colombia el recurso hídrico permite que la generación de energía eléctrica tenga un alto porcentaje de representación en la matriz energética (70\%), sin embargo, el recurso hídrico se concentra en centrales hidroeléctricas que almacenan dicho recurso en embalses para su operación. Las grandes centrales hidroeléctricas se consideran centrales de generación eléctrica convencional, dado que al almacenar el agua a partir de embalses alteran los cursos de los ríos provocando impactos socioambientales. Dichos impactos no permiten considerar a este tipo de generación eléctrica de tipo renovable, aunque su recurso lo sea. Sucede lo contrario con los aprovechamientos a "filo de agua" típicos de las pequeñas centrales hidroeléctricas ( $\mathrm{PCH}^{\prime} \mathrm{s}$ ) las cuales aprovechan una parte del caudal del rio para convertirlo en energía eléctrica, sin necesidad de embalse, y luego se retorna el recurso al cauce lo que genera un bajo impacto socioambiental.

Los factores de paso se construyeron tomando como referencia el balance energético para Colombia BECO [23] [47], reportado la página de la unidad de planeamiento minero energético.

La Tabla 120 presenta los factores de paso de energía final a energía primaria para el caso de Colombia. 
Tabla 120. Factores de paso de energía final a Energía primaria - Colombia

\begin{tabular}{|c|c|c|c|c|c|}
\hline \multirow[b]{2}{*}{ Tipo } & \multirow[b]{2}{*}{ Energético } & \multicolumn{3}{|c|}{2017} & \multirow[b]{2}{*}{$\begin{array}{c}\text { Factor } \mathrm{CO} 2 \\
{[\mathrm{~kg} \mathrm{CO} 2 / \mathrm{kW}]}\end{array}$} \\
\hline & & $\begin{array}{c}\text { Generación } \\
\text { [GW] }\end{array}$ & $\begin{array}{c}\text { Consumo } \\
{[\mathrm{GW}]}\end{array}$ & $\begin{array}{c}\text { Factor } \\
\text { Electricidad }\end{array}$ & \\
\hline \multirow{2}{*}{ Renovable } & Eólica & 68 & \multirow{6}{*}{56970} & $1,19 \mathrm{E}-03$ & \multirow{6}{*}{0,0818} \\
\hline & Solar FV & 3 & & 5,27 E-05 & \\
\hline \multicolumn{2}{|c|}{ Total Renovable } & 71 & & $1,25 \mathrm{E}-03$ & \\
\hline \multirow{2}{*}{$\begin{array}{c}\text { No } \\
\text { Renovable } \\
\end{array}$} & Hidroeléctrica & 44.682 & & 0,784 & \\
\hline & Térmica & 21.272 & & 0,373 & \\
\hline \multicolumn{2}{|c|}{ Total No Renovable } & 65.954 & & 1,158 & \\
\hline
\end{tabular}

Las tablas 121 y 122 presentan los IE de energía primaria no renovable, renovable y total para el CAMPUS UAO.

Tabla 121. IE de energía primaria no renovable $\mathrm{Kw} \mathrm{h}$, renovable y total en el CAMPUS UAO

\begin{tabular}{|c|c|c|c|c|c|c|c|c|c|}
\hline \multirow[b]{2}{*}{ Año/Consumo } & \multicolumn{3}{|c|}{2017} & \multicolumn{3}{|c|}{2018} & \multicolumn{3}{|c|}{2019} \\
\hline & $\begin{array}{l}\text { Consumo de } \\
\text { Energía } \\
\text { primaria no } \\
\text { renovable }\end{array}$ & $\begin{array}{c}\text { Energia } \\
\text { primaria } \\
\text { consumida } \\
\text { renovable } \\
\text { Solar FV } \\
\end{array}$ & $\begin{array}{c}\text { Consumo de } \\
\text { energia } \\
\text { primaria } \\
\text { Total }\end{array}$ & $\begin{array}{c}\text { Consumo de } \\
\text { Energía primaria } \\
\text { no renovable }\end{array}$ & $\begin{array}{c}\text { Energia } \\
\text { primaria } \\
\text { consumida } \\
\text { renovable } \\
\text { Solar FV }\end{array}$ & $\begin{array}{l}\text { Consumo de } \\
\text { energia } \\
\text { primaria } \\
\text { Total }\end{array}$ & $\begin{array}{l}\text { Consumo de } \\
\text { Energía } \\
\text { primaria no } \\
\text { renovable }\end{array}$ & $\begin{array}{c}\text { Energia } \\
\text { primaria } \\
\text { consumida } \\
\text { renovable } \\
\text { Solar FV }\end{array}$ & $\begin{array}{c}\text { Consumo de } \\
\text { energia } \\
\text { primaria } \\
\text { Total }\end{array}$ \\
\hline Total Año & 3.313.173 & 424.450 & 3.737 .623 & 2.999 .937 & 545.660 & 3.545 .597 & 3.121 .281 & 537.160 & 3.658 .441 \\
\hline & \multicolumn{2}{|c|}{ IE kWh/m2 año } & \multicolumn{2}{|c|}{2017} & 2018 & \multicolumn{2}{|c|}{2019} & & \\
\hline & \multicolumn{2}{|c|}{ EpNoRenovable } & \multicolumn{2}{|c|}{77,024} & 69,742 & \multicolumn{2}{|c|}{72,563} & & \\
\hline & \multicolumn{2}{|c|}{ EpRenovable } & \multicolumn{2}{|c|}{8,606} & 11,033 & \multicolumn{2}{|c|}{10,865} & & \\
\hline & \multicolumn{2}{|l|}{ EpTotal } & \multicolumn{2}{|c|}{85,631} & 80,775 & \multicolumn{2}{|c|}{83,428} & & \\
\hline & \multicolumn{2}{|l|}{ EER } & \multicolumn{2}{|c|}{$10,05 \%$} & $13,66 \%$ & \multicolumn{2}{|c|}{$13,02 \%$} & & \\
\hline
\end{tabular}

Tabla 122. IE de energía primaria no renovable, renovable y total en kWh en el Edificio de Aulas 4

\begin{tabular}{|c|c|c|c|c|c|c|c|c|c|}
\hline \multirow[b]{2}{*}{ Año/Consumo } & \multicolumn{3}{|c|}{2017} & \multicolumn{3}{|c|}{2018} & \multicolumn{3}{|c|}{2019} \\
\hline & $\begin{array}{l}\text { Consumo de } \\
\text { Energía } \\
\text { primaria no } \\
\text { renovable }\end{array}$ & $\begin{array}{c}\text { Energia } \\
\text { primaria } \\
\text { consumida } \\
\text { renovable } \\
\text { Solar FV } \\
\end{array}$ & $\begin{array}{c}\text { Consumo de } \\
\text { energia } \\
\text { primaria } \\
\text { Total }\end{array}$ & $\begin{array}{l}\text { Consumo de } \\
\text { Energía } \\
\text { primaria no } \\
\text { renovable }\end{array}$ & $\begin{array}{c}\text { Energia } \\
\text { primaria } \\
\text { consumida } \\
\text { renovable } \\
\text { Solar FV } \\
\end{array}$ & $\begin{array}{c}\text { Consumo de } \\
\text { energia } \\
\text { primaria } \\
\text { Total }\end{array}$ & $\begin{array}{l}\text { Consumo de } \\
\text { Energía } \\
\text { primaria no } \\
\text { renovable }\end{array}$ & $\begin{array}{c}\text { Energia } \\
\text { primaria } \\
\text { consumida } \\
\text { renovable } \\
\text { Solar FV } \\
\end{array}$ & $\begin{array}{c}\text { Consumo de } \\
\text { energia } \\
\text { primaria } \\
\text { Total }\end{array}$ \\
\hline \multirow{6}{*}{ Total Año } & 151.630 & 34.832 & 186.462 & 133.715 & 54.666 & 188.381 & 157.555 & 50.821 & 208.376 \\
\hline & \multicolumn{2}{|c|}{ IE kWh/m2 año } & \multicolumn{2}{|l|}{2017} & \multicolumn{2}{|l|}{2018} & 2019 & & \\
\hline & \multicolumn{2}{|c|}{ EpNoRenovable } & \multicolumn{2}{|l|}{56,849} & \multicolumn{2}{|l|}{50,133} & \multicolumn{2}{|l|}{59,071} & \\
\hline & \multicolumn{2}{|c|}{ EpRenovable } & \multicolumn{2}{|l|}{11,342} & \multicolumn{2}{|l|}{17,758} & \multicolumn{2}{|l|}{16,522} & \\
\hline & \multicolumn{2}{|l|}{ EpTotal } & \multicolumn{2}{|l|}{68,191} & \multicolumn{2}{|l|}{67,890} & \multicolumn{2}{|l|}{75,593} & \\
\hline & \multicolumn{2}{|l|}{ EER } & $16,63 \%$ & & \multicolumn{2}{|l|}{$26,16 \%$} & $21,86 \%$ & & \\
\hline
\end{tabular}




\section{B) Caso de España}

En este caso se realiza el análisis considerando la energía hidráulica como renovable, los factores de paso son presentados en la Tabla 123.

Tabla 123. Factores de paso de energía final a Energía primaria - España

\begin{tabular}{|c|c|c|c|c|c|}
\hline \multirow[b]{2}{*}{ Tipo } & \multirow[b]{2}{*}{ Energético } & \multicolumn{3}{|c|}{2017} & \multirow[b]{2}{*}{$\begin{array}{c}\text { Factor } \mathrm{CO} 2 \\
{[\mathrm{~kg} \mathrm{CO} 2 / \mathrm{kW}]}\end{array}$} \\
\hline & & $\begin{array}{c}\text { Generación } \\
\text { [GW] }\end{array}$ & $\begin{array}{c}\text { Consumo } \\
\text { [GW] }\end{array}$ & $\begin{array}{c}\text { Factor } \\
\text { Electricidad }\end{array}$ & \\
\hline \multirow{3}{*}{ Renovable } & Eólica & 68 & \multirow{6}{*}{56.970} & $1,19 \mathrm{E}-03$ & \multirow{6}{*}{0,0818} \\
\hline & Solar FV & 3 & & 5,27 E-05 & \\
\hline & Hidroeléctrica & 44.682 & & 7,84 E-01 & \\
\hline \multicolumn{2}{|c|}{ Total Renovable } & 44.753 & & 7,86 E-01 & \\
\hline $\begin{array}{c}\text { No } \\
\text { Renovable }\end{array}$ & Térmica & 21.272 & & 0,373 & \\
\hline \multicolumn{2}{|c|}{ Total No Renovable } & 21.272 & & 0,373 & \\
\hline
\end{tabular}

Las tablas 124 y 125 , presentan los IE de energía primaria no renovable, renovable y total para el edificio de Aulas 4 respectivamente.

Tabla 124. IE de energía primaria no renovable, renovable y total en kWh en el CAMPUS UAO

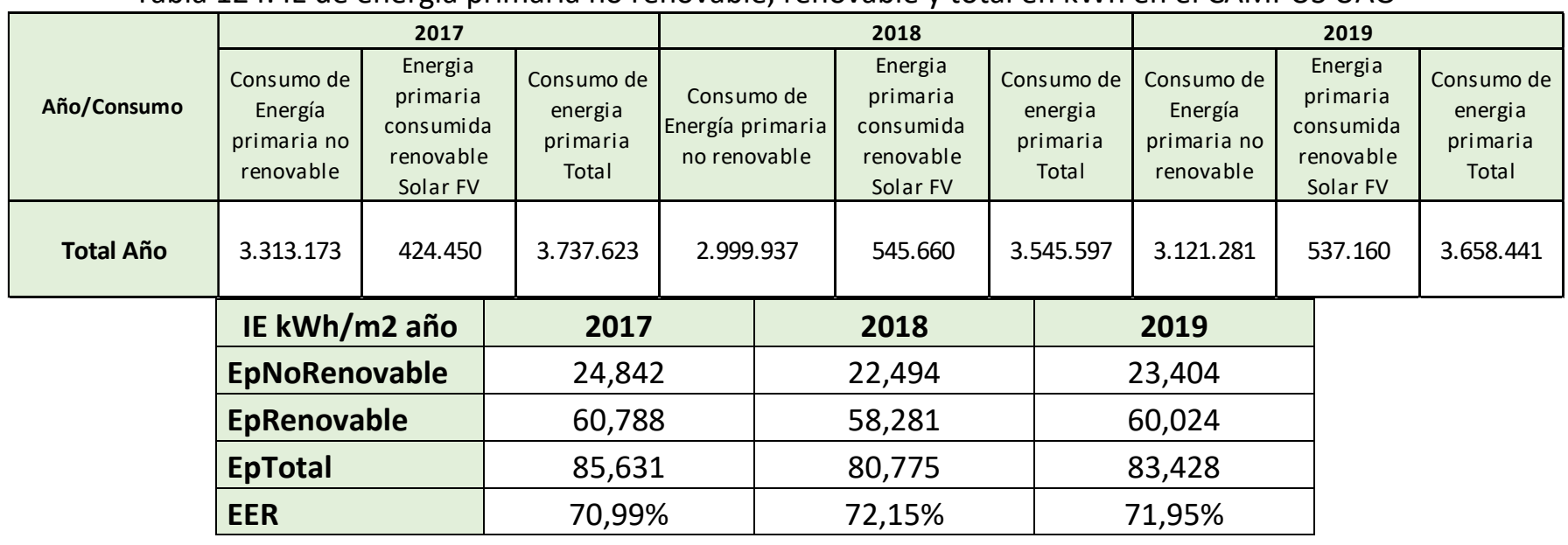

Tabla 125. IE de energía primaria no renovable, renovable y total en kWh en el Edificio de Aulas 4

\begin{tabular}{|c|c|c|c|c|c|c|c|c|c|}
\hline \multirow[b]{2}{*}{ Año/Consumo } & \multicolumn{3}{|c|}{2017} & \multicolumn{3}{|c|}{2018} & \multicolumn{3}{|c|}{2019} \\
\hline & $\begin{array}{l}\text { Consumo de } \\
\text { Energía } \\
\text { primaria no } \\
\text { renovable }\end{array}$ & $\begin{array}{c}\text { Energia } \\
\text { primaria } \\
\text { consumida } \\
\text { renovable } \\
\text { Solar FV }\end{array}$ & $\begin{array}{c}\text { Consumo de } \\
\text { energia } \\
\text { primaria } \\
\text { Total }\end{array}$ & $\begin{array}{l}\text { Consumo de } \\
\text { Energía } \\
\text { primaria no } \\
\text { renovable }\end{array}$ & $\begin{array}{c}\text { Energia } \\
\text { primaria } \\
\text { consumida } \\
\text { renovable } \\
\text { Solar FV }\end{array}$ & $\begin{array}{c}\text { Consumo de } \\
\text { energia } \\
\text { primaria } \\
\text { Total }\end{array}$ & $\begin{array}{l}\text { Consumo de } \\
\text { Energía } \\
\text { primaria no } \\
\text { renovable }\end{array}$ & $\begin{array}{c}\text { Energia } \\
\text { primaria } \\
\text { consumida } \\
\text { renovable } \\
\text { Solar FV }\end{array}$ & $\begin{array}{c}\text { Consumo de } \\
\text { energia } \\
\text { primaria } \\
\text { Total }\end{array}$ \\
\hline Total Año & 151.630 & 34.832 & 186.462 & 133.715 & 54.666 & 188.381 & 157.555 & 50.821 & 208.376 \\
\hline
\end{tabular}




\begin{tabular}{|l|c|c|c|}
\hline IE $\mathbf{k W h} / \mathbf{m} \mathbf{2}$ año & $\mathbf{2 0 1 7}$ & $\mathbf{2 0 1 8}$ & $\mathbf{2 0 1 9}$ \\
\hline EpNoRenovable & 18,335 & 16,169 & 19,052 \\
\hline EpRenovable & 49,855 & 51,721 & 56,541 \\
\hline EpTotal & 68,191 & 67,890 & 75,593 \\
\hline EER & $73,11 \%$ & $76,18 \%$ & $74,80 \%$ \\
\hline
\end{tabular}

La Tabla 126 presenta una tabla comparativa de los IE de energía primaria no renovable, renovable y total en el edificio de aulas 4 en su estado actual y del edificio con las MAE'S propuestas.

Tabla 126. Tabla comparativa Edificio de aulas 4 vs Edificio con MAE's propuestas

\begin{tabular}{|c|c|c|c|c|c|c|}
\hline \multirow[b]{2}{*}{ Año/Consumo } & \multicolumn{3}{|c|}{ EDIFICIO ACTUAL } & \multicolumn{3}{|c|}{ EDIFICIO CON MAE'S PROPUESTAS } \\
\hline & $\begin{array}{l}\text { Consumo de } \\
\text { Energía } \\
\text { KWh/mes }\end{array}$ & $\begin{array}{c}\text { Sistema Solar } \\
\text { Fotovoltaica } \\
\text { KWh/mes }\end{array}$ & $\begin{array}{c}\text { Consumo } \\
\text { Total } \\
\text { kWh/mes }\end{array}$ & $\begin{array}{c}\text { Consumo de } \\
\text { Energía KWh/mes }\end{array}$ & $\begin{array}{c}\text { Sistema Solar } \\
\text { Fotovoltaica } \\
\text { KWh/mes }\end{array}$ & $\begin{array}{c}\text { Consumo } \\
\text { Total } \\
\text { kWh/mes }\end{array}$ \\
\hline Total Año & 151.630 & 34.832 & 186.462 & 137.997 & 34.832 & 172.829 \\
\hline IE kwh/m2 año & \multicolumn{3}{|c|}{ EDIFICIO ACTUAL } & \multicolumn{3}{|c|}{ EDIFICIO CON MAE'S PROPUESTAS } \\
\hline EpNoRenovable & \multicolumn{3}{|c|}{19,052} & \multicolumn{3}{|c|}{11,336} \\
\hline EpRenovable & \multicolumn{3}{|c|}{56,541} & \multicolumn{3}{|c|}{51,738} \\
\hline EpTotal & \multicolumn{3}{|c|}{68,191} & \multicolumn{3}{|c|}{63,074} \\
\hline EER & \multicolumn{3}{|c|}{$16,63 \%$} & \multicolumn{3}{|c|}{$17,97 \%$} \\
\hline
\end{tabular}

\section{EDIFICIO nZEB DE CONSUMO DE ENERGIA CASI NULO}

El concepto de edificio nZEB viene expresado en la EPBD 2010 de conformidad con el artículo 2, apartado 2, y EN 15603:2008, donde se entiende por «edificio de consumo de energía casi nulo, nZEB» como un edificio con un nivel de eficiencia energética muy alto, que se determinará de conformidad con el anexo I. La cantidad casi nula o muy baja de energía requerida debería estar cubierta, en muy amplia medida, por energía procedente de fuentes renovables, incluida energía procedente de fuentes renovables producida in situ o en el entorno.

Por lo tanto, la definición de un edificio $\mathrm{ZZEB}$, muestra el hecho de que la integración de energía renovable y las medidas de eficiencia energética en un edificio van unidas.

En la EU los indicadores para saber si un edificio se comporta como un nZEB son la Ep no renovable y el EER. Para un edificio universitario con carga interna media alta en EU y considerando un clima suave marítimo el valor límite de Ep no renovable es $90 \mathrm{Kwh} / \mathrm{m} 2$ año y en España sería $135 \mathrm{Kwh} / \mathrm{m} 2$ año. Además, en EU el EER sería mayor del 20\%.

Si analizamos nuestros indicadores en el caso $A$ y en el caso $B$, se observan que la Ep no renovable cumpliría como nZEB en los dos casos para el Campus y para el aula 4 sin embargo el indicador de Ep renovable queda reducido en el caso $A$, lo que sería necesario integrar más sistemas de energía renovables y sin embargo si cumpliría en el caso $B$ como nZEB. 
En resumen, si consideramos los factores de paso de España tanto el campus UAO como el edificio aulas 4 según los criterios EU y de España en el nuevo CTE HEO serían edificios nZEB sin embargo si consideramos los factores de paso de Colombia, aun siendo muy eficientes los edificios no cumplirían el porcentaje de energías renovables como nZEB, siendo necesario incrementar las energías renovables.

\subsubsection{Indicador del Impacto Ambiental - Emisiones de CO2}

El cambio climático es, sin duda, el mayor reto al que se enfrenta la sociedad actual. Según informes del IPCC se estima que las actividades humanas han causado un calentamiento global de aproximadamente $1,0^{\circ} \mathrm{C}$ con respecto a los niveles preindustriales, con un rango probable de $0,8^{\circ} \mathrm{C}$ a $1,2^{\circ} \mathrm{C}$. Si el ritmo de calentamiento global continúa al ritmo actual, es posible que el calentamiento global llegue a $1,5^{\circ} \mathrm{C}$ entre 2030 y 2050.

Como explican los objetivos de la Agenda 2030, nuestra vulnerabilidad al cambio climático nos debe hacer trabajar en la mitigación de los riesgos y en la adaptación al mismo. Las prioridades de actuación son reducir el impacto ambiental negativo de las ciudades, atendiendo especialmente a la calidad del aire y a la gestión de residuos, y proteger el patrimonio cultural y natural. Especial importancia con el cambio climático tienen los objetivos de desarrollo sostenibles. En ellos se pretende adoptar medidas urgentes para combatir el cambio climático y sus efectos. La lucha contra el cambio climático, tanto la reducción de emisiones de gases de efecto invernadero como la adaptación al cambio climático, son una prioridad en la actualidad.

La alerta climática planteada por la comunidad científica ha hecho que, en el horizonte 2020-2050, las emisiones de $\mathrm{CO}_{2}$ se constituyan como el principal vector de transformación del sector de la energía. La descarbonización sistemática y profunda del sistema energético es el horizonte político prioritario a lograr en el siglo XXI. Europa se ha comprometido a limitar sus emisiones de $\mathrm{CO}_{2}$, con el objetivo de lograr un desarrollo sostenible.

Esto se ve reflejado en el Objetivo 7 de los ODS. "Energía asequible y no contaminante" cuyas metas son aumentar considerablemente la proporción de energía renovable, duplicar la tasa mundial de mejora de la eficiencia energética, aumentar la cooperación internacional para facilitar el acceso a la investigación y la tecnología relativas a la energía limpia, incluidas las fuentes renovables, la eficiencia energética y las tecnologías avanzadas y menos contaminantes de combustibles fósiles, y promover la inversión en infraestructura energética y tecnologías limpias en los próximos 10 años.

Para conocer cuantitativamente la huella de carbono y el impacto ambiental en los edificios usaremos un indicador llamado $I_{M}$ cuya ecuación de cálculo es la siguiente:

$$
I_{M}=\frac{C_{\text {final }} * \text { FactorElectricidad }}{C O 2}
$$

Factor de $\mathrm{CO} 2=0.0818$ [KG CO2/Kw], fuente: UPME (Colombia) 
La Tabla 127 y las figuras 237 - 239, presentan las emisiones de CO2 y el indicador ambiental $I_{M}$ mensual y anual de los años 2017 - 2019 en el campus UAO.

Tabla 127. Consumo de energía final total y emisiones de $\mathrm{CO} 2$ por meses en el CAMPUS UAO

\begin{tabular}{|c|c|c|c|c|c|c|c|c|c|}
\hline Año & \multicolumn{3}{|c|}{2017} & \multicolumn{3}{|c|}{2018} & \multicolumn{3}{|c|}{2019} \\
\hline $\begin{array}{c}\text { Consumo / } \\
\text { Mes }\end{array}$ & $\begin{array}{c}\text { Consumo de } \\
\text { energía final } \\
\text { Total } \\
{[\mathrm{kWh} / \mathrm{mes}]}\end{array}$ & Kg CO2 & $\begin{array}{c}\mathrm{IM} \\
{[\mathrm{Kg} \mathrm{CO2} / \mathrm{m} 2]}\end{array}$ & $\begin{array}{c}\text { Consumo de } \\
\text { energía final } \\
\text { Total } \\
{[\mathrm{kWh} / \mathrm{mes}]}\end{array}$ & $\mathrm{Kg} \mathrm{CO2}$ & $\begin{array}{c}\mathrm{IM} \\
{[\mathrm{Kg} \mathrm{CO2} / \mathrm{m} 2]}\end{array}$ & $\begin{array}{c}\text { Consumo de } \\
\text { energía final } \\
\text { Total } \\
{[\mathrm{kWh} / \mathrm{mes}]}\end{array}$ & Kg CO2 & $\underset{[\mathrm{IM} \mathrm{CO} 2 / \mathrm{m} 2]}{\mathrm{Ka}}$ \\
\hline Enero & 280.370 & 22.934 & 0,46 & 260.424 & 21.303 & 0,43 & 237.635 & 19.439 & 0,39 \\
\hline Febrero & 344.658 & 28.193 & 0,57 & 322.472 & 26.378 & 0,53 & 305.260 & 24.970 & 0,50 \\
\hline Marzo & 350.748 & 28.691 & 0,58 & 302.893 & 24.777 & 0,50 & 328.690 & 26.887 & 0,54 \\
\hline Abril & 296.426 & 24.248 & 0,49 & 315.173 & 25.781 & 0,52 & 290.152 & 23.734 & 0,48 \\
\hline Mayo & 342.111 & 27.985 & 0,56 & 324.232 & 26.522 & 0,53 & 349.274 & 28.571 & 0,57 \\
\hline Junio & 254.574 & 20.824 & 0,42 & 236.592 & 19.353 & 0,39 & 246.547 & 20.168 & 0,40 \\
\hline Julio & 289.544 & 23.685 & 0,48 & 281.635 & 23.038 & 0,46 & 302.101 & 24.712 & 0,50 \\
\hline Agosto & 346.242 & 28.323 & 0,57 & 332.242 & 27.177 & 0,55 & 351.491 & 28.752 & 0,58 \\
\hline Septiembre & 366.798 & 30.004 & 0,60 & 321.359 & 26.287 & 0,53 & 345.877 & 28.293 & 0,57 \\
\hline Octubre & 344.414 & 28.173 & 0,57 & 333.627 & 27.291 & 0,55 & 359.493 & 29.406 & 0,59 \\
\hline Noviembre & 315.131 & 25.778 & 0,52 & 287.228 & 23.495 & 0,47 & 317.697 & 25.988 & 0,52 \\
\hline Diciembre & 206.608 & 16.901 & 0,34 & 227.720 & 18.627 & 0,37 & 224.224 & 18.342 & 0,37 \\
\hline Total Año & 3.737 .623 & 305.738 & 6,14 & 3.545.597 & 290.030 & 5,82 & 3.658.441 & 299.260 & 6,01 \\
\hline
\end{tabular}

Emisiones anuales de CO2 - Campus UAO

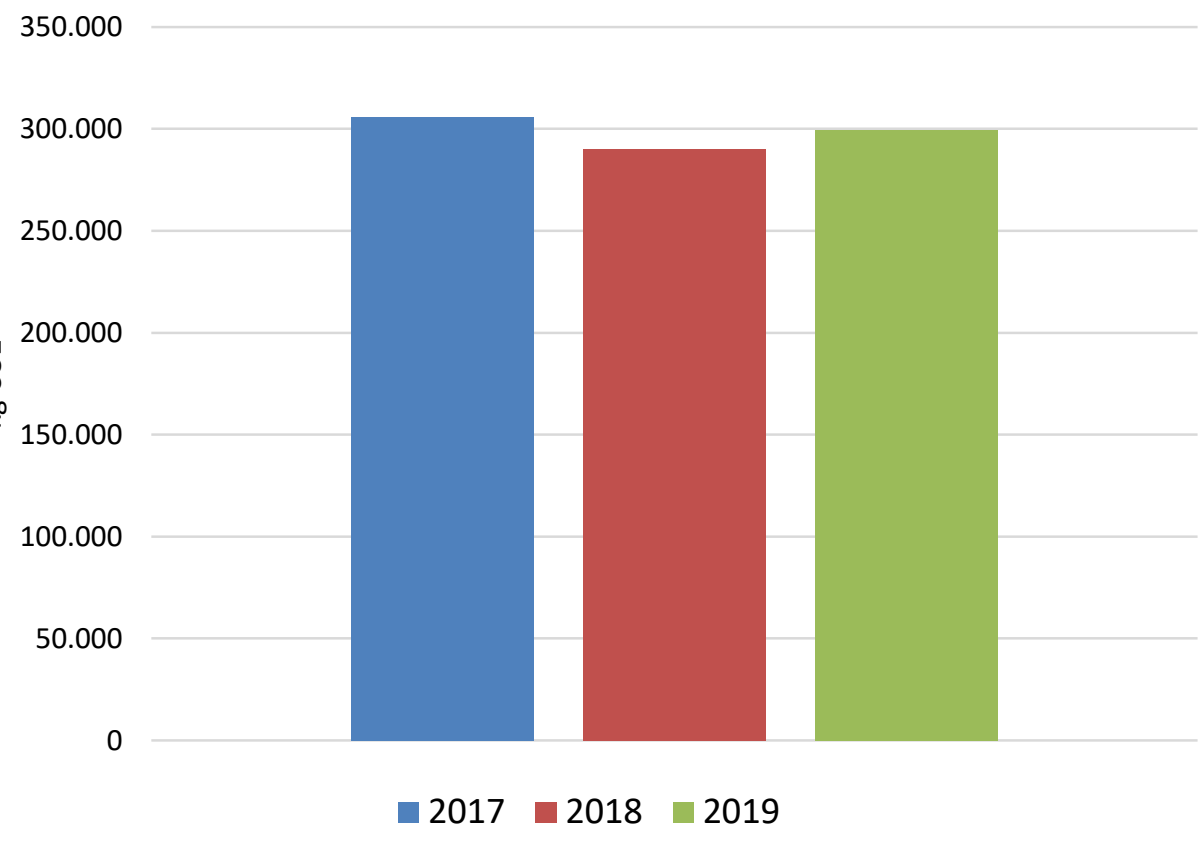

Figura 237. Emisiones anuales de CO2 de los años 2017 - 2019 campus UAO 


\section{Emisiones de CO2 - Campus UAO}

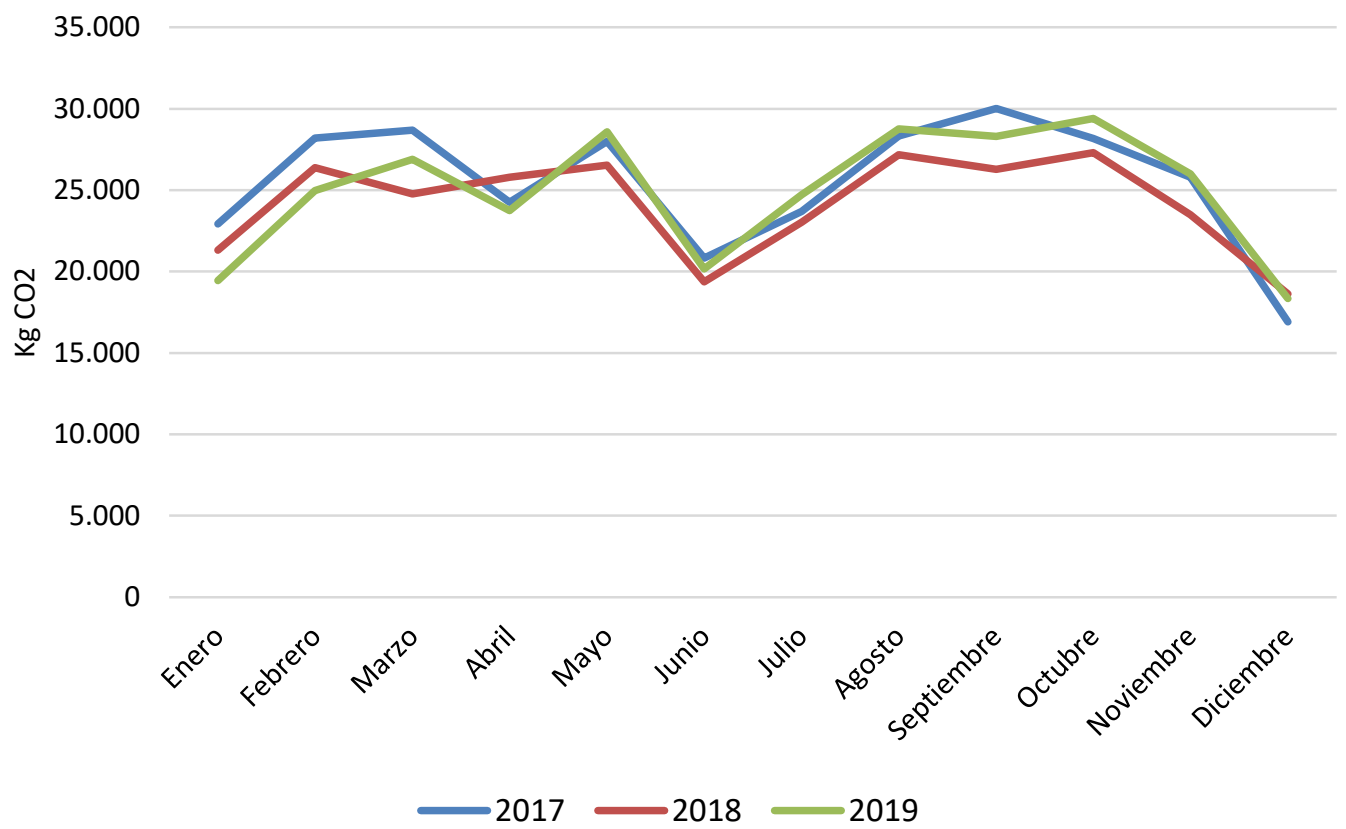

Figura 238. Emisiones mensuales de CO2 de los años 2017 - 2019 campus UAO

Indicador Ambiental IM - Campus UAO

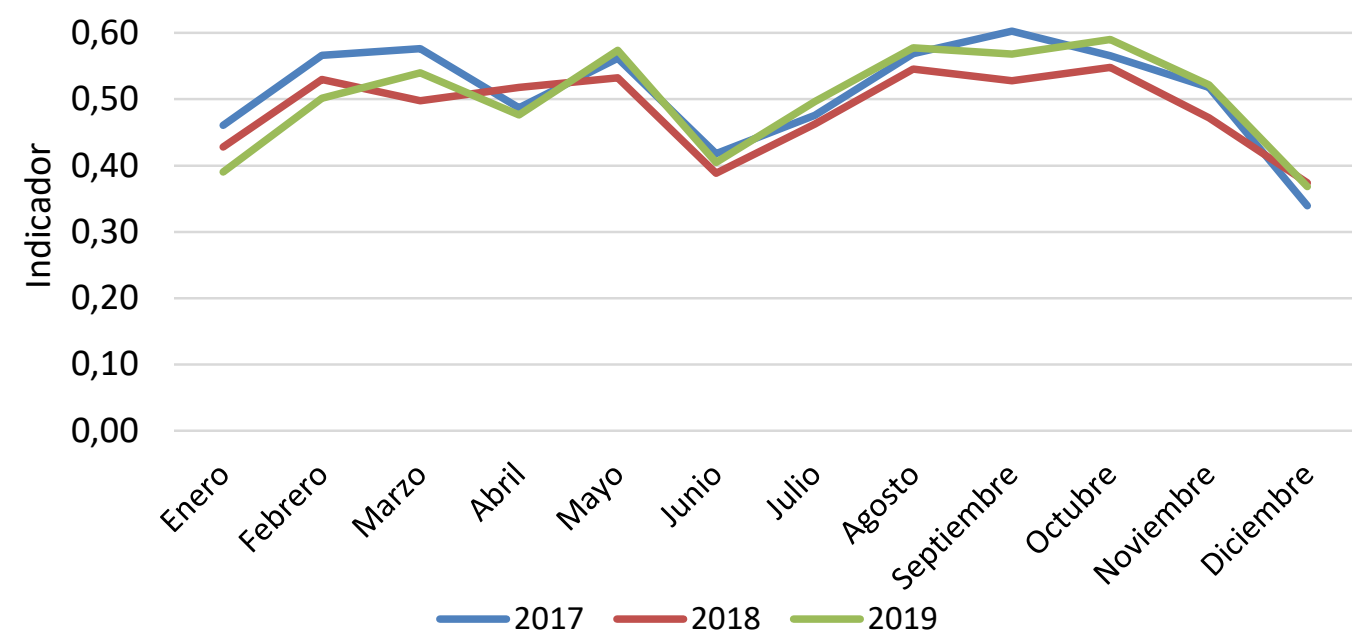

Figura 239.Indicador Ambiental mensual de los años 2017 - 2019 campus UAO

Tabla 128 y las figuras 240 - 242, presentan las emisiones de CO2 y el indicador ambiental $I_{M}$ mensual y anual de los años 2017 - 2019 en el Edificios de Aula 4 de UAO. 
Tabla 128. Consumo de energía final total y emisiones de CO2 por meses en el Edificio de Aulas 4

\begin{tabular}{|c|c|c|c|c|c|c|c|c|c|}
\hline Año & \multicolumn{3}{|c|}{2017} & \multicolumn{3}{|c|}{2018} & \multicolumn{3}{|c|}{2019} \\
\hline $\begin{array}{c}\text { Consumo / } \\
\text { Mes }\end{array}$ & $\begin{array}{l}\text { Consumo } \\
\text { de energía } \\
\text { final Total } \\
\text { [kWh/mes] }\end{array}$ & Kg CO2 & $\begin{array}{c}\mathrm{IM} \\
{[\mathrm{Kg} \mathrm{CO} 2 / \mathrm{m} 2]}\end{array}$ & $\begin{array}{c}\text { Consumo } \\
\text { de energía } \\
\text { final Total } \\
\text { [kWh/mes] }\end{array}$ & $\mathrm{Kg} \mathrm{CO} 2$ & $\begin{array}{c}\mathrm{IM} \\
{[\mathrm{Kg} \mathrm{CO} / \mathrm{m} 2]}\end{array}$ & $\begin{array}{c}\text { Consumo } \\
\text { de energía } \\
\text { final Total } \\
\text { [kWh/mes] }\end{array}$ & Kg CO2 & $\begin{array}{c}\mathrm{IM} \\
{[\mathrm{Kg} \mathrm{CO} 2 / \mathrm{m} 2]}\end{array}$ \\
\hline Enero & 8.621 & 705,20 & 0,23 & 11.968 & 978,99 & 0,32 & 8.157 & 667,27 & 0,22 \\
\hline Febrero & 19.672 & $1.609,17$ & 0,52 & 18.612 & $1.522,43$ & 0,49 & 18.339 & $1.500,10$ & 0,49 \\
\hline Marzo & 20.782 & $1.699,97$ & 0,55 & 17.855 & $1.460,55$ & 0,47 & 19.271 & $1.576,36$ & 0,51 \\
\hline Abril & 17.120 & $1.400,42$ & 0,45 & 18.971 & $1.551,85$ & 0,50 & 15.445 & $1.263,42$ & 0,41 \\
\hline Mayo & 20.919 & $1.711,17$ & 0,55 & 18.237 & $1.491,76$ & 0,48 & 18.876 & $1.544,03$ & 0,50 \\
\hline Junio & 10.869 & 889,08 & 0,29 & 10.451 & 854,88 & 0,28 & 12.135 & 992,60 & 0,32 \\
\hline Julio & 11.163 & 913,13 & 0,30 & 13.730 & $1.123,11$ & 0,36 & 20.271 & $1.658,15$ & 0,54 \\
\hline Agosto & 18.805 & $1.538,25$ & 0,50 & 19.142 & $1.565,80$ & 0,51 & 24.242 & $1.983,02$ & 0,64 \\
\hline Septiembre & 18.620 & $1.523,12$ & 0,49 & 18.290 & $1.496,10$ & 0,48 & 22.723 & $1.858,77$ & 0,60 \\
\hline Octubre & 17.007 & $1.391,17$ & 0,45 & 17.515 & $1.432,73$ & 0,46 & 21.390 & $1.749,73$ & 0,57 \\
\hline Noviembre & 14.861 & $1.215,63$ & 0,39 & 14.198 & $1.161,36$ & 0,38 & 17.109 & $1.399,53$ & 0,45 \\
\hline Diciembre & 8.023 & 656,28 & 0,21 & 9.414 & 770,03 & 0,25 & 10.418 & 852,17 & 0,28 \\
\hline Total & 186.462 & 15.253 & 4,94 & 188.381 & 15.410 & 4,99 & 208.376 & 17.045 & 5,52 \\
\hline
\end{tabular}

Emisiones anuales de $\mathrm{CO} 2$ - Aulas 4

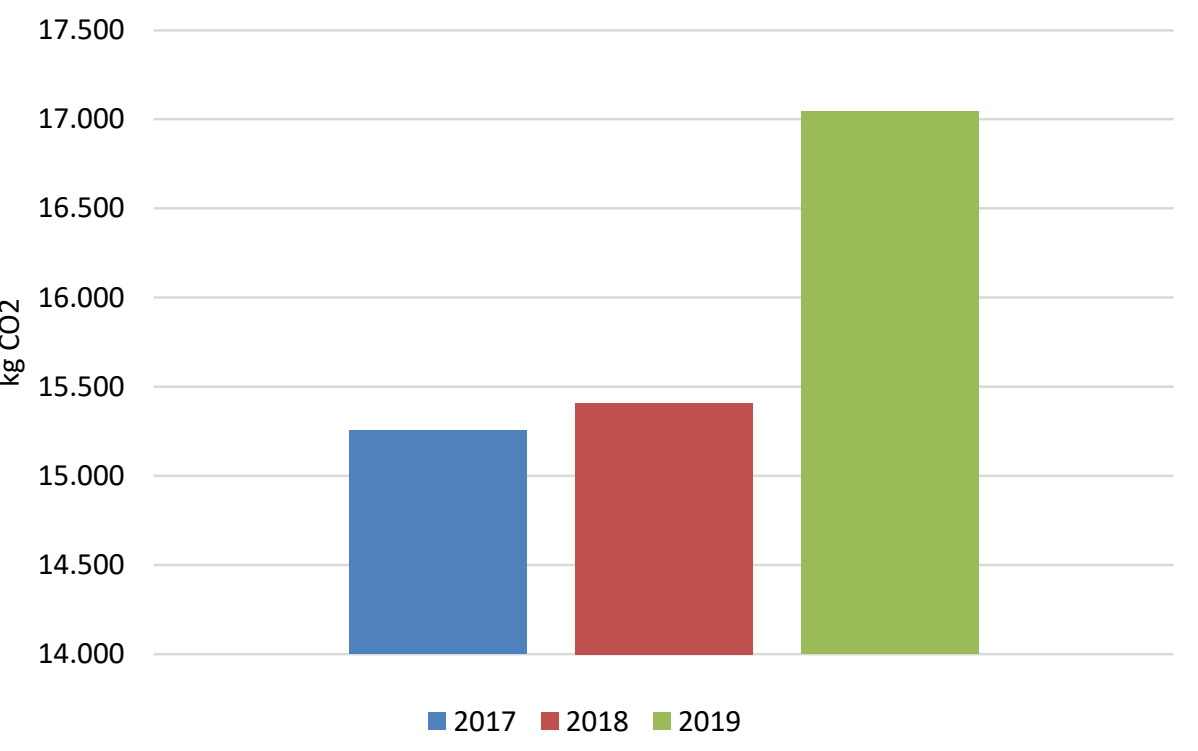

Figura 240. Emisiones anuales de CO2 de los años 2017 - 2019 campus UAO

Como se evidencia en las emisiones de $\mathrm{CO} 2$ y los indicadores ambientales $I_{M}$ del edificio de Aulas 4, el valor en el año 2019 aumentó en un 10,6\% con respecto al año 2018, debido al incremento en el consumo de energía del edificio, al normalizar sus actividades e incluir la climatización total de sus aulas. En el mismo porcentaje que incrementó el consumo de energía eléctrica, incrementaron las emisiones de CO2. 
Emisiones de $\mathrm{CO} 2$ - Aulas 4

$2.500,00$

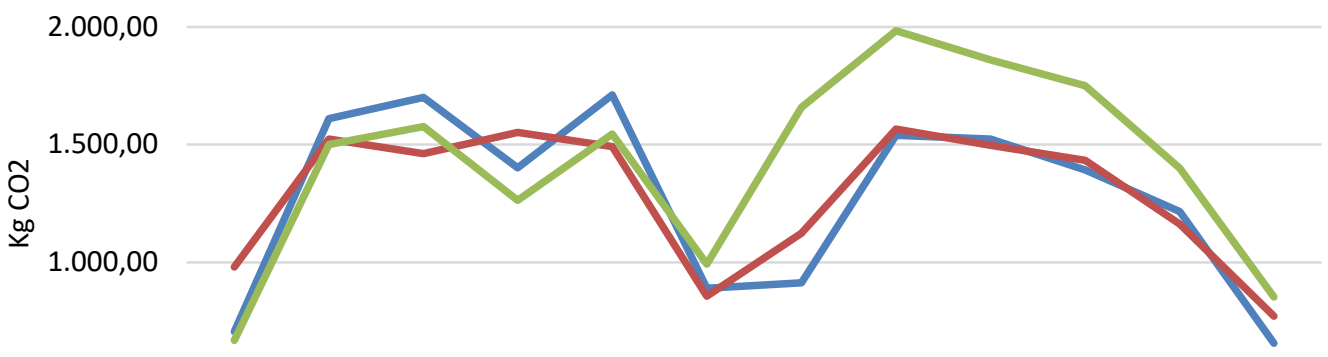

500,00

0,00

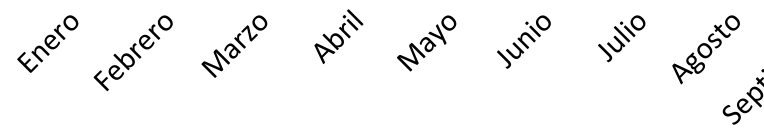

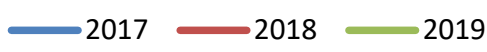

Figura 241. Emisiones mensuales de CO2 de los años 2017 - 2019 campus UAO

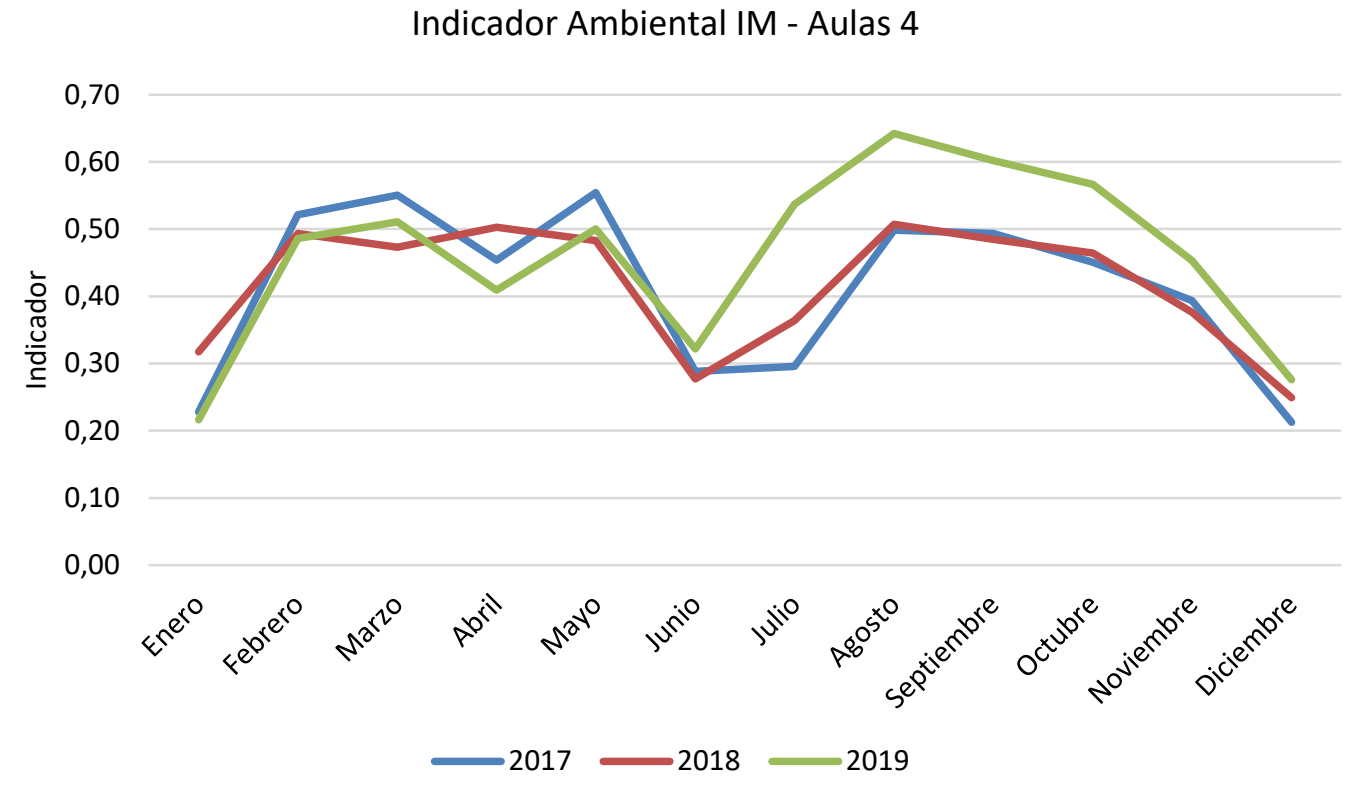

Figura 242. Indicador Ambiental mensual de los años 2017 - 2019 campus UAO 


\subsubsection{Indicadores de Gestión Energética}

A continuación, se presenta los resultados de los indicadores de gestión energética o indicadores que reflejan el desempeño energético (IDE) del edificio de aulas 4 . Estos indicadores permiten evaluar, de manera integral, todos los aspectos de la gestión energética asociados al funcionamiento del edificio. Abarca la planeación del mismo en función de las actividades desarrolladas en el campus, desde el punto de vista energético, el desempeño con miras a mejores prácticas de uso de energía, la estandarización como un proceso de mejora continua, y la medición de resultados de las políticas y acciones implementadas.

Tabla 129 siguiente tabla se presenta los consumos mensuales de los años 2017, 2018, 2019 y los valores estimados de sus líneas bases según el modelo de regresión multivariable.

Tabla 129. Consumo eléctrico real y estimado para los años $2017-2019$ del edificio de aulas 4

\begin{tabular}{|c|c|c|c|c|c|c|}
\hline \multirow{2}{*}{ Año } & \multicolumn{2}{|c|}{2017} & \multicolumn{2}{c|}{2018} & \multicolumn{2}{c|}{2019} \\
\cline { 2 - 7 } & $\begin{array}{c}\text { Consumo } \\
\text { Real }\end{array}$ & $\begin{array}{c}\text { Consumo } \\
\text { Estimado LBE }\end{array}$ & $\begin{array}{c}\text { Consumo } \\
\text { Real }\end{array}$ & $\begin{array}{c}\text { Consumo } \\
\text { Estimado LBE }\end{array}$ & $\begin{array}{c}\text { Consumo } \\
\text { Real }\end{array}$ & $\begin{array}{c}\text { Consumo } \\
\text { Estimado LBE }\end{array}$ \\
\hline Enero & 8.621 & 10.314 & 11.968 & 10.262 & 8.157 & 10.224 \\
\hline Febrero & 19.672 & 18.583 & 18.612 & 12.106 & 18.339 & 16.856 \\
\hline Marzo & 20.782 & 16.327 & 17.855 & 14.399 & 19.271 & 17.034 \\
\hline Abril & 17.120 & 20.438 & 18.971 & 11.371 & 15.445 & 16.635 \\
\hline Mayo & 20.919 & 21.719 & 18.237 & 10.576 & 18.876 & 18.204 \\
\hline Junio & 10.869 & 10.828 & 10.451 & 8.955 & 12.135 & 11.611 \\
\hline Julio & 11.163 & 12.111 & 13.730 & 10.576 & 20.271 & 19.073 \\
\hline Agosto & 18.805 & 18.328 & 19.142 & 10.393 & 24.242 & 24.326 \\
\hline Septiembre & 18.620 & 17.527 & 18.290 & 13.347 & 22.723 & 23.388 \\
\hline Octubre & 17.007 & 15.838 & 17.515 & 7.626 & 21.390 & 21.814 \\
\hline Noviembre & 14.861 & 16.457 & 14.198 & 8.622 & 17.109 & 19.236 \\
\hline Diciembre & 8.023 & 8.032 & 9.414 & 10.236 & 10.418 & 9.974 \\
\hline Anual & 186.462 & 186.502 & 188.383 & 128.470 & 208.376 & 208.375 \\
\hline
\end{tabular}

\subsubsection{Indicador de eficiencia energética (IEE)}

Este indicador permite comparar el comportamiento de los resultados de consumo energético de una instalación en el edificio durante un período operativo, respecto a los valores de consumo energético base o de tendencia del mismo.

Matemáticamente se define como:

$$
I E E=\frac{E_{\text {medida }}}{E_{\text {Base }}}
$$

Para evaluar el indicador de eficiencia, se calcula el cociente entre el valor de consumo de energía, medido para un período de referencia, respecto al consumo de tendencia calculado a partir de la LBE para el mismo periodo. El resultado del indicador de eficiencia puede analizarse de acuerdo a tres estados, los cuales se encuentran dentro de los rangos numéricos $<1,>1$, e =1. 
La Tabla 130, presenta el indicador de Eficiencia Energética mensual del Edificio de aulas 4, para los años 2017, 2018 y 2019. En la Figura 243, se evidencia el indicador IEE anual de los años mencionados anteriormente.

Tabla 130. Indicador de Eficiencia Energética IEE del edificio de aulas 4 años 2017 - 2019

\begin{tabular}{|c|c|c|c|}
\hline \multicolumn{4}{|c|}{ INDICADOR DE EFICIENCIA IEE } \\
\hline Mes/Año & 2017 & 2018 & 2019 \\
\hline Enero & 0,84 & 1,17 & 0,80 \\
\hline Febrero & 1,06 & 1,54 & 1,09 \\
\hline Marzo & 1,27 & 1,24 & 1,13 \\
\hline Abril & 0,84 & 1,67 & 0,93 \\
\hline Mayo & 0,96 & 1,72 & 1,04 \\
\hline Junio & 1,00 & 1,17 & 1,05 \\
\hline Julio & 0,92 & 1,30 & 1,06 \\
\hline Agosto & 1,03 & 1,84 & 1,00 \\
\hline Septiembre & 1,06 & 1,37 & 0,97 \\
\hline Octubre & 1,07 & 2,30 & 0,98 \\
\hline Noviembre & 0,90 & 1,65 & 0,89 \\
\hline Diciembre & 1,00 & 0,92 & 1,04 \\
\hline Anual & 1,00 & 1,47 & 1,00 \\
\hline
\end{tabular}

Donde:

Zona de Eficiencia Igualdad a la tendencia

Zona de Ineficiencia

Indicador de Eficiencia Energética

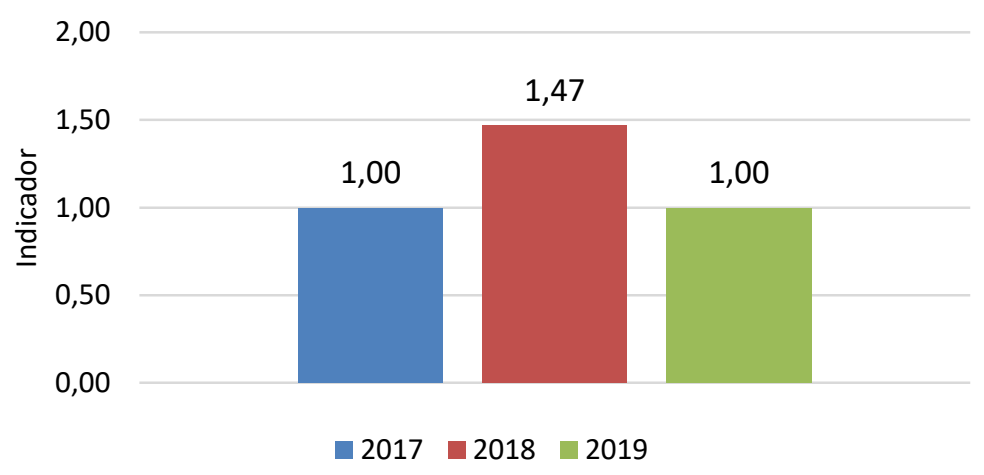

Figura 243. Indicador de Eficiencia Energética anual - Edificio de Aulas 4 


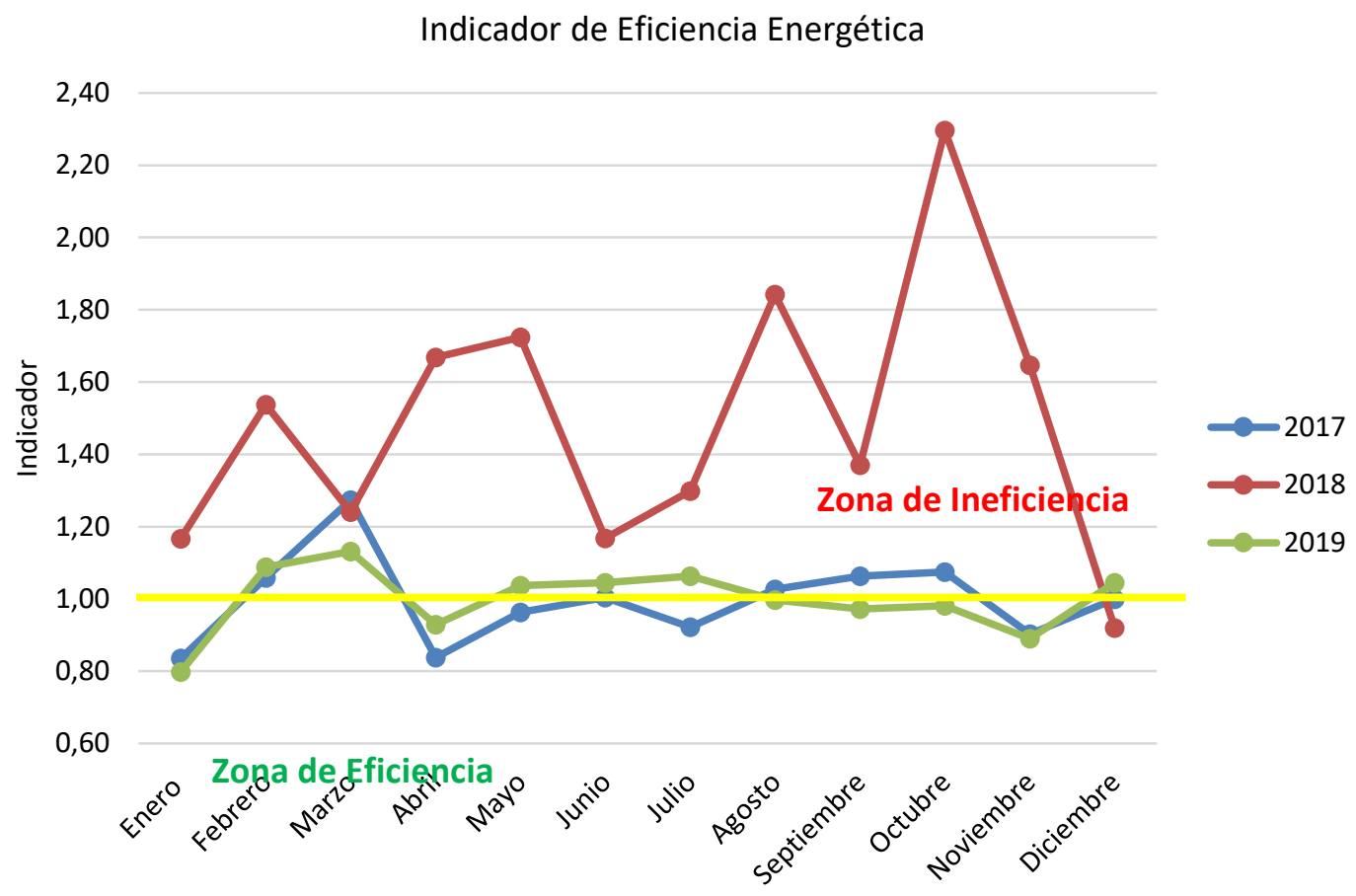

Figura 244. Indicador de Eficiencia Energética IEE del edificio de aulas 4 años 2017 - 2019

Indicador de Eficiencia Energética

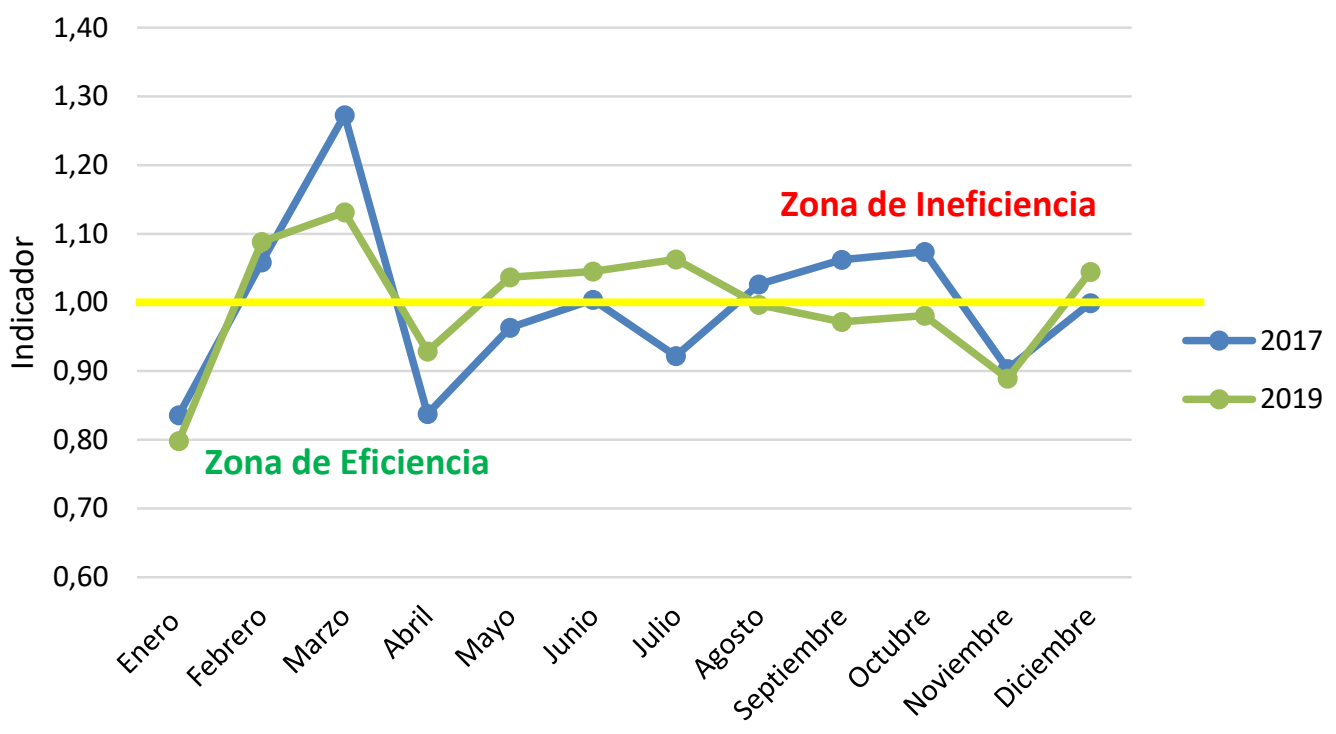

Figura 245. Indicador de Eficiencia Energética IEE del edificio de aulas 4 años 2017 y 2019

En la Figura 244 se puede visualizar el comportamiento del indicador de eficiencia para los años 2017, 2018, 2019, donde en el 2018 se aprecia una fluctuación del indicador con respecto a la base de comparación (1) con una tendencia hacia la ineficiencia. Lo anterior, en razón a los múltiples cambios que se han realizado en el aula 4 relacionados con: remodelación y adecuación oficina egresados, 10 salones de postgrado (piso 4) y cambio 
del sistema de climatización de todas las aulas auditorios del edificio. De otro lado, para el 2019 se observa una estabilidad en el indicador siendo enero y noviembre los meses de mayor eficiencia. En este sentido, el indicador de eficiencia energética IEE puede ser monitoreado en intervalos de tiempo cortos o largos (horario, diario, mensual), dependiendo de la necesidad del usuario. Por su utilidad se recomienda ser utilizado por el personal táctico (directores, jefes de áreas) y operativo (supervisores, operarios).

\subsubsection{Indicador sumas acumulativa CUSUM}

En la Tabla 131 se presenta los cálculos realizados para obtener el indicador de sumas acumuladas CUSUM, el mismo tiene como objetivos mostrar a lo largo del tiempo los sobre sobre consumos y la energía que se ha dejado de consumir, para brindar una alternativa de gestión que permita monitorear al final del periodo de análisis diario, semana, mensual y anual los ahorros obtenidos. Como IDE, ofrece un mecanismo básico y efectivo para la verificación y monitoreo de las mejoras en el desempeño energético y de los ahorros reales alcanzados dentro de los límites establecidos.

Por lo tanto, este indicador, hace visible cualquier ahorro o sobreconsumo energético o, en términos económicos relacionados a la energía que haya tenido la organización. El gráfico se utiliza para monitorear la tendencia de la empresa, en cuanto a la variación de sus consumos energéticos, respecto a un período o línea de base energética usada como referencia. Sí no hay cambios en los patrones del consumo, la curva CUSUM simplemente fluctuará alrededor de una línea horizontal. Sin embargo, cualquier cambio que produzca ahorros o sobreconsumos causará que la curva cambie de dirección: una tendencia de la curva hacia abajo significa ahorros, mientras que la ascendencia significa pérdidas.

En resumen, se plantea el CUSUM como un indicador de desempeño energético estratégico para la alta dirección de una organización, puesto que permite realizar seguimiento al desempeño de todas las áreas o dependencias, dentro de los límites del SGE. Y, sumado a ello, proporciona resultados totales de las acciones ejecutadas de un plan de acción para la gestión energética, en forma de unidades de energía ahorradas o consumidas en exceso, lo cual puede traducirse directamente en dinero.

La Tabla 131, presenta el Indicador de sumas acumulativas CUSUM de los años 2017, 2018 y 2019 del edificio de aulas 4. 
Tabla 131. CUSUM edificio de aulas 4 años $2017-2019$

\begin{tabular}{|c|c|c|c|c|c|c|}
\hline \multicolumn{7}{|c|}{ CUSUM } \\
\hline Año & \multicolumn{2}{|c|}{2017} & \multicolumn{2}{|c|}{2018} & \multicolumn{2}{|c|}{2019} \\
\hline Mes & $\begin{array}{c}\text { Energía ahorrada } \\
\text { o } \\
\text { sobreconsumida }\end{array}$ & CUSUM & $\begin{array}{c}\text { Energía ahorrada } \\
0 \\
\text { sobreconsumida }\end{array}$ & CUSUM & $\begin{array}{c}\text { Energía ahorrada } \\
0 \\
\text { sobreconsumida }\end{array}$ & CUSUM \\
\hline Enero & $-1.693,1$ & $-1.693,1$ & $1.706,1$ & $1.706,1$ & $-2.066,8$ & $-2.066,8$ \\
\hline Febrero & $1.089,1$ & $-604,0$ & $6.505,7$ & $8.211,7$ & $1.482,3$ & $-584,6$ \\
\hline Marzo & $4.455,0$ & $3.851,0$ & $3.455,7$ & $11.667,4$ & $2.236,4$ & $1.651,8$ \\
\hline Abril & $-3.317,7$ & 533,3 & $7.599,9$ & $19.267,4$ & $-1.190,2$ & 461,7 \\
\hline Mayo & $-800,1$ & $-266,8$ & $7.661,2$ & $26.928,6$ & 671,7 & $1.133,4$ \\
\hline Junio & 41,2 & $-225,5$ & $1.496,0$ & $28.424,6$ & 523,7 & $1.657,1$ \\
\hline Julio & $-947,9$ & $-1.173,4$ & $3.154,0$ & $31.578,5$ & $1.198,3$ & $2.855,4$ \\
\hline Agosto & 477,2 & $-696,2$ & $8.749,1$ & $40.327,6$ & $-83,4$ & $2.772,0$ \\
\hline Septiembre & $1.092,6$ & 396,4 & $4.942,7$ & $45.270,3$ & $-664,6$ & $2.107,4$ \\
\hline Octubre & $1.168,6$ & $1.564,9$ & $9.888,8$ & $55.159,1$ & $-423,6$ & $1.683,8$ \\
\hline Noviembre & $-1.595,9$ & $-30,9$ & $5.575,9$ & $60.735,0$ & $-2.126,7$ & $-442,9$ \\
\hline Diciembre & $-9,0$ & $-40,0$ & $-822,1$ & $59.912,9$ & 443,9 & 1,0 \\
\hline
\end{tabular}

\section{CUSUM}

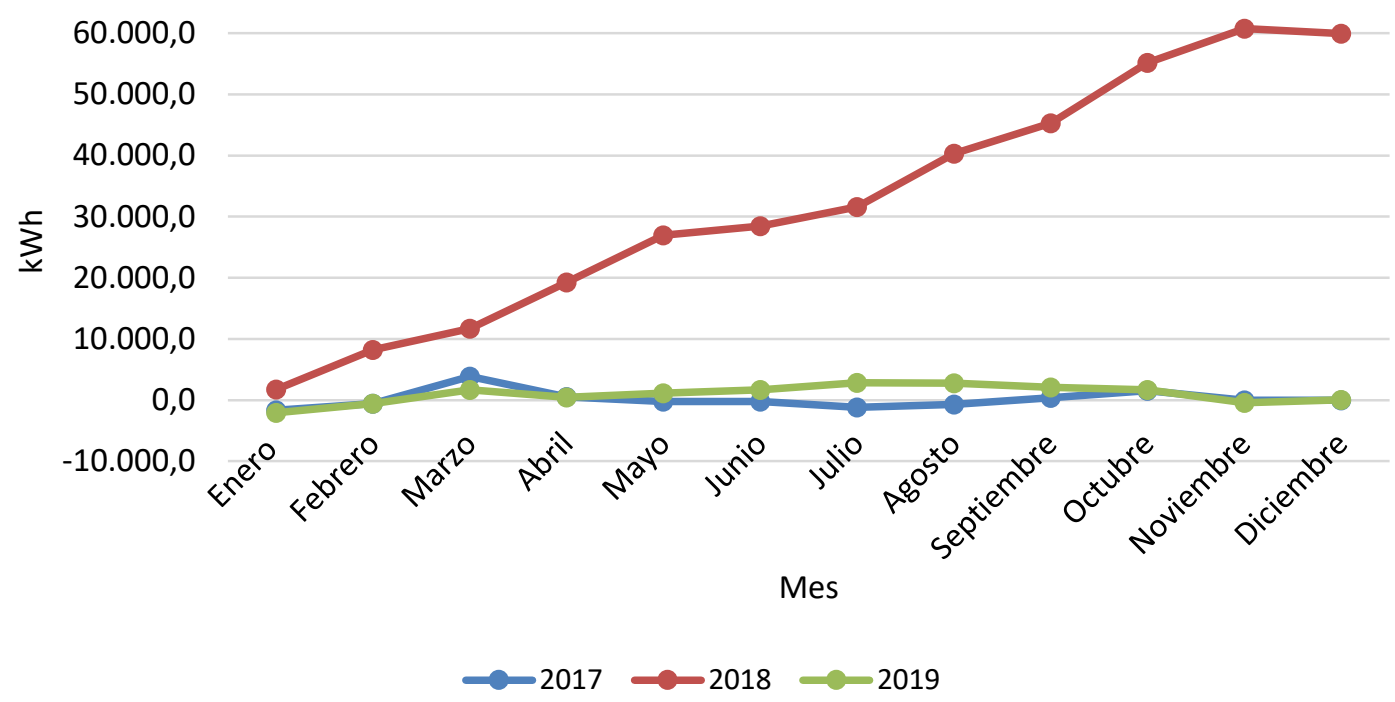

Figura 246. Indicador de Sumas Acumulativas CUSUM del edificio de aulas 4 años 2017 - 2019 


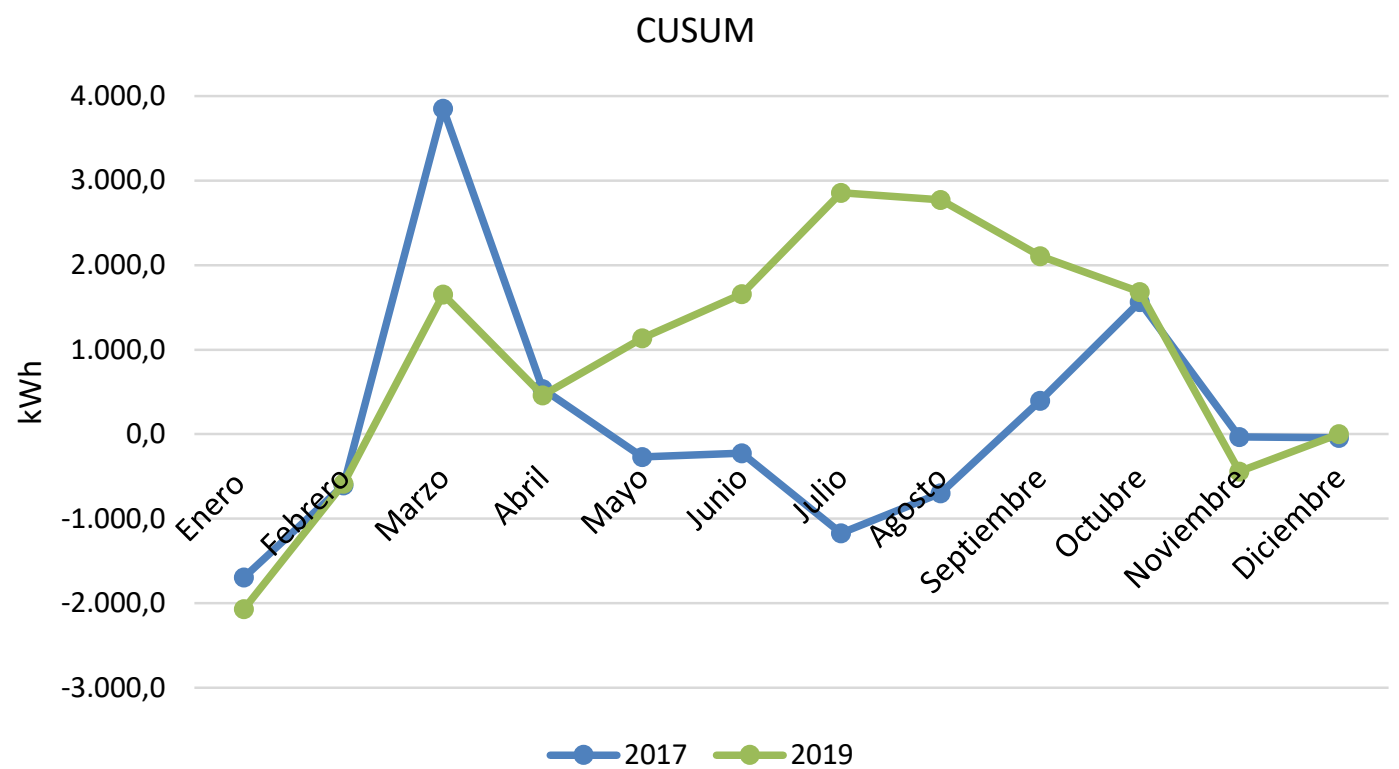

Figura 247. Indicador de Sumas Acumulativas CUSUM del edificio de aulas 4 años 2017 y 2019

Los resultados mostrados en la Figura 246 y 247 dejan en evidencia que la gestión energética realizada en el año 2018 tuvo algunas dificultades, debido a todas las adecuaciones que se realizaron en el aula. Lo anterior se muestra con una tendencia casi constante hacia la ineficiencia donde el modelo establecido como línea base, subestima los consumos de energía dando como resultado un sobre consumo de 59.912 kWh. Mientras que, en el 2019 los meses de mayor tendencia al ahorro son enero y noviembre. Es importante destacar que, pese a la los cambios tecnológicos relacionados con la instalación de ascensor y la climatización y remodelación de salones, los mismo no ha sido significativos debido a la tecnología adquirida. Este incremento ha representado $10.5 \%$ con respecto al año 2018.

En cuanto al análisis del indicador CUSUM para el 2019 se observa que el modelo planteado como línea base, realiza un pronóstico de consumo muy cercano al valor real, lo que facilita evaluar el desempeño y comportamiento de la eficiencia del aula. En ese sentido, se observa a lo largo del año, en la segunda mitad del mismo, aparece una tendencia marcada hacia la eficiencia dado la estabilidad del aula en cuanto a las adecuaciones realizadas. No obstante, aunque hay varios meses con tendencia a la ineficiencia los valores no son significativos y, hacia el final el año, se observa una relación igual en cuanto al consumo pronosticado frente al real. Esto evidencia que en la operación del aula no existan ahorros ni sobreconsumos.

La Tabla 132, presenta en resumen los indicadores del Campus UAO, la Tabla 133 recopila los indicadores del Edificio de Aulas 4. 
Tabla 132. Resumen indicadores del campus UAO

\begin{tabular}{|c|c|c|c|}
\hline \multirow{2}{*}{ INDICADOR } & \multicolumn{3}{|c|}{ VALOR DEL INDICADOR } \\
\cline { 2 - 4 } & $\mathbf{2 0 1 7}$ & $\mathbf{2 0 1 8}$ & $\mathbf{2 0 1 9}$ \\
\hline Intensidad Energética & 75,06 & 71,20 & 73,47 \\
\hline $\begin{array}{c}\text { Indicador IE referido al consumo de energía primaria } \\
\text { No renovable. Edificios nZEB }\end{array}$ & 85,63 & 80,77 & 83,48 \\
\hline Impacto Ambiental & 6,14 & 5,82 & 6,01 \\
\hline
\end{tabular}

Tabla 133. Resumen de indicadores del Edificio de Aulas 4

\begin{tabular}{|c|c|c|c|}
\hline \multirow{2}{*}{ INDICADOR } & \multicolumn{3}{|c|}{ VALOR DEL INDICADOR } \\
\cline { 2 - 4 } & $\mathbf{2 0 1 7}$ & $\mathbf{2 0 1 8}$ & $\mathbf{2 0 1 9}$ \\
\hline Intensidad Energética & 60,39 & 61,01 & 67,48 \\
\hline $\begin{array}{c}\text { Indicador IE referido al consumo de energía primaria } \\
\text { no renovable. Edificios nZEB }\end{array}$ & 68,19 & 67,89 & $\mathbf{7 5 , 5 9}$ \\
\hline Impacto Ambiental & 4,94 & 4,99 & 5,52 \\
\hline Eficiencia Energética IEE & 1,00 & 1,47 & 1,00 \\
\hline Sumas acumulativas CUSUM & $-40,00$ & 59.913 & 1,00 \\
\hline
\end{tabular}

\subsection{EFECTOS DE LOS MODELOS DE ESTIMACIÓN DE LÍNEA BASE E INDICADORES SOBRE LA ESTIMACIÓN DE AHORROS ENERGÉTICOS}

A continuación, se presentan los resultados obtenidos de los indicadores de gestión, el indicador de eficiencia IEE y el indicador de sumas acumuladas CUSUM, así como las variaciones obtenidas cuando se utilizan distintos modelos para la estimación de la línea base tal como lo recomienda la norma ISO50006. En este sentido, en el aparatado 6.2 se desarrollaron los modelos propuestos siguiendo lineamientos matemáticos y estadísticos.

Se debe tener en cuenta que la utilización de estos modelos hace parte de las características establecidas en la metodología propuesta. A continuación, se presenta los resultados obtenidos de todos los modelos realizados para el año 2019, con el fin de mostrar las variaciones en los mismos y las opciones en cuanto a la estimación de ahorros.

La Tabla 134, presenta el consumo eléctrico y el estimado, bajo los diferentes modelos planteados en el capítulo para el año 2019. En la

Tabla 135 y en la Figura 248, se muestran los resultados del indicador de eficiencia IEE, en donde es importante tener en cuenta los siguientes aspectos: 
La utilización del modelo depende del recurso de datos de medición que se tenga en el las instalaciones del edificio.

El empleo de distintos modelos implica sub estimación y sobre estimación en la estimación de los ahorros. En ese sentido, la validación estadística juega un papel importante en la decisión de usar un modelo de mejor pronóstico y menor error.

Los cálculos de ahorro de energía pueden verse afectados por errores sistemáticos y aleatorios. Los errores sistemáticos son sesgo en la medición, supuestos y análisis. Los errores aleatorios son el resultado de la calidad de la medición, equipo, técnicas de medición y muestreo. De igual forma la funcionalidad de los mismos depende de la inclusión de más variables para su modelación.

Tabla 134. Consumo eléctrico real y estimados en kWh en los diferentes modelos para el año de 2019

\begin{tabular}{|c|c|c|c|c|c|c|c|c|c|}
\hline \multirow{2}{*}{2019} & \multirow{2}{*}{ Consumo Real } & \multicolumn{6}{|c|}{ Series de Tiempo } & \multicolumn{2}{|c|}{ Regresión Lineal } \\
\hline & & Modelo 1 & Modelo 2 & Modelo 3 & Modelo 4 & Modelo 5 & Modelo 6 & Univariable & Multivariable \\
\hline Enero & $8.157,39$ & $9.369,00$ & $10.110,00$ & $9.917,78$ & $15.699,00$ & $10.054,00$ & $10.178,62$ & $9.417,98$ & $10.224,23$ \\
\hline Febrero & $18.338,60$ & $19.136,00$ & $19.050,00$ & $20.257,09$ & $15.381,00$ & $17.857,00$ & $17.856,71$ & $17.176,60$ & $16.856,33$ \\
\hline Marzo & $19.270,85$ & $18.186,00$ & $18.508,00$ & $19.251,92$ & $15.358,00$ & $19.770,00$ & $19.228,21$ & $17.472,40$ & $17.034,45$ \\
\hline Abril & $15.445,27$ & $18.346,00$ & $18.350,00$ & $19.421,75$ & $15.476,00$ & $16.129,00$ & $16.359,01$ & $15.875,11$ & $16.635,44$ \\
\hline Mayo & $18.875,69$ & $18.855,00$ & $18.993,00$ & $19.960,26$ & $15.182,00$ & $19.770,00$ & $20.158,89$ & $18.301,88$ & $18.203,96$ \\
\hline Junio & $12.134,52$ & $8.774,00$ & $9.682,00$ & $9.287,88$ & $15.236,00$ & $12.334,00$ & $11.667,40$ & $13.332,53$ & $11.610,77$ \\
\hline Julio & $20.270,80$ & $11.086,00$ & $11.980,00$ & $11.735,77$ & $15.376,00$ & $12.640,00$ & $12.152,20$ & $18.213,77$ & $19.072,51$ \\
\hline Agosto & $24.242,27$ & $19.269,00$ & $19.149,00$ & $20.398,15$ & $15.921,00$ & $17.459,00$ & $17.830,02$ & $21.113,82$ & $24.325,69$ \\
\hline Septiembre & $22.723,39$ & $18.496,00$ & $18.448,00$ & $19.580,60$ & $16.346,00$ & $16.896,00$ & $16.810,70$ & $22.049,03$ & $23.387,98$ \\
\hline Octubre & $21.390,40$ & $16.742,00$ & $17.044,00$ & $17.723,30$ & $16.715,00$ & $17.459,00$ & $16.724,73$ & $23.770,93$ & $21.814,02$ \\
\hline Noviembre & $17.109,19$ & $13.979,00$ & $14.199,00$ & $14.798,72$ & $17.038,00$ & $16.896,00$ & $17.100,00$ & $21.327,29$ & $19.235,86$ \\
\hline Diciembre & $10.417,76$ & $7.494,00$ & $8.222,00$ & $7.933,60$ & $17.281,00$ & $7.909,00$ & $7.920,03$ & $10.322,98$ & $9.973,85$ \\
\hline Anual & $208.376,13$ & $179.732,00$ & $183.735,00$ & $190.266,83$ & $191.009,00$ & $185.173,00$ & $183.986,52$ & $208.374,33$ & $208.375,09$ \\
\hline \multicolumn{2}{|c|}{ MAPE } & $13,7 \%$ & $11,8 \%$ & $8,7 \%$ & $8,3 \%$ & $11,1 \%$ & $11,7 \%$ & $0,0 \%$ & $0,0 \%$ \\
\hline
\end{tabular}

Tabla 135. Indicador de Eficiencia Energética de los diferentes modelos

\begin{tabular}{|c|c|c|c|c|c|c|c|c|}
\hline \multirow{2}{*}{2019} & \multicolumn{8}{|c|}{ INDICADOR DE EFICIENCIA ENERGÉTICA } \\
\hline & Modelo 1 & Modelo 2 & Modelo 3 & Modelo 4 & Modelo 5 & Modelo 6 & Univariable & Multivariable \\
\hline Enero & 0,87 & 0,81 & 0,82 & 0,52 & 0,81 & 0,80 & 0,87 & 0,80 \\
\hline Febrero & 0,96 & 0,96 & 0,91 & 1,19 & 1,03 & 1,03 & 1,07 & 1,09 \\
\hline Marzo & 1,06 & 1,04 & 1,00 & 1,25 & 0,97 & 1,00 & 1,10 & 1,13 \\
\hline Abril & 0,84 & 0,84 & 0,80 & 1,00 & 0,96 & 0,94 & 0,97 & 0,93 \\
\hline Mayo & 1,00 & 0,99 & 0,95 & 1,24 & 0,95 & 0,94 & 1,03 & 1,04 \\
\hline Junio & 1,38 & 1,25 & 1,31 & 0,80 & 0,98 & 1,04 & 0,91 & 1,05 \\
\hline Julio & 1,83 & 1,69 & 1,73 & 1,32 & 1,60 & 1,67 & 1,11 & 1,06 \\
\hline Agosto & 1,26 & 1,27 & 1,19 & 1,52 & 1,39 & 1,36 & 1,15 & 1,00 \\
\hline Septiembre & 1,23 & 1,23 & 1,16 & 1,39 & 1,34 & 1,35 & 1,03 & 0,97 \\
\hline Octubre & 1,28 & 1,26 & 1,21 & 1,28 & 1,23 & 1,28 & 0,90 & 0,98 \\
\hline Noviembre & 1,22 & 1,20 & 1,16 & 1,00 & 1,01 & 1,00 & 0,80 & 0,89 \\
\hline Diciembre & 1,39 & 1,27 & 1,31 & 0,60 & 1,32 & 1,32 & 1,01 & 1,04 \\
\hline Anual & 1,16 & 1,13 & 1,10 & 1,09 & 1,13 & 1,13 & 1,00 & 1,00 \\
\hline
\end{tabular}


Indicador de Eficiencia Enegética

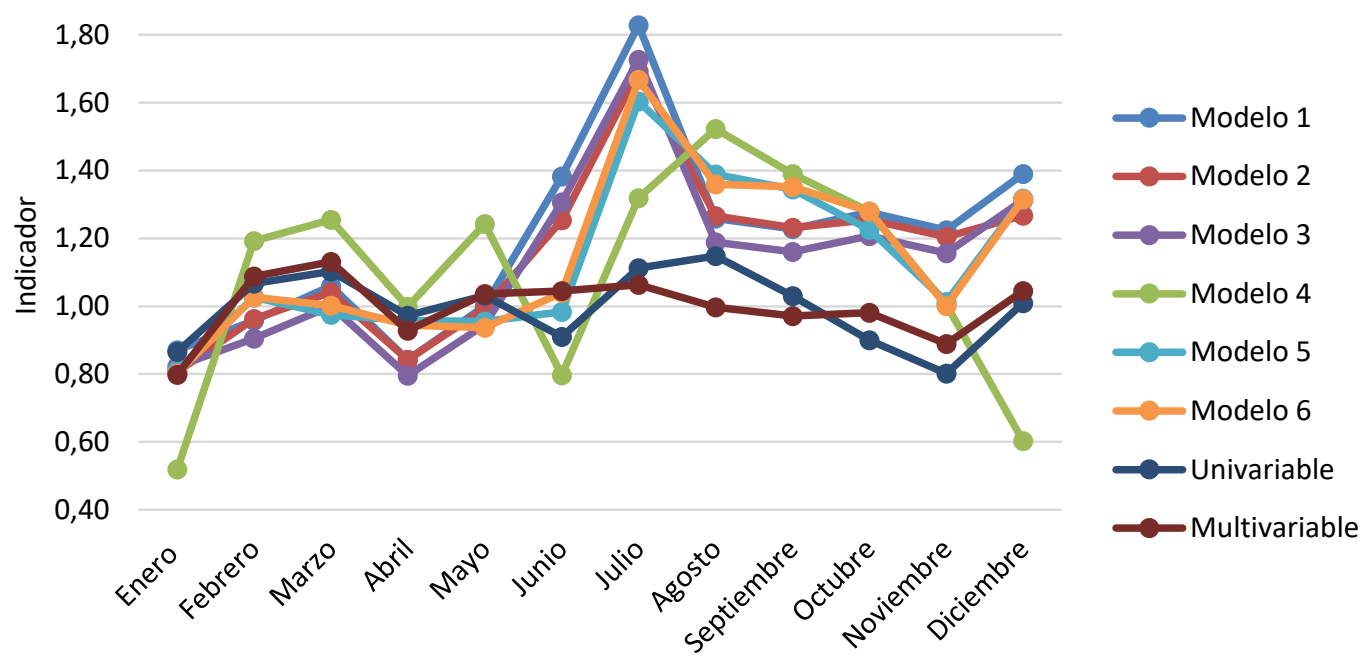

Figura 248. Indicador de Eficiencia Energética mensual de los diferentes modelos

Tabla 136 y la Figura 249 presentan los resultados del Indicador de Sumas acumulativas CUSUM.

Tabla 136. Indicador CUSUM de los diferentes modelos

\begin{tabular}{|c|c|c|c|c|c|c|c|c|}
\hline \multirow[b]{3}{*}{2019} & \multicolumn{8}{|c|}{ CUSUM } \\
\hline & \multicolumn{2}{|c|}{ Modelo 1} & \multicolumn{2}{|c|}{ Modelo 2} & \multicolumn{2}{|c|}{ Modelo 3} & \multicolumn{2}{|c|}{ Modelo 4} \\
\hline & \begin{tabular}{|c|} 
Energía Ahorrada \\
o \\
sobreconsumida
\end{tabular} & CUSUM & $\begin{array}{c}\text { Energía Ahorrada } \\
\text { o } \\
\text { sobreconsumida }\end{array}$ & CUSUM & \begin{tabular}{|c} 
Energía Ahorrada \\
o \\
sobreconsumida
\end{tabular} & CUSUM & $\begin{array}{c}\text { Energía Ahorrada } \\
\text { o } \\
\text { sobreconsumida }\end{array}$ & CUSUM \\
\hline Enero & $-1.211,61$ & $-1.211,61$ & $-1.952,61$ & $-1.952,61$ & $-1.760,39$ & $-1.760,39$ & $-7.541,61$ & $-7.541,61$ \\
\hline Febrero & $-797,40$ & $-2.009,02$ & $-711,40$ & $-2.664,02$ & $-1.918,49$ & $-3.678,88$ & $2.957,60$ & $-4.584,02$ \\
\hline Marzo & $1.084,85$ & $-924,16$ & 762,85 & $-1.901,16$ & 18,93 & $-3.659,96$ & $3.912,85$ & $-671,16$ \\
\hline Abril & $-2.900,73$ & $-3.824,89$ & $-2.904,73$ & $-4.805,89$ & $-3.976,48$ & $-7.636,44$ & $-30,73$ & $-701,89$ \\
\hline Mayo & 20,69 & $-3.804,20$ & $-117,31$ & $-4.923,20$ & $-1.084,57$ & $-8.721,01$ & $3.693,69$ & $2.991,80$ \\
\hline Junio & $3.360,52$ & $-443,68$ & $2.452,52$ & $-2.470,68$ & $2.846,64$ & $-5.874,37$ & $-3.101,48$ & $-109,68$ \\
\hline Julio & $9.184,80$ & $8.741,12$ & $8.290,80$ & $5.820,12$ & $8.535,03$ & $2.660,67$ & $4.894,80$ & $4.785,12$ \\
\hline Agosto & $4.973,27$ & $13.714,39$ & $5.093,27$ & $10.913,39$ & $3.844,12$ & $6.504,79$ & $8.321,27$ & $13.106,39$ \\
\hline Septiembre & $4.227,39$ & $17.941,78$ & $4.275,39$ & $15.188,78$ & $3.142,79$ & $9.647,58$ & $6.377,39$ & $19.483,78$ \\
\hline Octubre & $4.648,40$ & $22.590,18$ & $4.346,40$ & $19.535,18$ & $3.667,10$ & $13.314,68$ & $4.675,40$ & $24.159,18$ \\
\hline Noviembre & $3.130,19$ & $25.720,37$ & $2.910,19$ & $22.445,37$ & $2.310,47$ & $15.625,14$ & 71,19 & $24.230,37$ \\
\hline Diciembre & $2.923,76$ & $28.644,13$ & $2.195,76$ & $24.641,13$ & $2.484,15$ & $18.109,30$ & $-6.863,24$ & $17.367,13$ \\
\hline \multirow[b]{2}{*}{2019} & \multicolumn{2}{|c|}{ Modelo 5} & \multicolumn{2}{|c|}{ Modelo 6} & \multicolumn{2}{|c|}{ Univariable } & \multicolumn{2}{|c|}{ Multivariable } \\
\hline & \begin{tabular}{|c|} 
Energía Ahorrada \\
o \\
sobreconsumida
\end{tabular} & CUSUM & $\begin{array}{c}\text { Energía Ahorrada } \\
\text { o } \\
\text { sobreconsumida }\end{array}$ & CUSUM & \begin{tabular}{|c} 
Energía Ahorrada \\
o \\
sobreconsumida
\end{tabular} & CUSUM & $\begin{array}{c}\text { Energía Ahorrada } \\
\text { o } \\
\text { sobreconsumida }\end{array}$ & CUSUM \\
\hline Enero & $-1.896,61$ & $-1.896,61$ & $-2.021,23$ & $-2.021,23$ & $-1.260,59$ & $-1.260,59$ & $-2.066,84$ & $-2.066,84$ \\
\hline Febrero & 481,60 & $-1.415,02$ & 481,89 & $-1.539,35$ & $1.161,99$ & $-98,60$ & $1.482,27$ & $-584,57$ \\
\hline Marzo & $-499,15$ & $-1.914,16$ & 42,64 & $-1.496,70$ & $1.798,45$ & $1.699,86$ & $2.236,40$ & $1.651,83$ \\
\hline Abril & $-683,73$ & $-2.597,89$ & $-913,74$ & $-2.410,44$ & $-429,84$ & $1.270,02$ & $-1.190,17$ & 461,66 \\
\hline Mayo & $-894,31$ & $-3.492,20$ & $-1.283,20$ & $-3.693,64$ & 573,81 & $1.843,83$ & 671,73 & $1.133,39$ \\
\hline Junio & $-199,48$ & $-3.691,68$ & 467,12 & $-3.226,52$ & $-1.198,02$ & 645,82 & 523,75 & $1.657,14$ \\
\hline Julio & $7.630,80$ & $3.939,12$ & $8.118,60$ & $4.892,08$ & $2.057,03$ & $2.702,85$ & $1.198,29$ & $2.855,43$ \\
\hline Agosto & $6.783,27$ & $10.722,39$ & $6.412,25$ & $11.304,33$ & $3.128,45$ & $5.831,30$ & $-83,42$ & $2.772,01$ \\
\hline Septiembre & $5.827,39$ & $16.549,78$ & $5.912,69$ & $17.217,02$ & 674,36 & $6.505,66$ & $-664,58$ & $2.107,43$ \\
\hline Octubre & $3.931,40$ & $20.481,18$ & $4.665,67$ & $21.882,69$ & $-2.380,54$ & $4.125,12$ & $-423,62$ & $1.683,80$ \\
\hline Noviembre & 213,19 & $20.694,37$ & 9,19 & $21.891,88$ & $-4.218,10$ & $-92,98$ & $-2.126,67$ & $-442,86$ \\
\hline Diciembre & $2.508,76$ & $23.203,13$ & $2.497,73$ & $24.389,61$ & 94,78 & 1,80 & 443,90 & 1,04 \\
\hline
\end{tabular}




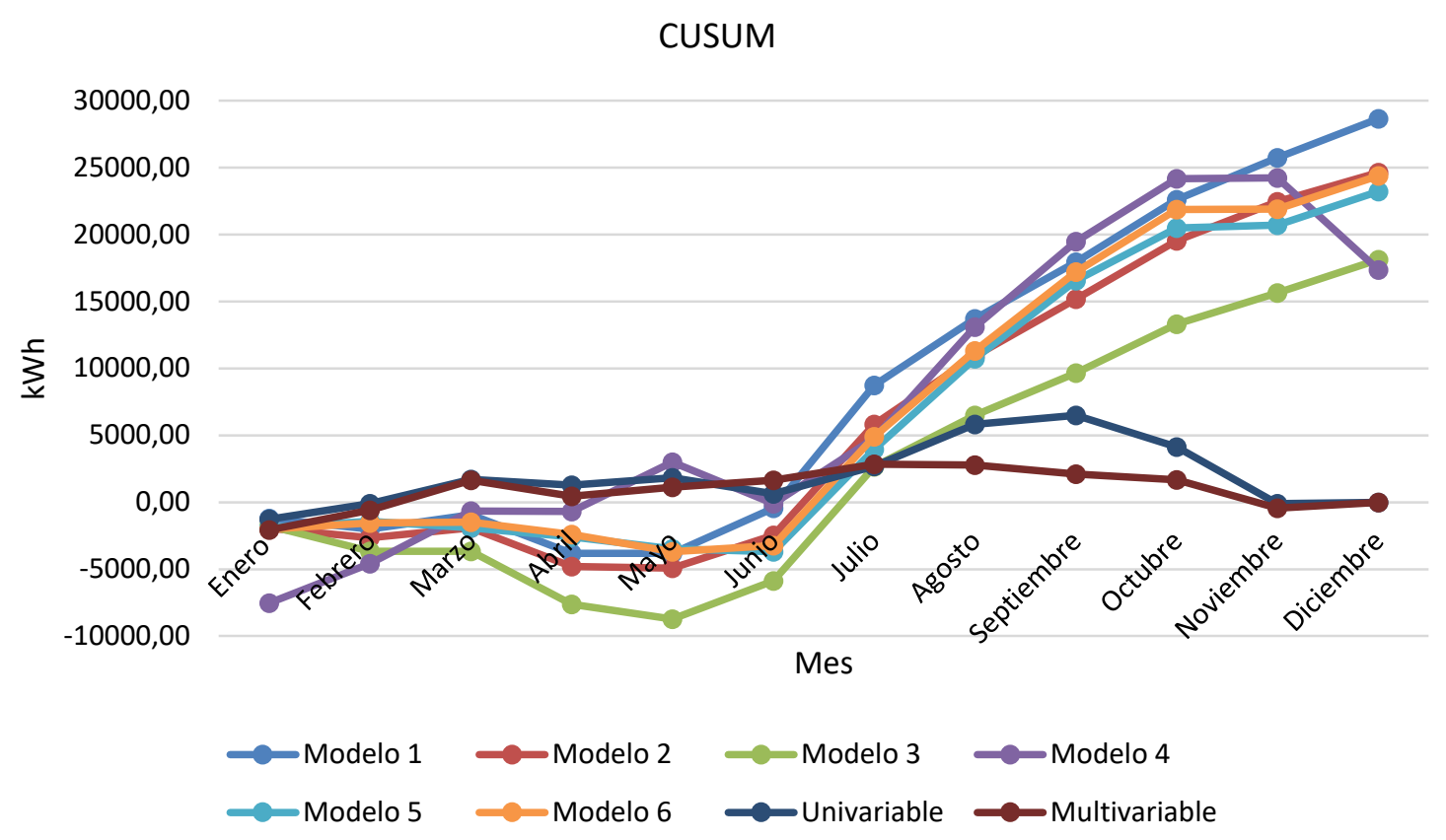

Figura 249. Indicador CUSUM de los diferentes modelos

Esta herramienta genera alertas en cuanto a variaciones positivas o negativas de la eficiencia del proceso, facilitando el análisis y generación de planes de acción en función de las mejores prácticas energéticas en la edificación.

Los resultados obtenidos en la tabla 56 y la Figura 51, nos muestran los ahorros proyectados en cada uno de los modelos planteados para estimar la línea base energética. En este sentido, los modelos 1 al 6 corresponden a los estimados mediante series de tiempo, los resultados en la estimación de ahorros están fuertemente ligados al error de pronóstico del modelo, lo que se traduce para este caso en sobreconsumos del aula y una tendencia marcada hacia la ineficiencia. En el caso de los ahorros obtenidos con el modelo regresión univariable y multivariable, se observa que para algunos meses existe una tendencia marcada hacia la eficiencia, para los meses de enero, abril, junio, octubre y noviembre. No obstante, para el resto de los meses la tendencia es hacia la ineficiencia. Es decir, más consumo con respecto a la tendencia. Finalmente, no se identifica un valor significativo de ahorro energético, pero si se observa una estabilidad en la operación del aula luego de realizar todas las adecuaciones antes mencionadas. 


\subsubsection{Análisis del modelo 2019 considerando datos diarios, semanales y mensuales}

En este apartado se analiza el modelo de regresión lineal multivariable con distinta periodicidad de datos diarios, semanal y mensual, lo anterior con la finalidad de evaluar el nivel pronóstico en la estimación de la línea base y su relación con la valoración de ahorros.

Tabla 137. Consumo eléctrico real y estimados en kWh bajo las LBE diaria, semanal, mensual y propuesta de 2019

\begin{tabular}{|c|c|c|c|c|c|}
\hline \multirow{2}{*}{ Mes } & \multicolumn{5}{|c|}{2019} \\
\cline { 2 - 6 } & Consumo Real & $\begin{array}{c}\text { Consumo Estimado } \\
\text { LBE Diaria }\end{array}$ & $\begin{array}{c}\text { Consumo Estimado } \\
\text { LBE Semanal }\end{array}$ & $\begin{array}{c}\text { Consumo Estimado } \\
\text { LBE Mensual }\end{array}$ & $\begin{array}{c}\text { Consumo Estimado } \\
\text { LBE Propuesta }\end{array}$ \\
\hline Febrero & 18.282 & 11.297 & 16.805 & 16.856 & 16.805 \\
\hline Marzo & 19.293 & 19.320 & 18.618 & 17.034 & 19.320 \\
\hline Abril & 14.801 & 15.661 & 16.464 & 16.635 & 15.661 \\
\hline Mayo & 19.173 & 19.573 & 19.813 & 18.204 & 19.573 \\
\hline Junio & 12.370 & 12.605 & 12.984 & 11.611 & 12.605 \\
\hline Julio & 21.059 & 8.580 & 20.678 & 19.073 & 20.678 \\
\hline Agosto & 24.720 & 23.569 & 25.721 & 24.326 & 23.569 \\
\hline Septiembre & 23.053 & 24.225 & 22.301 & 23.388 & 24.225 \\
\hline Octubre & 21.968 & 20.866 & 23.575 & 21.814 & 20.866 \\
\hline Noviembre & 17.374 & 19.238 & 18.299 & 19.236 & 19.238 \\
\hline Diciembre & 10.456 & 11.076 & 9.635 & 9.974 & 11.076 \\
\hline Anual & 202.549 & 186.010 & 204.891 & 198.151 & 203.616 \\
\hline & MAPE & $8,2 \%$ & $1,2 \%$ & $2,2 \%$ & $0,5 \%$ \\
\hline
\end{tabular}

En la Tabla 137, se observa las diferencias en los consumos estimados de la línea base diaria, semanal, mensual y la línea base propuesta, para la estimación de ahorros energéticos. En este sentido, podemos observar que en la línea base diaria, la estimación funciona de modo adecuado para los meses de operación normal del semestre, donde el modelo depende de variables como humedad, temperatura y ocupación. Mientras que para el mes de julio donde la ocupación es baja por vacaciones, el modelo no cuenta con la capacidad de pronosticar el valor de consumo esperado. En el caso del modelo semanal, los resultados obtenidos son mejores en pronóstico de consumo o línea base, en razón a la integración de variables y la compensación de las mismas al trabajar en periodos de tiempos más amplios, lo propio sucede con el modelo semanal. En resumen, los errores obtenidos de cada uno de los modelos son del orden $8.2 \%, 1.2 \%, 2,2 \%$ y $0.5 \%$ para el modelo diario, semanal, mensual y el de línea base propuesta. Dada las condiciones anteriormente mencionadas, se propone una línea base energética donde se utiliza para los meses de operación normal del Aula el modelo diario y, para los meses de baja ocupación o vacaciones, el modelo semanal. Así los resultados obtenidos muestran valores de pronósticos entre la línea base real y pronosticada con menor nivel de error. 
Tabla 138. Indicador de Eficiencia Energética de los modelos de LBE diaria, semanal mensual y propuesta del 2019

\begin{tabular}{|c|c|c|c|c|}
\hline \multicolumn{5}{|c|}{ INDICADOR DE EFICIENCIA ENERGÉTICA } \\
\hline Mes/Año & $\begin{array}{c}\text { Consumo Estimado } \\
\text { LBE Diaria }\end{array}$ & $\begin{array}{c}\text { Consumo Estimado } \\
\text { LBE Semanal }\end{array}$ & $\begin{array}{c}\text { Consumo Estimado } \\
\text { LBE Mensual }\end{array}$ & $\begin{array}{c}\text { Consumo Estimado } \\
\text { LBE Propuesta }\end{array}$ \\
\hline Febrero & 1,62 & 1,09 & 1,08 & 1,09 \\
\hline Marzo & 1,00 & 1,04 & 1,13 & 1,00 \\
\hline Abril & 0,95 & 0,90 & 0,89 & 0,95 \\
\hline Mayo & 0,98 & 0,97 & 1,05 & 0,98 \\
\hline Junio & 0,98 & 0,95 & 1,07 & 0,98 \\
\hline Julio & 2,45 & 1,02 & 1,10 & 1,02 \\
\hline Agosto & 1,05 & 0,96 & 1,02 & 1,05 \\
\hline Septiembre & 0,95 & 1,03 & 0,99 & 0,95 \\
\hline Octubre & 1,05 & 0,93 & 1,01 & 1,05 \\
\hline Noviembre & 0,90 & 0,95 & 0,90 & 0,90 \\
\hline Diciembre & 0,94 & 1,09 & 1,05 & 0,94 \\
\hline Anual & 1,09 & 0,99 & 1,02 & 0,99 \\
\hline
\end{tabular}

Indicador de Eficiencia Energética

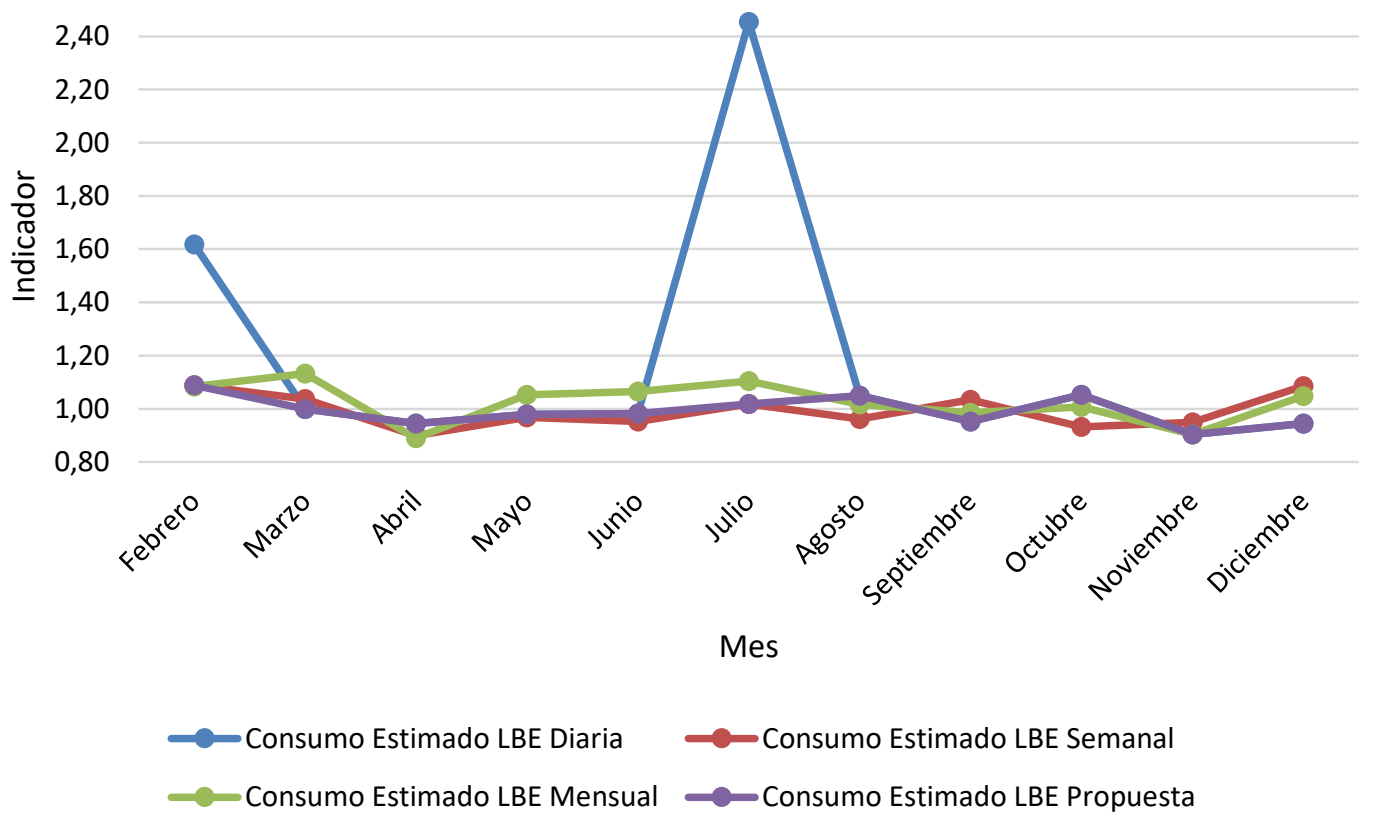

Figura 250. Indicador de Eficiencia Energética de los modelos de LBE diaria, semanal, mensual y propuesta del 2019

En la Tabla 138 y la Figura 250, se muestran los resultados del indicador de eficiencia donde se observa que, en los cuatro modelos propuestos se conserva la misma tendencia hacia la eficiencia o ineficiencia, con la diferencia que el modelo que denominado como línea base propuesta, responde de manera más exacta al pronóstico y, por ende, proporciona mejor respuesta en la caracterización de la eficiencia. 
Tabla 139. Indicador CUSUM de los modelos de LBE diaria, semanal mensual y propuesta del 2019

\begin{tabular}{|c|c|c|c|c|}
\hline \multicolumn{5}{|c|}{ CUSUM } \\
\hline & \multicolumn{2}{|c|}{ Consumo Estimado LBE Diaria } & \multicolumn{2}{|c|}{ Consumo Estimado LBE Semanal } \\
\hline Mes & $\begin{array}{c}\text { Energía ahorrada o } \\
\text { sobreconsumida }\end{array}$ & CUSUM & $\begin{array}{l}\text { Energía ahorrada o } \\
\text { sobreconsumida }\end{array}$ & CUSUM \\
\hline Febrero & $6.984,9$ & $6.984,9$ & $1.476,8$ & $1.476,8$ \\
\hline Marzo & $-27,1$ & $6.957,8$ & 675,2 & $2.152,0$ \\
\hline Abril & $-860,0$ & $6.097,8$ & $-1.662,2$ & 489,8 \\
\hline Mayo & $-400,2$ & $5.697,6$ & $-640,1$ & $-150,3$ \\
\hline Junio & $-235,2$ & $5.462,4$ & $-614,0$ & $-764,2$ \\
\hline Julio & $12.479,3$ & $17.941,7$ & 381,7 & $-382,6$ \\
\hline Agosto & $1.151,3$ & $19.093,0$ & $-1.000,2$ & $-1.382,8$ \\
\hline Septiembre & $-1.172,5$ & $17.920,5$ & 751,9 & $-630,8$ \\
\hline Octubre & $1.102,4$ & $19.022,9$ & $-1.606,6$ & $-2.237,5$ \\
\hline Noviembre & $-1.864,1$ & $17.158,8$ & $-925,4$ & $-3.162,8$ \\
\hline \multirow[t]{2}{*}{ Diciembre } & $-620,4$ & $16.538,4$ & 821,0 & $-2.341,9$ \\
\hline & \multicolumn{2}{|c|}{ Consumo Estimado LBE Mensual } & \multicolumn{2}{|c|}{ Consumo Estimado LBE Propuesta } \\
\hline Mes & $\begin{array}{c}\text { Energía ahorrada o } \\
\text { sobreconsumida }\end{array}$ & CUSUM & $\begin{array}{c}\text { Energía ahorrada o } \\
\text { sobreconsumida }\end{array}$ & CUSUM \\
\hline Febrero & $1.425,7$ & $1.425,7$ & $1.476,8$ & $1.476,8$ \\
\hline Marzo & $2.258,5$ & $3.684,2$ & $-27,1$ & $1.449,7$ \\
\hline Abril & $-1.834,0$ & $1.850,3$ & $-860,0$ & 589,7 \\
\hline Mayo & 968,8 & $2.819,1$ & $-400,2$ & 189,5 \\
\hline Junio & 759,0 & $3.578,0$ & $-235,2$ & $-45,7$ \\
\hline Julio & $1.986,8$ & $5.564,9$ & 381,7 & 336,0 \\
\hline Agosto & 394,8 & $5.959,7$ & $1.151,3$ & $1.487,3$ \\
\hline Septiembre & $-335,2$ & $5.624,5$ & $-1.172,5$ & 314,8 \\
\hline Octubre & 153,9 & $5.778,4$ & $1.102,4$ & $1.417,2$ \\
\hline Noviembre & $-1.862,3$ & $3.916,0$ & $-1.864,1$ & $-446,9$ \\
\hline Diciembre & 481,7 & $4.397,8$ & $-620,4$ & $-1.067,3$ \\
\hline
\end{tabular}

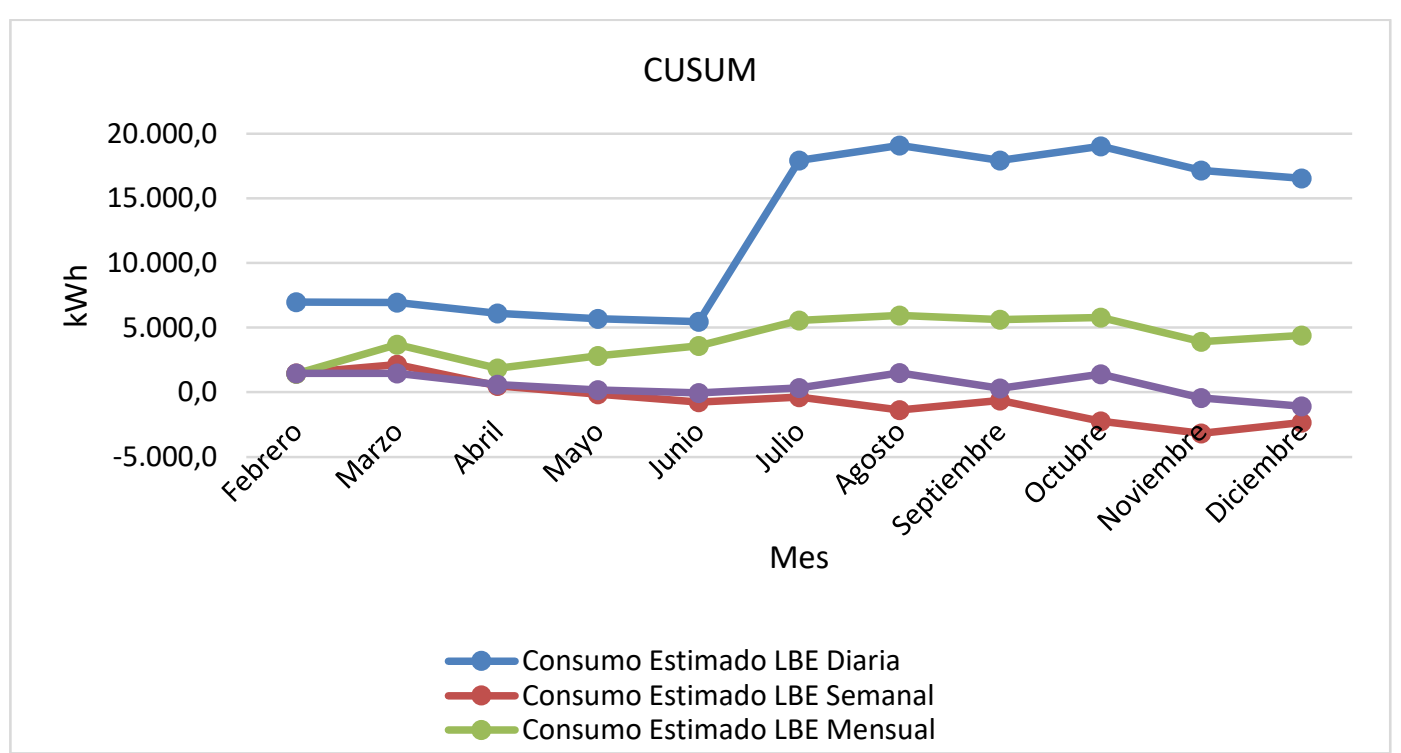

Figura 251. Indicador CUSUM de los modelos de LBE diaria, semanal, mensual y propuesta del 2019 
En la Tabla 139 y la Figura 251, se muestran los resultados obtenidos en la evaluación de ahorros de año 2019 para los modelos de línea base diaria, semanal, mensual y propuesta. Esto permite evidenciar las diferencias obtenidas entre un modelo y otro, para el caso de la línea base diaria, se observa una tendencia marcada hacia la ineficiencia y una subestimación de $16538 \mathrm{kWh}$ anuales que representan un $9.1 \%$ con respecto al consumo real del aula. Resultado que obedece principalmente a lo mencionado anteriormente con respecto a los errores en el pronóstico de los meses de baja ocupación. De otro lado, en los modelos semanal, mensual se identificaron consumos de 2342 kWh y 4397 kWh respectivamente, los mismos representan un $1.2 \%$ y $9.7 \%$ por debajo del valor real anual de consumo del Aula. Para el caso del modelo de línea base propuesto, el valor de ahorro corresponde a $1067 \mathrm{KWh}$ los cuales representan el 1.01\% con respecto al consumo real. Este modelo permite evaluar de manera más precisa las variaciones mes a mes $y$, dado el ajuste realizado en los meses de baja ocupación permite obtener un menor porcentaje de erro en la estimación de la línea base. Lo anterior da la posibilidad de realizar una gestión detallada en el aula considerando que al momento existe una estabilidad en la operación de la misma.

A manera de conclusión podemos decir que, el uso de cada modelo va a depender del recurso disponible de información, en este caso, de la frecuencia y numero de variables asociadas al consumo. Para edificaciones que disponen solo de datos de consumo mensual de facturación, un modelo de series de tiempo resulta adecuado de emplear. Por el contrario, si se dispone de equipos de monitoreo de consumo con recurso para bajar información y adicionalmente de variables meteorológicas y de otras derivadas de la ocupación, el uso de modelos de regresión lineal y multivariable resultan más precisos a la hora de establecer una línea base energética con miras hacer pronóstico de consumo. En este sentido, se aplican una variedad de pruebas estadísticas a los resultados de ahorro de energía y datos para revelar cuál modelo describe mejor y refleja la evolución del consumo de energía en la instalación y, si los porcentajes de mejora del rendimiento energético obtenidos tienen sentido en función de los patrones de operación de la instalación.

El análisis presentado en este capítulo, tiene como finalidad mostrar un abanico de posibilidades con la validación de recursos matemáticos y estadísticos a la hora de seleccionar un modelo para establecer una línea base energética. Los modelos desarrollados muestran que la selección de uno u otro, implica la sobreestimación o subestimación en el pronóstico de consumo de energía que afecta los valores de ahorro. De la misma forma, los modelos de series de tiempo son modelos funcionales cuando no se tienen datos adicionales al consumo de energía, mientras que los modelos de regresión dan resultados más precisos a los acontecimientos en el edificio (ya sean de tipo climatológico, como de ocupación o demás), es decir, la inclusión de más variables en el modelo hace que sea más preciso. Mientras que los modelos de series de tiempo resultan siendo modelos iniciales para empezar a hacer gestión del edificio. De otro lado, es importante evaluar que la variación en las estimaciones de ahorro de energía son el resultado de cambios inevitables en la operación y las condiciones entre la línea de base y los periodos de reporte de la línea base, que afectan significativamente los resultados de la evaluación. 
En última instancia, el método seleccionado debe incluir un período de modelado que abarque valores de variables relevantes que se encuentren cerca de los niveles futuros esperados, de modo que los resultados de la evaluación resulten más significativos e indicativos del ahorro de energía futuro de la instalación. 


\section{BIBLIOGRAFIA}

[1] ISO, ISO 50001:2018 Energy management systems - Requirements with guidance for use. SUIZA, 2018.

[2]B. L. Bowerman, T. O. C. Richard, y B. K. Anne, Pronósticos, series de tiempo y regresión. Un enfoque aplicado, 4 edicion. Cengage Learning Books Cole, 2006.

[3]J. H. Wilson y B. Keating, Pronósticos para los negocios con ForecastX basado en inglés, 5a ed. Ciudad de México: McGraw-Hill Interamericana, 2007.

[4]ISO 50006, "Energy management systems - Measuring energy performance using energy baselines (EnB) and energy performance indicators (EnPI) - General principles and guidance", 2016.

[5]C. Salazar, "Cálculo de correlaciones", RPubs, 2018. [En línea]. Disponible en: https://rpubs.com/camilamila/correlaciones. [Consultado: 25-mar-2020].

[6]C. de Igor, "Correlation tests, correlation matrix, and corresponding visualization methods in R", 2017. [En línea]. Disponible en: https://rstudio-pubsstatic.s3.amazonaws.com/240657_5157ff98e8204c358b2118fa69162e18.html.

[Consultado: 25-mar-2020].

[7]J. Amat, “Correlación lineal y regresión lineal simple en R", RPubs, 2016. [En línea]. Disponible en: https://rpubs.com/Joaquin_AR/223351. [Consultado: 25-mar-2020].

[8]E. T. Area, "The effect of linear regression modeling approaches on determining facility wide energy savings", 2019.

[9]RStudio, "RStudio | Open source \& professional software for data science teams", 2019. [En línea]. Disponible en: https://rstudio.com/. [Consultado: 25-mar-2020].

[10]J. Amat, "Ejemplo práctico de regresión lineal simple, múltiple, polinomial e interacción entre predictores", RPubs, 2016. [En línea]. Disponible en: https://rpubs.com/Joaquin_AR/254575. [Consultado: 25-mar-2020].

[11]R. Castrillón y A. Gonzalez, Metodología Para la Planificación Energética a Partir de la Norma ISO 50001. Cali, 2018.

[12]Analytics with R, "Linear Regression". [En línea]. Disponible en: http://analyticswithr.com/ols.html. [Consultado: 25-mar-2020].

[13]L. C. Siebert et al., "Energy efficiency indicators assessment tool for the industry sector", 2014 IEEE PES Transm. Distrib. Conf. Expo. PES T D-LA 2014 - Conf. Proc., vol. 2014-Octob, núm. i, pp. 1-6, 2014.

[14]W. Eichhammer y M. Wilhelm, "Industrial energy efficiency: Indicators for a European cross-country comparison of energy efficiency in the manufacturing industry", Energy Policy, vol. 25, núm. 7, pp. 759-772, 1997.

[15]D. Bosseboeuf, B. Chateau, y B. Lapillonne, "Cross-country comparison on energy efficiency indicators: the on-going European effort towards a common methodology", Energy Policy, vol. 25, núm. 7, pp. 673-682, 1997.

[16]L. Pérez-Lombard, J. Ortiz, I. R. Maestre, y J. F. Coronel, “Constructing HVAC energy efficiency indicators", Energy Build., vol. 47, pp. 619-629, abr. 2012.

[17]O. Alves, E. Monteiro, P. Brito, y P. Romano, "Measurement and classification of energy efficiency in HVAC systems", Energy Build., vol. 130, pp. 408-419, oct. 2016. 
[18]M. G. Perroni, S. E. Gouvea da Costa, E. Pinheiro de Lima, W. Vieira da Silva, y U. Tortato, "Measuring energy performance: A process based approach", Appl. Energy, vol. 222, núm. April, pp. 540-553, 2018.

[19]M. Bourdeau, X. Guo, y E. Nefzaoui, "Buildings energy consumption generation gap: A post-occupancy assessment in a case study of three higher education buildings", Energy Build., vol. 159, pp. 600-611, 2018.

[20]M. Khoshbakht, Z. Gou, y K. Dupre, "Energy use characteristics and benchmarking for higher education buildings", Energy Build., vol. 164, pp. 61-76, 2018.

[21]E. A. Ocampo Batlle, J. C. Escobar Palacio, E. E. Silva Lora, A. M. Martinez Reyes, M. Melian, y M. B. Morejon, "A methodology to estimate baseline energy use and quantify savings in electrical energy consumption in higher education institution buildings: Case study, Federal University of Itajubá (UNIFEI)", J. Clean. Prod., núm. xxxx, p. 118551, 2019. [22]Ministerio de Fomento, Documento de bases para la actualización del Documento Básico DB-HE. España, 2016, p. 13.

[23]UPME, "BALANCE ENERGETICO COLOMBIANO - BECO". [En línea]. Disponible en: https://www1.upme.gov.co/InformacionCifras/Paginas/BalanceEnergetico.aspx.

[Consultado: 07-may-2020]. 


\section{CONCLUSIONES}

El desarrollo de esta tesis doctoral nos ha permitido establecer las siguientes conclusiones aplicadas al conjunto de edificios educativos superiores que compone un campus universitario.

1. Se ha realizado un estudio del estado del arte de la energética edificatoria existente en EU y especialmente en Colombia. En él se muestran los parámetros más relevantes que influyen en el comportamiento energético de un edificio, destacando el componente pasivo o arquitectónico y la componente activa cuyos responsables son las instalaciones HVAC e iluminación, así como los sistemas de energía renovables que integran el edificio. En este sentido, es importante para un país como Colombia avanzar en los lineamientos y políticas enfocadas a mejorar la eficiencia energética en las edificaciones. Se ha avanzado en el tema industrial y se tiene una política como el PROURE que, de cierta manera, propone lineamientos en todos los sectores $y$, en relación al tema de edificios centra su orientación con algunas resoluciones códigos y manuales de construcción para algunas ciudades donde se destaca Bogotá y Cali.

Se necesita avanzar hacia consolidar esquemas de certificación para los edificios, donde se puedan tener etiquetados de eficiencia como los maneja Europa, avanzar en la operación de edificios, donde cobra importancia el tema que nos atañe en esta tesis relacionado con la implementación de los sistemas de gestión y las herramientas y elementos que conduzcan a su correcta implementación en edificios.

Resulta importante el avance e implementación en el sector público como ejemplo, y aunque se han acuñado algunas acciones y actividades en el país, aun es importante avanzar en el tema de los diseños en los edificios nuevos. Esto en razón a que en el país se encuentran previstas gran número de construcciones, de almacenes de amplias superficies como centros comerciales, bodegas, así como las viviendas de interés social. Estas construcciones vienen siendo el resultado de la masificación de este sector, impulsado por parte de políticas del Ministerio de Vivienda, Ciudad y Territorio en los últimos gobiernos. Por esta razón resulta importante la etapa de diseño, donde se tengan en cuenta criterios de orientación, uso de materiales autóctonos de cada región y, en donde, prevalezca el uso e integración de las energías renovables.

Implementación de una gestión de la demanda propia para el edificio donde el usuario se hace participe en ella, con el uso de medición inteligente que día a día se hará de forma más masiva en el país pues es necesario fortalecer en vía de realizar una buena gestión de los edificios y mejoras en la Eficiencia Energética de las edificaciones tanto nuevas como existentes.

2. Se hace una recopilación de las herramientas de planificación energética que compone un sistema de gestión energética, describiendo su importancia y la relación con aspectos 
normativos, haciendo una descripción de las herramientas y técnicas utilizadas para la elaboración del proceso de la revisión energética que provee una visión sobre cómo mejorar su desempeño en una organización. Es decir, optimizar los usos, los consumos y la eficiencia energética y aspectos representativos en lo que se refiere a los conceptos de líneas de base e indicadores energéticos y su aporte en el mejoramiento de la eficiencia energética en edificaciones.

3. Se presenta los soportes teóricos para desarrollar los 4 modelos propuestos por la norma ISO50006, norma de apoyo a la Is050001, en lo concerniente a la estimación de líneas bases e de indicadores. Para lo anterior se propone el uso de los modelos basados en series de tiempos que utilizan solo la variable consumo y modelos de regresión univariable y multivariable, cuando existan recursos de medición de otros parámetros adicionales al consumo energético. De igual forma, se analiza el uso de la simulación dinámica de edificaciones que utiliza el motor de cálculo energy plus y se denomina Design Builder, como un recurso importante para establecer condiciones iniciales que permitan establecer líneas bases y plantear indicadores cuando se plantean diseños nuevos y cuando se cuente con recursos de información arquitectónica y monitorización en los existentes.

Cada uno de los modelos se sustenta tanto en la validación estadística como en su respectivo análisis de error. Lo anterior como elementos que permiten validar los resultados del pronóstico en las líneas bases y posterior uso de indicadores válidos para hacer seguimiento energético en las edificaciones y responder a los vacíos normativos en torno a los modelos matemáticos y estadísticos a utilizar en cada caso propuesto. Esto, como aporte a la aplicación de la norma, dado que la misma propone los modelos, pero no desarrolla ni las bases teóricas, ni métodos estadísticos, tampoco criterios para determinar si una línea base o un indicador son válidos para establecer una referencia de consumo y posteriormente un ahorro energético.

4. Se desarrolló una metodología para implementar la selección y aplicación de modelos para la estimación de líneas bases e indicadores energéticos en edificios. En la misma, se establecen criterios en cuanto a la selección de los límites y periodo de reporte de la información, la verificación de la fuente y calidad de los datos, así como la revisión de las variables relevantes de mayor afectación al consumo energético, el análisis muestral y los patrones de comportamiento de los datos. Lo anterior, para definir el modelo a usar siguiendo las respectivas validaciones estadísticas con apoyo del software R y, por último, el cálculo de las mejoras del rendimiento energético con fines de cuantificar ahorros energéticos y niveles de eficiencia.

5. Se analizó los efectos en la estimación de ahorros energéticos de los modelos propuestos para estimar la línea base e indicadores, exhibiendo que la selección de uno u otro implica la sobreestimación o subestimación en el pronóstico de consumo de energía que 
afecta los valores de ahorros estimados en un análisis de eficiencia energética. En este sentido, los modelos de series de tiempo son modelos funcionales cuando no se tienen datos adicionales al consumo de energía y, resultan siendo modelos para empezar a hacer gestión del edificio mientras que, los modelos de regresión dan resultados más precisos a la operación del edificio, relacionado con las condiciones de tipo climatológico, ocupación horas de usos de los equipos de uso final entre otros más. En este sentido, en la tesis se aplican una variedad de pruebas estadísticas a los resultados de ahorro de energía y datos para revelar cuál modelo describe mejor y refleja la evolución del consumo de energía en la instalación y, contemplar si los porcentajes de mejora del rendimiento energético obtenidos tienen sentido en función de los patrones de operación de la instalación y los periodos seleccionados como reporte de la línea base.

6. Seleccionamos un campus universitario en Cali (Colombia) como caso de estudio experimental y de simulación, correspondiente a la UAO. Se presentan los datos experimentales de medida para el campus de la universidad a fin de determinar parámetros de eficacia energética y consumo de energía. Se seleccionó un edificio singular del campus UAO, el edificio aulario 4, en donde se realizó una monitorización de parámetros físicos que nos permitieron obtener los consumos energéticos, el impacto ambiental y los costes energéticos.

7. Mediante el modelo de simulación energética se obtienen 7 medidas de ahorro energético MAE's (separadas en medidas pasivas que afectan la arquitectura del edificio y en sistemas activos que afectan los equipos HVAC) para optimizar energéticamente el edificio. Además, se propone el uso de acumulación eléctrica mediante baterías combinada con el sistema renovable PV y así evitar la inyección a la Red y el mayor uso del sistema en horas nocturnas.

8. La tesis doctoral finaliza con el cálculo de los indicadores propuestos de intensidad energética, otro indicador de impacto medioambiental, gestión energética y finalmente dos indicadores como lo son EPnorenovable y ERR que nos indican el comportamiento del edificio hacia un edificio de consumo energético casi nulo nZEB. Elementos que resultan importantes en la evaluación de las edificaciones en Colombia.

9. Mediante el cálculo de todos los indicadores propuestos podemos obtener un análisis energético más detallado del edificio, siendo extrapolable a otras edificaciones similares que existen en Colombia con fines de contribuir en nuevas reglamentaciones del gobierno colombiano. Siendo un aporte significativo a lo establecido en la hoja de ruta sobre lineamientos de eficiencia energética en edificaciones en Latinoamérica elaborado por la IEA, en lo concerniente a Reducir la energía operativa y las emisiones a través de herramientas mejoradas de gestión de energía y creación de capacidad operativa de edificaciones existentes. 


\section{TRABAJOS FUTUROS}

Los nuevos trabajos futuros de I+D+i que pueden seguir realizandose en esta linea de investigación, serán:

1.- El desarrollo de herramientas propias de calificación energética y etiquetado en edificios, teniendo en cuenta las distintas tipologías de edificaciones para el fortalecimiento de los planes de transición energética en Colombia.

2.-Proponer una metodologia propia para Colombia sobre el desarrollo de edificio de consumo energético casi nulo nZEB generando indicadores propios de medición como elemento de aporte a la descarbonizaciòn del sector que en nuestro país representa $20 \%$ de la matriz energética.

3.-Desarrollar instrumentos que permitan la evaluación comparativa del rendimiento energético de un edificio, adecuando esquemas de divulgación para permitir la comparación e incentivar la mejora del rendimiento energético y fortalecer el acceso a incentivos tributarios en esta materia.

4.-Hacer extensiva la elaboración de manuales de construcción sostenibles en otras ciudades del país, esto en razón a las distintas condiciones climáticas y requerimientos propios de las regiones en cuanto a tipo y usos de las viviendas. Específicamente en la región pacifico donde se encuentra asentada la mayor parte de la población afro en el País.

5.-Continuar el análisis y modelamiento matemático - estadísticos de estimación y pronóstico de líneas bases e indicadores en gestión energética, incorporando técnicas de inteligencia artificial.

6.-Implementación de herramientas computacionales que permitan integrar la gestión energética de una edificación, incorporando validación estadística y simulación dinámica. De tal forma que permita evaluar distintos escenarios de ahorro y metas energéticas según la evolución de los esquemas de medición con los que pueda contar la edificación.

7.-Integrar a los análisis de gestión de demanda propuestos por las distintas empresas de suministro eléctrico, los modelos y herramientas metodológicas desarrolladas en esta investigación doctoral. 
ANEXOS:

\section{ARTÍCULOS PUBLICADOS}


Article

\title{
Analysis of the Methodology to Obtain Several Key Indicators Performance (KIP), by Energy Retrofitting of the Actual Building to the District Heating Fuelled by Biomass, Focusing on nZEB Goal: Case of Study
}

\author{
Rosaura Castrillón Mendoza ${ }^{1,2}$, Javier M. Rey Hernández 2,3,*, Eloy Velasco Gómez ${ }^{2}$ (), \\ Julio F. San José Alonso ${ }^{2}$ and Francisco J. Rey Martínez ${ }^{2}$ \\ 1 Department of Energy and Mechanics, University Autónoma de Occidente Cali (UAO), Cali 760030, \\ Colombia; rcastrillon@uao.edu.co \\ 2 Department of Energy and Fluid Mechanics, School of Engineering (EII), University of Valladolid (UVa), \\ 47002 Valladolid, Spain; eloy@eii.uva.es (E.V.G.); julsan@eii.uva.es (J.F.S.J.A.); rey@eii.uva.es (F.J.R.M.) \\ 3 Higher Polytechnic College, European University Miguel de Cervantes (UEMC), 47012 Valladolid, Spain \\ * Correspondence: javier.rey@uva.es; Tel.: +34-983-423-366
}

Received: 20 November 2018; Accepted: 21 December 2018; Published: 28 December 2018

\begin{abstract}
In order to achieve the objectives of the European 20/20/20 strategy, and to obtain a greater energy efficiency, integration of renewable energies and the reduction of carbon emissions, a District Heating (DH) system has been designed by the University of Valladolid (UVa), Spain, one of the most important DH fed by biomass fuel in Spain, supplying heating and domestic hot water (DHW) to 31 buildings in Valladolid, the majority of them, educational buildings on the University Campus. The aims of this paper were to study the change from an energy system fueled by natural gas to District Heating by biomass in a building on the campus of the University of Valladolid - the School of Engineering (EII) - studying its consumption from its connection to the District Heating system. An energy management methodology such as ISO 50001 is carried out, applied to efficiency systems in buildings, thus establishing new criteria of sustainability and economic value. In this paper, energy management will also be analyzed in accordance with the proposed tools of an Energy Management System (EMS) applied to the EII building, through the measurement of energy parameters, calculation of thermal consumption, thermal energy savings as a result of the change from system to District Heating by biomass, economic savings, reduction of environmental impact and indicators of thermal efficiency $\mathrm{I}_{100}$ and CUSUM indicator. Finally, the primary renewable and non-renewable energy efficiency indicators for the new District Heating system will be determined. The concept of the near Zero Energy Buildings is defined in the European Union (EU) in order to analyze an approach to an nZEB which results from replacing the natural gas heating system by a biomass District Heating system.
\end{abstract}

Keywords: district heating; biomass; energy management in renovated building; nZEB

\section{Introduction}

The spread of university campuses in recent years has led to a significant increase in energy consumption. The total amount of energy consumption includes lighting, DHW, heating or air conditioning systems in all campus buildings.

Due to the large amount of energy consumption in these buildings, a policy of promoting energy savings, energy management, supply of energy useful to the final energy consumption, perfectly planned at a local scale, can maintain a standard of energy consumed on campuses in a controlled 


\title{
PV Energy Performance in a Sustainable Campus
}

\author{
Rosaura Castrillón-Mendoza ${ }^{1, *(\mathbb{D})}$, Paul Andrés Manrique-Castillo ${ }^{2}(\mathbb{D}$, \\ Javier M. Rey-Hernández ${ }^{3, *}$ (), Francisco J. Rey-Martínez ${ }^{4}$ (i) and Gabriel González-Palomino ${ }^{1}$ \\ 1 Department of Energy and Mechanics, University Autónoma de Occidente, Cali 115-25, Colombia; \\ ggonzalezp@uao.edu.co \\ 2 Ingeniería Sistemas Fotovoltaicos, Celsia Colombia SA ESP, Yumbo 760502, Colombia; \\ pmanrique@celsia.com \\ 3 Higher Polytechnic College, European University Miguel de Cervantes (UEMC), 47012 Valladolid, Spain \\ 4 Department of Energy and Fluid Mechanics, School of Engineering (EII), University of Valladolid (UVa), \\ 47002 Valladolid, Spain; rey@eii.uva.es \\ * Correspondence: rcastrillon@uao.edu.co (R.C.-M.); jrey@uemc.es (J.M.R.-H.)
}

Received: 23 September 2020; Accepted: 4 November 2020; Published: 7 November 2020

\begin{abstract}
The challenge of photovoltaic integration as the basis of an energy generation system has been achieved and carried out by the University Autónoma de Cali, Colombia, using an avant-garde energy technology model. This innovative sustainable campus not only fulfills its purpose as an advanced model of a renewable energy integration system, it also aims at environmental research, e-mobility, and energy efficiency. This paper describes how the university implements the technological innovation of integrating the photovoltaic system installation in a university campus, showing its relevant contribution to the electricity generation in the campus buildings by analyzing the different electrical parameters together with the system performance indicators. The implementation of technological solutions has allowed the generation of a quantity of renewable energy within the campus, supplying a sustainable energy response based on energy efficiency and carbon emissions savings. This innovation has been applied following the international standards for the evaluation of the energy performance of photovoltaic systems (IEC 61724), reaching very optimal values for this type of renewable solution. In this paper, the dynamic monitoring of several parameters has been carried out in order to analyze the energy performance, and an energy simulation has been used to achieve optimal solutions and to obtain the perfect modeling of the system. This study shows how to evaluate the performance of an integration of a photovoltaic system in a smart university campus, according to international standards. It achieves complete viability due to its economic savings, energy efficiency and reduction of carbon emission.
\end{abstract}

Keywords: energy efficiency; smart campus; grid-connected photovoltaic systems; energy simulation; performance evaluation

\section{Introduction}

Environmental issues, energy independence, and the high costs of fossil fuels have motivated the use and development of renewable and sustainable energy technologies [1,2]. The EU aims to achieve a $20 \%$ share of renewable energy sources in final energy consumption by the end of 2020 [1]. Grid-connected photovoltaic systems have become the best alternative for renewable energy on both a small and large scale [3]. One of the most challenging implementations of photovoltaic systems is their integration into buildings. In 2018, according to REN21 [4], the worldwide photovoltaic (PV) system market achieved $505 \mathrm{GW}$ of total power around the world. Similarly, the deployment of PV roofs aimed at generation has increased significantly in recent years, and it is expected that backup systems will also do the same. According to the International Energy Agency, in 2018 the added capacity of 
Article

\title{
Industrial Decarbonization by A New Energy- Baseline Methodology-Case Study
}

\author{
Rosaura Castrillón-Mendoza ${ }^{1, *}$, Javier M. Rey-Hernández ${ }^{2}$ and Francisco J. Rey-Martínez ${ }^{3}$ \\ 1 Department of Energy and Mechanics, University Autónoma de Occidente Cali (UAO), Cali 115-85, \\ Colombia \\ 2 Higher Polytechnic College, European University Miguel de Cervantes (UEMC), Valladolid 47012, Spain; \\ jrey@uemc.es \\ 3 Department of Energy and Fluid Mechanics, School of Engineering (EII), University of Valladolid (UVa), \\ Valladolid 47002, Spain; rey@eii.uva.es \\ * Correspondence: rcastrillon@uao.edu.co
}

Received: 21 January 2020; Accepted: 02 March 2020; Published: 4 March 2020

\begin{abstract}
The main target of climate change policies in the majority of industrialized countries is to reduce energy consumption in their facilities, which would reduce the carbon emissions that are generated. Through this idea, energy management plans are developed, energy reduction targets are established, and energy-efficient technologies are applied to achieve high energy savings, which are environmentally compatible. In order to evaluate the impact of their operations and investments, companies promote measures of performance in their energy management plans. An integral part of measuring energy performance is the establishment of energy baselines applicable to the complete facility that provide a basis for evaluating energy efficiency improvements and incorporating energy performance indicators. The implementation of energy management systems in accordance with the requirements of ISO Standard 50001 is a contribution to the aim and strategies for improving cleaner production in industries. This involves an option for the industry to establish energy benchmarks to evaluate performance, predict energy consumption, and align production with the lowest possible consumption of primary and secondary forms of energy. Ultimately, this goal should lead to the manufacturing of cleaner products that are environmentally friendly, energy efficient, and are in accordance with the global environmental targets of cleaner manufacturing. This paper discusses an alternative for establishing energy baselines for the industrial sector in which several products are produced from a single raw material, and we determined the energy consumption of each product and its impact on the overall efficiency of the industry at the same time. The method is applied to the plastic injection process and the result is an energy baseline (EBL) in accordance with the requirements of ISO 50001, which serves as a reference for determining energy savings. The EBL facilitates a reduction in energy consumption and greenhouse gas emissions in sectors such as plastics, a sector which accounts for $15 \%$ of Colombia's manufacturing GDP.
\end{abstract}

Keywords: energy efficiency; sustainable consumption; ISO standards 50001; standardization;

\section{Introduction}

The growth of industrial activity since 2000 in the countries which are members of the International Energy Agency (IEA) and other major economies, has led to increases in energy use. For 2017, the annual increase in global energy use was estimated to be roughly $2 \%$. However, energy efficiency has prevented further increases in consumption due to efficiency improvements in the industry and service sectors [1-3]. The growth in energy consumption has been largely driven by a 